\title{
La bonanza de
}

los recursos

naturales para

el desarrollo

Dilemas de gobernanza

\section{RICARDO J. SÁNCHEZ}

Editor

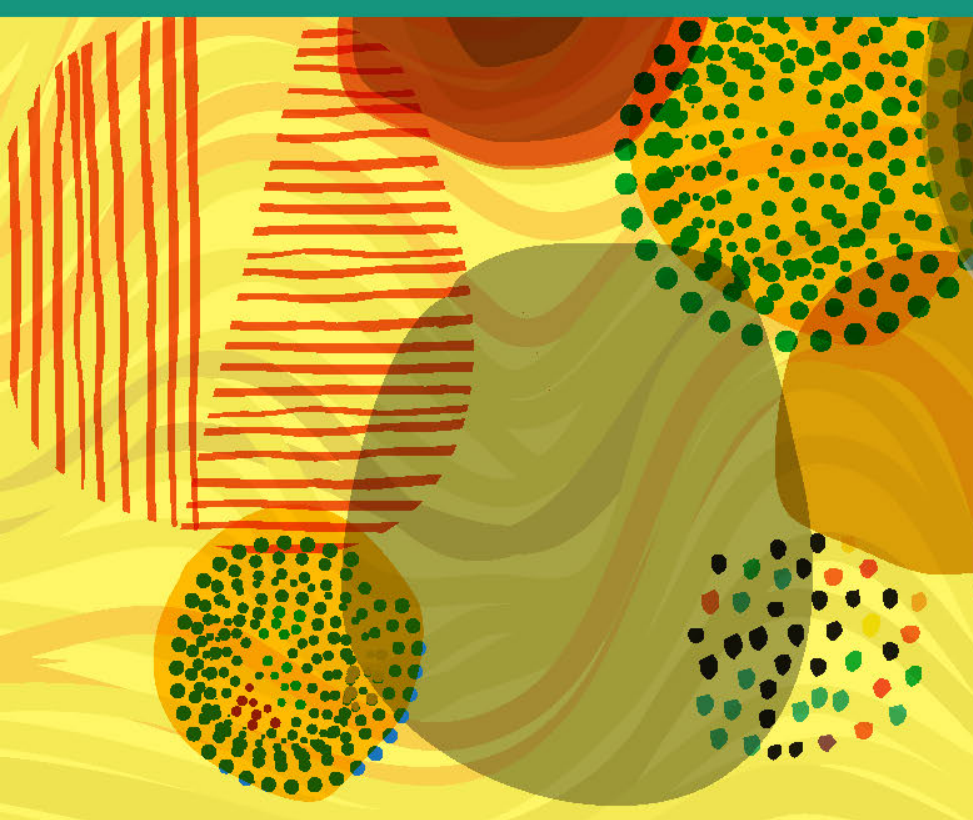

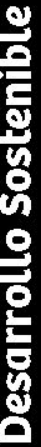

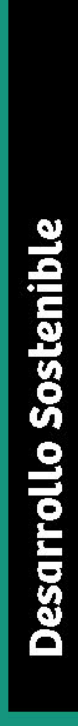




\section{Gracias por su interés en esta}

\section{publicación de la CEPAL}

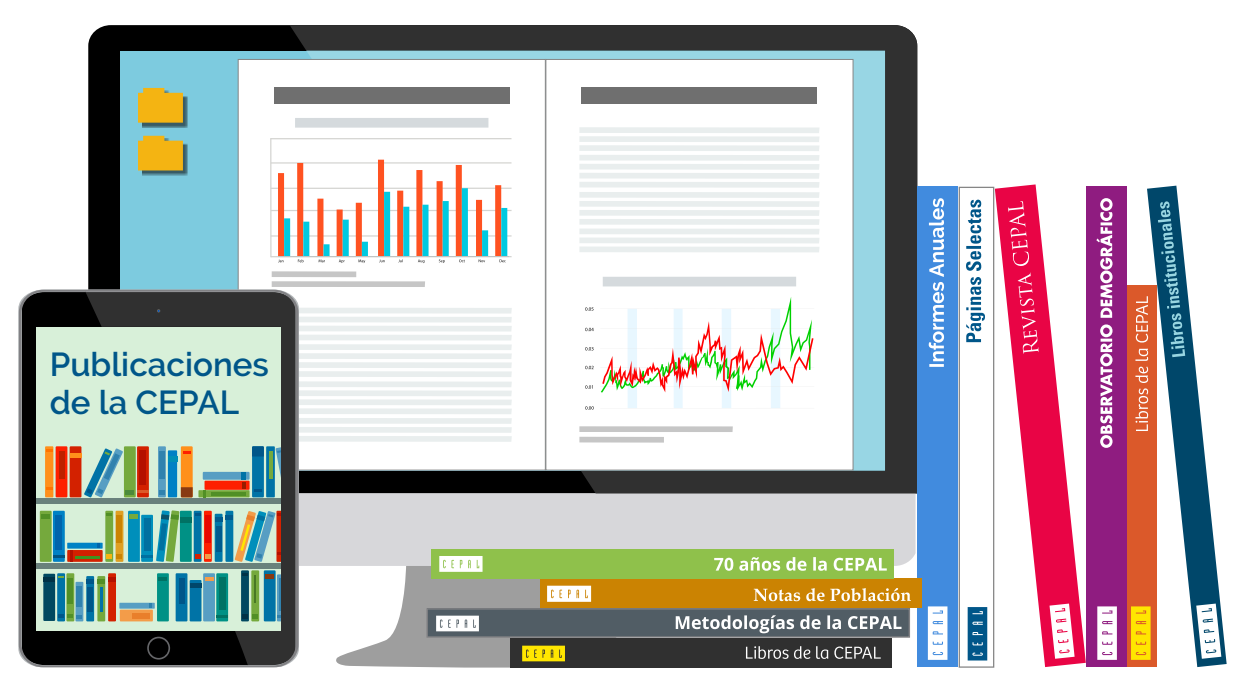

Si desea recibir información oportuna sobre nuestros productos editoriales y actividades, le invitamos a registrarse. Podrá definir sus áreas de interés y acceder a nuestros productos en otros formatos.

\section{Deseo registrarme}
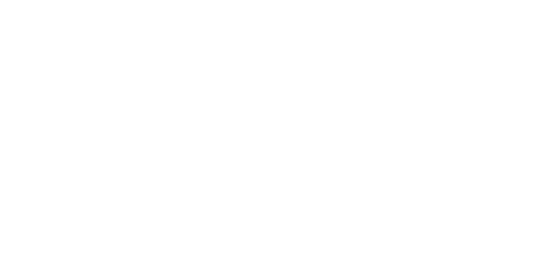

www.cepal.org/es/publications

facebook.com/publicacionesdelacepal

D.w.cepal.org/apps 


\section{La bonanza de los recursos naturales para el desarrollo}

\section{Dilemas de gobernanza}

Ricardo J. Sánchez

Editor
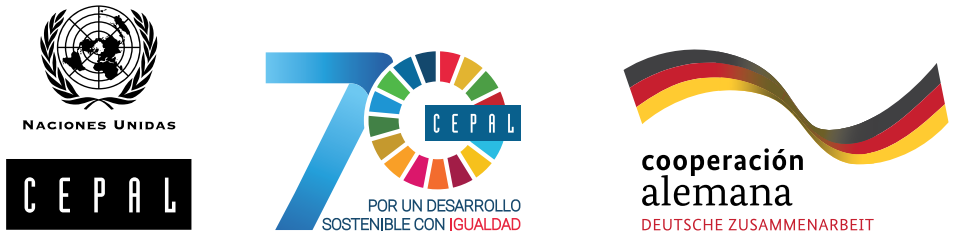


\section{Libros de la CEPAL}

157

\section{Alicia Bárcena}

Secretaria Ejecutiva

Mario Cimoli

Secretario Ejecutivo Adjunto

Raúl García-Buchaca

Secretario Ejecutivo Adjunto

para Administración y Análisis de Programas

\section{Jeannette Sánchez}

Directora de la División de Recursos Naturales

\section{Ricardo Pérez}

Director de la División de Publicaciones y Servicios Web

Este libro fue elaborado con el apoyo del programa Cooperación Regional para la Gestión Sustentable de los Recursos Mineros en los países Andinos por encargo del Ministerio Federal de Cooperación Económica y Desarrollo (BMZ) de Alemania e implementado por la Deutsche Gesellschaft für Internationale Zusammenarbeit (GIZ).

El editor desea expresar su profundo agradecimiento a los autores que contribuyeron con capítulos de este libro y que se mencionan en la Introducción, en particular a Ernesto Cussianovich, quien además hizo valiosos aportes a la preparación general.

Las opiniones expresadas en este documento son de exclusiva responsabilidad de los autores y pueden no coincidir con las de la Organización.

Los límites y los nombres que figuran en los mapas incluidos en esta publicación no implican su apoyo o aceptación oficial por las Naciones Unidas.

Diseño de portada: María Luisa Avaria U.

Publicación de las Naciones Unidas

ISBN: 978-92-1-122021-6 (versión impresa)

ISBN: 978-92-1-047943-1 (versión pdf)

ISBN: 978-92-1-358258-9 (versión ePub)

Número de venta: S.19.II.G.14

LC/PUB.2019/13-P

Distribución: $\mathrm{G}$

Copyright (c) Naciones Unidas, 2019

Todos los derechos reservados

Impreso en Naciones Unidas, Santiago

S.18-00746

Esta publicación debe citarse como: R. Sánchez (ed.), La bonanza de los recursos naturales para el desarrollo: dilemas de gobernanza, Libros de la CEPAL, N 157 (LC/PUB.2019/13-P), Santiago, Comisión Económica para América Latina y el Caribe (CEPAL), 2019.

La autorización para reproducir total o parcialmente esta obra debe solicitarse a la Comisión Económica para América Latina y el Caribe (CEPAL), División de Publicaciones y Servicios Web, publicaciones.cepal@un.org. Los Estados Miembros de las Naciones Unidas y sus instituciones gubernamentales pueden reproducir esta obra sin autorización previa. Solo se les solicita que mencionen la fuente e informen a la CEPAL de tal reproducción. 


\section{Índice}

Prólogo

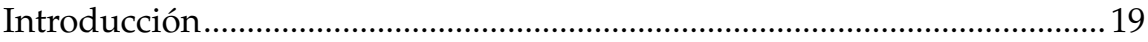

Ricardo J. Sánchez

\section{Capítulo I}

Recursos minerales: capacidad de carga y desarrollo sostenible......

Diego Azqueta, Daniel Sotelsek Salem

A. Aproximación conceptual ...................................................................29

B. Los retos del desarrollo sostenible ......................................................30

C. Marco legal: derechos sobre los recursos del subsuelo......................32

D. Sostenibilidad económica....................................................................3

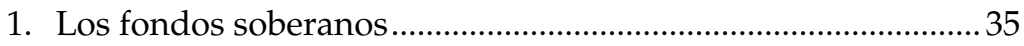

E. Sostenibilidad social......................................................................... 39

1. El papel de las comunidades locales............................................. 40

2. Licencias sociales para operar: evaluación crítica.........................41

F. Sostenibilidad ambiental ...................................................................... 42

1. Los impactos ambientales de la minería ........................................ 43

2. Los impactos de la minería sobre el bienestar de la población local....................................................................... 44

3. Los impactos de la minería sobre la sostenibilidad ambiental: el capital natural crítico

y la diversidad biológica.

4. Compromisos sin pérdidas netas y compensaciones por pérdida de biodiversidad: evaluación crítica ........................ 48

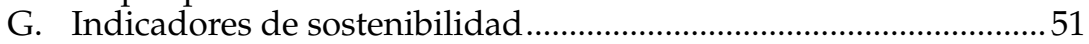

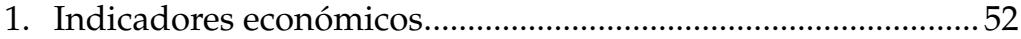

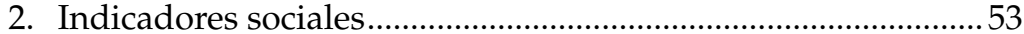

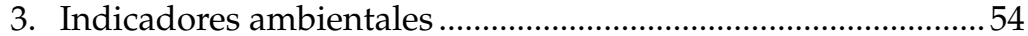

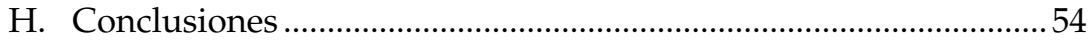

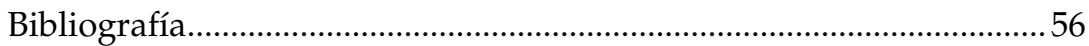


Capítulo II

Coyuntura económica en América Latina y el Caribe y su vínculo con los recursos naturales

Miryam Saade Hazin

A. Evolución y coyuntura económica vinculada con los recursos naturales en América Latina y el Caribe

B. Reflexiones finales

Bibliografía.

Capítulo III

Situación de los minerales en América Latina y el Caribe

José Luis Lewinsohn

A. La importancia de los minerales en el mundo y en América Latina y el Caribe

B. Ciclos del precio de los metales y su influencia en el sector....

C. Producción minera de América Latina y el Caribe y desarrollo económico del sector respecto

a los principales actores del mundo

D. Evolución de la inversión minera en América Latina y el Caribe.

E. Minerales y metales críticos en el mundo. 105

F. Situación de los minerales industriales y de construcción en la región

G. Perspectivas de la minería en América Latina y el Caribe ........... 110

Bibliografía. 114

Capítulo IV

Estado de situación y perspectivas de los hidrocarburos en la región...... 117 Andrés Arroyo

A. La industria ante la mayor disrupción del mercado petrolero .. 118

1. El punto máximo de la demanda de hidrocarburos a nivel mundial

2. La merma de la producción y las reservas inmovilizadas en América Latina

B. La regulación ambiental en las políticas de las empresas de hidrocarburos de la región.

1. Aspectos socioambientales y alianzas para la reducción de la huella ambiental

2. La gestión corporativa para una producción sostenible de hidrocarburos

C. Conclusiones

Bibliografía.

Capítulo V

El papel de la logística en las redes globales de recursos naturales desde una perspectiva multiescalar

Cristina Muñoz, Gabriel Pérez-Salas

Introducción

A. Los vínculos olvidados de las redes globales de recursos naturales 
B. Integración de infraestructuras logísticas: de la competencia por precios a una estrategia de desarrollo sostenible de largo plazo.

C. El impacto de las transformaciones geopolíticas en las redes globales comerciales

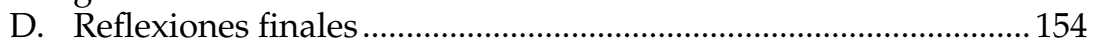

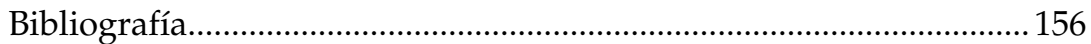

Capítulo VI

La gobernanza de los recursos naturales y su vínculo con los Objetivos de Desarrollo Sostenible.

Shreya Kumra

A. Relevancia de los Objetivos de Desarrollo Sostenible para una gobernanza sostenible de los recursos naturales

B. Gobernanza de los recursos naturales: implicaciones y desafíos en el contexto de los ODS.

C. Desarrollo de estrategias de gobernanza basadas en sinergias, conflictos y compensaciones entre los ODS

D. La gobernanza de los recursos naturales y las interacciones de los ODS: la perspectiva del nexo

E. Consideraciones clave para la formulación y ejecución de las políticas.

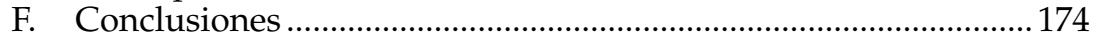

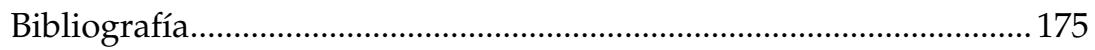

Capítulo VII

Recursos naturales y crecimiento sostenible: lecciones aprendidas del período de auge de precios

José María Fanelli

A. Las características particulares de los recursos naturales, la macroeconomía y la experiencia de tres países latinoamericanos.

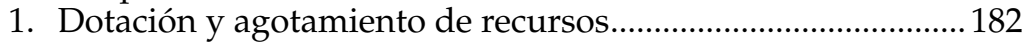

2. Generación de renta y apropiación ................................................186

3. Recursos naturales y saldo neto de divisas................................. 198

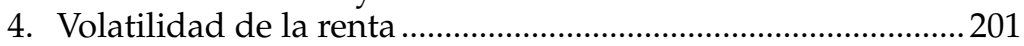

B. Implicaciones de políticas e institucionales para la gestión de los períodos de bonanza ................................................................206

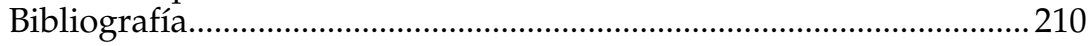

Capítulo VIII

La bendición o la maldición de los recursos naturales:

un breve análisis empírico.....

Ricardo J. Sánchez, Silvana Sánchez di Doménico, Beatriz Tovar de la Fe

A. Breve revisión de la literatura empírica ...........................................2214

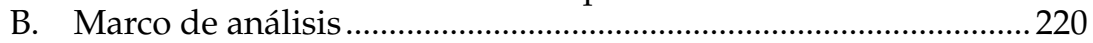

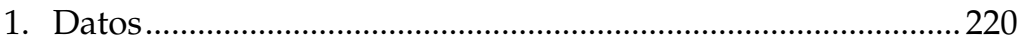

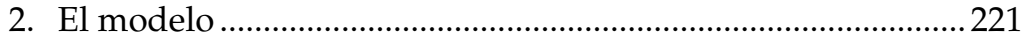

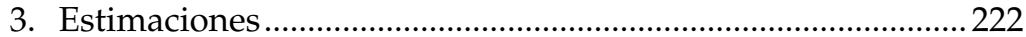

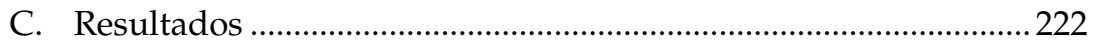


D. Comentarios y reflexiones finales 225

Bibliografía.

Capítulo IX

Evidencia estadística de superciclos en las series de precios de los metales y el petróleo, 1900-2015 Jean J. Acquatella, Omar D. Bello, Félix Berríos

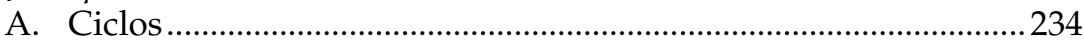

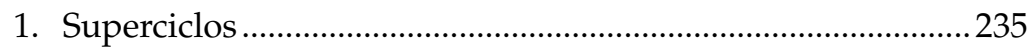

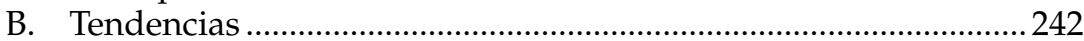

1. Tendencia Cuddington y Jerret (CJ) ………...........................2242

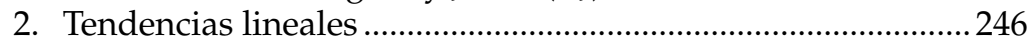

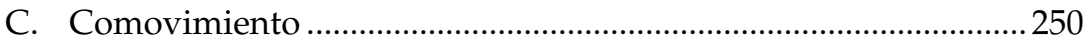

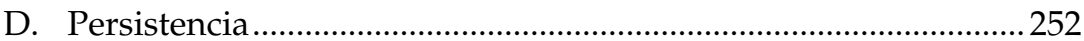

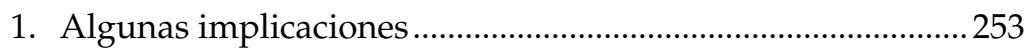

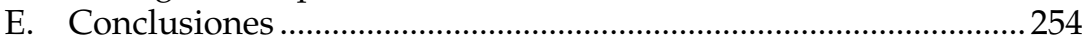

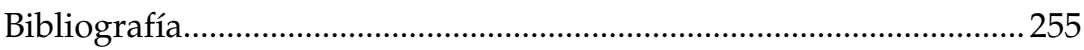

Capítulo X

La gobernanza de los recursos naturales desde la mirada

de los ciudadanos.

\section{Ernesto Cussianovich}

A. Una gobernanza para la mayoría ....................................................225

B. Gobernanza mundial y regional de los recursos naturales..........262

C. Los recursos naturales en el imaginario de los ciudadanos.........266

D. Corrección política y presencia del Estado en la visión de los recursos naturales

E. Conclusión: la conceptualización de la gobernanza de los recursos naturales

Bibliografía.

Capítulo XI

Avances y retos en iniciativas y políticas de transparencia y rendición de cuentas en las industrias extractivas.

Víctor Andrés Garzón, Michael Röesch

A. La discusión sobre la transparencia en las industrias extractivas .......280

B. Enfoques e instrumentos de transparencia respecto de la gobernanza de los recursos naturales

C. Impactos de la transparencia: ¿cuál es el papel de los diferentes actores?.

D. Estado (nacional y subnacional).......................................................28

E. Sociedad civil (nacional e internacional) .......................................2290

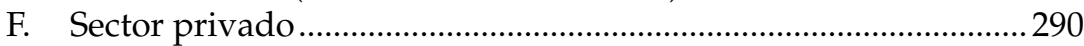

G. Entidades internacionales, multilaterales y cooperación internacional

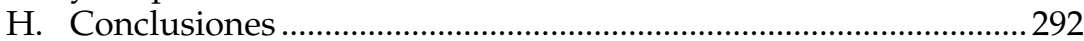

Bibliografía.......................................................................................... 293 


\section{Capítulo XII}

Regímenes fiscales vinculados a los recursos naturales no renovables en América Latina y el Caribe y su relación con el ciclo de precios: evolución reciente y desafíos pendientes

Michael Hanni, Juan Pablo Jiménez, Ignacio Ruelas

A. Instrumentos fiscales en las industrias extractivas .....

1. Características particulares del sector extractivo

2. Propiedad de los recursos naturales y regímenes e instrumentos fiscales en las industrias extractivas

3. Objetivos buscados y criterios de evaluación de los instrumentos fiscales.

B. Instrumentos utilizados, evolución y reformas recientes en la región

1. Período previo a 2003 .

2. Período 2003-2012

3. Reformas de 2013 al presente

C. Indicadores y evolución de los ingresos fiscales provenientes de los recursos naturales no renovables en América Latina y el Caribe

D. Conclusiones

Bibliografía.

Capítulo XIII

Asignación del espacio fiscal y recursos naturales: un marco conceptual con perspectiva latinoamericana....

José María Fanelli

A. Recursos naturales, desarrollo sostenible y espacio fiscal.

B. Sostenibilidad, estabilidad y flexibilidad

C. Conclusiones

Bibliografía.

Capítulo XIV

Implementación, adaptación y funcionamiento de los fondos

soberanos de inversión.

Miryam Saade Hazin, Daniel Sotelsek Salem

A. Antecedentes y definición de los fondos soberanos de inversión.

B. Apertura de los fondos soberanos de inversión

a nuevas carteras

C. El índice de gobernanza y su vínculo con los fondos soberanos de inversión

D. Reflexiones finales

Bibliografía.

Capítulo XV

La conflictividad vinculada a los recursos naturales en América Latina: tendencias y mecanismos institucionales de respuesta.

Nicolás González

A. Estudio de la conflictividad

B. Hacia una caracterización de los conflictos vinculados a los recursos naturales. 
C. Sobre la conflictividad asociada a las industrias extractivas .......364

D. La respuesta desde el Estado ............................................................366

1. Sistemas de alerta y respuesta temprana (prevención operativa)...

2. Implementación de mecanismos de intervención para la gestión de conflictos sociales (prevención estructural)...........368

3. Mecanismos de gestión y coordinación institucional ...............368

4. Desarrollo de capacidades para la solución pacífica

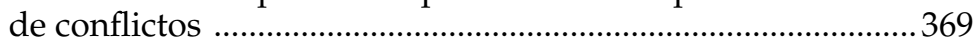

E. Institucionalización de los mecanismos de respuesta.....................370

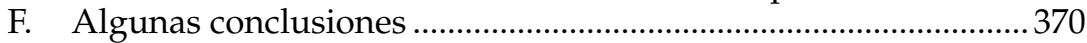

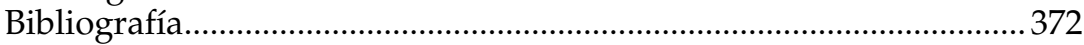

Capítulo XVI

Pasivos ambientales mineros: retos para la sostenibilidad

Carlos de Miguel, Mauricio Pereira

A. Estado de los pasivos ambientales mineros

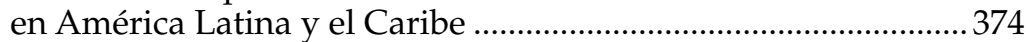

1. Número de pasivos y su estado en la región..............................377

B. Causas y principales problemas socioambientales vinculados con los pasivos ambientales mineros ............................378

C. La importancia de la gestión de los pasivos

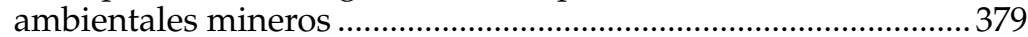

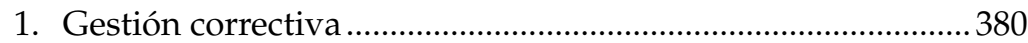

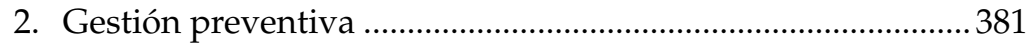

3. Monitoreo de los pasivos ambientales mineros

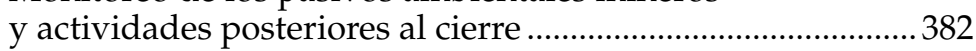

4. Recomendaciones internacionales ...........................................382

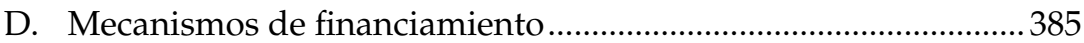

E. Análisis de riesgos y resiliencia en torno a los pasivos

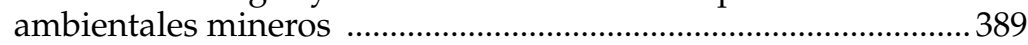

F. Reflexiones finales y recomendaciones .........................................392

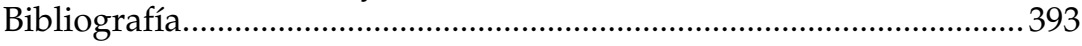

Capítulo XVII

Conclusiones: asuntos críticos de la gobernanza

y los desafíos regionales

Ricardo J. Sánchez

Publicaciones recientes de la CEPAL

\section{Cuadros}

II.1 América Latina y el Caribe y países en desarrollo de Asia: tasa de crecimiento del producto interno bruto (PIB) y PIB per cápita.

III.1 América Latina y el Caribe (10 países): ingresos públicos derivados de la minería, por país y tipo de ingreso, 2014-2015.

III.2 Proporción del suministro de materias primas críticas que corresponde a los 20 países productores más significativos, 2010, 2011 y 2012 
IV.1 Productores de hidrocarburos (países seleccionados): situación y metas para las energías renovables

IV.2 Renta económica y huella ambiental en la producción de un barril de equivalente en petróleo, 2010 y 2015

IV.3 Planes, programas e iniciativas medioambientales implementados por empresas estatales de hidrocarburos seleccionadas en la región, 2015

VI.1 La participación de los actores privados: una dimensión significativa para lograr los Objetivos de Desarrollo Sostenible (ODS)

VII.1 Chile, Colombia y Perú: gobernanza de los recursos naturales..... 188

VII.2 Chile, Colombia y Perú: marcos legales que rigen la distribución y el uso de los ingresos fiscales

VII.3 Chile: evolución y descomposición del valor de mercado del Fondo de Estabilización Económica y Social (FEES), 2007-2015

VII.4 Chile: evolución y descomposición del valor de mercado del Fondo de Reservas de Pensiones (FPR), 2006-2015.

VII.5 Perú: monto de ahorro acumulado del Fondo de Estabilización Fiscal, 2000-2015.

VIII.1 Resumen de los trabajos revisados

VIII.2 Resultados de las estimaciones realizadas con los mejores modelos

IX.1 Ingresos fiscales por explotación de hidrocarburos y explotación minera.

IX.2 Superciclos: fechas de los máximos y mínimos..................................235

IX.3 Estadísticas de superciclos, 1900-2015 ………...................................236

IX.4 Tendencias lineales: fecha de cambio de signo..................................247

IX.5 Precios reales de los productos básicos: correlaciones cruzadas, del primer trimestre de 1960 al cuarto trimestre de $2015 \ldots \ldots \ldots \ldots \ldots . . . .251$

IX.6 Persistencia: estimación del parámetro de integración de facciones de las series

XIV.1 Fondos soberanos de inversión (FSI) y fondos de pensiones...........343

XV.1 Componentes del análisis de la conflictividad ...................................362

XV.2 Conflictos por tipo de actividad a mayo de 2016 .............................363

XVI.1 América Latina (5 países): definiciones de pasivos ambientales mineros.

XVI.2 Pasos para evaluar riesgos y priorización de faenas mineras abandonadas o paralizadas.... 390

\section{Gráficos}

II.1 América Latina y el Caribe y países en desarrollo de Asia: tasa de crecimiento del producto interno bruto (PIB) y el PIB per cápita, 1980-2016

II.2 América Latina y el Caribe y regiones seleccionadas: formación bruta de capital fijo, 1970-2016. 
II.3 Composición de las exportaciones de bienes según producto e intensidad tecnológica, 1990, 2000 y 2016

II.4 Regiones y países seleccionados: gasto en investigación y desarrollo, 2002 y 2014

II.5 Índice de precios internacionales de las materias primas, 1992-2017.

II.6 América Latina y el Caribe (países y grupos de países seleccionados): tasa de variación de los términos de intercambio, 2001-2017

II.7 América Latina y el Caribe (países y grupos de países seleccionados): tasa de variación de las exportaciones y las importaciones de bienes según volumen y precio, 2016

II.8 América Latina y subregiones seleccionadas: tasa de variación del PIB y contribución de los componentes de la demanda agregada al crecimiento, primer trimestre de 2008 a segundo trimestre de 2016 .

II.9 América Latina y el Caribe: entradas de inversión extranjera directa (IED), 1990-2016

II.10 América Latina y el Caribe: distribución sectorial de los montos de los proyectos de inversión extranjera directa anunciados, 2005-2016

II.11 República de Corea, Japón, Estados Unidos y China: solicitudes de patentes, 2002-2016

II.12 América Latina (países seleccionados): índice del tipo de cambio nominal con respecto al dólar, enero de 2014 a noviembre 2016 ........75

II.13 Ingresos provenientes de recursos naturales no renovables, 2000-2017

II.14 América Latina (países seleccionados): deuda pública del gobierno central, 2000-2016

III.1 Precio de los metales, 2000-2017.

III.2 Precio de los metales y minerales, 2000-2017

III.3 América Latina y el Caribe y países seleccionados: participación de la producción minera y de la producción y el consumo de refinado en la producción y el consumo mundiales, 1980-2016

III.4 Proporción de la explotación de minas y canteras respecto al total del producto interno bruto anual, 2000, 2005, 2010 y 2016 ............... 96

III.5 América Latina y el Caribe: exportaciones de minerales y comparación con el resto del mundo, 1962-2015

III.6 Inversión mundial en exploración minera no ferrosa, 2004-2016....99

III.7 Inversión mundial en exploración minera por regiones y países, 2003-2016.

III.8 Reservas mundiales de metales base, preciosos y ferrosos, 2016..... 101

III.9 Anuncios de inversión mundial en proyectos mineros, 2000, 2010, 2012, 2014 y 2016 
III.10 Distribución de los anuncios mundiales de inversión en proyectos mineros entre los diez países principales, 2000, 2010, 2012, 2014 y 2016

IV.1 Producción mundial de hidrocarburos por tipo, fuente y escenarios del Acuerdo de París y senda de $2{ }^{\circ} \mathrm{C}, 2015-2035$.

IV.2 América Latina y el Caribe: escenarios de producción, reservas de hidrocarburos y emisiones acumuladas de $\mathrm{CO}_{2}, 2015-2040$..... 125

VII.1 Chile, Colombia y Perú: agotamiento de los recursos naturales, ahorro e inversión, 2000-2014.

VII.2 Chile, Colombia y Perú: posición de inversión internacional neta e inversión extranjera directa neta.

VII.3 Chile, Colombia y Perú: evolución de la recaudación derivada de los recursos naturales, 2001-2014

VII.4 Chile, Colombia y Perú: participación de la minería y los hidrocarburos en los ingresos por recursos naturales.

VII.5 Chile, Colombia y Perú: evolución del superávit primario y total, 1990-2014.

VII.6 Chile, Colombia y Perú: evolución del gasto público en educación e inversión pública, 2000-2014.

VII.7 Chile, Colombia y Perú: evolución de las exportaciones basadas en recursos naturales

VII.8 Chile, Colombia y Perú: evolución de la productividad total de los factores

VII.9 Chile, Colombia y Perú: cuenta corriente y pago a factores del exterior

VII.10 Chile, Colombia y Perú: evolución del tipo de cambio real, 1995-2013.

VII.11 Chile, Colombia y Perú: evolución de los superávits público y privado, 2000-2014.

IX.1 Superciclos: precio real de los metales industriales, 1900-2015 .....240

IX.2 Metales industriales: precio real y tendencia Cuddington y Jerret (CJ), 1900-2015

IX.3 Metales utilizados como reserva de valor: precio real y tendencia Cuddington y Jerret (CJ), 1900-2015

IX.4 Petróleo: precio real y tendencia Cuddington y Jerret (CJ), 1900-2015.

IX.5 Metales industriales: precio real y tendencia lineal, del primer trimestre de 1960 al cuarto trimestre de 2015

IX.6 Petróleo: precio real y tendencia lineal, del primer trimestre de 1960 al cuarto trimestre de 2015

IX.7 Metales industriales y metales de reserva de valor: factores comunes, del primer trimestre de 1960

al cuarto trimestre de 2015.

X.1 Argentina: respuesta a la pregunta “¿cuál de las siguientes palabras cree que se asocia con los recursos naturales en el país?" 
X.2 Argentina: respuesta a la pregunta “¿cuán interesados están usted, el Gobierno, la gente y las empresas en el cuidado de los recursos naturales en el país?".

X.3 Argentina: respuesta a la pregunta "en caso de que la extracción y explotación de un recurso natural importante en el país genere un impacto negativo sobre el medio ambiente, ¿qué cree que se debería hacer?"

XII.1 América Latina y el Caribe: ingresos fiscales provenientes de recursos naturales no renovables, por producto, e indicadores de precios internacionales relacionados, 1990-2016.

XII.2 América Latina y el Caribe (países seleccionados): participación de los ingresos fiscales provenientes de los recursos naturales no renovables en los ingresos públicos totales, 2000-2016.

XII.3 América Latina y el Caribe: ingresos fiscales provenientes de recursos naturales no renovables, por producto e instrumento, 2000-2016

XII.4 América Latina y el Caribe: participación efectiva del Estado en las ganancias (rentas) generadas por la explotación de recursos naturales no renovables, 2003-2011.

XII.5 América Latina y el Caribe (países seleccionados): ingresos fiscales provenientes de la extracción de hidrocarburos, 2000-2016.

XII.6 América Latina y el Caribe (países seleccionados): ingresos fiscales provenientes de la extracción de hidrocarburos, 2000-2016

XII.7 Estado Plurinacional de Bolivia: ingresos fiscales provenientes de la extracción de hidrocarburos, 1990-2016 ........................................ 314

XII.8 América Latina y el Caribe (5 países): ingresos fiscales provenientes de la minería, 2000-2016.

XII.9 América Latina y el Caribe (3 países): ingresos fiscales provenientes de la minería, 2000-2016.

\section{Recuadros}

XI.1 Iniciativa para la Transparencia de las Industrias Extractivas.......281

XI.2 Enumeración de estándares internacionales seleccionados para la minería

\section{Diagramas}

III.1 Valor de la minería y los metales en los sectores económicos clave, 2015

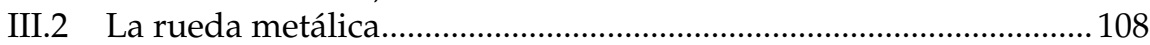

V.1 Un marco conceptual alternativo para analizar el comercio mundial

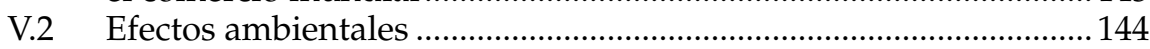

V.3 Vínculos con el sector extractivo ………………………………….... 147

VI.1 América Latina y el Caribe: gobernanza de los recursos naturales

VI.2 Los Objetivos de Desarrollo Sostenible ..........................................167

XIII.1 Espacio fiscal 


\section{Prólogo}

Los dilemas sobre la explotación de los recursos naturales tanto para el desarrollo como para la preservación del medio ambiente fueron muy tempranamente objeto de un llamado de alerta de la Comisión Económica para América Latina y el Caribe (CEPAL). Hace casi cuatro décadas, Raúl Prebisch, entonces director de la Revista de la CEPAL, advertía sobre la incapacidad de la economía para prever y enfrentar los problemas inherentes al medio ambiente y al agotamiento de los recursos naturales. Prebisch hacía referencia a la relación entre los recursos naturales y la amenaza de la contaminación y la concentración urbana, temas que en aquellos años ya estaban instalados en la agenda y la mirada de líderes políticos y académicos y organizaciones congregadas en torno al Programa de las Naciones Unidas para el Medio Ambiente (PNUMA). Asimismo, el ex Secretario Ejecutivo de la CEPAL resaltaba las consecuencias del desarrollo en términos de lo que él llamaba la "depredación de recursos naturales agotables"1. Finalmente, Prebisch alertó sobre las inciertas vicisitudes de los factores ambientales y su influencia en la desigualdad social, trazando lo que pocos años después se convirtió en una parte constitutiva de la agenda de la CEPAL.

Las preocupaciones sobre el medio ambiente y los recursos naturales, así como sobre la igualdad y el cambio estructural progresivo, se han constituido en temas claves de la labor de la CEPAL. La igualdad pasó a ser medular en la agenda cepalina de la última década, como queda de manifiesto en la literatura institucional de los períodos de sesiones celebrados en los últimos años, así como en innumerables informes y

R. Prebisch, "Biosfera y desarrollo", Revista de la CEPAL, No 12 (E/CEPAL/G.1130), Santiago, Comisión Económica para América Latina (CEPAL), 1980. 
estudios publicados por la CEPAL en ese mismo lapso. La igualdad está presente incluso en los títulos de los documentos presentados en esos períodos de sesiones, que comenzaron con La hora de la igualdad: brechas por cerrar, caminos por abrir ${ }^{2}$ y siguieron con Cambio estructural para la igualdad: una visión integrada del desarrollo ${ }^{3}$, Pactos para la igualdad: hacia un futuro sostenible $^{4}$, Horizontes 2030: la igualdad en el centro del desarrollo sostenible ${ }^{5} \mathrm{y}$, finalmente, La ineficiencia de la desigualdad ${ }^{6}$.

En todos los casos se puso de manifiesto el objetivo central de reducir la desigualdad en la región, cuya existencia y persistencia representa una condición inadmisible y contraria a todo sentido ético y a la propia lógica del ansiado desarrollo. En el caso de los recursos naturales, la centralidad del concepto de igualdad favoreció el surgimiento de una mirada más amplia de dichos recursos, en la medida en que se trata de dotaciones que se constituyen en salvaguarda económica del presente y el futuro de los países de la región. Avanzar hacia la igualdad implica activar esfuerzos para mejorar la distribución de la riqueza, más allá de la asistencia prioritaria que requieren los sectores más vulnerables de la sociedad. En este escenario, aspectos como el acceso y la propiedad de los recursos naturales y la apropiación y distribución de las rentas provenientes de su explotación deben desempeñar un rol coherente con la búsqueda de la igualdad intra- e intergeneracional.

La igualdad impone una visión de largo plazo sobre las ventajas, riesgos, costos y beneficios de la explotación de los recursos naturales que considere el bienestar y la reproducción de la vida de todas las personas en el tiempo. Con el objeto de hacer realidad esta visión, que reconoce las tensiones, mutaciones y contradicciones que puede generar la explotación de los recursos naturales en el contexto de economías políticas complejas y culturas de privilegio dominantes en la región, se requiere de un Estado que impulse cambios estructurales sostenibles con adecuados efectos distributivos y que garantice el patrimonio natural y los servicios ecosistémicos críticos para la vida actual y futura.

El logro de la igualdad requiere también de una sociedad organizada con acceso a información pertinente y a la participación en temas relevantes que afecten su vida y su entorno. En este ámbito, el pacto social cumple un papel esencial como instrumento político destinado a

\footnotetext{
Comisión Económica para América Latina y el Caribe (CEPAL), La hora de la igualdad: brechas por cerrar, caminos por abrir (LC/G.2432(SES.33/3)), Santiago, 2010.

CEPAL, Cambioestructural paralaigualdad: unavisión integradadel desarrollo(LC/G.2524(SES.34/3)), Santiago, 2012.

4 CEPAL, Pactos para la igualdad: hacia un futuro sostenible (LC/G.2586(SES.35/3)), Santiago, 2014.

5 CEPAL, Horizontes 2030: la igualdad en el centro del desarrollo sostenible (LC/G.2660/Rev.1), Santiago 2016.

6 CEPAL, La ineficiencia de la desigualdad (LC/SES.37/3-P), Santiago, 2018.
} 
la resolución de los dilemas políticos en la sociedad, que somete a cada ciudadano al respeto y la obediencia de la voluntad general puesta a disposición para la mejora de sus instituciones, su integridad física y su propio futuro. La CEPAL concibe el pacto como un dispositivo destinado a poner en marcha políticas públicas y reformas institucionales que los países de la región requieren para responder a los dilemas del desarrollo.

La centralidad que la CEPAL otorga a la igualdad y la sostenibilidad ambiental se ha orientado también al cumplimiento de los Objetivos de la Agenda 2030 para el Desarrollo Sostenible y los compromisos surgidos del Acuerdo de París, de 2015. De esta forma, las agendas política, económica, social y ambiental han comenzado a activarse e interrelacionarse en favor de una reflexión más útil sobre la correspondencia que existe entre la igualdad, los recursos naturales y el medio ambiente. Falta aún mucho por discutir a nivel regional, nacional y subnacional, pero en la última década se dieron pasos importantes en esa dirección.

Los países de la región, aunque de manera heterogénea, han incorporado en sus planes de desarrollo estas preocupaciones y las han relacionado progresivamente con los Objetivos de Desarrollo Sostenible. Sin embargo, el diseño y la aplicación de políticas concretas de manejo sostenible de los recursos naturales, así como su efecto distributivo en favor de la población, siguen siendo todavía un desafío, al mismo tiempo que emergen de manera creciente conflictos socioambientales relacionados con su explotación. Por otra parte, el último ciclo de bonanza de precios de materias primas, que favoreció a varios países de la región y permitió mejorar su desempeño económico y social, no logró un vuelco hacia un desarrollo más sostenible económica, social y ambientalmente en los años posteriores a la bonanza.

Por ello, la CEPAL reconoce la necesidad de apoyar una adecuada gobernanza de los recursos naturales en los países de la región, así como de favorecer las instancias y mecanismos de coordinación regional en los ámbitos fiscal, comercial, tecnológico y de infraestructura, entre otros, que apoyen un manejo más sostenible de dichos recursos en favor de un desarrollo más incluyente y menos vulnerable.

Las transformaciones ocurridas en la economía de la región durante la última década y media, particularmente en lo relacionado con la propiedad, el manejo, el aprovechamiento y la transferencia de las rentas obtenidas de los recursos naturales, plantean la necesidad de un cambio de paradigma en la relación del Estado con el sector privado y la sociedad civil, en que el Estado debe desempeñar un papel clave como conductor de dichos cambios, en cuanto tiene poder legítimo y autoridad para tutelar y tomar decisiones en favor del bien común. Esto no impide, sino que, al contrario, hace indispensable gobernar con las partes interesadas involucradas, incluidas las comunidades, las empresas y la sociedad civil. 
Una adecuada gobernanza de los recursos naturales requiere instituciones fuertes $\mathrm{y}$, al mismo tiempo, normas, procesos $\mathrm{y}$ conductas acordes con el ejercicio del poder público con participación, responsabilidad, efectividad y coherencia. Requiere, además, de una activa interacción entre los distintos niveles de gobierno que aporte al buen uso y manejo de los recursos naturales y sus rentas. Así, la gobernanza "es la contraparte institucional para potenciar cambios estructurales, velando al mismo tiempo por que la explotación de los recursos naturales redunde en un genuino desarrollo económico, con encadenamientos productivos virtuosos, una infraestructura que promueva sinergias entre usos productivos y sociales, sostenibilidad ambiental y pleno respeto de los derechos de pueblos y comunidades"7.

La gobernanza de los recursos naturales exige una visión de largo plazo y una nueva apreciación de los conceptos de igualdad, cambio estructural progresivo y pactos o acuerdos de cooperación regional que la propia CEPAL ha impulsado a lo largo de siete décadas de trabajo. Es un instrumento adecuado para mediar en la correlación de fuerzas sociales y políticas, que permite una mayor coordinación de las economías de los países, pero también un ordenamiento de sus decisiones en materia social y ambiental. Se trata de una plataforma que promueve la interacción de actores públicos y privados y que mejora la capacidad de acción y planificación del Estado y su compromiso con la implementación de políticas en un marco de transparencia y apertura al diálogo entre los distintos grupos sociales y en cada uno de los países.

Mediante el gobierno adecuado y efectivo de los recursos naturales, con la participación de las diversas partes interesadas, se puede apoyar el cambio desde "la trayectoria del pasado, insostenible y asociada a un conflicto distributivo de creciente intensidad, con fragmentación social, institucional y política" ${ }^{\prime \prime}$ hacia "un nuevo estilo de desarrollo, en que la acción colectiva y los pactos de largo plazo en sociedades democráticas promuevan la igualdad, la transparencia y la participación, con foco en la productividad, el empleo de calidad y el cuidado del medio ambiente, a partir de la difusión de las nuevas tecnologías en un gran impulso ambiental"

Como aporte a este debate, este libro presenta una compilación de trabajos sobre los recursos naturales y el desarrollo en América Latina y el Caribe, y los desafíos de su gobernanza, incluidos ejemplos y experiencias de casos específicos en la región. Se trata de una serie de investigaciones, reflexiones y experiencias de trabajo conjunto del equipo de la División 
de Recursos Naturales ${ }^{10}$ de la CEPAL, con aportes de las Divisiones de Desarrollo Económico, y Desarrollo Sostenible y Asentamientos Humanos y del Programa de las Naciones Unidas para el Desarrollo (PNUD), así como de investigadores y académicos invitados.

A través de más de una docena de artículos que combinan distintos tópicos y áreas de trabajo con nuevos conceptos e hipótesis relacionados con la situación de los recursos naturales en América Latina y el Caribe, se presenta un diagnóstico sobre los recientes años de bonanza económica sustentada en el auge de precios, demanda y rentas y, consecuentemente, en los favorables escenarios que se ofrecieron y que, lamentablemente, los países y la región en su conjunto no pudieron aprovechar para llevar adelante un cambio estructural. Temas como la sostenibilidad ambiental, la diversificación productiva, el espacio fiscal, las cadenas de valor o las inversiones son tratados a la luz de los resultados de la explotación de los recursos naturales en la región, pero también, y fundamentalmente, en el marco de la necesidad de contar con una gobernanza de dichos recursos que haga posible una mejor distribución del ingreso y asegure beneficios para las generaciones del presente y el futuro.

Los autores son, en ese sentido, agudos en sus análisis, pero también muy rigurosos con las estadísticas, los datos y la bibliografía que utilizan en sus capítulos para mostrar las oportunidades y los escenarios con que cuenta hoy la región para encaminarse hacia la ruta del desarrollo sostenible. Se trata de mirar el pasado con cautela y de reflexionar sobre los dilemas del presente, pero desde una óptica que busca aportar teniendo presentes las oportunidades y el amplio espacio que aún siguen teniendo los países para la toma de decisiones políticas y económicas, en un marco de justicia social y en favor de la protección del medio ambiente y de los ciudadanos.

\author{
Alicia Bárcena \\ Secretaria Ejecutiva \\ Comisión Económica para \\ América Latina y el Caribe (CEPAL)
}

10 Hasta 2018 División de Recursos Naturales e Infraestructura. 



\section{Introducción}

Ricardo J. Sánchez

Este libro sobre la bonanza más reciente de los recursos naturales, el desarrollo y los dilemas de gobernanza en América Latina y el Caribe es resultado de una sumatoria de esfuerzos y del trabajo de la División de Recursos Naturales ${ }^{1}$, así como de los aportes de las Divisiones de Desarrollo Económico y de Desarrollo Sostenible y Asentamientos Humanos de la Comisión Económica para América Latina y el Caribe (CEPAL), a los que se añaden los de funcionarios de otras entidades del sistema de las Naciones Unidas y los de distintos académicos y profesionales de universidades y centros de estudios públicos y privados de países de la región y de Europa. Este libro ha sido posible gracias a la confianza y colaboración de la agencia alemana de cooperación técnica para el desarrollo Deutsche Gesellschaft für Internationale Zusammenarbeit (GIZ), que trabaja con la CEPAL desde hace algunos años.

A poco más de dos años de la anterior publicación Hacia una nueva gobernanza de los recursos naturales en América Latina y el Caribe ${ }^{2}$, los artículos reunidos en este libro continúan la reflexión de ese trabajo, ponen de relieve las consecuencias negativas de la excesiva dependencia económica de un solo recurso e incluyen en esas reflexiones los escenarios

Hasta 2018 División de Recursos Naturales e Infraestructura.

2 H. Altomonte y R. J. Sánchez, Hacia una nueva gobernanza de los recursos naturales en América Latina y el Caribe, Libros de la CEPAL, No 139 (LC/G.2679-P), Santiago, Comisión Económica para América Latina y el Caribe (CEPAL), 2016. 
de agotamiento de los recursos naturales y el incremento del impacto de su explotación desmedida sobre el medio ambiente. Se alerta sobre la necesidad de concentrar esfuerzos para avanzar hacia una mayor diversificación productiva de los países de la región y se insiste en la necesidad de transformar el capital natural en capital físico y social, sin mermar el patrimonio natural y los servicios ecosistémicos críticos, bajo la guía de la Agenda 2030.

En ese sentido, los capítulos de este libro constituyen una buena síntesis y, simultáneamente, un avance en torno a las investigaciones, reflexiones y debates más recientes sobre el último auge de los recursos naturales, el desarrollo y los dilemas de gobernanza en los países de América Latina y el Caribe. Más aún, forman una colección amplia de casos muy representativos, datos estadísticos e información bibliográfica sobre las nuevas perspectivas de trabajo y de pensamiento sobre este tema.

Este libro es, además de una colección de estudios que combinan análisis, opiniones y evidencia sobre los diversos aspectos relacionados con los recursos naturales, como la sostenibilidad, la macroeconomía, las instituciones o la conflictividad social y ambiental, un compendio de enfoques conceptuales y comentarios críticos sobre diversos autores y líneas de investigación relacionadas con los recursos naturales. El escenario principal de los capítulos reunidos en este volumen es el contexto económico regional de la primera década del actual milenio hasta 2013, período en el que se observa el comienzo y el final de un cómodo ciclo de bonanza de precios y de rentas provenientes de la explotación de recursos naturales no renovables de la región. Por lo tanto, en esta compilación subsisten diversos ejemplos y casos de países ricos en recursos naturales, básicamente en el sector minero y de hidrocarburos.

Se trata de un libro sobre aspectos de la historia económica regional reciente y —al mismo tiempo- sobre la política económica y la macroeconomía de los países enfocadas principalmente en los precios, las inversiones, la distribución de las rentas, el espacio fiscal, los fondos soberanos y la diversificación productiva asociada a la explotación de los recursos naturales. Sin embargo, es también una colección de reflexiones sobre diversos escenarios vinculados con la agenda social, la legislación, las instituciones, la política y - en consecuencia- las decisiones políticas de los gobiernos de la región con respecto a sus recursos naturales. Conceptos como la sostenibilidad o el capital natural crítico se contraponen con los de abundancia, agotamiento, maldición o bendición de los recursos naturales. Asimismo, temas como la reprimarización de la economía, la dependencia de los recursos naturales o la enfermedad holandesa ayudan a entender la emergencia de la conflictividad social y ambiental.

En Hacia una nueva gobernanza de los recursos naturales en América Latina y el Caribe ya se reflexionaba sobre la bendición o maldición de 
los recursos naturales. Se hablaba de la necesidad de reexaminar la gobernanza vigente, en la certeza de que la evidencia histórica arrojaba resultados claros: era necesario ir hacia una nueva gobernanza para acompañar la propuesta de un modelo de desarrollo más inclusivo y pleno, en el que la equidad y la igualdad entre los ciudadanos sea un propósito y una meta. En este nuevo libro se avanza en esta discusión y se alerta sobre los dilemas de gobernanza en un contexto económico concreto y sobre los desafíos socioambientales.

Además, el libro confirma la necesidad de analizar y aportar a una gobernanza adecuada de los recursos naturales como una estrategia importante que contribuya al logro de los objetivos de desarrollo sostenible en la región. Si bien los distintos autores debaten con miradas variadas los dilemas de gobernanza, a lo largo de la lectura de cada uno de los capítulos se advierte la variabilidad y, al mismo tiempo, la extrema complejidad que implica el manejo adecuado de los recursos naturales. Los ejemplos sobre la situación de los recursos mineros y los hidrocarburos en distintos países de la región son múltiples y aportan información valiosa para entender casi de manera directa los dilemas de la gobernanza y los desafíos que deberán abordar los países en las próximas décadas.

En esa línea, los estudios compilados en este libro toman en consideración los cambios en la economía de la región, a los que se suman los cambios de orientación política, el movimiento social y la preocupación por la dinámica de los riesgos inherentes al medio ambiente en el mediano y largo plazo. Al respecto, el capítulo de Diego Azqueta y Daniel Sotelsek Salem, "Recursos minerales: capacidad de carga y desarrollo sostenible", cumple su función de apertura de este libro al exponer una buena parte de los temas que recorren los demás capítulos. En ese análisis, quizás uno de los más didácticos y conceptuales, se presenta un marco general de la sostenibilidad para identificar y entender los obstáculos asociados a la gestión de los recursos naturales.

Si bien el foco de atención está puesto en los minerales, la minería funciona como el sustrato sobre el cual los autores despliegan un conocimiento y una capacidad destacables para explicar de manera simple cuestiones complejas de la economía ambiental asociada a la economía política. Para estos autores, una gestión sostenible de los recursos deberá tener un marco básico de condiciones, entre las que se destacan una visión de largo plazo, una perspectiva nacional por sobre la local y un sistema de garantías de preservación del capital natural crítico, incluida la posibilidad de financiar los denominados costos de oportunidad en favor de comunidades o países que poseen recursos naturales.

Con una parte importante de los temas instalados en el capítulo introductorio, la primera sección sobre coyuntura y sostenibilidad se inicia con el capítulo de Miryam Saade Hazin sobre "Coyuntura económica en 
América Latina y el Caribe y su vínculo con los recursos naturales". En él se evalúa el desempeño económico de la región a través del análisis de los indicadores asociados a la explotación de los recursos naturales no renovables durante la reciente década y media, cuando se produjo la última bonanza de los recursos naturales en América Latina. Saade no examina per se "una década perdida", sino que aborda un diagnóstico factual y estadístico de lo ocurrido. Evita especulaciones sobre las trampas dicotómicas que remiten a la existencia (o no) de una maldición o una bendición de los recursos naturales y, focalizándose en la abundancia (de por sí, un dato de la realidad de los recursos naturales), explica los impactos sociales, económicos o financieros generados luego de la caída de los precios. Como ocurre con otros artículos del libro, focalizarse en la caída de los precios es mirar solo el resultado y no el origen de los dilemas asociados a los recursos naturales. Para Saade fue una inadecuada gobernanza lo que no permitió aprovechar esa coyuntura virtuosa de la economía en la región, y no los precios de los productos básicos.

Esa crítica a la gobernanza está implícita también en el capítulo de José Luis Lewinsohn sobre "Situación de los minerales en América Latina y el Caribe" y en el de Andrés Arroyo sobre el "Estado de situación y perspectivas de los hidrocarburos en la región". El primero analiza la importancia de los minerales en el contexto de los ciclos de precios de los metales, pero también con relación al desarrollo de la minería en otras regiones, incluida la denominada producción de mina en comparación con la producción de refinado $\mathrm{y}$, consecuentemente, el consumo de ese refinado. El peso del primero en comparación con el último es ya un indicador del nivel de atraso de los procesos de industrialización y diversificación en la región. Lewinsohn examina la ponderación de la inversión y la participación de empresas transnacionales privadas frente a las estatales (con excepción de la Corporación Nacional del Cobre de Chile (CODELCO) en Chile), motivadas por ese auge de precios, pero también por la profusión de yacimientos y el incentivo a la inversión por los gobiernos. La preocupación por la situación del medio ambiente está presente en este capítulo y en esa línea el autor formula algunas sugerencias para fortalecer el uso de las nuevas tecnologías y reglamentaciones, así como una mayor transparencia y, en general, una mejor gobernanza del sector minero.

En esa misma línea, el artículo de Arroyo examina los principales desafíos del sector de los hidrocarburos en América Latina y el Caribe a partir de las nuevas condiciones que crea la presión global de reducir las emisiones de gases de efecto invernadero. Las restricciones ambientales han puesto a este sector en el centro de la opinión pública respecto de su responsabilidad en el actual escenario de cambio climático que afecta al planeta. Ante estos desafíos, Arroyo analiza las oportunidades de restructuración que se le presentan a este sector con miras a la consecución de los Objetivos de Desarrollo Sostenible incluidos en la 
Agenda 2030 para el Desarrollo Sostenible aprobada en 2015 y el Acuerdo de París. Se trata de una agenda que muestra las prioridades en torno al aumento del acceso universal a la energía, la eficiencia energética y la penetración tecnológica para la generación y el consumo de energía menos contaminante.

El último capítulo de esta sección es el de Cristina Muñoz y Gabriel Pérez-Salas sobre "El papel de la logística en las redes globales de recursos naturales desde una perspectiva multiescalar", donde se explora la relación entre la logística y la explotación de los recursos naturales, partiendo del concepto de cadenas globales de valor, que actualmente es la noción más extendida para explicar el estudio del intercambio de bienes y servicios a nivel global, local o "glocal", como indican los autores. El foco está puesto en los elementos que contribuyen a una integración de las infraestructuras logísticas y a la búsqueda de un equilibrio entre costos y desarrollo sostenible en el largo plazo. Muchos de los problemas actuales de la explotación de recursos naturales surgen de una inadecuada planificación histórica del territorio, de la escasez de servicios de infraestructura y de las externalidades negativas sobre la población y el medio ambiente. Por ello, se señala que una adecuada gobernanza de los recursos naturales requiere de una gobernanza de la infraestructura ad hoc, que permita implementar, entre otros, el uso compartido de la infraestructura y el diseño de políticas públicas orientadas a reducir costos logísticos y ambientales.

La segunda sección del libro está referida a políticas y estrategias de largo plazo e incluye un artículo sobre la gobernanza de los recursos en relación a los Objetivos de Desarrollo Sostenible. El artículo de Shreya Kumra sobre "La gobernanza de los recursos naturales y su vínculo con los Objetivos de Desarrollo Sostenible" fija su atención en las diversas alternativas de una buena gobernanza de los recursos naturales. Los aportes de la tecnología, pero fundamentalmente las políticas públicas para una transformación de los hábitos actuales de uso y consumo de bienes en la sociedad, son cruciales para entender la complejidad de los desafíos impuestos y la escala de su aplicabilidad a nivel global, regional, nacional y local. Dicha transformación solo será posible mediante la concienciación sobre los riesgos sociales o ambientales y el aumento de la información y el conocimiento sobre el papel de los recursos y sobre su estado actual.

Por su parte, en el capítulo de José María Fanelli, "Recursos naturales y crecimiento sostenible: lecciones aprendidas del período de auge de precios", se analizan los recursos naturales y las condiciones macroeconómicas de los países de la región con el fin de comprender mejor las posibilidades reales que existen en la región para convertir la bonanza en procesos de crecimiento sostenido. Efectivamente, uno de los objetivos es entender que la bonanza implica cambios, pero también procesos de adaptación de las propias economías expuestas a choques de inversiones y de demanda. En ese sentido las lecciones que menciona el autor alcanzan a la macroeconomía y al marco institucional y de políticas 
públicas por igual. Así, enfocado en un marco conceptual que sale de la dicotomía sobre la supuesta maldición o bendición de los recursos, Fanelli utiliza las vicisitudes de los procesos generadas por la explotación de los recursos mineros y de los hidrocarburos durante la bonanza de precios en Chile, Colombia y el Perú para, desde un ángulo comparativo, identificar algunas enseñanzas generales y otras lecciones específicas. Se trata de un análisis que detrás de su constitución didáctica y exploratoria, y sin cruzar completamente una línea de enfoque contrafáctico, ofrece hipótesis certeras sobre la relación entre los recursos naturales y las posibilidades de crecimiento sostenido para los países de América Latina y el Caribe.

En una línea similar, aunque más experimental en sus comprobaciones, el capítulo de Ricardo J. Sánchez, Silvana Sánchez di Doménico y Beatriz Tovar de la Fe sobre "La bendición o la maldición de los recursos naturales: un breve análisis empírico", despunta un exhaustivo trabajo de correlaciones entre los recursos naturales y la distribución del ingreso en los países de América Latina y el Caribe. A tal fin construyeron un panel de datos estadísticos de comercio exterior de 21 países a los que se sumaron los indicadores de desigualdad del índice Gini y algunas variables representativas (proxy) para evaluar la calidad institucional en base a los índices de gobernabilidad y de corrupción elaborados por el Banco Mundial y Transparencia Internacional. Con el análisis de una selección de lecturas de distintos autores que analizaron la relación entre recursos naturales e ingreso, el artículo exhibe con objetividad la utilidad del ejercicio empírico para sacar algunas conclusiones sobre la desigualdad del ingreso y la explotación de los recursos naturales en los países de la región. Ponen en duda o al menos cuestionan la idea de la existencia de una maldición asociada a una mayor o menor abundancia de recursos y analizan la correlación que puede existir con factores asociados a la propia índole de esos recursos o la condición de su explotación. Como en el caso de otros capítulos, la gobernanza, o, mejor dicho, la vigencia de una gobernanza inadecuada, aparece como una señal de alarma que, no obstante, puede corregirse con buenas instituciones y políticas públicas adecuadas.

Finalmente, está sección cierra con el capítulo de Jean J. Acquatella, Omar D. Bello y Félix Berríos, sobre "Evidencia estadística de superciclos en las series de precios de los metales y el petróleo, 1900-2015", una exhaustiva labor que identifica y evalúa datos estadísticos de al menos cuatro componentes cíclicos de periodicidad de entre 20 y 70 años en todas las series históricas de precio real entre 1900-2015. Según este estudio, el último superciclo comenzó en 2000 y tuvo una duración media de 15 años para niveles de precio no observados desde la década de 1970, algo que para la mayoría de los países significó un impulso al crecimiento, traducido en este caso en una reducción de la pobreza y en una mejora del consumo no vistos en la región por más de tres décadas. Más importante aún, los datos ponen en tela de juicio características que se consideraban estructurales o decisiones de política económica referida a la especialización excesiva 
de algunos países en relación a las exportaciones de bienes primarios $\mathrm{u}$ originados en recursos naturales, lo que reitera las recomendaciones sobre la necesidad que tiene la región de mejorar su capacidad y horizonte de diversificación productiva. El capítulo hace referencia también, a la luz de los acontecimientos, a la movediza y atractiva dinámica de los recursos naturales y sus comportamientos económicos, toda vez que es posible actualmente encontrar diferencias entre el momento actual y los resultados del período analizado.

En la tercera sección se reúnen dos trabajos relacionados con la institucionalidad. En uno de ellos se examina la definición de gobernanza per se y en relación con los recursos naturales en América Latina y en el otro se analizan las políticas e iniciativas globales con relación a la transparencia y la rendición de cuentas en las industrias extractivas. El primero es un trabajo de Ernesto Cussianovich sobre "La gobernanza de los recursos naturales desde la mirada los ciudadanos", que examina algunas definiciones sobre el concepto de gobernanza en relación con el concepto de gobernabilidad y ofrece algunos ejemplos sobre el uso y la comprensión del primero en relación con los recursos naturales. A su vez, dichos recursos se analizan en asociación con el valor e influencia que tienen sobre el común de los ciudadanos en tanto generadores de una identidad y un ideal de soberanía, riqueza y futuro. El capítulo examina, además, la opinión y percepción de los ciudadanos en relación con los recursos naturales, en especial a la hora de confrontar y sopesar el valor de su explotación y la obtención de rentas respecto de los beneficios que ofrecen bajo el influjo de la presencia o intervención del Estado.

Por su parte, el capítulo de Víctor Andrés Garzón y Michael Röesch, "Avances y retos en iniciativas y políticas de transparencia y rendición de cuentas en las industrias extractivas", sobre las implicancias de la ausencia de información de calidad por parte de gobiernos y empresas ligadas a la explotación de recursos naturales, completa esta sección. Los autores muestran de forma recurrente los obstáculos que se crean cuando las industrias extractivas defienden una cultura de opacidad o falta de transparencia sostenida en el temor infundado de que la provisión de información puede, en ocasiones, dañar su competitividad. Garzón y Röesch muestran como la apertura y ampliación de la información al público, lejos de afectar el posicionamiento de empresas y gobiernos, contribuyen a mejorarlo. Más y mejor información sobre los procesos productivos de los recursos naturales o, en general, de las vicisitudes de su explotación redundan en beneficios que pueden incluso medirse o calcularse. Los autores insisten en la necesidad de impulsar aún con más fuerza las exigencias de transparencia y de rendición de cuentas que - afortunadamente- han aumentado sustancialmente en los últimos años, por ejemplo, en el sector minero, sin embargo, todavía hay una agenda pendiente que habría que completar y continuar en los países de la región. 
En la cuarta sección sobre macroeconomía y asuntos fiscales se incluyen tres capítulos. En el primero, de Michael Hanni, Juan Pablo Jiménez e Ignacio Ruelas, que lleva como título "Regímenes fiscales vinculados a los recursos naturales no renovables en América Latina y el Caribe y su relación con el ciclo de precios: evolución reciente y desafíos pendientes", los autores se proponen revisar las reformas fiscales referidas a los recursos naturales, diferenciando las implementadas en cada fase del ciclo, y la relación con la evolución y el impacto sobre las cuentas públicas. El acento está puesto, ciertamente, en los desafíos que enfrentan los regímenes fiscales de los países donde abundan los recursos naturales. Al respecto, los autores señalan que la evolución de los ingresos fiscales generados por la explotación de los recursos naturales muestra fuertes fluctuaciones en la última década. El desempeño de estos ingresos se relaciona tanto con las variaciones de los precios de los productos gravados como con las transformaciones de los regímenes fiscales. A partir de 2003 se registró un significativo incremento de los precios de las materias primas que permitió una mayor disponibilidad de divisas para la financiación del crecimiento, pero también diversas reformas tributarias que permitieron una ampliación del espacio fiscal de los países especializados en materias primas.

El objetivo del capítulo de José María Fanelli sobre "Asignación del espacio fiscal y recursos naturales: un marco conceptual con perspectiva latinoamericana" es examinar los vínculos entre la asignación del espacio fiscal y los recursos naturales desde una mirada más conceptual. Fanelli se pregunta sobre la importancia de este vínculo para justipreciar la relevancia de los recursos naturales en tanto generadores de una parte sustancial de los fondos fiscales de los países ricos en materias primas. Asimismo, insiste en tener en cuenta que las rentas provenientes de los recursos naturales tienen características particulares, entre las que se destacan la volatilidad, el agotamiento, la distorsión de precios y el impacto visible sobre el medio ambiente. Más aún, el autor destaca que las rentas generan procesos de apropiación que dan lugar a conflictos distributivos por lo que es imprescindible un marco institucional y de gobernanza.

Algunos de estos argumentos son reelaborados en el capítulo de Miryam Saade Hazin y Daniel Sotelsek Salem sobre "Implementación, adaptación y funcionamiento de los fondos soberanos de inversión". En él los autores evalúan los fondos soberanos en cuanto instrumentos que, en años recientes, se han convertido en el punto de referencia o han servido para la canalización del ahorro proveniente de las rentas de la explotación de los recursos naturales. Los autores aseguran que, por definición, la propia constitución de estos fondos merece analizarse en detalle, así como los fines que cumplirían y su capacidad de mejorar la administración y recaudación rentas. Pero según estos especialistas, se debe reconocer también que se trata de instrumentos que van más allá de su función, ya que incorporan o adoptan una estructura de reglas 
fiscales y presupuestarias que ayudan a comprender la importancia de la gobernanza de los recursos naturales.

La última sección de la compilación, sobre conflictos sociales y ambientales, incluye un capítulo de Nicolás González sobre "La conflictividad vinculada a los recursos naturales en América Latina: tendencias y mecanismos institucionales de respuesta", y otro de Carlos de Miguel y Mauricio Pereira sobre los "Pasivos ambientales mineros: retos para la sostenibilidad". El primero de estos artículos describe las características más importantes de la conflictividad social asociada a los recursos naturales en los países de la región y explora algunas de las respuestas más innovadoras ensayadas por los propios países para prevenir y transformar los conflictos. Se trata de destacar lecciones valiosas para la implementación de los Objetivos de Desarrollo Sostenible y para los esfuerzos dirigidos a mantener la paz en la región, aún a pesar de algunos obstáculos, como la inexistencia de datos de calidad para determinar la magnitud del fenómeno de la conflictividad.

Finalmente, De Miguel y Pereira analizan las externalidades ambientales y los potenciales riesgos sobre la salud de las personas y de los ecosistemas que trae aparejada la explotación minera en los países de América Latina y el Caribe. Los autores analizan los pasivos ambientales mineros como una de las fuentes de presión más significativas de la minería sobre el medio ambiente; originados hace décadas o incluso siglos, el registro de su número, cantidad o calidad es muy pobre. La gestión, monitoreo y remediación de estos pasivos ambientales mineros, incluidos los marcos tanto legales como institucionales y los aspectos preventivos asociados al cierre de faenas mineras, se estudian a la luz de las recomendaciones internacionales y de las acciones llevadas a cabo en países con mayor experiencia.

En suma, los trabajos reunidos en este libro contribuyen a reflexionar sobre las condiciones políticas, sociales, económicas y ambientales de los países de la región en relación con la explotación de sus recursos naturales. Este libro es continuidad del anterior, Hacia una nueva gobernanza de los recursos naturales en América Latina y el Caribe, publicado en 2016. En ambos casos la gobernanza está en el centro de la escena, en especial para los países con recursos mineros y de hidrocarburos y para aquellos que hoy necesitan revisar sus marcos legales, institucionales y políticos en conjunción con la agenda económica y social, pero también con la cada vez más extendida preocupación por la situación del medio ambiente.

Es preciso cerrar esta introducción con el reconocimiento a los autores de los capítulos que forman parte de este libro. Se trata de un grupo de profesionales de altísimas calificaciones humanas y académicas, que permitieron que el proceso de concepción, elaboración y preparación de este libro haya sido un gran honor. 

Capítulo I

\title{
Recursos minerales: capacidad de carga y desarrollo sostenible
}

\author{
Diego Azqueta \\ Daniel Sotelsek Salem
}

El presente capítulo incluye una aproximación conceptual a la sostenibilidad, como así también sus principales retos en materia jurídica y de decisiones de fondo con respecto a la explotación de los recursos minerales. Se analizan brevemente los principales pilares de la sostenibilidad, para dar lugar después al análisis sobre los diversos impactos de la minería.

\section{A. Aproximación conceptual}

La gestión sostenible de los recursos naturales no renovables comporta un claro desafío dado que, por definición, sus existencias son finitas. Es por ello que el concepto de sostenibilidad en este caso no se refiere a una gestión que permita un flujo permanente del recurso a lo largo del tiempo, sino a aquella que proporcione a la sociedad que lo posee un flujo de rentas sostenible en el tiempo en un contexto de estabilidad social. En este sentido es que hay que entender el concepto de capacidad de carga de estos recursos: es la capacidad para proporcionar ese flujo de rentas netas, atendiendo a la sostenibilidad económica, social y ambiental.

Los recursos de los que trata este capítulo, buscando los elementos esenciales de su gestión sostenible, son básicamente de cuatro tipos:

i) Minerales metálicos: hierro, cobre, cinc y otros. 
ii) Minerales de construcción: piedra, arena, grava, rocas industriales y ornamentales, áridos y otros.

iii) Minerales energéticos: carbón, petróleo y gas natural.

iv) Minerales industriales: carbonato de calcio, boro, caolín y talco.

Estos recursos se consideran convencionalmente como no renovables, aunque conviene distinguir entre los que se transforman y desaparecen con el uso (energéticos) y aquellos que, si bien se disipan, permanecen. La sostenibilidad física en el manejo de estos recursos viene condicionada por el tamaño de sus reservas y, en el caso de los segundos, también por el reciclaje. Como señala Nordhaus (1974), entre las reservas probadas y la presencia en la corteza terrestre se encuentran los recursos recuperables, que son los económicamente relevantes. El tamaño de estos últimos es una variable dinámica que depende de la inversión en exploración y en tecnología de extracción, transporte y uso final.

Desde el punto de vista geográfico, todos los recursos mencionados en la clasificación anterior están localizados originalmente en un determinado territorio, lo que condiciona el comienzo de su explotación y la vuelve referenciada respecto de la geografía. En el caso de algunos recursos no energéticos, sin embargo, el reciclaje rompe esta dependencia y hace que la oferta ya no esté limitada por la presencia de yacimientos, sino por la tecnología, el marco legal y los costos de transporte.

En este contexto, la gobernanza de los recursos naturales no renovables es un tema central en el reto que supone un desarrollo sostenible, ya que este debe incluir aspectos en muchos casos enfrentados y que pueden derivar en un conflicto o trilema de la sostenibilidad a partir de diferenciar los aspectos económicos, sociales y ambientales.

\section{B. Los retos del desarrollo sostenible}

La gestión de los recursos no renovables con una perspectiva social debe tratar de maximizar el valor presente neto de su explotación para la sociedad como un todo. Es decir que se ha de intentar que el impacto positivo de la gestión de estos recursos sobre el bienestar social sea el máximo posible, incluso para las generaciones futuras. Para ello es necesario enfrentarse a dos interrogantes que, si bien están relacionados, a los efectos expositivos pueden abordarse por separado.

i) Lo primero es la decisión de extraer o no extraer, que, por supuesto, dependerá de los costos y beneficios asociados a la tarea. Desde el punto de vista de los beneficios, estos vendrán determinados por el valor que la sociedad otorgue a las necesidades humanas satisfechas con el producto de la explotación (por ejemplo, las necesidades cubiertas con las divisas obtenidas de la exportación, que pueden invertirse en salud, alimentación, educación y otras áreas). Desde el punto de vista de los costos, estos incluirán no solo los costos 
económicos relativos a la exploración, extracción, transporte y transformación, en su caso, de los recursos no renovables, sino también los costos ambientales y sociales que estas operaciones conllevan (ocupación del suelo, transformación del territorio, impactos culturales, pérdida de diversidad biológica y demás). La extracción y explotación de estos recursos solo deberían llevarse a cabo si los primeros superan a los segundos.

ii) En segundo lugar, y una vez decidida la explotación del recurso, se plantea el dilema de decidir la velocidad de extracción, teniendo en cuenta que los yacimientos, con las matizaciones planteadas anteriormente, son agotables. Este dilema encierra un problema de equidad intergeneracional. La solución canónica —el modelo de Hotelling - reposa sobre el principio de que la rentabilidad social del recurso, en el margen, debe ser la misma bajo tierra que fuera (esto es, extraído que no extraído). La rentabilidad social de no extraer viene dada por la revalorización esperada del recurso, dependiente, a su vez, del precio futuro de dicho recurso y de la mejora de las técnicas de extracción y explotación; en definitiva, del eventual abaratamiento de costos. El hecho de que el recurso sea finito tenderá a empujar al alza su precio futuro, pero esta presión alcista se verá atemperada por el progreso técnico asociado a la existencia de sustitutivos, la eficiencia de su uso en el proceso productivo, los costos de explotación, como ya se ha apuntado, y los costos relativos del reciclaje. Todo ello está condicionado por la gran volatilidad que se manifiesta en los precios de los mercados futuros de estos recursos y que complica enormemente la toma de una decisión que, una vez adoptada y en términos generales, deja poco margen para la flexibilidad.

¿Cuáles son las exigencias que implica garantizar un desarrollo sostenible en la gestión de los recursos minerales? Dado que desde la lógica resulta imposible garantizar una explotación físicamente sostenible de un recurso que es, por definición, finito, el requisito de la sostenibilidad se desdobla en tres componentes:

i) Sostenibilidad económica. Hace referencia a la necesidad de que el flujo de rentas derivado de la explotación de estos recursos, y de las actividades económicas afectadas por dicha explotación, sea sostenible en el tiempo.

ii) Sostenibilidad social. Implica el requisito de que el modo de vida y de organización social del colectivo en cuyo nombre se gestiona el recurso no se ponga en peligro ni se vea alterado más allá de lo que desean sus propios componentes.

iii) Sostenibilidad ambiental. Introduce la restricción de que la explotación de estos recursos no ponga en peligro el capital natural crítico ni el equilibrio ecológico del ecosistema ${ }^{1}$. 
A lo expuesto se añade el problema de garantizar la equidad en el reparto intergeneracional de estos recursos, problema que puede plantearse de una forma más rigurosa, como se verá más adelante, con ayuda de la institución de los fondos soberanos. Ello permitiría garantizar la constancia del acervo de capital a disposición de la sociedad, sustituyendo capital natural por capital físico, social, humano o tecnológico. No puede perderse de vista, sin embargo, que la rentabilidad social del capital depende del nivel de renta de la sociedad, lo que en economías de bajos ingresos quiere decir que esta va disminuyendo con el aumento de la renta y la riqueza, al ir disminuyendo la urgencia de las necesidades que se satisfacen con la inversión².

\section{Marco legal: derechos sobre los recursos del subsuelo}

La consecución del desarrollo sostenible requiere, como primer paso, la determinación del colectivo social en cuyo nombre se busca alcanzar este objetivo. La respuesta más obvia, desde la perspectiva del análisis económico, sería la humanidad en su conjunto, incluidas las generaciones futuras, pero esta determinación choca con el catálogo de derechos que los diversos grupos sociales se han concedido con respecto a los recursos naturales y, más en concreto, a los recursos del suelo y del subsuelo. En efecto, si bien la sostenibilidad ambiental puede llegar a involucrar al planeta como un todo, la sostenibilidad económica y la sostenibilidad social se plantean, en la práctica, con referencia a un colectivo humano mucho más limitado.

En términos generales, por tanto, se considera que la gestión de los recursos del subsuelo debe realizarse teniendo como objetivo el desarrollo sostenible de la nación, tanto desde el punto de vista económico como social. Esto implica, como es obvio, que los recursos del subsuelo pertenecen a todos los ciudadanos. Sin embargo, la relación entre la propiedad del suelo y los recursos del subsuelo hace que esta presunción sea más que problemática.

Cuando la propiedad del suelo conlleva la de los recursos del subsuelo, como ocurre, por ejemplo, en los Estados Unidos, la gestión sostenible ha de negociarse con el propietario de la tierra. En estos casos, el marco legal que establece lo que se puede hacer y cómo se debe hacer es el llamado a garantizar la sostenibilidad ambiental y el marco fiscal es el que determina el reparto de las utilidades obtenidas en la explotación.

En la mayoría de los casos, si bien la propiedad de los recursos del subsuelo se reserva para la nación, la comunidad local, muchas veces

Es por ello que la tasa contable de interés (expresión de la rentabilidad social de la inversión), que en un principio es superior a la tasa de descuento del consumo (expresión de la preferencia temporal de la sociedad), debe tender a disminuir con las políticas apropiadas hasta, en equilibrio, quedar igual a ella. 
propietaria de la tierra, tiene reconocidos algunos derechos con respecto a la explotación de los recursos minerales y energéticos que se encuentran en su territorio. Aunque la casuística es muy amplia, el problema fundamental al que se va a enfrentar el decisor social en este caso es el de la pronunciada asimetría existente en el reparto de los costos y beneficios de la explotación de estos recursos.

Con respecto al reparto de los beneficios, y una vez descontados los costos de explotación (incluidos los correspondientes beneficios de la empresa extractora), el abanico iría desde el beneficio per cápita correspondiente a un reparto que incluyera a todos los ciudadanos del Estado hasta el que correspondería a cada miembro de la comunidad local en exclusiva, si esta tuviera reconocido este derecho. Como es obvio, la diferencia de beneficios per cápita puede llegar a ser muy sustancial (no es lo mismo dividir una determinada cantidad entre cientos de personas que entre miles o millones), lo que explica la presión de las comunidades locales para controlar la explotación de estos recursos.

A ello se suma que el mismo cálculo de los beneficios puede ser diferente. Por una parte, porque es probable que la comunidad local atienda a la rentabilidad financiera de los flujos recibidos, dada por el mercado de capitales. Por la otra, y en el hipotético caso de que tanto la comunidad local como el decisor nacional atendieran a la rentabilidad social de estos fondos, esta no tiene por qué ser la misma. Lo más probable es que la rentabilidad social de la inversión nacional (y, por tanto, los beneficios nacionales) sea superior a la rentabilidad social de la inversión local (beneficios locales), aunque solo sea porque el abanico de posibilidades de inversión social nacional es muy superior al local, y además lo incluye.

\section{Sostenibilidad económica}

La sostenibilidad económica hace referencia, como ya se ha indicado, a la necesidad de garantizar un flujo constante de rendimientos netos - directos e indirectos- a lo largo del tiempo y con base en la explotación de los recursos minerales. Al ser estos, por definición, agotables, lo que se requiere es mantener el acervo total de capital de la nación, sustituyendo el capital natural que constituyen los yacimientos, y que se irá agotando con el paso del tiempo, por otro tipo de capital (físico o humano) ${ }^{3}$. Esto implica respetar la denominada "regla de Hartwick", lo que no supone necesariamente suscribir el paradigma de la sostenibilidad débil. La sustitución de un tipo de capital por otro garantiza el mantenimiento de las rentas hicksianas derivadas de dicho capital, es decir, aquellas rentas que se pueden consumir en un período de tiempo sin que el acervo de capital inicial disminuya.

El agotamiento de cada yacimiento dependerá no solo de la presencia física del recurso en dicho yacimiento, sino también de la tecnología, los precios relativos y los costos de extracción. 
Ahora bien, esta sustituibilidad no se extiende hasta el denominado "capital natural crítico", mencionado anteriormente, ya que este se considera insustituible y aparece como una restricción adicional en el problema de maximización del bienestar social. Es ahí donde se respeta el principio de la sostenibilidad fuerte. Si bien es muy improbable que los recursos naturales de los que trata este capítulo formen parte de este capital natural crítico, máxime teniendo en cuenta las posibilidades de reciclaje, su explotación sí puede poner en peligro su mantenimiento, como se verá en la sección I.D, donde se aborda la sostenibilidad ambiental.

El primer problema al que se enfrenta la sostenibilidad económica es el referente al reparto de los beneficios de la explotación del recurso entre el agente - $\mathrm{o}$ los agentes - que lo explota y comercializa y el Estado como representante de la colectividad. Cuando bajo el denominado "régimen propietario" (Abdo, 2014) el Estado es no solo el dueño del recurso, como representante de la nación, sino también quien lo explota, a través, por ejemplo, de una empresa pública, las utilidades netas derivadas de la presencia del recurso quedan en manos del sector público y este debe decidir sobre su destino. Incluso en este caso, resulta difícil distinguir entre la renta de explotación de la actividad y la renta obtenida por los derechos de propiedad.

El conflicto aparece de forma mucho más aguda en el caso en que el Estado, si bien es el propietario de los recursos del subsuelo, no lleva a cabo directamente su explotación, sino que la concesiona a una empresa independiente, pública (incluso de otro país) o privada.

La fiscalidad de los recursos naturales no renovables es un tema muy complejo que se aborda en el capítulo XII. No es este pues el momento ni el lugar para detenerse en ello. Cabría señalar simplemente que, desde una perspectiva teórica, el sistema adoptado deberá enfrentar al menos los siguientes dilemas:

- A pesar de que estos recursos han sido producidos o proporcionados por la naturaleza y, en virtud de ello, aparecen como gratuitos, tienen un costo de oportunidad que debe reflejarse en su valor —el denominado "costo para el usuario" y que pertenece al propietario. La empresa concesionaria debería pagar este valor, más allá de las regalías, tasas o impuestos asociados a su actividad ${ }^{4}$.

- La fiscalidad, por tanto, o bien se refiere a las condiciones pactadas para la realización de un servicio concreto (la explotación del recurso: sistema de contratación) o bien se aplica a las utilidades obtenidas en la explotación de dicho recurso, una vez descontado su valor (sistema de concesión). El problema que se plantea en este contexto es el de hacer compatible este reparto con los

\footnotetext{
4 Sobre el cálculo del costo para el usuario del capital natural véase El Serafy (2013, cap. 5).
} 
incentivos, por parte de la empresa concesionaria, para invertir en el mantenimiento de las instalaciones, la exploración de nuevos yacimientos y el uso eficiente de los que ya existen. Como señalan Arroyo y Perdiel (2015), el sistema fiscal no debe enfocarse hacia la maximización de la producción a corto plazo, sino hacia la maximización de los volúmenes recuperables y del valor presente neto de su explotación.

- En tercer lugar, se presenta el problema de la volatilidad de los precios de estos recursos. En un contexto caracterizado por una alta volatilidad de precios, el sistema fiscal diseñado debe ser capaz de proporcionar un reparto de utilidades, o un pago por el servicio prestado, que no resulte inaceptable para ninguna de las partes ante un cambio sustancial en el precio del recurso. Esto debe hacerlo, además, con una vocación de permanencia; como ha señalado Abdo (2014), el cambio en las reglas del juego ante cambios en los precios puede ser muy contraproducente. Sería fundamental, en este contexto, fijar claramente las reglas del juego que permitieran modificar las reglas establecidas.

Una vez diseñado el sistema fiscal y el reparto de utilidades correspondiente, el siguiente paso es garantizar la sostenibilidad económica de este rendimiento en el tiempo.

\section{Los fondos soberanos}

En este marco aparece como muy adecuada la constitución de un fondo soberano: un fondo de inversión de propiedad del Estado que se alimenta con los beneficios netos de la explotación de los recursos naturales. En este sentido, cumple una doble función:

- Por una parte, permite neutralizar los perjuicios asociados a la enfermedad holandesa.Alcontrolarelflujodedivisas proveniente de la explotación del recurso, puede impedir su entrada en el sistema económico y, de esta forma, esterilizándolo, prevenir la apreciación del tipo de cambio. También es fundamental poner en marcha una política contracíclica que aísle el sistema fiscal de las fluctuaciones en los precios internacionales de las materias primas y los recursos naturales.

- Por otra parte, puede lograr el mantenimiento del acervo total de capital, invirtiendo una parte de estas utilidades en incrementar el capital físico o humano, de forma tal que se cumpla la mencionada regla de Hartwick y que este aumento sustituya el capital natural perdido. Con ello se garantizaría la equidad intergeneracional en el reparto de los beneficios asociados a la presencia de un recurso natural no renovable. 
El principio fundamental tras la constitución de estos fondos es evitar que los rendimientos de la explotación de recursos naturales no renovables sirvan para financiar gasto corriente. Se trata de ahorrar o invertir estos rendimientos para garantizar a las generaciones futuras una parte de los beneficios asociados a la existencia de estos recursos. En ocasiones, también se utilizan para un objetivo intermedio: garantizar el sistema de pensiones. Es por ello que existen distintos tipos de fondos, aun cuando todos comparten esta característica común (véase una exposición detallada en Altomonte y Sánchez, 2016) 5 . Varios países de América Latina han constituido este tipo de fondos (en ocasiones incluso más de uno) y otros han dictaminado por ley la imposibilidad de financiar gasto corriente con los rendimientos derivados de la explotación de recursos no renovables.

\section{a) Mantenimiento del capital total y rentabilidad social de la inversión}

Una vez garantizada la continuidad del capital total a través, por ejemplo, de la constitución de un fondo soberano, la siguiente interrogante que surge es obvia: ¿en qué invertir esos fondos? ¿En activos financieros que garanticen su permanencia y rentabilidad? ¿En capital humano: educación y salud? ¿En infraestructuras necesarias? ¿En investigación? ¿Cómo se garantiza mejor la equidad con respecto a las generaciones futuras sin perder de vista las acuciantes necesidades de la generación presente en muchos de estos países? ¿Garantizando el mantenimiento y el crecimiento del fondo? ¿Invirtiendo parte de dicho fondo en políticas de desarrollo?

Es muy probable que, dadas las graves carencias existentes en los países poseedores de estos recursos naturales, la rentabilidad social de la inversión sea muy superior a la rentabilidad financiera del capital en términos reales ${ }^{6}$. Por ello, una gestión prudente de estos fondos justificaría su dedicación parcial a la inversión en sectores clave para el desarrollo. El propio Fondo Monetario Internacional (FMI) aboga por un régimen fiscal que, abandonando la hipótesis conservadora de la renta permanente, abra un espacio para este tipo de inversiones (Altomonte y Sánchez, 2016).

Se puede argumentar, por tanto, que lo mejor es invertir estos fondos en educación, salud, capacitación, infraestructura e investigación, desarrollo e innovación. Si bien esto es indudablemente acertado, no ayuda mucho al decisor social. Se necesita algo más de precisión, sobre todo a la vista de que, por ejemplo, como se resalta una y otra vez en los estudios empíricos, un mayor gasto en educación no siempre viene acompañado de una mejora en

Es fundamental, asimismo, garantizar la elevada calidad institucional en estos fondos para evitar desvíos, corrupción e ineficiencia. Entre los índices de gobernanza de estos fondos se destacan el índice de transparencia Linaburg-Maduell, el índice de la gobernanza de los recursos naturales y el índice de los fondos soberanos de Truman (Altomonte y Sánchez, 2016, págs. 157-159).

$6 \quad$ La excepción aparece cuando el riesgo país es muy alto y la rentabilidad financiera de amortizar deuda también lo es. Sin embargo, no puede perderse de vista que esta amortización de deuda finalmente libera recursos que pueden utilizarse para la inversión interna. 
el rendimiento educativo. En este sentido es muy pertinente la observación de Wright y Czelusta (2004) con respecto a la conveniencia de relacionar estas inversiones en capacitación, formación e innovación tecnológica con el propio sector de origen de estos fondos (por ejemplo, el sector de la minería). Es decir, tratar de explotar de una forma más eficiente la ventaja comparativa que su presencia conlleva, invirtiendo en aquello que posibilitará la prolongación de esta ventaja comparativa en el tiempo, así como de retener un mayor volumen de valor añadido en la economía nacional.

La elevada tasa social de rendimiento de la inversión pública en estas economías, además de servir como una justificación para destinar a ella parte de los rendimientos de la explotación de los recursos naturales, puede generar un efecto negativo con respecto a la gestión de estos recursos que no puede perderse de vista.

La velocidad de extracción del recurso está condicionada, entre otras variables y como se establece en la regla de Hotelling, por la rentabilidad social de las inversiones que sus beneficios permiten. En economías de bajos ingresos y con una tasa de ahorro subóptima, esta rentabilidad social viene dada por la denominada "tasa de interés contable" que, como se apuntó anteriormente, es superior a la tasa social de descuento del consumo. Incluso desde la perspectiva de la mayor eficiencia social, esto generará una presión en favor de una más rápida extracción del recurso, lo que obliga a analizar con detenimiento el impacto de esta mayor velocidad sobre la viabilidad del propio yacimiento, así como sobre la sostenibilidad social y ambiental de su explotación. Por una parte, con respecto a la sostenibilidad social, porque una mayor velocidad de extracción implica un agotamiento más rápido - quizá incluso prematuro- del recurso y el cierre de las instalaciones, con el correspondiente efecto abandono. Por la otra, con respecto a la sostenibilidad ambiental, porque este incremento de la velocidad de extracción puede exacerbar los impactos ambientales negativos de la explotación.

Ahora bien, mantener constante el acervo total de capital es una condición necesaria, pero no suficiente, para garantizar la sostenibilidad económica. Es obligatorio, asimismo, analizar los impactos indirectos de las explotaciones mineras sobre la economía de la zona donde operan.

\section{b) Impactos indirectos sobre la economía local}

El impacto directo de la explotación de los recursos minerales se materializa, además de en lo apuntado anteriormente, en la creación de una serie de puestos de trabajo - directos, indirectos e inducidos-, que tienen el consiguiente impacto multiplicador sobre la economía local7.

Cabe señalar que los puestos de trabajo creados por la inversión en el sector de la minería son muy inferiores a los generados por una inversión equivalente en el comercio y la construcción (CEPAL, 2013). 
Este es un impacto económico positivo para la economía de la zona y muy valorado por las autoridades locales, que, sin embargo, se asocia a explotaciones con una vigencia temporal limitada. Conviene distinguir, en este sentido, los empleos generados en las fases de apertura y puesta en funcionamiento de las instalaciones de aquellos generados en las fases de funcionamiento y cierre y decomiso final.

Es muy importante, por tanto, gestionar la dinámica de las operaciones de forma que en la economía local no se produzca un efecto de desertización cuando estas lleguen a su fin. Se hace necesario reducir progresivamente la dependencia y la vulnerabilidad de la economía local con respecto a las operaciones mineras, diversificando las fuentes de creación de riqueza y la capacitación del factor humano local. Esto es algo mucho más fácil de plantear en la teoría que de llevar a la práctica en cada caso concreto.

Asimismo, reviste especial importancia analizar el impacto que la explotación del recurso tendrá sobre la distribución local de la renta, ya que, en función del marco institucional en la que esta se lleve a cabo, se puede producir una tendencia regresiva hacia el empeoramiento (los beneficios se concentran en manos de una élite) o, por el contrario, hacia la mejora (los beneficios repercuten sobre los más desfavorecidos).

La otra cara de la moneda la constituyen los efectos indirectos de las operaciones asociadas a la minería que repercuten negativamente sobre distintos sectores económicos locales y que también han de ser tomados en cuenta. Entre ellos pueden mencionarse:

- La competencia por el recurso agua. Las operaciones asociadas a la minería tienden a hacer un uso muy intensivo del recurso hídrico y en ello compiten con los usos tradicionales de dicho recurso, tanto en lo que respecta al uso humano, como al uso ganadero y agrícola. Por otra parte, y como se analizará más adelante, estas mismas operaciones tienden a tener un impacto negativo sobre la calidad del recurso debido a la cantidad de elementos contaminantes que se utilizan y producen, entre otros, en el proceso de extracción y procesado de los minerales, tranques de relave y balsas de remediación. Muchos de estos contaminantes encuentran su camino hacia las aguas subterráneas y superficiales y contaminan ambas.

- El impacto sobre los precios. La presencia de las empresas que llevan a cabo la explotación del yacimiento, con todo lo que ello comporta, presiona al alza los precios de determinados bienes y servicios cuya oferta no es perfectamente elástica. Esto ocurre en primer lugar con el precio de la tierra, del suelo y de todo tipo de inmuebles, debido a la necesidad de un espacio para las instalaciones de la empresa y la vivienda de sus trabajadores. 
En segundo término se encuentran los salarios de la mano de obra, básicamente no cualificada, que por lo general abandona el sector informal para incorporarse a un puesto de trabajo formal. En tercer lugar están los precios de muchos bienes y servicios perecederos y no perecederos que constituyen la canasta básica (como alimentos, combustible y otros) ${ }^{8}$.

- Por último, no pueden perderse de vista los efectos que la presencia de las nuevas operaciones tendrá sobre el equilibrio demográfico de la zona y, en concreto, sobre los flujos migratorios (véase la sección I.C.1).

Garantizar la sostenibilidad económica va entonces más allá de mantener constante el acervo de capital total de la economía y debe ocuparse también de los efectos que la presencia de las explotaciones mineras tiene sobre las actividades económicas tradicionales de la zona en la que operan.

\section{E. Sostenibilidad social}

El objetivo de la sostenibilidad social hace referencia a la necesidad de mantener la estabilidad económica y social de un determinado colectivo a través del tiempo. Planteado así, resulta en exceso genérico y ofrece poca información al decisor. Desde el punto de vista económico, es de suponer que cuando la explotación de un recurso se efectúa en un contexto de pobreza y desigualdad, el objetivo será precisamente superar esta situación. En otras palabras, sostenibilidad social sería equivalente a garantizar al grupo objetivo un nivel de vida digno (esto es, tener sus necesidades básicas satisfechas) a lo largo del tiempo. Se trata, por tanto, de una aspiración que dependerá de la propia capacidad del recurso para lograrlo y, sobre todo, de la delimitación del grupo en cuestión.

Introducir otros componentes, tales como el mantenimiento de la propia organización social o de su cultura, dentro del requisito de la sostenibilidad social resulta más problemático, pues ello podría llevar a cuestionar, por una parte, tanto la bondad del sistema de organización social prevaleciente, como el acervo cultural del grupo (en lo que respecta a las normas sociales de comportamiento como algo distinto de su historia y de su conocimiento), y, por la otra, quién está legitimado para cuestionarlo.

En cualquier caso, se hace necesario, de nuevo, delimitar con precisión el o los colectivos sociales involucrados en la explotación de los recursos naturales y sus derechos con respecto a dichos recursos. De otra forma, es difícil dar un contenido preciso al significado de sostenibilidad económica y social.

8 En algunos sectores caracterizados por la presencia de economías de escala no capturadas, la aparición de las nuevas instalaciones puede, por el contrario, llevar a un abaratamiento de costos y, por tanto, de precios. Muchas veces esto ocurre, por ejemplo, con el transporte público, la energía eléctrica y los servicios financieros y educativos. 


\section{El papel de las comunidades locales}

En general, la explotación de los recursos minerales se realiza fuera de los núcleos urbanos. El equilibrio social y cultural de las comunidades afectadas tiende a ser además muy frágil, en presencia de una economía cada vez más globalizada. Son muchos los elementos que amenazan este equilibrio y, en su caso, una transición no traumática hacia nuevos modelos de organización social. Uno de ellos es la inmigración descontrolada de personas de otros ámbitos culturales.

En este sentido, la apertura y explotación de nuevos yacimientos es muy probable que tenga como consecuencia la llegada de nuevos inmigrantes por numerosos motivos, entre los que cabría destacar:

- la oferta de puestos de trabajo que la propia explotación minera comporta,

- la aparición de minería a pequeña escala, minería informal y minería ilegal, a las que invita la presencia del yacimiento, y

- la apertura de nuevas vías de comunicación y facilidades de infraestructura que pueden utilizarse para la colonización agrícola.

En definitiva, hay un flujo potencial de nuevos inmigrantes que pueden poner en peligro el equilibrio social y cultural existente y su adaptación a nuevas realidades.

Es importante resaltar, en este sentido, que tanto la participación de la comunidad local en el reparto de las utilidades de las explotaciones mineras como la inversión pública en dicha comunidad pueden conspirar contra este mismo equilibrio y su evolución no traumática. Una participación muy elevada de la comunidad local en las ganancias de la explotación producirá un enriquecimiento de los favorecidos, en función de cómo se reparta, con el consiguiente efecto multiplicador, que se traducirá en un efecto llamada para potenciales inmigrantes. Lo mismo ocurrirá con aquellas inversiones públicas que permiten o mejoran el acceso y las condiciones de vida de estos inmigrantes potenciales. Es por ello que debe tenerse sumo cuidado en estos dos campos si se quiere preservar el equilibrio local y su evolución, ya que, si no es así, el resultado bien pudiera ser el enriquecimiento de unos pocos a costa del empobrecimiento de la mayoría y la ruptura del tejido social.

Resulta fundamental, por tanto, articular una participación de la sociedad local en la explotación de los recursos que sea satisfactoria para todos, teniendo en cuenta tanto el corto como el largo plazo. El marco normativo en el que esta participación ha de estructurarse viene dado, en general, por el respeto a los principios del consentimiento libre, previo e informado?

El consentimiento libre, previo e informado es un principio establecido en la Declaración de las Naciones Unidas sobre los Derechos de los Pueblos Indígenas (2007) y diseñado e implementado en el contexto de las recomendaciones del Foro Permanente para las Cuestiones Indígenas (FPCI). Aunque en principio solo afecta a las comunidades indígenas, sus recomendaciones tienden a hacerse extensivas a cualquier tipo de comunidad local. Véase una exposición muy completa 
Los costos económicos y sociales, sin embargo, se reparten de una forma más asimétrica, tanto entre la propia comunidad local como en ámbitos más amplios. En los casos de la pérdida de diversidad biológica, por ejemplo, o del cambio climático, se reparten entre todos los habitantes del planeta y las generaciones futuras. A ello se añade que el horizonte temporal en el que los responsables de la comunidad local resuelven el problema de maximización de la utilidad tiende a circunscribirse al corto o muy corto plazo, y que las externalidades negativas generadas sobre otro tipo de actividades económicas no suelen recaer sobre ellos. Todo esto conspira a favor de una solución que prioriza los beneficios financieros apropiables en el corto plazo frente a los costos sociales y ambientales, tanto en el corto como en el largo plazo. El resultado bien puede ser una explotación - o un ritmo de explotación - socialmente ineficiente y sin equidad.

\section{Licencias sociales para operar: evaluación crítica}

Desde hace algunos años, distintas compañías mineras comenzaron a firmar las denominadas "licencias sociales para operar" con las comunidades locales donde se proponen operar. Este es el caso, por ejemplo, de Tambogrande (Manhattan Minerals) y Minera Yanacocha (Newmont Mining) en el Perú, Las Cristinas (Placer Dome) en la República Bolivariana de Venezuela y Minera San Cristóbal (Sumitomo Corporation) en el Estado Plurinacional de Bolivia. Los resultados han sido muy variados, si bien el esquema no ha escapado a las críticas.

Por una parte, los defensores de este sistema argumentan que es una forma de incorporar a la comunidad local en la gestión del recurso, negociando con ella las características de la explotación y el reparto de beneficios. Ello garantiza - en principio - la paz social durante la vigencia de las operaciones y su buen desarrollo (Prno y Scott Slocombe, 2012). Bien articulados, estos acuerdos pueden ser clave para evitar algunos de los riesgos más graves asociados al comienzo y posterior desarrollo de las operaciones, como los derivados del atractivo para inmigrantes potenciales y la presencia de la minería de pequeña escala.

Estos acuerdos pueden contemplar no solo la necesidad de contratar población local en la explotación, sino también mecanismos de capacitación y formación de personal cualificado, sobre todo en los grados superiores. De esta forma, como ya se indicó, se buscaría prolongar la vida útil de la explotación diversificando su economía y reteniendo un mayor valor añadido para el país y la comunidad. La Fundación Alejandría en la provincia de Neuquén (Argentina), asociada a la explotación de hidrocarburos no convencionales, constituye una interesante iniciativa en este sentido (Arroyo y Perdiel, 2015).

del consentimiento libre, previo e informado en McGee (2009). Cabe destacar que la Corte Interamericana de Derechos Humanos estableció con claridad las propiedades que debió tener esta consulta en el caso del pueblo Saramaka vs. Suriname (véase Arroyo y Perdiel, 2015, pág. 88). 
Los críticos, por su parte, señalan que estos acuerdos se redactan y firman sobre la base de las expectativas y no de los resultados. Desde el punto de vista de la empresa minera son muy convenientes, ya que reducen la conflictividad social y también cierta incertidumbre, si bien no eliminan totalmente los conflictos dado el carácter cambiante y dinámico del proceso. Al respecto, véase, por ejemplo, el caso de la Minera San Cristóbal mencionado anteriormente ${ }^{10}$.

Los problemas aparecen, sin embargo, cuando se analiza el papel que cumple la población local y los beneficios que obtiene. Así surge el problema de la determinación, tanto del colectivo que ha de negociar la licencia con la empresa minera (la comunidad local, la provincia, el Estado u otro), como de la representatividad y legitimidad de sus dirigentes. En los contextos en que la institucionalidad es débil, las presiones con respecto a una gestión que favorezca los intereses de unos pocos a corto plazo en detrimento del bienestar colectivo a corto, medio y largo plazo tienden a ser más efectivas. Tanto más cuanto, como se indicó con anterioridad, mayores son las ganancias financieras por repartir y menor es el tamaño del grupo que participa en ese reparto.

Como es de esperar, en los contextos mencionados de pobre institucionalidad esto se ve agravado por problemas de corrupción. De tal forma que, para muchos críticos, la licencia social para operar corre el riesgo de convertirse más en un instrumento en favor de las empresas mineras y las élites locales que en una herramienta para garantizar una adecuada participación de la comunidad. Instrumentos como los acuerdos de impactos y beneficios, los acuerdos para el desarrollo de la comunidad y los acuerdos sobre la utilización de las tierras indígenas (para el caso de las comunidades indígenas) aparecen como más prometedores en este terreno, por ser más específicos (Owen y Kemp, 2013).

\section{F. Sostenibilidad ambiental}

La sostenibilidad ambiental en la gestión de los recursos naturales no renovables hace referencia a la necesidad de que su explotación no ponga en peligro la estabilidad del ecosistema.

Los impactos ambientales de las explotaciones mineras son indudables. Sin embargo, a efectos del análisis conviene distinguir entre los que afectan la sostenibilidad económica y social, así como el bienestar de las poblaciones afectadas, y los que repercuten directa o indirectamente sobre la sostenibilidad ambiental en el largo plazo. Los primeros, con sus correspondientes medidas de mitigación, deberán ser objeto de particular

10 El lector interesado en estos compromisos encontrará de interés Aranibar, Chaparro Ávila y Salgado Pavez (2011). 
atención en el contexto del análisis costo-beneficio que necesariamente se ha de realizar con respecto a la rentabilidad social que implica permitir la explotación. Los segundos, por involucrar potencialmente el capital natural crítico, aparecerán como una restricción adicional en el proceso de toma de decisiones con respecto a la conveniencia de la explotación y sus condiciones.

\section{Los impactos ambientales de la minería}

Las operaciones de minería, ya sean a cielo abierto o subterráneas, tienen impactos ambientales ciertamente relevantes. Aunque cada caso muestra sus propias peculiaridades y los peligros de la generalización son evidentes, podrían señalarse los siguientes impactos ambientales negativos sobre distintos sistemas receptores:

- Sobre el medio atmosférico. "Las variadas actividades mineras y de construcción asociadas, movilizan grandes cantidades de partículas de polvo. Éstas pueden producir impactos negativos debido tanto a su naturaleza física como química. (...) El procesamiento de minerales y específicamente las operaciones de fundición, emiten cantidades masivas de partículas y gases aéreos potencialmente tóxicos." (Moran, 2001).

- Sobre el medio hídrico. "La minería rompe y comprime la roca, creando nuevos túneles para que el oxígeno, aire y microbios, reaccionen con los minerales. En consecuencia, las rocas pueden generar ácido, movilizando otros muchos constituyentes químicos, los que podrían contaminar cuerpos de agua por décadas o incluso cientos de años después del cierre de la mina. Incluso el uso de explosivos aumenta las concentraciones de nitrato y amoníaco, provocando el incremento de la eutroficación y la contaminación de cuerpos de agua. La roca residual a menudo contiene concentraciones elevadas de sulfatos, metales tóxicos, no metales, y componentes radioactivos. Dicha roca generalmente se desecha en montones en la superficie del suelo, al borde de los tajos o fuera de las obras. Muchos contaminantes se pueden filtrar de estos montones de desecho, contaminando las aguas superficiales y subterráneas. El procesamiento del mineral generalmente requiere de tratamientos químicos para remover los metales pesados. Estos metales a menudo son filtrados directamente del mineral usando ácidos fuertes." (Morán, 2001).

- Sobre el suelo. Las operaciones mineras implican, en general, el movimiento y la transformación de grandes volúmenes de tierra, así como el depósito de desechos inertes y balsas de remediación y tranques de relave que modifican la morfología del territorio con la consiguiente modificación del paisaje. Estos impactos no solo son los directamente asociados al espacio que ocupan las 
explotaciones mineras y las infraestructuras asociadas, sino que también se derivan del impacto de estas sobre el ciclo hídrico, la erosión hídrica y eólica, y demás.

Como resultado, las personas se ven afectadas directamente mediante los efectos sobre la salud e indirectamente mediante el impacto sobre las actividades económicas, sociales y culturales. También se ven afectadas la flora y fauna, así como los procesos ecológicos (por ejemplo, las cadenas tróficas) y geofísicos (como los procesos de erosión y sedimentación) (Ayala Carcedo y Vadillo, 2004) ${ }^{11}$.

Estos impactos directos normalmente se verán agravados por la aparición de una serie de impactos indirectos, algunos de ellos de especial gravedad. En este último aspecto se destacan las siguientes marcas:

- En primer lugar, es probable que, por la presencia cierta del recurso, las explotaciones mineras legales establecidas en un territorio atraigan operaciones de minería artesanal, de pequeña escala y, a menudo, ilegales, que, por sus técnicas y preparación inadecuadas, agravarán los impactos antemencionados (Altomonte y Sánchez, 2016) $^{12}$.

- En segundo término, la apertura de nuevas vías de comunicación para acercar la maquinaria y los trabajadores para extraer el mineral y colocarlo en los circuitos de comercialización, y conectar las distintas operaciones entre sí, abre la posibilidad de una colonización de la frontera agrícola que acentúe la presión sobre el territorio y sobre la pérdida de ecosistemas muy valiosos. Este es el caso, por ejemplo, de la deforestación del bosque tropical primario que sigue a la apertura de vías de comunicación por parte de las empresas petroleras (Azqueta y Delacámara, 2008).

En definitiva, se trata de una serie de impactos ambientales - directos, indirectos e inducidos - que ciertamente afectan el bienestar social. Como ya se apuntó, conviene, sin embargo, distinguir dos familias de impactos en función de los componentes del bienestar social afectados, ya que se requiere un tratamiento diferenciado para cada grupo.

\section{Los impactos de la minería sobre el bienestar de la población local}

Los impactos ambientales de las explotaciones mineras sobre el suelo, el agua y la atmósfera inciden, como ya se mencionó, en el bienestar de las personas de distintas formas.

\footnotetext{
11 Véase una descripción de los impactos ambientales de la explotación de gas de esquisto en Arroyo y Perdiel (2015).

12 Véase una muy buena exposición de la situación de la minería artesanal del oro y sus impactos sobre la población y el medio natural en Saldarriaga-Isaza, Villegas-Palacio y Arango (2013).
} 
- Impacto sobre la salud. Tanto la contaminación del aire como la del agua pueden causar graves problemas de salud en las comunidades afectadas y elevar las tasas de morbilidad y mortalidad correspondientes. Asimismo, es posible que el movimiento de vehículos y maquinaria pesada, así como el uso de explosivos, cause accidentes que también incrementarán estas tasas. El análisis económico presenta toda una serie de metodologías basadas en la denominada "ruta de impacto" que posibilitan el cálculo monetario de la pérdida de bienestar social asociada a estos efectos negativos. En el caso de los cambios en las tasas de morbilidad, y una vez identificado el catálogo de sustancias contaminantes emitidas a los distintos medios receptores (aire, agua, suelo), su dispersión en el territorio, los agentes afectados y las correspondientes funciones exposición-respuesta, se aplica el denominado "método de los costos de tratamiento" o, alternativamente, las funciones de producción de salud. Con ello se valora monetariamente la pérdida de bienestar social que supone el hecho de que una persona caiga enferma o resulte accidentada como consecuencia de las operaciones mineras.

Para el caso de las tasas de mortalidad se aplica el valor de la vida estadística o de los años de vida perdidos, en función de cuál sea la causa del incremento y el colectivo de personas afectadas. Estos valores, que reflejan la pérdida de bienestar social asociada a un incremento en la probabilidad de muerte en el colectivo afectado, y no la pérdida de vidas humanas, se obtienen a partir del análisis de los salarios hedónicos o, alternativamente, de la aplicación del método de valoración contingente. El uso de los años de vida perdidos en lugar del valor de la vida estadística se justifica cuando la edad es una variable relevante a la hora de explicar la incidencia de determinadas afecciones derivadas de la contaminación, o en la aparición de muertes prematuras, como suele ser el caso de las enfermedades cardiovasculares y respiratorias.

- Impacto sobre las actividades económicas. Conviene en este caso distinguir dos contextos que merecen una aproximación diferenciada. La contaminación del aire y, sobre todo, del agua puede hacer inviables una serie de actividades económicas en los sectores agrícola, ganadero, forestal, piscícola y turístico. Se trata de una pérdida neta de recursos que, como tal, debe ser valorada. De nuevo, el análisis económico posibilita el cálculo de esta pérdida de bienestar social a través de los métodos basados en el estudio de las funciones de producción afectadas (por ejemplo, el método de los precios hedónicos para el caso de la agricultura y el método del costo de viaje para el del turismo). 
Ya se mencionó que el incremento en el precio de la tierra, del suelo o de la mano de obra no cualificada pueden tener el mismo efecto. En este segundo caso nos encontramos, sin embargo, ante una externalidad parcialmente pecuniaria, que en realidad implica una redistribución de la renta, ya que lo que pierden los agentes económicos que ven imposibilitada la continuidad de sus operaciones lo ganan los dueños de los recursos productivos revalorizados. Su tratamiento, por tanto, ha de ser distinto.

Por último, no debería perderse de vista que en ocasiones los impactos ambientales sobre los valores culturales son irreversibles, lo que plantea un serio problema. El propio desarrollo económico y social hace que lo que en un momento se valoró como fuente de recursos necesarios para satisfacer una serie de necesidades muy básicas, con el transcurso del tiempo y la mejora de la calidad de vida se transforma en una demanda de la naturaleza como un bien superior: la naturaleza como patrimonio social ambiental. En el caso de impactos irreversibles, este paso, que elevaría considerablemente el bienestar social, ya no es posible (Azqueta y Sotelsek, 2007).

Lo expuesto enfatiza la importancia del horizonte temporal en el que se decide sobre la gestión de los recursos. Una visión de corto plazo prioriza la extracción de ciertos recursos naturales que permiten satisfacer necesidades muy urgentes. Al hacerlo, sin embargo, y si no se toman las debidas precauciones cuando ello es posible, se sacrifica un patrimonio natural al que, con el paso del tiempo y la mejora de las condiciones de vida, la sociedad otorgaría un mayor valor. Este problema se agrava cuando existe una diferencia marcada entre el colectivo que se beneficia del recurso y el colectivo que valora el patrimonio, que suele ser sustancialmente mayor.

De todas formas, si bien repercuten sobre el bienestar de las personas afectadas, los impactos mencionados pueden no tener un efecto sobre la sostenibilidad ambiental. En este caso, afectarían la sostenibilidad económica y social y deberían identificarse, valorarse e incorporarse al análisis costo-beneficio sobre la conveniencia social de la explotación y de las condiciones en las que se lleva a cabo. Vale la pena, por tanto, centrar la atención en el segundo caso: cuando los impactos ambientales ponen en peligro el capital natural crítico o los equilibrios ecológicos relevantes.

\section{Los impactos de la minería sobre la sostenibilidad ambiental: el capital natural crítico y la diversidad biológica}

Los impactos indirectos sobre el agua y la atmósfera, junto con la ocupación directa e indirecta del suelo, pueden tener graves consecuencias sobre la diversidad biológica. La contaminación de la atmósfera y de las aguas superficiales y subterráneas, así como la transformación y ocupación del 
suelo, tanto por las propias actividades de la minería como por la colonización inducida, pueden afectar ecosistemas muy valiosos, tales como bosques primarios o manglares. Esto incide en uno de los principales valores ecológicos de estos ecosistemas: el hecho de ser un espacio de conservación de la diversidad biológica.

A diferencia de lo que ocurre con otros servicios ecológicos de los activos naturales, tales como el secuestro de carbono o la protección frente a la erosión, el valor económico de la conservación de la diversidad biológica es muy difícil de medir, si no imposible. El motivo es simple: en la actualidad está prácticamente fuera de nuestro alcance conocer el escenario de referencia con el que comparar el valor de la preservación. ¿Cómo serían las cosas si se perdiera un porcentaje de la diversidad biológica existente? Es decir, ¿cómo entra la diversidad biológica en las funciones de producción de bienes y servicios y de utilidad? ¿Es un argumento más de dichas funciones, con sus correspondientes relaciones de independencia, complementariedad o sustituibilidad, o es una restricción crítica que obliga a trabajar con funciones tipo Leontief? Esto, junto con el desconocimiento de la forma funcional de la relación existente entre la riqueza en diversidad biológica y el estado del medio, así como de la relación que existe entre la superficie de un determinado territorio y su riqueza en biodiversidad, impide llevar a cabo apropiadamente este proceso de valoración económica ${ }^{13}$.

En la literatura hay una gran cantidad de trabajos que afirman, no obstante, haber llevado a cabo un ejercicio de valoración económica de la biodiversidad, normalmente con la ayuda del mencionado método de valoración contingente. Es muy probable, sin embargo, que estos trabajos hayan incurrido en alguno de los siguientes problemas:

- El objeto de valoración. Muchos de estos ejercicios no han valorado la conservación de la biodiversidad como tal, sino la conservación de una determinada especie emblemática o de determinados recursos biológicos. Este es el caso, por ejemplo, de los estudios que descubren la disposición de la población a pagar por asegurar la conservación de una determinada especie.

- Su cobertura. Tal es el caso, por ejemplo, de uno de los métodos más utilizados para descubrir el valor de conservación de la diversidad biológica: el método basado en el pago de las empresas farmacéuticas por asegurarse el acceso a un determinado territorio para investigación. El caso pionero y paradigmático es el acuerdo

13 No es de extrañar este desconocimiento cuando todavía no se sabe con certeza cuál es la cantidad de especies existentes en el planeta, cuando se están perdiendo especies que ni siquiera se han llegado a conocer y cuando los expertos nos invitan a diferenciar distintos tipos de biodiversidad (genética, de especies, de ecosistemas, funcional y otras) que, aunque están íntimamente relacionadas, cumplen funciones diferentes (Nunes y Van den Bergh, 2001). 
de la empresa Merck con el Instituto Nacional de Biodiversidad (INBio) de Costa Rica: un esquema elaborado de pago por servicios ambientales que ha sido replicado con otras empresas (INBio con Bristol-Myers Squibb) y en otros países del área (GlaxoWellcome en el Brasil; Glaxo, el programa International Cooperative Biodiversity Groups (ICBG) y Bristol-Myers Squibb en el Perú; ICBG y Bristol en Suriname, y otros) (Bhatia y Chugh, 2015). En esta ocasión, si bien podría argumentarse que sí se valora la biodiversidad, y no la preservación de una determinada especie, el problema es que se trata de una valoración parcial, ya que solo se valora uno de los servicios que proporciona.

- El método utilizado. Como ya se mencionó, muchos de estos trabajos serealizan aplicandoelmétododevaloración contingente, que consiste en simular un mercado en el que el producto que se ofrece es la conservación de la diversidad biológica y se pregunta a una muestra representativa de la población por su disposición a pagar por dicho producto. Es difícil dar un gran valor a respuestas que parten del hecho constatable de que muy poca gente comprende a cabalidad el significado de la diversidad biológica y nadie conoce el impacto que ella tiene sobre nuestras vidas (Nunes y Van den Bergh, 2001).

Por todo lo expuesto, la diversidad biológica no se aborda como un servicio de los ecosistemas, sino que aparece como una parte fundamental del capital natural crítico y, como tal, su preservación se presenta como una de las restricciones del sistema ${ }^{14}$. La pregunta es, entonces, cómo tratar, en este contexto, las amenazas que supone la presencia de una explotación minera con respecto a la conservación de la diversidad biológica.

\section{Compromisos sin pérdidas netas y compensaciones por pérdida de biodiversidad: evaluación crítica}

Teniendo en cuenta que el objetivo de la sostenibilidad ambiental es conservar la diversidad biológica en términos generales y que las operaciones mineras tienen un impacto que en muchas ocasiones puede traducirse en una pérdida de diversidad biológica, aparece una posibilidad interesante de la mano de las llamadas "compensaciones por pérdida de biodiversidad". Algunas empresas mineras, ya sea por su política de responsabilidad social corporativa o para garantizar una licencia social para operar, han suscrito, con respecto a sus operaciones en territorios sensibles, los compromisos denominados "sin pérdidas netas" con referencia a la diversidad biológica (ICMM/UICN, 2013). Este es el caso, por ejemplo, de Rio Tinto, Sherritt, Sumitomo, Newmont, Anglo American Platinum y otras (Virah-Sawmy, Ebeling y Taplin, 2014).

14 De hecho, la Evaluación de los Ecosistemas del Milenio no considera la biodiversidad como uno de los servicios que proporcionan los ecosistemas, sino como una característica de estos que le permite proporcionarlos con una determinada calidad. 
Al aceptar el hecho de que las operaciones asociadas a las explotaciones mineras van a tener un impacto negativo sobre la diversidad biológica, lo que las empresas causantes garantizan, a partir de la firma de estos compromisos, es que van a tomar una serie de medidas que compensarán esta pérdida recuperando un valor equivalente de biodiversidad en otro espacio (Gardner y otros, 2013).

El esquema funciona como se indica a continuación.

El primer paso consiste en calcular la pérdida neta de biodiversidad que acarrearán las operaciones que llevará adelante la empresa minera con respecto al escenario de referencia, lo que implica una limitación de partida. Es decir, si la empresa va a talar un determinado número de hectáreas de bosque tropical primario, se toma en cuenta que, incluso en ausencia de sus operaciones, algunas de ellas también se habrían perdido debido, por ejemplo, a la colonización agrícola. En segundo lugar, se pondera este número de hectáreas con ayuda de una serie de parámetros que toman en cuenta la importancia de la diversidad presente en ese ecosistema particular. A continuación, se presenta un proyecto de compensación alternativo, que consiste en la defensa (prevención de la pérdida) o en la recuperación de un ecosistema amenazado o deteriorado, en otro lugar, cuyo valor ecológico, en términos de la unidad de medida utilizada para reflejar la pérdida de diversidad biológica, sea equivalente al perdido.

Como es obvio, un sistema como el mencionado enfrenta una serie de problemas y retos cuya solución no es fácil.

- El cálculo del escenario de referencia debe realizarse con todo rigor, incluidos los impactos indirectos que la presencia de la empresa minera, o el anuncio de dicha presencia, tendrán sobre la ocupación del suelo. Es decir, el mero anuncio de la posibilidad de una futura explotación minera puede provocar un movimiento de población hacia la zona, con la consiguiente ocupación de tierras y deforestación inducida que, si no se toma en cuenta, falsea el escenario de referencia y subestima la pérdida real. Este quizá sea el elemento más crítico para la realización de una estimación correcta de la pérdida neta incurrida (Virah-Sawmy, Ebeling y Taplin, 2014).

- Por otra parte, y como ya se ha señalado, la búsqueda de una medida de la importancia de la biodiversidad y sus características es una empresa que probablemente desborde nuestras posibilidades. El problema se complica enormemente cuando aparecen especies raras o amenazadas, dado que no existen aún unidades de medida consensuadas y se apelan a medidas transitorias que por el momento son aproximaciones discutibles y susceptibles de mejora en el corto y medio plazo (Virah-Sawmy, Ebeling y Taplin, 2014). 
- Por último, a la hora de presentar el proyecto de conservación alternativo es importante tener en cuenta tanto la tasa de éxito en la defensa o recuperación planteada, que rara vez será del 100\%, como la posibilidad de fugas. Es decir, la posibilidad de que las actividades reprimidas para proteger un área, como el cultivo o la ganadería, se trasladen a otra zona cercana e igualmente valiosa.

En cualquier caso, es necesario recordar que estos acuerdos no evitan la pérdida de biodiversidad biológica allí donde las empresas mineras realizan sus actividades, sino que tratan de compensar esta pérdida con un beneficio equivalente en términos también de biodiversidad. En este sentido son similares a los acuerdos basados en la equivalencia de hábitat (Azqueta, 2007). Ahora bien, como en el caso de estos últimos, el requisito básico para que se puedan llevar a cabo es que la pérdida, en este caso de biodiversidad, sea asumible.

Sea como fuere, y exista o no compensación, en términos operativos, el problema básico en la búsqueda de este necesario compromiso con la sostenibilidad ambiental no es otro - de nuevo- que el derivado de una asimetría adicional en el reparto de los costos y beneficios que conlleva garantizarlo.

- El costo de garantizar dicho compromiso se traduce o bien en la renuncia a aprovechar unos recursos naturales cuya explotación podría poner en peligro el capital natural crítico, como se ha indicado, o bien en hacerlo de una forma más cuidadosa con el entorno y, por tanto, más costosa financieramente. En ambos casos, el costo recaerá sobre el país en cuyo territorio se encuentren estos recursos (probablemente, un país en desarrollo).

- Una parte importante de los beneficios, sin embargo, como por ejemplo los derivados de la conservación de la biodiversidad o el mantenimiento de un depósito de carbono, repercuten sobre la humanidad como un todo. No solo eso, sino que a ello se añade el hecho de que, debido a la elevada elasticidad-renta de la demanda de seguridad, salud y calidad ambiental, estos beneficios repercuten de forma más intensa en el bienestar de las sociedades más ricas.

En otras palabras, las sociedades más ricas se benefician relativamente más de unos beneficios cuyo costo, en términos de bienestar social sacrificado, han pagado sobre todo las sociedades más pobres. Ello no solo dificulta el logro de los acuerdos necesarios para conseguir la sostenibilidad ambiental en la explotación de los recursos naturales, sino que es regresivo desde un punto de vista distributivo y, probablemente, inaceptable desde un punto de vista ético. Aun cuando no se cuestione este reparto de costos y beneficios desde la ética, es obvio que, desde una perspectiva de estricta eficiencia económica, es un hecho que no se puede obviar. Esto da cuenta de la conveniencia, e 
incluso la necesidad, de contar con acuerdos institucionales que obliguen a los países beneficiarios de esta sostenibilidad ambiental a compartir los costos de conseguirla, en función de su renta relativa ${ }^{15}$.

Conviene, por último, hacer una reflexión rigurosa sobre la sostenibilidad económica y social, y su especificidad geográfica.

Garantizada la sostenibilidad ambiental, si un análisis de la rentabilidad social de un emprendimiento minero ha llegado a la conclusión de que la economía tradicional de la zona, así como su tejido social, van a resultar afectados de forma irreversible, pero que los beneficios sociales del emprendimiento para el resto de la población del país compensan con creces esta pérdida, ¿tiene sentido tratar de garantizar la sostenibilidad económica y social en dicha comunidad a cualquier costo? La respuesta no es sencilla pues la comparación, en este caso entre costos y beneficios, no es simétrica.

\section{G. Indicadores de sostenibilidad}

Recientemente, y siguiendo las directrices de la Global Reporting Initiative, se han incorporado a la literatura sobre los recursos naturales los índices de capacidad de carga, propios de cada caso (Azapagic, 2004). Estos índices, además de proporcionar transparencia, aparecen como una herramienta útil en la búsqueda de la sostenibilidad.

En términos generales, los índices se completan a partir de la información contenida en los tres grandes apartados que constituyen las facetas de la sostenibilidad: económico, social y ambiental. En cada uno de estos apartados se recoge una serie de indicadores que tratan de reflejar la importancia del recurso analizado y su contribución al desarrollo económico y social en el largo plazo. A modo de ejemplo, los indicadores que se suelen contemplar son del tipo que se detalla a continuación.

- Económicos. Importancia de la explotación del recurso en el PIB nacional y local. Porcentaje del ingreso total en divisas originado en la exportación del recurso. Regalías e impuestos pagados a la administración central y a las administraciones locales. Porcentaje de los insumos de las operaciones proporcionados por proveedores extranjeros, nacionales y locales. Porcentaje de la producción que se exporta. Porcentaje de la producción que se transforma en el país y en la localidad. Inversión en investigación, desarrollo e innovación. Beneficio antes de intereses e impuestos. Duración estimada de las reservas.

15 Si bien no se ignoran los serios problemas que impidieron que fructificara, iniciativas del tipo Yasuní-ITT se encontrarían en la línea apuntada (véase [en línea] http://web.archive.org/ web/20150503143932/http://yasuni-itt.gob.ec/Inicio.aspx). 
- Sociales. Empleos generados en la explotación (directos, indirectos e inducidos; formales e informales; cualificados y no cualificados). Porcentaje sobre el empleo total de la zona. Programas de capacitación. Siniestralidad laboral. Impacto sobre las tasas de mortalidad y morbilidad. Impacto sobre las tasas de pobreza y necesidades básicas insatisfechas. Salud y seguridad en el trabajo. Acuerdos con la comunidad local.

- Ambientales. Ocupación del territorio. Emisiones al agua, al aire y al medio edáfico. Consumo de agua. Generación de residuos (tipo y volumen). Consumo de energía. Exigencias ambientales a los proveedores. Inversiones en control y remediación de la contaminación. Presencia de zonas protegidas. Certificación, en su caso, del producto obtenido. Responsabilidad social corporativa.

En definitiva, se trata de una familia de indicadores que permiten aproximar la importancia relativa de las operaciones asociadas a la explotación del recurso, tanto positiva como negativa, en el desarrollo económico y social de la zona y del país.

Ahora bien, así contemplados, la relación de estos indicadores con la sostenibilidad entendida en sentido amplio es problemática.

Se analizarán a continuación las grandes líneas en las que se sugiere que debería producirse la depuración de los índices convencionales.

\section{Indicadores económicos}

Como se señaló, los indicadores económicos incluyen, entre otras cosas, información sobre el aporte de la explotación del recurso al PIB local y nacional. Lo mismo ocurre en el caso del empleo (formal e informal), los ingresos fiscales, las divisas, la inversión local en educación, salud, infraestructura y demás. También proporcionan información sobre las ventas netas, el beneficio antes de intereses e impuestos y otras variables relacionadas con la salud financiera de la explotación. A todo ello se suma un indicador que recoge la información sobre las reservas del yacimiento, ponderada por las distintas categorías de dichas reservas. Se echa en falta, sin embargo, algún indicador que informe sobre el impacto de la explotación del recurso en la distribución de la renta y la riqueza.

Ahora bien, si de lo que se trata es de calibrar la sostenibilidad económica en el tiempo de la explotación analizada, estos indicadores han de manejarse con cuidado. No cabe duda de que una explotación que genera un gran volumen de empleo, rentas e ingresos fiscales es muy positiva tanto para la zona como para el país. El problema estriba en la vulnerabilidad que esta situación pudiera comportar. Los indicadores económicos respecto del uso deberían completarse, por tanto, con otros que informaran del peso 
relativo de la explotación en las rentas, el empleo, las divisas y los recursos fiscales, de tal forma que a mayor peso del indicador, menor capacidad del recurso para contribuir a la sostenibilidad económica. Esta menor capacidad se agravaría cuanto menores sean las reservas del recurso.

En otras palabras, es necesario establecer una familia de indicadores críticos que alerten sobre una excesiva dependencia económica con respecto a un determinado recurso natural agotable y que pongan de relieve el peligro de no planificar con el tiempo necesario la ineludible reconversión económica. En sentido contrario, y con una ponderación positiva, deberían incluirse indicadores que reflejen la contribución de las regalías de la explotación, no a las arcas locales o nacionales, sino a un eventual fondo soberano que garantizara una inversión adecuada de dichas regalías. También tendrían una ponderación positiva las inversiones en capacitación de la mano de obra local y el porcentaje de empleos cualificados creados. Todo ello, como es natural, ponderado por el tamaño de las reservas.

\section{Indicadores sociales}

En el caso de los indicadores de sostenibilidad social, el problema es básicamente el mismo: la dependencia de algunos servicios públicos clave, como salud, educación o infraestructuras de transporte y comunicación, respecto de ciertas operaciones mineras que tienen un horizonte temporal limitado. Es positivo que la empresa invierta en educación, salud e infraestructuras, pero no resulta tan positivo que estos servicios dependan en exceso de dicha inversión. Se vuelve necesario, por tanto, establecer de nuevo unas señales de alerta que informen sobre lo ineludible de articular mecanismos que garanticen la continuidad de unos servicios básicos para el desarrollo social de la comunidad.

Desde el punto de vista de la sostenibilidad social también es importante tomar en cuenta el impacto de la explotación minera sobre los movimientos poblacionales y, en especial, sobre los flujos migratorios. Deberían, por tanto, incorporarse algunos indicadores que recogieran el flujo de inmigración inducida por los puestos de trabajo (directos, indirectos e inducidos) creados por la explotación. Estos indicadores se deberían construir tomando como punto de partida el tamaño de la población local y el número de puestos de trabajo de la explotación minera no cubiertos por ella, así como el número de puestos de trabajo indirectos e inducidos generados por las operaciones de extracción, transporte y transformación (en su caso) del recurso no renovable. Este indicador numérico debería ponderarse para tener en cuenta las diferencias culturales entre la población local y los inmigrantes potenciales. 


\section{Indicadores ambientales}

Los indicadores ambientales convencionales utilizados en la literatura tienden a estar correctamente asociados a la problemática de la sostenibilidad ambiental, si bien en muchos casos convendría completarlos con aquellos que recogen los impactos indirectos sobre el ecosistema (como los asociados a la colonización agrícola inducida). En el caso del agua, por ejemplo, no solo deberían precisarse los indicadores convencionales sobre demanda de agua en las operaciones mineras, así como sobre contaminación del recurso hídrico por efluentes, en términos relativos con respecto a la disponibilidad del recurso, sino que también se deberían identificar los usos competitivos del agua afectados y su papel en la economía local. Con respecto al uso y ocupación del suelo, además de la superficie ocupada directa e indirectamente, y su valor ecológico, debería hacerse especial hincapié en la existencia de acuerdos de pérdida neta cero de biodiversidad y compensaciones de biodiversidad, como advertencia sobre la sensibilidad del territorio afectado. Por lo general, el indicador sobre ocupación del suelo solo hace referencia a la superficie ocupada directamente por las actividades relacionadas con la extracción del mineral (Azapagic, 2004) y no incluye los efectos indirectos e inducidos sobre la ocupación del suelo, como, por ejemplo, la mencionada colonización agrícola inducida. Deberían pues introducirse indicadores que reflejaran estos impactos tomando en cuenta el valor ecológico del espacio ocupado.

\section{H. Conclusiones}

La capacidad de carga de los recursos no renovables es entendida aquí como el conjunto de limitaciones a su gestión, que implica garantizar una explotación sostenible de dichos recursos desde un punto de vista económico, social y ambiental. Bajo esta perspectiva, el decisor social enfrenta una triple contradicción.

En primer lugar, debe decidir entre una aproximación que priorice los intereses nacionales $\mathrm{u}$ otra que priorice los intereses locales. Esta primera contradicción está muy condicionada por el contexto jurídico aplicable en cada caso y por los derechos reconocidos a las comunidades locales con respecto a los recursos existentes en su territorio. El análisis económico, en cualquier caso, muestra que los intereses nacionales y locales no siempre coinciden y que, cuando divergen, como cabe esperar, las modalidades de explotación de estos recursos son notablemente diferentes en función de cuál prime. Cuando se priorizan los intereses locales, se experimenta una presión hacia la explotación intensiva del recurso, con poca atención a los impactos ambientales negativos que esta conlleva. Esto no está en desacuerdo con el hecho, muchas veces contemplado, de que las comunidades locales ofrecen una seria resistencia a la explotación de estos recursos en su territorio, resistencia que puede explicarse por un 
desacuerdo con respecto al reparto de beneficios de dicha explotación y la búsqueda de una posición más favorable en la negociación de este reparto.

En segundo término, el decisor social debe optar entre una gestión que priorice el corto plazo u otra que contemple el problema con un horizonte más amplio, de medio y largo plazo. Esta contradicción se cruza con la anterior. Las comunidades locales tienden a resolver el problema de la gestión óptima del recurso con una perspectiva de corto plazo. El gobierno nacional, en principio, como garante de los derechos de las generaciones futuras, debería adoptar una perspectiva de largo plazo. Sin embargo, el propio ciclo político conspira contra esta aproximación al problema, aun cuando la gestión cortoplacista sea socialmente ineficiente. La explotación de los recursos no renovables con una perspectiva de corto plazo tiende a acelerar la extracción, incluso al costo de no agotar eficientemente los yacimientos, así como a financiar gasto corriente con las rentas del recurso, desestimulando inversiones adicionales en mantenimiento y exploración de nuevos yacimientos.

Como tercer punto, debe decidir entre la sostenibilidad económica y la sostenibilidad ambiental, ya que estas no tienen por qué ir juntas. El caso de los recursos naturales renovables lo muestra con claridad: un bosque puede ser enteramente talado y los beneficios financieros de esta operación se pueden invertir en un emprendimiento que genere puestos de trabajo, rentas directas e indirectas, impuestos y demás, y que, bien gestionado, permanezca en el tiempo. Ello garantizaría la sostenibilidad económica, pero no la sostenibilidad ambiental. En este sentido, es importante tener en cuenta que una sostenibilidad económica y social no garantiza la sostenibilidad ambiental. Ahora bien, la sostenibilidad ambiental apela al principio de máxima precaución en lo que a ella respecta, cuando lo que está en juego es el capital natural crítico. Esto quiere decir que no debería plantearse un intercambio entre ambas.

En definitiva, una gestión sostenible de los recursos no renovables debería adoptar una perspectiva nacional y no local, sin que ello obste para que la comunidad local participe en el reparto de beneficios, como el resto de los ciudadanos, y sea compensada por los perjuicios netos que la explotación en su territorio conlleva. Debe adoptar una visión de largo plazo para garantizar que las generaciones futuras también se beneficien de los regalos de la naturaleza, sin desmedro de que la mejora en las condiciones de vida de la sociedad con el paso del tiempo irá reduciendo la rentabilidad social de la inversión, al caer la utilidad marginal del consumo.

Por último, debe introducir la sostenibilidad ambiental como una restricción en el proceso de toma de decisiones con respecto a la gestión, cuando lo que está en juego es el capital natural crítico, teniendo en cuenta que normalmente son los impactos indirectos de la explotación, y no los directos, los que la ponen en peligro, y atendiendo al principio de máxima precaución. 
A lo mencionado es necesario añadir un punto fundamental: para poder garantizar esta triple sostenibilidad en el largo plazo, y dado que una parte relevante de los beneficios de dicha sostenibilidad recae sobre las sociedades de los países desarrollados, estos deberían financiar el costo de oportunidad económico en el que incurren los países depositarios de estos recursos para asegurar la sostenibilidad ambiental, atendiendo al valor de los beneficios recibidos por sus ciudadanos. Finalmente, los indicadores de capacidad de carga de los recursos no renovables deberían reformularse para introducir no solo la importancia del recurso en la economía, sino también, y sobre todo, una serie de señales de alerta sobre la vulnerabilidad del sistema económico y social con respecto a ellos.

\section{Bibliografía}

Abdo, H. (2014), "Investigating the effectiveness of different forms of mineral resources governance in meeting the objectives of the UK petroleum fiscal regime", Energy Policy, vol. 65, Elsevier.

Altomonte, H. y R. J. Sánchez (2016), Hacia una nueva gobernanza de los recursos naturales en América Latina y el Caribe, Libros de la CEPAL, No 139 (LC/G.2679-P), Santiago, Comisión Económica para América Latina y el Caribe (CEPAL).

Aranibar, A. M., E. Chaparro Ávila y R. Salgado Pavez (2011), "La industria extractiva en América Latina y el Caribe y su relación con las minorías étnicas", serie Recursos Naturales e Infraestructura, $\mathrm{N}^{\circ} 156$ (LC/L.3411), Santiago, Comisión Económica para América Latina y el Caribe (CEPAL).

Arroyo, A. y A. Perdiel (2015), "Gobernanza del gas natural no convencional para el desarrollo sostenible de América Latina y el Caribe", serie Recursos Naturales e Infraestructura, $\mathrm{N}^{\circ} 169$ (LC/L.3948), Santiago, Comisión Económica para América Latina y el Caribe (CEPAL).

Ayala Carcedo, F. J. y L. Vadillo (2004), "Manual de restauración de terrenos y evaluación de impactos ambientales en minería", serie Guías y Manuales, $\mathrm{N}^{\circ}$ 2, Madrid, Instituto Geológico y Minero de España.

Azapagic, A. (2004), "Developing a framework for sustainable development indicators for the mining and minerals industry", Journal of Cleaner Production, vol. 12, No 6, Amsterdam, Elsevier.

Azqueta, D. (2007), Introducción a la economía ambiental, $2^{\mathrm{a}}$ edición, Madrid, McGraw-Hill.

Azqueta, D. y D. Sotelsek (2007), “Valuing nature: from environmental impacts to natural capital", Ecological Economics, vol. 63, No 1, Elsevier.

Azqueta, D. y G. Delacámara (2008), “El costo ecológico de la extracción de petróleo: una simulación", Revista de la CEPAL, No 94 (LC/G. 2357-P), Santiago, Comisión Económica para América Latina y el Caribe (CEPAL).

Bhatia, P. y A. Chugh (2015), "Role of marine bioprospecting contracts in developing access and benefit sharing mechanism for marine traditional knowledge holders in the pharmaceutical industry", Global Ecology and Conservation, vol. 3, Elsevier. 
CEPAL (Comisión Económica para América Latina y el Caribe) (2013), Recursos naturales: situación y tendencias para una agenda de desarrollo regional en América Latina y el Caribe (LC/L.3748), Santiago, Comisión Económica para América Latina y el Caribe (CEPAL).

Ekins, P. (2003), "Identifying critical natural capital: conclusions about critical natural capital", Ecological Economics, vol. 44, N ${ }^{\circ} 2-3$, Elsevier.

El Serafy, S. (2013), Macroeconomics and the Environment: Essays on Green Accounting, Cheltenham, Edward Elgar Publishing.

Gardner, T. A. y otros (2013), "Biodiversity offsets and the challenge of achieving no net loss", Conservation Biology, vol. 27, N 6, Wiley.

Helm, D. (2014), "Taking natural capital seriously", Oxford Review of Economic Policy, vol. 30, N 1, Oxford University Press.

ICMM/UICN (Consejo Internacional de Minería y Metales/Unión Internacional para la Conservación de la Naturaleza) (2013), Independent Report on Biodiversity Offsets, Londres.

Marnika, E., E. Christodoulou y A. Xenidis (2015), "Sustainable development indicators for mining sites in protected areas: tool development, ranking and scoring of potential environmental impacts and assessment of management scenarios", Journal of Cleaner Production, vol. 101, Elsevier.

McGee, B. (2009), "The community referendum: participatory democracy and the right to free, prior and informed consent to development", Berkeley Journal of International Law, vol. 27, $\mathrm{N}^{\circ}$ 2, Universidad de California.

Moran, R. (2001), “Algunos ejemplos en Estados Unidos y Canadá: aproximaciones al costo económico de impactos ambientales en la minería", Ambiente y Desarrollo, vol. XVII, N 1 , Centro de Investigación y Planificación para el Medio Ambiente (CIPMA).

Nordhaus, W. (1974), "Resources as a constraint on growth", The American Economic Review, vol. 64, N² 2, Asociación Estadounidense de Economía.

Nunes, P. y J. C. van den Bergh (2001), “Economic valuation of biodiversity: sense or nonsense?", Ecological Economics, vol. 39, N 2 , Elsevier.

Owen, J. y D. Kemp (2013), "Social licence and mining: a critical perspective", Resources Policy, vol. 38, No 1, Elsevier.

Prno, J. y D. Scott Slocombe (2012), "Exploring the origins of 'social licence to operate', in the mining sector: perspectives from governance and sustainability theories", Resources Policy, vol. 37, No 3, Elsevier.

Saldarriaga-Isaza, A., C. Villegas-Palacio y S. Arango (2013), "The public good dilemma of a non-renewable common resource: a look at the facts of artisanal gold mining", Resources Policy, vol. 38, No 2, Elsevier.

Virah-Sawmy, M., J. Ebeling y R. Taplin (2014), “Mining and biodiversity offsets: a transparent and science-based approach to measure "no net-loss'", Journal of Environmental Management, vol. 143, Elsevier.

Wang, R. y otros (2016), "Research on diversity of mineral resources carrying capacity in Chinese mining cities", Resources Policy, vol. 47, Elsevier.

Wright, G. y J. Czelusta (2004), "Mineral resources and economic development", Working Paper, N ${ }^{\circ}$ 209, Stanford Center for International Development. 

Capítulo II

\section{Coyuntura económica en América Latina y el Caribe y su vínculo con los recursos naturales}

Durante décadas, muchos países de América Latina y el Caribe basaron sus políticas de crecimiento económico en la explotación de los recursos naturales. Este estilo de desarrollo se consolidó durante los años noventa, gracias a la mayor apertura financiera y comercial en dichos países y a una mayor inversión en ampliaciones y nuevos proyectos, principalmente en el sector extractivo. En el nuevo milenio, las circunstancias favorecieron aún más este modelo económico con el auge de los precios de las materias primas impulsado por una mayor demanda de países como China y la India.

Si bien el modelo extractivo atrajo nuevos flujos de capital que contribuyeron a la mejora de algunos indicadores económicos y sociales, América Latina y el Caribe sigue siendo la región más desigual del planeta. Es decir, a pesar del crecimiento económico, el aumento del consumo y los ingresos fiscales, el mejoramiento de los términos de intercambio, las exportaciones y los índices de pobreza, no se ha logrado derribar las barreras de la desigualdad en la región.

Por otra parte, los períodos de altos precios de los productos básicos y los años de bonanza económica pasaron y, al menos por ahora, se llevaron consigo la oportunidad que tenían los países de la región para reinvertir de manera distinta sus rentas excedentes. Con ello, se frenó el avance hacia una mayor diversificación de las actividades económicas, necesaria para mitigar o eliminar la dependencia de un solo recurso y, al 
mismo tiempo, posibilitar un crecimiento sostenible a largo plazo. Más aún, y al contrario de lo esperado, lo que esos países consiguieron durante el auge de los precios fue una reprimarización de sus economías.

Así, como resultado de la persistente dependencia económica de los recursos naturales, en particular de los no renovables, la región se enfrenta actualmente a una coyuntura económica compleja. Esta condición ha determinado que muchos países de la región sean hoy más vulnerables a la volatilidad de los precios de las materias primas y a su impacto directo en las exportaciones y los ingresos fiscales, así como a la fragilidad externa originada durante las reformas de liberalización adoptadas en los años noventa.

De acuerdo con la evidencia empírica de muchos países de la región, la maldición de los recursos naturales como tal no existe ${ }^{1}$. El hecho de que la abundancia de recursos naturales se haya convertido en una bendición o una maldición ha dependido fundamentalmente de las distorsiones que la propia abundancia ha generado en los distintos sectores de la economía (Altomonte y Sánchez, 2016).

Es evidente que la falta de una gobernanza adecuada de los recursos naturales impidió el pleno aprovechamiento de la bonanza económica y esto, a su vez, impidió el establecimiento de una perspectiva más sostenible y equilibrada de desarrollo ${ }^{2}$. La problemática es compleja, pues involucra elementos internos y externos que generan distorsiones en el ámbito económico y obstaculizan el desarrollo sostenible, objetivos clave de los países de la región que aún siguen dependiendo de los recursos naturales como motor de sus economías. Para resolver estos dilemas es necesario alinear los elementos de política vinculados con la gobernanza de los recursos naturales propuestos por la Comisión Económica para América Latina y el Caribe (CEPAL) con un desarrollo sostenible (CEPAL, 2014; Altomonte y Sánchez, 2016; Duque, Medina y Saade, 2017).

En esa línea, el objetivo de este capítulo es evaluar el desempeño económico de la región, haciendo hincapié en el análisis de los principales indicadores económicos vinculados con los recursos naturales no renovables antes, durante y después del período de bonanza económica que tuvo lugar a partir del comienzo de este milenio.

1 En 1993, Richard Auty fue el primer economista que utilizó la expresión "maldición de los recursos naturales", para expresar que los países que contaban con recursos naturales en abundancia mostraban menores tasas de crecimiento económico que los países que carecían de ellos.

2 La gobernanza de los recursos naturales es el gobierno del sistema de relaciones y conductas que articulan el funcionamiento de la industria en su entorno social, político, económico y natural. La gobernanza debe enmarcar el conjunto de mecanismos, procesos y reglas a través del cual se ejerce la autoridad sobre dicha actividad, las conductas entre las partes y la protección de la naturaleza y de los derechos básicos, y se refiere al funcionamiento de las instituciones en la amplia diversidad de agentes y reglas que influyen sobre ella, con miras al presente y al futuro (Altomonte y Sánchez, 2016).Véanse también las definiciones mencionadas en ese libro. 


\section{A. Evolución y coyuntura económica vinculada con los recursos naturales en América Latina y el Caribe}

El origen y el manejo de las crisis económicas vinculadas con la gestión de la deuda externa y los sistemas financiero y cambiario observadas en las décadas de 1980 y 1990 en algunos países de América Latina y Asia fueron aleccionadores para los responsables de la formulación de políticas macroeconómicas de muchas economías en desarrollo. Dichas lecciones se han reflejado en el éxito de las medidas adoptadas en muchos países para equilibrar la inflación, aunque no así para el control, la estabilización y la sostenibilidad de la tasa de crecimiento económico.

Como afirma Ocampo (2015), la región exhibió una gran volatilidad del ingreso medido a través del producto interno bruto (PIB) en los períodos 1950-1980 y 1990-2013 y, en forma más significativa aún, en el período más reciente, en el que se observa una mayor vulnerabilidad externa frente a las reformas de mercado iniciadas en la década de $1990^{3}$. No obstante los períodos de bonanza debidos al incremento de los precios de las materias primas, el desempeño económico de América Latina y el Caribe en las últimas tres décadas ha sido volátil y muy limitado (véase el gráfico II.1).

En un estudio realizado por Aravena y Fuentes (2013) se confirma la baja y persistente productividad laboral como una de las principales causas del escaso dinamismo económico observado en la región. Los autores analizan el componente del valor agregado en algunos países de la región en el período 1981-2010 y lo descomponen en el cambio de la productividad laboral y la cantidad de horas trabajadas. En su estudio concluyen que, salvo algunas excepciones como la Argentina y Chile, el valor agregado obtenido del 2,8\% estuvo principalmente determinado por el aumento de las horas trabajadas y no por una mayor productividad laboral, que de hecho resultó negativa para el promedio de los países bajo estudio $(-0,3 \%)$.

Aravena, López y Pineda (2018) realizaron un estudio relativo al período 1990-2015 y constataron, con inquietud, que el crecimiento económico en la región se basó completamente en el cambio en los factores productivos (capital y trabajo) y que, al contrario de lo que se creía, la productividad total de los factores no solo no contribuyó positivamente al

De acuerdo con Ocampo (2015), el crecimiento económico promedio fue del 5,5\% y el 3,3\% en los períodos 1950-1980 y 1990-2013, respectivamente, mientras que la desviación estándar y el coeficiente de variación fueron del $1,7 \%$ y el $2,2 \%$ y 0,313 y 0,678 , respectivamente, en los mismos períodos.

4 Los países que se consideraron en el estudio fueron: Argentina, Bolivia (Estado Plurinacional de), Brasil, Chile, Colombia, Costa Rica, Ecuador, Guatemala, Honduras, México, Nicaragua, Panamá, Paraguay, Perú, Uruguay y Venezuela (República Bolivariana de). 
crecimiento, sino que fue negativa ${ }^{5}$. Cabe destacar que el único período en el cual la productividad total de los factores realizó una contribución positiva al PIB fue durante el auge de los precios de las materias primas entre 2004 y 2008, en particular en los países de América del Sur.

\section{Gráfico II.1 \\ América Latina y el Caribe y países en desarrollo de Asia ${ }^{a}$ tasa de crecimiento del producto interno bruto (PIB) y el PIB per cápita, 1980-2016}

(En porcentajes y en dólares calculados en paridad

de poder adquisitivo a precios de 2011)

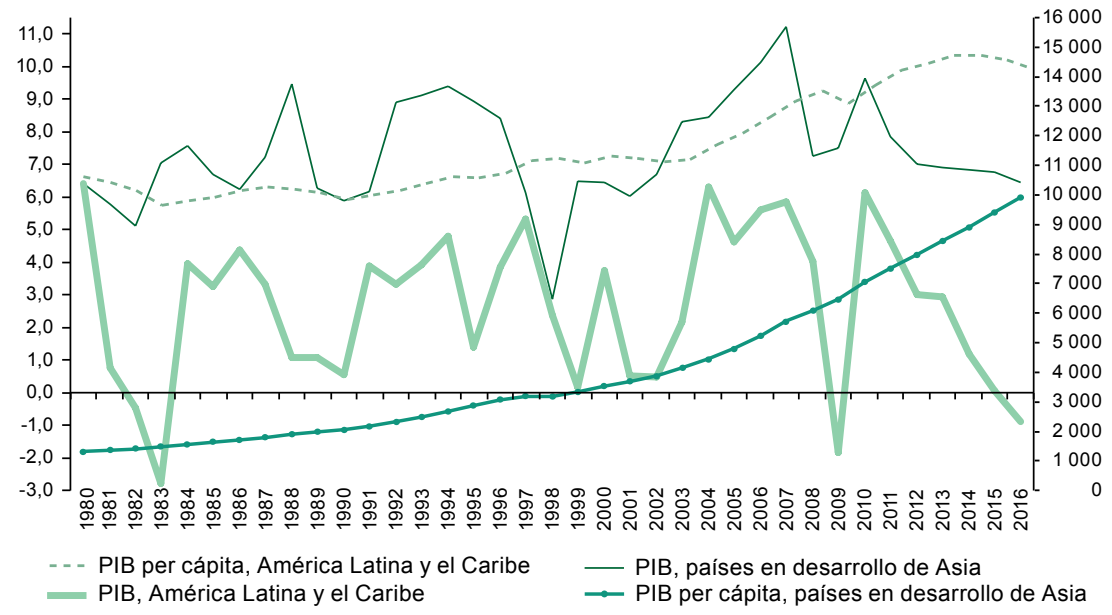

Fuente: Elaboración propia, sobre la base de datos del Fondo Monetario Internacional (FMI), World Economic Outlook Database, octubre de 2017.

a Los países en desarrollo de Asia que se consideran son: Bangladesh, Bhután, Brunei Darussalam, Camboya, China, Fiji, Filipinas, India, Indonesia, Islas Marshall, Islas Salomón, Kiribati, Malasia, Maldivas, Micronesia, Mongolia, Myanmar, Nauru, Nepal, Palau, Papua Nueva Guinea, República Democrática Popular Lao, Samoa, Sri Lanka, Tailandia, Timor-Leste, Tonga, Tuvalu, Vanuatu y Viet Nam.

Para efectuar un análisis del factor capital y su evolución, es necesario distinguir entre la cantidad, la composición y la calidad de la inversión que, en el caso de América Latina y el Caribe, fue muy limitada. Si bien la inversión ha sido el motor para muchas economías emergentes, esta presenta un comportamiento heterogéneo entre las distintas regiones (véase el gráfico II.2). Al comparar la formación bruta de capital fijo (FBCF) de América Latina y el Caribe con la de Asia Oriental y el Pacífico, se aprecia que, a pesar de los esfuerzos de los países latinoamericanos y caribeños por incrementar la inversión como porcentaje del PIB, la FBCF se mantuvo en torno al $20 \%$ del PIB, mientras que en la región de Asia Oriental y el Pacífico logró superar el $40 \%$.

\footnotetext{
El estudio considera los siguientes países de la región: Argentina, Bolivia (Estado Plurinacional de), Brasil, Chile, Colombia, Costa Rica, Ecuador, El Salvador, Guatemala, Honduras, México, Nicaragua, Panamá, Paraguay, Perú, República Dominicana, Uruguay y Venezuela (República Bolivariana de).
} 


\section{Gráfico II.2}

América Latina y el Caribe y regiones seleccionadas: formación bruta de capital fijo, 1970-2016

(Como porcentaje del PIB)

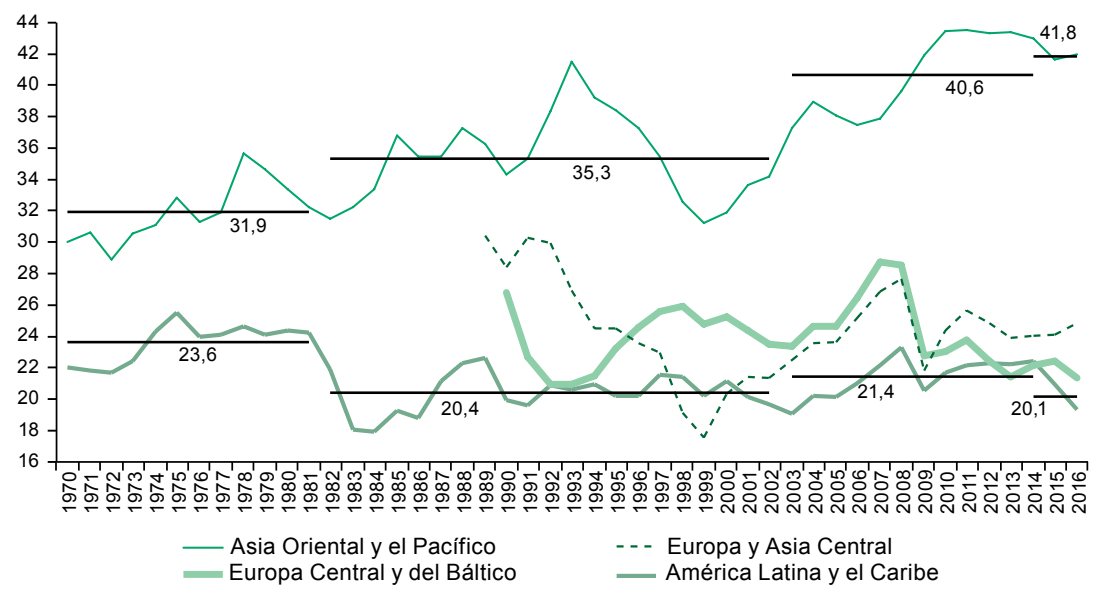

Fuente: Comisión Económica para América Latina y el Caribe (CEPAL) y Banco Mundial, sobre la base de cifras oficiales.

Por otra parte, Aravena, Escobar y Hofman (2015) desagregan la formación bruta de capital fijo del período 1990-2012 en la Argentina, el Brasil, Chile, Colombia y México y comprueban que, con excepción del Brasil, en promedio las tasas de inversión dirigidas el sector terciario (servicios) resultaron superiores a las alcanzadas por los sectores primario $\mathrm{y}$ secundario. Estos autores muestran que el sector de transporte y comunicaciones fue el más dinámico, mientras que, con excepción de México, la inversión en la industria manufacturera en la Argentina, el Brasil, Chile y Colombia fue menor. Como señalan los citados autores, esto lleva a preguntarse si la inversión en los sectores de servicios, que en general son no transables o regulados, puede garantizar una mayor rentabilidad.

En la medida en que la inversión se concentre en sectores protegidos, no transables o regulados, podría asignarse a sectores con escaso potencial de crecimiento a largo plazo, por el hecho de que estos sectores en general están menos expuestos a la competencia y, por ende, tienen menos incentivos para innovar. En ese sentido, como afirman Aravena, Escobar y Hofman (2015), las políticas macroeconómicas desempeñan un papel clave para incentivar la competitividad de los sectores transables de la economía con el fin de incrementar la productividad en los sectores donde la competencia y la innovación pueden materializarse, salvo excepciones como el área de las telecomunicaciones, en la que se ha logrado impulsar una mayor productividad. 
Durante décadas, la evidencia teórica y empírica ha expuesto la importancia de la industrialización como motor del crecimiento económico ${ }^{6}$. Sin embargo, de acuerdo con Szirmai (2011), no obstante el sector manufacturero continuará siendo significativo para acelerar el crecimiento económico, el sector de servicios desempeñará un papel cada vez más activo como fuente de crecimiento en los países en desarrollo. El autor destaca que, en la actualidad, los países desarrollados han generado una parte importante de su crecimiento económico en este último sector? ${ }^{7}$.

Timmer y de Vries (2009) también confirman la importancia del sector de servicios como fuente de crecimiento y, a su vez, comprueban de manera empírica que el sector manufacturero es el que más aporta al crecimiento durante los períodos normales de crecimiento, mientras se amplía la participación del sector de servicios en los períodos de aceleración, que se suma a la contribución positiva de las manufacturas. El mayor protagonismo que adquirió el sector servicios en la región en el período 1990-2012 se confirma en el estudio realizado por Aravena, Escobar y Hofman (2014) para los casos de la Argentina, el Brasil, Chile, Colombia y México.

Al comparar el crecimiento económico de los países de la región con el de los países en desarrollo de Asia entre 1980 y 2016, se hace más que evidente el bajo desempeño económico de los primeros durante más de tres décadas. Como se observa en el cuadro II.1, a lo largo de esos años se consolidó la brecha entre el crecimiento económico alcanzado por los países de la región y el de los países en desarrollo de Asia. Incluso durante la crisis económica que experimentaron algunos países asiáticos en la década de 1990, cuando registraron sus valores mínimos, dichos países crecieron en promedio a un ritmo del 2,9\% anual (1998), una cifra superior a

\footnotetext{
Según Szirmai (2011), los argumentos teóricos y empíricos a favor de la industrialización como motor de crecimiento económico se resumen en que: i) existe una correlación positiva entre el grado de industrialización y los niveles de ingreso per cápita en los países en desarrollo; ii) la productividad es mayor en el sector manufacturero que en el agrícola; iii) la transferencia de los recursos del sector manufacturero al de servicios genera una carga de cambio estructural que asume la forma de la enfermedad de Baumol, es decir, a medida que el sector de servicios aumenta, el crecimiento económico per cápita tiende a disminuir; iv) el sector manufacturero ofrece más oportunidades para acumular capital que el agrícola (la intensidad en capital es mayor en este sector y en subsectores como la minería, los servicios públicos y la construcción, y menor en los sectores agrícola y de servicios) y la acumulación de capital es una fuente importante de crecimiento; v) el sector manufacturero ofrece mayores economías de escala con respecto a los sectores agrícola y de servicios; vi) el sector manufacturero incorpora mayores avances en tecnología; vii) los encadenamientos y los efectos indirectos son mayores en el sector manufacturero que en el agrícola y el minero; y viii) a medida que el ingreso per cápita aumenta, la participación de los gastos agrícolas en el total de gastos disminuye y la participación de los gastos en manufactura aumenta (Ley de Engel). De esta forma, los países que se especializan en agricultura y productos básicos no logran aprovechar la expansión de los mercados mundiales de los bienes manufacturados.

7 El autor estima que, en los países desarrollados, la participación del sector de servicios con respecto al PIB es superior al $70 \%$.
} 
la tasa media de expansión del PIB del 2,7\% alcanzada por América Latina y el Caribe en el período 1980-2016. Más aún, mientras América Latina creció un 2,7\% anual en ese período, los países asiáticos lo hicieron a un ritmo del $7,4 \%$.

\section{Cuadro II.1}

América Latina y el Caribe y países en desarrollo de Asiaa: tasa de crecimiento del producto interno bruto (PIB) y PIB per cápita

(En porcentajes y en dólares calculados en paridad de poder adquisitivo a precios de 2011)

\begin{tabular}{lrrrrr}
\hline & $1980-2016$ & $1990-2016$ & $2003-2008$ & $2003-2011$ & $2012-2016$ \\
\hline Producto interno bruto (PIB) & & & & & \\
\hline Países en desarrollo de Asia & 7,4 & 7,6 & 9,1 & 9,0 & 6,8 \\
\hline América Latina y el Caribe & 27 & 2,9 & 4,8 & 4,1 & 1,3 \\
\hline PIB per cápita & & & & & \\
\hline Países en desarrollo de Asia & 4073 & 4986 & 5082 & 5728 & 8937 \\
\hline América Latina y el Caribe & 11589 & 12131 & 12389 & 12821 & 14544 \\
\hline
\end{tabular}

Fuente: Elaboración propia, sobre la base de datos del Fondo Monetario Internacional (FMI), World Economic Outlook Database, octubre de 2017.

a Los países en desarrollo de Asia que se consideran son: Bangladesh, Bhután, Brunei Darussalam, Camboya, China, Fiji, Filipinas, India, Indonesia, Islas Marshall, Islas Salomón, Kiribati, Malasia, Maldivas, Micronesia, Mongolia, Myanmar, Nauru, Nepal, Palau, Papua Nueva Guinea, República Democrática Popular Lao, Samoa, Sri Lanka, Tailandia, Timor-Leste, Tonga, Tuvalu, Vanuatu y Viet Nam.

La comparación del PIB per cápita de América Latina y el Caribe con el de los países en desarrollo de Asia es aún más preocupante. Mientras que en 1980 el PIB per cápita latinoamericano era ocho veces mayor, en 2016 la región solo superó a los países asiáticos en un 43\%. Si bien este dispar desempeño económico puede explicarse de varias maneras, como afirman Rosales y Herreros (2017), una de las principales causas es la mayor inserción de los países asiáticos en el comercio internacional mundial, que ha aumentado de forma acelerada.

De acuerdo con Rosales y Herreros (2017), el papel de los países latinoamericanos y caribeños en el comercio exterior se ha tornado cada vez más complejo ante la pérdida de participación de las exportaciones de manufacturas de alta complejidad y servicios modernos (véase el gráfico II.3). La participación de las exportaciones de recursos naturales en la región disminuyó entre 1990 y 2000, para dar paso a una reprimarización a partir del nuevo milenio.

Como se aprecia en el gráfico II.3, los países en desarrollo de Asia constituyen la región que más ha avanzado en la exportación de productos con una alta intensidad tecnológica a nivel mundial. Esto fue el resultado de una amplia y sostenida política de inversión orientada a gastos en investigación y desarrollo (I+D), en particular en las nuevas tendencias tecnológicas de la cuarta revolución industrial, como se muestra en el gráfico II.4. 


\section{Gráfico II.3}

\section{Composición de las exportaciones de bienes según producto e intensidad tecnológica, 1990, 2000 y 2016}

(En porcentajes)

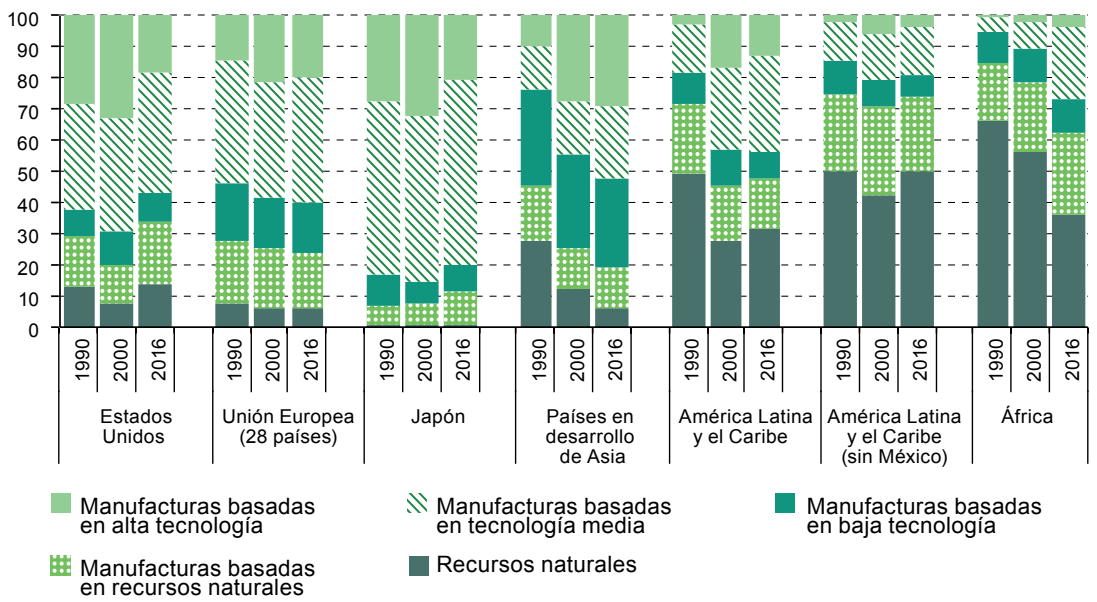

Fuente: Comisión Económica para América Latina y el Caribe (CEPAL), sobre la base de Base de Datos Estadísticos de las Naciones Unidas sobre el Comercio de Productos Básicos (COMTRADE).

Gráfico II.4

Regiones y países seleccionados: gasto en investigación y desarrollo, 2002 y 2014

(Como porcentaje del PIB)

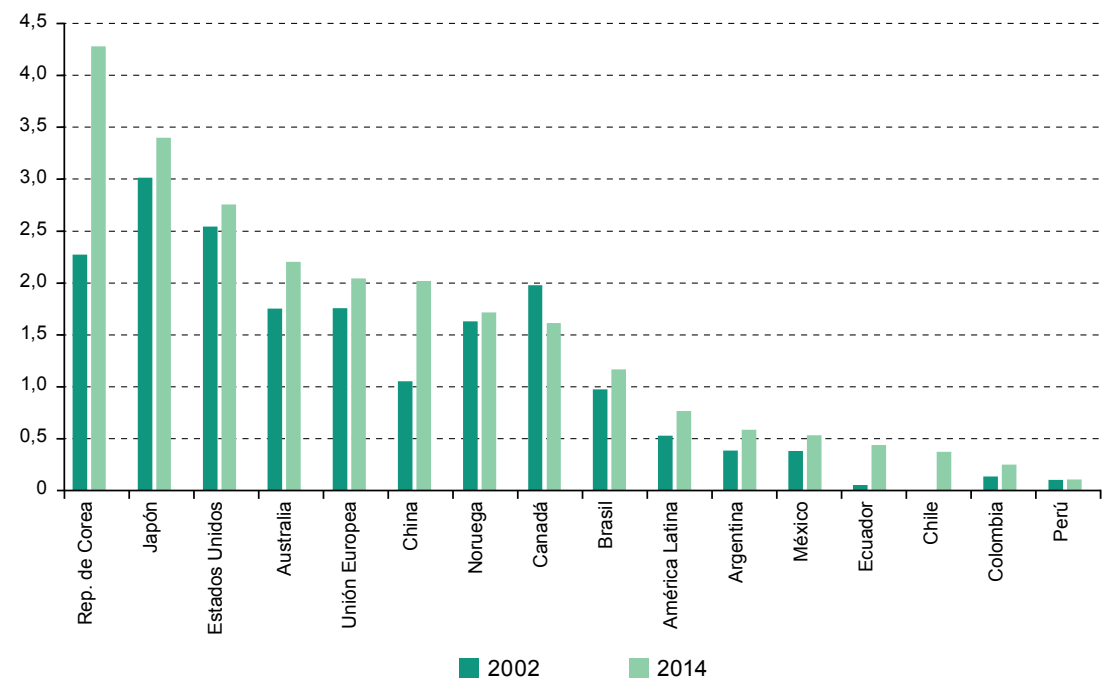

Fuente: Elaboración propia, sobre la base de datos del Banco Mundial y de los países. 
Es indudable que las tasas de crecimiento económico en la región han tenido un correlato directo con el precio de las materias primas, especialmente en América del Sur. A partir del nuevo milenio, la consolidación de la clase media en diversas economías en desarrollo y la irrupción de los países asiáticos — en particular China y la India- en los mercados internacionales impulsaron una fuerte demanda de productos básicos que, a partir de 2003, tuvo un efecto directo en sus precios (véase el gráfico II.5) y en el crecimiento económico (véase el gráfico II.1). No obstante, la tendencia creciente de los precios de las materias primas resultó afectada por la crisis financiera mundial de 2008-2009 y el desequilibrio de la Unión Europea. Luego de alcanzar sus valores mínimos en 2009, dichos precios retomaron su tendencia ascendente hasta llegar a sus máximos niveles históricos en 2011-2012.

Gráfico II.5

Índice de precios internacionales de las materias primas, 1992-2017 (Índice de enero de 2005=100)

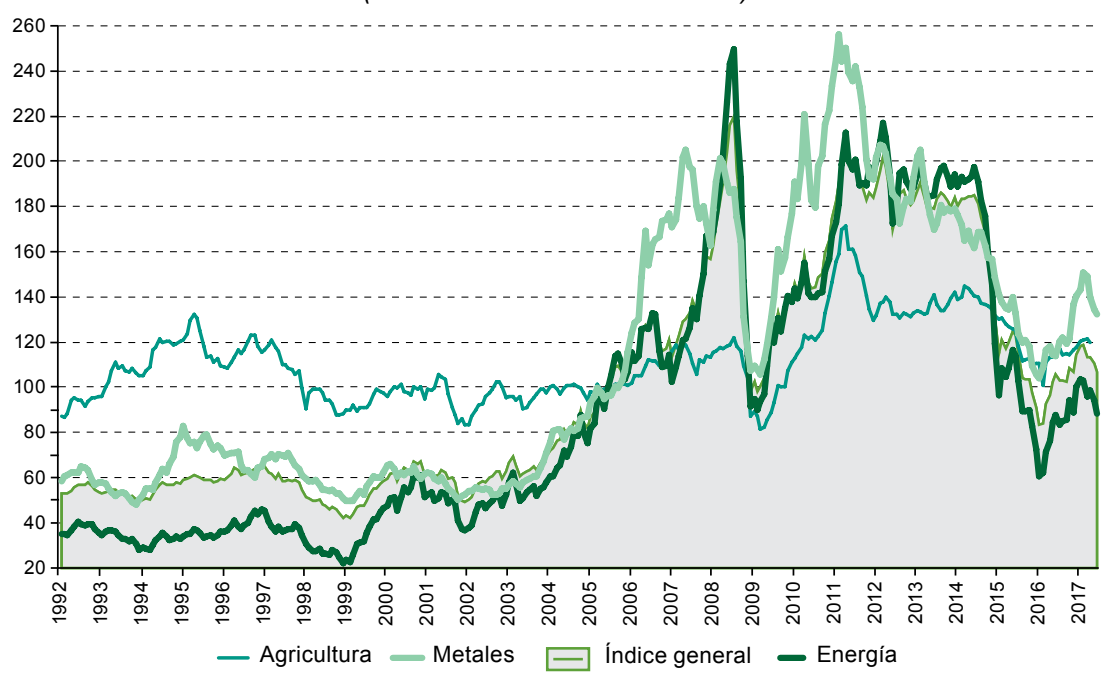

Fuente: Comisión Económica para América Latina y el Caribe (CEPAL), sobre la base de información del Fondo Monetario Internacional (FMI).

A partir de 2012, el moderado ritmo de expansión que comenzó a exhibir China y la débil demanda internacional de los países desarrollados afectaron negativamente los precios de las exportaciones de materias primas de origen extractivo. Esta situación se acentuó como resultado de las nuevas señales de política de las autoridades chinas con respecto a su modelo de desarrollo, que apuntaron a dar un peso mayor al consumo de los hogares y menor a las exportaciones y la inversión (CEPAL, 2015). 
Pese a que un aumento en los precios de las materias primas brinda beneficios económicos a los países que dependen económicamente de sus recursos extractivos (además de mayores ingresos fiscales extractivos y mayores exportaciones, entre otras ventajas), la realidad es muy diferente para los países importadores de productos básicos, la mayoría de los cuales deben enfrentarse a presiones inflacionarias por el aumento del nivel de precios de dichos productos. Como se aprecia en el gráfico II.6, el auge de los precios también mejoró los términos de intercambio, en particular para las economías de América del Sur, y esto contribuyó a su vez al incremento de las exportaciones, en particular en los países exportadores de productos mineros e hidrocarburos.

\section{Gráfico II.6}

América Latina y el Caribe (países y grupos de países seleccionados): tasa de variación de los términos de intercambio, 2001-2017 (En porcentajes)

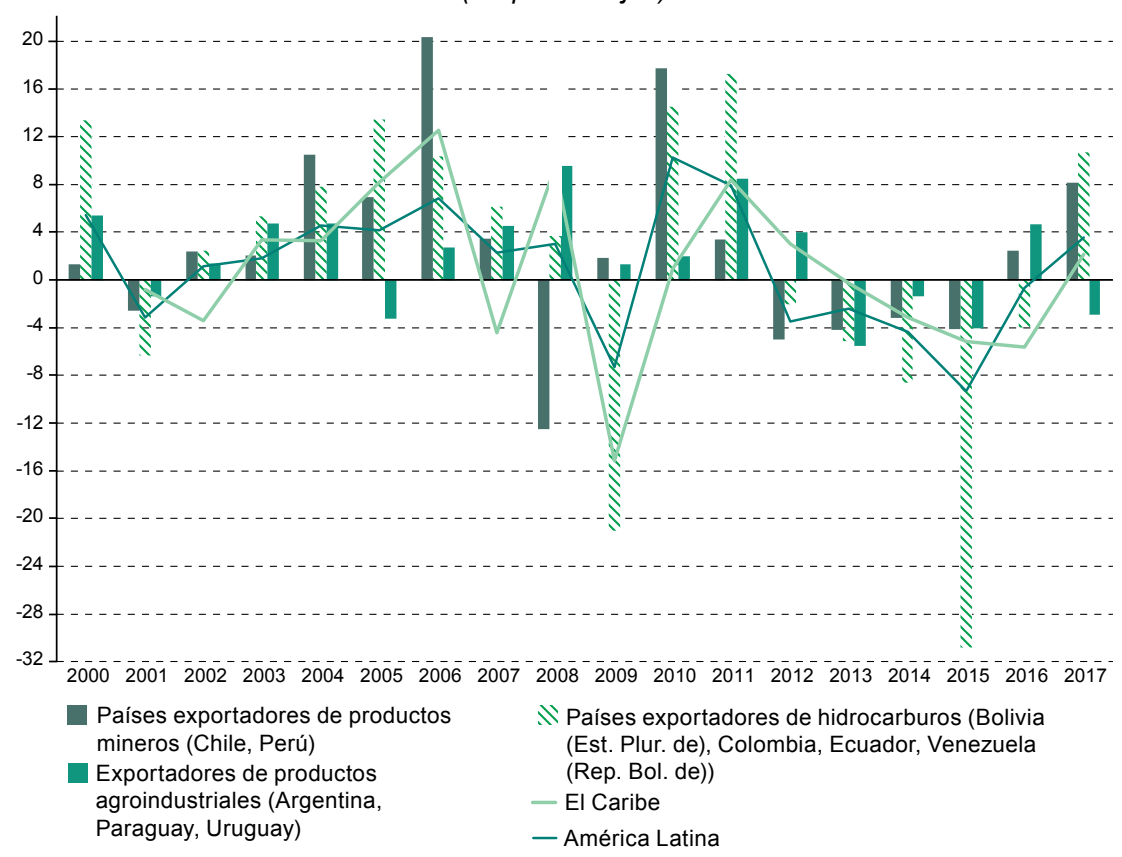

Fuente: Comisión Económica para América Latina y el Caribe (CEPAL), sobre la base de cifras oficiales. a Las cifras de 2017 corresponden a proyecciones.

Al descomponer las exportaciones y las importaciones en los componentes precios y volumen, se observa que los primeros (con excepción del Brasil en las importaciones y los productos agroindustriales) determinan en gran medida el flujo de las exportaciones y las importaciones para América Latina en 2016 (véase el gráfico II.7). No obstante, este 
resultado no es homogéneo para todas las economías y todos los tipos de exportadores. Por ejemplo, en algunos países exportadores de minerales, como Chile y el Perú, el componente precios fue casi compensado por un aumento en el volumen, que llevó a un menor valor de las exportaciones.

\section{Gráfico II.7}

América Latina y el Caribe (países y grupos de países seleccionados): tasa de variación de las exportaciones y las importaciones de bienes según volumen y precio, 2016

(En porcentajes)

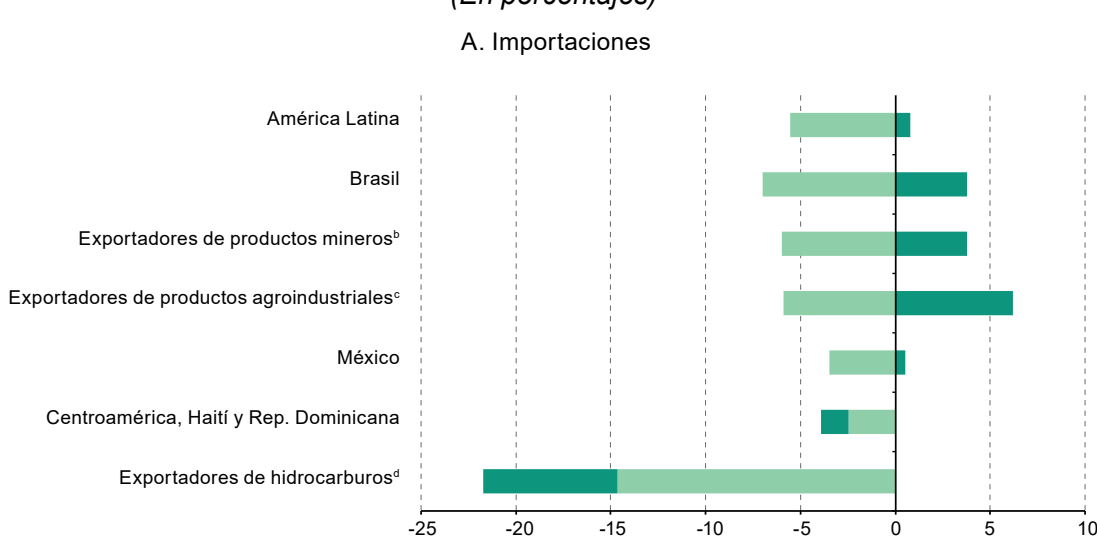

B. Exportaciones

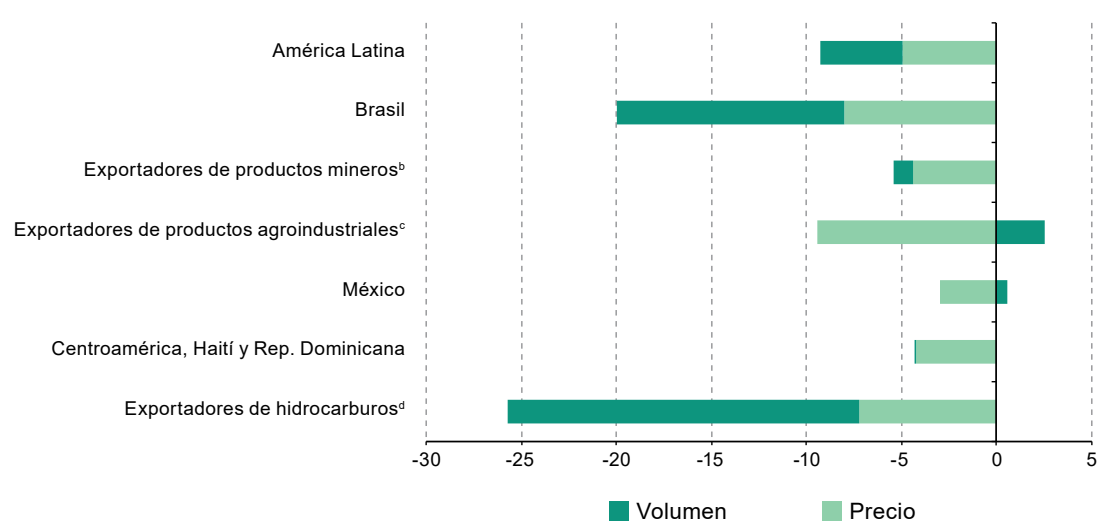

Fuente: Comisión Económica para América Latina y el Caribe (CEPAL), sobre la base de cifras oficiales.

a Estimaciones.

b Chile y Perú.

c Argentina, Paraguay y Uruguay.

d Bolivia (Estado Plurinacional de), Colombia, Ecuador, Venezuela (República Bolivariana de) y Trinidad y Tabago. 
Durante los años de bonanza de precios, el dinamismo económico estuvo impulsado por la demanda agregada, el consumo privado, las exportaciones y la inversión. Sin embargo, a raíz de la reducción de los precios, a partir de 2010 comenzó a observarse una desaceleración económica en América Latina (véase el gráfico II.8A), que condujo a una disminución de las exportaciones y de la inversión, en particular en las economías de América del Sur. De acuerdo con la CEPAL (2017a), las exportaciones y la inversión, variables que deberían desempeñar un papel clave en la acumulación de capital, la generación de capacidades productivas y, sobre todo, el impulso al crecimiento a largo plazo, se encuentran actualmente en un segundo plano como motores del crecimiento económico.

La composición de la demanda agregada en América Latina y el Caribe es muy heterogénea. En la actualidad, muchos países de América del Sur se enfrentan al costo de haber mantenido una gran dependencia de los recursos extractivos en su canasta exportadora y, en 2014, dicha subregión incluso comenzó un período de tasas de crecimiento económico negativas (véase el gráfico II.8B). En México y el Brasil se ha avanzado en materia de políticas de diversificación productiva (el caso de México se refleja en el gráfico II.8C).

Efectivamente, en el caso de Centroamérica y México, las tasas de crecimiento económico han sido positivas, con excepción del período de la crisis financiera mundial de 2008-2009. Se puede apreciar que los componentes de la demanda agregada que impulsaron el crecimiento económico se originaron en el consumo privado, las exportaciones y la inversión (véase el gráfico II.8C).

\section{Gráfico II. 8 \\ América Latina y subregiones seleccionadas: tasa de variación del PIB y contribución de los componentes de la demanda agregada al crecimiento, primer trimestre de 2008 a segundo trimestre de 2016} (En porcentajes)

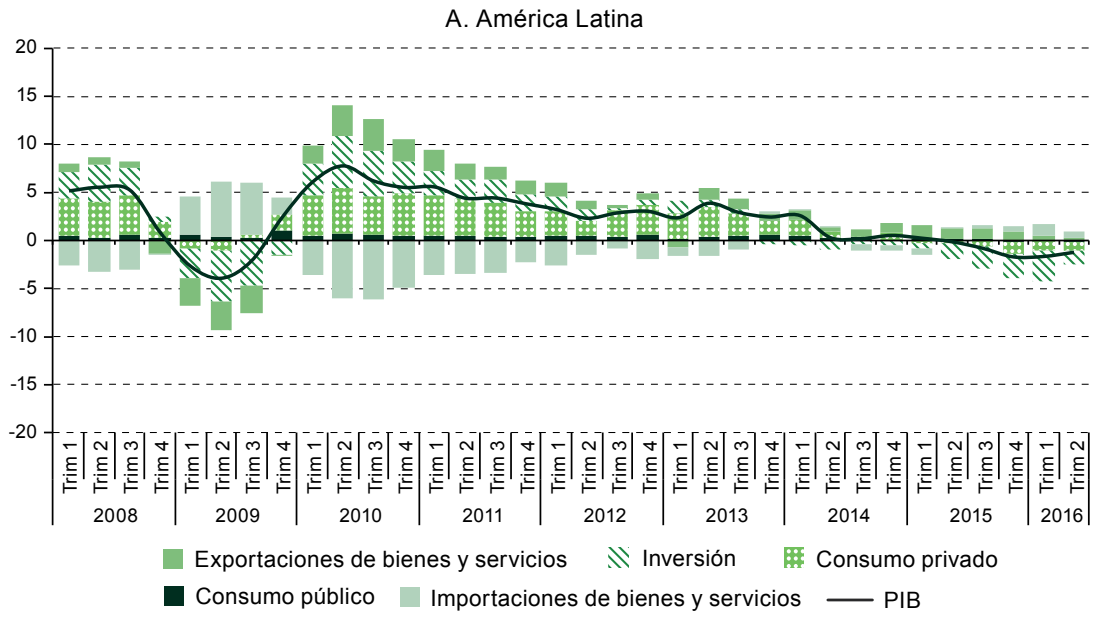


Gráfico II.8 (conclusión)

B. América del Sur

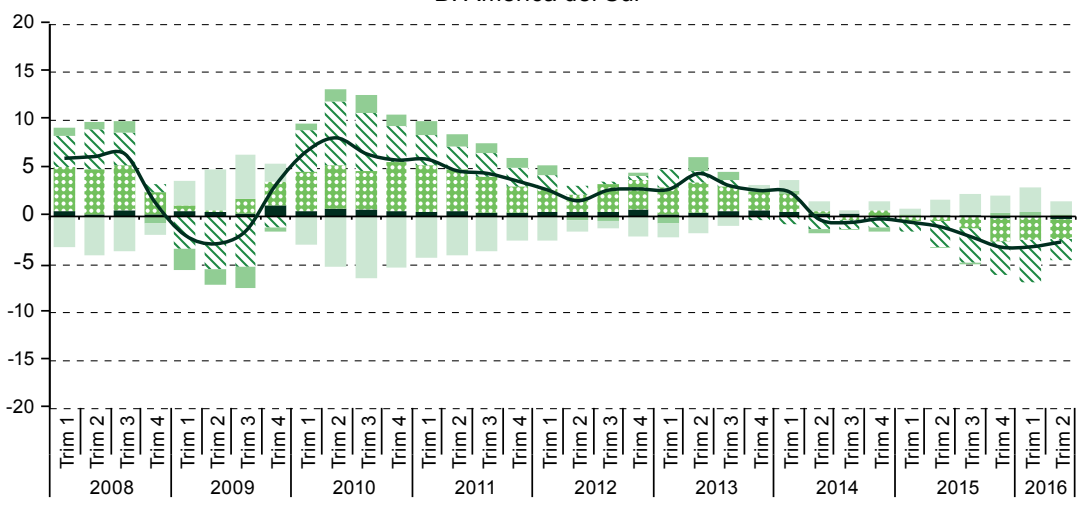

C. Centroamérica y México

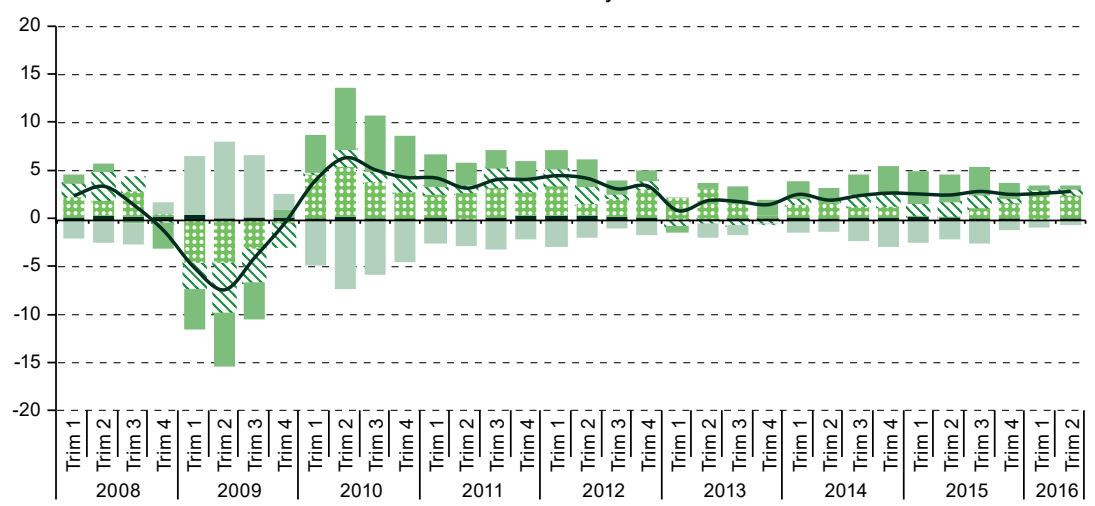

Exportaciones de bienes y servicios Nㅡ Inversión 遇 Consumo privado

a Consumo público Importaciones de bienes y servicios — PIB

Fuente: Comisión Económica para América Latina y el Caribe (CEPAL), Balance Preliminar de las Economías de América Latina y el Caribe, 2016 (LC/PUB.2017/28-P), Santiago, 2016.

Es importante destacar la resiliencia de la región frente a la crisis financiera mundial de 2008-2009, como resultado de una buena gestión de las políticas macroeconómicas y de los beneficios económicos observados previamente (mayor holgura fiscal, acumulación de reservas internacionales, entre otros). Asimismo, la mayor estabilidad económica alcanzada en los años previos a la crisis, los altos precios de las materias primas observados a partir de 2003 y las amplias reservas de recursos extractivos en la región, en particular en América del Sur, propiciaron que muchos países se convirtieran en importantes receptores de inversión extranjera directa (IED) (véase el gráfico II.9). 


\section{Gráfico II.9}

América Latina y el Caribe: entradas de inversión

extranjera directa (IED), 1990-2016

(En millones de dólares y como porcentaje del PIB)

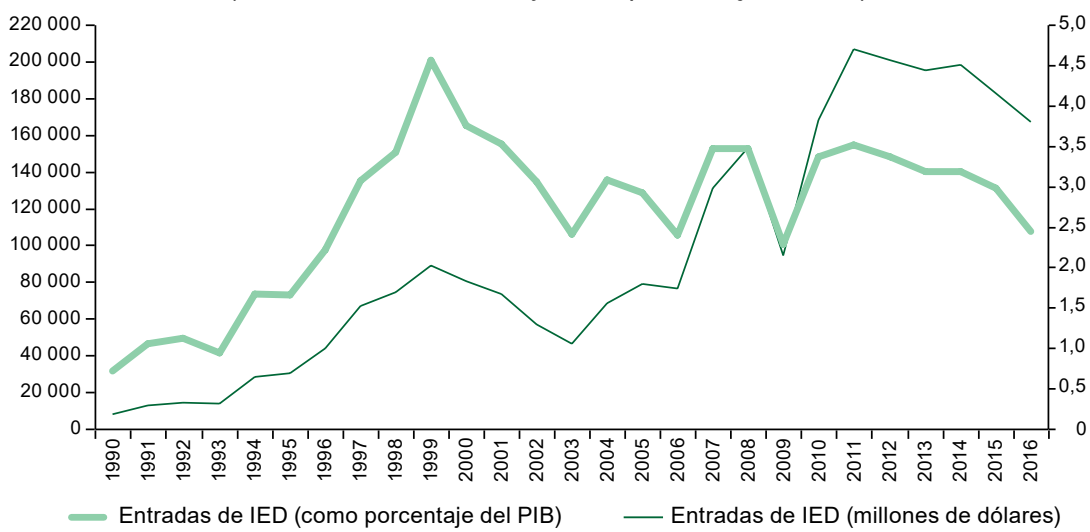

Fuente: Comisión Económica para América Latina y el Caribe (CEPAL), La Inversión Extranjera Directa en América Latina y el Caribe, 2017 (LC/PUB.2017/18-P), Santiago, 2017.

Sin embargo, la inversión extranjera - en particular la destinada a la extracción de recursos naturales- comenzó a contraerse frente a la disminución de los precios de los minerales y los hidrocarburos, en paralelo al surgimiento de conflictos o la intensificación de los existentes, debido a los efectos sociales y ambientales de las actividades extractivas, que en muchos casos también tuvieron altos costos económicos y financieros. A ello hay que sumar el cambio en la composición de la inversión extranjera directa en la región, que llevó a una reorientación de los proyectos hacia las energías renovables (véase el gráfico II.10).

Entre 2010 y 2016, la participación de las inversiones extranjeras en proyectos de energías renovables pasó del 7\% al 18\%, de manera que el sector registró el mayor número de proyectos anunciados. A partir de 2015 las economías desarrolladas retomaron su liderazgo, al captar el $55 \%$ y el 59\% de la inversión extranjera directa mundial en 2015 y 2016, respectivamente, mientras que las economías en desarrollo registraron una disminución del $42 \%$ al $37 \%$ en los mismos años. De acuerdo con la CEPAL (2017b), en el período 2014-2016, los principales países receptores de IED fueron los Estados Unidos, el Reino Unido y el conjunto de China y Hong Kong (Región Administrativa Especial de China). Por su parte, China ha sido un importante receptor de recursos naturales y en 2016 las inversiones de este país en el exterior superaron las entradas de capitales y alcanzaron un nuevo máximo histórico: 183.100 millones de dólares, que representaron un incremento del 43,5\% respecto de 2015. 
Gráfico II.10

América Latina y el Caribe: distribución sectorial de los montos de los proyectos de inversión extranjera directa anunciados, 2005-2016 (En porcentajes)

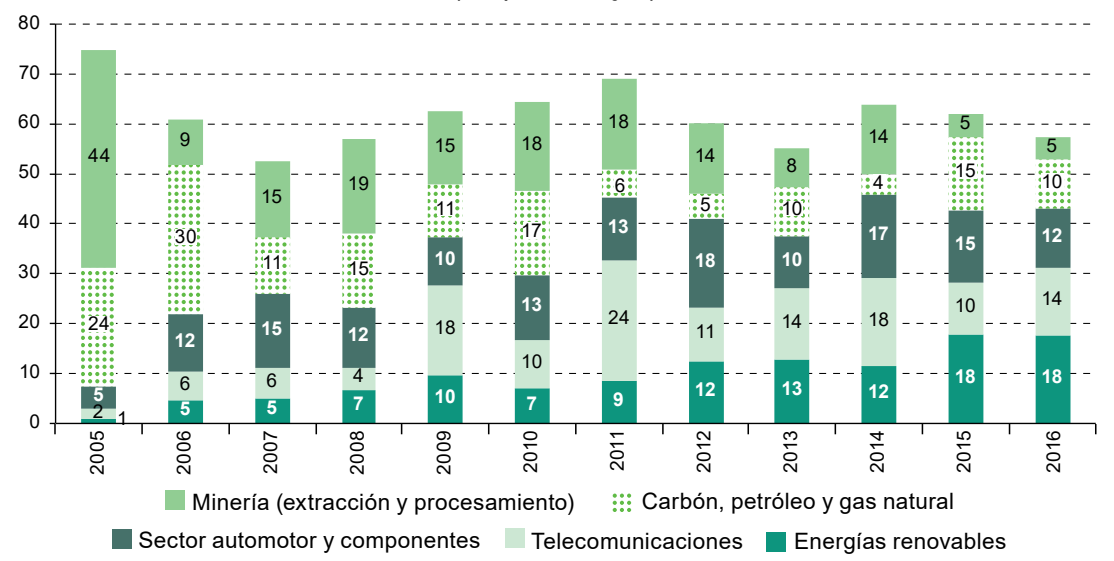

Fuente: Elaboración propia, sobre la base de datos de la Comisión Económica para América Latina y el Caribe (CEPAL).

La tendencia decreciente de los precios de las materias primas observada a partir de 2011-2012 tuvo un punto de inflexión en 2016. De acuerdo con el FMI (2017), el cambio en la tendencia de los precios de las materias primas se explica por diversas causas, entre las que destacan: el recorte de la producción de petróleo anunciado por la Organización de Países Exportadores de Petróleo (OPEP) en septiembre de 2016; la importancia de China en el sector de la construcción, que incidió en los precios de los metales; los recortes en la producción carbonífera impulsados por el Gobierno de China y las interrupciones en Australia, que afectaron su producción y envío; y la moderación de las condiciones de sobreoferta, que contribuyó a la recuperación de los precios de los alimentos.

Durante el nuevo milenio, el posicionamiento de China en la economía mundial ha sido innegable, no solo por su gran demanda de materias primas —en particular de minerales metálicos- sino también por haber invertido en la refinación y fundición de metales, que resultó en un gran avance en la cadena de valor minero-metalúrgica (CEPAL, 2016a). En América Latina y el Caribe aumentó la producción de minerales, que promovió un patrón de crecimiento de las exportaciones de mineral de mina y no de metales refinados, como se hubiera deseado.

Además de haber satisfecho la demanda de metales y manufacturas de metal tanto localmente como en el mercado internacional, las empresas chinas han superado a las manufacturas de hierro, acero y aluminio de Alemania, los Estados Unidos, el Japón y la Federación de Rusia, entre otros países (CEPAL, 2016a). 
Las políticas de inversión en China se han centrado en sectores cada vez más sofisticados, que incorporan las nuevas tendencias tecnológicas de la cuarta revolución industrial (CEPAL, 2017b). Dichas políticas se reflejan en el aumento sustancial de las solicitudes de patentes en China, país que ha superado con creces en ese rubro a naciones como los Estados Unidos, la República de Corea y el Japón, que tradicionalmente mantenían una amplia diferencia con el resto de los países (véase el gráfico II.11).

\section{Gráfico II.11}

República de Corea, Japón, Estados Unidos y China: solicitudes de patentes, 2002-2016 (Como porcentaje del total mundial)

A. Porcentaje del total mundial

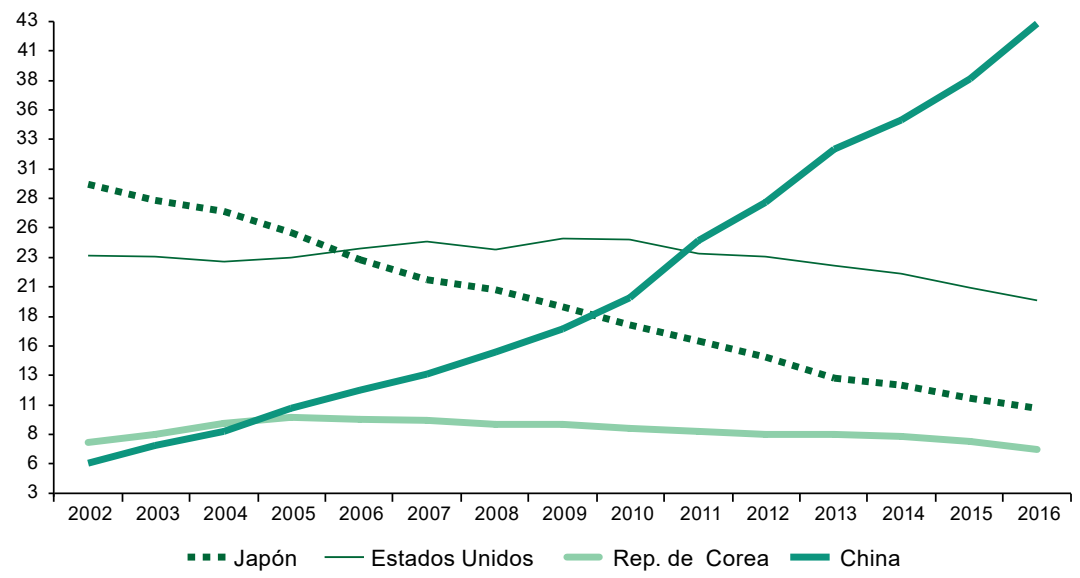

B. Porcentaje del total mundial acumulado

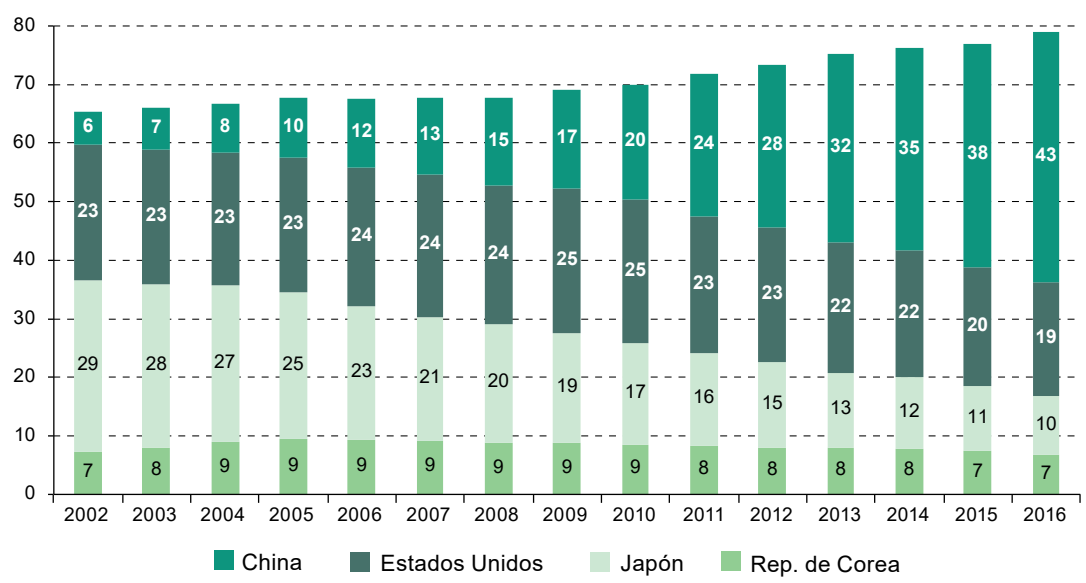

Fuente: Elaboración propia, sobre la base de datos de la Organización Mundial de la Propiedad Intelectual (OMPI). 
Durante el primer auge de los precios en 2003-2008, la entrada de inversiones extranjeras propició una importante apreciación del tipo de cambio real y, tras la crisis financiera mundial de 2008-2009, muchas economías desarrolladas dirigieron sus capitales hacia algunas economías latinoamericanas, atraídos por su mayor apertura financiera y por una mayor estabilidad macroeconómica alcanzada durante la primera década del actual milenio. Es necesario diferenciar entre una apreciación del tipo de cambio real causada por factores endógenos, como la entrada de capitales propia de la abundancia de recursos naturales, y la apreciación generada por factores exógenos, como en el caso del aumento de la liquidez internacional a raíz de dicha crisis, debido a que países como Chile, Colombia, México y el Perú resultaron muy atractivos para los inversionistas extranjeros por tener, entre otras características, mayores tasas de interés.

Como se aprecia en el gráfico II.12, una vez terminado el superciclo de los precios, el tipo de cambio nominal en muchos países de la región ha sido creciente y volátil. Esta situación se explica en gran medida por la incertidumbre política que ha prevalecido en muchos de ellos, las perspectivas de políticas comerciales más proteccionistas por parte de los Estados Unidos y la continua desconfianza relacionada con mayores ajustes a las políticas monetarias de las economías desarrolladas, entre otros factores.

Gráfico II.12

América Latina (países seleccionados): índice del tipo de cambio nominal con respecto al dólar, enero de 2014 a noviembre 2016

(Base enero de 2014=100)

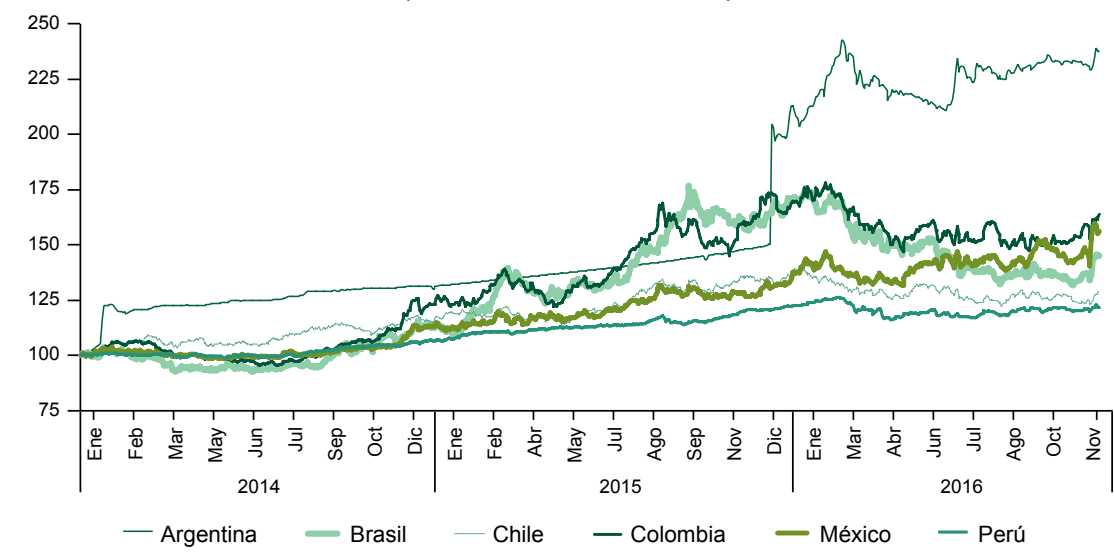

Fuente: Comisión Económica para América Latina y el Caribe (CEPAL), Balance Preliminar de las Economías de América Latina y el Caribe, 2017 (LC/PUB.2017/28), Santiago, 2018; y datos de Bloomberg.

Como se mencionó antes, el fin de la bonanza económica se tradujo en una disminución de las exportaciones, pero condujo también a una reducción de los ingresos fiscales de origen extractivo (véase el gráfico II.13). Por otra parte, lograr una apropiación de las rentas eficiente y equilibrada sigue siendo un gran desafío para los países ricos en recursos extractivos, 
en particular los que poseen minerales. En América Latina y el Caribe, la apropiación de las rentas ha sido muy heterogénea, tanto entre los países como entre los propios sectores extractivos, ya sea de recursos minerales o hidrocarburíferos.

\section{Gráfico II.13}

Ingresos provenientes de recursos naturales no renovables, 2000-2017 (Como porcentaje del PIB)

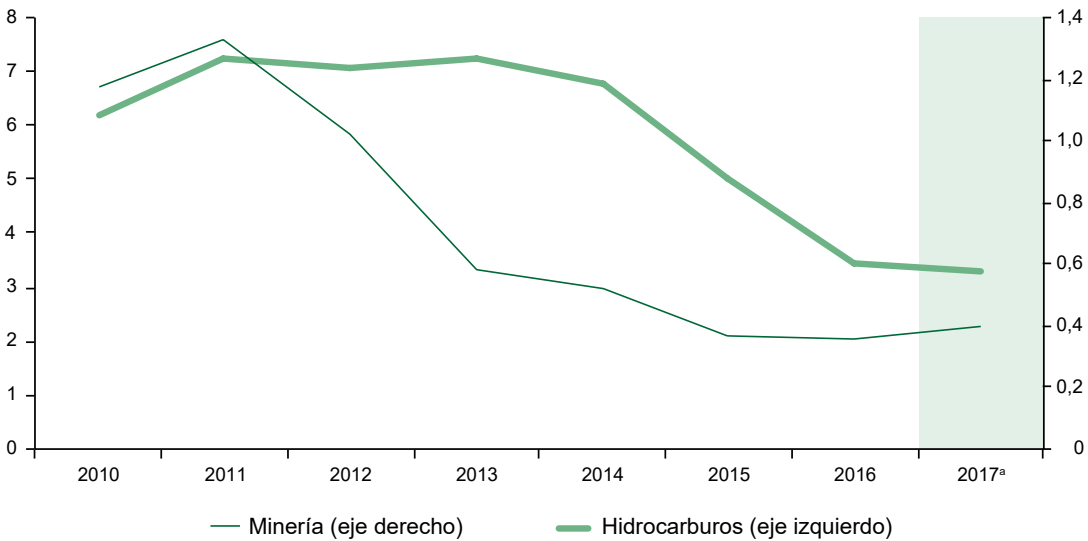

Fuente: Comisión Económica para América Latina y el Caribe (CEPAL).

Nota: En la minería se incluye: Argentina, Bolivia (Estado Plurinacional de), Brasil, Chile, Colombia, Jamaica, México, Perú, República Dominicana y Suriname. En los hidrocarburos se incluye: Argentina, Bolivia (Estado Plurinacional de), Brasil, Colombia, Ecuador, México, Perú, Suriname, a Valor estimado Trinidad y Tabago y Venezuela (República Bolivariana de).

De acuerdo con Gómez Sabaíni, Jiménez y Morán (2015), durante el auge de los precios de 2003-2012 la participación económica del Estado en los países ricos en hidrocarburos mostró un aumento generalizado de la recaudación fiscal en relación con la renta económica potencial de la mayoría de los países, mientras que, en los países mineros - con algunas excepciones como Chile y el Perú- dicha participación no aumentó en la misma magnitud.

En términos generales, la participación fiscal del Estado fue creciente en términos absolutos, pero su incremento fue relativamente menor al registrado en la renta económica potencial del sector minero. Esto pone en evidencia la falta de eficiencia de los regímenes fiscales vinculados con este último sector. En los países mineros - caracterizados por una mayor presencia de empresas privadas en la explotación de los recursos- los gobiernos se han enfrentado al desafío de lograr una mayor progresividad de las rentas sin desalentar las inversiones. En algunos casos, los cambios en los marcos fiscales en busca de mayores rentas y la falta de reglas claras han sido fuente de disputas entre el Estado y algunas empresas mineras. 
El impacto de los menores precios de los recursos extractivos en los ingresos fiscales condujo a muchos países a implementar políticas de ajuste fiscal. Ante la reducción de los ingresos fiscales de los sectores extractivos y de acuerdo con el Estudio Económico de América Latina y el Caribe de la CEPAL (2017a), en América Latina (especialmente en los países de América del Sur) se prevé un recorte de los gastos corrientes primarios - excluidos los pagos de intereses-y los gastos de capital — que incluyen la inversión pública- a corto y mediano plazo.

Esto expone el rezago de la mayoría de los países de la región en la implementación de políticas anticíclicas y, algo más preocupante aún, expresa la reducción de la inversión pública, una variable crucial para alcanzar un crecimiento económico sostenible. Asimismo, comienza a observarse un aumento en el servicio de la deuda pública, debido a la depreciación del tipo de cambio en algunos países, especialmente en el norte de América Latina. De acuerdo con el estudio citado, el espacio fiscal a nivel de los gobiernos se ha reducido y la mayor volatilidad de los balances fiscales se ha observado en los países productores de recursos naturales no renovables.

En algunos países de América del Sur, la generación de menores ingresos fiscales de los sectores extractivos se reflejó en la necesidad de financiarse por medio de deuda pública del gobierno central (véase el gráfico II.14). Sin embargo, de acuerdo con la CEPAL (2017a), se prevé una moderada disminución de la tasa de endeudamiento a corto plazo, en virtud de la expectativa de una mejora en el déficit fiscal de los países productores de minerales en América del Sur como resultado de los recientes incrementos de precios.

\section{Gráfico Il.14 \\ América Latina (países seleccionados): deuda pública \\ del gobierno central, 2000-2016 \\ (Como porcentaje del PIB)}

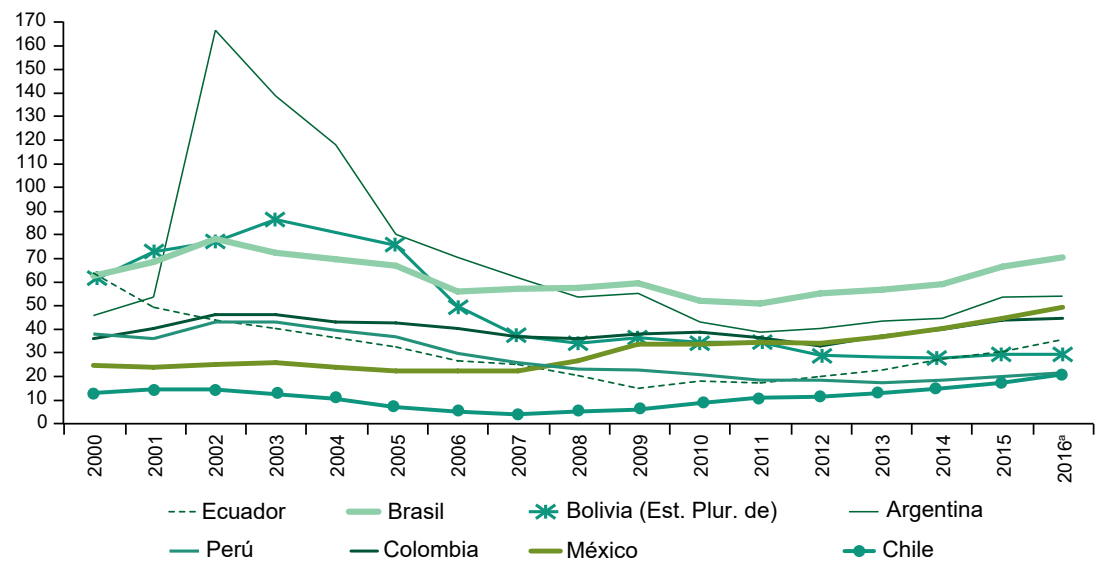

Fuente: Elaboración propia, sobre la base de datos de CEPALSTAT.

a Valor estimado. 


\section{B. Reflexiones finales}

De acuerdo con la evidencia teórica y empírica, el paradigma de desarrollo actual en América Latina y el Caribe es insostenible. Al examinar brevemente el contexto económico y su vínculo con los recursos naturales en la región en las últimas décadas surge la gran interrogante: ¿cómo alcanzarán un desarrollo sostenible las economías de la región que aún deben superar una combinación de retos? Esta combinación de retos incluye:

- una dotación finita de recursos naturales no renovables;

- una gran dependencia económica de dichos recursos no renovables;

- una alta proporción de rentas extractivas gestionadas de forma ineficiente e inequitativa;

- una baja productividad total de los factores y limitadas tasas de inversión que inhiben el crecimiento económico a largo plazo;

- una disminución de la inversión extranjera dirigida a la industria extractiva;

- una intensificación de los conflictos debido a los efectos sociales y ambientales de la explotación de los recursos extractivos;

- un ritmo de extracción de los combustibles fósiles cada vez más cuestionado frente a las nuevas exigencias en virtud del Acuerdo de París, y

- una serie de cambios exógenos de una demanda variable.

Las respuestas son complejas y plantean grandes desafíos que requieren una nueva y apropiada gobernanza de los recursos naturales para cambiar el actual paradigma de desarrollo. Aunque se trata de una situación complicada, todavía se dispone de tiempo para corregirla.

En efecto, como resultado de la disminución de los ingresos fiscales de los sectores extractivos y de la inversión extranjera en los sectores relacionados con esta industria, los encargados de la formulación de políticas macroeconómicas se enfrentan a un contexto económico difícil. La inestabilidad política, la mayor volatilidad cambiaria y las presiones por un mayor proteccionismo comercial, entre otros aspectos, han dificultado la tarea de los bancos centrales de alcanzar una inflación baja y estable. Sin lugar a duda, los ministerios de economía o hacienda de los países de la región se enfrentan hoy a un espacio fiscal más reducido. Si bien en algunas economías de la región se ha optado por reducir los gastos, en particular los de capital, para compensar la reducción de los precios, esta política ha limitado sus posibilidades de crecimiento. En otros países los mayores déficits se han financiado mediante un mayor endeudamiento pero, dado el actual incremento de las tasas de interés en los Estados Unidos, el servicio de la deuda externa para muchos de ellos está aumentando desproporcionadamente. 
Cabe mencionar la importancia que tuvieron en algunos países los fondos soberanos de estabilización y la implementación de políticas anticíclicas, que, entre otras cosas, les permitieron enfrentar de mejor manera la crisis financiera mundial de 2008-2009. No obstante, muchos países tienen necesidades apremiantes. A esto se añade la incertidumbre que han generado las crecientes medidas proteccionistas comerciales en países fuera de la región, como ocurre en el caso de los Estados Unidos. Sin embargo, esto debe tomarse como una oportunidad, en el sentido de que surge como marco adecuado para finalmente integrarse y avanzar hacia una verdadera diversificación productiva y exportadora.

La falta de una adecuada gobernanza de los recursos naturales en el último período de bonanza económica generó distorsiones económicas que obstaculizaron el camino hacia un desarrollo sostenible. Entre las distorsiones más comunes se encuentra la llamada enfermedad holandesa, que se ha constatado en muchos países de la región. En lugar de avanzar hacia objetivos de sostenibilidad y políticas industriales más profundas, en muchas economías se observó una mayor participación de los sectores extractivos y primarios en el total exportado que, sumada a la menor participación del sector manufacturero, condujo a una reprimarización. Esto supuso la desindustrialización de las economías a partir del nuevo milenio y la pérdida de competitividad de otros sectores, como por ejemplo el agrícola.

Muchos países de la región siguen atrapados en la dependencia de los recursos naturales no renovables. México y el Brasil constituyen excepciones, pues han registrado importantes avances en materia de diversificación productiva. No obstante, se trata todavía de avances insuficientes. Si bien las razones que han impedido mejorar las políticas de diversificación son distintas, en muchos casos la capacidad del Estado, las instituciones, la voluntad política, el financiamiento económico, los niveles de educación y capacitación y la inversión en innovación y tecnología han estado ausentes o han sido insuficientes para potenciar y favorecer la competitividad en otras industrias. Cabe mencionar el avance del sector de servicios como motor del crecimiento económico en muchos países de la región durante la última década. A pesar de que la evidencia teórica y empírica ha puesto de relieve al sector manufacturero como el de mayor potencial para generar crecimiento a largo plazo, hoy se abre una oportunidad para que los países ricos en recursos extractivos aprovechen los beneficios del sector de servicios mientras las economías transitan hacia otros sectores productivos.

Mientras esto sucede, el rezago en las cadenas de valor del sector extractivo en los países latinoamericanos es preocupante. Si se analiza el caso de China, que a partir de la década de 2000 comenzó a invertir de forma acelerada en investigación y desarrollo orientados a distintos sectores estratégicos como el de fundición y refinación de los metales, se 
observa que este país avanzó significativamente en la cadena de valor minero-metalúrgica. América Latina invierte menos del 1\% del PIB en investigación y desarrollo. Esta situación llama a las autoridades de los gobiernos a integrar el sector extractivo en los planes de diversificación productiva. Actualmente se requieren inversiones mayores y de mejor calidad que incluyan activos de mayor contenido tecnológico.

Incluso dentro del mismo sector extractivo hay necesidad de mayor diversificación y mejor gobernanza. En el ciclo bajo de los precios de los hidrocarburos actual, existe la expectativa de un aumento de los precios de algunos minerales, que se reforzó después de la firma del Acuerdo de París en 2015. De conformidad con un estudio realizado por el Banco Mundial (2015), bajo la perspectiva de un menor uso de la energía fósil, la demanda de minerales como el aluminio, el cobalto, el cobre, el acero, el estaño, el manganeso y el litio, entre otros, podría cobrar cada vez más importancia en virtud de la ineludible transición hacia las energías renovables - solar, eólica y eléctrica - para generar energía con bajas o nulas emisiones de carbono. La generación de energía eólica y eléctrica requeriría grandes cantidades de dichos minerales y muchos de los países de la región poseen importantes reservas a nivel mundial. El litio es uno de los minerales que pueden asumir un papel cada vez más protagónico, debido a su función en la producción de baterías para el almacenamiento de energía, utilizadas por ejemplo en los vehículos eléctricos. La Argentina, el Estado Plurinacional de Bolivia, el Brasil y Chile poseen el $68 \%$ de las reservas mundiales de litio, por lo que hoy más que nunca deben prepararse para implementar una gobernanza apropiada de este mineral con miras a aprovechar esta nueva coyuntura.

El cambio de la matriz energética es inminente. Actualmente se discute acerca de la capacidad y el compromiso de los países para generar energías limpias con bajos niveles de carbono. Por mucho tiempo prevaleció la gran interrogante acerca del nivel de reservas extractivas y la decisión del ritmo de explotación. Hoy, frente a la nueva demanda de energías limpias, se hace hincapié en la necesidad de definir el momento en que los combustibles fósiles podrían quedarse bajo tierra (activos varados) y si es correcto o no hacer grandes inversiones en este tipo de recursos. Esto ha generado indecisión, tanto entre quienes invierten en proyectos de combustibles fósiles como en los países que gozan de grandes reservas de dichos recursos. Los países que mantienen una gran dependencia de dichos combustibles se enfrentan al desafío de planear y gestionar los recursos de la manera más eficiente posible e invertir en otros sectores para lograr una rápida diversificación productiva.

Sumado a todo esto, la explotación de los recursos naturales que permitió el crecimiento económico también acarreó altos costos sociales, ambientales y laborales que no se han tratado como es debido y se han traducido en conflictos cada vez más intensos y frecuentes en muchos 
países de la región. Esto supone una doble exigencia. Por una parte, los países enfrentan el reto de captar e invertir de manera eficiente y sostenible las rentas extraordinarias derivadas del auge de los precios de los productos básicos para lograr sus metas económicas. Por otra, deben prevenir y mitigar los efectos sociales y ambientales negativos y promover una distribución más amplia de los beneficios, tema que se aborda con detalle en el presente libro.

Es un hecho que la riqueza de los recursos del subsuelo es finita. Esta situación insta a los responsables de la formulación de políticas a planear y gestionar los ingresos provenientes del sector extractivo de una manera más eficiente y, sobre todo, con una visión estratégica a largo plazo, que al mismo tiempo prevenga y mitigue los efectos sociales y ambientales negativos de las actividades extractivas. La experiencia en la extracción de los recursos naturales enseña que para alcanzar una adecuada gobernanza de los recursos naturales no renovables no solo se requiere la legitimidad primaria por parte del Estado en el manejo de dichos recursos, ya de suyo importante, sino también una legitimidad secundaria que la fortalezca - diálogos, pactos, consensos, consentimientos y coalicionesy esté respaldada por todos los actores involucrados en las actividades extractivas (gobiernos, empresas, trabajadores, comunidades directamente afectadas por los proyectos y sociedad civil en general, entre otros). Es en la legitimidad secundaria donde hoy se presentan los principales obstáculos para avanzar hacia una gobernanza eficiente y equitativa en la extracción de los recursos naturales no renovables.

Este nuevo contexto, dentro y fuera del sector extractivo, supone la necesidad de mecanismos más sofisticados para los procesos de planificación y decisión a nivel nacional y regional, así como para la gestión de los recursos. Lo cierto es que los países de la región no pueden volver a dejar pasar la oportunidad de establecer una adecuada gobernanza de los recursos naturales, que incluya políticas fiscales, monetarias, cambiarias e industriales coordinadas, que aseguren las condiciones para sacar el mayor provecho posible ante las variaciones del mercado y que los beneficios de la explotación contribuyan mejor a alcanzar el cambio estructural con igualdad que precisa la región, sin comprometer su capital natural crítico a largo plazo.

Una gobernanza apropiada constituye el principal instrumento con que pueden contar los países de América Latina y el Caribe para cambiar la orientación que se ha dado hasta hoy al manejo económico y fiscal de los recursos naturales y avanzar en el camino de la equidad, la sostenibilidad, los derechos humanos y la protección de la naturaleza. Mientras no existan políticas públicas que incentiven las inversiones para construir infraestructura y aumentar la productividad, generar innovación, tecnología, educación y capacitación y que, sobre todo, faciliten la diversificación de las actividades económicas, América Latina no podrá lograr el necesario cambio estructural con igualdad. 


\section{Bibliografía}

Altomonte, H. y R. J. Sánchez (2016), Hacia una nueva gobernanza de los recursos naturales, Libros de la CEPAL, $\mathrm{N}^{\circ} 139$ (LC/G.2679-P), Santiago, Comisión Económica para América Latina y el Caribe (CEPAL).

Aravena, C., L. E. Escobar y A. Hofman (2014), “Fuentes del crecimiento económico y la productividad en América Latina y el Caribe, 1990-2013", serie Macroeconomía del Desarrollo, № 164 (LC/L.4024), Santiago, Comisión Económica para América Latina y el Caribe (CEPAL).

Aravena, C. y J. A. Fuentes (2013), “El desempeño mediocre de la productividad laboral en América Latina: una interpretación neoclásica", serie Macroeconomía del Desarrollo, № 140 (LC/L.3725), Santiago, Comisión Económica para América Latina y el Caribe (CEPAL).

Aravena, C., G. López y R. Pineda (2018), "Producto potencial de mediano plazo en América Latina", Santiago, Comisión Económica para América Latina y el Caribe (CEPAL), por aparecer.

Auty, R. M. (1993), Sustaining Development in Mineral Economies: The Resource Curse Thesis, Londres, Routledge.

Banco Mundial (2015), Informe sobre el Desarrollo Mundial. Panorama general, Washington,D.C. [enlínea] https://openknowledge.worldbank.org/bitstream/ handle / 10986/20597/928630WDR0v20O00Box385381B00PUBLIC0.pdf? sequence $=30 \&$ isAllowed $=y$.

CEPAL (Comisión Económica para América Latina y el Caribe) (2017a), Estudio Económico de América Latina y el Caribe: la dinámica del ciclo económico actual y los desafíos de política para dinamizar la inversión y el crecimiento (LC/PUB.2017/17-P), Santiago. (2017b), La Inversión Extranjera Directa en América Latina y el Caribe, 2017 (LC/PUB.2017/18-P), Santiago.

(2017c), Perspectivas del Comercio Internacional de América Latina y el Caribe, 2017 (LC/PUB.2017/22-P), Santiago.

(2016a), La Inversión Extranjera Directa en América Latina y el Caribe, 2016 (LC/G.2680-P), Santiago.

(2016b), Balance Preliminar de las Economías de América Latina y el Caribe, 2016 (LC/G.2698-P), Santiago.

(2015), "América Latina y el Caribe y China: hacia una nueva era de cooperación económica" (LC/L.4010), Santiago.

(2014), Pactos para la igualdad: hacia un futuro sostenible (LC/G.2586(SES.35/3)), Santiago.

Duque, D., M. Oscar y M. Saade (2017), "Infraestructura logística para una mejor gobernanza de la cadena del carbón en Colombia", Documentos de Proyectos (LC/TS.2017/75), Santiago, Comisión Económica para América Latina y el Caribe (CEPAL).

FMI (Fondo Monetario Internacional) (2017), World Economic Outlook Database, octubre.

Gómez Sabaíni, J. C., J. P. Jiménez y D. Morán (2015), “El impacto fiscal de la explotación de los recursos naturales no renovables en los países de América Latina y el Caribe", Documentos de Proyectos (LC/W.658), Santiago, Comisión Económica para América Latina y el Caribe (CEPAL). 
Lahn, G. y S. Bradley (2016), "Left stranded? Extractives-led growth in a carbon-constrained world", Research Paper, Londres, The Royal Institute of International Affairs.

Ocampo, J. A. (2015), "Los retos del desarrollo latinoamericano a la luz de la historia", Cuadernos de Economía, vol. 34, N 66, Bogotá, Universidad Nacional de Colombia.

OMPI (Organización Mundial de la Propiedad Intelectual) (2017), World Intellectual Property Indicators, 2017, Ginebra.

OMPI/PCT (Organización Mundial de la Propiedad Intelectual/Tratado de Cooperación en Materia de Patentes) (s/f), "The Changing Geography of the PCT System" [en línea] http://www.wipo.int/export/sites/www/pct/ en/2million/pdf/pct_geography.pdf.

Rosales, O. y S. Herreros (2017), "Desafío de la competitividad exportadora en América Latina y el Caribe", Estudios Internacionales, Santiago, Instituto de Estudios Internacionales, Universidad de Chile.

Saade, M. (2013), "Desarrollo minero y conflictos socioambientales. Los casos de Colombia, México y el Perú", serie Macroeconomía del Desarrollo, N 137 (LC/L.3706), Santiago, Comisión Económica para América Latina y el Caribe (CEPAL).

Szirmai, A. (2011), "Manufacturing and economic development", WIDER Working Paper, $N^{\circ}$ 2011/75, Instituto Mundial de Investigaciones de Economía del Desarrollo (UNU/WIDER).

Timmer, M. P. y G. J. de Vries (2009), "Structural change and growth accelerations in Asia and Latin America: new sectoral data set", Cliometrica, vol. 3, $\mathrm{N}^{\circ} 2$, Springer. 



\section{Capítulo III \\ Situación de los minerales en América Latina y el Caribe}

José Luis Lewinsohn

En este capítulo se espera resaltar la importancia de los metales y los minerales en todo su valor, desde su influencia en la vida cotidiana hasta el análisis del ciclo de los precios destinado a la toma de decisiones en el sector. Uno de los temas destacables es la estrecha relación entre los precios y la inversión en exploración y explotación, que es de largo plazo e intensiva en capital. Por otra parte, en este trabajo se incluye un análisis actualizado sobre la toma de decisiones políticas y económicas que han configurado la inversión dirigida a las materias primas en América Latina y el Caribe. Se usan datos macroeconómicos para examinar el alto y mediano grado de dependencia de algunos países de la región que tienen importantes reservas de minerales base, preciosos o ferrosos a nivel mundial.

Por otro lado, atendiendo a la incorporación de nuevas tecnologías en la elaboración de bienes de consumo variados y a la paulatina readecuación de la matriz energética para disminuir las emisiones de dióxido de carbono, se identifican algunos metales críticos necesarios para elaborar manufacturas cada vez más especializadas. Esto hace pensar que el desafío de la región es identificar ventajas comparativas relacionadas con estos minerales particulares y escasos, con el fin de generar mejoras a través de la investigación y el desarrollo para lograr una explotación altamente tecnológica, encadenamientos productivos y niveles de comercialización e integración que permitan elaborar una propuesta 
regional minera que responda a los desafíos de la economía verde y la gobernanza de los recursos del sector.

Finalmente, es posible afirmar que algunos fenómenos como la urbanización, el aumento de la población y la brecha de la infraestructura incrementarán la demanda de materiales de construcción. Este escenario ejercerá presión tanto en los productores de minerales como en el propio medio ambiente, debido al impacto que genera la explotación de toda la gama de minerales que demanda la sociedad actual. En consecuencia, se hace necesario proponer el desacople entre el crecimiento económico y la intensidad del consumo de los minerales. Para alcanzar este complejo propósito, algunas de las acciones, instrumentos y procesos que podrían revisarse son los siguientes: la innovación tecnológica; las reglamentaciones ambientales que exijan la gestión de los pasivos ambientales; la concurrencia de nuevas técnicas, como la minería secundaria; las iniciativas orientadas a construir un sistema de gestión internacional de "certificación verde" para la extracción; el cambio de los patrones de producción y consumo; el metabolismo social; la economía circular; la consolidación de la trasparencia en la gestión, y, finalmente, la gobernanza de los recursos naturales. Todas las anteriores constituyen algunas de las dimensiones esenciales que permitirían aportar al desarrollo sostenible desde la perspectiva del sector minero.

\section{A. La importancia de los minerales en el mundo y en América Latina y el Caribe}

La amplia gama de minerales metálicos y no metálicos son esenciales para el desarrollo de los distintos sectores económicos y para la economía mundial. Asimismo, se ha determinado que el desarrollo futuro depende en términos relativos del suministro continuo de estos productos básicos. Cada día se emplean minerales de diversas explotaciones mineras para elaborar distintos bienes de consumo y productos que se utilizan en la movilidad (los autos, los aviones y los trenes, entre otros), el cultivo y el procesamiento de alimentos, y la infraestructura urbana (las carreteras, el alcantarillado, la generación de energía y otros) ${ }^{1}$.

En lo que respecta al uso de los principales metales y a su relación con los sectores económicos asociados, cabe señalar que, del acero que se demanda a nivel mundial, el $52 \%$ se utiliza en infraestructura y desarrollo urbano, el $17 \%$ en movilidad y el $27 \%$ en maquinarias y manufacturas (véase el diagrama III.1). En 2015, el acero produjo movimientos económicos en el orden de los 969.700 millones de dólares. El cobre, por su parte, se destina principalmente a la infraestructura, la generación de energía y la electricidad.

Véase Mineral Education Coalition (MEC) [en línea] http://mineralseducationcoalition.org/ education-database/mining-101-presentation/. 


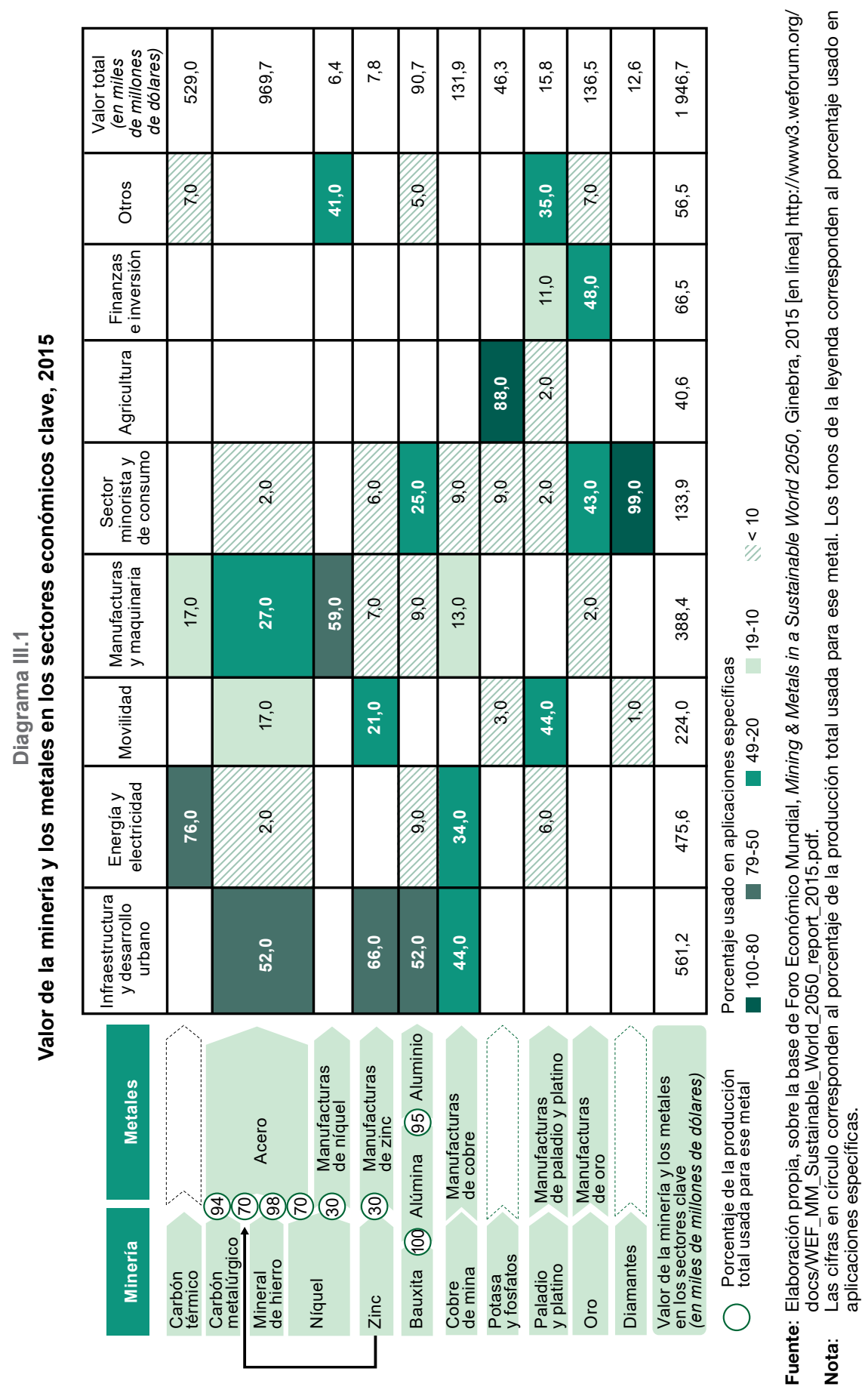


En varios de los países industrializados se han agotado los yacimientos económicamente explotables. Para satisfacer la demanda, se ha intensificado la oferta desde yacimientos de alto potencial geológico agrupados principalmente en regiones como África, y América Latina y el Caribe.

\section{B. Ciclos del precio de los metales y su influencia en el sector}

El precio de los metales es un factor preponderante en el desarrollo del sector extractivo de los minerales. En el último superciclo de los precios, la inversión dirigida al sector aumentó en la región y consolidó la oferta mundial de estos productos básicos. Además, se incrementaron las rentas y los ingresos fiscales, y mejoraron los términos de intercambio. Sin embargo, también aumentó el grado en que los países productores dependen del sector.

En el estudio de Acquatella, Bello y Berríos (véase el capítulo IX de este libro), para entender el principal determinante del modo en que el precio de los metales varía en el tiempo, se explica que los ciclos de los precios responden a los desequilibrios de corto plazo entre la oferta y la demanda de estos metales. Debido a que los proyectos mineros son de mediano a largo plazo, las curvas de la oferta y la demanda presentan una inelasticidad elevada en el corto plazo, es decir, toma un tiempo considerable que la oferta aumente para satisfacer la nueva demanda.

El aumento sostenido de la demanda de estos productos básicos se ha reflejado en diversas fases del desarrollo industrial y la urbanización de las grandes economías, como en los Estados Unidos (entre 1890 y 1910), en el Japón durante la posguerra (entre 1945 y 1970) y en China en el más reciente período de expansión (Heap, 2005). El efecto principal del incremento sostenido de la demanda es el incremento de los precios, equilibrado por el aumento de la oferta. En el trabajo de Acquatella, Bello y Berríos, se analizan las series de precios trimestrales de los minerales y los hidrocarburos desde 1900 hasta 2015, y se concluye que en las series anuales hubo de tres a cuatro superciclos. La duración media de cada superciclo fue de 31,6 años, y la de las fases de auge y caída de los precios, de 16 años. Por ejemplo, el último superciclo se inició alrededor de 2000 y tuvo una duración media de 15 años, con alta correlación entre el precio del petróleo crudo, el oro y la plata.

A partir de 2000 y hasta 2008, el precio del cobre se incrementó y llegó a cuadruplicarse (véase el gráfico III.1). Hacia 2009 se observó una caída generalizada, que posteriormente se revirtió hasta alcanzar valores máximos en 2011. Después de eso, el precio volvió a caer hasta inicios de 2016, cuando se estabilizó y volvió a repuntar de forma moderada hacia fin de año. 


\section{Gráfico III.1}

Precio de los metales, 2000-2017

(En dólares por tonelada métrica)

A. Aluminio, cobre, plomo y zinc

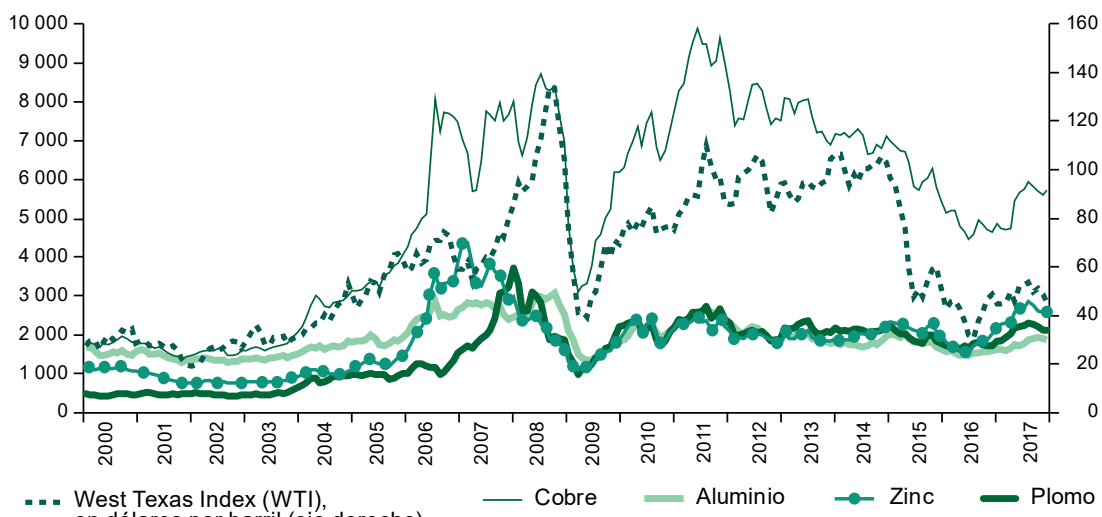

en dólares por barril (eje derecho)

B. Níquel y estaño

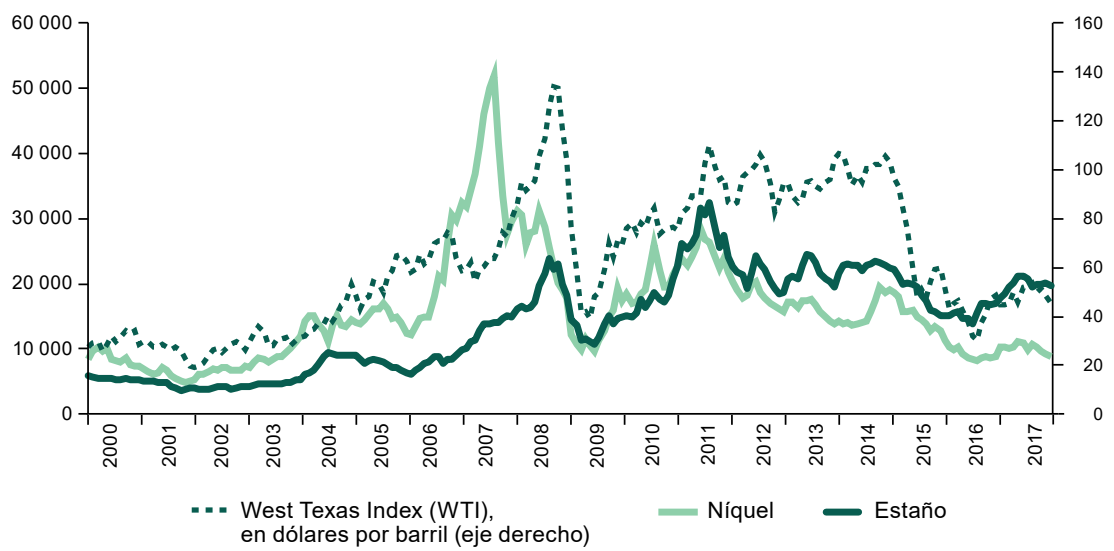

Fuente: Fondo Monetario Internacional (FMI) [en línea] http://www.imf.org/external/np/res/commod/ index.aspx.

En el caso del oro (véase el gráfico III.2), el precio aumentó cerca de 2,5 veces desde 2005 hasta el primer pico que ocurrió en 2008. Luego de una leve caída en 2009 (este metal se utilizó como reserva de valor durante la crisis financiera internacional), siguió una trayectoria ascendente hasta alcanzar un máximo histórico en 2011 y situarse en 1.800 dólares la onza $(4,5$ veces el precio de 2005). Posteriormente, se observó una tendencia leve a la baja que se volvió abrupta en 2013: hacia finales de 2015, el precio había llegado a unos 1.000 dólares la onza. Por último, hacia fines de 2016, el precio se estabilizó en torno a 1.200 dólares la onza. 


\section{Gráfico III.2}

\section{Precio de los metales y minerales, 2000-2017}

A. Oro y plata

(en dólares por onza troy)

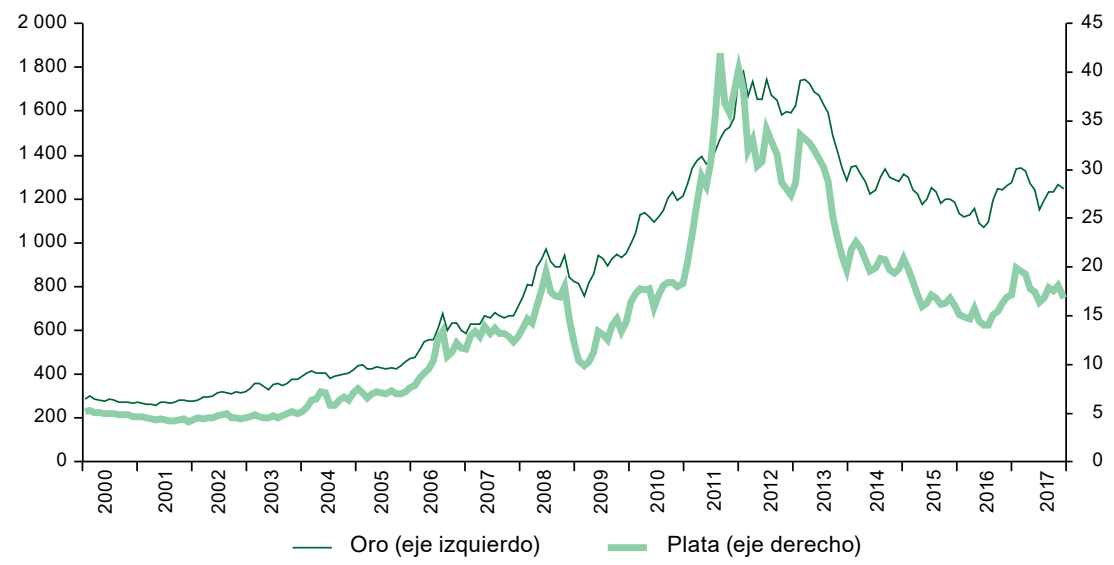

B. Hierro y carbón

(en dólares por tonelada métrica)

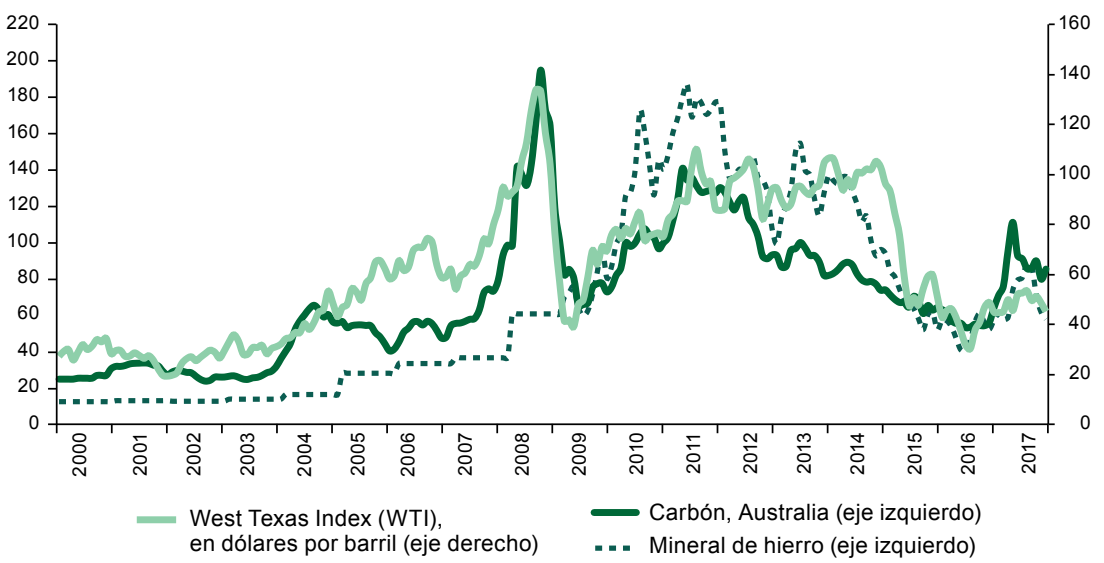

Fuente: Elaboración propia, sobre la base de datos del Fondo Monetario Internacional (FMI) y de la Comisión Chilena del Cobre (COCHILCO). 
En cuanto al hierro, los precios comenzaron a aumentar en 2004 y no descendieron de forma significativa en 2009, sino que mantuvieron una trayectoria al alza hasta fines de 2011, cuando alcanzaron el máximo y superaron en más de diez veces los de 2004. Desde 2012 se inició una tendencia a la baja que llegó al mínimo a principios de 2016, cuando se igualaron los precios de 2008. Por último, en el caso del carbón, el precio máximo de 2008 fue cinco veces mayor que el de 2004. Luego, se presentó un descenso abrupto en 2009 y dos años más tarde, en 2011, se volvió a alcanzar un máximo que casi cuadriplicó el precio de 2004. A partir de 2012 se inició una tendencia a la baja que llegó a su mínimo en 2016, lo que significó un retorno a los precios de 2004.

\section{Producción minera de América Latina y el Caribe y desarrollo económico del sector respecto a los principales actores del mundo}

Desde principios de la década de 2000, las condiciones macroeconómicas mundiales propiciaron una alta inversión en minería en América Latina y el Caribe. Las condiciones que más influyeron fueron los precios de los productos básicos, la apreciación cambiaria en relación con el dólar estadounidense, el crecimiento de la demanda en China, la regulación y las políticas de atracción de la inversión, y las ventajas comparativas en cuanto a la riqueza geológica. Como consecuencia, se acrecentó la proporción de las materias primas en la producción de la región, aunque sin avanzar hacia una adición de valor.

Para observar los cambios de la configuración, tanto de los importadores como de los productores a nivel mundial, se hace necesario comparar la producción minera, la producción de refinado y el consumo de este en América Latina y el Caribe respecto de los principales actores del mundo, en especial en lo que respecta a cómo evolucionó la refinación de metales en China a partir de 1980 (véase el gráfico III.3). 


\section{Gráfico III.3 \\ América Latina y el Caribe y países seleccionados: participación de la producción minera y de la producción y el consumo de refinado en la producción y el consumo mundiales, 1980-2016 \\ (En porcentajes)}

A. Cobre

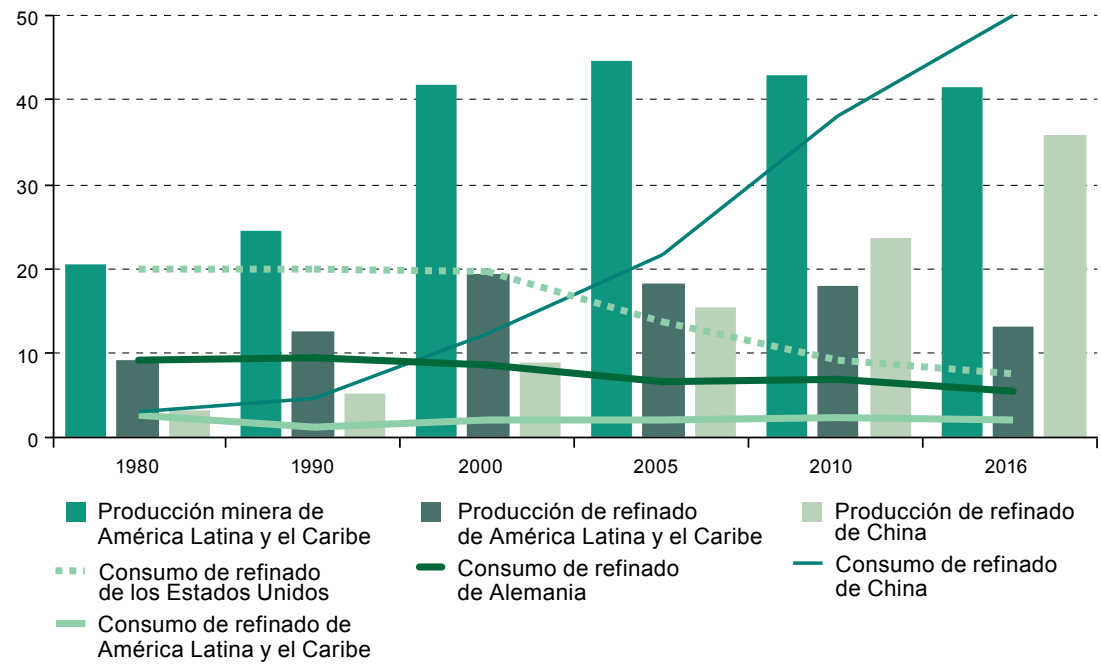

\section{B. Zinc}

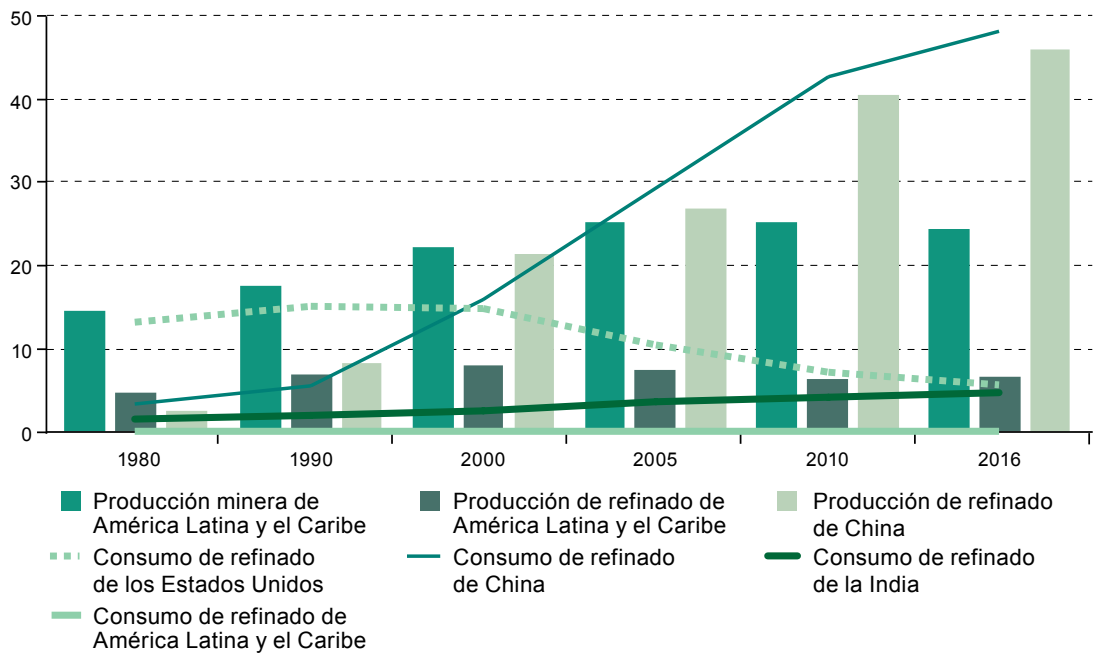


Gráfico III.3 (continuación)

\section{Estaño}

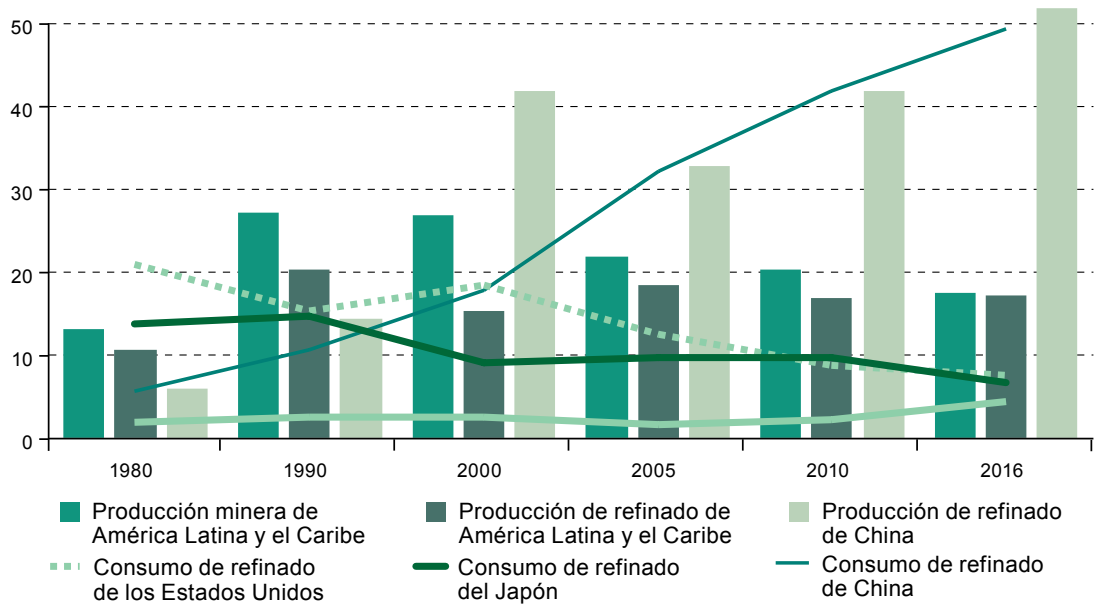

- Consumo de refinado de América Latina y el Caribe

\section{Níquel}

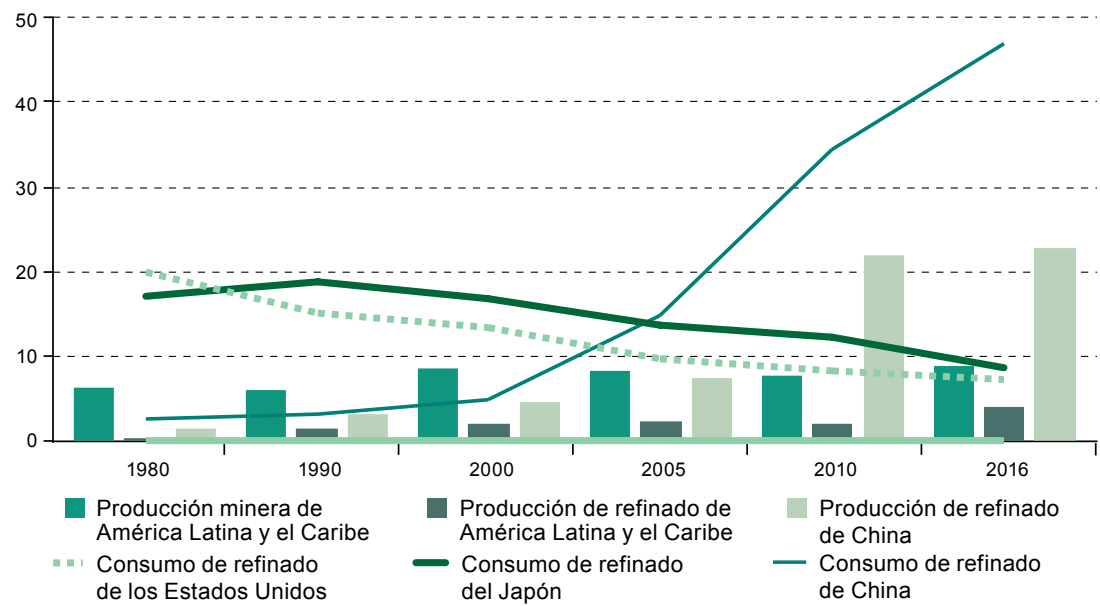

- Consumo de refinado de América Latina y el Caribe 
Gráfico III.3 (continuación)

\section{E. Plomo}

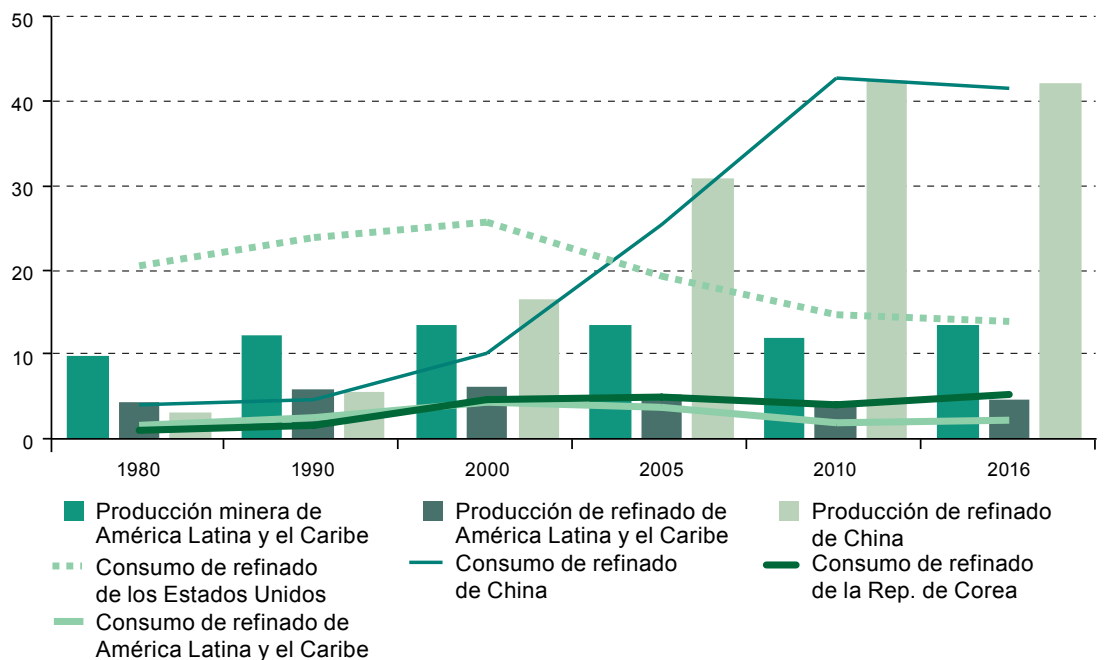

\section{F. Hierro y acero}

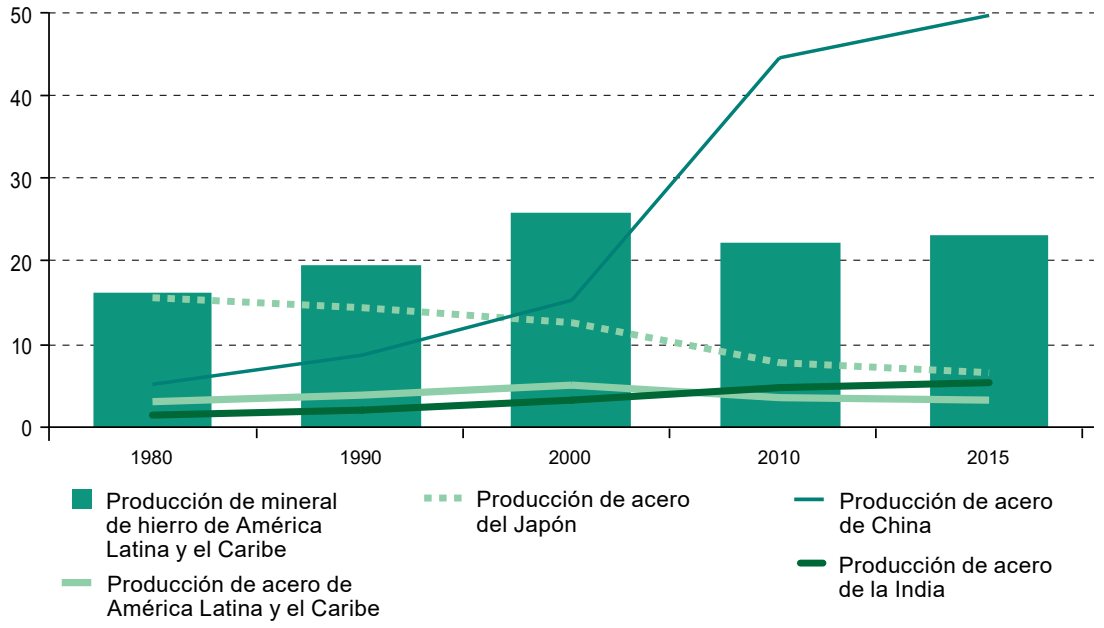


Gráfico III.3 (conclusión)

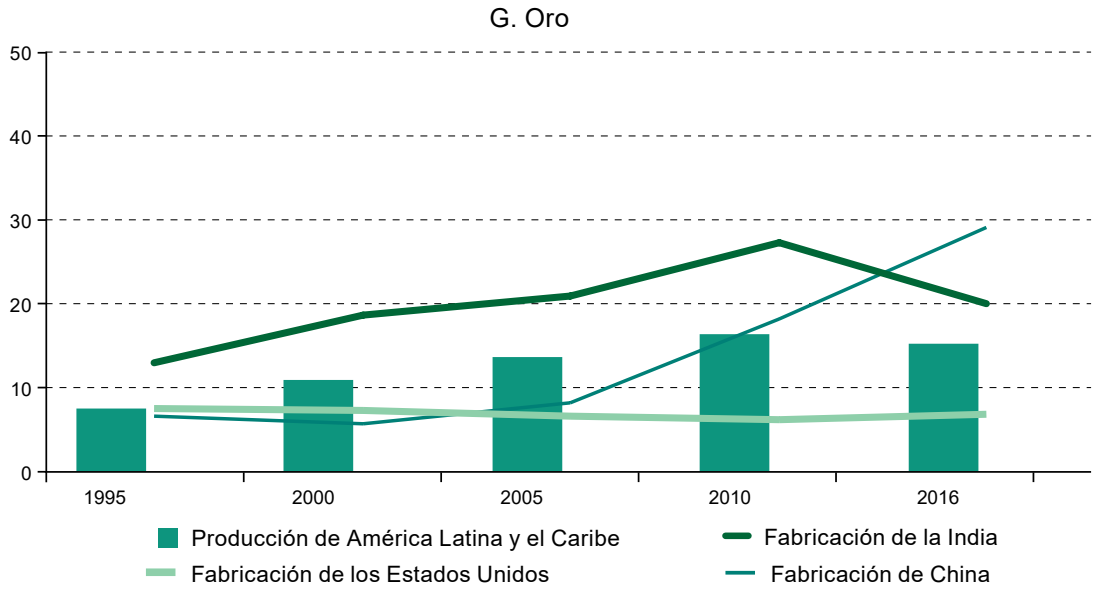

\section{H. Plata}

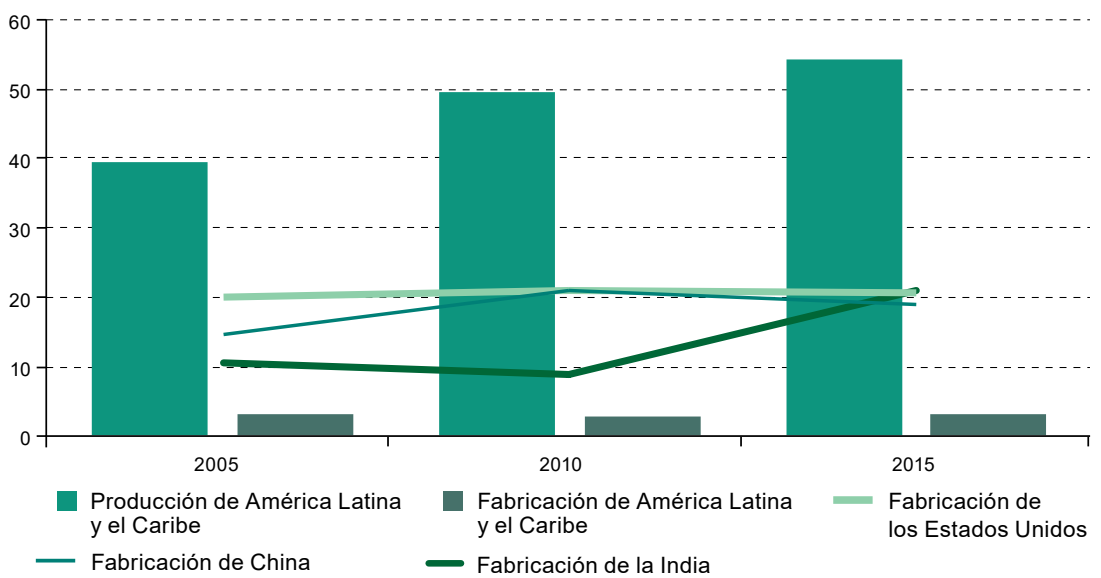

Fuente: Elaboración propia, sobre la base de Banco Mundial, Commodity Markets Outlook, Washington, D.C., abril de 2017 [en línea] https://openknowledge.worldbank.org/handle/10986/26457.

Nota: En el caso de la plata, la fabricación se refiere a joyas y platería, e incluye chatarra; en el caso del oro, la fabricación incluye chatarra. 
Como se observa, China se convirtió en el principal importador de mineral de hierro, concentrados de cobre y bauxita del mundo, y superó notablemente a países líderes como Alemania, los Estados Unidos y el Japón, entre otros. Además, después de satisfacer sus necesidades internas, China tuvo la capacidad de exportar sus metales y sus respectivas manufacturas. Esto último dejó en evidencia el avance de la cadena de valor minero y metalúrgico de dicho país, en contraste con la de América Latina y el Caribe, donde solo creció la producción de los minerales de mina y quedó limitada la capacidad de producir metales refinados (CEPAL, 2016).

En 2016, los países cuyo sector minero representaba la mayor proporción del producto interno bruto (PIB) eran los siguientes: Guyana, 22,4\%; Trinidad y Tabago, 18,3\%; Chile, 13,3\%; Estado Plurinacional de Bolivia, 12,9\%; Perú, 12,1\%; Ecuador, 10,2\%, y Colombia, 7,7\%. El promedio de la región en cuanto a la proporción del sector minero en el total del PIB en los años considerados fue del 6,5\%: el 8,2\% en el Caribe y el 6,5\% en América Latina (véase el gráfico III.4).

\section{Gráfico III.4}

Proporción de la explotación de minas y canteras respecto al total del producto interno bruto anual, 2000, 2005, 2010 y 2016

(En porcentajes)

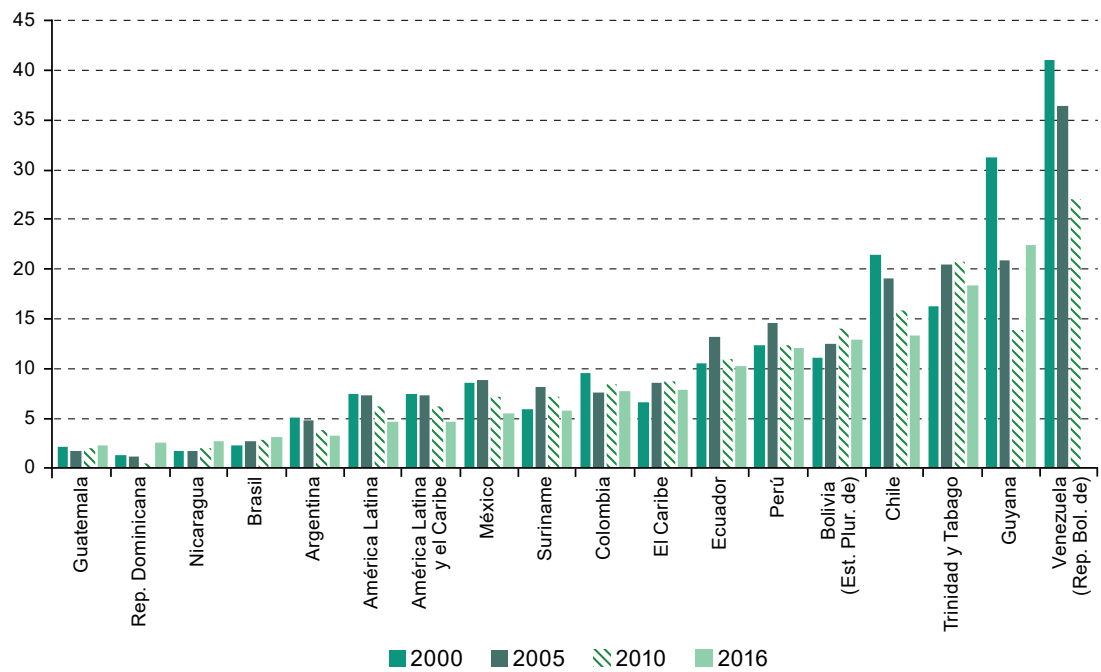

Fuente: Comisión Económica para América Latina y el Caribe (CEPAL), CEPALSTAT

Nota: A precios constantes en dólares, año base 2010. No hay datos de Venezuela (Rep. Bol. de) disponibles para 2016. 
Las exportaciones de minerales son un componente importante de las exportaciones de la región (véase el gráfico III.5). En particular, en el período 2005-2015, se observó que la participación de las exportaciones de minerales de la región en las exportaciones de minerales del mundo fue del $16 \%$ en promedio, en tanto que la participación en las exportaciones totales de la región fue del $12 \%$ en promedio. Cabe señalar que la participación de los minerales en las exportaciones de países como Chile y el Perú superó el 50\%.

Gráfico III.5

América Latina y el Caribe: exportaciones de minerales y comparación con el resto del mundo, 1962-2015

(En porcentajes)

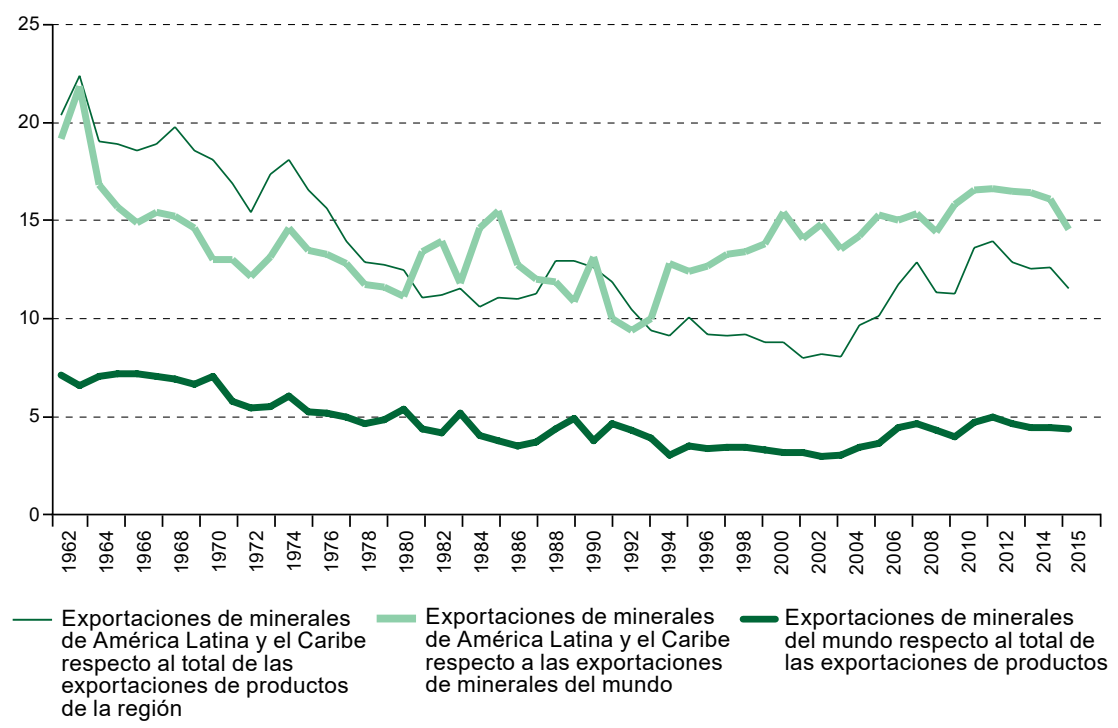

Fuente: Elaboración propia, sobre la base de datos del Banco Mundial [en línea] https://datos. bancomundial.org/indicador/TX.VAL.MMTL.ZS.UN.

Los ingresos públicos derivados de la actividad minera registraron una variación negativa en los países seleccionados que aparecen en el cuadro III.1, con excepción de Jamaica. Esto se explicaría en parte por la disminución del precio de los metales, que afectó más a los países con economías dependientes de estos, como Chile, donde se observó la mayor variación total $(-0,56 \%)$, Suriname $(-0,42 \%)$ y el Perú $(-0,28 \%)$. 


\section{Cuadro III.1}

América Latina y el Caribe (10 países): ingresos públicos derivados de la minería, por país y tipo de ingreso, 2014-2015

(En porcentajes del PIB)

\begin{tabular}{|c|c|c|c|c|c|c|c|c|c|}
\hline \multirow{2}{*}{ País } & \multicolumn{3}{|c|}{ Total } & \multicolumn{3}{|c|}{ Ingresos tributarios } & \multicolumn{3}{|c|}{ Ingresos no tributarios } \\
\hline & $2014(r)$ & $2015(p)$ & $\Delta$ & $2014(r)$ & $2015(p)$ & $\Delta$ & $2014(r)$ & $2015(p)$ & $\Delta$ \\
\hline Argentina & 0,08 & 0,05 & $-0,03$ & 0,08 & 0,05 & $-0,03$ & 0,00 & 0,00 & 0,00 \\
\hline $\begin{array}{l}\text { Bolivia (Estado } \\
\text { Plurinacional de) }\end{array}$ & 0,66 & 0,50 & $-0,16$ & 0,09 & 0,07 & $-0,03$ & 0,57 & 0,43 & $-0,14$ \\
\hline Brasil & 0,08 & 0,05 & $-0,03$ & 0,04 & 0,02 & $-0,02$ & 0,04 & 0,03 & 0,00 \\
\hline Chile & 1,83 & 1,27 & $-0,56$ & 1,57 & 1,27 & $-0,30$ & 0,26 & 0,00 & $-0,26$ \\
\hline Colombia & 0,30 & 0,26 & $-0,04$ & 0,09 & 0,05 & $-0,04$ & 0,21 & 0,21 & 0,00 \\
\hline Jamaica & 0,04 & 0,17 & 0,13 & 0,00 & 0,00 & 0,00 & 0,04 & 0,17 & 0,13 \\
\hline México & 0,21 & 0,19 & $-0,02$ & 0,20 & 0,16 & $-0,03$ & 0,01 & 0,03 & 0,01 \\
\hline Perú & 0,67 & 0,38 & $-0,28$ & 0,46 & 0,24 & $-0,22$ & 0,21 & 0,15 & $-0,06$ \\
\hline $\begin{array}{l}\text { República } \\
\text { Dominicana }\end{array}$ & 0,50 & 0,35 & $-0,15$ & 0,42 & 0,29 & $-0,13$ & 0,07 & 0,06 & $-0,01$ \\
\hline Suriname & 0,85 & 0,43 & $-0,42$ & 0,38 & 0,06 & $-0,32$ & 0,48 & 0,37 & $-0,10$ \\
\hline Promedio simple & 0,52 & 0,37 & $-0,16$ & 0,33 & 0,22 & $-0,11$ & 0,19 & 0,14 & $-0,04$ \\
\hline
\end{tabular}

Fuente: Comisión Económica para América Latina y el Caribe (CEPAL).

Nota: Los ingresos tributarios se refieren a impuestos de sociedades en la Argentina, el Estado Plurinacional de Bolivia, el Brasil (Companhia Vale do Rio Doce), Chile, Colombia, México, Jamaica, el Perú, la República Dominicana y Suriname (IAMGOLD), a derechos de exportación en la Argentina y Chile (Impuesto Ley $\left.\mathrm{N}^{\circ} 13.196\right)$, y a otros impuestos específicos del sector (en Chile, el impuesto específico a la minería; en el Perú, el impuesto especial a la minería (IEM), y en la República Dominicana, el impuesto mínimo anual minero y el impuesto a los beneficios netos de la minería). Los ingresos no tributarios se refieren principalmente a gravámenes sobre la producción: en el Estado Plurinacional de Bolivia, se refieren a regalías; en el Brasil, a la Compensación Financiera por la Exploración de Recursos Minerales (CFEM), la Tasa Anual por Hectárea (TAH) y la tasa de fiscalización de recursos minerales (TFRM) en Minas Gerais; en Chile, a dividendos de la Corporación Nacional del Cobre de Chile (CODELCO); en Colombia, a regalías; en la República Dominicana, al neto de regalía de retorno de fundición; en Jamaica, al gravamen sobre la bauxita y las regalías sobre la bauxita; en México, a los derechos de minería; en el Perú, a regalías y al Gravamen Especial a la Minería (GEM), y, en Suriname, a regalías (IAMGOLD). Las cifras pueden no sumar exactamente debido al redondeo; $(r)$ significa "revisada" y $(p)$ significa "preliminar". A partir de los datos anteriores, se observa que varios países de la región tienen un grado de dependencia alto o mediano respecto de los recursos mineros, lo que presenta un gran desafío que impulsa a continuar mejorando la gobernanza en este sector.

\section{Evolución de la inversión minera en América Latina y el Caribe}

Las características que diferencian al sector extractivo de recursos no renovables respecto de otros sectores son las inversiones intensivas en capital, el riesgo elevado, la alta rentabilidad y, a excepción de lo que ocurre con el gas natural, el bajo encadenamiento con las economías locales. Por estas particularidades, las condiciones económicas internas de los países anfitriones suelen tener escasa incidencia en las decisiones de inversión. En el sector de la minería existen varios agentes privados y, a excepción de la Corporación Nacional del Cobre de Chile (CODELCO), no hay otras compañías públicas que exploten recursos mineros en la región.

Debido al carácter estratégico de los minerales, las transnacionales suelen invertir incluso en condiciones que podrían considerarse adversas 
para la inversión extranjera directa (IED). Entre estas condiciones figuran los marcos normativos ambientales cambiantes, la inestabilidad política y los conflictos armados, entre otros. En la región ha habido un ingreso constante de inversiones en exploración (véanse los gráficos III.6 y III.7), lo que ha permitido cuantificar y clasificar las reservas de los metales base, preciosos y ferrosos. Esto ha consolidado la posición mundial de la región en las reservas medidas e indicadas, requisito fundamental para que se invierta en proyectos de explotación.

\section{Gráfico III.6 \\ Inversión mundial en exploración minera no ferrosa, 2004-2016}

(En millones de dólares)

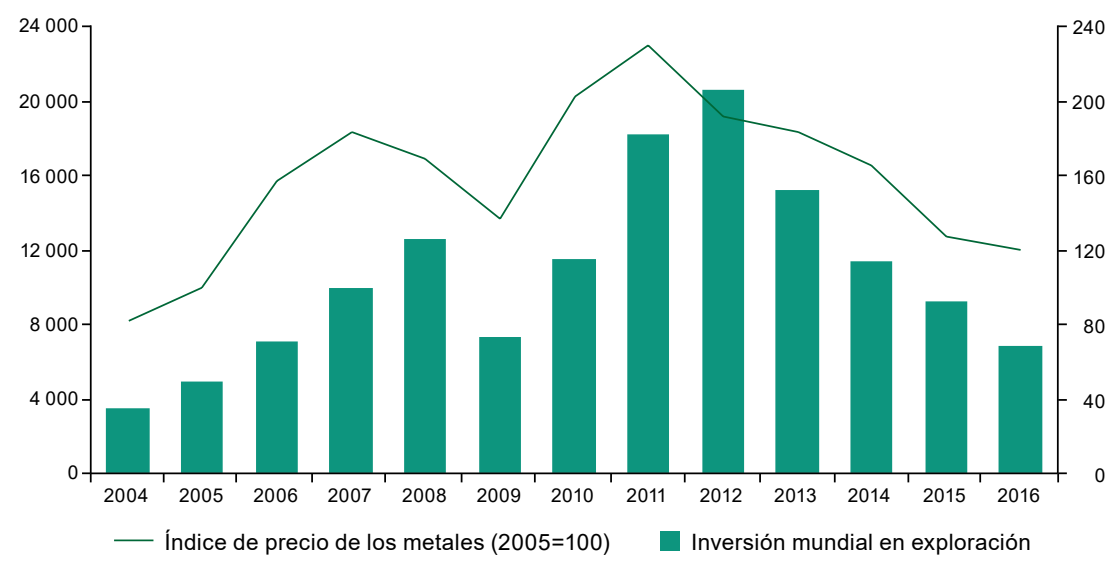

Fuente: Elaboración propia, sobre la base de S\&P Global Market Intelligence, Tendencias mundiales en la exploración, 2017 [en línea] y datos del Fondo Monetario Internacional (FMI).

\section{Gráfico III.7}

Inversión mundial en exploración minera por regiones y países, 2003-2016 (En porcentajes)
A. Regiones

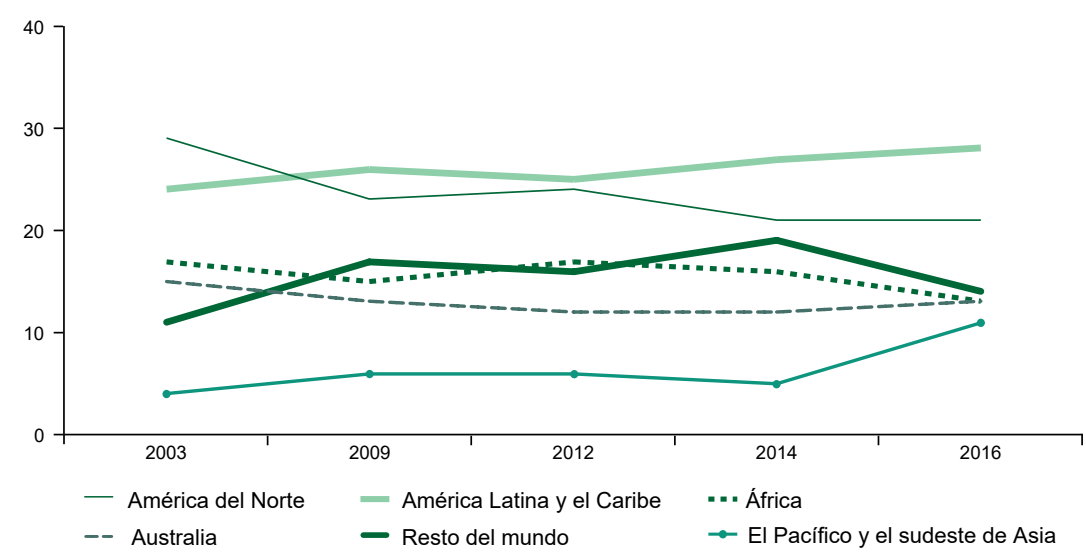


Gráfico III.7 (conclusión)

\section{B. Países}

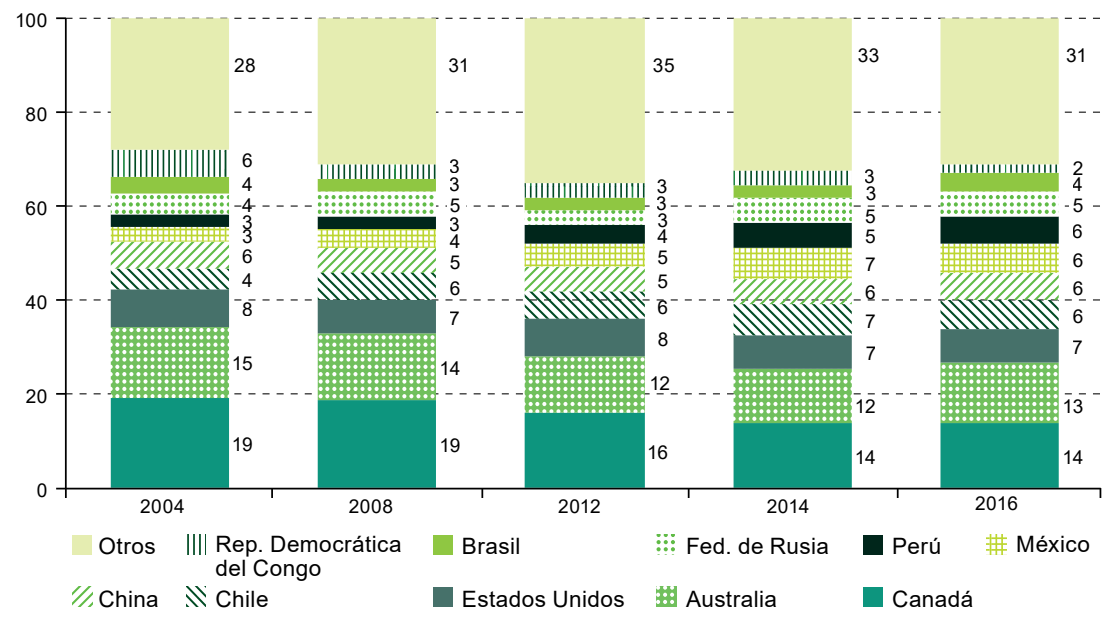

Fuente: Elaboración propia, sobre la base de datos de S\&P Global Market Intelligence.

En cuanto al destino de las inversiones en exploración, es relevante mencionar la participación de la región y los países receptores (véase el gráfico III.7). Desde la década de 2000, en América Latina y el Caribe se observan importantes flujos de inversión en exploración, con un $26 \%$ del total mundial en promedio. El promedio de la inversión en América del Norte, por su parte, es del 24\%, y, en África, del 17\%. En tanto, países como Chile, el Brasil, México y el Perú han recibido un flujo constante de inversión que ha representado entre el 3\% y el $8 \%$ de la inversión mundial.

La posición de las reservas de minerales de América Latina y el Caribe a nivel mundial es dominante. La región cuenta con el 66\% de las reservas mundiales de litio, el $47 \%$ de las de cobre, el $45 \%$ de las de plata, el $26 \%$ de las de estaño, el 23\% de las de níquel y el 21\% de las de zinc. Respecto al hierro, el plomo, el molibdeno, la bauxita y el aluminio, las reservas de la región representan alrededor del 15\% de las reservas del mundo, mientras que, en cuanto al oro, la región posee el 11\% del total (véase el gráfico III.8).

Junto con la inversión, la evolución política de la región ha determinado la configuración productiva desde fines de la década de 1970 y comienzos de la siguiente. A principios de los años ochenta, hubo una fuerte caída de los términos de intercambio en la región, lo que generó efectos negativos sobre los ingresos por concepto de exportaciones y secuelas en la balanza de pagos. El crecimiento económico se desaceleró y la estrategia dominante en aquellos años, que consistía en sustituir importaciones, dio muestras de agotamiento. Posteriormente, el endeudamiento externo llegó a niveles sin precedentes, lo que condujo a una crisis generalizada y a una fuerte restricción del financiamiento externo (CEPAL, 2003). 
Reservas mundiales de metales base, preciosos y ferrosos, 2016

(En porcentajes)

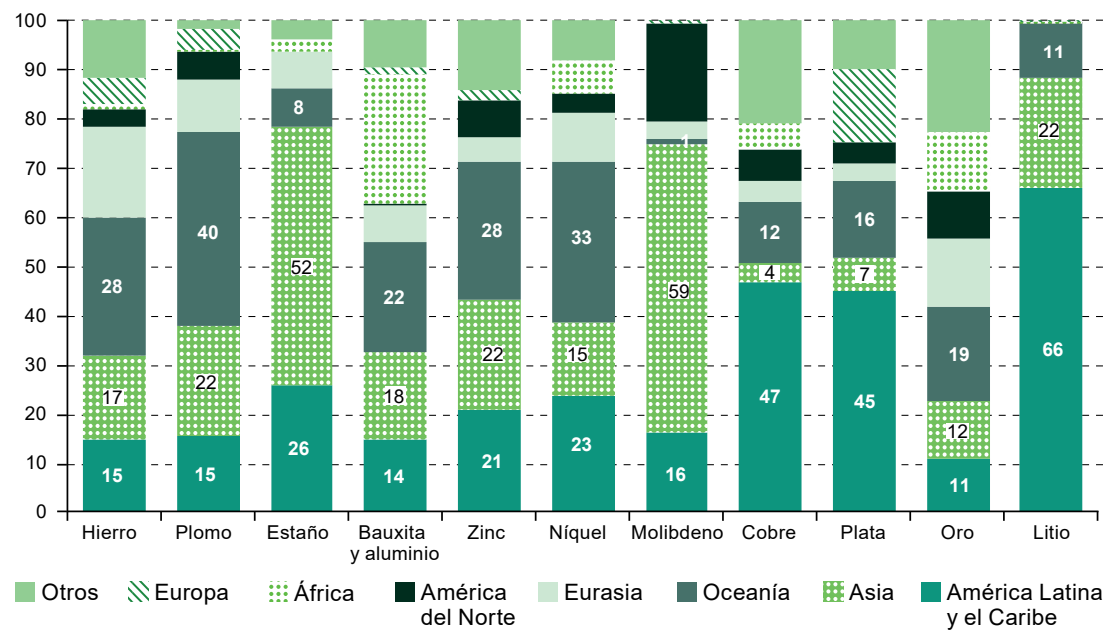

Fuente: Elaboración propia, sobre la base de datos del United States Geological Survey (USGS), Mineral Commodity Summaries, 2017 [en línea] https://minerals.usgs.gov/minerals/pubs/mcs/2017/ mcs2017.pdf.

Nota: La clasificación "Otros" se refiere a la proporción de reservas que hay en varios países que tienen magnitudes menores.

En consecuencia, la crisis llevó a los países andinos a replantearse el papel de la IED en el desarrollo y, después de 16 años, la Decisión 24 fue sustituida por la Decisión 220 de $1987^{2}$. Esta norma flexibilizó el tratamiento de la inversión extranjera al eliminar algunos requerimientos de registro y autorización de inversiones y remesas de utilidades al exterior, suprimir los sectores reservados y otorgar la posibilidad de que cada país miembro legislara en forma individual en materia de inversión extranjera. Las reglamentaciones internas se hicieron progresivamente más receptivas al capital extranjero y se introdujeron simplificaciones administrativas que se convirtieron en normas de carácter más promocional.

En 1991, en un contexto de reestructuración de los Estados, en paralelo con profundas reformas económicas, como la liberalización comercial y financiera, los países miembros del Acuerdo de Cartagena sustituyeron la Decisión 220 por la Decisión 291. Las principales modificaciones fueron suprimir toda referencia a autorizaciones previas, dejando únicamente el requisito de registro ante el organismo nacional competente. Asimismo, se consagró el principio de "igualdad de trato" entre empresas extranjeras,

La Decisión 24 era el régimen común de tratamiento a los capitales extranjeros y sobre marcas, patentes, licencias y regalías, que posteriormente adquirió carácter normativo en el Pacto Andino. Su finalidad era limitar la influencia financiera del exterior, asegurar una mayor contribución del sector privado local, reducir progresivamente la participación de las empresas privadas extranjeras en las locales y eliminar el capital extranjero en sectores estratégicos, entre varias disposiciones de carácter restrictivo (CEPAL, 2003). 
mixtas y nacionales, así como el reconocimiento de la remesa de utilidades y capital, sin establecer topes máximos. Finalmente, se estableció el acceso a todas las ventajas arancelarias vigentes para la Comunidad Andina.

A principios de los años noventa, los Estados nacionales comenzaron a salir de la actividad minera y a otorgar a inversionistas privados (en su mayoría extranjeros) derechos para explorar y explotar los recursos mineros disponibles. Además, se facilitó el otorgamiento de concesiones, se fortaleció la estabilidad jurídica y se dieron mayores garantías e incentivos.

En Colombia, por ejemplo, se constituyó la Empresa Nacional Minera Limitada (Minercol) y se estableció una política gubernamental respecto al carbón en 1999. En 2001, se aprobó un nuevo Código Minero en el que se aseguraba a los inversionistas mayor estabilidad contractual y condiciones más favorables, con el propósito de mejorar la competitividad de la industria minera. Las importantes reservas de níquel posicionaron al país entre los diez mayores productores mundiales. En el Ecuador, en 1991 se promulgó la Ley de Minería, que mejoró la protección de los inversionistas locales y extranjeros; posteriormente, en 2000, se hicieron cambios para aumentar el atractivo del sector.

Al comenzar el nuevo milenio, el Estado Plurinacional de Bolivia era el mayor productor mundial de estaño, mientras que Colombia tenía las mayores reservas de carbón de América Latina y era el cuarto exportador mundial de ese recurso. La República Bolivariana de Venezuela era el tercer productor de carbón de América Latina y poseía importantes recursos de bauxita, mineral de hierro y metales preciosos, principalmente oro. El Perú era el séptimo productor de oro y cobre del mundo (poseía el 15\% de las reservas mundiales de este último mineral), el segundo productor mundial de plata y tenía una participación significativa en el zinc y el plomo.

Las exportaciones del sector minero se incrementaron un $115 \%$ de 1990 a 2002, y el interés de las transnacionales en invertir en el sector de las materias primas se mantuvo vigente a pesar de las crisis por las que atravesaron varios países latinoamericanos. En 2003, el sector primario exportador fue clave en las economías de algunos países de América del Sur. En 2005, los recursos primarios encabezaron las exportaciones de la región, con una participación del $47 \%$. La empresa estatal más grande en la categoría de la explotación minera fue la Corporación Nacional del Cobre de Chile (CODELCO), que registró ventas en torno a los 15.000 millones de dólares. Las empresas privadas que tuvieron ventas similares fueron la Companhia Vale do Rio Doce (CVRD) del Brasil (originalmente estatal) y el Grupo México.

La concentración de la actividad minera se debió a las fusiones y adquisiciones iniciadas en la segunda mitad de la década de 1990, que se prolongaron hasta 2005. El sector estaba dominado por un pequeño grupo de agentes australianos, británicos, canadienses, latinoamericanos 
y norteamericanos, que se concentraron en cinco países - la Argentina, el Brasil, Chile, México y el Perú-, como parte de un proceso que atrajo IED en forma considerable.

En 2008, en plena crisis financiera, las empresas mineras postergaron proyectos y expansiones. En un contexto de caída de los precios, restricción del financiamiento, desaceleración de la economía y mayor incertidumbre, las empresas se vieron forzadas a ajustar sus operaciones reduciendo la producción o recortando el personal, lo que en 2009 afectó los flujos de IED en la región.

La tendencia al alza de los anuncios de inversión se mantuvo hasta 2012 (véase el gráfico III.9), sin embargo, progresivamente se dio a conocer que algunos proyectos mineros estaban provocando la oposición de pueblos indígenas y grupos defensores del medio ambiente. Los proyectos Pascua Lama (Argentina-Chile) y Junín (Ecuador) fueron foco de conflictos entre las empresas, el Estado y la sociedad. Las comunidades involucradas en los proyectos demandaban de forma cada vez más enérgica beneficios por la extracción y exportación de los recursos.

\section{Gráfico III.9 \\ Anuncios de inversión mundial en proyectos mineros, 2000, 2010, 2012, 2014 y 2016 \\ (En millones de dólares)}

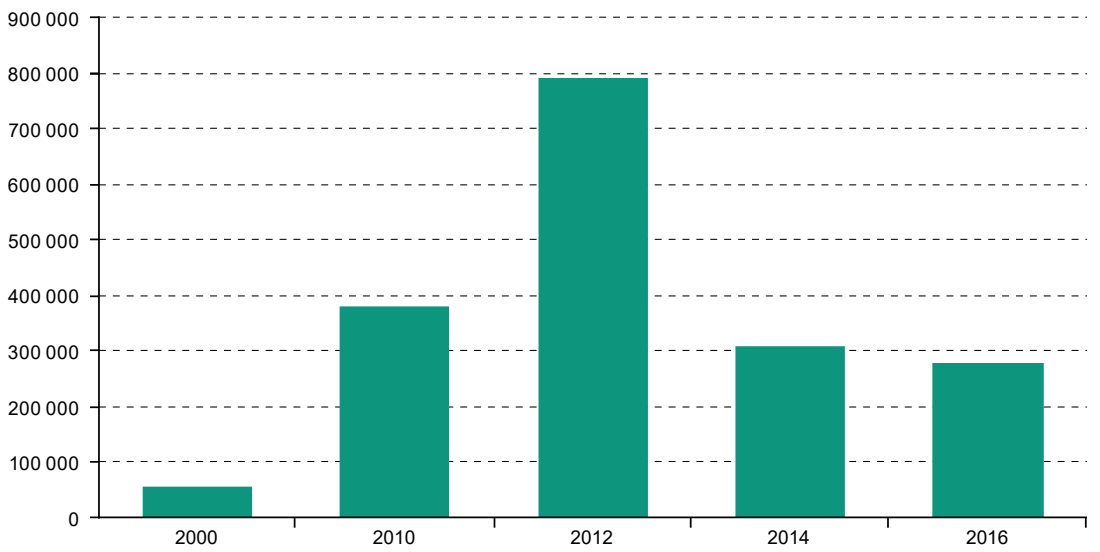

Fuente: Elaboración propia, sobre la base de datos de Engineering and Mining Journal (E\&MJ), 2001, 2011, 2013, 2015 y 2017 [en línea] https://www.e-mj.com/.

Algunos factores que dificultaron la IED fueron la falta de claridad en materia de contratos, el alza de las regalías aplicables a la minería, y los conflictos ambientales y sociales. Sin embargo, el precio internacional alto y sostenido de muchos recursos naturales, la calidad de los yacimientos y la ampliación del acceso fueron factores que - contrariamentecontribuyeron a la entrada de IED. 
En 2012, un grupo de países fueron el principal destino de los anuncios de inversión (véase el gráfico III.10). Existen patrones distintos entre las subregiones: en América del Sur (excepto en el Brasil) se consolidó un patrón sectorial donde los recursos naturales - en particular la minería- fueron el principal destino de la IED (el 51\% en 2012). En el caso de México, Centroamérica y el Caribe, dichos recursos representaron el 10\%, tanto en 2012 como en los cinco años anteriores.

\section{Gráfico III.10}

Distribución de los anuncios mundiales de inversión en proyectos mineros entre los diez países principales, 2000, 2010, 2012, 2014 y 2016a

(En porcentajes)

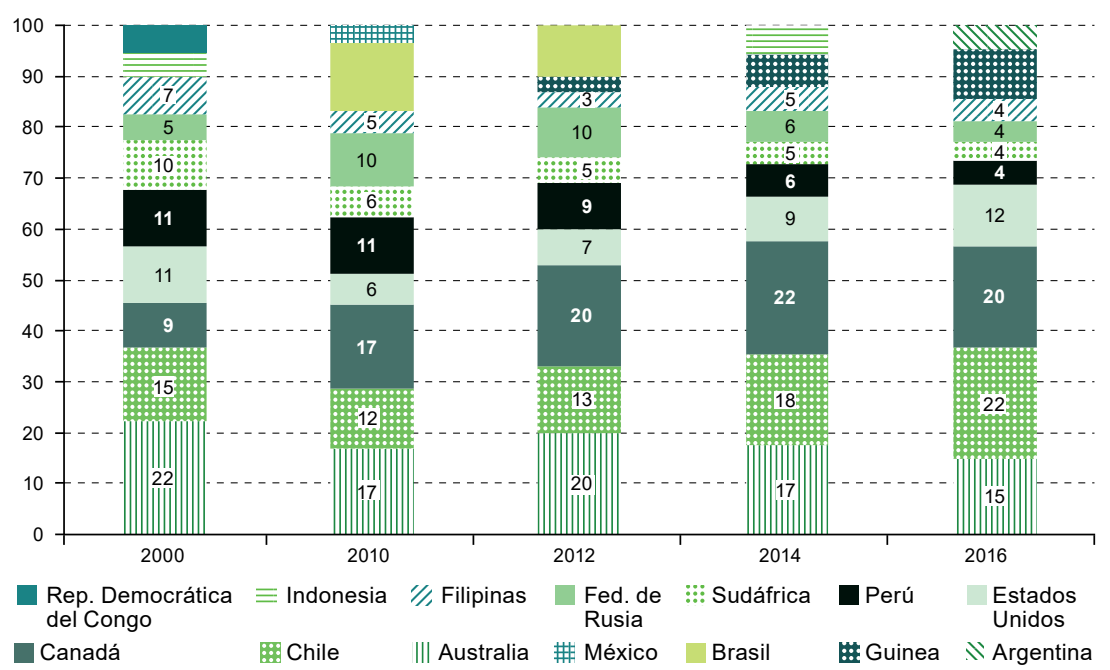

Fuente: Elaboración propia, sobre la base de datos de Engineering and Mining Journal (E\&MJ), 2001, 2011, 2013, 2015 y 2017 [en línea] https://www.e-mj.com/.

a Se consideran los diez países respecto de los cuales se anunciaron los mayores montos de inversión cada año. En los distintos años hay distintos países entre los diez principales. En 2012, a los diez países les corresponde un monto de 546.000 millones de dólares de un total de 791.304. En 2014, dicho monto es de 224.011 millones de dólares de un total de 306.864 y, en 2016, de 213.552 millones de dólares de un total de 278.315.

En 2014, se produjeron descensos en todos los aspectos de la minería a nivel mundial. Los presupuestos de prospección se redujeron el $26 \%$ en relación con 2013 y el $47 \%$ con respecto a 2012 . No obstante, Chile y México seguían estando entre los cinco países con más actividad de exploración del mundo (SNL Metals \& Mining, 2015). En 2015, la contracción de la IED se hizo evidente en la región y afectó principalmente a las economías productoras de minerales e hidrocarburos cuyo intercambio con China era importante. En 2016, el precio de varios metales alcanzó un mínimo y se hicieron evidentes algunos déficits en cuanto a las existencias de minerales en el corto plazo, por lo que, de forma pausada, el precio comenzó a aumentar. 
Sin embargo, esto no fue suficiente para estimular el ingreso de IED en el sector de los recursos naturales, que solo atrajo un 13\% del total de este tipo de inversión. En 2016, la rentabilidad promedio de esta fue del 4,2\%, el mínimo en comparación con los últimos 15 años. El mayor descenso de la rentabilidad se observó en los países con recursos mineros.

\section{E. Minerales y metales críticos en el mundo}

En las economías desarrolladas de Europa y los Estados Unidos se han realizado importantes investigaciones respecto del suministro de materias primas y la criticidad de estas en el corto y mediano plazo. En 2010, en la Unión Europea se publicó el primer estudio sobre materias primas críticas y se identificaron 14 elementos de un total de 41. Luego, en 2014, se publicó la segunda edición, en la que se aumentaron a 20 las materias primas críticas, de un total de 54. En ambos años se utilizó una metodología basada en los siguientes criterios: i) importancia económica, y ii) riesgo de suministro. Una cuestión relevante es que el $90 \%$ del suministro de materias primas se encuentra fuera de la Comunidad Europea, con China como el principal oferente a nivel mundial. Otros países importantes son la Federación de Rusia, Sudáfrica, el Brasil y los Estados Unidos (véase el cuadro III.2).

En 2007, la Unión Europea, por medio del Centro Común de Investigación, lanzó el Plan Estratégico Europeo de Tecnología Energética (Plan EETE), con el propósito de afrontar la problemática del cambio climático, incrementar la seguridad del suministro energético y fomentar la sostenibilidad y la competitividad de la economía de la región. El objetivo fue priorizar políticas para establecer una economía con bajas emisiones de carbono que redujeran los gases de efecto invernadero, mejoraran la eficiencia energética e incrementaran el suministro energético europeo promoviendo los recursos renovables.

En un estudio de 2011 se identificaron riesgos en cuanto al suministro de varios metales y se determinó también que Europa dependía de muchos de ellos. Las principales causas de los riesgos que se identificaron eran las siguientes: i) el rápido incremento de la demanda de algunos materiales, ii) la limitada oferta mundial, iii) los riesgos políticos asociados con la concentración geográfica del suministro, y iv) la competencia por el control de esos recursos.

Se evaluaron 54 elementos metálicos y se identificaron 14 metales en riesgo y cinco en alto riesgo. Entre estos últimos se encontraban el neodimio y el disprosio, que son tierras raras, y el indio, el telurio y el galio, que son subproductos de la transformación de otros metales. Según las estimaciones, entre 2020 y 2030 la demanda de estos para implementar las tecnologías bajas en carbono aumentará el $1 \%$ o más por año (y en algunos casos mucho más) respecto de la oferta mundial de 2010. 


\section{Cuadro III.2}

Proporción del suministro de materias primas críticas que corresponde a los 20 países productores más significativos, 2010, 2011 y 2012

(En porcentajes)

\begin{tabular}{lcl}
\hline Materia prima crítica & $\begin{array}{c}\text { Proporción del suministro que } \\
\text { corresponde a los 20 productores } \\
\text { más significativos }\end{array}$ & Principal proveedor \\
\hline Antimonio & 93 & China (87) \\
\hline Berilio & 99 & Estados Unidos (90) \\
\hline Borato & 88 & Turquía (38) Estados Unidos (30) \\
\hline Cromo & 88 & Sudáfrica (43) Kazajstán (20) \\
\hline Cobalto & 82 & $\begin{array}{l}\text { República Democrática del } \\
\text { Congo (56) }\end{array}$ \\
\hline Carbón coquizable & 94 & China (51) \\
\hline Fluorita & 84 & China (56) \\
\hline Galio & 90 & China (69) \\
\hline Germanio & 94 & China (59) \\
\hline Indio & 81 & China (58) \\
\hline Magnesita & 86 & China (69) \\
\hline Magnesio & 96 & China (86) \\
\hline Grafito natural & 93 & China (69) \\
\hline Niobio & 99 & Brasil (92) \\
\hline Metales del grupo platino \\
(platino, paladio, iridio, rodio, \\
rutenio y osmio) & 93 & Sudáfrica (61) \\
\hline Federación de Rusia (27) & & \\
\hline Rocas fosfóricas & & \\
\hline Tierras raras (pesadas) & 66 & China (38) \\
\hline Tierras raras (livianas) & 100 & China (99) \\
\hline Silicio metálico & 100 & China (87) \\
\hline Tungsteno & 79 & China (56) \\
\hline Funa (85) & 91 & China \\
\hline
\end{tabular}

Fuente: Elaboración propia, sobre la base de Comisión Europea, Report on Critical Raw Materials for the EU, 2014 [en línea] https://ec.europa.eu/docsroom/documents/10010/attachments/1/ translations/en/renditions/pdf.

Si se consideran los elementos metálicos necesarios para la implementación de tecnologías bajas en carbono asociadas a la generación y transmisión eléctrica, en particular energías alternativas como la nuclear, la solar, la eólica, la bioenergía, y las redes eléctricas y la captura y almacenamiento de dióxido de carbono, es posible suponer, debido a la escasez del suministro mundial de algunos metales, la tensión relativa que generaría Europa si implementara estas tecnologías; la limitada disponibilidad de algunos de esos elementos podría aplazar dicha implementación.

Las estrategias destinadas a mitigar el riesgo asociado al suministro de estos metales consistirían en expandir la producción en Europa, aumentar el reciclaje, reutilizar, reducir los residuos y buscar sustitutos en sus principales aplicaciones. Además, se recomienda elaborar estadísticas de los materiales utilizados, hacer estudios regulares de la oferta y la demanda de los metales críticos, promover la investigación y el desarrollo (I+D) relacionados con nuevos procesos de separación de bajo costo, en 
particular los procedentes de productos o relaves que contengan tierras raras $\mathrm{y}$, finalmente, dialogar de forma activa con los refinadores de zinc, cobre y aluminio para recuperar los minerales de alto riesgo. A su vez, también se recomienda hacer estudios similares sobre los vehículos eléctricos, la iluminación con baja emisión de carbono, el almacenamiento de electricidad, las pilas de combustible y el uso del hidrógeno.

En 2010 y 2011, el Departamento de Energía de los Estados Unidos llevó a cabo unas investigaciones en las que se examinó el rol de las tierras raras y otros materiales en la economía de las energías limpias, como las turbinas de viento, los vehículos eléctricos, las películas fotovoltaicas delgadas y la iluminación de bajo consumo energético. En un análisis tecnológico y de mercado se puntualizó que una falla en el suministro de cinco metales de tierras raras (disprosio, neodimio, terbio, europio e itrio) podría afectar el desarrollo de estas tecnologías. Las principales conclusiones fueron que la educación y la capacitación respecto a los materiales críticos son fundamentales para identificar vulnerabilidades y oportunidades. Además, es importante recabar información para apoyar las políticas en general. La evolución de la oferta y la demanda estaría sujeta a lo siguiente: i) la irrupción de nuevas tecnologías; ii) la escasez de los materiales, y iii) otros factores aún no considerados.

La Organización de Cooperación y Desarrollo Económicos (OCDE), por su parte, hizo un análisis de los minerales críticos con el fin de identificar cómo las posibles tendencias del desarrollo económico podrían afectar el suministro de estos hasta 2030. En dicho análisis, los minerales críticos se definen como aquellos cuyo suministro presenta un riesgo relativamente alto de interrupción y que, eventualmente, podrían tener un impacto económico importante. En consecuencia, se contempla un escenario base de desarrollo económico con dependencia continua de los combustibles fósiles para generar energía, y se deja sin variación la importancia de los minerales energéticos, pero se plantea la interrogante de si esto es válido para forjar un camino hacia el crecimiento bajo en carbono (Coulomb y otros, 2015).

De esta manera, se caracterizan como críticos de 12 a 20 minerales, entre los que se encuentran los de alto riesgo, como las tierras raras, el germanio y el grafito natural. Las causas del riesgo asociado al suministro serían, en este caso, la concentración de la producción, los peligros geopolíticos, la creciente demanda de los mercados emergentes, las nuevas tecnologías que requieren grandes cantidades de estos minerales, las bajas tasas de reciclaje y los pocos materiales sustitutos en las aplicaciones. Las principales conclusiones son que es necesario mejorar la sustitución de los minerales y analizar si las tasas de reciclaje son suficientes para mitigar los riesgos de suministro.

Por otra parte, el consejo de investigaciones medioambientales del Reino Unido (Natural Environmental Research Council (NERC)), mediante el programa de investigación Security of Supply of Mineral 
Resources (SoS Minerals), se ha enfocado en entender cómo se concentran en los sistemas naturales las materias primas utilizadas en la elaboración de tecnologías y aplicaciones que permiten la generación de energía más limpia y su uso más eficiente (e-tech), y cómo predecir y mitigar los efectos ambientales causados por la extracción y recuperación de estos elementos. En la "rueda metálica" (véase el diagrama III.2) se exponen las asociaciones mineralúrgicas de los metales principales que son portadores de coproductos y subproductos metálicos.

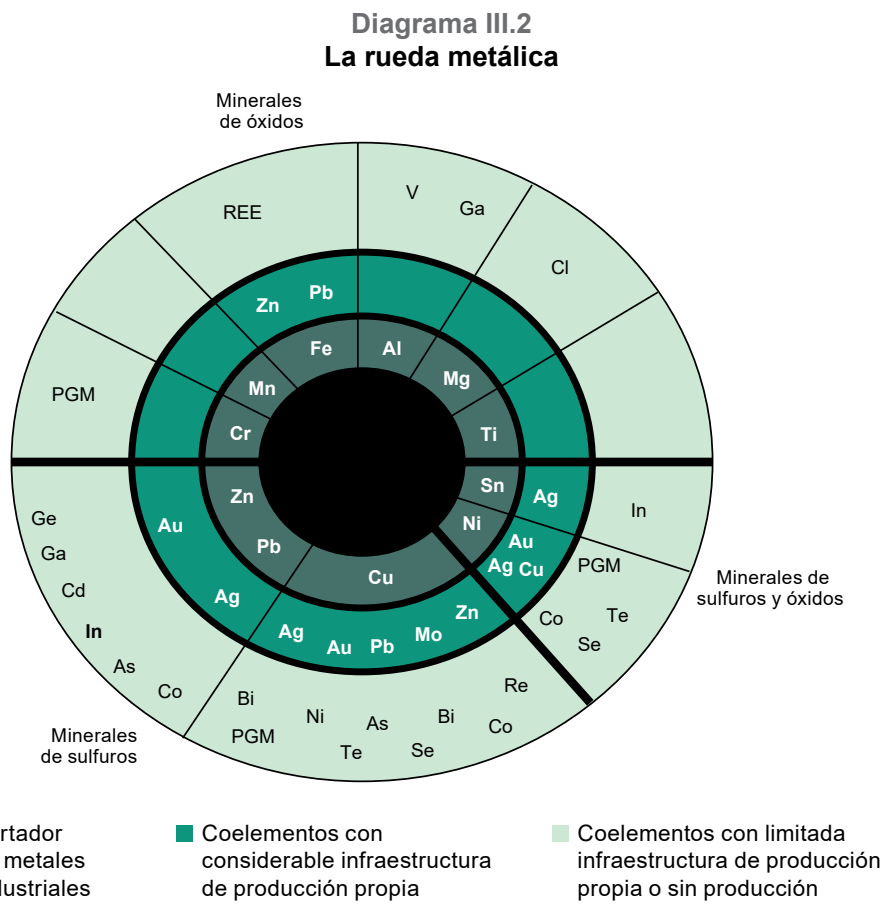

Fuente: Elaboración propia, sobre la base de Security of Supply of Mineral Resources (SoS MinErals), "Research Programme, 2012-2017"; M. A. Reuter y otros, The Metrics of Material and Metal Ecology. Harmonizing the Resource, Technology and Environmental Cycles, Amsterdam, Elsevier, 2005; y E. V. Verhoef, "Process knowledge, system dynamics and metal ecology", Journal of Industrial Ecology, vol. 8, N 1-2, 2004.

Los dos anillos interiores contienen elementos que se pueden recuperar, lo que maximiza los beneficios y minimiza el impacto ambiental. El anillo exterior contiene los elementos que se pierden en los residuos del proceso o en las emisiones, como es el caso del indio, el galio o el germanio, lo que indica que no existe infraestructura productiva o que la que hay es muy limitada.

En América Latina y el Caribe hay una gran cantidad de yacimientos minerales que podrían cumplir con las características que se indican en la rueda metálica. La relevancia de los metales críticos para la región es 
que ofrecen la posibilidad de aplicar los resultados de la investigación y el desarrollo, de forma de generar nuevos procesos para recuperar los elementos e-tech o las materias primas críticas identificadas por la Unión Europea, la OCDE y los Estados Unidos.

Si la obtención de dichos elementos se lograra mediante procesos favorables al medio ambiente que pudieran generar rentabilidad, y si se considerara además que se podría aplicar el uso circular de los metales desde las mismas líneas productivas de beneficio (en las minas de cobre, oro o hierro, entre otras) o desde un nuevo tratamiento de los relaves mineros frescos, los tranques en servicio o los pasivos ambientales mineros, se podrían lograr externalidades positivas con este tipo de actividades, entre ellas, la mitigación o la renaturalización de dichos pasivos, su autofinanciamiento y una eventual rentabilidad económica derivada de esto.

\section{F. Situación de los minerales industriales y de construcción en la región}

Se demandan minerales industriales en distintos sectores productivos, como la construcción, la industria y el sector agrícola, entre otros (SERNAGEOMIN, 2015). Estos minerales, incluidos los que se utilizan en la infraestructura y aquellos que satisfacen de forma indirecta distintas necesidades básicas, han sido un constante aporte para las economías nacionales. En consecuencia, es posible señalar que el aumento de la tasa de urbanización y la brecha que existe en materia de infraestructura podría afectar el incremento de la demanda de los minerales de construcción (PNUMA, 2013a).

Las características principales de la minería de los materiales de construcción son el bajo valor de sus productos, su explotación principalmente por la pequeña minería o la minería artesanal y la complejidad de proveer las cantidades demandadas cuando existe un exceso de demanda. Este tipo de minerales son usualmente calificados como menores dentro del sector minero, por lo que reciben menor apoyo de los gobiernos (Cárdenas y Chaparro, 2004).

Por otra parte, en la región existe una brecha en lo que respecta a la institucionalidad de este subsector, que incluye la falta de regulación, planificación e instrumentos, lo que podría tener consecuencias ambientales relevantes, como la extracción no regulada de arena para la construcción en las zonas costeras y, por consiguiente, la eliminación de las defensas naturales más importantes contra las tormentas y los huracanes.

Los principales minerales que se utilizan en la construcción son los áridos, y entre ellos hay arenas, arcillas y tizas que se emplean como materias primas del ladrillo, el cemento, la cerámica y otros materiales. Sobre la base de los datos de PNUMA (2013a), la demanda de estos 
minerales en América Latina creció el 3,5\% anual entre 1970 y 2008. Sin embargo, del total de materiales consumidos en la región, la proporción correspondiente a los minerales de construcción varió del 21,3\% en 1970 al 22\% en 2008. En la región de Asia y el Pacífico, el consumo de minerales de construcción en 1970 representó el 23\% del total, mientras que en 2008 llegó a casi el 50\%. El nivel de consumo de minerales de construcción indicaría una acumulación de infraestructura.

En la Nueva Agenda Urbana de la Conferencia de las Naciones Unidas sobre la Vivienda y el Desarrollo Urbano Sostenible (Hábitat III) (ONUHábitat, 2017), se indica que se espera una rápida urbanización en todo el mundo: en 2030, más del $60 \%$ de la población mundial viviría en ciudades y, en 2050, lo haría casi el 70\%. Esta situación demandaría una mayor proporción de minerales y materiales de construcción que ejercería una presión ambiental, pero que también produciría rentabilidad económica. Por ejemplo, según algunos datos ambientales relevantes de la industria del cemento, dicha industria produce el $5 \%$ de las emisiones antropogénicas de $\mathrm{CO}_{2}$ a nivel mundial, además del $10 \%$ de las emisiones de mercurio. Por su parte, la producción de ladrillos genera altas emisiones de carbono negro (hollín), sustancias tóxicas y otros contaminantes. Sin embargo, el desarrollo de tecnologías limpias para producir ladrillos podría disminuir las emisiones contaminantes entre el 10\% y el 50\% (PNUMA, 2013b).

Los aspectos que se deben considerar para que la explotación de los materiales de construcción se centre en un marco sostenible son los siguientes (PNUMA, 2013b):

- Agregar valor al recurso natural para posibilitar el reciclaje y la disposición de productos y los subproductos.

- Dar participación a los grupos de interés en el ciclo minero, incluidos el sector privado, la pequeña minería y la minería artesanal.

- Proponer nuevos patrones de uso y producción que respondan a las necesidades básicas y al mejoramiento de la calidad de vida (vivienda y dotación de infraestructura física urbana, planificación del uso del suelo y desarrollo de nuevas tecnologías).

\section{G. Perspectivas de la minería en América Latina y el Caribe}

La extracción y el consumo intensivo de minerales (metálicos, de construcción e industriales) ejerce presiones sobre la naturaleza, derivadas de la producción de desechos y los efectos ambientales en las zonas geográficas donde se explotan, lo que se contrapone al planteo de desacoplar el desarrollo económico y el uso intensivo de materias primas. Además, podrían acrecentarse las externalidades negativas si se considera el rápido aumento demográfico 
mundial. Para anticipar, gestionar y mitigar los efectos de estas acciones, es necesario abordar algunas dimensiones de la actividad minera actual y futura, más aún si se considera la incidencia que podría tener sobre el cambio climático debido a que varios de los minerales utilizados en la elaboración de las tecnologías de generación de energías limpias provienen de explotaciones mineras y que en la misma explotación se producen emisiones contaminantes.

Respecto a la tecnología de los procesos de información y datos, hay que destacar los macrodatos - vinculados con el monitoreo de los procesos mediante sensores e instrumentación de medición en línea (redes) - por sus aportes relativos al acceso a la información en tiempo real. Más aún, estos datos pueden almacenarse y analizarse, lo que ayudaría a comprender mejor los subprocesos y también a integrar variables de entrada y salida entre ellos. Es decir, harían posible mejorar de forma continua la gestión y la eficiencia en el uso de los recursos.

Los vehículos y las máquinas telecomandados, los equipos autónomos y la robótica también son parte del quiebre tecnológico en las operaciones de la gran minería. La incorporación de la nanotecnología a procesos como la desalación del agua o el tratamiento de aguas ácidas con nanofiltración está irrumpiendo en el sector de manera incipiente. Otro avance relevante sería reutilizar el agua en las plantas de beneficio de la mediana y pequeña minería, tecnología que en las grandes explotaciones se viene utilizando desde hace más de dos décadas. Gracias a eso, los procesos y los equipos están validados y mejorados, además de ser cada vez más accesibles desde el punto de vista económico. La biotecnología aplicada a los procesos de beneficio (como la lixiviación bacteriana de sulfuros), la realidad aumentada y la inteligencia artificial son asimismo algunas tecnologías disruptivas que serán implementadas en el mediano y largo plazo (Lewinsohn y Salgado, 2017).

La acción relacionada con los asuntos ambientales ha tomado mayor relevancia en las naciones, los agentes y las sociedades. En China, desde 2013 y hasta fines de 2017 se estableció un plan para mejorar las condiciones del aire. El plazo determinado ejerció presión para que se tomaran medidas drásticas que permitieran alcanzar los objetivos, como ocurrió en la provincia de Hebei, donde se concretaron cierres temporales de la producción debido a los altos índices de contaminación que se alcanzaron por utilizar principalmente carbón, tanto en la generación de energía como en el proceso de obtención de acero. La misma suerte han corrido otras fundiciones de cobre y aluminio (National Geographic, 2017; EcoWatch, 2017; South China Morning Post, 2018a, 2018b y 2017; BCN, 2015; Mining, 2017a y 2017b).

Respecto a los agentes, el caso de BHP es un ejemplo de los cambios que están ocurriendo. Esta empresa es uno de los mayores productores de carbón del mundo y pretende bajar su nivel de participación en este producto básico. Ha condicionado su membrecía en el Minerals Council of 
Australia (MCA), en la Cámara de Comercio de los Estados Unidos y en la Asociación Mundial del Carbón, porque tiene diferencias en cuanto a las políticas energéticas y climáticas que se aplican (BHP, 2017).

Por otro lado, a causa de los conflictos socioambientales provocados por la actividad minera, se han llevado a cabo una serie de estudios para identificar, caracterizar, cuantificar y relevar las causas de los conflictos en el sector, lo que ha permitido obtener una línea base de datos, como ocurre en el caso de la información de los Estados, las organizaciones no gubernamentales como el Observatorio de Conflictos Mineros de América Latina (OCMAL) y otros actores. El manejo estratégico de esta información permitiría anticipar de forma eficiente las causas potenciales de los conflictos, así como gestionar una consulta previa adaptativa según las zonas geográficas, las comunidades con sus características culturales y los efectos esperados.

La minería secundaria (desde los tranques de relaves o botaderos mineros, que pueden ser antiguos o estar abandonados, cerrados $\mathrm{u}$ operativos) podría ser una alternativa técnica y económicamente factible para mitigar algunos pasivos ambientales mineros o disminuir los desechos de las plantas de beneficio. Sin embargo, aún existen desafíos normativos, regulatorios y políticos, además de ciertos requisitos que se deben cumplir, para que la explotación sea viable desde el punto de vista económico. Entre ellos se encuentra identificar, caracterizar y cuantificar los depósitos que tengan minerales con valores competitivos de mercado, así como las cantidades que permitan lograr economías de escala y una explotación sustentable.

La extracción sostenible de los recursos minerales podría convertirse en un sistema de gestión internacional y obtener "certificación verde" si se cumplen un conjunto de normas. El caso de la Corporación Nacional del Cobre de Chile (CODELCO) marca una tendencia en los mercados internacionales debido a una propuesta de la empresa estatal relativa a la oferta responsable, sustentable y trazable de cobre. El propósito de la iniciativa es tener en cuenta aspectos ambientales y sociales como la huella de carbono, la huella de agua, el respeto por los derechos humanos, el impacto comunitario, la seguridad y salud ocupacional, la inclusión y la igualdad de oportunidades, la transparencia, la ética y el impacto territorial (CODELCO, 2017). Esto permitiría a los productores diferenciarse de otros al incorporar a su producción un sello de "cobre trazable".

Respecto a los desafíos en materia de políticas, en la región se está trabajando para mejorar los marcos normativos, las leyes y los reglamentos más específicos, con el propósito de abarcar temas donde se han detectado vacíos legales (por ejemplo, el cierre de minas y las emisiones permisibles, entre otros). Además, se procura reforzar los instrumentos de control y fiscalización y que la aplicación de multas, sanciones y penalidades a quienes incumplan sean acordes a los impactos producidos. 
La transparencia es uno de los ejes centrales de la actividad. Cada Estado debería gestionar y velar por que se democratice la información, y los agentes podrían aportar la información que establecen en las distintas etapas de los proyectos. Los gobiernos deberían tener un diálogo abierto y participativo con la sociedad y los agentes, sobre todo respecto a las orientaciones dirigidas al sector en relación con los impuestos y las normas ambientales y sociales, entre otras. La sociedad debería participar de forma organizada para lograr el bien común, basándose en los intereses comunitarios y la información compartida por el gobierno y las empresas. Lo anterior implica ejercer la gobernanza entre múltiples actores y a múltiples niveles, lo que contribuiría al logro de las metas de los Objetivos de Desarrollo Sostenible hacia 2030.

Las estadísticas sectoriales son cruciales para mejorar las políticas que se han de implementar, además de ser un aporte a la transparencia, la democracia y la gobernanza. En la actualidad es insuficiente indicar solo la cantidad que se produce: también es crucial complementar con otros tipos de estadísticas. Entre ellas se encuentran las económicas (precio de los productos básicos, tipos de contratos, impuestos y regalías recaudados, cantidades y tipos de minerales contenidos en los concentrados, y precios de transferencia, entre otros), las sociales (consulta previa, salarios, seguro social y cumplimiento territorial, entre otros) y las ambientales (cantidad de emisiones, desechos e impacto, entre otros). También se debe proporcionar información sobre la demanda y la eficiencia en cuanto al uso de insumos estratégicos como el agua, la energía y otros.

Las cuentas de flujo de materiales serían un complemento pujante de las cuentas nacionales, que permitiría hacer un levantamiento cuantitativo de las presiones que la extracción de los recursos naturales ejerce sobre el medio ambiente, así como también del impacto de los desechos y las emisiones que produce su obtención. Los conceptos asociados a las cuentas de flujo de materiales serían el cambio de los patrones de producción y consumo, el ciclo de vida de los productos, el metabolismo social y la economía circular, entre otros. Todos estos presionarían sobre el modelo de desarrollo imperante que hoy incrementa la desigualdad, la concentración de la riqueza y el cambio climático.

El aumento de la demanda de los minerales que se utilizan en las nuevas tecnologías de generación de energía, baterías, movilidad, superaleaciones y otros ha ejercido una presión importante sobre la oferta de litio, cobalto, tierras raras y niobio, entre otros. Es por ello que, para promover un desarrollo sostenible de la extracción y refinación de estos minerales, ampliar la oferta desde distintos países en diferentes regiones y evitar que se formen monopolios productivos que controlen los precios y el suministro mundial, se podrían proponer políticas de incentivos en la región, a fin de propiciar el desarrollo de la exploración, la explotación y la investigación, así como del tratamiento y el beneficio de estos. 


\section{Bibliografía}

Altomonte, H. y R. J. Sánchez (2016), Hacia una nueva gobernanza de los recursos naturales, Libros de la CEPAL, N 139 (LC/G.2679-P), Santiago, Comisión Económica para América Latina y el Caribe (CEPAL).

BCN (Biblioteca del Congreso Nacional de Chile) (2015), "Política para reducir la polución en Beijing se centra en optimizar procedimientos transparentes" [en línea] https://www.bcn.cl/observatorio/asiapacifico/noticias/politicareduccion-polucion-beijing-transparencia.

BHP (2017), "Industry association review", 19 de diciembre [en línea] https:/ / www.bhp.com/-/media/documents/ourapproach/operatingwithintegrity/ industryassociations/171219_bhpindustryassociationreview.pdf?la=en.

Blomström, M. y A. Kokko (2003), "The economics of foreign direct investment incentives", NBER Working Paper, N 9489, Cambridge, Massachusetts, Oficina Nacional de Investigaciones Económicas.

Cárdenas, M. y E. Chaparro (2004), Industria minera de los materiales de construcción: su sustentabilidad en América del Sur (LC/L.2186-P), Santiago, Comisión Económica para América Latina y el Caribe (CEPAL).

CEPAL (Comisión Económica para América Latina y el Caribe) (2016), La Inversión Extranjera Directa en América Latina y el Caribe, 2016 (LC/G.2680-P), Santiago. (2015), La Inversión Extranjera Directa en América Latina y el Caribe, 2015(LC/G.2641-P), Santiago.

(2014), La Inversión Extranjera Directa en América Latina yel Caribe, 2013(LC/G.2613-P), Santiago.

(2013), La Inversión Extranjera Directa en América Latina y el Caribe, 2012(LC/G.2571-P), Santiago.

(2009), La Inversión Extranjera Directaen América Latina y el Caribe, 2008(LC/G.2406-P), Santiago.

(2008), La Inversión Extranjera Directa en América Latina yel Caribe, 2007(LC/G.2360-P), Santiago.

(2006), La Inversión Extranjera Directa en América Latina y el Caribe, 2005(LC/G.2309-P), Santiago.

(2005), La inversión extranjera en Latinoamérica y el Caribe, 2004 (LC/G.2269-P), Santiago.

(2004), La Inversión Extranjera Directaen América Latina yel Caribe, 2003(LC/G.2226-P), Santiago.

(2003), La Inversión Extranjera Directaen América Latina y el Caribe, 2002 (LC/G.2198-P), Santiago.

(2002), La Inversión Extranjera Directaen América Latina yel Caribe, 2001 (LC/G.2178-P), Santiago.

(2001), La Inversión Extranjera Directa en América Latina yel Caribe, 2000 (LC/G.2125-P), Santiago.

(2000), La Inversión Extranjeraen América Latina yel Caribe. Informe1999(LC/G.2061-P), Santiago.

(1998), La Inversión Extranjera en América Latina yel Caribe. Informe 1998(LC/G.2042-P), Santiago.

(1995), La Inversión Extranjera en América Latina y el Caribe. Informe 1995 (LC/G.1890/ CORR.1), Santiago. 
CODELCO (Corporación Nacional del Cobre de Chile) (2017), “CODELCO: lecciones aprendidas y desafíos futuros", diciembre [en línea] https://www.codelco. com/prontus_codelco/site/artic/20170301/asocfile/20170301095611/121217_ clasemagistral_olnp.pdf.

Comisión Europea (2014), Report on Critical Raw Materials for the EU. Report of the Ad Hoc Working Group on Defining Critical Raw Materials, mayo [en línea] https:/ / ec.europa.eu/docsroom/documents/10010/attachments/1/translations/en/ renditions/pdf.

(2011), "Comunicación de la Comisión al Parlamento Europeo, al Consejo, al Comité Económico y Social y al Comité de las Regiones. Abordar los retos de los mercados de productos básicos y de las materias primas" (COM(2011) 25 final), Bruselas, febrero.

Coulomb, R. y otros (2015), "Critical minerals today and in 2030: an analysis for OECD countries", Environment Working Paper, N 91, París, Organización de Cooperación y Desarrollo Económicos (OCDE).

Departamento de Energía de los Estados Unidos (2011), Critical Materials Strategy, Washington, D.C., diciembre.

(2010), Critical Materials Strategy, Washington, D.C., diciembre.

EcoWatch (2017), "China just shut down thousands of factories to fight pollution", octubre [en línea] https://www.ecowatch.com/china-shut-downfactories-2500717543.html.

Foro Económico Mundial (2015), Mining \& Metals in a Sustainable World 2050, Ginebra [en línea] http://www3.weforum.org/docs/WEF_MM_Sustainable_ World_2050_report_2015.pdf.

Golub, S. S., C. Kauffmann y P. Yeres (2011), "Defining and measuring green FDI. An exploratory review of existing work and evidence", OECD Working Papers on International Investment, $\mathrm{N}^{\circ} 2011 / 02$, París, OECD Publishing.

Heap, A. (2005), "China: the engine of a commodities super cycle", Citigroup Smith Barney [en línea] http://www.fallstreet.com/Commodities_China_ Engine0331.pdf.

Lewinsohn, J. L. y R. Salgado (2017), “La eficiencia en el uso del agua y la energía en los procesos mineros: casos de buenas prácticas en Chile y el Perú", Documentos de Proyectos (LC/TS.2017/141), Santiago, Comisión Económica para América Latina y el Caribe (CEPAL).

Martín, L. y J. B. Justo (2015), “Análisis, prevención y resolución de conflictos por el agua en América Latina y el Caribe", serie Recursos Naturales e Infraestructura, No 171 (LC/L.3991), Santiago, Comisión Económica para América Latina y el Caribe (CEPAL).

Mining (2017a), "China top copper producer halts output after pollution order", 27 de diciembre [en línea] http://www.mining.com/web/china-top-copperproducer-halts-output-pollution-order/.

(2017b), "Copper rallies to three-year high as China plant halts output", 27 de diciembre [en línea] http:/ / www.mining.com/web/copper-rallies-threeyear-high-china-plant-halts-output/.

Moss, R. L. y otros (2011), Critical Metals in Strategic Energy Technologies: Assessing Rare Metals as Supply-Chain Bottlenecks in Low-Carbon Energy Technologies, Luxemburgo, Oficina de Publicaciones de la Unión Europea. 
Naden, J. (s/f), "Science and Implementation Plan: Security of Supply of Mineral Resources (SoS MinErals) Research Programme 2012-2017", Nottingham, Natural Environment Research Council [en línea] https://nerc.ukri.org/ research/funded/programmes/minerals/science-and-implementation-plan/.

National Geographic (2017), “China empieza a adoptar soluciones drásticas para acabar con la contaminación atmosférica", 9 de noviembre [en línea] https:/ / www.nationalgeographic.es / medio-ambiente/2017/05/china-empiezaadoptar-soluciones-drasticas-para-acabar-con-la-contaminacion.

ONU-Hábitat (Programa de las Naciones Unidas para los Asentamientos Humanos) (2017), Global Activities Report, 2017. Strengthening Partnerships of the New Urban Agenda and the Sustainable Development Goals, Nairobi [en línea] https:/ / unhabitat.org/books/global-activities-report-2017/.

PNUMA (Programa de las Naciones Unidas para el Medio Ambiente) (2013a), Tendencias del flujo de materiales y productividad de recursos en América Latina [en línea] https://wedocs.unep.org/rest/bitstreams/14565/retrieve. (2013b), Environmental Risks and Challenges of Anthropogenic Metals Flows and Cycles [en línea] https://europa.eu/capacity4dev/file/14506/download?token= vHHWKKVO.

(2011a), "Eficiencia en el uso de los recursos en América Latina: perspectivas e implicancias económicas" [en línea] www.pnuma.org/reeo.

(2011b), Decoupling Natural Resource Use and Environmental Impacts from Economic Growth [en línea] http:/ / www.gci.org.uk/Documents/Decoupling Report_English.pdf.

(1998), Manual for Sand Dune Management in the Wider Caribbean, Programa Ambiental del Caribe.

PNUMA/OMM (Programa de las Naciones Unidas para el Medio Ambiente/ Organización Meteorológica Mundial) (2011), "Integrated Assessment of Black Carbon and Tropospheric Ozone: Summary for Decision Makers" [en línea] http:/ / www.unep.org/dewa/Portals/67/pdf/Black_Carbon.pdf.

SERNAGEOMIN (Servicio Nacional de Geología y Minería) (2015), Anuario de la minería de Chile, 2015, Santiago.

SNL Metals \& Mining (2015), World Exploration Trends, 2015 [en línea] https:/ /issuu. com/ediarte/docs/wetreport_0215_2_for the PDAC International Convention.

South China Morning Post (2018a), "Smog returns across north days after China claims progress in winter pollution campaign", 15 de enero [en línea] http:/ / www.scmp.com/news / china / policies-politics / article / 2128311/smogreturns-across-north-days-after-china-claims.

(2018b), "Beijing to halt construction as smog closes in just weeks after clearest skies in five years", 12 de enero [en línea] https://www.scmp.com/news/ china / society / article/2127950/beijing-halt-construction-smog-closes-justweeks-after-clearest.

(2017), "China vows big winter air pollution cuts in northern cities", 24 de agosto [en línea] https://www.scmp.com/news/china/policies-politics/ article/2108109/china-vows-big-winter-air-pollution-cuts-northern. 
Capítulo IV

\section{Estado de situación y perspectivas de los hidrocarburos en la región}

Andrés Arroyo

El análisis y la discusión contemporánea de los desafíos y oportunidades que enfrenta el sector de los hidrocarburos ante la urgencia de disminuir las emisiones de gases de efecto invernadero resultan ser de sumo interés para las estrategias nacionales de inserción en la senda del desarrollo sostenible de los países de América Latina y el Caribe. Los compromisos de reducción de emisiones de gases de efecto invernadero asumidos por los países en el Acuerdo de París, celebrado en ocasión de la vigésimo primera Conferencia de las Partes de la Convención Marco de las Naciones Unidas sobre el Cambio Climático (COP 21), y establecidos en los Objetivos de Desarrollo Sostenible (ODS) de las Naciones Unidas, ambos lanzados en 2015, implican que el denominado "gran impulso ambiental" para 2030 se centre en el financiamiento de inversiones relacionadas con el acceso universal a la energía, la penetración de las energías renovables, la eficiencia energética y el acercamiento a tecnologías menos contaminantes para la producción y el consumo de combustibles fósiles.

Este marco, caracterizado por la necesidad de contar, a mediano plazo, con una menor demanda mundial de hidrocarburos que, a su vez, propicie un desacople entre el crecimiento económico y el uso de energía y la generación de emisiones, impone desafíos de gestión para los países dependientes de la producción y exportación de hidrocarburos. Se trata de retos relacionados con la diversificación económica y energética, sostenidas por la producción de energía renovable y un mayor uso del gas natural como producto energético de transición. 
Ante este contexto, en el presente capítulo se analiza la manera en que la emergencia climática incide sobre las perspectivas futuras de una menor producción de hidrocarburos, así como sobre los espacios disponibles para un desarrollo energético limpio y un posicionamiento estratégico en el contexto de una nueva realidad ambiental y de desarrollo. Asimismo, se revisan los aspectos regulatorios y las experiencias de empresas estatales de hidrocarburos de la región, con un análisis comparativo de las buenas prácticas y los planes y programas corporativos que, en materia socioambiental, coadyuvan a la obtención de la licencia social y la producción sostenible de hidrocarburos para avanzar hacia la senda de la sostenibilidad climática y ambiental.

\section{A. La industria ante la mayor disrupción del mercado petrolero}

Los acuerdos y las políticas para disminuir las emisiones de gases de efecto invernadero implican que la industria mundial y regional de hidrocarburos deberá enfrentar grandes desafíos de supervivencia ante el inminente alcance del punto máximo y la contracción de la demanda mundial de hidrocarburos a mediano plazo. Se trata de un escenario que los expertos sectoriales han definido como la mayor disrupción histórica del mercado petrolero.

Esta situación podría repercutir en los países económicamente dependientes de los hidrocarburos por medio de un menor precio del petróleo en el mercado internacional, una producción limitada y una mayor cantidad de reservas inmovilizadas en el subsuelo. Pese a ello, al mismo tiempo existen oportunidades para una diversificación económica y energética que se suman a los renovados desafíos de desarrollo tecnológico, comercial y de negocios que se espera para los países y las empresas estatales de energía.

\section{El punto máximo de la demanda de hidrocarburos a nivel mundial}

Para el sector de los hidrocarburos, el éxito de la agenda global del cambio climático implicó la acuñación del concepto de "punto máximo de la demanda" en reemplazo del concepto de "cenit de la producción de petróleo", o curva de Hubbert, de fines de los años cincuenta ${ }^{1}$. El primer concepto se define por el alcance de una demanda máxima de hidrocarburos en el marco de

\footnotetext{
La teoría de la curva de Hubbert que se genera bajo un modelo logístico predice que la producción mundial de petróleo llegará a su cenit y después declinará, y resalta el hecho de que el factor limitante de la extracción es la energía requerida y no su costo económico. En este sentido aplicaciones de esta teoría establecieron que el cénit de la producción mundial petrolera se debiera haber dado entre 2000 y 2010 (Dahl, 2004).
} 
un interés medioambiental destinado a reducir las emisiones de gases de efecto invernadero, mientras que el segundo se define por el análisis de la producción máxima ante un agotamiento de los recursos en el marco de un interés geopolítico guiado por la afirmación de la seguridad e independencia energética, un interés muy característico del siglo $X^{2}$.

Debido a su interrelación con los coeficientes de emisiones, la emisión mundial de $\mathrm{CO}_{2}$ generada por la combustión de los hidrocarburos en su uso final seguiría una trayectoria relacionada con la evolución de los perfiles de producción de los hidrocarburos. En este sentido, las sendas de reducción de emisiones requeridas para prevenir un peligroso aumento de la temperatura mundial por encima de los $2^{\circ} \mathrm{C}-\mathrm{y}$ en resguardo del presupuesto mundial del carbono de 1.000 gigatoneladas de $\mathrm{CO}_{2}$ hasta fines de siglo- serían más difíciles de lograr en tanto el tiempo de demora en alcanzar niveles máximos de emisiones continúe siendo mayor.

Ante un escenario reducido de gases de efecto invernadero y un aumento de la temperatura mundial de hasta $2^{\circ} \mathrm{C}$, la cúspide teórica en la demanda mundial de petróleo de 93 millones de barriles por día debería ocurrir alrededor de 2020, mientras que los 393.000 millones de pies cúbicos de gas por día deberían registrarse una década después, es decir, hacia 2030. A partir de los años de máxima producción y hasta fines de siglo, los volúmenes deberán decrecer en torno al 1\% por año, hasta mínimos que no afecten a sectores como el transporte aéreo o la industria petroquímica (es decir, sectores donde aún no haya sido posible encontrar una sustitución energética técnica y económicamente viable) ${ }^{3}$. Debemos suponer que para entonces, el transporte terrestre, principal sector de consumo de los derivados del petróleo, ya debería estar diversificado y contar con vehículos híbridos, eléctricos, a biocombustible o a gas natural.

En el mercado se estima que no serían necesarios los volúmenes a ser descubiertos a partir de la próxima década, algo que puede tener implicancias en la cancelación de las decisiones actuales de inversión en exploración petrolera. Sin embargo, otra estimación sostiene que sí se requeriría de esta producción futura a partir del quinto año — según la temporalidad de la industria- y con inversiones destinadas al desarrollo de campos ya descubiertos. En el caso del gas natural, al ser un producto energético más limpio que el petróleo, las estimaciones y tendencias son menos evidentes y dramáticas (véase el gráfico IV.1).

Las cuatro etapas de los ciclos de precios estuvieron marcadas por: a) el uso del motor vehicular de inicios del siglo XX, b) la Segunda Guerra Mundial, c) la política de la Organización de Países Exportadores de Petróleo (OPEP) en los años setenta y d) el crecimiento económico de China desde mediados de la década de 2000, que produjo un choque de la demanda.

3 Dado que actualmente la disminución interanual de la producción en campos maduros en el mundo es de hasta un $-5 \%$ por año, aún serían necesarias inversiones para reducir esta caída a la tasa que requiere la sostenibilidad ambiental. 


\section{Gráfico IV.1 \\ Producción mundial de hidrocarburos por tipo, fuente y escenarios \\ del Acuerdo de París y senda de $2{ }^{\circ} \mathrm{C}$, 2015-2035 \\ (En millones de barriles de petróleo al día y en miles de millones \\ de pies cúbicos de gas natural al día)}

A. Petróleo

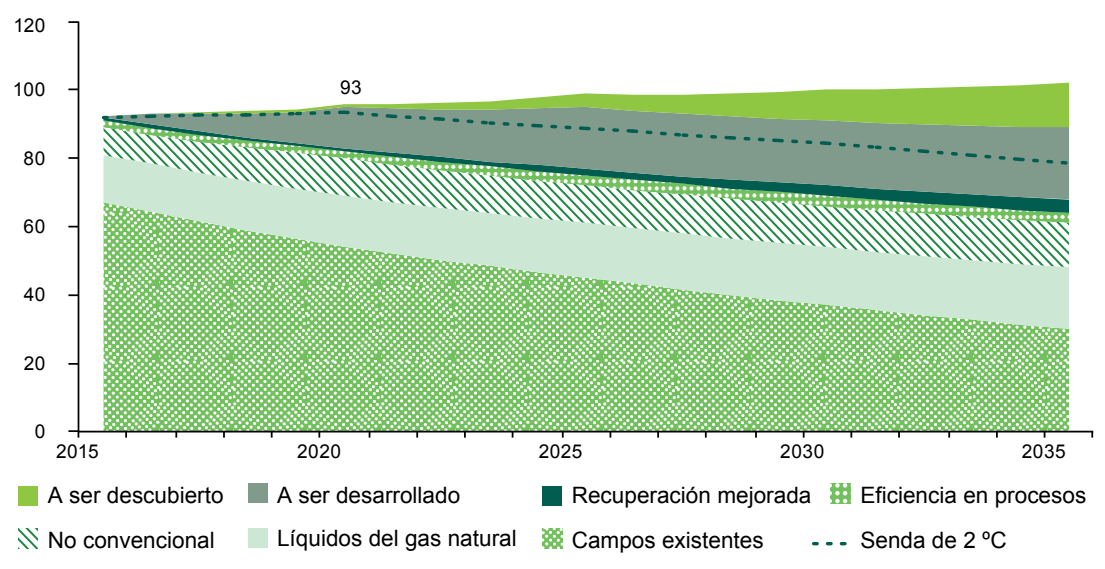

B. Gas natural

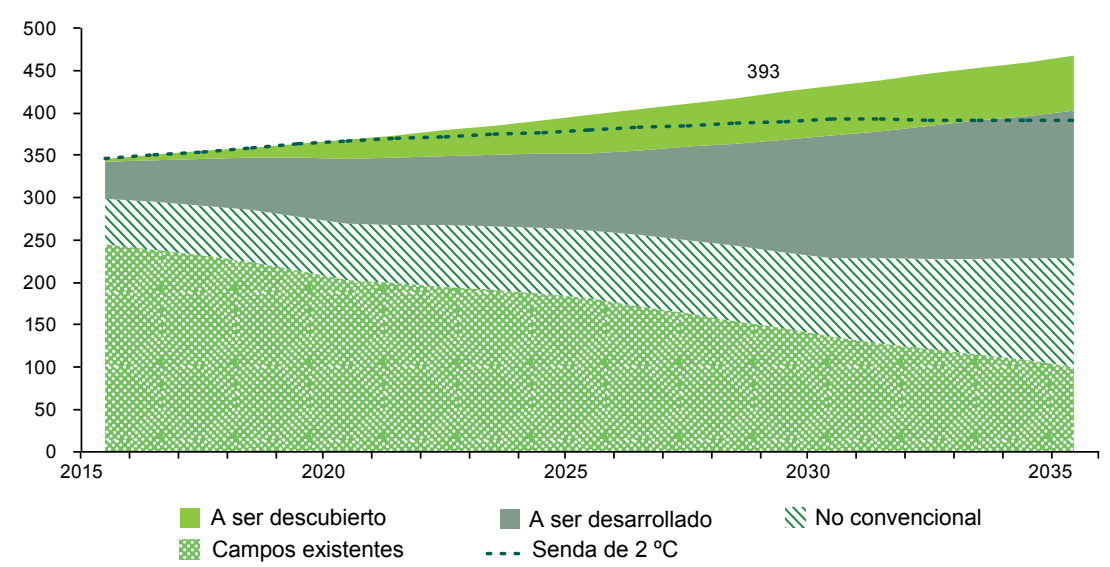

Fuente: A. Arroyo, "El gran impulso ambiental en el sector de la energía", Documentos de Proyectos (LC/TS.2017/108), Santiago, Comisión Económica para América Latina y el Caribe (CEPAL), noviembre de 2017.

Nota: El escenario del Acuerdo de París es el nuevo escenario de política de la Agencia Internacional de la Energía (AIE).

Al prescindirse de mayores actividades de exploración y de descubrimientos en depósitos de complejidad geológica caracterizados por largos períodos de repago y una importante huella ambiental (como aquellos ubicados en arenas bituminosas, en aguas ultraprofundas o en el mar Ártico), la búsqueda de petróleo barato sería la prioridad. En 
otras palabras, se trataría de redirigir las estrategias de inversión desde el descubrimiento de nuevas fuentes de petróleo hacia la explotación de recursos existentes y el hallazgo de alternativas para su sustitución ${ }^{4}$.

Para el corto plazo, sin embargo, todavía sería necesaria una recuperación de las decisiones de inversión para el desarrollo anual de alrededor de 12.500 millones de barriles, cifra que duplicaría los niveles históricamente bajos observados durante la crisis de precios del período 2015-2016. De no recuperarse la inversión, es muy probable que surjan problemas de desabastecimiento de petróleo y de inestabilidad en los precios, por más que se desarrolle a pleno el petróleo de esquistos en los Estados Unidos y se termine con el exceso de oferta e inventarios de petróleo, lo que complicaría aún más la ansiada transición hacia una economía libre de carbono (AIE, 2016).

A largo plazo, tanto la menor demanda de hidrocarburos como su influencia sobre pronósticos conservadores de precios en torno a 70 dólares el barril de petróleo y 5 dólares el millón de unidades térmicas británicas (BTU) de gas natural propiciarían que muchas de las reservas probadas no sean económicamente rentables, por lo que se optaría por mantenerlas bajo tierra como activos inmovilizados ${ }^{5}$. En este sentido, se estima que a mitad de siglo el 33\% de las reservas mundiales de petróleo y el 50\% de las reservas de gas natural permanecerán inmovilizadas bajo tierra, y estos porcentajes pueden ser incluso mayores en el caso de América Latina y el Caribe (McGlade y Ekins, 2015).

Para los países productores y exportadores de petróleo, y en menor medida para los productores y exportadores de gas natural, las perspectivas de cancelación de actividades exploratorias y de menores inversiones extranjeras en la industria ocasionarían una reducción en la renta económica proveniente de la extracción de estos recursos, así como en los espacios fiscales que se requieren para financiar el desarrollo. En este contexto, sería importante contar con un mayor compromiso nacional e internacional para implementar políticas públicas en instituciones robustas destinadas al cambio de la matriz productiva y al impulso ambiental, políticas que deberían ir acompañadas de renovadas fuentes de financiamiento provenientes de alianzas estratégicas entre el sector privado y los organismos internacionales.

En ese sentido, Arabia Saudita, como miembro de la OPEP, inició en 2016 su camino hacia la diversificación económico-energética por medio

4 El recorte de los presupuestos de inversión en exploración y producción se manifestaría por una caída anual del 1,3\% para los dirigidos a reservorios de petróleo y por un limitado crecimiento anual del $0,4 \%$ para los dirigidos a reservorios de gas natural, situaciones que por último generan una inversión mundial agregada promedio de 550.000 millones de dólares al año durante el período 2020-2040 (Debarre, Fulop y Lajoie, 2016).

5 La mala calidad de los hidrocarburos, su alto costo de producción y un limitado consumo interno harían que se generara un mayor porcentaje de activos inmovilizados. 
de una privatización bien planificada de parte de la estatal Saudi Aramco. En esta política, denominada Visión 2030 (Saudi Vision 2030), se contempla que los ingresos derivados de la venta accionaria se destinen a la creación de un fondo soberano de más de 150.000 millones de dólares, así como a la inversión en tecnologías relacionadas con las energías renovables. Esta decisión se convirtió en un ejemplo de cómo las expectativas pesimistas del mercado pueden impulsar la búsqueda de un cambio estructural con sostenibilidad ambiental.

Fruto de este nuevo escenario y de la nueva agenda climática será cada vez más frecuente que los accionistas, los inversionistas, la sociedad civil y los grupos de interés relacionados con el ambiente exijan a las empresas petroleras internacionales y a las petroleras estatales que cotizan en bolsa, el desglose voluntario y transparente de sus planes futuros de administración y contingencia ante eventuales regulaciones climáticas más restrictivas en los países donde operan. En estos últimos años se observaron diferentes efectos en los resultados y la gestión operativa de algunas corporaciones, incluidas pérdidas en valores accionarios ante mayores controles en la valoración y recertificación a la baja de las reservas (como en el caso de la estadounidense ExxonMobil en 2016) y mayores prácticas de transparencia y abordaje de la agenda climática en los planes corporativos (como en los casos de Total, Shell y BHP Billiton). Por otra parte, si bien las prácticas de transparencia y de gestión corporativa coadyuvarían a alcanzar los imprescindibles pactos sociales y el necesario financiamiento de las inversiones, se estima que una regulación estricta pondría en desventaja a las empresas privadas respecto de sus pares estatales y dificultaría su acceso a créditos concesionales o no reembolsables (The Economist, 2016).

Asimismo, muchas de estas empresas, en su afán de reducir riesgos ante un menor valor corporativo favorecido por las reservas inmovilizadas de hidrocarburos en sus portafolios, se verían en la necesidad de:

- diversificar su inversión hacia la sustitución de reservorios y entre hidrocarburos, $\mathrm{o}$

- cambiar su actividad de negocios y pasar de la exploración y producción tradicional de hidrocarburos (de riesgo exploratorio implícito) a la producción de energía renovable y de tecnologías de energía limpia 6 .

La inversión en energía renovable en América Latina aumentó de 4.600 millones de dólares en 2005 a más de 16.400 millones de dólares en 2015, y los países de mayor tradición petrolera, como el Brasil y México, se han convertido en los principales destinos de esta inversión. La eólica es la principal fuente energética y ha logrado desplazar a los biocombustibles en su primacía, vigente hasta 2009 (IRENA, 2016). A pesar de que esta inversión regional en energías renovables ha representado cerca del $25 \%$ de la inversión destinada a la producción de hidrocarburos, la primera estuvo cada vez menos influida por la volatilidad y los bajos precios del petróleo y más por la reducción de costos de capital en plantas eólicas y solares. 
La estrategia corporativa de sustitución entre fósiles se concretaría en la medida en que el gas natural sea el combustible que finalmente genere menos emisiones de $\mathrm{CO}_{2}$ respecto de las que originan el petróleo o el carbón, lo que propiciaría que tenga una mayor esperanza de vida en las sendas del desarrollo sostenible al actuar como energía de base y complemento de la generación eléctrica intermitente de las energías renovables. Sin embargo, las ventajas del gas natural podrían verse opacadas por el grado de sus emisiones de metano $\left(\mathrm{CH}_{4}\right)$, que tienen un potencial de calentamiento 25 veces mayor que el $\mathrm{CO}_{2}$ en un siglo de vida. Estas emisiones provienen de fugas en válvulas y equipos durante la producción y el transporte del gas natural, o de las actividades de quema y venteo en pozos que se realizan ya sea por razones de seguridad industrial o por la carencia de infraestructura de transporte ${ }^{7}$.

Las decisiones de inversión dirigidas a reservorios de gas natural se dan en la medida en que algunas empresas estadounidenses como Pioneer, en virtud de su experiencia, se centran en vender activos internos para financiar sus actividades en reservorios de esquisto en vez de otros más convencionales, al representar esta una alternativa competitiva y flexible ante las perspectivas restrictivas e inciertas del mercado ${ }^{8}$.

En esa línea, la petrolera angloholandesa Shell estima que su demanda máxima de hidrocarburos llegaría en los próximos 5 a 15 años, por lo que está buscando concretar alianzas con empresas estatales de petróleo de la región con el objeto de financiar las inversiones en reservorios gasíferos que resulten ser económicos y recuperables dentro ese período. Esto es lo que está ocurriendo con los reservorios existentes en aguas profundas del Brasil o en los esquistos de la Argentina9. Estas políticas de inversión cuadran con la estrategia de mercado de la empresa, tendiente a aumentar la producción de gas natural en su portafolio y que se ejemplifica con la fusión en 2016 con la británica British Gas (BG), también con operaciones gasíferas en la región.

7 En cuencas estadounidenses, como Eagle Ford o Bakken, la cuantificación de las fugas de metano es un tema sobre el cual no hay consenso y estas pueden representar entre el 1,2\% y el $10 \%$ de la producción de gas (dependiendo del estudio científico). Por otra parte, un nivel mayor al 3,2\%, al remplazar al carbón en la generación eléctrica, puede eliminar los beneficios del gas en la reducción de emisiones de gases de efecto invernadero (IHS Markit, 2014).

8 Estas estrategias resultaron ser útiles a partir de la revolución estadounidense del gas de esquisto, que permitió desplazar al carbón y con ello ahorrar emisiones de $\mathrm{CO}_{2}$ respecto de la década anterior. Las mejoras en las productividades, el aumento en las tasas de recuperación y la deflación de costos a 50 dólares hicieron que estos reservorios sean más competitivos.

9 Para el reservorio Vaca Muerta, la Argentina busca inversiones del orden de los 5.000 millones de dólares durante los próximos años. Son inversiones provenientes de Shell, Chevron, BP y Total, que tienen como motor la garantía de precios estables del gas natural en boca de pozo (7,5 dólares/MMBtu hasta 2020) y la promesa de inversión pública en infraestructura logística cercana a los campos de producción. 
De igual forma, algunas empresas transnacionales, como Total o BP, tienen la oportunidad de reinvertir las utilidades del negocio petrolero en energías renovables (una práctica que se compara con el funcionamiento de un fondo soberano como el de Noruega). Esto se hace por medio de la compra de empresas relacionadas con los rubros de baterías eléctricas, energía solar, energía eólica u otros, por lo que en un futuro podrían, por ejemplo, aplicar sus conocimientos en sus operaciones regionales en la Argentina o Bolivia (Estado Plurinacional de).

\section{La merma de la producción y las reservas inmovilizadas en América Latina}

El exceso de oferta respecto de la demanda mundial de petróleo y la contracción de los precios a un rango de entre 30 dólares el barril y 50 dólares el barril se hicieron evidente a partir de 2015. Esto coadyuvó a profundizar la recesión económica de muchos países sudamericanos ya golpeados por crisis internas en los ámbitos económico, político y social, como ocurrió con el Brasil y Venezuela (República Bolivariana de).

La incertidumbre en torno a la duración de las crisis económicas y al grado de volatilidad del mercado petrolero se complementa con la necesidad de profundizar y financiar los compromisos de reducción de emisiones de gases de efecto invernadero más allá del Acuerdo de París de $2015^{10}$. El sector energético de la región necesitará propiciar el desacople entre el crecimiento económico y el uso de la energía y las emisiones de $\mathrm{CO}_{2}$, en la medida en que actúe como sumidero de carbono al pasar de tasas de crecimiento positivas a negativas en las emisiones interanuales de $\mathrm{CO}_{2}{ }^{11}$.

Asimismo, estos mayores requerimientos de reducción de emisiones implican que se necesite una menor producción de hidrocarburos respecto de lo planificado por los países (i. e. las sendas de producción sostenible del petróleo y del gas natural serían menores que los perfiles de producción petrolera y gasífera que sustentan implícitamente los compromisos del Acuerdo de París). Pese a que la producción de petróleo de América Latina y el Caribe necesita disminuir cuanto antes a razón de 100.000 barriles

10 Las contribuciones determinadas a nivel nacional resultan ser los compromisos voluntarios de reducción de emisiones de gases de efecto invernadero plasmados en el Acuerdo de París de 2015. Para los países y sectores económicos de la región, estos se basaron en un año meta a 2030 y se ubicaron entre un $15 \%$ y un $25 \%$, ya sea sobre años base distintos o sobre la proyección de escenarios tendenciales habituales con supuestos específicos de acuerdo con cada país. Sin embargo, estos compromisos, tanto a nivel regional como mundial, no serían suficientes para alcanzar el límite acordado de aumento de la temperatura por debajo de $2{ }^{\circ} \mathrm{C}$ a fines de siglo.

11 Con respecto a las contribuciones determinadas a nivel nacional, se estima que esto se lograría por un aumento del $50 \%$ en las tasas de mejora de la intensidad energética regional comprometidas al -2\% por año hasta 2040 (por medio de una mayor eficiencia energética) y por una triplicación en las tasas de mejora de la intensidad carbónica regional comprometidas al $-2 \%$ por año hasta 2040 (por medio de una mayor participación de energías renovables y adopción de la captura y secuestro del carbono). 
por día, o un $1 \%$ interanual (en todo caso, por debajo del 3\% del descenso de la producción que presentaron los campos maduros de la Argentina, México o Venezuela (República Bolivariana de) durante la última década), se estima que los niveles de producción anual de gas natural aún pueden mantenerse en torno a los 20.000 millones de pies cúbicos por día hasta 2040, para recién desde ese año comenzar a descender (AIE, 2016) (véase el gráfico IV.2).

\section{Gráfico IV.2}

América Latina y el Caribe: escenarios de producción, reservas de hidrocarburos y emisiones acumuladas de $\mathrm{CO}_{2}, 2015-2040$

A. Petróleo

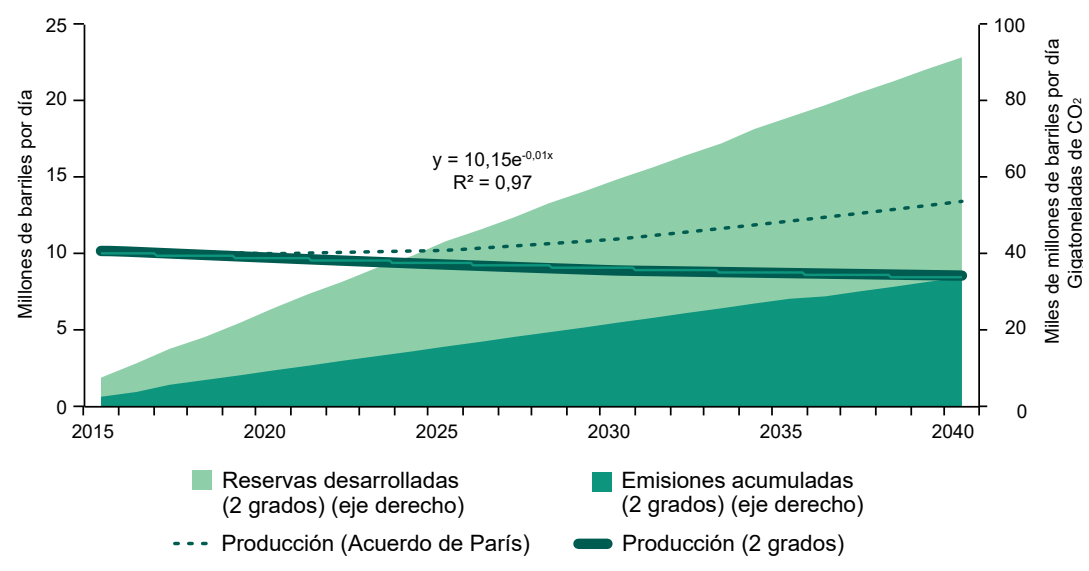

B. Gas natural

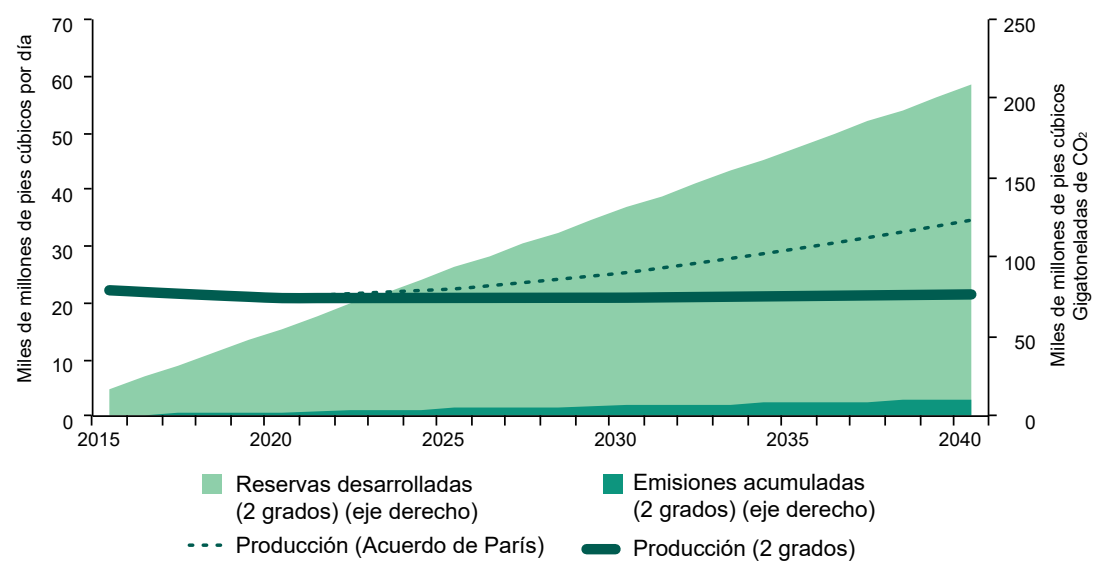

Fuente: A. Arroyo, "El gran impulso ambiental en el sector de la energía", Documentos de Proyectos (LC/TS.2017/108), Santiago, Comisión Económica para América Latina y el Caribe (CEPAL), noviembre de 2017. 
Para los países de la región, mantener la producción de gas natural permitiría que esta represente cerca del $22 \%$ de la demanda primaria de energía necesaria para 2040. Esta importante participación del gas en la matriz energética tendría implicancias para la seguridad e independencia energética, $\mathrm{y}$, por ende, también para el crecimiento económico y la reducción de la pobreza en países con importantes recursos gasíferos, como la Argentina, Bolivia (Estado Plurinacional de), el Brasil, México, el Perú y Venezuela (República Bolivariana de). En los hogares de estos países, un mayor consumo de gas natural por redes, gas licuado de petróleo (GLP) o electricidad (a partir de este recurso) podría promover el acceso universal, asequible, seguro y sostenible a la energía. Por su parte, en el sector del transporte su uso debería permitir la diversificación energética por medio del gas natural comprimido (GNC), gas natural vehicular (GNV) o coadyuvar al impulso de la electromovilidad, ya que para el sector industrial o eléctrico la generación de energía base por medio del gas natural complementaría la generación intermitente que se ofrecería con las energías renovables.

Ante la perspectiva de reservas petroleras regionales inmovilizadas, menores precios internacionales del petróleo a largo plazo (en torno a 70 dólares el barril) y una posible merma anual en la producción de acuerdo con la senda de sostenibilidad, los países pueden enfrentar el riesgo de contar con recaudaciones fiscales y exportaciones por hidrocarburos muy reducidas, y que ello tenga posibles efectos sobre sus balances fiscales y externos en cuenta corriente. A estos impactos macroeconómicos y a los elevados niveles de endeudamiento público y privado (de ser persistentes) se sumarán menores flujos de inversión extranjera directa (IED) para las actividades de exploración y producción de hidrocarburos, lo que en conjunto generaría menores espacios fiscales y monetarios destinados a financiar un crecimiento económico inclusivo de largo plazo y también a la eliminación de la pobreza.

En este contexto, y a pesar de los eventuales condicionantes, hay que apuntar que los países y las empresas productoras de hidrocarburos de la región se encuentran, al mismo tiempo, ante la oportunidad y el desafío de encaminarse hacia un gran impulso ambiental y un cambio estructural mediante:

- La producción sostenible de los hidrocarburos que aún serán necesarios en las próximas décadas, que deberá llevarse a cabo en el marco de un régimen fiscal progresivo centrado en la búsqueda del equilibrio entre la participación estatal y el inversionista en las rentas económicas, ante los riesgos económicos y de mayor regulación ambiental.

- La diversificación productiva y la orientación hacia un cambio estructural caracterizado - en este caso- por la sustitución de 
exportaciones de materias primas a partir de la producción de bienes con mayor valor agregado y servicios de conocimiento.

- La diversificación de la matriz energética, tendiente a desacoplar el crecimiento económico del uso energético y el impacto ambiental. La mayoría de los países productores de hidrocarburos de la región cuentan con metas futuras de participación de las energías renovables en el sector eléctrico tendientes a reducir sus emisiones e incrementar sus tasas de mejora (disminución) en la intensidad del $\mathrm{CO}_{2}$. Sin embargo, como se explicó anteriormente, podría ser necesario que los países sean más ambiciosos a la hora de profundizar sus compromisos de reducción de emisiones para alcanzar la senda de sostenibilidad climática (véase el cuadro IV.1).

\section{Cuadro IV.1 \\ Productores de hidrocarburos (países seleccionados): situación y metas para las energías renovables}

\begin{tabular}{|c|c|c|c|}
\hline País & $\begin{array}{l}\text { Variación interanual de } \\
\text { la tasa de intensidad } \\
\text { carbónica }\left(\mathrm{tCO}_{2} / \mathrm{boe}\right) \\
\text { (2005-2014) } \\
\text { (en porcentajes) }\end{array}$ & $\begin{array}{c}\text { Energía renovable } \\
\text { (sin hidroelectricidad) } \\
\text { en generación } \\
\text { eléctrica (2013) } \\
\text { (en porcentajes) }^{\text {(en }}\end{array}$ & $\begin{array}{l}\text { Metas de participación } \\
\text { de la energía renovable } \\
\text { en el sector eléctrico } \\
\text { respecto de } 2013^{b}\end{array}$ \\
\hline Argentina & $+0,8$ & $24(2)$ & $\begin{array}{l}\text { Del } 2 \% \text { al } 20 \% \text { de la } \\
\text { generación (sin } \\
\text { hidroelectricidad) a } 2025\end{array}$ \\
\hline $\begin{array}{l}\text { Bolivia (Estado } \\
\text { Plurinacional de) }\end{array}$ & $-1,5$ & $32(1)$ & $\begin{array}{l}\text { De } 463 \mathrm{MW} \text { a } 646 \mathrm{MW} \\
\text { de capacidad a } 2025\end{array}$ \\
\hline Brasil & $+0,8$ & $77(8)$ & $\begin{array}{l}\text { Del } 77 \% \text { al } 86,1 \% \text { de } \\
\text { la generación a } 2023\end{array}$ \\
\hline Colombia & $-1,2$ & $72(3)$ & $\begin{array}{l}\text { Del } 3 \% \text { al } 6,5 \% \text { de la } \\
\text { generación (sin } \\
\text { hidroelectricidad) a } 2020\end{array}$ \\
\hline Ecuador & $-1,2$ & $49(1,5)$ & $\begin{array}{l}\text { De } 2,3 \mathrm{MW} \text { a } 4,5 \mathrm{GW} \text { de } \\
\text { capacidad a } 2022\end{array}$ \\
\hline Guatemala & $+0,5$ & $67(20)$ & $\begin{array}{l}\text { Un } 80 \% \text { de la generación } \\
\text { a largo plazo }\end{array}$ \\
\hline México & $-1,0$ & $15(8)$ & $\begin{array}{l}\text { Del } 15 \% \text { al } 35 \% \text { de la } \\
\text { generación a } 2024\end{array}$ \\
\hline $\begin{array}{l}\text { Venezuela (República } \\
\text { Bolivariana de) }\end{array}$ & $-3,8$ & $68(0)$ & $\begin{array}{l}\text { De } 15 \mathrm{MW} \text { a } 16 \mathrm{GW} \text { de } \\
\text { capacidad a } 2019\end{array}$ \\
\hline $\begin{array}{l}\text { América Latina } \\
\text { y el Caribe }\end{array}$ & $-0,6$ & $58(8)$ & $\begin{array}{l}\text { Del } 58 \% \text { al } 69 \% \text { de } \\
\text { la generación a } 2030 \\
\text { Del } 51 \% \text { al } 65 \% \text { de } \\
\text { la capacidad a } 2030\end{array}$ \\
\hline
\end{tabular}

Fuente: Elaboración propia, sobre la base de Agencia Internacional de Energías Renovables (IRENA), Renewable Energy Market Analysis: Latin America, Abu Dhabi, 2016; Organización Latinoamericana de Energía (OLADE), Informe de estadísticas energéticas, 2015, Quito, 2015; y Agencia Internacional de la Energía (AIE), World Energy Outlook 2016, París, 2016.

Los datos son aproximados y redondeados.

b Las metas para América Latina y el Caribe corresponden al nuevo escenario de política de la Agencia Internacional de la Energía (AIE) y no necesariamente implican las metas requeridas para alcanzar la senda de sostenibilidad climática. 


\section{B. La regulación ambiental en las políticas de las empresas de hidrocarburos de la región}

El resguardo medioambiental, así como la implementación práctica de los procesos de consulta previa indígena, la participación ciudadana y la rendición de cuentas por medio del desglose y la transparencia de las actividades petroleras, ayudan a alcanzar un consenso político y social en la industria de los hidrocarburos. Esto es importante dado que la obtención de la licencia social representa una variable de potencial riesgo y costo, que atenta contra las decisiones de inversión petrolera, la generación y apropiación fiscal de la renta económica, y el financiamiento del desarrollo sostenible. Las empresas estatales de hidrocarburos, por su parte, deberían ampliar el cumplimiento con las legislaciones nacionales y la participación en iniciativas voluntarias internacionales enfocadas en la eficiencia en el uso de recursos naturales (ecoeficiencia), la minimización de emisiones de gases de efecto invernadero y la reducción de la huella ambiental.

\section{Aspectos socioambientales y alianzas para la reducción de la huella ambiental}

La producción de hidrocarburos, como cualquier proceso industrial, crea beneficios económicos dados por la generación de renta y empleo, así como por los costos de la huella ambiental en el uso de recursos naturales como el agua, el aire, la tierra y la biodiversidad. A esto se suman las repercusiones sociales en las áreas de exploración y explotación. Estos impactos pueden ser significativos en la medida en que no exista una regulación e instituciones ambientales robustas que enfrenten los desafíos en torno a la aplicación de medidas de precaución, prevención, mitigación, remediación y sanción, ya que estas ayudarán a que el inversionista internalice estos costos ambientales en sus programas de inversión ${ }^{12}$. Asimismo, la coordinación interministerial es esencial para evitar la duplicación de funciones o las posibles pugnas por intereses contrapuestos entre distintas reparticiones estatales con implicancias sobre el desarrollo sostenible ${ }^{13}$.

Dado que muchos yacimientos de hidrocarburos están situados en territorios indígenas, cualquier decisión de ejecutar un proyecto debe considerar la consulta previa, libre e informada y el consentimiento de los pueblos afectados, según lo establecido en el Convenio sobre Pueblos

12 Antes de la concesión de áreas petroleras, el Estado tiene que determinar métodos cuantitativos de prevención y compensación respecto de eventuales impactos sobre el agua, la tierra, el aire y las comunidades indígenas.

13 La duración o el procedimiento para la emisión de las licencias ambientales o las intenciones de levantar la intangibilidad de un área protegida para fines petroleros podrían ser algunos temas de conflictividad entre los ministerios de ambiente y los de hidrocarburos y finanzas. En muchos casos, el Ministerio del Medio Ambiente recién se hace partícipe después, y no antes, del proceso de licitación y adjudicación de propuestas de inversión con impactos socioambientales, pese a que estas cuestiones deberían coordinarse entre todos los ministerios desde el inicio. 
Indígenas y Tribales, 1989 (núm. 169) de la Organización Internacional del Trabajo (OIT). Esta es una obligación primordial de los Estados que no debe traspasarse a las operadoras. Cumplir con este requisito social y, a la vez, establecer mecanismos de compensaciones y distribución de beneficios permitirá crear un clima propicio para la atracción de inversiones y una mayor aceptación social tendiente a disminuir los riesgos de paralizaciones de obra y posibles demandas ante la Corte Interamericana de Derechos Humanos por afectaciones sobre los derechos de los pueblos (Arroyo y Perdriel, 2015) ${ }^{14}$. En el mencionado convenio se establece que los pueblos indígenas no necesitan reconocimiento ni contar con título de propiedad, y que es suficiente con que los individuos se autoidentifiquen como indígenas y vivan en el territorio con potencial hidrocarburífero. La propiedad comunal de los pueblos indígenas se sobrepone a la propiedad privada sobre un territorio en disputa, por lo que se debería reconocer la obligación de pago a propietarios indígenas.

Asimismo, las controversias sociales generadas por el desarrollo de hidrocarburos obedecen, en gran medida, a una ausencia de participación ciudadana en los procesos de evaluación del impacto ambiental (EIA) ${ }^{15}$. La opinión pública tiene un papel importante en este proceso, ya que cuando dispone de información suficientemente clara, transparente y objetiva, ofrece una respuesta social que se ajusta a la realidad. Para ello, la información proporcionada debe generarse en organismos independientes y ser divulgada por entes estatales cuyo objetivo sea identificar los riesgos, así como analizar si estos son mitigables con tecnologías actuales. Ambos aspectos están relacionados con el cumplimento del Principio 10 de la Declaración de Río sobre el Medio Ambiente y el Desarrollo de 1992.

En general, las compañías petroleras nacionales e internacionales comprenden que el pacto social y el consenso político se concretan mediante el cumplimiento regulatorio, la implementación práctica de los procesos de consulta previa indígena y la rendición de cuentas por medio del desglose y la transparencia de las actividades petroleras hacia los grupos de interés.

14 Países como Bolivia (Estado Plurinacional de), Colombia y el Perú cuentan con reglamentos en los que se busca implementar la consulta en territorios indígenas con posible afectación ambiental. En varias ocasiones, sin embargo, estas normas no han evitado conflictos sociales, aunque no por falta de consulta per se, sino porque esta se realiza con posterioridad a la aprobación del proyecto entre el Estado y el sector privado, lo que implica la obligación de aceptar la actividad petrolera. Es necesario que la consulta se realice antes del diseño del proyecto y que se haga partícipes a las comunidades de los mecanismos de distribución de utilidades e indemnizaciones por impactos ambientales.

15 Por ejemplo, en 2014 ocurrió en el Estado Plurinacional del Bolivia un enfrentamiento entre campesinos y fuerzas de seguridad por los intentos de exploración y desarrollo del Bloque Iñau. Asimismo, en el departamento Casanare de Colombia los campesinos destruyeron instalaciones petroleras y paralizaron las actividades productivas a raíz de las pérdidas económicas por sequías y la muerte de animales domésticos y de fauna silvestre local a causa de las actividades de sísmica y perforación en la operación. 
A esta importante situación se la identifica con el "riesgo por encima del suelo" (entendido como la incertidumbre en la obtención de la licencia social para operar), una variable de potencial riesgo y costo que atenta contra las decisiones de inversión petrolera, así como con la generación y apropiación fiscal de la renta económica y posterior financiamiento para el desarrollo.

Las legislaciones nacionales para una producción sostenible de hidrocarburos van acompañadas de normas y estándares de desempeño internacional de la Organización Internacional de Normalización (ISO) en torno a la aplicación de buenas prácticas industriales y mediante la adhesión voluntaria a iniciativas mundiales de sostenibilidad en alianza con la banca multilateral (Banco Mundial, Banco Interamericano de Desarrollo (BID)), organismos internacionales (Naciones Unidas) y coaliciones entre Estados o entre empresas del sector. Este tipo de adhesiones voluntarias generalmente se enfocan en acciones o principios orientados a:

- La mitigación de impactos ambientales y de desarrollo tecnológico. Algunos ejemplos se originan en iniciativas como la Asociación Mundial para la Reducción de la Quema de Gas (GGFR), la Iniciativa Global del Metano (GMI), la Asociación de la Industria Petrolera Internacional para la Conservación del Medio Ambiente (IPIECA), la Asociación Internacional de Productores de Petróleo y Gas (IOGP) o la Asociación Regional de Empresas del Sector de Petróleo, Gas y Biocombustibles en Latinoamérica y el Caribe (ARPEL).

- La promoción de principios de derechos humanos, mercado laboral, sistemas anticorrupción, resguardo del medio ambiente y desarrollo sostenible. Algunas iniciativas de este tipo son el Pacto Mundial, la iniciativa Energía Sostenible para Todos y los ODS, todas impulsadas por las Naciones Unidas.

- La implementación de prácticas de transparencia y rendición de cuentas en materia de información fiscal, ambiental y de sostenibilidad. Algunos ejemplos son la Iniciativa para la Transparencia de las Industrias Extractivas (EITI), el proyecto de información sobre las emisiones de carbono (Carbon Disclosure Project, CDP) y la Iniciativa Mundial de Presentación de Informes (Global Reporting Initiative, GRI).

Cada vez más empresas estatales que operan en la región (como Petróleo Brasileiro (Petrobras), Empresa Colombiana de Petróleos (Ecopetrol), Yacimientos Petrolíferos Fiscales (YPF), Petróleos Mexicanos (Pemex) o Petroamazonas) y empresas privadas internacionales (como Shell, BP, Repsol, Total, Pan American Energy (PAE) o Pluspetrol) se someten anualmente a muchas de estas iniciativas voluntarias, que les permiten financiar sus inversiones en las bolsas de valores en las que cotizan o en la banca adscrita a los Principios del Ecuador. Asimismo, son de gran valor para alcanzar el pacto social y la obtención de la licencia social en sus operaciones. Del mismo modo, el desglose de la información proveniente de 
las iniciativas mencionadas permite a las empresas, los países y las regiones comparar sus rendimientos socioambientales y mejorar sus estándares y prácticas para reducir los impactos ambientales fruto de sus actividades.

\section{La gestión corporativa para una producción sostenible de hidrocarburos}

Para muchas empresas estatales de la región, la implementación y el cumplimiento de las legislaciones nacionales y las iniciativas voluntarias internacionales en materia social y ambiental representan un desafío de gestión corporativa centrada principalmente en la minimización de los efectos de sus actividades sobre los recursos naturales sensibles, como ocurre con el aire, el uso del suelo, el agua, la energía o la biodiversidad. En este sentido, por ejemplo, se observa que la huella ambiental por la producción de un barril de petróleo y gas natural en América Latina y el Caribe tiende a reducirse en la medida en que las métricas de emisiones, consumo de energía y derrames de petróleo disminuyeron entre 2010 y 2015 (véase el cuadro IV.2).

\section{Cuadro IV.2}

Renta económica y huella ambiental en la producción de un barril de equivalente en petróleo, 2010 y 2015

\begin{tabular}{|c|c|c|c|c|c|c|}
\hline \multirow[t]{2}{*}{ Parámetros } & \multirow[t]{2}{*}{ Unidades } & \multicolumn{2}{|c|}{$\begin{array}{l}\text { América Latina } \\
\text { (sin México) }\end{array}$} & \multicolumn{2}{|c|}{ Mundo } & \multirow{2}{*}{$\begin{array}{l}\text { Procedencia } \\
\text { o proceso }\end{array}$} \\
\hline & & 2010 & 2015 & 2010 & 2015 & \\
\hline Renta económicaa & Dólares & 45 & 14 & 44 & 17 & \\
\hline $\begin{array}{l}\text { Emisiones } \\
\text { de } \mathrm{CO}_{2}\end{array}$ & $\begin{array}{l}\text { Kilogramos } \\
\text { de } \mathrm{CO}_{2} \mathrm{e}\end{array}$ & 23 & 18 & 22 & 21 & $\begin{array}{l}\text { Uso de energía, } \\
\text { quema y venteo }\end{array}$ \\
\hline $\begin{array}{l}\text { Quema } \\
\text { de gas }\end{array}$ & Barriles & $13,0 \times 10^{-3}$ & $6,9 \times 10^{-3}$ & $15,5 \times 10^{-3}$ & $13,6 \times 10^{-3}$ & Producción \\
\hline Uso de energía ${ }^{b}$ & Barriles & $4,2 \times 10^{-2}$ & $2,5 \times 10^{-2}$ & $3,5 \times 10^{-2}$ & $3,3 \times 10^{-2}$ & $\begin{array}{l}\text { Producción interna } \\
\text { o comprada }\end{array}$ \\
\hline $\begin{array}{l}\text { Descargas y } \\
\text { derrames de } \\
\text { petróleo }\end{array}$ & Barriles & $11,3 \times 10^{-6}$ & $9,4 \times 10^{-6}$ & $11,8 \times 10^{-6}$ & $10,7 \times 10^{-6}$ & \\
\hline Descargas & Barriles & $7,3 \times 10^{-6}$ & $8,6 \times 10^{-6}$ & $7,3 \times 10^{-6}$ & $6,9 \times 10^{-6}$ & $\begin{array}{l}\text { Vertimiento de } \\
\text { agua de producción }\end{array}$ \\
\hline Derrames & Barriles & $4,0 \times 10^{-6}$ & $0,8 \times 10^{-6}$ & $4,5 \times 10^{-6}$ & $3,8 \times 10^{-6}$ & $\begin{array}{l}\text { Sabotaje, robo, } \\
\text { error operativo, } \\
\text { corrosión, fallas en } \\
\text { equipo }\end{array}$ \\
\hline \multirow{2}{*}{$\begin{array}{l}\text { Agua de } \\
\text { producción } \\
\text { reinyectada } \\
\text { en pozo }\end{array}$} & Metro cúbico & 0,19 & 0,17 & 0,13 & 0,15 & $\begin{array}{l}\text { Agua de } \\
\text { producción }\end{array}$ \\
\hline & $\begin{array}{l}\text { Tasa de } \\
\text { reinyección } \\
\text { (en porcentajes) }\end{array}$ & 67 & 66 & 63 & 65 & \\
\hline
\end{tabular}

Fuente: Elaboración propia, sobre la base de EY, Global Oil and Gas Reserves Study, 2014; Asociación Internacional de Productores de Petróleo y Gas (IOGP), Environmental Performance Indicators-2011 Data, Londres, noviembre de 2012; y Environmental Performance Indicators-2015 Data, Londres, noviembre de 2016.

Nota: Los datos consideran el $42 \%$ de la producción de América Latina (sin México) y el $30 \%$ de la producción mundial.

a La renta se calcula con precios del petróleo West Texas Intermediate (WTI) y con costos promedio durante el período 2010-2012.

b El inverso del consumo de energía es la tasa de retorno energético. 
Al quemar cerca del $50 \%$ menos de gas natural en pozos productores, en 2015 la región presentó menores niveles de emisiones de $\mathrm{CO}_{2} \mathrm{y} \mathrm{CH}_{4}$ por barril producido respecto del promedio mundial $\left(18 \mathrm{~kg}\right.$ de $\mathrm{CO}_{2} \mathrm{e}$ frente a $21 \mathrm{~kg}$ de $\mathrm{CO}_{2} \mathrm{e}$ ). De igual forma, los campos petroleros regionales requirieron menos energía que sus pares en el mundo: en 2015 se necesitaron 0,025 barriles de petróleo para producir un barril de equivalente en petróleo (o, a la inversa, por cada barril de petróleo, en términos energéticos invertidos, se produjeron 40 barriles equivalentes de petróleo) $)^{16}$.

Es importante orientar los esfuerzos hacia la reducción de las elevadas tasas regionales de descarga de petróleo en suelo o agua (i. e. 8,6 barriles por cada millón de barriles producidos) que se registran al momento del vertimiento del agua de producción ${ }^{17}$. Por otra parte, si bien en la región se aplican prácticas de reutilización y de reinyección del agua producida, los resultados de estas prácticas, en virtud de las tasas de reinyección del agua de producción, deberían ser comparados y monitoreados en forma constante respecto de los promedios mundiales. En todo caso, estos indicadores deberán tomarse con cautela debido a los rangos amplios y las variables en la producción petrolera a nivel regional y mundial, así como a las distintas características de medición y recopilación de información existente a nivel de reservorios, país o región.

Muchas de las empresas estatales de hidrocarburos de la región ponen en marcha planes, programas e iniciativas tendientes a minimizar el impacto ambiental de sus operaciones hacia una optimización de procesos. Además de la obtención de la licencia ambiental, que es de importancia transversal para todas las compañías que buscan aumentar la producción y las reservas de hidrocarburos, en un futuro, las métricas de emisiones para la industria podrían disminuir en mayor proporción. Esta situación se concretaría mediante la eficiencia de la combustión de hidrocarburos en las operaciones de pozos, plantas y refinerías; el mantenimiento de válvulas y tanques que reduzcan las fugas de metano en la producción, almacenamiento y transporte de hidrocarburos; un mayor consumo de gas natural dentro de las operaciones de campo y refinación; la eliminación de la quema y venteo de gas; la aplicación tecnológica de la captura y

\footnotetext{
La energía producida sobre la energía invertida se denomina "tasa de retorno energético". El agua de producción es agua generalmente salada que sale del pozo junto con el petróleo, en una cantidad que puede ser considerable dentro del fluido. En estos casos es necesaria la instalación de dispositivos para separar esta agua del petróleo y tratarla antes de eliminarla, preferiblemente enviándola a un pozo de inyección. Asimismo, pequeñas cantidades de agua pueden separarse en el entorno del pozo hasta su evaporación en un embalse de evaporación (Scuola Superiore Enrico Mattei, 2002).
} 
el secuestro del carbono, y la penetración de la energía eólica o solar en campos e instalaciones petroleras.

En este sentido, en algunos planes de negocios se consideran agendas ambientales que incluyen planes de mitigación y adaptación al cambio climático mediante iniciativas como el programa Emisiones de Petrobras o el Programa Especial de Cambio Climático 2014-2018 de Pemex. De igual forma, algunas empresas consideran necesaria la adopción de la tecnología de captura y secuestro de carbono, como el caso de Ecopetrol y Pemex, o un mayor uso interno y producción de gas natural en sus actividades, como el caso de YPF (véase el cuadro IV.3). Asimismo, muchos de estos planes, programas e iniciativas se relacionan con los ODS 2030 de las Naciones Unidas en aspectos principalmente relacionados con:

- Garantía de una vida sana y promoción de bienestar (ODS 3)

- Gestión sostenible del agua (ODS 6)

- Acceso universal a la energía segura, sostenible y moderna (ODS 7)

- Construcción de infraestructuras resilientes, promoción de la industrialización y fomento de la innovación (ODS 9)

- Producción y consumo responsable (ODS 12)

- Combate contra el cambio climático y sus efectos (ODS 13)

- Conservación y uso sostenible de los océanos (ODS 14)

- Uso sostenible de los ecosistemas (ODS 15)

La reducción de la quema y venteo del gas natural en campos mexicanos también es importante dado que Pemex es miembro de iniciativas como la Asociación Mundial para la Reducción de la Quema de Gas (GGFR), la Iniciativa Global del Metano (GMI), la Coalición Clima y Aire Limpio (CCAC) del Programa de las Naciones Unidas para el Medio Ambiente (PNUMA) y el proyecto de información sobre las emisiones de carbono (Carbon Disclosure Project, CDP) (Pemex, 2016b).

La eficiencia energética en maquinarias, plantas y equipos ocasionaría una reducción en el consumo energético de las empresas que, sin embargo, podría verse mermado por actividades en reservorios energético-demandantes, como aquellos maduros, lejanos, profundos o de complejidad geológica, como ocurre con los de petróleo pesado en Venezuela (República Bolivariana de), esquisto en la Argentina, pre-sal en el Brasil o en aguas ultraprofundas de México. 


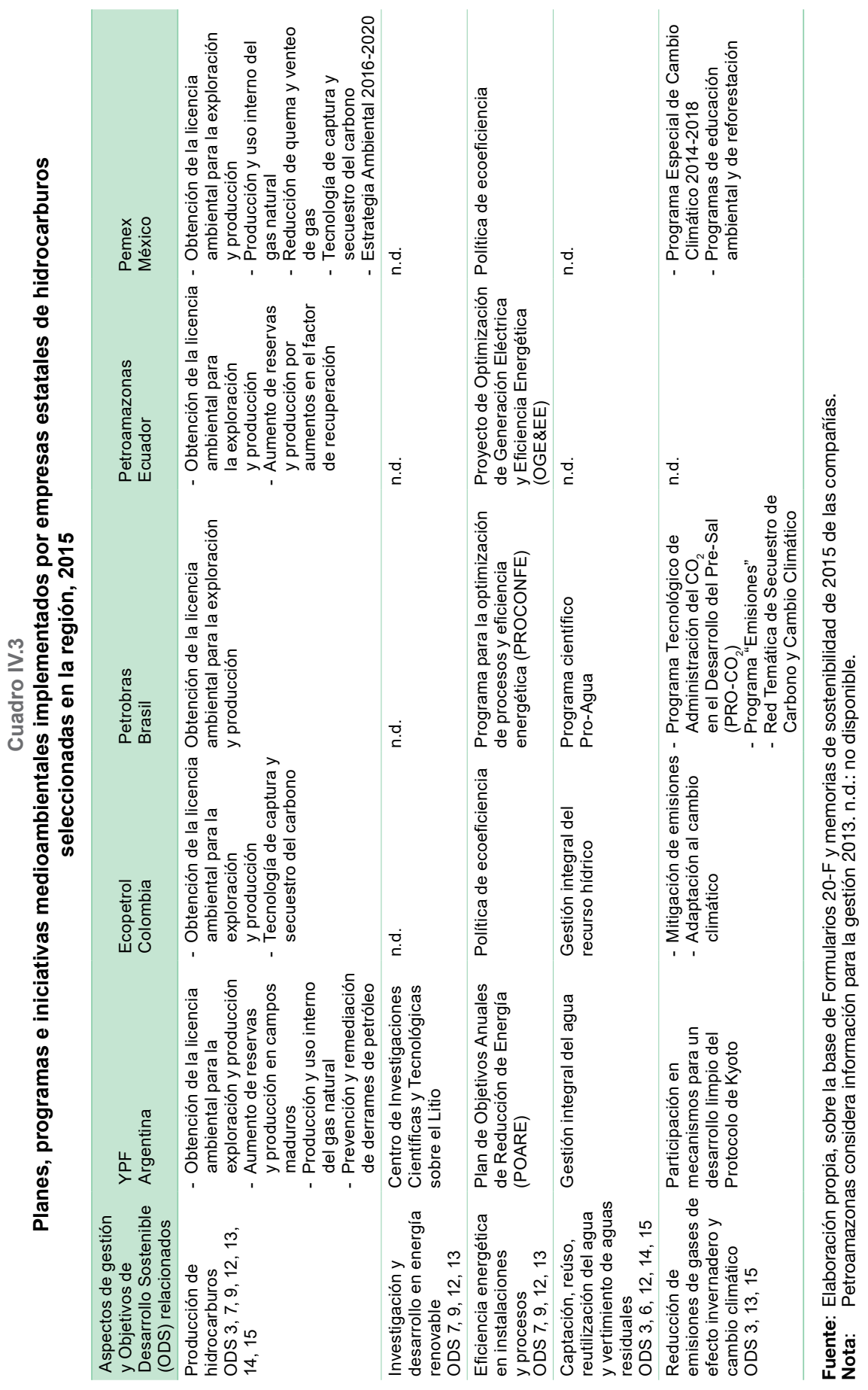


Es remarcable el esfuerzo que hacen muchas de las petroleras estatales para poner en práctica políticas de ecoeficiencia tendientes a minimizar el uso de la energía y el agua. Petrobras, por ejemplo, presenta interesantes iniciativas como el Programa para la Optimización de Procesos y Eficiencia Energética (PROCONFE) y el programa científico Pro-Agua, que en 2015 coadyuvó a un ahorro en costos de captación y disposición dado por un aumento en el volumen de agua reutilizada y comparable al consumo hídrico de una ciudad de más de medio millón de habitantes durante un año (Petrobras, 2016b).

Las descargas de petróleo y el vertimiento del agua de producción sobre cuerpos hídricos superficiales disminuirían en la medida en que se produzca un aumento de la tasa de reinyección/reutilización del agua de producción en pozos maduros con fines de recuperación secundaria para aumentar la producción de petróleo ${ }^{18}$. Por último, la disminución de derrames se daría en la medida en que compañías como YPF de la Argentina implementen exitosamente sus medidas de prevención y remediación de derrames, así como por la disminución y sanción de actividades ilícitas, como robos, sabotajes o vandalismo, con repercusiones no solo ambientales sino también sociales y económicas, como ocurre en el caso de México.

\section{Conclusiones}

Los acuerdos y las políticas nacionales e internacionales en torno a la disminución de las emisiones de gases de efecto invernadero implican que la industria mundial y regional de los hidrocarburos podría enfrentarse a importantes desafíos de supervivencia dentro de lo que se conoce como la "mayor disrupción histórica del mercado petrolero". Los retos se presentarían ante las perspectivas de alcanzar un inminente nivel máximo a mediano plazo y una contracción de la demanda mundial de hidrocarburos entre 2020 y 2030.

Algunos países económicamente dependientes de la producción y exportación de petróleo, y, en menor medida, aquellos que dependen del gas natural, podrían verse afectados por un menor precio de los hidrocarburos en los mercados internacionales, una producción limitada por la demanda mundial y una inmovilización de reservas de hidrocarburos en el subsuelo. No obstante, hay que mencionar que existirían oportunidades para una mayor diversificación económica y energética, así como una serie de nuevos desafíos de desarrollo tecnológico, comercial y de negocios para los países y las empresas de hidrocarburos.

18 Es común el vertimiento y almacenamiento del agua de producción en pozos de disposición, descarga o no productores. 
En la medida en que se requiera una producción de hidrocarburos acorde a las limitantes impuestas por la agenda climática, esta deberá considerar alcanzar el necesario pacto social y consenso político al contemplar en las actividades de la industria el resguardo del medioambiente, la implementación práctica de los procesos de consulta previa indígena, la participación ciudadana y la transparencia en la rendición de cuentas hacia los grupos de interés. Esto es relevante dado que la obtención de la licencia social es una variable de potencial riesgo y costo que atenta contra las decisiones de inversión en hidrocarburos y contra la generación y apropiación fiscal de la renta económica y el consecuente financiamiento del cambio estructural.

Para muchas de las empresas estatales de hidrocarburos de la región, el cumplimiento de las legislaciones nacionales y su participación en iniciativas voluntarias internacionales en materia ambiental representan un desafío de gestión corporativa. Este desafío se da sobre todo por la necesidad de minimizar el impacto ambiental sobre recursos naturales sensibles, como el aire, el uso del suelo, del agua o de la energía. Cabe destacar que se observa un interesante avance en la consideración de estos temas en las políticas corporativas que se enfocan en la eficiencia en el uso de la energía y el agua (ecoeficiencia), la minimización de las emisiones de gases de efecto invernadero y la reducción de la huella ambiental en la producción de hidrocarburos, condiciones necesarias para lograr un desarrollo energético sostenible.

\section{Bibliografía}

AIE (Agencia Internacional de la Energía) (2016), World Energy Outlook, 2016, París. (2015), World Energy Outlook, 2015, París.

Arroyo, A. (2017), "El gran impulso ambiental en el sector de la energía", Documentos de Proyectos (LC/TS.2017/108), Santiago, Comisión Económica para América Latina y el Caribe (CEPAL), noviembre.

Arroyo, A. y A. Perdriel (2015), “Gobernanza del gas natural no convencional para el desarrollo sostenible de América Latina y el Caribe", serie Recursos Naturales e Infraestructura, $\mathrm{N}^{\circ} 169$ (LC/L.3948), Santiago, Comisión Económica para América Latina y el Caribe (CEPAL), enero.

CEPAL (Comisión Económica para América Latina y el Caribe) (2016), Horizontes 2030: la igualdad en el centro del desarrollo sostenible (LC/G.2660/Rev.1), Santiago.

Dahl, C. (2004), International Energy Markets: Understanding Pricing, Policies, and Profits, Oklahoma, PennWell.

Debarre, R., T. Fulop y B. Lajoie (2016), Consequences of COP 21 for the Oil and Gas Industry, Accenture Strategy [en línea] https://www.accenture.com/ t00010101T000000__w__/br-pt/_acnmedia/PDF-11/Accenture-StrategyEnergy-Perspectives-Consequences-COP21.pdf. 
Ecopetrol (Empresa Colombiana de Petróleos) (2016a), "Form 20F 2015 SEC". (2016b), Reporte integrado de gestión sostenible, 2015, Bogotá.

EY (2014), Global Oil and Gas Reserves Study [en línea] https:/ /www.amcham.ro/ UserFiles / articleFiles / EYG\%20No\%20\%20DW0454\%20Global\%20oil\%20 and\%20gas\%20reserves\%20study_12151230.pdf.

HIS Markit (2014), "New research sees high methane leak rates in Bakken, Eagle Ford unconventional energy" [en línea] https://ihsmarkit.com/researchanalysis/new-research-sees-high-methane-leak-rates-in-bakken-eagle-fordunconventional-energy.html.

IOGP (Asociación Internacional de Productores de Petróleo y Gas) (2016), "Environmental Performance Indicators - 2015 Data", Londres, noviembre. (2015), "Environmental Performance Indicators - 2014 Data", Londres, noviembre. (2012), "Environmental Performance Indicators - 2011 Data", Londres, noviembre.

IRENA (Agencia Internacional de Energías Renovables) (2016), Renewable Energy Market Analysis: Latin America, Abu Dhabi.

McGlade, C. y P. Ekins (2015), “The geographical distribution of fossil fuels unused when limiting global warming to $2 C^{\prime \prime}$, Nature, $\mathrm{N}^{\circ} 517,8$ de enero.

OLADE (Organización Latinoamericana de Energía) (2015), Informe de estadísticas energéticas, 2015, Quito.

Pemex (Petróleos Mexicanos) (2016a), "Form 20F 2015 SEC". (2016b), Informe de sustentabilidad, 2015 [en línea] http://www.pemex.com/ etica-e-integridad/sustentable/informes / Documents/inf_sustentabilidad_ 2015_esp.pdf.

Petroamazonas EP (2013), Memoria de sostenibilidad, Quito.

Petrobras (Petróleo Brasileiro) (2016a), "Form 20F 2015 SEC". (2016b), Relatório de sustentabilidade, 2015 [en línea] http://www. investidorpetrobras.com.br/download/4512.

Scuola Superiore Enrico Mattei (2002), Glossario dell'industria petrolifera, Milán, Biblioteca Eni.

The Economist (2017), "Clean energy's dirty little secret", 25 de febrero. (2016), "The burning question", 26 de noviembre.

YPF (Yacimientos Petrolíferos Fiscales) (2016), "Form 20F 2015 SEC". (2015), Reporte de sustentabilidad, 2014 [en línea] https://www.ypf.com/ LaCompania/Documents/ypf-reporte-sustentabilidad-2014.pdf. 

Capítulo V

\section{El papel de la logística en las redes globales de recursos naturales desde una perspectiva multiescalar}

Cristina Muñoz

Gabriel Pérez-Salas

\section{Introducción}

La explotación y comercialización de los recursos naturales continúa siendo el principal motor de crecimiento en muchos países de América Latina y el Caribe. Por ello, insertarse de manera efectiva en las cadenas globales de valor es una condición vital para el desarrollo sostenible futuro de cada uno de estos países. Esto se debe a las ventajas que dichas cadenas presentan para, por ejemplo, promover el comercio de manufacturas con valor agregado, aumentar el empleo de calidad, equilibrar la demanda preservando los sectores básicos de la economía, reducir la exposición a la volatilidad cambiaria y favorecer la inversión en sectores estratégicos (BID y otros, 2016).

En el presente capítulo se reflexiona sobre las interrelaciones entre la logística y los recursos naturales. Como se verá más adelante, en buena parte de los análisis de los flujos globales de comercio se ha relegado u omitido un conjunto de vínculos prioritarios, sin los cuales resulta imposible realizar un análisis holístico. Entre otras cosas, se ha omitido la importancia de la infraestructura logística, entendida como la hebra física y lógica que conecta los distintos eslabones de las cadenas globales de valor. Una adecuada articulación logística permite que los flujos entre las diversas escalas geográficas se movilicen de una forma 
adecuada, oportuna y segura, y a un costo competitivo. Esto, además, incide enormemente en la articulación del territorio, en la conectividad y accesibilidad de los servicios básicos y de transporte, y en la mitigación de las externalidades negativas generadas por la actividad sobre el medio ambiente y las poblaciones. Aportar una mirada holística y multiescalar a los procesos de comercio mundial resulta una tarea compleja debido al foco de análisis propuesto por los trabajos y los casos de estudios realizados en empresas, sectores y países.

El aumento en la escala e intensidad de extracción y producción de los recursos naturales ha incrementado la escala de los mercados objetivo y el grado de interdependencia de los Estados, generando nuevas dinámicas y patrones de desarrollo desigual entre las regiones. Es por ello que el concepto de red, más dinámico y en contraposición con el de cadena, se utiliza aquí con el propósito de ilustrar de manera más apropiada la complejidad existente en la movilización de los recursos naturales entre regiones, países, actores y personas. El desafío consiste en localizar el impacto de los procesos en territorios concretos, analizando los efectos tangibles y los retos persistentes de la región con relación a su lugar en el mundo.

\section{A. Los vínculos olvidados de las redes globales de recursos naturales}

Existen múltiples formas de conceptualizar, imaginar y organizar el intercambio de bienes y servicios en las diversas escalas geográficas. Entre estas se destacan las cadenas de los productos básicos, las cadenas de producción, las cadenas de consumo, los circuitos de los productos básicos, los sistemas de provisión, las teorías del actor-red, las redes globales de producción y las cadenas globales de valor (Muñoz y Pérez, 2017). El concepto de cadenas globales de valor ha sido el más utilizado y diseminado desde ámbitos académicos, gubernamentales e intergubernamentales ${ }^{1}$. Esto incluye organizaciones internacionales como el Banco Mundial, la Conferencia de las Naciones Unidas sobre Comercio y Desarrollo (UNCTAD), la Organización de Cooperación y Desarrollo Económicos (OCDE) y el Foro Económico Mundial². Su amplia utilización se debe a su utilidad pragmática y a la multitud de estudios de caso que se realizaron y dejaron diversas lecciones aprendidas relevantes.

Como su nombre lo indica, las cadenas globales de valor rastrean la generación y apropiación de valor a lo largo de la cadena. Es por esta

\footnotetext{
Mediante el análisis del contexto institucional, la política comercial, la regulación y los estándares, en la aproximación de las cadenas globales de valor se revisa la organización de las industrias globales, examinando la estructura y las dinámicas de los diversos actores involucrados en una industria determinada (Gereffi, 2015; Gereffi y Fernández-Stark, 2016). Como metodología, las cadenas globales de valor rastrean los patrones cambiantes de la producción mundial, así como el vínculo entre actividades geográficamente dispersas y actores dentro de una misma industria, determinando las funciones que tienen cada uno (Gereffi, 1994).

2 En la página web Global Value Chains (http://www.globalvaluechains.org), mantenida por la Universidad Duke, se incluyen en 2018 más de 1065 publicaciones sobre las cadenas globales de valor y más de 1.300 investigadores.
} 
razón que la concepción vertical de esta última ilustra fácilmente esta idea de transformación secuencial desde los insumos hasta los productos. Bajo este enfoque, el proceso de mejora de una empresa dentro de la cadena es un requisito obligatorio para el desarrollo económico de un país, la creación de empleo y la reducción de la pobreza, debido a su vínculo con un incremento en la competitividad que permite la captura de un mayor valor agregado en el proceso de producción. En esta línea, Gereffi, Humphrey y Sturgeon (2005) apuntan a que la empresa debe "escalar" en la cadena mediante diversos tipos de mejora ${ }^{3}$. En la práctica, los estudios de caso han revelado las dificultades que deben enfrentar las empresas para lograr estas mejoras en las cadenas como consecuencia de las barreras de entrada y la estructura de gobernanza, es decir, debido al creciente poder de las empresas líderes en la cadena en las actividades relacionadas con la comercialización, el diseño y el desarrollo de la marca (Bair, 2005).

El foco en el proceso de mejora de las empresas en las cadenas no ilustra oportunamente la desigualdad con que los procesos de mejora se distribuyen entre las diversas regiones, países y grupos de trabajadores, especialmente entre los grupos más vulnerables y en los que se destacan migrantes, mujeres y minorías étnicas (Dicken, 2011). Mientras que las cadenas globales de valor permiten investigar de manera empírica qué tipo de actividades son de alto y bajo valor agregado y dónde se localizan, el vínculo directo que se establece en esta literatura entre la agregación de valor y el desarrollo es inconcluso. El foco principal en las empresas como unidad de análisis dificulta la extrapolación de los resultados a la escala estatal y regional. Este punto ciego se debe a que, según Gereffi (1995), las perspectivas de desarrollo de un país están condicionadas por su forma de incorporación en las industrias globales y también por el modo de inserción de las empresas en una determinada cadena. En un gran número de casos, sin embargo, la mejora salarial de los trabajadores depende más del mercado laboral local y de la fuerza de los sindicatos y los acuerdos colectivos que de las estrategias individuales de las empresas, lo que apunta a la importancia de la economía política y el contexto nacional.

Pese a la utilidad metodológica y conceptual de las cadenas globales de valor, su análisis secuencial dificulta la visualización de su inserción en territorios específicos, haciendo invisible, de esta manera, algunos vínculos prioritarios constitutivos de los flujos globales. Entre estos vínculos prioritarios ocultos se destacan: la ausencia de una conexión circular entre los nodos de la cadena (específicamente entre el consumo y la producción), el análisis exhaustivo del territorio en donde aterriza cada nodo de la cadena, la vital importancia de la logística en las cadenas y los impactos y externalidades que estas generan sobre el medio ambiente y

Tales como el proceso de mejora funcional, el incremento del rango de actividades realizadas, las mejoras del producto (lo que implica la producción de bienes más sofisticados con precios por unidad más elevados) o las mejoras del proceso (que suponen mejorar la tecnología o el sistema de producción) (Gereffi y Kaplinsky, 2001). 
las poblaciones. En esta línea, las variables ambientales y culturales que moldean la configuración y la geografía de las cadenas son consideradas por los diversos enfoques señalados como factores externos, cuando en realidad se trata de elementos constitutivos e inherentes a su conformación.

La producción y el consumo de bienes y servicios se encuentran relacionados a nivel estructural y en un proceso dinámico de mutua definición. En ese sentido, el concepto de red refleja más apropiadamente esta naturaleza relacional de cada nodo desde la producción y la distribución hasta el consumo, incluido el reciclaje y la gestión de residuos. Los procesos de circulación mediante los cuales se conectan los nodos de una red en un sentido funcional y físico se encuentran integrados en un conjunto más amplio de relaciones sociales no lineares y horizontales (Coe, Dicken y Hess, 2008). La perspectiva circular permite identificar una gran variedad de actores, partes constitutivas del sistema, más allá de las empresas. Bajo esta visión circular se pueden observar los flujos complejos de capital, conocimiento y personas, así como las interdependencias que existen entre ellos.

Cada nodo de la cadena aterriza y se integra en un territorio específico que la propia cadena va modificando a su paso y con el tiempo, de forma que las cadenas atraviesan lugares específicos y economías nacionales y locales, con amplias implicancias para el desarrollo (Dicken, 2011). Las cadenas operan y se moldean en ambientes institucionales y territorios específicos, de forma material e igualmente menos tangible (relaciones sociales y prácticas culturales específicas), y existen procesos de dependencia, aunque no de determinación, en los que se presentan las diversas capas y escalas de acción que moldean el comercio mundial (véase el diagrama V.1).

En línea con lo expuesto, en el análisis de las cadenas globales de valor se debe incluir necesariamente una revisión histórica, social y ambiental de las consecuencias surgidas de la inserción subordinada de la región al sistema internacional. Esta inserción desigual en el comercio mundial se articuló desde la época colonial mediante el establecimiento de América Latina y el Caribe como una región periférica orientada al abastecimiento de materias primas a los centros de poder político. Este proceso de periferialización fue y es parcialmente generador del desarrollo desigual que ha caracterizado a la región y que se extiende más allá del sector extractivo para impactar y modificar las identidades sociales, la gobernanza, la economía y el medio ambiente (Le Billon, 2008). La periferialización de las economías de la región modificó la articulación espacial del territorio y generó enclaves productivos destinados a la extracción de recursos naturales desconectados de la economía local. En cierta medida, la existencia de estos enclaves productivos imposibilita la reproducción de vínculos hacia delante, hacia atrás y espaciales con la economía local y nacional. 
Diagrama V.1

Un marco conceptual alternativo para analizar el comercio mundial

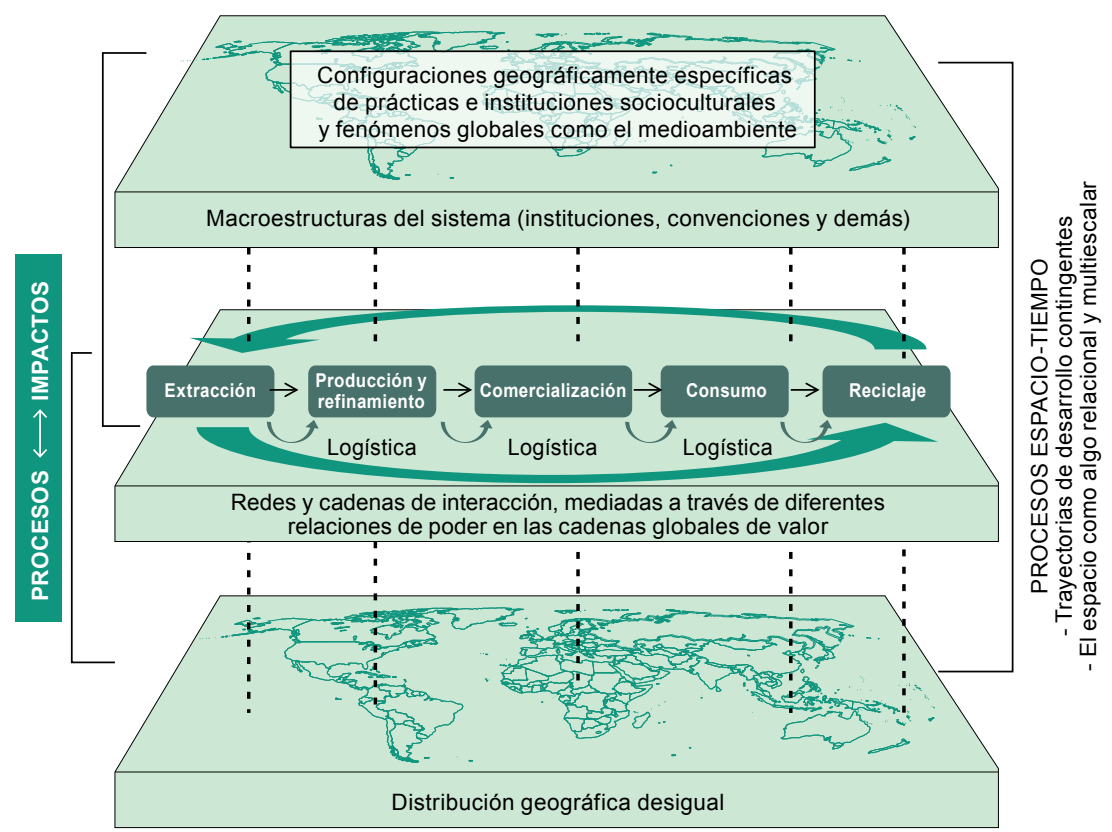

Fuente: Elaboración propia, sobre la base de N. M. Coe, P. Dicken y M. Hess, "Global production networks: realizing the potential”, Journal of Economic Geography, vol. 8, N 3, Oxford, Oxford University Press, 2008.

Con la excepción de algunos autores (Dicken, 2011; Hesse y Rodrigue, 2004 y 2006), en la mayoría de las investigaciones relativas al comercio mundial se parte de la asunción de que con la compresión del espacio-tiempo como consecuencia del desarrollo de las tecnologías de transporte y las comunicaciones se ha resuelto el problema del movimiento de materiales, componentes y productos. Sin embargo, con la desterritorialización de la producción y la creciente complejidad, interdependencia y extensión geográfica que han adquirido las cadenas, la infraestructura y los servicios logísticos (incluido el transporte) se han convertido en requerimientos fundamentales en la interacción global. El continuo progreso tecnológico también provoca cambios radicales en la forma de consumo y en los requerimientos de infraestructura económica para atender una demanda cada vez más exigente y de nicho, impulsando la necesidad de desarrollar servicios y procesos de circulación mediante los cuales los nodos de la red se conectan funcional y físicamente.

Pese a la creciente importancia del transporte y la logística como consecuencia de la profundización de estas redes, el foco continúa en la 
creación de valor en detrimento de los flujos físicos, lo que hace que la producción, la distribución y el consumo aparezcan muy desconectados. En esta línea, Hesse y Rodrigue (2006) proponen una aproximación que busca analizar el valor agregado proporcionado por las actividades relacionadas con los flujos que apoyan la distribución de las mercancías, debido a que la distribución se encuentra supeditada a la producción, mientras que el transporte se supedita a una parte integral de la generación de valor en la red. Con el fin de aprovechar el potencial que representan las cadenas globales de valor, se requiere de una integración logística (física y de servicios) que brinde la conectividad y fluidez necesarias para que los productos primarios y los bienes intermedios puedan transitar entre los nodos con la seguridad y calidad y en la cantidad y el tiempo requeridos, a un costo que sea competitivo a nivel internacional (Muñoz y Pérez, 2017).

Así como las cadenas globales de valor tienen la capacidad de producir valor, también pueden destruirlo mediante la generación de externalidades negativas sobre el medio ambiente y las poblaciones. La concepción de red permite capturar — visual y analíticamente- el modo en que la transformación de los recursos naturales en bienes y servicios, junto con su distribución, comercialización, consumo y reciclaje, implica la generación de productos no deseados (véase el diagrama V.2).

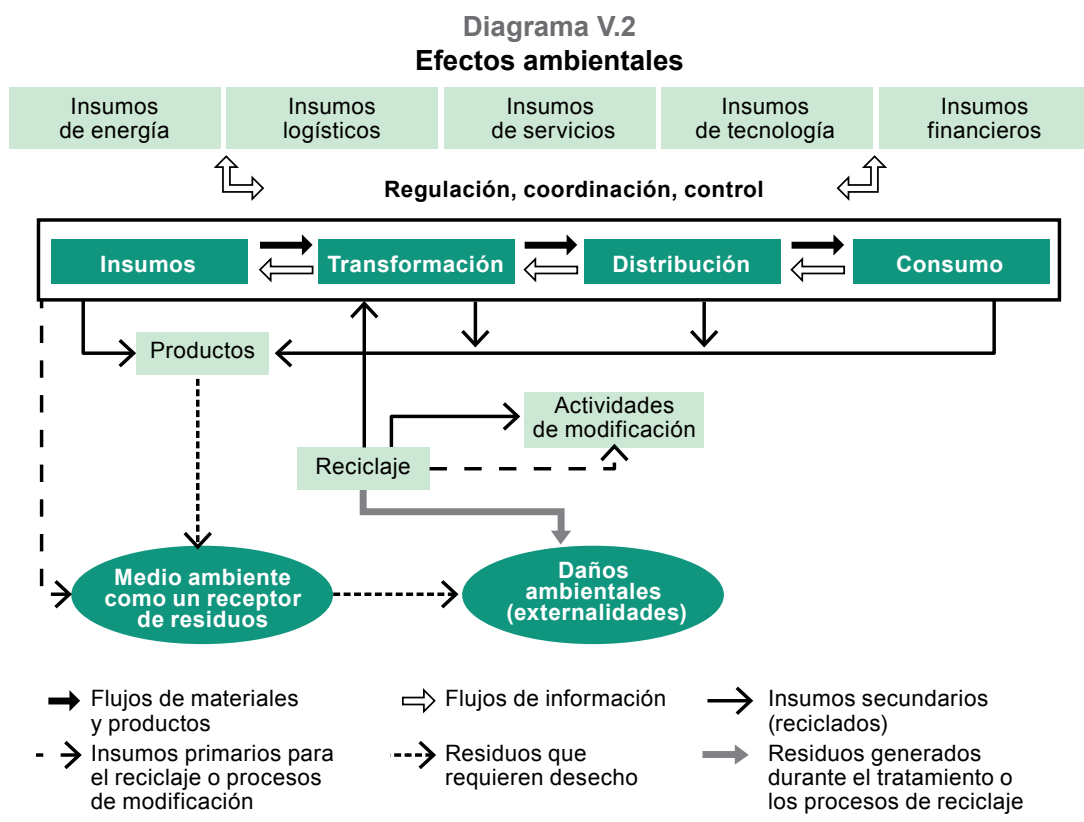

Fuente: Elaboración propia, sobre la base de P. Dicken, Global Shift: Mapping the Changing Contours of the World Economy, Nueva York, The Guilford Press, 2011. 
La red, compuesta por diversas interconexiones entre cada nodo y en su totalidad, muestra la existencia de diversos actores involucrados, tanto humanos como no humanos, tangibles e intangibles. La mayoría de los insumos físicos utilizados regresan al medio ambiente en la forma de contaminación o residuos (Matthews y otros, 2000), con lo que se genera una economía material informal de la contaminación que acontece al margen de la movilización masiva de recursos naturales (Bridge, 2009; Muradian, Walter y Martínez-Alier, 2012).

Como apunta Bridge (2009), la economía es en esencia, aunque no exclusivamente, un proceso de transformación material mediante el cual los recursos naturales se transforman en productos básicos y residuos derivados que se distribuyen de manera desigual a nivel social y geográfico. Pensar en las economías como máquinas metabólicas de transformación de materiales permite mostrar cómo la disponibilidad de los recursos y el cambio ambiental se encuentran estrechamente relacionados con la organización de la propia economía. De esta forma, el descenso de los precios de los recursos refleja cómo la polución y los residuos asociados con la extracción, el procesamiento, el transporte y el consumo de los recursos no están internalizados en el precio (Bridge, 2009), lo que vuelve invisibles los costos ambientales y sociales asociados.

El incremento del consumo y la producción de recursos naturales ha supuesto la búsqueda de nuevos territorios para el cultivo y la extracción, expandiendo la frontera de los productos básicos a nuevas localizaciones (Moore, 2000). Esto ha tenido implicancias sociales y ha transformado el ambiente, generando e intensificando conflictos socioambientales e ilustrando la manera en que los procesos económicos globales redefinen dichas fronteras a escala mundial y conforman interdependencias multiescalares. El incremento de la producción y la explotación ha generado un declive en la calidad de los minerales extraídos y un aumento de la competición sobre usos alternativos del suelo. La extracción de minerales de menor calidad implica un mayor uso de energía, lo que, a su vez, aumenta las emisiones de gases de efecto invernadero (PNUMA, 2013). En esa línea, y dependiendo del recurso, hoy se necesita transportar aproximadamente tres veces más material para la extracción de lo que se necesitaba hace un siglo (PNUMA, 2011 y 2013).

Según Matthews y otros (2000), la eficiencia de los materiales ha mejorado en relación con el crecimiento económico, pero el uso de los recursos y las cantidades de residuos se han mantenido estables a nivel per cápita y han continuado creciendo en términos absolutos. En cuanto a la productividad agrícola, las ganancias y mejoras en su rendimiento en las últimas décadas se han logrado en gran parte sobre la base del incremento masivo del uso de fertilizantes de nitrógeno, provenientes principalmente de los combustibles fósiles usados como materias primas 
para la fabricación de dichos fertilizantes (Bridge, 2009). El continuado incremento de las emisiones de toneladas de dióxido de carbono a la atmosfera demuestra que los logros alcanzados por la eficiencia, basada en las nuevas tecnologías y en mejores prácticas de gestión, se han visto aminorados por las opciones de los consumidores que favorecen formas de vida con un uso intensivo de materiales y energía (Matthews y otros, 2000), lo que refleja la conexión esencial entre el consumo y la producción.

\section{B. Integración de infraestructuras logísticas: de la competencia por precios a una estrategia de desarrollo sostenible de largo plazo}

Históricamente, las industrias extractivas han optado por el desarrollo de infraestructuras bajo un enfoque de enclave productivo como un modo de asegurar que la infraestructura básica para sus operaciones esté disponible de forma continua para la producción y distribución de sus productos. Sin embargo, la explotación en modo de enclaves productivos ha imposibilitado iniciar una senda de desarrollo sostenible debido a que su estructura organizativa lastra la creación de encadenamientos con el tejido productivo local y hace que la economía dependa totalmente de la obtención del recurso natural, actuando de forma desarticulada del resto de la economía (García Alonso, 2017). Este esquema no solo ha forjado una infraestructura disociada e inconexa con el territorio, sino que también ha dificultado los encadenamientos productivos y el desarrollo de nuevos sectores económicos que permitan mantener el crecimiento nacional una vez agotado el recurso natural o cuando su explotación ya no sea rentable.

Tanto la CEPAL como otros organismos de la banca multilateral de desarrollo han expresado la necesidad de una nueva gobernanza de los recursos naturales y de la infraestructura asociada a esta. Una gobernanza capaz de abordar de forma integral estas transformaciones productivas y de convertir los activos naturales extraídos en un nuevo tipo de riqueza de más largo plazo, como pueden ser las inversiones en recursos humanos e infraestructura productiva y una mayor diversificación hacia sectores con más contenido de conocimiento y tecnología. Para ello, y con el fin de alcanzar un desarrollo más sostenible, es fundamental mejorar la infraestructura pública y las capacidades para incorporar valor a nivel local, nacional y regional, con el desarrollo de encadenamientos hacia adelante, hacia atrás y espaciales/territoriales (Halland y otros, 2015) (véase el diagrama V.3). Consciente de la magnitud que representa este desafío, en la presente sección se analiza el papel de las políticas públicas y las decisiones de inversión pública en el desarrollo sostenible de las industrias extractivas y la diversificación económica, centrándose en los vínculos espaciales y de infraestructura. 


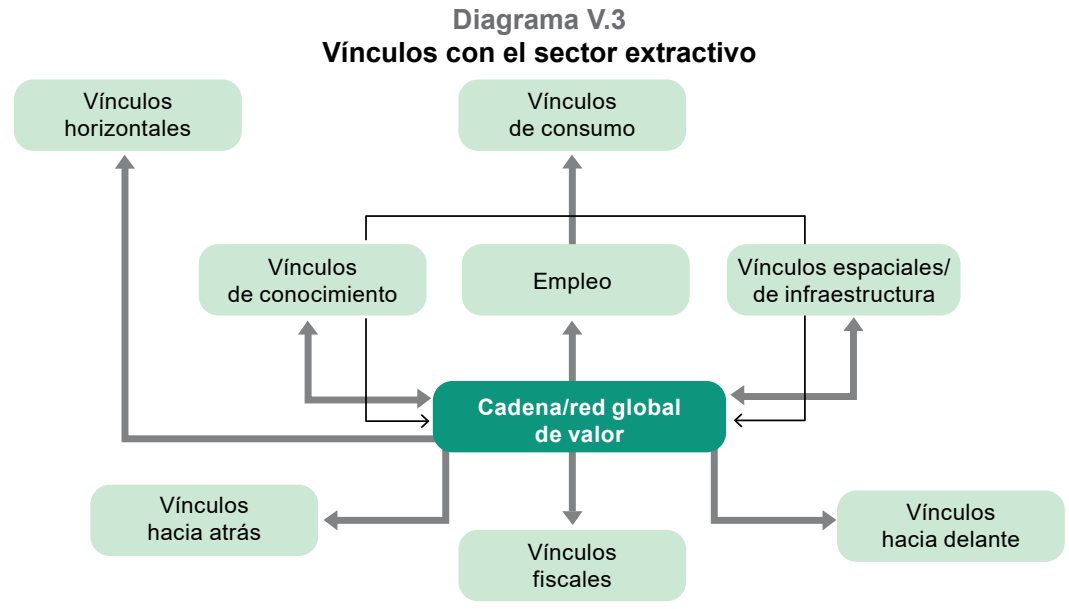

Fuente: Elaboración propia, sobre la base de Columbia Center on Sustainable Investment (CCSI), Linkages to the Resource Sector: The Role of Companies, Government and International Development Cooperation, Eschborn, Agencia Alemana de Cooperación Internacional (GIZ), 2016.

La CEPAL ha señalado que la dinámica de la inversión actual es preocupante, pues implica que la región no está construyendo las capacidades, la infraestructura y las bases de innovación requeridas por un ciclo de expansión como el propuesto por la institución para avanzar hacia los Objetivos de Desarrollo Sostenible (ODS) (CEPAL, 2016). Más aún, la falta de infraestructura, junto con los problemas de facilitación y la poca innovación en los procesos productivos, explica, en buena medida, los altos costos logísticos que afectan la competitividad de la región y que impiden su participación en los nodos más rentables de las redes regionales y globales de valor.

La demanda de infraestructura económica seguirá al alza en el período 2016-2030, cuando la CEPAL estima que se requerirá una inversión anual de entre un $2 \%$ y un $6 \%$, dependiendo del crecimiento del PIB anual. Dicho rango solo considera las necesidades de inversión y mantenimiento de infraestructura en transporte terrestre (carreteras y vías férreas), electricidad, telecomunicaciones y agua y saneamiento, asumiendo que se mantiene el patrón de planificación tradicional de las inversiones, es decir, sin propiciar cambios fundamentales en términos de mejoras en la calidad, eficiencia o sostenibilidad de la infraestructura proyectada (Sánchez y otros, 2017).

Esta demanda de infraestructura aparece en un contexto donde el período de bonanza económica asociada a algunos recursos naturales parece haber llegado a su fin, por lo que el espacio fiscal para la inversión será más reducido y, por tanto, las autoridades tratarán de mantener el gasto social sin afectar la sostenibilidad futura de la economía nacional. De hecho, algunas estimaciones econométricas realizadas utilizando datos 
del Banco Mundial establecen que solo pavimentar todas las rutas que no estarán pavimentadas en el período comprendido entre 2015 y 2030 excedería las rentas de recursos naturales de muchos países y en otros superaría el 30\% del total recaudado (Fuss y otros, 2015).

En este contexto, resulta esencial buscar nuevas alternativas para incrementar la inversión en infraestructura productiva. Una de estas alternativas, que también podría ayudar a resolver el déficit de infraestructura al dar un impulso a la transformación productiva, consiste en promover un uso compartido de la infraestructura logística, tanto por las empresas extractivas como por otros sectores económicos nacionales y, eventualmente, incluso por otros países (Halland y otros, 2015). Para hacer un uso eficiente y competitivo de este tipo de infraestructuras es necesario alinear una serie de elementos. Más aún, el papel del sector público es crucial, particularmente en cuanto a la planificación de las obras en el territorio, así como en la regulación económica y técnica de las operaciones.

Así, por ejemplo, en cuanto al desarrollo de infraestructura ferroviaria compartida, el Columbia Center on Sustainable Investment destaca la necesidad de que las nuevas obras, o la rehabilitación de las que ya existen para un uso compartido, estén debidamente coordinadas y conectadas con los planes de desarrollo territorial y de infraestructuras futuras, tanto en el ámbito nacional como subregional. Con ello se busca identificar las sinergias operacionales, verificar el cumplimiento de las condiciones técnicas necesarias para las empresas extractivas y asegurar que el diseño de la infraestructura sirva como bien público destinado a un uso compartido por otros sectores de la sociedad. Favorecer y fortalecer los vínculos entre proyectos asociados a los recursos naturales y la producción local resulta crítico y, a veces, incluso crucial para la propia sostenibilidad de esos proyectos, las economías de escala y los eventuales encadenamientos que se puedan alcanzar (Toledano y otros, 2014).

El segundo aspecto tiene relación con el diseño, la construcción y la regulación de estas infraestructuras y los servicios que se prestan sobre ellas. Para que los sectores económicos no asociados a los recursos naturales puedan sacar ventaja de la infraestructura desarrollada para los proyectos extractivos, resulta crucial que el diseño, el trazado, la propiedad y las regulaciones técnicas y económicas de la infraestructura estén pensadas para un uso compartido no discriminativo entre distintos sectores o empresas de diferente tamaño. En el caso particular de la infraestructura logística o de transporte (como puertos, ferrovías y carreteras), este tipo de soluciones es más resistido por las empresas concesionarias de recursos naturales, debido a que se trata de estructuras de integración vertical que las propias empresas han aprovechado y propiciado como barreras de entrada al sector. 
Desde el punto de vista de la logística, y dado que la capacidad del sistema es soportada principalmente por el volumen de productos básicos que posee la empresa, el aporte potencial de volumen que los nuevos actores harían sería tan marginal que no alcanzaría a compensar los costos de coordinación que su entrada trae aparejada. Ahora bien, si los nuevos actores son del mismo sector, los incentivos para la empresa extractiva dominante son nulos, puesto que la existencia de una infraestructura propietaria es una ventaja competitiva que se refleja directamente en el precio del producto. No obstante, existen experiencias interesantes en el uso compartido de infraestructura logística en el sector minero de Australia, el Brasil, los Estados Unidos y la India, así como prácticas de uso similar en una vasta extensión de África, incluidas experiencias en países tan disímiles como Burkina Faso, Camerún, Côte d'Ivoire, Guinea, Madagascar, Sudáfrica y Zambia (Toledano, 2012).

Por ello, el establecimiento de un organismo regulador especial, que sea independiente y esté bien estructurado para el tipo de tareas que necesita cumplir, resulta crucial para la gestión de una infraestructura de uso compartido, teniendo en cuenta que este ente deberá mediar ágilmente ante las eventuales disputas entre participantes del sistema, actuando de manera transparente sobre la fijación de las tarifas de acceso y operación para asegurar el acceso competitivo de nuevos actores y la no discriminación o diferenciación entre ellos o entre productos de distinto tamaño. Sin embargo, la regulación y fijación de tarifas es un tema que debe analizarse con extremo cuidado, ya que si se introducen tarifas demasiado altas, estas incrementarán los costos de acceso a la infraestructura para el proyecto extractivo ancla, haciéndolo menos atractivo o incluso volviendo la nueva infraestructura inviable por completo. Si, por el contrario, las tarifas son demasiado bajas o se permite la integración vertical entre el yacimiento y la infraestructura, la empresa dominante puede utilizar su poder de mercado para actuar de manera discriminatoria con los usuarios más pequeños, convirtiendo el recurso en uno monopólico y de difícil regulación.

Para resolver este dilema, algunos países han recurrido a un modelo de gestión que se utiliza frecuentemente en concesiones ferroviarias y que consiste en separar la infraestructura de la operación de los servicios que se prestan sobre ella. La finalidad, en este caso, es incorporar a una tercera empresa cuyo único fin sea operar la infraestructura, de manera que tenga incentivos suficientes para favorecer la entrada de nuevos actores y aprovechar al máximo la infraestructura disponible. Independientemente de la forma de operación seleccionada, el Estado debería quedarse con los derechos de paso o servidumbres asociadas a la infraestructura de uso compartido, de manera que en el futuro pueda desarrollar otras infraestructuras en ese mismo terreno (Toledano y otros, 2014). 


\section{El impacto de las transformaciones geopolíticas en las redes globales comerciales}

A lo largo del tiempo, todas las sociedades han basado su desarrollo en los recursos naturales. Sin embargo, la intensidad y la escala en el uso de dichos recursos (especialmente en los metales), se han incrementado exponencialmente en el último siglo debido a los acelerados avances científico-tecnológicos y al desarrollo de la actual sociedad hipertecnológica y de consumo de masas.

El resurgimiento de China ha supuesto la transformación de los centros tradicionales de la economía mundial y con ello la ocurrencia de diversos cambios en la extracción y provisión de recursos naturales, que han tenido mayores implicancias para los países ricos en estos recursos. Esto ha implicado un desplazamiento geográfico del poder en dirección a Asia y un desligamiento de algunas de las periferias tradicionales de sus centros de referencia, lo que en cierta medida ha modificado el sistema del centro y la periferia (Arrighi y Silver, 2001) y las redes globales de recursos naturales. Esta transformación ha supuesto la expansión del comercio y de los flujos de energía y de materiales debido al incremento de la intensidad y la escala del consumo y también por la producción de recursos naturales. Estas nuevas tendencias han desplazado los costos ambientales a las regiones productoras (Muradian, Walter y Martínez-Alier, 2012), profundizando las diferencias sociales y ambientales entre estas e incidiendo aún más en la desigual distribución mundial y regional de la riqueza.

Esta transformación ha estado marcada por el desplazamiento de la producción de recursos naturales (específicamente de metales) de los países desarrollados a los países en desarrollo desde los años noventa hasta la actualidad. Países como los Estados Unidos y la Federación de Rusia, que en 1994 eran responsables del 6\% y el 13\%, respectivamente, del suministro de metales a nivel mundial, en 2013 produjeron solo el $2 \%$ y el 3,5\% (Habib, Hamelin y Wenzel, 2016). Este desplazamiento geográfico de la producción minera ha ido acompañado de un incremento significativo del porcentaje global de la producción de metales de China del 23\% al $44 \%$, junto con un aumento paralelo de su participación en el consumo global de dichos recursos (Habib, Hamelin y Wenzel, 2016). Actualmente, China es el principal proveedor de al menos 34 metales diferentes, mientras que en 1994 proveía alrededor de 24 (Habib, Hamelin y Wenzel, 2016). Sin embargo, el consumo per cápita de recursos de China y otros países asiáticos aún se encuentra lejos del de los países desarrollados, destacándose en esa distancia la persistencia de una brecha que apunta a un continuado incremento futuro de la extracción y el consumo de recursos por parte de los países en desarrollo (Muradian, Walter y Martínez-Alier, 2012).

La emergencia de las grandes economías asiáticas está rediseñando las relaciones económicas y políticas Sur-Sur y, por ende, reconfigurando 
el sistema global de provisión de recursos naturales con importantes consecuencias ambientales y de desarrollo (Muradian, Walter y MartínezAlier, 2012). La reconfiguración actual, aún en proceso, se encuentra impulsada por una política exterior de China en los países en desarrollo ricos en recursos naturales (específicamente en África), caracterizada por un conjunto de instrumentos que incluyen la cooperación para el desarrollo, la intensificación de los flujos financieros, la movilización de trabajadores chinos, el incremento en la inversión en comercio e infraestructura, la implementación de préstamos respaldados parcialmente por recursos naturales y la intensificación de los flujos armamentísticos (Muradian, Walter y Martínez-Alier, 2012). En particular, la inversión en infraestructura de China en los países en desarrollo se ha concentrado principalmente en el sector primario, caracterizado por un alto nivel de presencia estatal.

Este desplazamiento geográfico de la producción de recursos naturales ha intensificado la dependencia de los países desarrollados del suministro de dichos recursos provenientes de África, Asia y América Latina y el Caribe. Esto ha rearticulado la geopolítica clásica de los recursos naturales y ha impulsado la clasificación de algunos de estos recursos como críticos debido al riesgo geopolítico que conlleva su provisión a través de las cadenas globales de valor. En esta línea, el Consejo Nacional de Investigación de los Estados Unidos clasificó los recursos críticos en virtud del impacto de un posible riesgo y constreñimiento de su suministro en la sociedad (The National Academies, 2007). La Comisión Europea (2014), por su parte, ha medido este riesgo geopolítico a través de la volatilidad y el incremento de los precios de estos recursos, los que, a su vez, han generado una reducción de la competitividad manufacturera de la Unión Europea frente a otras economías ${ }^{4}$.

En términos generales, China es el proveedor más importante de la mayoría de las 20 materias primas críticas identificadas por la Unión Europea. Sin embargo, otros países son determinantes en el abastecimiento de materiales críticos específicos, como es el caso de la Federación de Rusia y Sudáfrica para el grupo de metales de platino, y de los Estados Unidos para el berilio. La criticidad entonces aparece como un concepto dinámico, modificándose en virtud del suministro y los patrones de oferta y demanda de los recursos naturales, factores a los que se suma el contexto geopolítico.

\footnotetext{
En línea con lo manifestado, para asegurar el suministro de recursos esenciales, el Gobierno japonés seleccionó 30 minerales especialmente críticos debido al riesgo en su suministro y a su papel esencial en la industria nacional. La aproximación del país a la política minera se ha articulado alrededor del aseguramiento de un suministro estable de las minas del extranjero, la sustitución de materiales, el almacenamiento y el reciclaje (PNUMA, 2013). El Japón se centra, principalmente, en la creación de empresas conjuntas de explotación en colaboración con países como Viet Nam. Mediante esta estrategia, el Japón ha fomentado su posicionamiento como uno de los inversionistas más importantes en el desarrollo y financiamiento de la explotación de recursos minerales y metales, sobre todo en Australia, el Brasil, el Canadá, Chile y Sudáfrica.
} 
La disrupción del suministro de diversos recursos ha articulado el riesgo geopolítico del suministro de materias primas críticas en torno a su concentración de mercado ${ }^{5}$. En esta línea, el niobio ha estado sujeto a un alto riesgo geopolítico debido al incremento de su concentración de mercado actual en el Brasil, país que suministra el $89 \%$ del recurso (Habib, Hamelin y Wenzel, 2016). En 2050, esta concentración será aún mayor, debido a que el $95 \%$ de las reservas mundiales de niobio estarán localizadas en ese país (USGS, 2017). El suministro de litio, un material que juega un papel vital en las baterías de los vehículos eléctricos, presenta un alto grado de riesgo geopolítico debido al incremento de la concentración de su producción, ya que el 70\% del litio se localizará en solo cuatro países: Argentina, Bolivia (Estado Plurinacional de), Chile y China (Narins, 2017). En 2050, este riesgo será aún mayor debido a que las futuras reservas del recurso estarán localizadas en China y Bolivia (Estado Plurinacional de), el país con las mayores reservas del recurso a nivel mundial (Habib, Hamelin y Wenzel, 2016; Narins, 2017).

El constreñimiento del suministro de recursos críticos ha resultado en un incremento de los precios en el corto plazo, lo que obliga a la industria a rebajar la demanda del recurso, a buscar sustitutos y a incrementar las inversiones en programas de investigación y desarrollo para buscar nuevos yacimientos y nuevas alternativas a la producción primaria, como ocurre con el reciclaje. De esta forma, el reciclaje tiene una relevancia cada vez mayor en la reducción del riesgo geopolítico de los recursos críticos. Esto se debe a que el suministro secundario, originado en el reciclaje, no está circunscrito geográficamente al territorio en donde se encuentran los recursos naturales y puede originarse en países sin reservas geológicas. Según el PNUMA (2013), la producción de metales en la actualidad representa aproximadamente el $8 \%$ del consumo total de la energía mundial y un porcentaje parejo de las emisiones de $\mathrm{CO}_{2}$ relacionadas con los combustibles fósiles. El reciclaje supone una de las formas de reducir esta huella debido a que el proceso solo implica la fundición de los metales, utilizando un menor consumo de energía en la recuperación de metales del que se utiliza originalmente en la producción primaria ${ }^{6}$.

Sin embargo, el proceso de reciclaje resulta cada vez más complejo como consecuencia del creciente número de mezclas de metales y materiales que contienen los productos, lo que dificulta su recuperación (PNUMA, 2013). Por ello, en el diseño de los productos, como una de las fases más críticas, debería evitarse la incorporación de mezclas de

\footnotetext{
Son ejemplos de estos recursos el cobalto, el paladio y las tierras raras.

Debido a la gran escala de su uso, el hierro, el aluminio y el acero están incluidos en las listas de materiales prioritarios del Panel Internacional de Recursos para el desacople de la prosperidad mundial y el agotamiento ambiental. Una tonelada de oro tiene una huella de $\mathrm{CO} 25.000$ veces más grande que la huella de una tonelada de cobre. Sin embargo, debido a la producción de mayores cantidades de cobre, esta industria cada año emite aproximadamente 1,3 veces más CO2 que la producción de oro (PNUMA, 2013).
} 
metales incompatibles que imposibilitan su reciclaje. Cada material tiene diferentes tasas de recuperación y las de los metales especiales son muy bajas debido a su menor producción en comparación con metales como el hierro, el aluminio o el cobre, y a su mínima utilización en los productos finales ${ }^{7}$. En el mediano plazo, el porcentaje de reciclaje de los metales críticos provendrá de los principales países productores y consumidores de estos recursos, como es el caso de China para muchos de ellos. Con esto se reproduce el mismo riesgo geopolítico que existe actualmente en relación con el suministro de su producción primaria.

En la actualidad se registra una acelerada demanda de metales y elementos destinados al uso de nuevas tecnologías, al desarrollo de baterías y a la producción de redes y dispositivos electrónicos complejos y orientados hacia la sostenibilidad. Las proyecciones para 2030 apuntan a un pronunciado incremento en el uso del indio, el neodimio, el litio, el cobalto, el titanio y el cromo, entre otros materiales utilizados para estas tecnologías y para las baterías (Reuter y otros, 2005) ${ }^{8}$. El foco exclusivo en la extracción y la exportación de productos básicos en lo relativo al riesgo geopolítico ignora una perspectiva holística de toda la red, incluidos los riesgos y constreñimientos presentes en otros nodos relacionados, y que incluye, entre otros, la refinería, el transporte y la logística. En esta línea, la creciente importancia de los sistemas de recolección para la separación efectiva de los diferentes tipos de residuos asigna un papel protagónico a la infraestructura para el reciclaje.

El persistente crecimiento de la demanda de bienes y servicios a escala mundial ha supuesto, a su vez, un incremento correspondiente de la movilidad, la logística y el suministro de dichos productos y servicios, lo que genera una compleja red de nodos de gran escala de producción, o centros (hubs), como Shanghai, Singapur, Shenzen, Hong Kong y Busan, los puertos de contenedores más importantes del mundo (Hesse y Rodrigue, 2004). Debido a su función cada vez más importante como centros líderes de carga marítima y aérea, estas ciudades se han convertido en ciudades globales que articulan nuevos sistemas espaciales y que sobrepasan el ámbito de acción del Estado. La interrelación e interdependencia entre estas ciudades globales es mayor incluso que entre los Estados a los que pertenecen debido a la desconexión de sus economías respecto de las zonas interiores y de las economías nacionales (Sassen, 2005).

Entre los minerales especiales se encuentran el litio, el berilio, el galio, el arsénico, el indio, el lantano, el mercurio, el tungsteno y el tantalio.

8 Muchos de estos metales son indispensables en el desarrollo de la infraestructura requerida para la transición a una sociedad sostenible y baja en carbono, específicamente en la producción de energía (solar, eólica y de otro tipo), la purificación del agua (materiales de filtro o sistemas de agua inteligentes), el transporte (vehículos eléctricos) y la construcción. 
La permanente relocalización de los puntos logísticos estratégicos altera el carácter central y periférico de las regiones a lo largo del tiempo, en un proceso que además se encuentra en constante dinamismo. En esta línea, China juega un papel preponderante en el desarrollo de nuevas infraestructuras que hacen posible la generación de redes logísticas de recursos naturales alternativas para paliar su dependencia respecto de las existentes, como lo ilustra la iniciativa de la franja y la ruta lanzada en 2013 por el país asiático y su papel en la inversión y el desarrollo de la infraestructura en diversos países en desarrollo.

\section{Reflexiones finales}

Una adecuada gobernanza, ya sea de los recursos naturales o de la infraestructura, debe ser multiescalar, como una forma de prestar debida atención a los fenómenos y las dinámicas que se producen en los distintos nodos y territorios que las redes globales de recursos naturales cruzan desde su lugar de origen hasta el consumo final, incluido el reciclaje. En este sentido, el concepto "glocal" (Swyngedouw, 1997) releva la intersección fundamental entre las escalas global y local, entendiendo que cada ciudad, país y región se constituye, en buena parte, a través de relaciones de interdependencia que lo vinculan a otros lugares, y en donde ninguna de las escalas se encuentra aislada de las otras. Tanto la extracción de recursos naturales como la logística se encuentran presentes en cada escala geográfica, y la segunda desempeña un papel protagónico al conectar físicamente cada nodo en la forma, el tiempo y el costo requeridos. Ambos elementos se insertan profundamente en ambientes naturales, políticos, culturales e institucionales específicos, por lo que deben responder a determinadas regulaciones, tanto locales como nacionales.

De allí la relevancia del Estado como institución territorial garante del desarrollo de las políticas, la regulación de los mercados, la propiedad y la seguridad, así como de otros factores sin los cuales el sistema colapsaría (Swyngedouw, 2004). En muchos países de América Latina, el Estado es propietario de los recursos naturales del suelo y el subsuelo, además de ser un actor relevante en la regulación y la negociación de los aspectos culturales, sociales, económicos y territoriales. Esto explica la razón por la cual el Estado ha sido el centro de la cristalización de las tensiones y los conflictos socioambientales y el llamado a generar acciones de transformación. Sin embargo, la realidad se dibuja cada vez más porosa e inestable entre las escalas geográficas, en un proceso que genera nuevas formas de configuración espacial y, por tanto, de diferentes escalas de gobernanza.

Esta condición multiescalar se hace notoria, por ejemplo, en los temas de fiscalidad progresiva y de políticas sociales, que se encuentran dentro del ámbito de acción y decisión del Estado, mientras que la 
competitividad y algunas regulaciones de mercados se circunscriben al ámbito global. Esto genera una tensión entre las escalas con relación a una multitud de desafíos crecientes como, por ejemplo, la tensión entre ciertos fenómenos ambientales que son inherentemente globales y que sobrepasan el ámbito circunscrito de los Estados. Esto, a su vez, pone de relieve la tensión entre quienes tienen una relación de subsistencia con los recursos y aquellos cuya relación se basa en la lógica de la extracción o la siembra para el intercambio (Bridge, 2009).

La inserción de los países en desarrollo en las cadenas globales de valor supone una condición indispensable en su desarrollo presente y futuro, por lo que su gestión apropiada se convierte en una prioridad de política pública. Algunos países de la región articularon esta inserción mediante ventajas comparativas vinculadas a una mano de obra no cualificada de menor costo, limitando su desarrollo presente. Para avanzar hacia los sectores más rentables en las cadenas globales de valor son necesarios diversos elementos y condiciones entre los que sobresalen la mejora del acceso al crédito, el fomento de la producción destinada al mercado local, la inversión en educación y formación para superar déficits de capital humano, el fomento de la inversión extranjera directa (IED) y de empresas conjuntas, la inversión en tecnología, la promoción de la asistencia a las empresas en relación con los estándares requeridos por los compradores internacionales (Organización Internacional de Normalización, ISO) y el fomento de la diversificación de las empresas en múltiples productos, con mercados finales geográficamente dispersos, entre otros aspectos (Gereffi y Frederick, 2010).

El desarrollo de infraestructura y sus servicios asociados también es un elemento clave debido a su papel protagónico en el sustento del resto de los elementos. En esta línea, la brecha de infraestructura económica y la deficiente dotación de servicios logísticos competitivos, eficientes y seguros han imposibilitado, en conjunto con otros factores históricoestructurales, el avance de la región en los nodos de las cadenas globales de valor de recursos naturales con un mayor valor agregado.

Debido al papel que juegan la infraestructura y la logística como barrera de entrada a las cadenas globales de valor, resulta imperante poner en práctica una gestión diferente de la infraestructura logística de la región, diseñada originalmente para exportar grandes volúmenes al menor costo y en el menor tiempo posible, y sin favorecer la generación de encadenamientos productivos con el territorio ni una adecuada gestión de las externalidades negativas generadas. El aprovechamiento y uso compartido de la infraestructura originalmente diseñada de manera exclusiva para el transporte de recursos naturales permitiría avanzar hacia un marco conceptual que incluya la conversión del capital natural en otras formas tangibles de capital, con miras a las futuras generaciones. 
En esta línea, el marco conceptual de las cadenas globales de valor, enfocado en la captura de valor (definido únicamente en términos económicos), dificulta la utilización de un concepto sistémico y holístico como el de gobernanza de los recursos naturales. Es necesario avanzar hacia otras concepciones del valor que internalicen las externalidades ambientales y sociales generadas por la explotación de los recursos naturales con una mirada más intergeneracional.

\section{Bibliografía}

Arrighi, G. y B. Silver (2001), "Capitalism and world (dis)order", Review of International Studies, vol. 27, N 5, Nueva York, Cambridge University Press.

Bair, J. (2005), "Global capitalism and commodity chains: looking back, going forward", Competition \& Change, vol. 9, $\mathrm{N}^{\circ}$ 2, SAGE, junio.

Banco Mundial y otros (2016), "Notas de discusión de políticas: integración regional en el contexto de la desaceleración económica", documento presentado en la Octava Reunión de Ministros de Hacienda de América y el Caribe, Washington, D.C., 5 de octubre.

Bridge, G. (2009), "Material worlds: natural resources, resource geography and the material economy", Geography Compass, vol. 3, N³, Wiley.

(2008), "Global production networks and the extractive sector: governing resource-based development", Journal of Economic Geography, vol. 8, № 3, Oxford, Oxford University Press.

CCSI (Columbia Center on Sustainable Investment) (2016), Linkages to the Resource Sector: The Role of Companies, Government and International Development Cooperation, Eschborn, Agencia Alemana de Cooperación Internacional (GIZ).

CEPAL (Comisión Económica para América Latina y el Caribe) (2016), Horizontes 2030: la igualdad en el centro del desarrollo sostenible (LC/G.2660/Rev.1), Santiago, Comisión Económica para América Latina y el Caribe (CEPAL).

Coe, N. M., P. Dicken y M. Hess (2008), "Global production networks: realizing the potential", Journal of Economic Geography, vol. 8, N 3, Oxford, Oxford University Press.

Comisión Europea (2014), Report on Critical Raw Materials for the EU. Report of the Ad hoc Working Group on Defining Critical Raw Materials, mayo [en línea] https://ec.europa.eu/docsroom/documents/10010/attachments/1/translations /en/renditions/pdf.

Dicken, P. (2011), Global Shift: Mapping the Changing Contours of the World Economy, Nueva York, The Guilford Press.

Fuss, S. y otros (2015), "Could resource rents finance universal access to infrastructure? A first exploration of needs and rents", Nota di Lavoro, Fondazione Eni Enrico Mattei.

García Alonso, L. (2017), “Aspectos metodológicos en el vínculo entre recursos naturales y logística regional", Documentos de Proyectos (LC/TS.2017/21), Santiago, Comisión Económica para América Latina y el Caribe (CEPAL).

Gereffi, G. (2015), "Global value chains, development and emerging economies", Inclusive and Sustainable Industrial Development Working Paper Series, $\mathrm{N}^{\circ}$ 18/2015, Viena, Organización de las Naciones Unidas para el Desarrollo Industrial (ONUDI). 
(1995), "Global production systems and third world development", Global Change, Regional Response, B. Stallings (ed.), Nueva York, Cambridge University Press.

(1994), "The organization of buyer-driven global commodity chains: how U.S. retailers shape overseas production networks", Commodity Chains and Global Capitalism, G. Gereffi y M. Korzeniewicz (eds.), Westport, Praeger.

Gereffi, G. y K. Fernández-Stark (2016), Global Value Chain Analysis: A Primer, Durham, Centro sobre globalización, gobernanza y competitividad.

Gereffi, G. y S. Frederick (2010), "The global apparel value chain, trade and the crisis: challenges and opportunities for developing countries", Policy Research Working Paper, N 5281, Washington, D.C., Banco Mundial.

Gereffi, G., J. Humphrey y T. Sturgeon (2005), "The governance of global value chains", Review of International Political Economy, vol. 12, $\mathrm{N}^{\circ} 1$, Routledge.

Gereffi, G. y R. Kaplinsky (eds.) (2001), The Value of Value Chains, Brighton, Institute of Development Studies.

Habib, K., L. Hamelin y H. Wenzel (2016), “A dynamic perspective of the geopolitical supply risk of metals", Journal of Cleaner Production, vol.133, Amsterdam, Elsevier.

Halland, H. y otros (2015), El sector de las industrias extractivas: aspectos esenciales para economistas, profesionales de las finanzas públicas, y responsables de políticas, Washington, D.C., Banco Mundial.

Hesse, M. y J. P. Rodrigue (2006), "Global production networks and the role of logistics and transportation", Growth and Change, vol. 37, N 4, Wiley. (2004), "The transport geography of logistics and freight distribution", Journal of Transport Geography, vol. 12, N³, Amsterdam, Elsevier.

Le Billon, P. (2008), "Diamond wars?: conflict diamonds and geographies of resource wars", Annals of the Association of American Geographers, vol. 98, N², Taylor \& Francis.

Matthews, E. y otros (2000), The Weight of Nations. Material Outflows from Industrial Economies, Washington, D.C., Instituto de los Recursos Mundiales.

Moore, J. W. (2000), "Sugar and the expansion of the early modern world-economy: commodity frontiers, ecological transformation, and industrialization", Review, vol. 23, N 3, Research Foundation of State University of New York.

Muñoz, C. y G. Pérez (2017), “Reflexiones sobre el rol de la logística en la explotación sostenible de los recursos naturales en América Latina y el Caribe", Boletín FAL, $\mathrm{N}^{\circ}$ 5, Santiago, Comisión Económica para América Latina y el Caribe (CEPAL).

Muradian, R., M. Walter y J. Martínez-Alier (2012), “Hegemonic transitions and global shifts in social metabolism: implications for resource-rich countries. Introduction to the special section", Global Environmental Change, vol. 22, $\mathrm{N}^{\circ} 3$, Amsterdam, Elsevier.

Narins, T. P. (2017), "The battery business: lithium availability and the growth of the global electric car industry", The Extractive Industries and Society, vol. 4, N², Amsterdam, Elsevier.

PNUMA (Programa de las Naciones Unidas para el Medio Ambiente) (2013), Metal Recycling: Opportunities, Limits, Infrastructure [en línea] https:/ / www.wrforum. org/wp-content/uploads/2015/03/Metal-Recycling-Opportunities-LimitsInfrastructure-2013Metal_recycling.pdf. (2011), Recycling Rates of Metals: A Status Report [en línea] http://www. resourcepanel.org/file/381/download?token=he_rldvr. 
Reuter, M. A. y otros (2005), The Metrics of Material and Metal Ecology: Harmonizing the Resource, Technology and Environmental Cycles, Amsterdam, Elsevier.

Sánchez, R. J. y otros (2017), "Inversiones en infraestructura en América Latina: tendencias, brechas y oportunidades", serie Recursos Naturales e Infraestructura, N 187 (LC/TS.2017/132), Santiago, Comisión Económica para América Latina y el Caribe (CEPAL).

Sassen, S. (2005), "The global city: introducing a concept", Brown Journal of World Affairs, vol. 11, $\mathrm{N}^{\circ} 2$.

Swyngedouw, E. (2004), “Globalisation or 'glocalisation'? Networks, territories and rescaling", Cambridge Review of International Affairs, vol. 17, № 1, Taylor \& Francis. (1997), "Neither global nor local: 'glocalisation' and the politics of scale", Spaces of Globalisation: Reasserting the Power of the Local, K. Cox (ed.), Nueva York, The Guilford Press.

The National Academies (2007), "Minerals, Critical Minerals, and the U.S. Economy", Washington, D.C. [en línea] https://www.nap.edu/resource/12034/critical_ minerals_final.pdf.

Toledano, P. (2012), “Leveraging extractive industry infrastructure investments for broad economic development: regulatory, commercial and operational models for railways and ports", Nueva York, Columbia Center on Sustainable Investment [en línea] https://academiccommons.columbia.edu/doi/10.7916/ D88W3NH6/download.

Toledano, P. y otros (2014), "A framework to approach shared use of miningrelated infrastructure", Columbia Center on Sustainable Investment [en línea] http: / / ccsi.columbia.edu / files / 2014 / 05 / A-Framework-for-Shared-use_ March-2014.pdf.

USGS (Servicio Geológico de los Estados Unidos) (2014), “The rare-earth elements: vital to modern technologies and lifestyles", Fact Sheet, $N^{\circ}$ 2014-3078 [en línea] https://pubs.usgs.gov/fs/2014/3078/pdf/fs2014-3078.pdf. 


\section{Capítulo VI \\ La gobernanza de los recursos naturales y su vínculo con los Objetivos de Desarrollo Sostenible}

En septiembre de 2015, los 193 Estados Miembros de las Naciones Unidas aprobaron la iniciativa Transformar nuestro mundo: la Agenda 2030 para el Desarrollo Sostenible, que incluye un conjunto de Objetivos de Desarrollo Sostenible (ODS) para 2015-2030. Se trata de una agenda ambiciosa, que configura las actividades de desarrollo internacional mediante 17 Objetivos y 169 metas. Asimismo destaca la complejidad y el amplio alcance de los desafíos de desarrollo y la necesidad de encontrar soluciones a los urgentes problemas de desarrollo del mundo, con todos los países y todas las partes interesadas actuando en colaboración para implementar este plan (Naciones Unidas, 2015).

Si bien inicialmente fueron considerados los sucesores de los Objetivos de Desarrollo del Milenio (ODM), la ambición y el alcance de los ODS son mucho más amplios. Los ODM abarcaron el período comprendido entre 2000 y 2015 y se aprobaron en la Cumbre del Milenio de las Naciones Unidas en 2000. Para mantener el impulso generado por los ODM, en 2012 se propusieron los ODS en la Conferencia de las Naciones Unidas sobre el Desarrollo Sostenible (Río+20). En 2014, la Asamblea General de las Naciones Unidas estableció el Grupo de Trabajo Abierto sobre los Objetivos de Desarrollo Sostenible, para facilitar el proceso de amplia investigación y consulta mundial sobre las múltiples 
facetas del desarrollo sostenible que condujo a la adopción de los ODS en 2015 (Naciones Unidas, 2014).

A diferencia de los ODM, los ODS tienen un alcance universal y reflejan las preocupaciones tanto de los países en desarrollo como de los desarrollados. Cabe notar que, mientras los ODM se centraron en las necesidades mínimas, los ODS continúan las gestiones mundiales para garantizar la satisfacción de las necesidades mínimas y, además, promueven una sociedad global inclusiva, equitativa y sostenible después de 2015 (Osborn, Cutter y Ullah, 2015).

Los ODS se basan en el documento final El futuro que queremos, aprobado en Río+20, en el que se reafirma el compromiso de la comunidad internacional con la construcción de un mundo justo, equitativo e inclusivo. Al integrar los "tres pilares del desarrollo sostenible", es decir, las dimensiones social, ambiental y económica, los ODS representan el plan de acción mundial para lograr la inclusión social, la sostenibilidad ambiental y el desarrollo económico y proporcionan un marco para el seguimiento del progreso hacia su consecución (Naciones Unidas, 2012a).

Restaurar y mantener la salud de la base de recursos naturales es una condición necesaria para erradicar la pobreza y sostener el progreso económico para todos. En este contexto, como se menciona en el documento El futuro que queremos de Rio+20, "la protección y ordenación de la base de recursos naturales del desarrollo económico y social" y el manejo eficiente de los recursos naturales pueden desempeñar un papel fundamental para contribuir al logro de los ODS (Naciones Unidas, 2012a).

Si bien la agenda mundial de desarrollo sostenible es relevante para el sector de los recursos naturales desde hace tiempo, solo recientemente el sector ha encontrado un lugar dentro de los acuerdos y textos internacionales definitorios. El papel de los recursos naturales en el desarrollo sostenible no fue muy visible en la Comisión Mundial sobre el Medio Ambiente y el Desarrollo celebrada en 1987, ni en el documento de resultados de la Conferencia de las Naciones Unidas sobre el Medio Ambiente y el Desarrollo (1992, Río de Janeiro, Cumbre para la Tierra) ni en la Declaración del Milenio de 2000 (Franks, 2014).

No obstante, debido a la mayor participación del sector en la sostenibilidad, en los últimos años se ha observado una mayor conciencia a nivel internacional del papel que pueden tener los recursos naturales en la configuración de un futuro sostenible y equitativo. En la Cumbre Mundial sobre el Desarrollo Sostenible (Cumbre de Johannesburgo 2002) y la Conferencia de las Naciones Unidas sobre el Desarrollo Sostenible (2012, Río+20) se hizo referencia a la minería y la energía y al papel del sector extractivo - cuando se maneja de manera efectiva y adecuadapara catalizar una economía de amplia base de desarrollo, reducir 
la pobreza y ayudar a los países a cumplir los objetivos de desarrollo acordados internacionalmente, incluidos los Objetivos de Desarrollo del Milenio (Naciones Unidas, 2012b; Franks, 2014). Conforme esta evolución, los ODS buscan directa e indirectamente abarcar la gestión de los recursos naturales.

Una adecuada gestión de los recursos naturales puede crear empleos, estimular la innovación y aportar inversión e infraestructura a gran escala y a largo plazo. Sin embargo, mal manejada, la explotación de los recursos naturales también puede conducir a la degradación ambiental, el desplazamiento de la población, la desigualdad y el aumento de los conflictos, entre otros desafíos.

\section{A. Relevancia de los Objetivos de Desarrollo Sostenible para una gobernanza sostenible de los recursos naturales}

La confluencia de las tendencias actuales en el crecimiento de la población, los cambios en los estilos de vida, la urbanización y la actividad económica aumentan la presión sobre los recursos naturales y el medio ambiente. Los signos de tensiones crecientes y combinadas son evidentes a nivel mundial, nacional y local y se reflejan en la escasez local y regional de recursos naturales vitales, la degradación generalizada de la tierra y la superación de umbrales mundiales críticos que conducen a la interrupción de procesos ecológicos, como la regulación del clima y el ciclo del nitrógeno. Los efectos colaterales de las trayectorias de desarrollo actuales, agravados por las desigualdades crecientes y los conflictos sociales, podrían, en un futuro no muy lejano, crear obstáculos insuperables para los esfuerzos de la comunidad internacional orientados a mejorar el bienestar humano e incluso conducir a riesgos cada vez mayores de perder los logros de desarrollo alcanzados hasta ahora (PNUMA, 2015).

Se estima que, en los próximos 20 años, más de 3.000 millones de personas ingresarán a la clase media (medida según los niveles de ingresos y los patrones de consumo), además de los 1.800 millones actuales (PNUMA, 2015). Aproximadamente 140 millones de personas pasan a formar parte de la clase media anualmente y este número podría aumentar a 170 millones en cinco años (Kharas, 2017)1. Estas tendencias de crecimiento intensificarán en gran medida la extracción y el uso de los

La definición de clase media empleada en este análisis comprende a los hogares con ingresos per cápita entre 10 y 100 dólares por persona por día en términos de paridad del poder adquisitivo (PPA) de 2005. Esto supone un ingreso anual para un hogar de cuatro personas de clase media de 14.600 a 146.000 dólares (Banco Mundial, 2007). Considerando la inflación, el rango de ingresos para las familias de clase media se puede expresar como de 11 a 110 dólares por día en términos de PPA de 2011. 
recursos naturales a nivel mundial, que, según las tendencias actuales, llegarían en 2050 a 140.000 millones de toneladas anuales, tres veces el monto registrado en 2000 (Reuter y otros, 2013). Esto ejercerá una enorme presión sobre el medio ambiente y los recursos naturales, muchos de los cuales ya muestran graves signos de escasez y estrés a nivel local, regional y mundial.

La evidencia en su conjunto sugiere que el cambio climático intensificará aún más esta presión, con el riesgo de provocar cambios sustanciales en la biosfera que reduzcan en gran medida su capacidad de producir bienes y servicios esenciales para el bienestar humano (Bastida, 2014). En el caso de América Latina, la incidencia de los desastres climáticos se ha duplicado con creces entre 1970 y 2005. El deterioro de nuestro sistema climático aumentará los riesgos y las preocupaciones que enfrentan en la actualidad las ciudades de América Latina, donde vive el 79,5\% de la población. Los centros urbanos en el norte de Chile, el noreste del Brasil y el norte de México, al igual que en otras regiones áridas y semiáridas, sufrirán una escasez importante de agua. La estimación del costo de los efectos del cambio climático en la región varía del 1,5\% al 5\% del producto interno bruto (PIB) regional, con una mediana del 2,3\%, asumiendo un incremento de la temperatura de $2,5^{\circ} \mathrm{C}$. El costo total estimado de los daños por fenómenos climáticos extremos en la región entre 2000 y 2010 —que afectaron a 40 millones de personas- excede los 40 billones de dólares (Margulis, 2016). Asimismo, la dependencia económica de los recursos naturales hace que América Latina y el Caribe sea muy vulnerable. Si bien la región cuenta con abundantes recursos naturales, ha tenido problemas para traducir esta riqueza en un proceso de desarrollo económico a largo plazo (véase el diagrama VI.1).

Estos riesgos ponen de relieve la importancia de conectar las estrategias y acciones de gobernanza para el alivio de la pobreza, el crecimiento económico sostenido y la cohesión social con las estrategias y acciones para reformar las políticas fiscales, incluidos los subsidios y los regímenes fiscales. Sostener el patrimonio para las generaciones actuales y futuras requerirá de la protección y gestión cuidadosa de la base de recursos naturales de la Tierra, que supone una transición hacia una gobernanza más sostenible de los recursos naturales, como se establece en los ODS (Foro Económico Mundial y otros, 2016).

Cabe resaltar la naturaleza integrada de los ODS, cuyas implicaciones y efectos no pueden ignorarse al formular políticas de gobernanza. Los 17 ODS están estrechamente interrelacionados y frecuentemente son indivisibles. Muchas de las oportunidades para desarrollar estrategias de gobernanza para la integración de los ODS en el manejo de los recursos naturales tendrán múltiples objetivos. El alcance de un objetivo 
individual a menudo dependerá de algunos o todos los demás objetivos y las condiciones de apoyo relacionadas, o tendrá consecuencias en ello. Las iniciativas también pueden atravesar y afectar las esferas económica, ambiental y social.

\section{Diagrama VI.1 \\ América Latina y el Caribe: gobernanza de los recursos naturales}

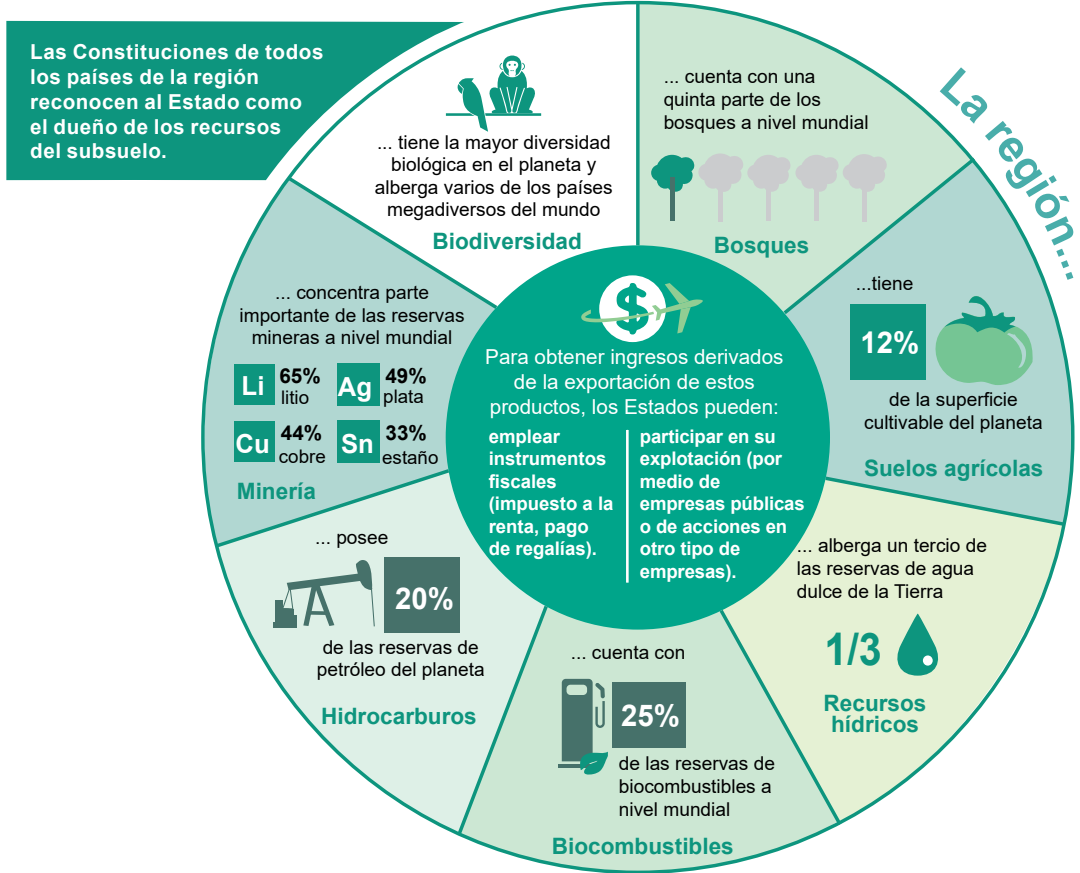

Fuente: Comisión Económica para América Latina y el Caribe (CEPAL), "CEPAL publica: 'Recursos naturales: situación y tendencias para una agenda de desarrollo regional en América Latina y el Caribe'”, Santiago, 18 de marzo de 2014 [en línea] https://www.cepal.org/es/notas-informativas/ cepal-publica-recursos-naturales-situacion-y-tendencias-para-una-agenda-de.

El combate del cambio climático constituye un buen ejemplo. Si bien se incluye como un objetivo independiente, tiene consecuencias para los demás ODS. Por ejemplo, el cambio climático puede afectar desproporcionadamente a los pobres y los más vulnerables, socavando los esfuerzos para erradicar la pobreza (ODS 1), lograr la igualdad de género (ODS 5) y reducir la desigualdad entre los países (ODS 10). El cambio climático puede aumentar la presión sobre los recursos hídricos (ODS 6), amenazar la seguridad alimentaria (ODS 2), alterar los ecosistemas y dañar la biodiversidad (ODS 14 y 15). También puede cambiar los patrones de distribución de enfermedades infecciosas y así afectar la salud global (ODS 3). Todos estos efectos pueden amenazar la 
paz y la seguridad (ODS 16). Al mismo tiempo, la respuesta al cambio climático también puede impulsar el progreso en otros ODS, por ejemplo, promoviendo una mayor eficiencia energética y estimulando la inversión en energías y tecnologías más limpias (ODS 7), que pueden abrir nuevas oportunidades económicas (ODS 8) (PNUD/IFC/IPIECA, 2017).

En resumen, es fundamental tener en cuenta la naturaleza integrada de los ODS, incluidas sus sinergias y efectos, mientras se configuran las estrategias de gobernanza para la gestión de los recursos naturales. Esto se examina con más detalle más adelante en este capítulo.

\section{B. Gobernanza de los recursos naturales: implicaciones y desafíos en el contexto de los ODS}

De acuerdo con Altomonte y Sánchez (2016), la gobernanza de los recursos naturales "se ejerce por medio del conjunto de instituciones formales (marcos constitucionales, leyes, contexto fiscal y regulación sectorial), instituciones informales (reglas implícitas en la práctica de uso común) y decisiones políticas soberanas, cuya acción conjunta rige el funcionamiento de los sectores extractivos. Se determinan así los regímenes de propiedad (por ejemplo, leyes de concesiones), marcos tributarios (tratamiento fiscal específico de estos sectores) y mecanismos de ahorro, distribución y uso de las rentas públicas provenientes de estos sectores (fondos de inversión y estabilización), así como otras funciones de ordenamiento de las actividades asociadas a los sectores extractivos de recursos naturales ${ }^{2}$. No obstante la clara responsabilidad y el rol del sector público en la gobernanza de los recursos naturales, esta no queda exclusivamente restringida a aquel ámbito. La gobernanza incluye a todos los sectores que participan de una actividad, directa o indirectamente, el gobierno, la industria, los trabajadores, las comunidades, la sociedad civil y el entorno natural".

En consecuencia, la definición de gobernanza, como lo apuntan los autores, puede ampliarse a sistema de relaciones y conductas entre actores gubernamentales y no gubernamentales en torno a la toma de decisiones y la gestión de los recursos naturales en función del interés colectivo. Ese gobierno articula el funcionamiento de la industria en su entorno social, político, económico y natural. Se trata, además, del conjunto de mecanismos, procesos y reglas a través del cual se ejerce la autoridad sobre la gestión de los recursos naturales, de las conductas entre las partes y la protección de la naturaleza y de los derechos básicos, y se relaciona con el funcionamiento de las instituciones en la amplia diversidad de agentes y reglas que influyen

Comisión Económica para América Latina y el Caribe (CEPAL), Pactos para la igualdad: hacia un futuro sostenible (LC/G.2586(SES.35/3)), Santiago, 2014. 
sobre ella, con miras al presente y al futuro. El análisis del presente capítulo se inicia utilizando la definición de gobernanza de los recursos naturales de Altomonte y Sánchez(2016) y se amplía con el análisis de gobernanza del capítulo X elaborado por Ernesto Cussianovic de este mismo libro.

En América Latina y el Caribe, las necesidades en términos de políticas, capacidad y otros factores críticos de gobernanza varían ampliamente entre los países extractivos reconocidos (como el Perú, Chile y México), los países extractivos "en crecimiento" (como Colombia y el Ecuador) y los países extractivos "emergentes" (como Guyana, Suriname y la República Dominicana). En consecuencia, no existe un solo conjunto de políticas de gobernanza que pueda proporcionar soluciones uniformes para los desafíos del sector extractivo y maximizar los beneficios potenciales para la región (Walter, 2016).

En definitiva, el desarrollo económico sostenido e inclusivo basado en los recursos naturales exige que todos los actores interesados sean conscientes de las externalidades del sector y que operen con una visión de largo plazo, que incluye, entre otros, el papel crítico de la geografía, las instituciones y la calidad de la gobernanza en la configuración del desempeño del sector. En este sentido, más que nada, se necesita un buen modelo de gobernanza para la planificación y la gestión responsable de los recursos naturales.

En efecto, algunos actores como las organizaciones no gubernamentales, los fondos de inversión privados y las comunidades indígenas, que antes tenían una visibilidad limitada, están encontrando maneras de moldear con mayor éxito las prácticas y decisiones en el sector (Walter, Vieyra y Masson, 2015). El caso de Repsol, una empresa privada de energía, y el Programa de las Naciones Unidas para el Desarrollo (PNUD), que colabora con los pueblos indígenas wayuu de Colombia, ilustra la manera en que una estrategia con múltiples partes interesadas puede ser exitosa. Los indígenas wayuu tienen un acceso limitado al agua potable. Repsol y el PNUD firmaron un acuerdo para llevar a cabo el Programa en Beneficio de las Comunidades (PBC) de la Península de la Guajira en el norte del país. El acuerdo prevé medidas para mejorar el acceso al agua potable para los wayuu, incluso mediante la construcción de dos microacueductos y el mantenimiento de cuatro depósitos de agua que benefician a más de 1.600 personas de 18 comunidades. Este proyecto también incluye medidas de desarrollo de capacidades para comunidades indígenas locales para habilitar el mantenimiento de 1.200 pozos de agua y molinos de viento ${ }^{3}$.

Véase Programa de las Naciones Unidas para el Desarrollo (PNUD), "El sueño del agua se hace realidad para aldeas indígenas en Colombia" [en línea] http://www.undp.org/content/ undp/es/home/ourwork/ourstories/el-sueno-del-agua-se-hace-realidad-para-comunidadesindigenas-de.html. 
La buena gestión de los recursos naturales conduce al desarrollo en fases ulteriores. En particular, hay un amplio margen para el desarrollo de las áreas remotas y alejadas de los centros urbanos, pues en algunos casos han incluso surgido nuevos municipios alrededor de una industria extractiva particular (Foro Económico Mundial y otros, 2016).

Si el potencial del sector para promover la industria y el desarrollo socioeconómico más amplio se aprovecha sin tener en cuenta las externalidades negativas, los efectos a largo plazo pueden superar los beneficios a corto plazo de las industrias extractivas. En este contexto, los responsables de la formulación de políticas y las partes interesadas en América Latina y el Caribe, sobre todo en los países exportadores de productos básicos, exploran activamente políticas para enfrentar los desafíos que plantea la recesión y garantizar que las operaciones en el sector extractivo contribuyan de manera efectiva a un crecimiento económico inclusivo, inocuo para el medio ambiente y a largo plazo (Walter, 2016). Asimismo, las políticas, la información, los incentivos y la transparencia que los gobiernos puedan brindar al sector privado facilitarán la participación y el compromiso de los actores privados para la consecución de los ODS (véase el cuadro VI.1).

\section{Cuadro VI.1 \\ La participación de los actores privados: una dimensión significativa para lograr los Objetivos de Desarrollo Sostenible (ODS)}

\begin{tabular}{|c|c|}
\hline $\begin{array}{l}\text { Establecimiento de } \\
\text { metas y seguimiento } \\
\text { del progreso hacia la } \\
\text { integración de los ODS }\end{array}$ & $\begin{array}{l}\text { Abordaje de áreas como el medio ambiente, la salud y la seguridad, la } \\
\text { lucha contra el soborno, las cuestiones de género, el aprovisionamiento } \\
\text { y la adquisición en las políticas, el cumplimiento de las normas y el } \\
\text { avance en los sistemas de gestión de la empresa, yendo más allá } \\
\text { de los requisitos reglamentarios. }\end{array}$ \\
\hline $\begin{array}{l}\text { Informes y diligencia } \\
\text { debida }\end{array}$ & $\begin{array}{l}\text { Mapeo e información sobre los ODS en los informes de sostenibilidad } \\
\text { de las empresas a los Gobiernos. La definición de las líneas de base } \\
\text { sociales, económicas y ambientales de las áreas respectivas de sus } \\
\text { proyectos y los efectos potenciales de las operaciones servirá de base } \\
\text { para las medidas de compromiso, contribución y mitigación. }\end{array}$ \\
\hline $\begin{array}{l}\text { Evaluación de riesgos } \\
\text { y oportunidades } \\
\text { y procesos de } \\
\text { planificación }\end{array}$ & $\begin{array}{l}\text { Incorporación de los ODS en los procedimientos de evaluación de } \\
\text { riesgos de las empresas, cruciales para definir y predecir los riesgos } \\
\text { potenciales e implementar medidas preventivas y que, con frecuencia, } \\
\text { deben presentarse a los organismos gubernamentales locales para su } \\
\text { autorización antes de iniciar un proyecto. }\end{array}$ \\
\hline $\begin{array}{l}\text { Diálogo y compromiso } \\
\text { con las comunidades, } \\
\text { los Gobiernos y otros } \\
\text { actores interesados }\end{array}$ & $\begin{array}{l}\text { Implementación de una estrategia de gobernabilidad sólida que aliente la } \\
\text { participación proactiva y la consulta con las partes interesadas -incluidas } \\
\text { las comunidades locales, los pueblos indígenas y la sociedad civil-para } \\
\text { establecer y mantener la confianza, comprender inquietudes y perspectivas } \\
\text { y asegurar y mantener una licencia social para operar. Este enfoque es } \\
\text { beneficioso tanto para los organismos gubernamentales como para las } \\
\text { partes interesadas privadas. }\end{array}$ \\
\hline $\begin{array}{l}\text { Investigación y } \\
\text { desarrollo }\end{array}$ & $\begin{array}{l}\text { Los incentivos del Gobierno para utilizar tecnologías inteligentes y limpias } \\
\text { podrían ser un elemento importante para lograr los ODS. }\end{array}$ \\
\hline
\end{tabular}

Fuente: Programa de las Naciones Unidas para el Desarrollo/Corporación Financiera Internacional/ Asociación de la Industria Petrolera Internacional para la Conservación del Medio Ambiente (PNUD/IFC/IPIECA), Mapping the Oil and Gas Industry to the Sustainable Development Goals: An Atlas, Nueva York, 2017. 


\section{Desarrollo de estrategias de gobernanza basadas en sinergias, conflictos y compensaciones entre los ODS}

La gobernanza sostenible de los recursos naturales será fundamental para el cumplimiento de los ODS. Sin embargo, debido a que los recursos naturales están intrínsecamente interconectados, las vías y las políticas diseñadas para lograr un Objetivo pueden impulsar o impedir el progreso hacia otros, en todo el espectro de los ODS (véase el diagrama VI.2).

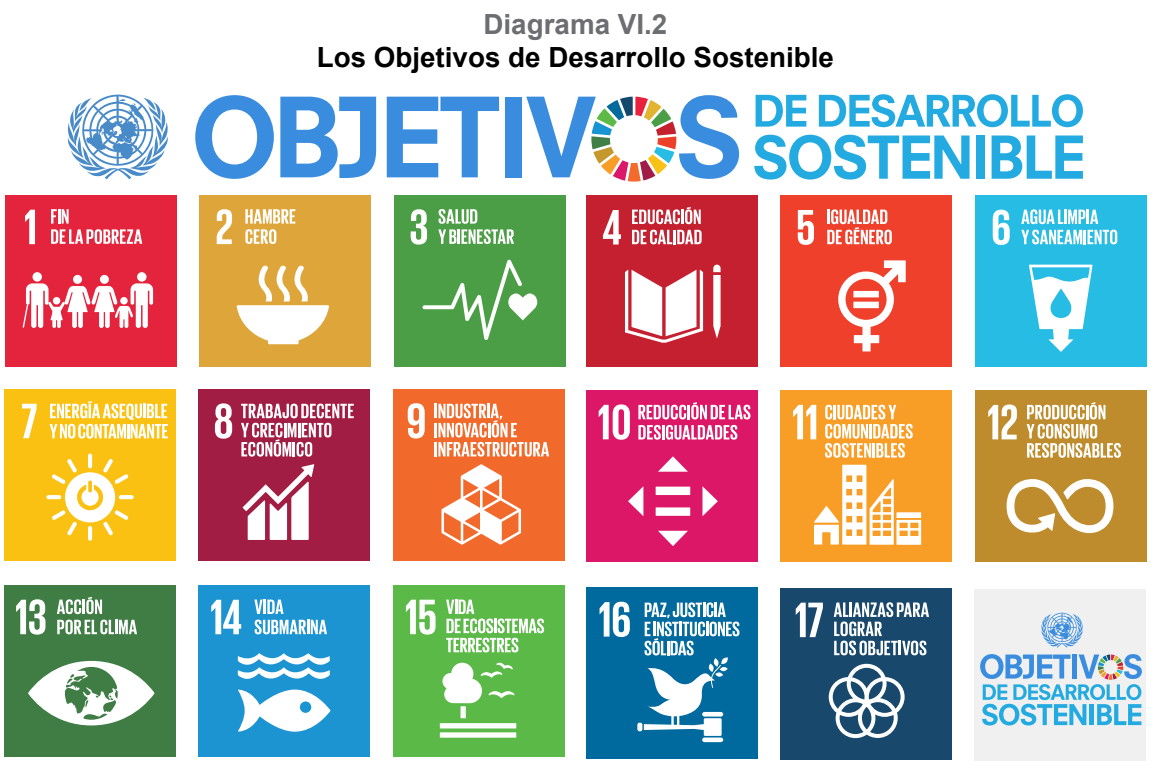

Fuente: Naciones Unidas, "Materiales de comunicación”, Nueva York [en línea] https://www.un.org/ sustainabledevelopment/es/news/communications-material/.

Por ejemplo, el acceso a la energía limpia, la promoción de la agricultura sostenible, la conservación de la biodiversidad, la mitigación del cambio climático y la protección del agua dulce constituyen objetivos fundamentales, pero todos conllevan posibles sinergias y compensaciones (trade-offs) con otros objetivos.

En otras palabras, las interacciones entre los ODS pueden causar resultados divergentes. Una correlación positiva significativa entre un par de indicadores ODS se clasifica como una sinergia, mientras que una correlación negativa significativa se clasifica como una compensación. Por ejemplo, el ODS 1 (Poner fin a la pobreza en todas sus formas en todo el mundo) tiene una relación sinérgica con la mayoría de los otros objetivos, mientras que el ODS 12 (Garantizar modalidades de consumo y producción 
sostenibles) es el más comúnmente asociado con las compensaciones. El logro de la agenda de los ODS dependerá en gran medida de la posibilidad de aprovechar las sinergias encontradas entre los Objetivos.

A modo de ejemplo, las estrategias dirigidas a tratar la producción de energía, la seguridad del agua y la producción de alimentos (ODS $2,6,7)$ a través de la dependencia de los mismos sistemas de tierras ejercerán una presión creciente sobre el uso de la tierra y aumentarán las compensaciones entre los ODS. La duplicación de la productividad agrícola (meta 2.3) podría comprometer la posibilidad de asegurar una agricultura sostenible y resiliente (meta 2.4), a menos que las dos se logren juntas. Los cambios en los sistemas de producción que abordan las ineficiencias estructurales, la productividad de los recursos y las estrategias de conservación reducirán la presión sobre la tierra, el agua y la energía para alcanzar los objetivos de seguridad alimentaria, acceso a la energía, seguridad hídrica y resiliencia climática solo de forma limitada (PNUMA, 2015). El objetivo de combatir el cambio climático no puede coordinarse y lograrse a menos que el objetivo en materia de energía se centre en tecnologías seguras, limpias y de bajas emisiones, mientras el progreso en los objetivos sociales, como el acceso al agua potable y alimentos nutritivos, tendrá efectos en los recursos de la tierra y el agua.

En forma análoga, el análisis de la demanda de energía en el sector de la salud indica que los efectos constantes de un clima cálido conducirán a un aumento de las enfermedades infecciosas y crónicas, como las alergias y las enfermedades respiratorias, que a su vez incrementará la demanda de energía en el sector de salud. Para satisfacer la creciente demanda de energía, el sector de la salud depende cada vez más de fuentes de energía alternativas. Por ejemplo, algunas estimaciones sugieren que los hospitales en los Estados Unidos podrían trasladar hasta el 30\% de sus necesidades de energía a fuentes renovables (como la energía eólica y solar) sin sacrificar la calidad de la atención (ABHAIF, 2017).

Por consiguiente, se deduce que las estrategias de gobernabilidad que abordan los Objetivos sin tener en cuenta las posibles compensaciones probablemente no sean exitosas.

En un documento publicado recientemente por la CEPAL se analiza el nexo entre el agua, la energía y la alimentación en la parte alta de la cuenca del río Reventazón en Costa Rica, en especial en la zona norte de la provincia de Cartago. La cuenca del río Reventazón es la mayor generadora de energía eléctrica a nivel nacional, contribuye al $85 \%$ de la producción de hortalizas y satisface las necesidades de agua potable del $25 \%$ de la población de la gran área metropolitana. El análisis de las interrelaciones de los nexos muestra que, incluso con la riqueza hídrica de la cuenca del río Reventazón, hay cada vez más conflictos debido a la competencia por el agua, lo que ha 
generado movilizaciones sociales y la búsqueda de soluciones. En el estudio se definen claramente las medidas de gobernanza necesarias para enfrentar esos desafíos y se destaca que una visión y una acción compartidas en la gobernanza de los recursos naturales permiten mayores equilibrios entre sectores, favorecen el desarrollo de la cuenca y pueden ser un modelo a seguir para el establecimiento de prioridades en otras cuencas del país, donde se requiere el uso múltiple de agua (Ballestero y López, 2017).

En el caso de la mina Pierina de Barrick Gold Corporation en el Perú, la comunidad local de Cuncashca, cercana a la mina, vive en la pobreza y practica la agricultura de subsistencia. La mina se encuentra en la Cordillera de los Andes, en el centro-norte del Perú, a 32 kilómetros al noroeste de la ciudad de Huaraz. La empresa minera trabajó con la comunidad para elaborar un plan de desarrollo comercial local para sacar a la gente de la pobreza. La empresa se asoció con los líderes de la comunidad para construir una granja modelo y capacitar a los agricultores locales en técnicas modernas de agricultura y cría de animales. También mejoró la infraestructura de gestión del agua, construyó una nueva planta de productos lácteos, mejoró genéticamente el ganado bovino, instaló corrales para para alentar el apareamiento del ganado y ayudó a establecer vínculos con los mercados locales. Entre 2002, cuando comenzó el proyecto, y 2007, los ingresos mensuales se cuadruplicaron y la malnutrición infantil disminuyó un 20\% (Barrick Gold Corporation, 2008).

Mediante sus efectos netos en la oferta y la demanda de recursos, las estrategias de implementación deben orientarse a alcanzar el máximo número de beneficios y la mitigación de las compensaciones entre diferentes ODS y determinar así el éxito o el fracaso de la iniciativa en su conjunto. Por este motivo, las políticas integradas e integrales son esenciales para el éxito de la visión de los ODS, al asegurar que se puedan cumplir múltiples Objetivos simultáneamente. Estas políticas deben anticipar y resolver posibles conflictos de recursos y mejorar los beneficios conjuntos entre los ODS. Asimismo, deben crear nuevas estrategias de gestión de recursos que aborden el conjunto de los ODS, evitando resultados de suma cero y generando resultados netos positivos en todos los ODS en general.

\section{La gobernanza de los recursos naturales y las interacciones de los ODS: la perspectiva del nexo}

En la planificación moderna de la gobernanza socioeconómica se reconoce cada vez más la importancia de los enfoques integrados para la gestión y el desarrollo de los recursos. Una buena estructura de gobierno considera los recursos naturales como componentes clave de los complejos sistemas interconectados que constituyen la economía integrada en la sociedad en 
general, que a su vez está integrada en el ecosistema global. La CEPAL tiene en cuenta estas interacciones del sistema socioeconómico en su "perspectiva del nexo" sobre la gestión sostenible de los recursos naturales.

La perspectiva del nexo en la gobernanza es un ejemplo de pensamiento sistémico basado en el hecho de que las interrelaciones entre los recursos naturales se ven significativamente afectadas por interacciones complejas con aspectos institucionales, sociales, económicos y con comportamientos humanos que se desarrollan de forma diferente a nivel local, regional y a escalas de operación mundiales (Lee y otros, 2012).

Bleischwitz y Johnson (2015) examinaron las interconexiones entre los recursos y su relación con las cadenas de suministro mundiales para demostrar los efectos de la producción de alimentos y el estrés hídrico en las actividades de extracción en países y regiones frágiles. Descubrieron que es probable que los conflictos aumenten en los países que son importantes proveedores mundiales de recursos. Esta dinámica es ilustrativa de las interacciones entre el sistema de recursos naturales y los procesos socioeconómicos y geopolíticos.

Por lo tanto, se deduce que el desarrollo de una estrategia de gobernanza sostenible y efectiva para gestionar los recursos naturales requiere un examen de los ODS desde una perspectiva de nexo. Por ejemplo, se considera el nexo entre los ODS relacionados con la energía, los recursos naturales, el empleo y la reducción de la pobreza. Los efectos económicos del desarrollo de la energía incluyen mayores ingresos del Gobierno y creación de empleo, lo que contribuye a una mayor prosperidad regional.

El empleo en el sector extractivo se extiende mucho más adelante en otros procesos de fabricación. Además de los puestos de trabajo creados mediante el empleo directo, es necesario tener en cuenta los que se crean mediante el empleo indirecto en la larga cadena de suministro, así como aquellos inducidos por un mayor gasto de los recursos naturales por parte de los Gobiernos. Las empresas mineras pueden adoptar estrategias proactivas para garantizar la igualdad de oportunidades en cada etapa del ciclo de empleo y un enfoque proactivo para reequilibrar la brecha salarial de género (Macdonald y Rowland, 2002). En promedio, la industria del petróleo y el gas generalmente muestra un multiplicador de empleo superior a tres, lo que significa que, por cada trabajo directo creado en el sector del petróleo, el gas natural y las industrias relacionadas, también se crean tres o más empleos indirectos e inducidos en la economía (Banco Mundial/FMI, 2016).

En el pasado, muchos objetivos socioeconómicos y ambientales se han experimentado como compensaciones. La adopción de los ODS representa la determinación de la comunidad mundial de romper con esta experiencia histórica y lograr sinergias entre los objetivos, en lugar de concesiones. 
No obstante, el riesgo de compensaciones permanece. Evitar este riesgo y alcanzar los ODS sinérgicamente requerirá una acción política concertada a nivel mundial, regional, nacional y local.

\section{E. Consideraciones clave para la formulación y ejecución de las políticas}

Sobre la base del análisis en las secciones anteriores, y en línea con las recomendaciones formuladas en la Semana de la Gobernanza de los Recursos Naturales y de la Infraestructura, celebrada la sede de la CEPAL en Santiago en noviembre de 2016 (CEPAL, 2016), en esta sección se presentan recomendaciones concretas de política para alinear las medidas de buena gobernanza de los recursos naturales con miras al logro de los ODS:

i) Abordar los tres pilares del desarrollo sostenible mediante enfoques integrados que tengan en cuenta las numerosas interacciones entre diferentes sistemas naturales, y entre estos y las economías y sociedades humanas. Como se señaló en las secciones anteriores, las políticas diseñadas para abordar un conjunto limitado de objetivos, por ejemplo, solo una de las tres dimensiones del desarrollo sostenible, pueden impedir el progreso en las otras dimensiones y tener un impacto negativo en el logro de una adecuada gobernanza de los recursos naturales. Los ODS se formularon para abordar todas las dimensiones del desarrollo sostenible - económica, social y ambiental — en el reconocimiento de que es necesario progresar en todos ellos juntos y de que las políticas para implementarlos deben basarse en una comprensión sistémica de los diferentes objetivos y diseñarse como un paquete integrado y coherente que gestione los beneficios colaterales y mitigue los efectos de las compensaciones.

Esto requiere coherencia y coordinación entre las estrategias de políticas para lograr múltiples ODS a fin de lograr beneficios colaterales y evitar resultados contraproducentes.

ii) Otorgar la más alta prioridad a las políticas y acciones que promuevan y permitan la disociación del crecimiento económico del consumo de recursos naturales y reduzcan los efectos negativos en el ambiente. Tales medidas deberán incrementar la eficiencia de los recursos de los sistemas de producción mundiales y la sostenibilidad de los estilos de vida de los pueblos.

Los enfoques incluyen reformas fiscales y reguladoras que internalizan los costos del daño a los recursos naturales y el medio ambiente, facilitando la adopción acelerada de estilos de vida y sistemas de producción basados en la minimización de los desperdicios, la extensión de la vida de los productos y 
de la responsabilidad del productor, la reutilización, el reciclaje, la reelaboración y otros métodos que efectivamente conservan recursos y reducen la contaminación, mejorando así el bienestar humano a largo plazo.

En términos económicos, en algunos casos esto requeriría la adaptación de los marcos fiscales de los sectores extractivos antes de los próximos ciclos de precios, para cambiar la participación del Estado en los ingresos extractivos en condiciones de progresividad y flexibilidad, junto con la implementación, adaptación e institucionalización de mecanismos de estabilización, ahorro e inversión de ingresos a largo plazo.

La actualización de los marcos tributarios existentes requiere una mayor coordinación entre los países de la región, para avanzar sin socavar el dinamismo de la inversión, construir incentivos alineados con la promoción de un mayor contenido local y vínculos productivos con la economía y estimular la reinversión de ganancias en una mayor exploración y desarrollo tecnológico de los sectores extractivos.

Esto requerirá nuevos programas de investigación, desarrollo, despliegue y transferencia de información, conocimiento y tecnología a una escala sin precedentes. La mayor inversión e innovación en que participan las empresas, los hacedores de políticas, los encargados de implementarlas y las comunidades permitirían a los países superar la dinámica del crecimiento económico del pasado y adoptar modelos regenerativos de desarrollo apropiados para el futuro (PwC, 2016).

iii) Implementar acciones a nivel nacional y subnacional. Si bien los ODS se formulan a nivel mundial, es en estas escalas que una integración total de los recursos en la política, la planificación y la implementación creará las condiciones para un resultado neto positivo a nivel mundial. Los países deben construir estrategias de largo plazo y políticas de Estado para garantizar que los sectores extractivos contribuyan al logro de los objetivos de pleno desarrollo con diversificación productiva, cambio estructural e inclusión social. Las economías más desarrolladas deberán adoptar estrategias para reducir el uso de sus recursos a niveles sostenibles a nivel mundial, incluso mediante la creación de tecnologías más limpias y su despliegue a gran escala. Al mismo tiempo, los países en desarrollo deberán esforzarse para mejorar la eficiencia de los recursos y los procesos de producción más limpios, incluso cuando el uso de su red de recursos naturales deba continuar durante un período hasta que sus sociedades alcancen una calidad de vida aceptable y transiten a otras actividades económicas que les permita alcanzar un desarrollo sostenible. 
iv) Fortalecer la capacidad de las instituciones públicas para gestionar y resolver de manera efectiva el creciente número de conflictos sociales, ambientales y laborales, entre otros, asociados con el desarrollo de los recursos naturales y los sectores extractivos. Para lograrlo, es necesario adaptar las instituciones regionales para que coincidan con las estrategias y políticas estatales. Asimismo, esto debe implementarse dentro de un marco de mayor transparencia y control social sobre los flujos, la gestión, el uso y la inversión de los ingresos derivados de la explotación de los recursos naturales por parte de los Gobiernos y las empresas.

v) Adoptar un enfoque de múltiples actores y crear conciencia sobre las oportunidades y los desafíos que representan los ODS para los sectores de recursos naturales y extractivos y sus partes interesadas y sobre la manera en que podrían abordarlos. Esto se puede lograr facilitando el diálogo y la colaboración entre múltiples actores interesados en el logro de los ODS. Como se destaca claramente en la Agenda 2030 para el Desarrollo Sostenible y en el ODS 17 en particular, la construcción de un mundo sostenible requiere el trabajo de múltiples partes interesadas (Foro Económico Mundial y otros, 2016).

Si bien la gobernanza efectiva de la industria minera requiere un enfoque coordinado en el que participen todos los ministerios relevantes y otras partes del Gobierno y no solo los responsables de la minería, el sector privado debe respetar los derechos humanos, cumplir con las regulaciones gubernamentales, maximizar las contribuciones positivas a la sociedad y evitar o minimizar los efectos negativos de sus operaciones comerciales. Las empresas también pagan impuestos y regalías, participan en diálogos sobre política responsable y pueden colaborar para aprovechar los recursos y realizar inversiones sociales, asegurando que estén alineadas con las prioridades de desarrollo local. Además, las organizaciones de la sociedad civil son responsables de trabajar junto con los Gobiernos y las empresas para cubrir lagunas y garantizar que ambos cumplan con sus responsabilidades frente a la sociedad.

Los asociados para el desarrollo en América Latina y el Caribe, incluidas las instituciones multilaterales y los donantes bilaterales, brindan diversos tipos de apoyo, desde la provisión condicionada de financiamiento para proyectos, el cumplimiento de estándares de sostenibilidad hasta la provisión de conocimientos técnicos y apoyo para el desarrollo de capacidades a Gobiernos, comunidades y empresas locales (Foro Económico Mundial, 2013).

El objetivo de las gestiones de múltiples partes interesadas es definir la manera de generar un mayor impacto positivo cuando diferentes partes interesadas colaboran, aprovechan y unen recursos, sin perder de vista las responsabilidades fundamentales de cada sector. 


\section{F. Conclusiones}

Tanto las aspiraciones de los ODS como la escala y la complejidad de los desafíos actuales requieren compromisos continuos, sustanciales e innovadores, así como la asociación de todos los actores para garantizar la incorporación de los ODS en las industrias relacionadas, de modo que puedan aplicarse de manera inclusiva y efectiva.

La gobernanza eficiente de los recursos naturales desempeña un papel fundamental en el logro de los ODS. Mediante el análisis de los vínculos directos e indirectos entre la gobernanza de los recursos naturales y los 17 ODS, este capítulo busca alentar a los interesados del sector público y privado a incorporar los ODS pertinentes en un marco de planificación estratégica de largo plazo, reforzar su labor actual y proporcionar nuevas ideas. El éxito de los ODS también depende de la asociación sustancial y continua y la coordinación entre los Gobiernos, el sector privado, el mundo académico, las comunidades y la sociedad civil.

En este capítulo se abordaron las diversas formas en que una gobernanza eficiente de los recursos naturales puede contribuir positivamente al logro de los ODS, al tiempo que se evitan las compensaciones y se aprovechan las sinergias entre los Objetivos. Esto requiere un cambio significativo en las políticas, las tecnologías y los hábitos de consumo a nivel mundial, regional, nacional y local. Sin embargo, este tendrá que llevarse a cabo de distintas maneras en diferentes lugares para obtener un resultado global neto positivo, pues no existe una solución única para este desafío.

En particular, los países de bajos ingresos deberán recibir apoyo en materia de tecnología e inversión mediante la cooperación internacional, con miras a la creación de capacidad, a un incremento de sus PIB más rápido con respecto al uso de recursos y a la promoción del crecimiento social y ambiental. La inversión y la innovación que vinculan a las empresas y los innovadores con los responsables de la formulación de políticas, los encargados de ejecutarlas y las comunidades deberían permitir la adopción de modelos de desarrollo adecuados para el futuro de las economías menos desarrolladas. Como se mencionó anteriormente, en los países desarrollados se debe hacer una transición rápida hacia el desacoplamiento de los recursos del crecimiento económico a fin de mantener la misma calidad de vida y la buena salud de los recursos naturales.

Por último, el proceso de transformación debe basarse en una mayor difusión de la información y el conocimiento sobre el estado actual de los recursos, que se traducirá en una mayor conciencia del riesgo de conflictos y compensaciones. Esto requerirá un amplio apoyo para mejorar la calidad 
de la recopilación de datos y la creación de herramientas para la toma de decisiones apropiadas en los países en desarrollo, como parte del proceso hacia la consecución de los ODS, y ayudará a contar con información más confiable para la planificación de políticas nacionales e internacionales.

Para ello se necesitarán nuevos programas de investigación, desarrollo, despliegue y transferencia de información, conocimiento y tecnología a una escala sin precedentes. La cooperación internacional deberá abordar las lagunas en las capacidades financieras, tecnológicas e institucionales para permitir que los países en desarrollo aceleren la adopción de modos de producción sostenibles y mejoren su bienestar social, económico y ambiental.

\section{Bibliografía}

ABHAIF (Abdullah Bin Hamad Al-Attiyah International Foundation for Energy and Sustainable Development) (2017), Sustainable Development Goals and Energy Nexus, Doha.

Altomonte, H. y R. Sánchez (2016), Hacia una nueva gobernanza de los recursos naturales en América Latina y el Caribe, Libros de la CEPAL, N 139 (LC/G.2679-P), Santiago, Comisión Económica para América Latina y el Caribe (CEPAL), mayo.

Ballestero, M. y L. López (2017), “El Nexo entre el agua, la energía y la alimentación en Costa Rica: el caso de la cuenca alta del río Reventazón", serie Recursos Naturales e Infraestructura, $\mathrm{N}^{\circ} 182$ (LC/TS.2017/105), Santiago, Comisión Económica para América Latina y el Caribe (CEPAL), noviembre.

Balza, L. y R. Espinasa (2015), "Oil sector performance and institutions: the case of Latin America", Technical Note, $\mathrm{N}^{\circ} 724$, Washington, D.C., Washington, D.C., Banco Interamericano de Desarrollo (BID), enero.

Banco Mundial (2007), Global Economic Prospects 2007: Managing the Next Wave of Globalization, Washington, D.C.

Banco Mundial/FMI (Banco Mundial/Fondo Monetario Internacional) (2016), Informe de seguimiento mundial 2015/2016: Los objetivos de desarrollo en una era de cambio demográfico. Sinopsis, Washington, D.C.

Barrick Gold Corporation (2008), "From subsistence farming to agribusiness: the Cuncashca story", Toronto, 29 de octubre [en línea] http:// barrickbeyondborders.com/people/2008/10/from-subsistence-farming-toagribusiness-the-cuncashca-story $/$.

Bastida, A. (2014), "From extractive to transformative industries: paths for linkages and diversification for resource-driven development", Mineral Economics, vol. 27, No 2-3, Berlín, Springer, diciembre.

Beylis, G. y B. Cunha (2017), Energy Pricing Policies for Inclusive Growth in Latin America and the Caribbean, Washington, D.C., Banco Mundial.

Bleischwitz, R. y C. Johnson (2015), "The global resource nexus: water challenges and policy conclusions", Reducing Vulnerability: A Transatlantic Approach to Energy Security, AICGS Policy Report, $N^{\circ}$ 60, R. Bleischwitz y otros (eds.), Baltimore, John Hopkins University. 
Brandi, C., C. Richerzhagen y K. Stepping (2013), “Post 2015: why is the waterenergy-land nexus important for the future development agenda?", Briefing Paper, $N^{\circ} 3 / 2013$, Bonn, Instituto Alemán de Desarrollo (IAD).

CEPAL (Comisión Económica para América Latina y el Caribe) (2018), Agenda 2030 y los Objetivos de Desarrollo Sostenible: una oportunidad para América Latina y el Caribe (LC/G.2681/Rev.2), Santiago, enero.

(2016), "Recomendaciones para promover una visión regional hacia una mejor gobernanza de los recursos naturales y de la infraestructura" (LC/L.4267), Santiago, noviembre [en línea] https://repositorio.cepal.org/bitstream/ handle/11362/40759/S1601194_es.pdf.

(2014), Pactos para la igualdad: hacia un futuro sostenible (LC/G.2586(SES.35/3)), Santiago, abril.

(2013), Recursos naturales: situación y tendencias para una agenda de desarrollo regional en América Latina y el Caribe (LC/L.3748), Santiago, diciembre.

Collier, P. (2010), "The political economy of natural resources", Social Research: An International Quarterly, vol. 77, $\mathrm{N}^{\circ}$ 4, Baltimore, John Hopkins University.

Consejo Internacional de Minería y Metales (2015), Guía de buenas prácticas: los pueblos indígenas y la minería. Segunda edición, Londres.

(2014), The Role of Mining in National Economies (2nd Edition), Londres, octubre.

Dente, B. y J. Subirats (2014), Decisiones públicas: análisis y estudio de los procesos de decisión en políticas públicas, Barcelona, Editorial Planeta.

Esteves, A., B. Coyne y A. Moreno (2012), "Local content in the oil, gas and mining sectors: enhancing the benefits at the subnational level", Washington, D.C., Revenue Watch Institute, octubre, inédito [en línea] https: / / resourcegovernance. org/sites/default/files/SubnationalLocalContentDRAFT.pdf.

EYGM (Ernst \& Young Global) (2016), Women in Power and Utilities Index 2016, Londres.

FMI (Fondo Monetario Internacional) (2005), Guide on Resource Revenue Transparency, Washington, D.C., junio [en línea] http://www.imf.org/external/pubs/ft/ grrt/eng/060705.pdf.

Foro Económico Mundial (2013), Responsible Mineral Development Initiative 2013, Ginebra, abril.

Foro Económico Mundial y otros (2016), "Mapping mining to the Sustainable Development Goals: an atlas", White Paper, Ginebra, julio.

Franks, D. (2014), "The extractive sector and the Post-2015 Development Agenda: cross sector cooperation to address environmental challenges", Brasilia, Gobierno del Brasil/ Programa de las Naciones Unidas para el Desarrollo (PNUD), diciembre [en línea] http://www.extractivedialogue.com/wpcontent/uploads/2014/09/TheExtractiveSector.pdf.

Jaimurzina, A. y R. Sánchez (2017), “Gobernanza de la infraestructura para el desarrollo sostenible en América Latina y el Caribe: una apuesta inicial", Boletín $F A L$, vol. 354, $\mathrm{N}^{\circ}$ 2, Santiago, Comisión Económica para América Latina y el Caribe (CEPAL), febrero.

Kharas, H. (2017), "The unprecedented expansion of the global middle class: an update", Global Economy and Development Working Paper, $\mathrm{N}^{\circ} 100$, Washington, D.C., Brookings, febrero.

Lee, B. y otros (2012), Resources Futures: A Chatham House Report, Londres, Chatham House, diciembre. 
Macdonald, I. y C. Rowland (eds.) (2002), Tunnel Vision: Women, Mining and Communities, Victoria, Oxfam, noviembre.

Margulis, S. (2016), "Vulnerabilidad y adaptación de las ciudades de América Latina al cambio climático", Documentos de Proyectos (LC/TS.2017/12), Santiago, Comisión Económica para América Latina y el Caribe (CEPAL), diciembre.

Naciones Unidas (2015), Transformar nuestro mundo: la Agenda 2030 para el Desarrollo Sostenible (A/RES/70/1), Nueva York, octubre.

(2014), Informe del Grupo de Trabajo Abierto de la Asamblea General sobre los Objetivos de Desarrollo Sostenible (A/68/970), Nueva York, agosto.

(2012a), El futuro que queremos (A/RES/66/288), Nueva York, septiembre.

(2012b), Informe de la Conferencia de las Naciones Unidas sobre el Desarrollo Sostenible (A/CONF.216/16), Nueva York.

(2007), Declaración de las Naciones Unidas sobre los derechos de los pueblos indigenas (A/RES/61/295), Nueva York, diciembre.

ODI (Overseas Development Institute) (2011), "Effective natural resources management for sustainable and inclusive growth", Londres, 20 de abril [en línea] https: / / www.odi.org/news/344-effective-natural-resources-managementsustainable-and-inclusive-growth.

OMS (Organización Mundial de la Salud) (2015), Estadísticas Sanitarias Mundiales 2015, Ginebra.

Osborn, D., A. Cutter y F. Ullah (2015), Universal Sustainable Development Goals: Understanding the Transformational Challenge for Developed Countries, Kent, Stakeholder Forum for a Sustainable Future, mayo

Oxfam (2009), "Women, communities and mining: the gender impacts of mining and the role of gender impact assessment", Victoria, diciembre [en línea] https:/ / oxfamilibrary.openrepository.com/bitstream/handle/10546/293093/ ml-women-communities-mining-011209-en.pdf.

PNUD/IFC/IPIECA (Programa de las Naciones Unidas para el Desarrollo/ Corporación Financiera Internacional/Asociación de la Industria Petrolera Internacional para la Conservación del Medio Ambiente) (2017), Mapping the Oil and Gas Industry to the Sustainable Development Goals: An Atlas, Nueva York.

PNUMA (Programa de las Naciones Unidas para el Medio Ambiente) (2015), Policy Coherence of the Sustainable Development Goals: A Natural Resource Perspective, París.

Pradhan, P. y otros (2017), "A systematic study of Sustainable Development Goal (SDG) interactions", Earth's Future, vol. 5, N 11, Hoboken, Wiley, noviembre.

PwC (2016), Navigating the SDGs: A Business Guide to Engaging with the UN Global Goals, Londres [en línea] https://www.pwc.com/gx/en/sustainability/ publications/PwC-sdg-guide.pdf.

(2015), Mining for Talent 2015: A Review of Women on Boards in the Mining Industry 2012-2014, Londres [en línea] https:/ / www.pwc.co.uk/assets / pdf / women-in-mining-2015.pdf.

Quiroz, J. (2015), “Estándares para medir transparencia y rendición de cuentas: retos y oportunidades para una gobernanza efectiva", Gobernanza con transparencia en tiempos de abundancia: experiencias de las industrias extractivas en América Latina y el Caribe, J. Vieyra y M. Masson (eds.), Washington, D.C., Banco Interamericano de Desarrollo (BID).

Reuter, M. y otros (2013), Metal Recycling: Opportunities, Limits, Infrastructure, Nairobi, Programa de las Naciones Unidas para el Medio Ambiente (PNUMA), abril. 
UNCTAD (Conferencia de las Naciones Unidas sobre Comercio y Desarrollo) (2012), Extractive Industries: Optimizing Value Retention in Host Countries, Ginebra.

Walter, M. (2016), "Extractives in Latin America and the Caribbean: the basics", Technical Note, N 907, Washington, D.C., Banco Interamericano de Desarrollo (BID), enero.

Walter, M., J. Vieyra y M. Masson (2015), “Legislación, estándares y comparaciones para fortalecer la transparencia en las industrias extractivas", Gobernanza con transparencia en tiempos de abundancia: experiencias de las industrias extractivas en América Latina y el Caribe, J. Vieyra y M. Masson (eds.), Washington, D.C., Banco Interamericano de Desarrollo (BID).

Weitz, N., M. Nilsson y M. Davis (2014), “A nexus approach to the post-2015 agenda: formulating integrated water, energy, and food SDGs", SAIS Review of International Affairs, vol. 34, N², Baltimore, John Hopkins University. 
Capítulo VII

\section{Recursos naturales y crecimiento sostenible: lecciones aprendidas del período de auge de precios ${ }^{1}$}

José María Fanelli

Entre 2003 y mediados de 2011, se aceleró la tasa de crecimiento del ingreso por habitante en los países ricos en recursos naturales no renovables, en consonancia con un incremento en los términos de intercambio. Sin embargo, ese crecimiento no se mantuvo cuando los precios descendieron.

En este trabajo se analizan los vínculos entre los recursos naturales no renovables -en particular, los recursos mineros y los hidrocarburosy la macroeconomía, con el propósito de determinar posibles maneras para traducir los períodos de bonanza en crecimiento sostenido. El trabajo se divide en dos partes. En la primera se recurre a la literatura sobre recursos naturales, macroeconomía y crecimiento para definir cuatro características distintivas de los primeros y, en función de esos ejes, analizar comparativamente la experiencia de tres países ricos en recursos no renovables - Chile, Colombia y el Perú - durante el citado período de bonanza.

Esos ejes son necesarios para organizar el análisis debido a que los períodos de bonanza operan macroeconómicamente a través de varios canales, que dependen tanto de la estructura económica como del marco

El autor agradece los valiosos comentarios de Ricardo J. Sánchez y el equipo de la Unidad de Recursos Naturales y Energía de la División de Recursos Naturales e Infraestructura de la Comisión Económica para América Latina y el Caribe (CEPAL). Asimismo, agradece la colaboración de Juan Pablo Jiménez e Ignacio Ruelas en lo referido a la información fiscal. 
regulatorio y de políticas. Al respecto, el período de bonanza seleccionado va de 2003 a 2013, porque puede considerarse que fue a partir de este último año que la disminución de los precios resultó más evidente. En la segunda parte, y a modo de conclusión, se discuten las implicaciones de política sobre la base de los hechos estilizados y definidos en la primera sección de este capítulo.

\section{A. Las características particulares de los recursos naturales, la macroeconomía y la experiencia de tres países latinoamericanos}

Si bien hasta ahora no se ha desarrollado un modelo económico que integre todos los aspectos del vínculo entre los recursos naturales y el crecimiento, existen aportes en la literatura que son útiles para determinar la manera en que las características distintivas de dichos recursos inciden en ese vínculo. A continuación, se hace una breve referencia a esa literatura para luego definir las características distintivas de los recursos naturales no renovables. De hecho, el análisis del vínculo entre los recursos naturales y la estructura económica tiene una larga tradición en América Latina, concentrada en el problema de la falta de diversificación productiva y en el hecho de que las explotaciones intensivas en capital pueden generar desigualdad (Prebisch, 1986). Al tener una función de producción intensiva en capital, la participación de los beneficios en el valor agregado es alta y, si bien la explotación de recursos naturales genera empleos con salarios altos, la cantidad de puestos de trabajo suele ser baja y de duración acotada, pues depende de las reservas existentes. Estos aspectos limitan en gran medida la contribución de los recursos naturales a la solución de problemas de dualidad estructural, como la informalidad laboral.

Recientemente, la función de los recursos naturales en el crecimiento se ha abordado en la literatura sobre la denominada "maldición de los recursos naturales". Sachs y Warner (1995) hallaron que los países ricos en recursos naturales crecieron menos que el resto entre 1970 y 1990, aunque posteriormente se introdujeron controles más sofisticados que cuestionaron este hallazgo (Frankel, 2010; Van der Ploeg, 2011). Los canales a través de los cuales operaría la maldición son la enfermedad holandesa, la dificultad para hacer frente a la volatilidad de las rentas y las debilidades institucionales y de las políticas aplicadas (Collier y Goderis, 2007; Frankel, 2010).

Debido a que los recursos naturales se agotan, hay que respetar restricciones en materia de extracción, ahorro e inversión, de forma de convertir las reservas de recursos naturales en capital reproducible, ya sea físico, humano o financiero (Hartwick, 1977; Krautkraemer, 1998; 
Venables, 2016; Hamilton, 2008; Collier y otros, 2009, y el capítulo XIII de este libro). En estos trabajos se diferencia la estrategia de inversión en función del grado de desarrollo del país y de su capacidad de gestión de la inversión pública. No obstante, los modelos de acumulación utilizados son agregados y dejan poco margen para analizar el cambio estructural y la falta de diversificación del comercio, que pueden conducir a la trampa de los ingresos medios (Eichengreen, 2011; Lin, 2012; Macmillan y Rodrik, 2011).

Un aspecto muy relacionado es la distribución de las rentas entre capital productivo, fondos diseñados con fines anticíclicos y de ahorro prudencial y fondos de equidad intergeneracional y de financiamiento de la seguridad social (FMI, 2012a y b). Cuando los países deben seguir estrategias de autoseguro mediante acumulación de reservas o fondos, se profundiza el problema de que los países en desarrollo invierten en activos seguros mientras los desarrollados - en particular los Estados Unidoslo hacen en activos de riesgo. Esto tiene un costo por las diferencias de rendimiento (Gourinchas y Rey, 2013; Fanelli, 2015). Estos temas fueron muy relevantes durante el período de bonanza latinoamericano.

Las restricciones de equidad intergeneracional y los efectos ambientales son fundamentales para promover la compatibilidad del crecimiento con el desarrollo sostenible. Algunos autores aportaron la visión de riqueza amplia, que incluye la riqueza natural, y afirmaron que la explotación de los recursos naturales puede generar externalidades que deberían considerarse al calcular el valor que la renta agrega al ingreso (Hamilton y Hassan, 2006; Smulders, Toman y Withagen, 2014). De esta forma, las consideraciones ambientales llevan a soluciones diferentes para los conflictos entre objetivos de crecimiento, combate a la pobreza y justicia intergeneracional en el uso de la riqueza natural (Dasgupta, 2009; Arrow y otros, 2004).

Por último, están los trabajos sobre la fiscalidad de los países ricos en recursos naturales en los que se analizan temas con consecuencias directas en el crecimiento, como la estructura tributaria, la asignación de recursos a los gobiernos subnacionales, las reglas fiscales y la sostenibilidad de la deuda pública (FMI, 2009; 2012a, Brosio y Jiménez, 2015; Jiménez y Tromben, 2006). Los cambios fiscales modifican los incentivos para el uso del capital natural y pueden redundar en daños a los ecosistemas. Por ejemplo, durante los períodos de bonanza, en los países con recursos hidrocarburíferos suele haber presiones para implementar subsidios al consumo de energía que dañan el ambiente (Fanelli, Jiménez y López Azcúnaga, 2015). De esta forma, sobre la base de cuatro características distintivas que surgen de la literatura analizada, a continuación se aborda la experiencia de Chile, Colombia y el Perú. 


\section{Dotación y agotamiento de recursos}

La significación económica de los recursos naturales depende del peso relativo de la dotación con respecto a otros factores de la economía y de la relación entre ritmo de consumo y nuevos descubrimientos. El Fondo Monetario Internacional (FMI) clasifica los países en fiscalmente dependientes o no dependientes de los recursos naturales en función del número de años de reservas y la participación de las rentas del sector en la recaudación total (Baunsgaard y otros, 2012). El desafío para sostener el crecimiento una vez agotados los recursos es transformarlos en capital reproducible físico, humano o en fondos en el exterior (Hamilton, 2008). La evaluación se dificulta debido a las fallas en los mercados financieros. Por una parte, es usual que la tasa de rentabilidad de los proyectos locales - particularmente en infraestructurasupere la tasa de rentabilidad de un fondo soberano y, por otra, es difícil tener la certeza del rendimiento del capital humano en presencia de dualidad estructural (McMillan y Rodrik, 2011).

Según el Banco Mundial (2011), durante el período de bonanza examinado la dotación de riqueza natural (recursos renovables y no renovables) ascendía a 18.870 dólares per cápita en Chile, 7.614 dólares per cápita en Colombia y 5.818 dólares per cápita en el Perú. La dotación de Chile es superior al promedio de los países de ingreso medio-alto y de América Latina que son, respectivamente, de 10.750 y 10.523 dólares per cápita. No obstante, la relación con el producto interno bruto (PIB) es similar en los tres países: 2,4 en Chile, 2,1 en el Perú y 2,2 en Colombia. La duración de las reservas es significativa solo en el Perú y Chile, donde corresponde a 35 y 27,3 años, respectivamente (Perry y Olivera 2012).

El ritmo de extracción y transformación de los recursos naturales da lugar a problemas complejos que aún no tienen solución. Hotelling (1931) planteó una regla según la cual los recursos no deben extraerse si la valorización esperada supera la tasa de interés, pero se considera poco aplicable (Krautkraemer, 1998). Si bien no hay consenso acerca de la regla que debería seguirse, el criterio más utilizado de equidad intergeneracional es usar los recursos asegurando que se deje a las generaciones futuras al menos la misma cantidad de riqueza total per cápita recibida, que permitiría mantener el nivel de actividad (Hartwick, 1977; Hamilton, 2008, y el capítulo XIII de este libro).

Con respecto a la manera de invertir los fondos generados en el período de bonanza, Collier y otros (2009) proponen un criterio que sesga la regla de valor presente a favor de los pobres de hoy y la inversión en infraestructura y en contra de la inversión en activos del exterior. Los autores argumentan que, en un mercado de capitales con fallas, la tasa de rentabilidad de la inversión interna supera el rendimiento en los mercados financieros del exterior. Por otra parte, Dasgupta (2009) afirma 
que la distribución óptima que surge de los cálculos del "planificador benevolente" puede ser incorrecta si el objetivo es mantener la riqueza para las generaciones futuras y los recursos naturales se agotan.

Siguiendo la línea de Hartwick (1977) y de otras elaboraciones posteriores (Hamilton, 2008), el Banco Mundial incluye en sus World Development Indicators cálculos anuales del ritmo de agotamiento de los recursos naturales, que constituyen la base para el cálculo del "ahorro ajustado" o "genuino". Este es el ahorro nacional neto del agotamiento de los recursos y de la depreciación del capital, pero incluye el gasto en educación para reflejar la acumulación de capital humano.

Según los cálculos del Banco Mundial, el coeficiente entre capital productivo y natural es similar y cercano a 1 en Chile y Colombia y a 0,8 en el Perú. Estos coeficientes son comparables con los de los países de ingreso medio-alto, muy superiores a los de los países pobres $(0,4)$ y marcadamente inferiores al promedio de los países de la Organización de Cooperación y Desarrollo Económicos (OCDE) (9). La distancia con respecto a estos últimos países es aún superior cuando se mide en función del capital intangible (capital humano e institucional). El peso del capital natural en estos países se debe principalmente al escaso desarrollo de otras actividades. Por otra parte, si no existen otros sectores altamente competitivos, se dificulta la reinversión de utilidades y puede generarse una cuña importante de carácter procíclico entre el ahorro interno y el ahorro nacional (Cavallo y Serebrisky, 2016). Durante el período de bonanza, el ritmo de consumo de recursos naturales en relación con el incremento del ingreso nacional aumentó considerablemente en los tres países examinados (véase el gráfico VII.1).

El gráfico VII.2 revela que, a pesar del incremento en el ahorro bruto durante el período de bonanza, las economías analizadas no lograron acumular activos externos en términos netos. Con respecto a la inversión, los altos requisitos de capital y tecnológicos crean un sesgo a favor de los inversionistas extranjeros con mayor acceso a tecnologías y financiamiento. Entre 2003 y 2013, la inversión extranjera representó en promedio un 3,6\% del PIB en Chile, un 3,9\% en Colombia y un 4,5\% en el Perú, con picos del $6 \%$ o el 7\% del PIB. En los tres casos la posición de inversión internacional neta se volvió cada vez más negativa durante el período de bonanza. Esto ocurrió de manera sistemática en Colombia y el Perú y tendió a revertirse luego de 2010 en Chile. Sin embargo, esto no significa que los residentes no hayan invertido en activos externos, en particular en el caso de Chile. Si bien la posición de inversión internacional neta es negativa, hay un incremento tanto del activo como del pasivo. El aumento de las posiciones brutas de los residentes en activos externos difícilmente se debió a la escasez de proyectos rentables, pues allí la inversión extranjera subió. 
Gráfico VII.1

Chile, Colombia y Perú: agotamiento de los recursos naturales, ahorro e inversión, 2000-2014

(En porcentajes)

A. Consumo de recursos

(como porcentaje del producto nacional bruto)

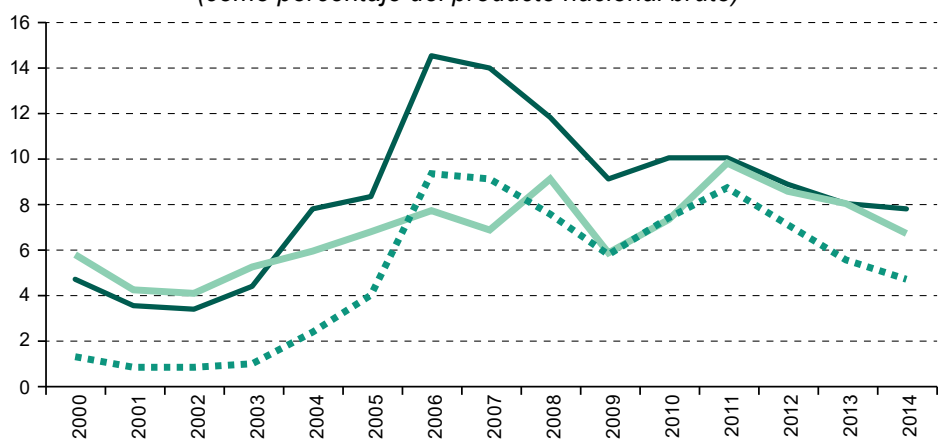

B. Ahorro bruto/PIB

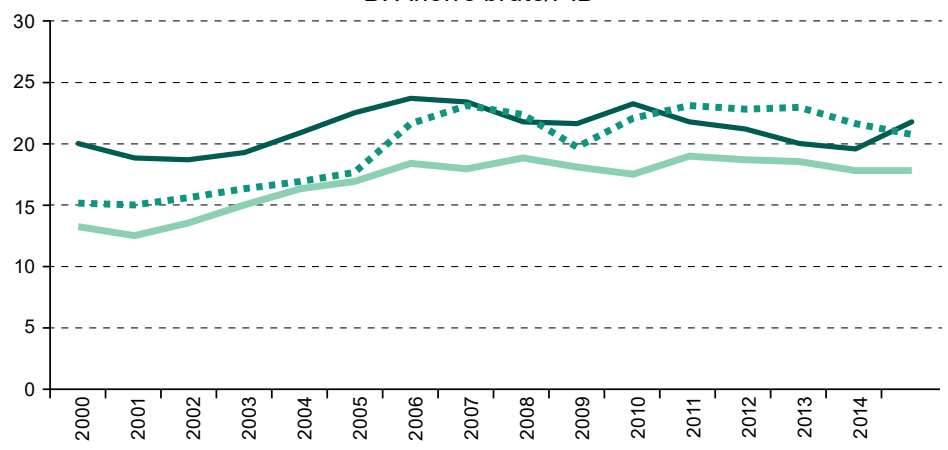

C. Formación bruta de capital/PIB

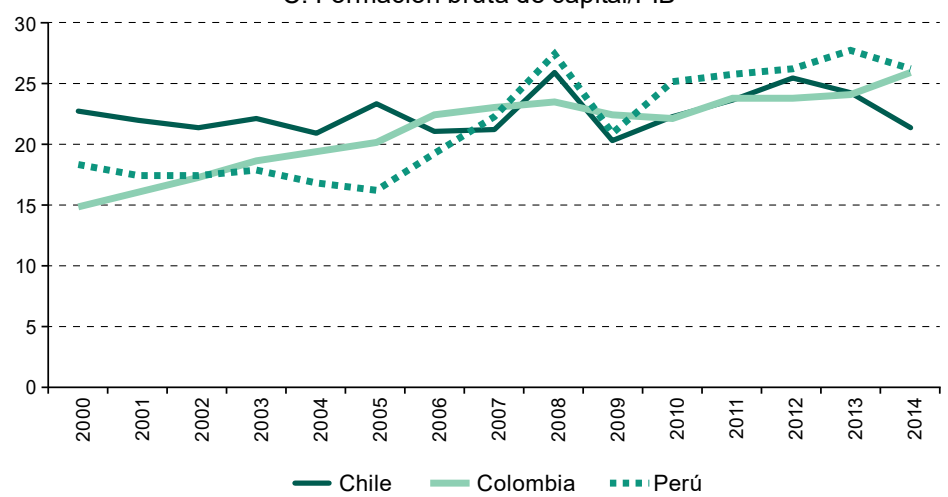

Fuente: Banco Mundial, World Development Indicators. 


\section{Gráfico VII.2}

Chile, Colombia y Perú: posición de inversión internacional neta e inversión extranjera directa neta

(En millones de dólares y porcentajes)

A. Chile

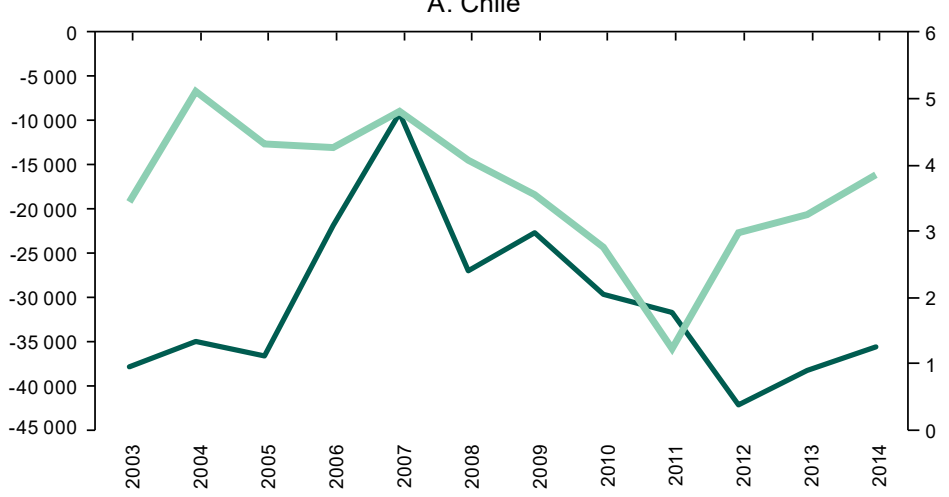

B. Colombia

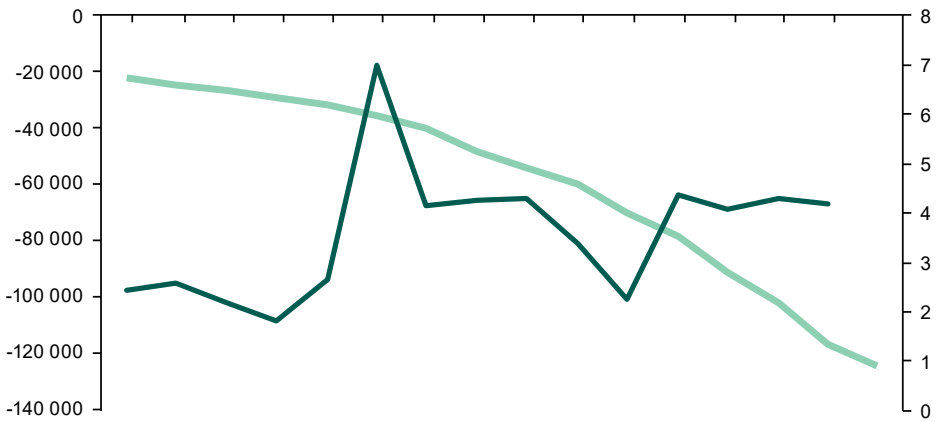

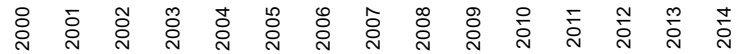

C. Perú

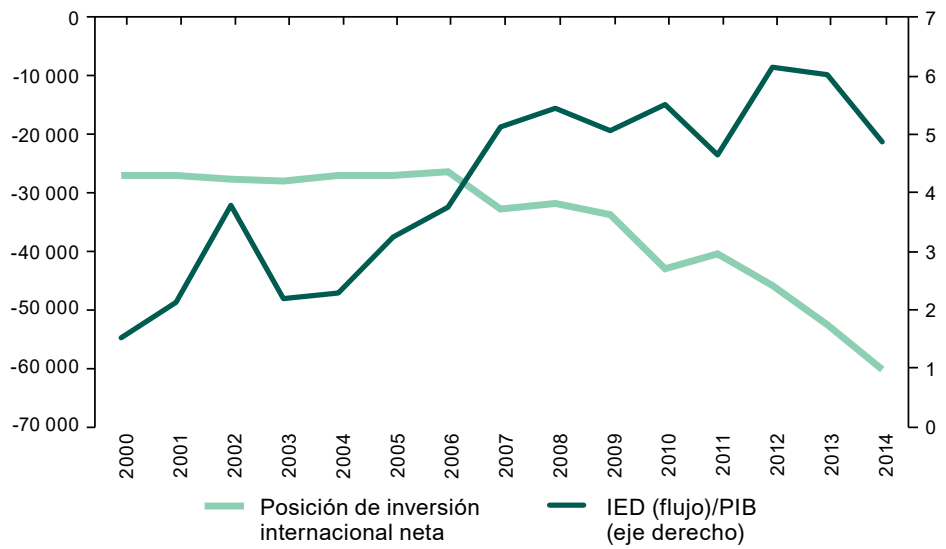

Fuente: Fondo Monetario Internacional (FMI) y Banco Interamericano de Desarrollo (BID), Latin Macro Watch. 
La evolución de las reservas de los bancos centrales explica parte de la inversión de los residentes en activos externos y sugiere la importancia de motivos macroeconómicos como la necesidad de intervenir en el mercado de cambios para estabilizar las fluctuaciones cambiarias y evitar el atraso del tipo de cambio real en el período de bonanza y la implementación de estrategias de autoseguro para inmunizarse contra reversiones súbitas de los flujos de capital. La relación entre las reservas y los pasivos brutos (incluida la inversión directa) se mantuvo relativamente constante en Chile y Colombia y aumentó significativamente en el Perú. De esta forma, el país que incrementaba las reservas se cubría ante la eventualidad de una interrupción súbita y, además, el inversionista de riesgo quedaba en parte cubierto ante depreciaciones bruscas con reducción del valor de los activos locales y el riesgo de iliquidez en divisas a la hora de repatriar el capital invertido en actividades del sector de los recursos naturales.

Estos hechos son relevantes desde el punto de vista demográfico, pues estos tres países (y la región) deben prepararse para el envejecimiento de la población y la forma de hacerlo es incrementar el ahorro nacional en la actualidad, cuando todavía se está cursando la etapa del bono demográfico. Debido a que existe una deuda neta en relación con el resto del mundo a pesar del período de bonanza, se deberán generar superávits de cuenta corriente en el futuro para honrar ese pasivo, una tarea que le tocará a las generaciones venideras.

\section{Generación de renta y apropiación}

El Banco Mundial calcula la renta como la diferencia entre el ingreso y los costos de explotación, donde incluye la renta normal de la inversión. La renta remunera un factor que no necesita acumularse y la opinión más extendida es que el Estado debe apropiarse de esa renta (Venables, 2016). La eficacia de los medios de apropiación es variable. La asimetría de información entre el Estado y quienes poseen los medios tecnológicos y financieros para la exploración y explotación pone al primero en desventaja a la hora de negociar precios, condiciones y contratos. No obstante, las empresas enfrentan el riesgo de captura (hold up) porque la mayor parte del capital queda hundido, es decir es inamovible del lugar donde se hizo la inversión al inicio del proyecto (FMI, 2009 y 2012a).

Según el Banco Mundial, en los tres países bajo estudio se obtuvieron niveles significativos de renta de los recursos naturales. Entre 2003 y 2013, Chile obtuvo un promedio de rentas del 17,6\% del PIB, Colombia del 9,8\% y el Perú del 10,3\%. En varios países de la región, la dotación abundante de petróleo o gas ha llevado frecuentemente a subsidiar su consumo, incentivando el gasto de las reservas de recursos naturales y agravando con 
ello las externalidades (di Bella y otros, 2015). Es probable que, debido a las externalidades, se sobreestimen las rentas de los recursos naturales en las cuentas nacionales y fiscales. La apropiación y las externalidades plantean el problema del diseño de la gobernanza de los recursos. La gama de instrumentos es amplia: regímenes de propiedad, licencias de exploración y explotación, contratos de explotación, regalías y participación en las ganancias, impuestos a las ganancias con tasas especiales y regulaciones (FMI, 2012a; Jiménez y Tromben, 2006). En el cuadro VII.1 se muestran sintéticamente las estructuras de gobernanza más significativas en materia de regalías, impuestos y propiedad pública en los tres países.

Con excepción de Chile, en la región predominan la propiedad estatal en el sector de los hidrocarburos y la propiedad privada en la minería. Estas estructuras de gobernanza dan lugar a costos de transacción que pueden ser muy distintos y en algunos casos superar los beneficios de la transacción debido a conflictos sobre la distribución de rentas, que pueden hacer de la renta una "maldición" en lugar de una "bendición" (Venables, 2016).

Los mecanismos de apropiación y las fallas de mercado inciden en el crecimiento. Un sistema financiero suficientemente desarrollado ayuda a canalizar el ahorro de los que se benefician de la renta hacia la inversión. $\mathrm{Si}$ el Estado - como propietario o recaudador- es el beneficiario, la capacidad para convertir los recursos naturales en capital reproducible pasa a depender de la calidad de la asignación del gasto público. La volatilidad de los precios de los recursos naturales se puede transmitir a la inversión si esta depende excesivamente de la apropiación de rentas de los recursos naturales y lo mismo puede ocurrir con los fondos para políticas de competitividad. Cuando las empresas multinacionales se apropian de parte de la renta, es importante lograr la reinversión de utilidades, ya sea en recursos naturales o en actividades diversificadas en las fases iniciales o ulteriores de la cadena de producción.

En virtud de la localización de los yacimientos se discute si la apropiación de las rentas debe ser local o nacional y en qué proporción. Como esto da lugar a pujas distributivas en países con gobiernos subnacionales relativamente fuertes, la gobernanza se vuelve más compleja (Brosio y Jiménez, 2015). Pueden desarrollarse síntomas de la "maldición de los recursos naturales" que afectan el crecimiento. Si la localización está muy concentrada es difícil aprovechar los efectos indirectos y se disipan las externalidades positivas que podría generar la infraestructura que se construye para la explotación y exportación de los recursos naturales. En el cuadro VII.2 se resumen los marcos legales que rigen la distribución y el uso de los ingresos fiscales en Chile, Colombia y el Perú. 


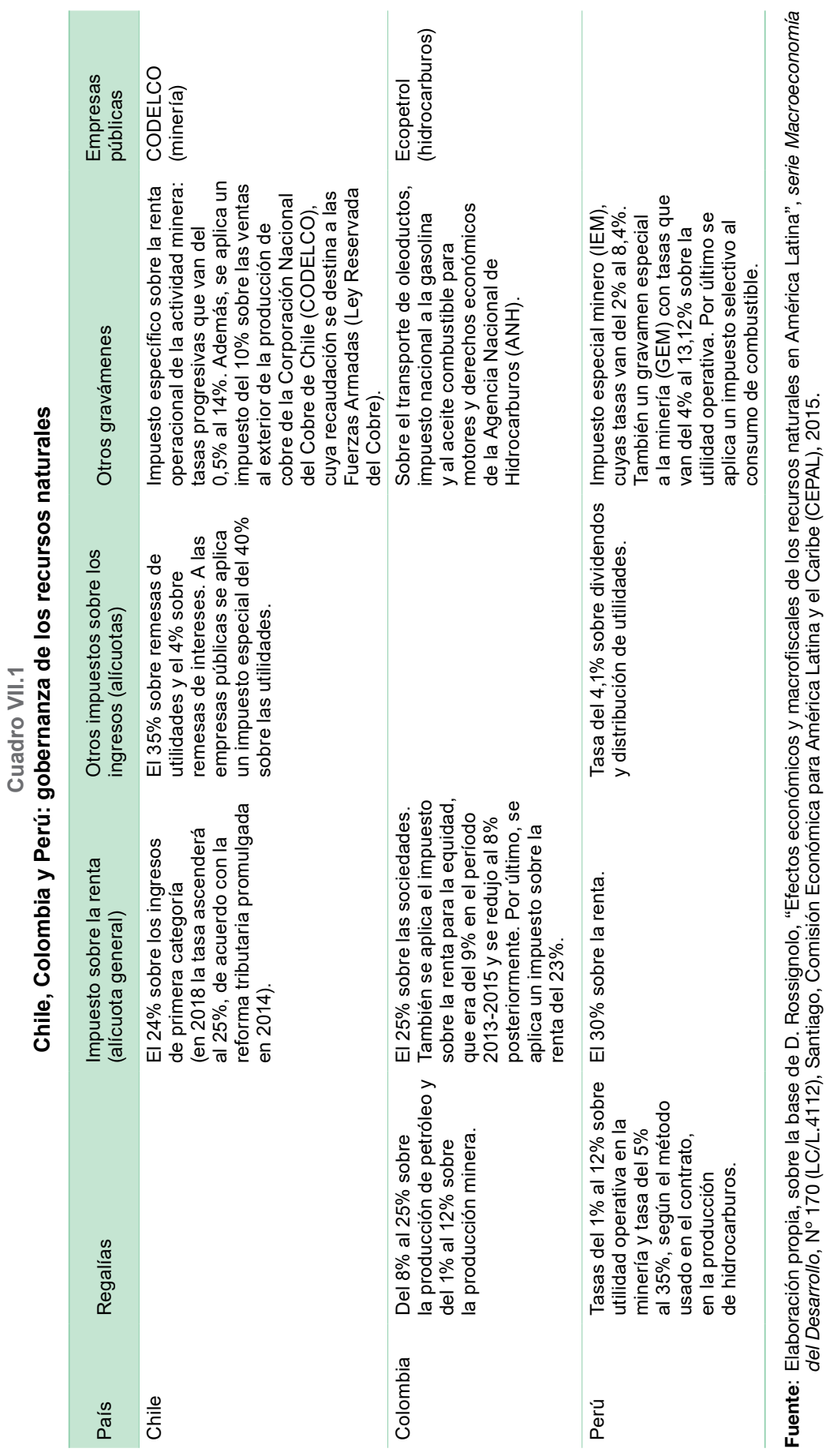




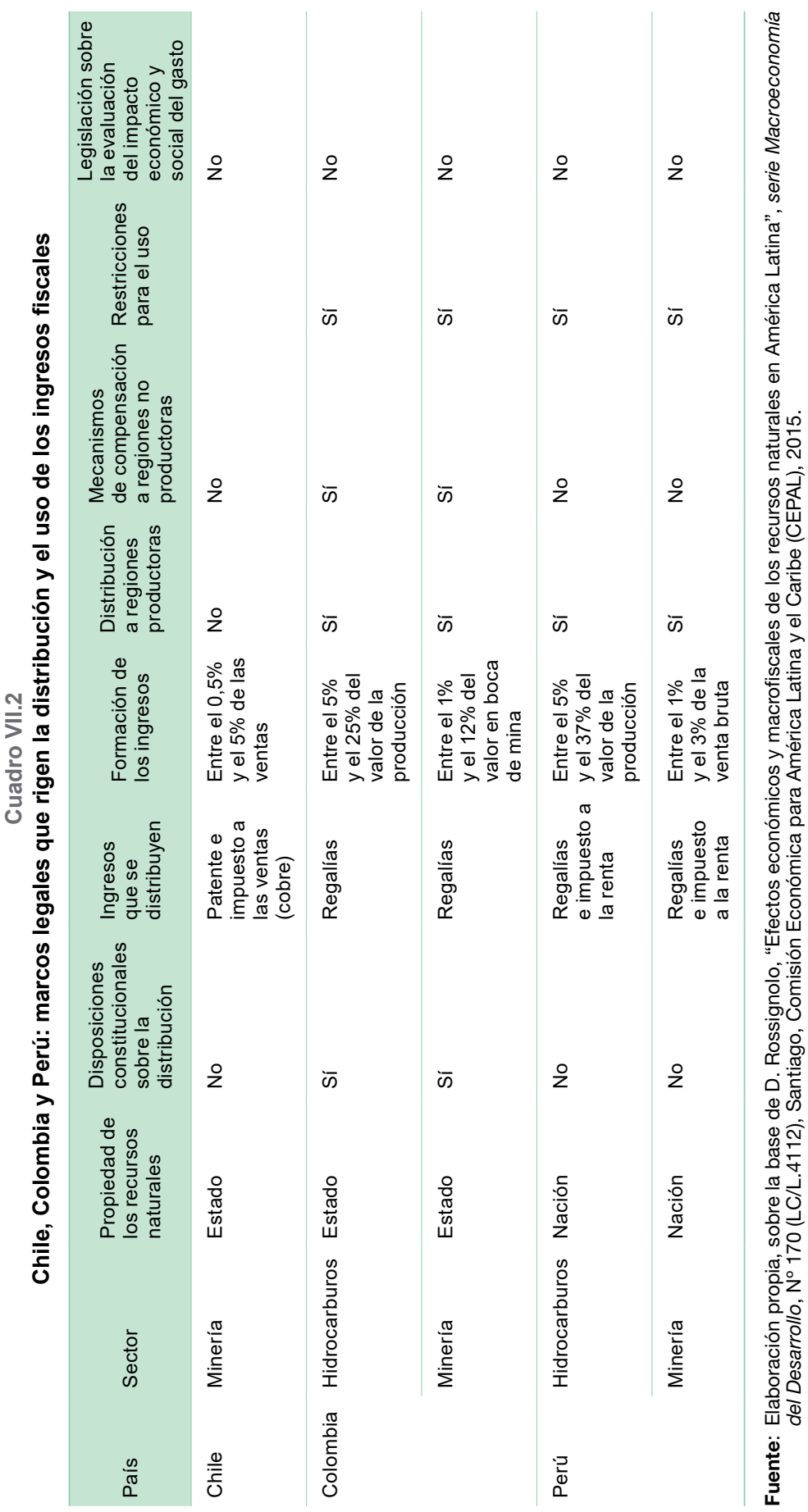


Como se muestra en el gráfico VII.3, la apropiación de rentas mediante la tributación se incrementó sustancialmente durante el período de bonanza. Los valores de la recaudación asociada con los recursos naturales no renovables en relación con el PIB aumentaron en forma considerable a partir de 2003 y se mantuvieron elevados durante el período de bonanza. Si bien disminuyeron en los últimos años, no volvieron a los valores observados previamente.

Gráfico VII.3

Chile, Colombia y Perú: evolución de la recaudación derivada de los recursos naturales, 2001-2014

(En porcentajes)

A. Chile

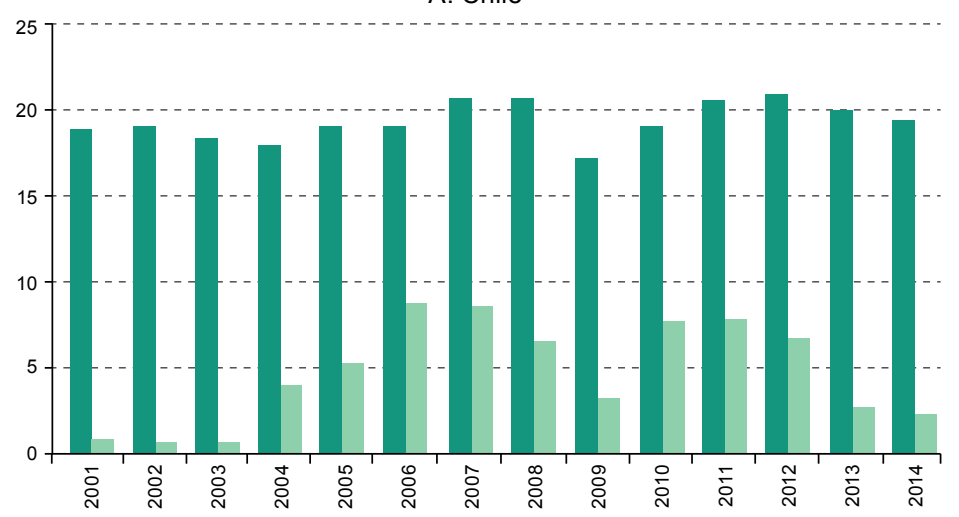

B. Colombia

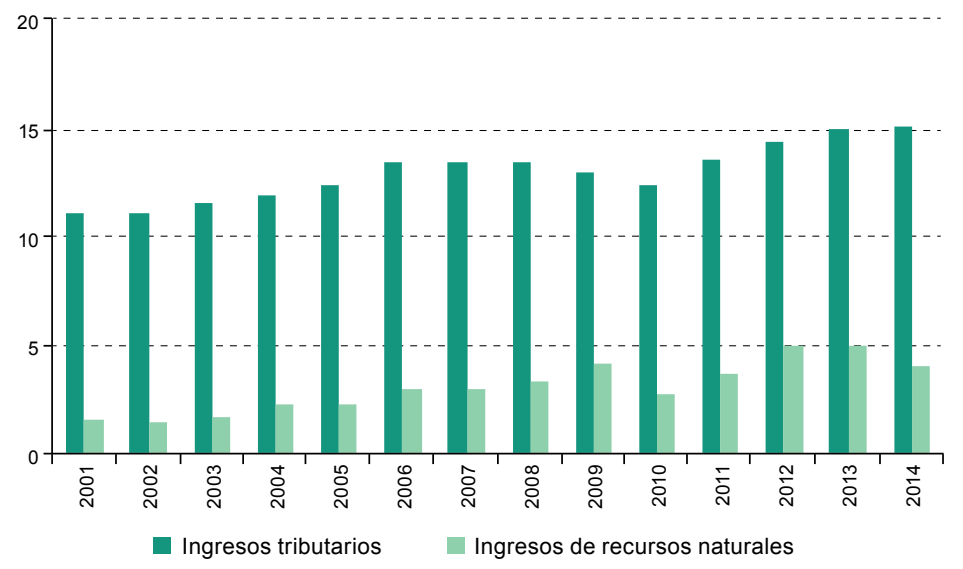


C. Perú

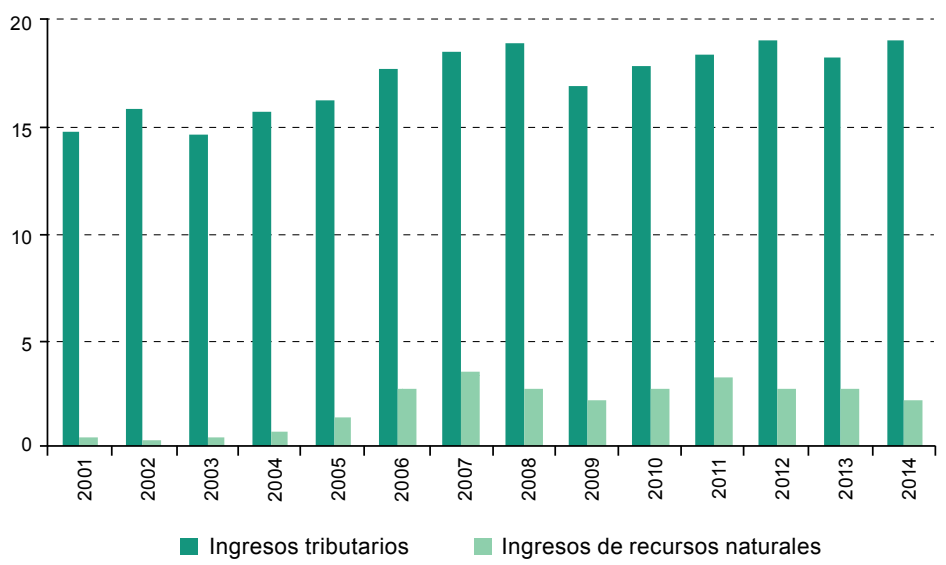

Fuente: Elaboración propia sobre la base de Organización de Cooperación y Desarrollo Económicos/ Comisión Económica para América Latina y el Caribe/Centro Interamericano de Administraciones Tributarias/Banco Interamericano de Desarrollo (OCDE/CEPAL/CIAT/BID), Estadísticas tributarias en América Latina y el Caribe 1990-2014, París, OECD Publishing, 2016.

La evolución de la relación entre la recaudación total y la derivada de los recursos naturales es diferente en cada país. Si bien Chile es donde más se incrementaron los ingresos por dichos recursos, la presión tributaria se mantuvo relativamente constante, tal vez porque ya era la más alta de los tres países. En Colombia y el Perú se incrementaron en forma similar al aumento de los impuestos sobre los recursos naturales. La generación de espacio fiscal pasó a ser más dependiente del sector. Según el FMI, los países se clasifican como dependientes de los recursos naturales cuando estos representan entre el $20 \%$ y el $25 \%$ de los ingresos fiscales totales (Baunsgaard y otros, 2012). Mientras Chile y Colombia superaron ese umbral durante el período de bonanza examinado, no ocurrió lo mismo en el caso del Perú.

Con respecto al aporte de los recursos naturales, en Chile la tributación corresponde en su totalidad a la minería, que en el Perú representa aproximadamente las tres cuartas partes (el resto corresponde a los hidrocarburos). Colombia es el único país donde los hidrocarburos dominan la tributación casi en su totalidad. Chile es el que tiene la cartera menos diversificada y esto lo hace más vulnerable a las variaciones en los precios del cobre, como se muestra en el gráfico VII.4. 
Gráfico VII.4

Chile, Colombia y Perú: participación de la minería y los hidrocarburos en los ingresos por recursos naturales

(En porcentajes)

A. Chile

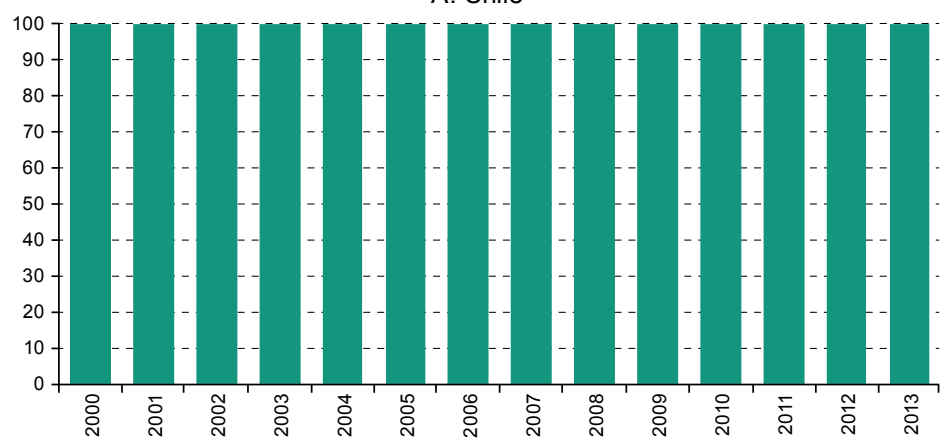

B. Colombia

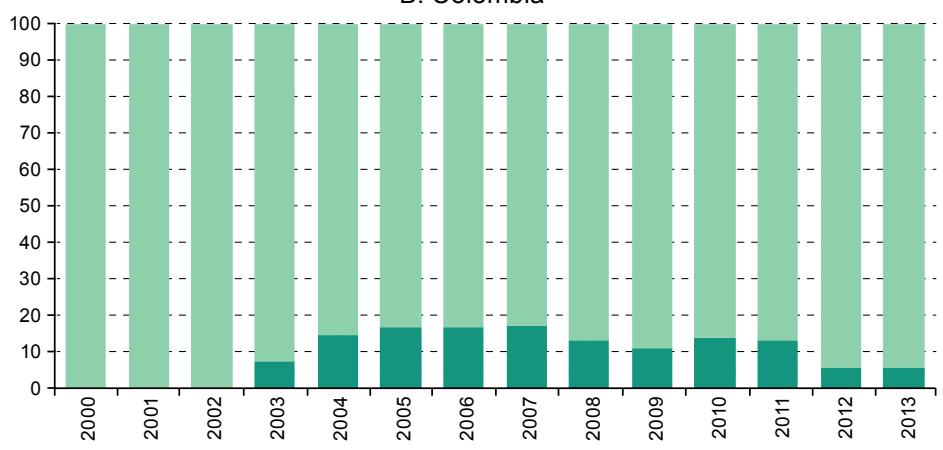

C. Perú

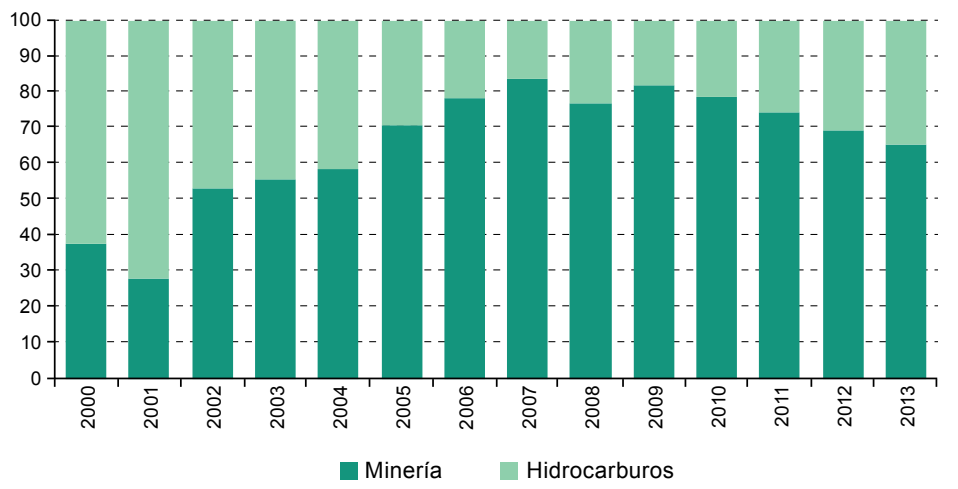

Fuente: Elaboración propia sobre la base de datos de CEPALSTAT y Organización de Cooperación y Desarrollo Económicos/Comisión Económica para América Latina y el Caribe/Centro Interamericano de Administraciones Tributarias/Banco Interamericano de Desarrollo (OCDE/CEPAL/CIAT/BID), Estadísticas tributarias en América Latina y el Caribe 1990-2014, París, OECD Publishing, 2016. 
Si bien en los tres países se incrementó el superávit primario durante el período de bonanza, , en Colombia no se pudo generar un superávit total relevante en ningún momento, algo que en cambio sí ocurrió en Chile y el Perú (véase el gráfico VII.5). Esto permitió generar fondos gubernamentales, como se puede apreciar en el cuadro VII.3 para el caso chileno.

\section{Gráfico VII.5}

Chile, Colombia y Perú: evolución del superávit primario y total, 1990-2014 (Como porcentaje del PIB)

A. Superávit primario

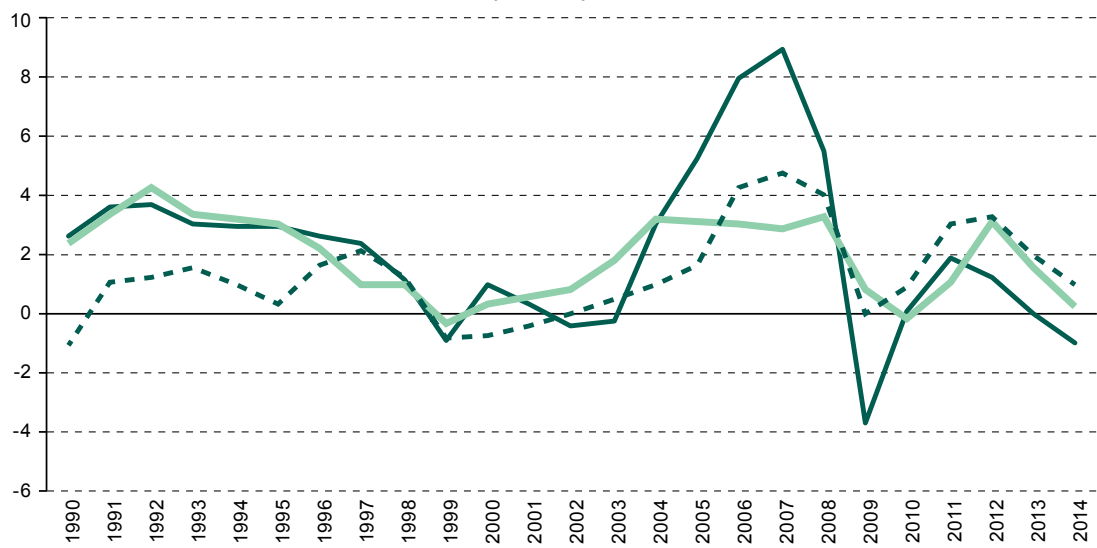

B. Superávit total

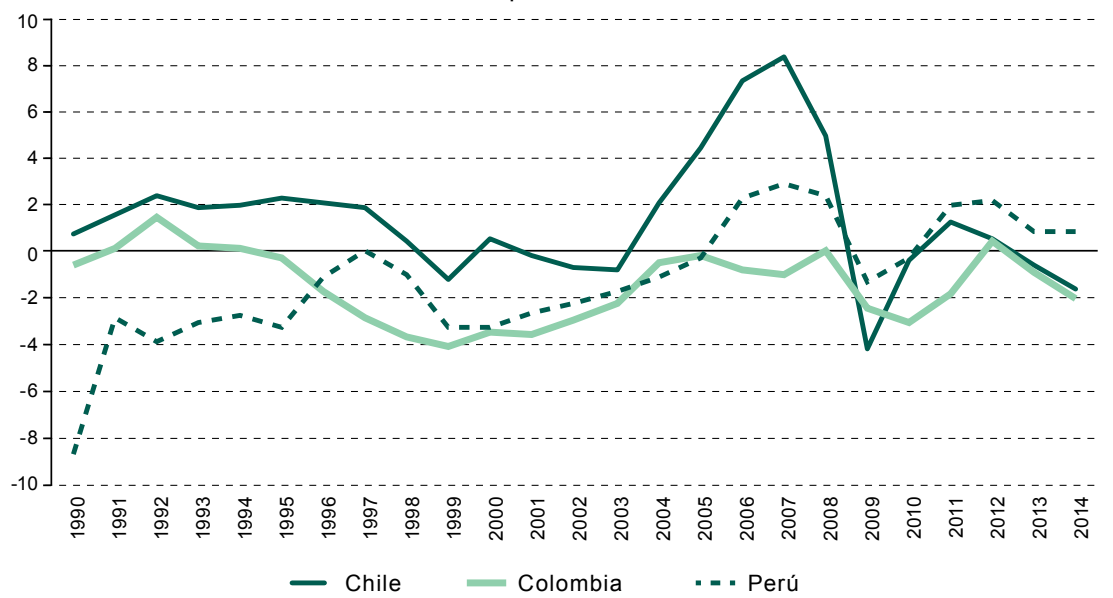

Fuente: Elaboración propia sobre la base de datos de CEPALSTAT. 


\section{Cuadro VII.3 \\ Chile: evolución y descomposición del valor de mercado del Fondo de Estabilización Económica y Social (FEES), 2007-2015}

(En millones de dólares)

\begin{tabular}{lrrrrrrrrr}
\hline & 2007 & 2008 & 2009 & 2010 & 2011 & 2012 & 2013 & 2014 & 2015 \\
\hline $\begin{array}{l}\text { Valor de mercado } \\
\text { inicial }\end{array}$ & 0 & 14033 & 20211 & 11284 & 12719 & 13156 & 14997 & 15419 & 14689 \\
\hline Aportes & 13100 & 5000 & 0 & 1362 & 0 & 1700 & 603 & 0 & 0 \\
\hline Retiros & 0,0 & 0,0 & $-9278,0$ & $-150,0$ & 0,0 & 0,0 & 0,0 & $-499,0$ & $-464,0$ \\
\hline $\begin{array}{l}\text { Interés devengado } \\
\text { Ganancias }\end{array}$ & 326,0 & 624,0 & 404,0 & 228,0 & 237,0 & 202,0 & 184,0 & 188,0 & 167,0 \\
$\begin{array}{l}\text { (pérdidas) } \\
\text { de capital }\end{array}$ & 607,0 & 556,0 & $-51,0$ & $-4,0$ & 201,0 & $-60,0$ & $-364,0$ & $-417,0$ & $-423,0$ \\
\hline $\begin{array}{l}\text { Costos de } \\
\text { administración, } \\
\text { custodia y otros }\end{array}$ & $-0,3$ & $-2,0$ & $-1,6$ & $-1,1$ & $-1,2$ & $-1,3$ & $-2,2$ & $-3,0$ & $-3,0$ \\
\hline $\begin{array}{l}\text { Ganancias } \\
\text { financieras netas }\end{array}$ & 933,0 & 1178,0 & 351,0 & 223,0 & 437,0 & 141,0 & $-182,0$ & & 13966,0 \\
\hline $\begin{array}{l}\text { Valor de mercado } \\
\text { final }\end{array}$ & 14 & 965,7 & 21389,0 & 11635,4 & 12941,9 & 13592,8 & 15137,7 & 15235,8 & 14688,0 \\
\hline $\begin{array}{l}\text { Como porcentaje } \\
\text { del PIB }\end{array}$ & 8,1 & 11,3 & 6,6 & 5,8 & 5,2 & 5,6 & 5,6 & 5,7 & 5,8 \\
\hline
\end{tabular}

Fuente: Dirección de Presupuestos, Ministerio de Hacienda de Chile.

Además de invertir en el Fondo de Estabilización Económica y Social (FEES) con fines macroeconómicos, Chile invirtió en un fondo de pensiones (véase el cuadro VII.4) y, de esa forma, fue el único país donde se tuvo en cuenta la demografía. El fondo de estabilización peruano es el que registró un crecimiento más uniforme durante el período de bonanza (véase el cuadro VII.5).

\section{Cuadro VII.4}

Chile: evolución y descomposición del valor de mercado del Fondo de Reservas de Pensiones (FPR), 2006-2015

(En millones de dólares)

\begin{tabular}{|c|c|c|c|c|c|c|c|c|c|c|}
\hline & 2006 & 2007 & 2008 & 2009 & 2010 & 2011 & 2012 & 2013 & 2014 & 2015 \\
\hline Valor de mercado inicial & 0 & 605 & 1467 & 2507 & 3421 & 3837 & 4406 & 5883 & 7335 & 7944 \\
\hline Aportes & 605 & 736 & 909 & 837 & 337 & 443 & 1197 & 1377 & 499 & 464 \\
\hline Retiros & 0 & 0 & 0 & 0 & 0 & 0 & 0 & 0 & 0 & 0 \\
\hline Interés devengado & & 46 & 71 & 72 & 70 & 75 & 131 & 174 & 190 & 194 \\
\hline $\begin{array}{l}\text { Ganancias (pérdidas) } \\
\text { de capital }\end{array}$ & & 80 & 60 & 6 & 9 & 51 & 151 & -95 & -76 & -485 \\
\hline $\begin{array}{l}\text { Costos de administración, } \\
\text { custodia y otros }\end{array}$ & & 0.0 & -0.3 & -0.3 & -0.4 & -0.4 & -1.2 & -44.0 & -4.6 & -4.5 \\
\hline $\begin{array}{l}\text { Ganancias financieras } \\
\text { netas }\end{array}$ & 0 & 126 & 131 & 78 & 79 & 126 & 281 & 35 & & \\
\hline Valor de mercado final & 605 & 1467 & 2507 & 3421 & 3837 & 4406 & 5883 & 7295 & 7944 & 8112 \\
\hline Como porcentaje del PIB & 0,4 & 0,8 & 1,4 & 2,0 & 1,8 & 1,8 & 2,2 & 2,6 & 3,1 & 3,4 \\
\hline
\end{tabular}

Fuente: Dirección de Presupuestos, Ministerio de Hacienda de Chile. 


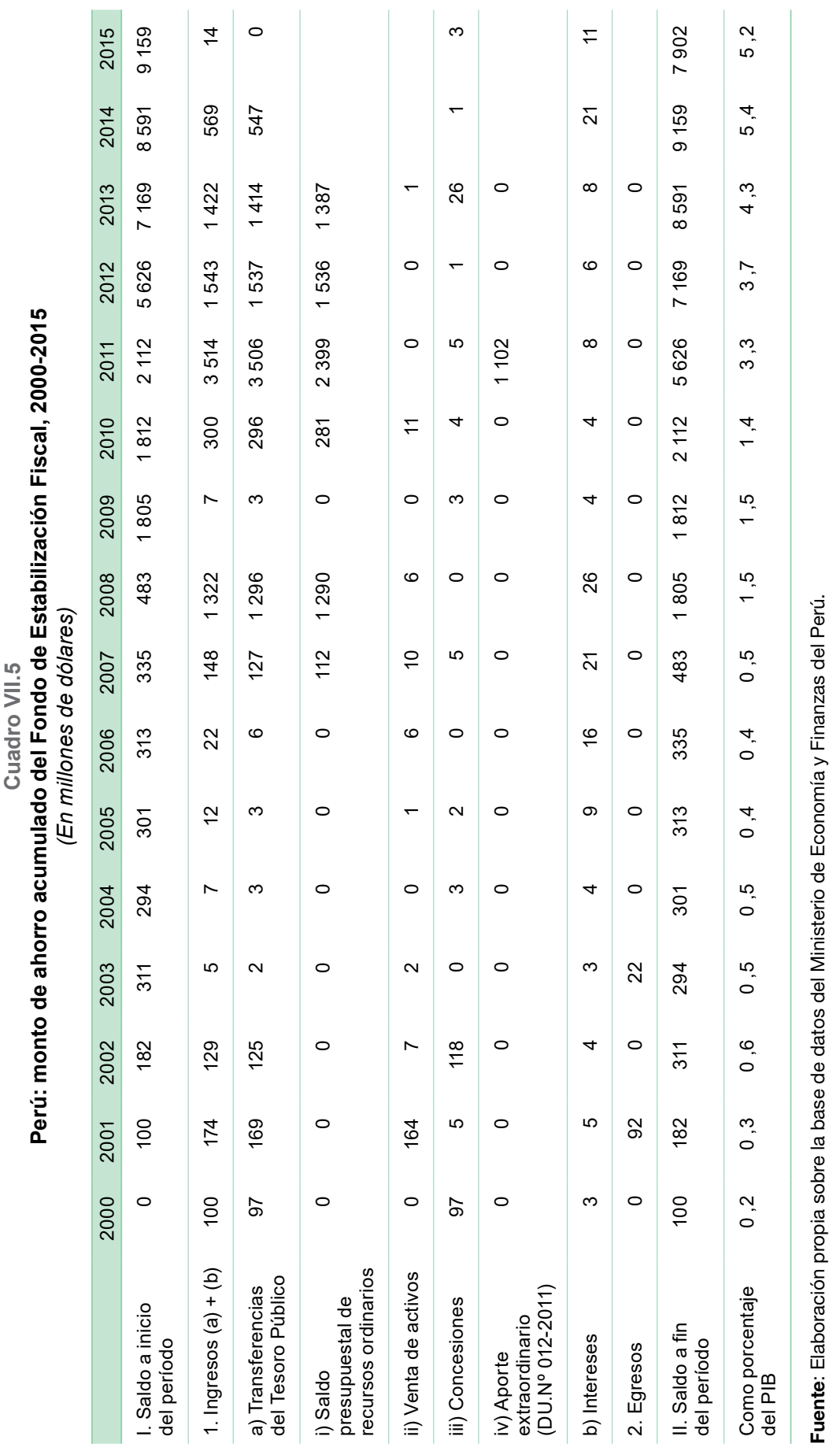


De los cuadros VII.3 y VII.5 surge que en Chile y el Perú se acumularon montos similares, de alrededor del $6 \%$, en relación con el PIB. Entre 2003 y 2008 el superávit primario promedio en Chile, Colombia y el Perú fue del 5\%, el 2,9\% y el 2,7\% del PIB, respectivamente. En las tres economías el superávit se convirtió abruptamente en déficit en 2009, luego de la crisis internacional (véase el gráfico VII.5). El superávit primario se recuperó posteriormente junto con el restablecimiento de los precios internacionales altos, para volver a ser negativo (Chile) o cercano a 0 (Colombia y el Perú) hasta una nueva reducción de los precios. Esto sugiere que el déficit primario ha seguido una trayectoria anticíclica, influida por las crisis internacionales y por el objetivo de mantener el nivel de actividad.

Para evaluar si se trata de superávits en línea con el objetivo central de convertir la renta derivada de los recursos naturales en activos reproducibles hay que observar la evolución de la inversión pública y el gasto en educación, pues el ahorro precautorio bajo la forma de superávits podría conseguirse a expensas de la acumulación de tales activos (véase el gráfico VII.6).

\section{Gráfico VII.6}

Chile, Colombia y Perú: evolución del gasto público en educación e inversión pública, 2000-2014

(En porcentajes del PIB)

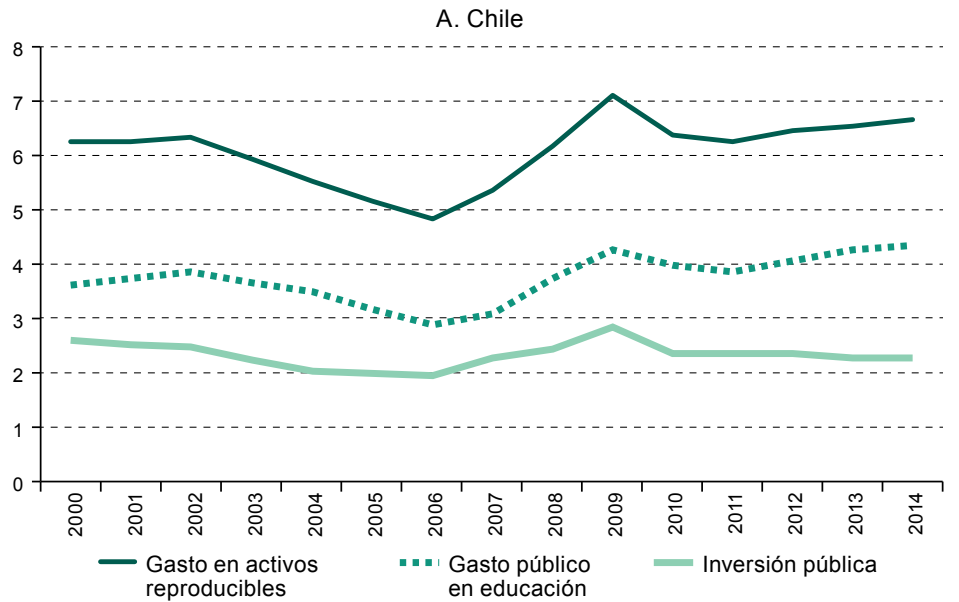


Gráfico VII.6 (conclusión)

\section{B. Colombia}

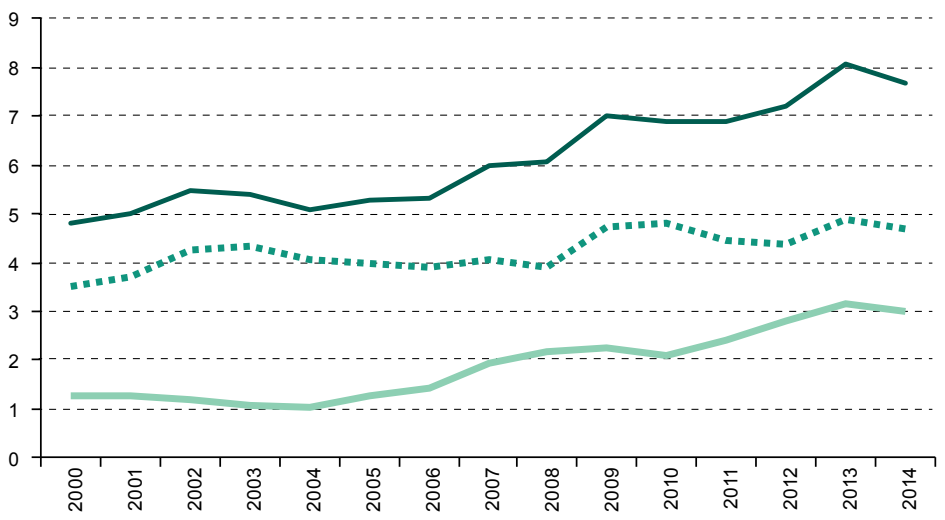

C. Perú

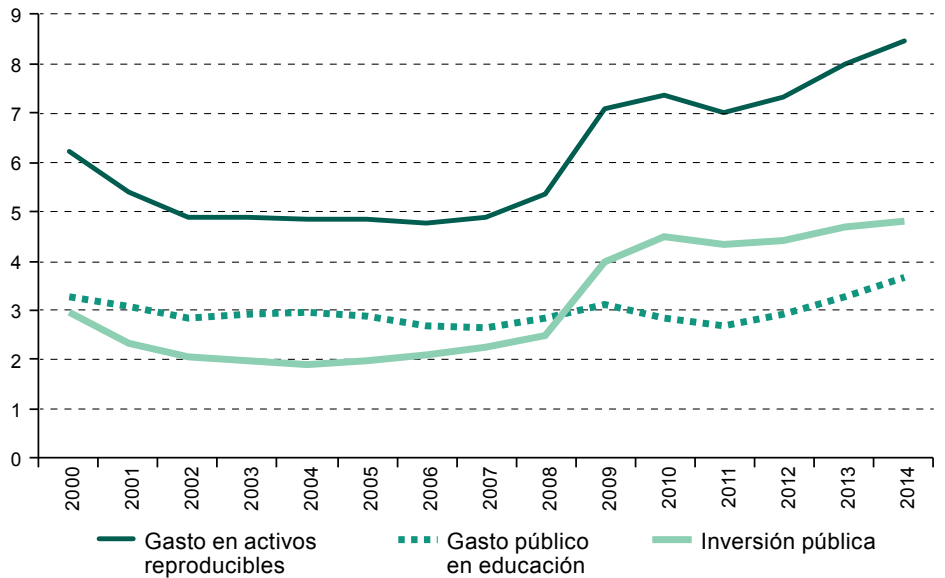

Fuente: Comisión Económica para América Latina y el Caribe (CEPAL).

La inversión pública estuvo lejos de lo requerido, sobre todo si se consideran las deficiencias de infraestructura (Perrotti y Sánchez, 2011). El gasto en educación muestra una evolución mixta. En Chile el coeficiente de inversión pública disminuyó durante el período de bonanza en relación con el quinquenio precedente, mientras el gasto en educación se mantuvo constante como proporción del producto, aunque muestra una tendencia creciente a partir de 2011. En Colombia ambos gastos se incrementaron y en el Perú aumentó el gasto en educación e 
inversión, pero solo luego de 2009, en consonancia con la reducción anticíclica del superávit primario. Esto sugiere que la evolución de estos rubros estuvo más influida por la coyuntura macroeconómica que por políticas de crecimiento orientadas a invertir las rentas de los recursos naturales en activos reproducibles.

\section{Recursos naturales y saldo neto de divisas}

Gran parte de los recursos naturales extraídos en la región se exporta. Debido a la falta de diversificación de sus economías, muchos países dependen fuertemente de los ingresos de divisas que derivan de la exportación de recursos naturales. Esto no ocurre en los países más industrializados, como el Brasil o México, cuya diversificación es algo mayor. En los tres países estudiados se observa una "primarización" de la estructura de exportaciones, como se muestra en el gráfico VII.7.

\section{Gráfico VII.7}

\section{Chile, Colombia y Perú: evolución de las exportaciones basadas en recursos naturales}

(Como porcentaje de las exportaciones totales)

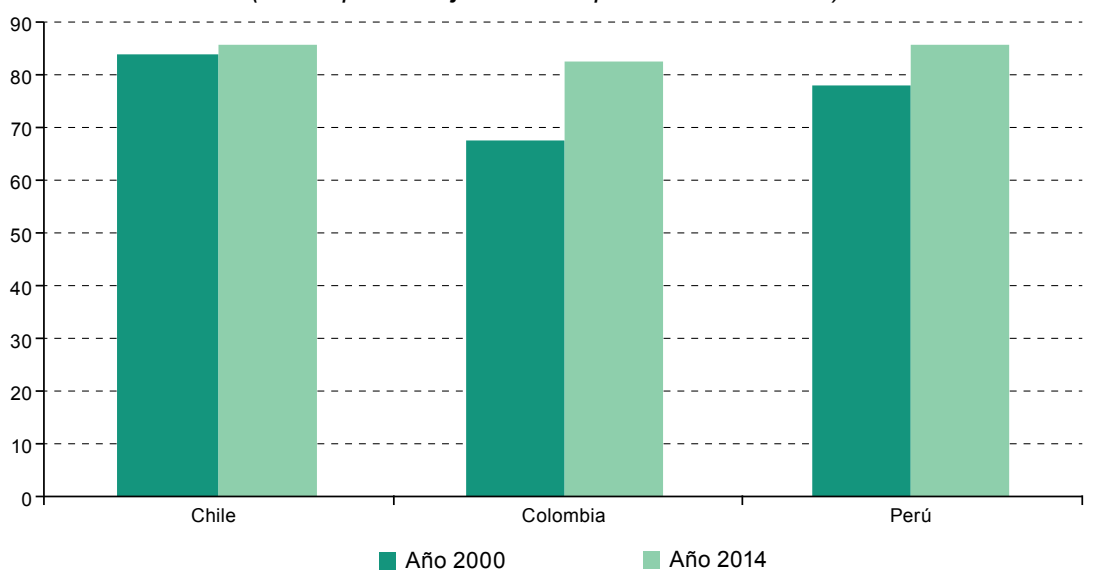

Fuente: Comisión Económica para América Latina y el Caribe (CEPAL).

Cuando los ingresos derivados de la exportación de recursos naturales se reducen, la capacidad de importar disminuye y restringe las actividades que dependen de insumos o bienes de capital importados. Para amortiguar los efectos a corto plazo de los cambios en la oferta de divisas, en varios países se adoptaron regímenes que combinan la flexibilidad del tipo de cambio con la acumulación de reservas, en un enfoque de metas de inflación adaptado a las peculiaridades de la región (Chang, 2007; Céspedes, Chang y Velasco, 2014). No obstante, las reservas 
pueden competir con la inversión o el pago de deudas en la asignación del ahorro.

En los períodos de bonanza, el exceso de oferta de divisas puede generar síntomas de enfermedad holandesa, con efectos dinámicos a largo plazo que se traducen en escasa diversificación de la estructura productiva e impiden el desarrollo de nuevas actividades de exportación (Rodrik, 2006). Esto puede crear las condiciones para la trampa de los ingresos medios (Eichengreen, 2011; Lin, 2012). Esta visión es coherente con la evolución de la productividad total de los factores durante el período de bonanza (véase el gráfico VII.8).

\section{Gráfico VII.8}

Chile, Colombia y Perú: evolución de la productividad total de los factores

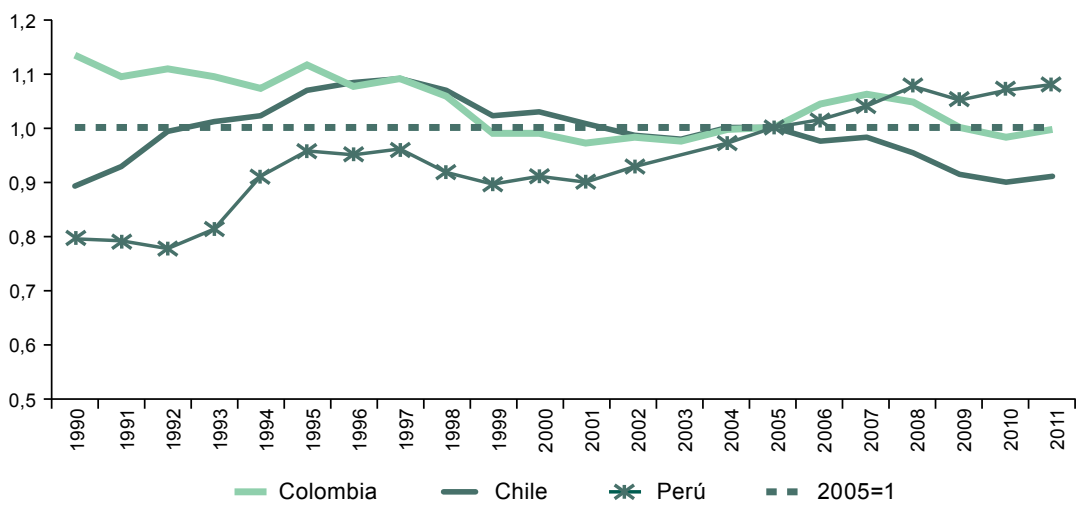

Fuente: Comisión Económica para América Latina y el Caribe (CEPAL), sobre la base de Universidad de Groningen, "Table 8", Penn World Table [base de datos en línea] https://www.rug.nl/ggdc/ productivity/pwt/.

Estos movimientos pueden amplificarse por los efectos de las variaciones de los precios internacionales en las existencias (véase el capítulo XIII de este libro). Cuando los precios internacionales suben, también lo hace el valor de las empresas que se encuentran en el sector transable y la deuda del gobierno parece más sostenible porque cobra más impuestos. Cuando los precios bajan ocurre lo contrario, acentuando el ciclo. Una forma de cubrirse de la escasez de divisas es ahorrar en el período de bonanza, pero - como se mencionó- no se observa ahorro neto en activos externos en los años examinados. Esto refleja que, en promedio, los saldos en cuenta corriente fueron negativos durante ese período. Este déficit no es independiente del hecho de que los extranjeros invierten en activos de riesgo y los residentes en activos seguros. La diferencia se refleja en los pagos a factores del exterior, que inciden negativamente en la cuenta corriente (véase el gráfico VII.9). 


\section{Gráfico VII.9}

Chile, Colombia y Perú: cuenta corriente y pago a factores del exterior (En millones de dólares)
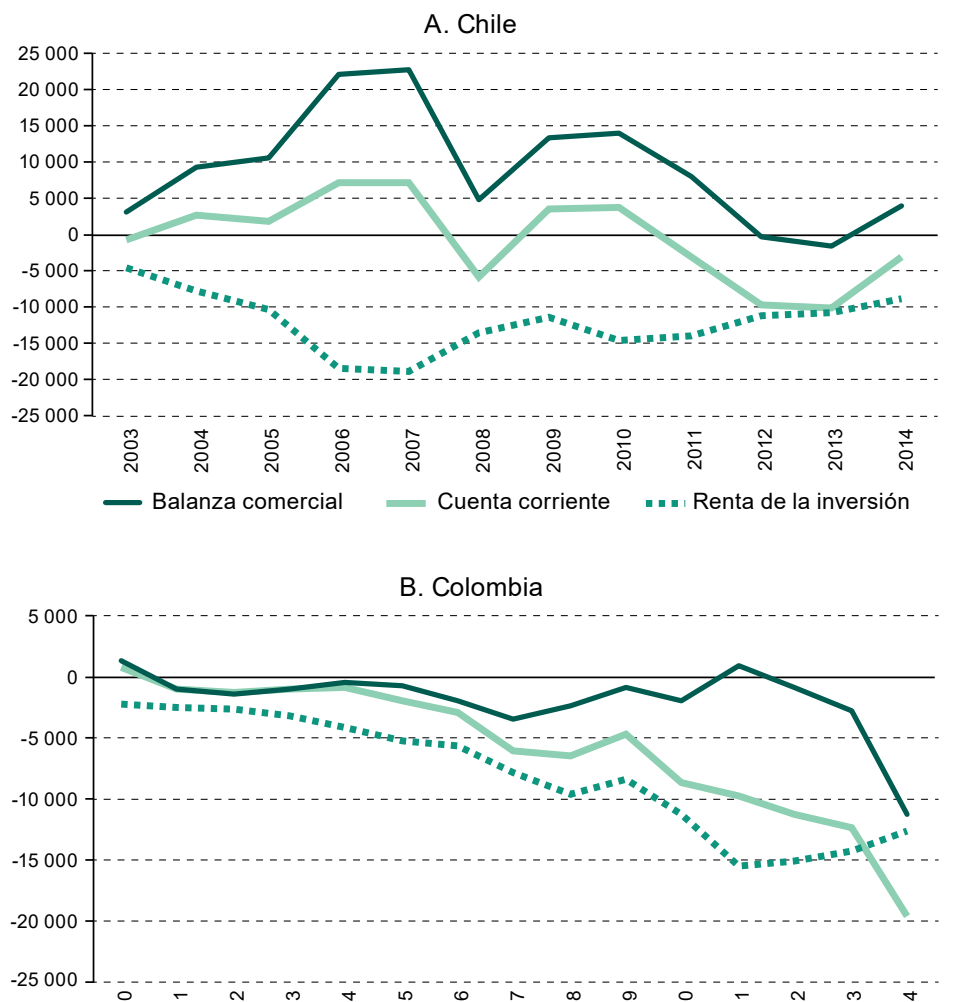

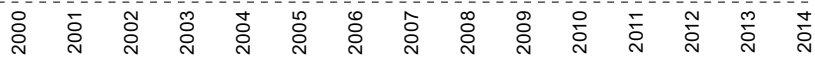

— Balanza comercial Cuenta corriente \#\#- Renta de factores

C. Perú

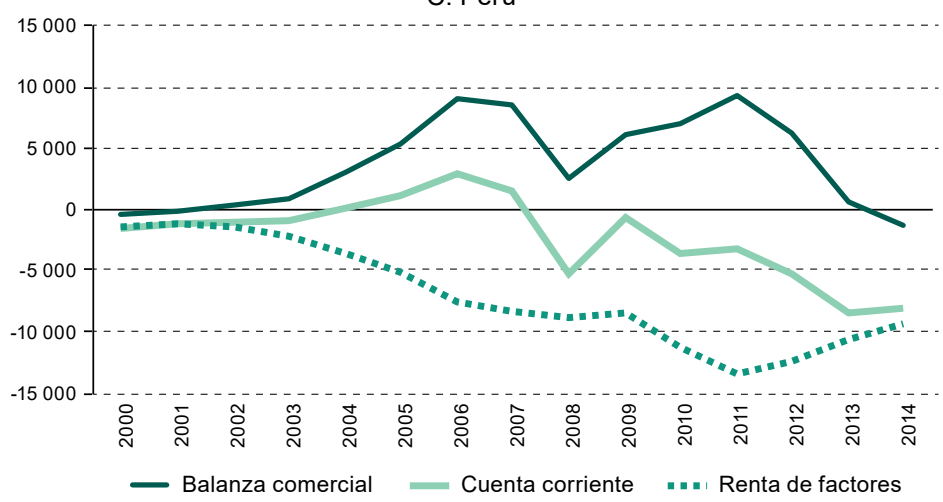

Fuente: Comisión Económica para América Latina y el Caribe (CEPAL). 
En promedio, los pagos a factores del exterior entre 2003 y 2013 fueron del 7,2\% del PIB en Chile, el 3,8\% en Colombia y el 6,5\% en el Perú. Estos pagos aumentaron durante el período de bonanza, de conformidad con la hipótesis de que las empresas extranjeras se apropiaron de parte de la renta. El gran peso de los pagos de dividendos al exterior hace que estos países deban destinar todo o casi todo el superávit comercial a financiarlos, haciendo que la capacidad de importar bienes de capital e intermedios para crecer dependa directamente del acceso al ahorro externo. Esto explica en parte por qué el crecimiento está tan expuesto a las crisis financieras y por qué el período de bonanza no se tradujo en un superávit de cuenta corriente y mejoras en la posición financiera externa.

\section{Volatilidad de la renta}

Los descubrimientos de recursos naturales son inciertos y los precios de los hidrocarburos y los minerales volátiles (Bilge y Ocampo, 2012; Acquatella, Bello y Berríos, 2016). En consecuencia, también las rentas son inciertas y volátiles. La amplitud de las fluctuaciones macroeconómicas inducidas por los recursos naturales puede incrementarse cuando los ingresos fiscales y la oferta neta de divisas dependen simultáneamente de dichos recursos. Ante una reducción de precios se deberán realizar los ajustes fiscales necesarios mientras se limita la actividad de las importaciones, de manera que la política fiscal resulta procíclica. La remisión de utilidades también puede acentuar el ciclo. Por ejemplo, en el período de bonanza, al aumento en el flujo de divisas debido a los precios se agregan la reinversión de utilidades y la entrada de capitales, que favorecen la apreciación del tipo de cambio y los síntomas de la enfermedad holandesa. En este contexto, es difícil distinguir entre crisis transitorias y permanentes para coordinar las políticas anticíclicas de transformación de los recursos naturales en activos reproducibles.

$\mathrm{Al}$ afectar la liquidez externa, las crisis de los recursos naturales tienen efectos monetarios sustanciales que son difíciles de gestionar solo con instrumentos monetarios. En varios países ricos en recursos de la región -incluidos los tres bajo análisis- se han establecido metas de inflación con flexibilidad cambiaria. Cuando los precios internacionales son altos, si el banco central no interviene, el tipo de cambio nominal se aprecia y es más fácil cumplir la meta de inflación, pero al costo de reducir la competitividad y arriesgarse a sufrir síntomas de enfermedad holandesa. En estas circunstancias, a menudo los bancos centrales de la región han intervenido en el mercado de cambios, acumulando y liberando reservas para suavizar los movimientos del tipo de cambio (Chang, 2007; Céspedes, Chang y Velasco, 2014). También han utilizado, como en el caso de Colombia, controles a la entrada de capitales (Hamann, Hofstetter y Urrutia, 2014). Más allá de la amenaza que la enfermedad holandesa representa para la diversificación productiva, 
intervenir para reducir la volatilidad macroeconómica también se justifica porque esta dificulta el crecimiento sostenido. Algunas investigaciones muestran que existe una relación negativa entre volatilidad agregada y crecimiento en la región (Catao, Fostel y Kapur, 2007; Fanelli, 2008). Además, de acuerdo con Cavalcanti, Mohaddes y Raissi (2011), la volatilidad de los términos de intercambio puede cancelar los beneficios de un período de bonanza.

En un contexto así, surgen problemas con facilidad. El banco central podría dejar que la tasa de interés se reduzca para que la moneda no se aprecie, pero esto, al incentivar el nivel de actividad, presionaría sobre la oferta de bienes no transables, erosionando la competitividad. Además, puede generar una expansión del crédito. Cuando los precios internacionales bajan, la moneda se deprecia, pero debido al efecto de traspaso la inflación puede tender a acelerarse por encima de la meta. Esto obligaría al banco central a incrementar la tasa de interés, lo cual resultaría procíclico. El caso del Brasil después del período de bonanza es probablemente el mejor ejemplo de este tipo de situación. Esto crea la necesidad de coordinar las políticas monetaria y fiscal para contar con más instrumentos.

A falta de mecanismos efectivos en la arquitectura financiera internacional, es posible que sea necesario acumular reservas para autoasegurarse y suavizar las fluctuaciones de liquidez externa, así como desarrollar reglas fiscales y fondos de estabilización para amortiguar las fluctuaciones en la recaudación vinculadas con los recursos naturales. Para evitar que el crédito interno y el sector privado se comporten procíclicamente y se presenten síntomas de la enfermedad holandesa, los fondos se deben invertir en activos seguros en el exterior. Esto tiene un costo de oportunidad por la diferencia con respecto a la inversión en activos productivos locales con mayor rendimiento. Las políticas fiscal y monetaria no deberían diseñarse e implementarse sin prestar atención a la necesidad de contar también con instrumentos para proteger la competitividad y el cambio estructural.

En el gráfico VII.10 se muestra la trayectoria del tipo de cambio real durante el período de bonanza. En los tres casos hubo una apreciación de las monedas con respecto al dólar, que superó sensiblemente la apreciación medida por el tipo de cambio multilateral. No obstante, la apreciación fue mucho menor en el Perú. La trayectoria del tipo de cambio presionó la inflación hacia abajo y creó la idea de que la inflación estaba bajo control con tasas bajas de interés. Sin embargo, la reducción del tipo de cambio y el fomento del gasto del sector privado mediante la expansión del crédito restó incentivos a la inversión en bienes transables. Al acabar el período de bonanza la depreciación debía ser más alta cuanto mayor la brecha entre la competitividad del sector transable de recursos naturales y otros sectores 
con posibilidad de devenir transables. La depreciación - mediante el efecto de traspaso- aceleró la tasa de inflación, dificultando el cumplimiento de las metas. Los bancos centrales aumentaron las tasas de interés para reducir la presión inflacionaria y ello acentuó el carácter procíclico del ajuste al disminuir la demanda agregada. El período posterior a la fase de bonanza configuró en los tres países un contexto de presiones recesivas.

\section{Gráfico VII.10}

Chile, Colombia y Perú: evolución del tipo de cambio real, 1995-2013

A. Tipo de cambio real bilateral con los Estados Unidos, 2003=100

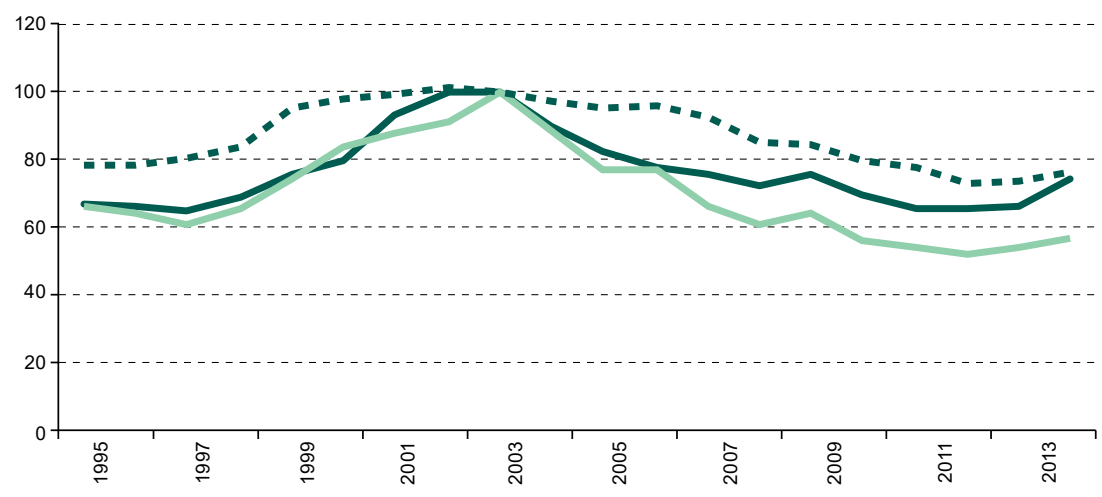

B. Tipo de cambio real multilateral, $2003=100$

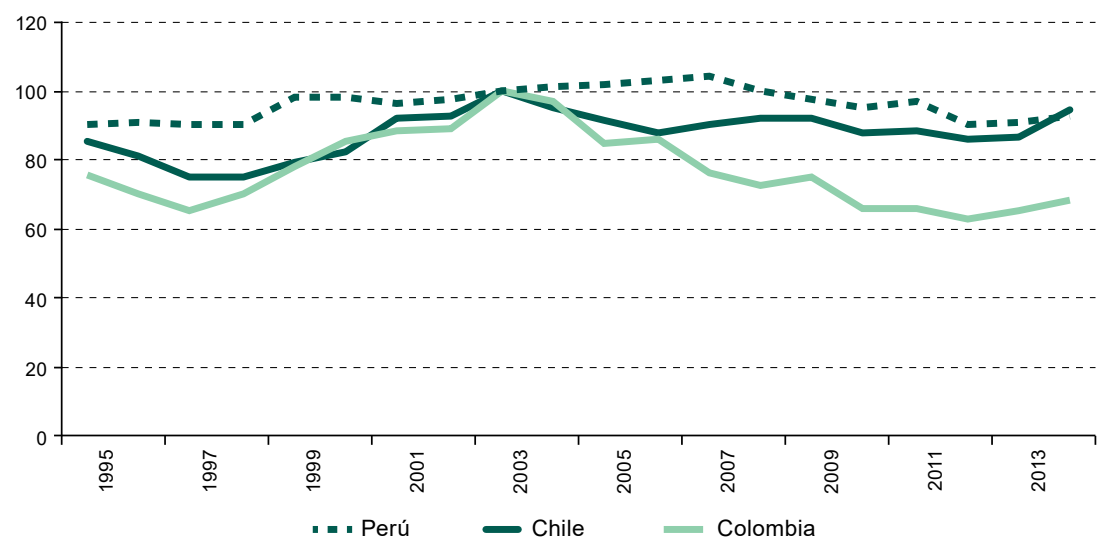

Fuente: Elaboración propia sobre la base de Banco Interamericano de Desarrollo (BID), Latin Macro Watch.

Cabe subrayar que el sector privado y el resto del mundo se podrían comportar de manera procíclica y neutralizar los esfuerzos del sector público. Una forma de constatarlo es observar la evolución de los superávits público, privado y del resto del mundo. Como la suma de esos tres superávits debe ser nula, en el gráfico VII.11 solo se representaron los dos primeros. 
Gráfico VII.11

Chile, Colombia y Perú: evolución de los superávits público y privado, 2000-2014 (En porcentajes del PIB)

A. Chile

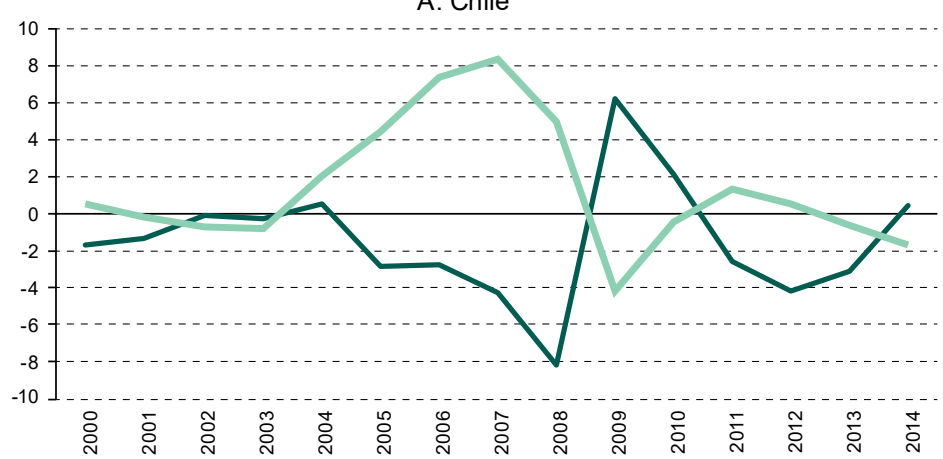

B. Colombia

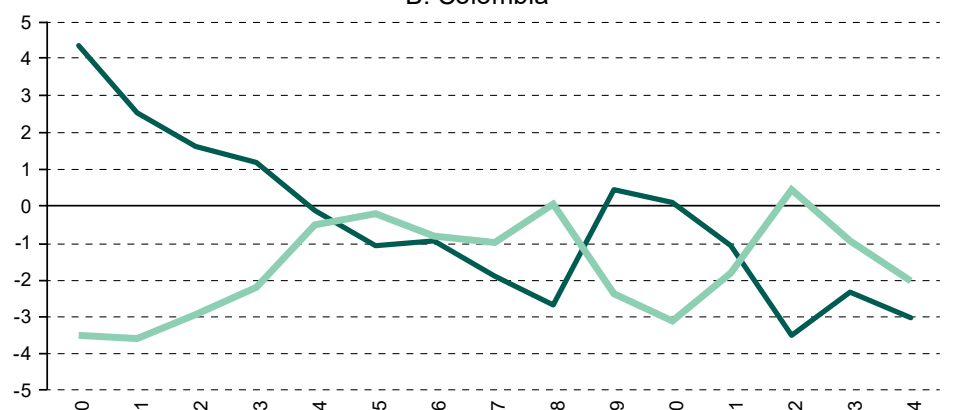

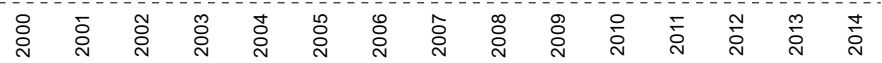

C. Perú

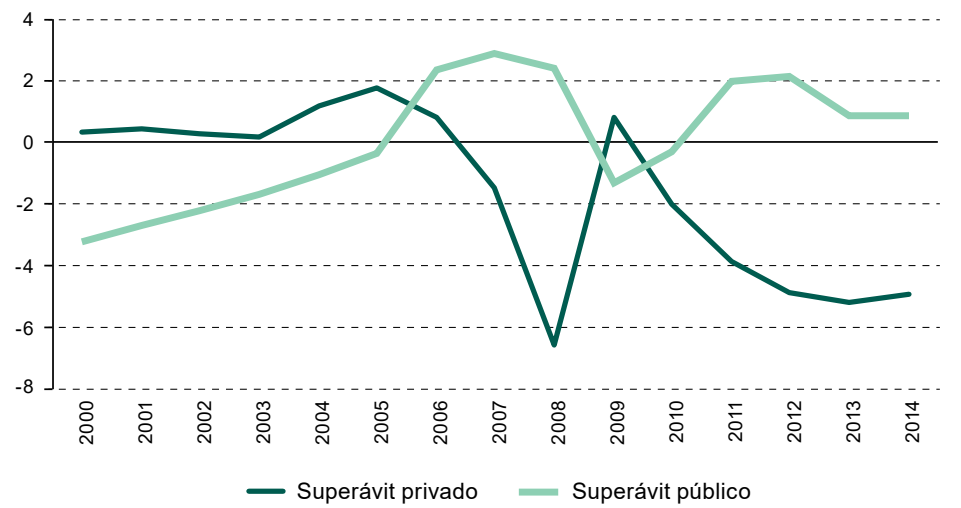

Fuente: Elaboración propia sobre la base de Banco Interamericano de Desarrollo (BID), Latin Macro Watch. 
En los tres países examinados, el superávit privado registró variaciones opuestas con respecto al público y el movimiento fue tan fuerte durante el período de bonanza que se produjo un déficit de cuenta corriente en el Perú y Chile, a pesar de los superávits de los respectivos Gobiernos en varios años. En estas condiciones, la inversión extranjera directa puede tener un efecto perjudicial en el ahorro. La generación actual ahorra menos porque el resto del mundo financia la inversión y las finanzas del Gobierno lucen sólidas gracias a la bonanza de los precios de los recursos naturales y los fondos del Estado en Chile y el Perú. Una vez que se revierte la crisis de precios, habrá que desandar el camino en circunstancias en que los ingresos del Gobierno se reducen. Este comportamiento acentúa la dinámica procíclica.

La volatilidad también induce inestabilidad en las reglas de juego y esto no es neutro para el crecimiento. En los períodos de precios bajos, las autoridades tratan de generar incentivos para la explotación de recursos naturales porque la disminución reduce simultáneamente los ingresos fiscales y de divisas. Cuando los precios suben -o hay un descubrimiento de dimensiones inesperadas - el Estado busca apropiarse de una porción mayor de la renta cambiando las reglas y, por ende, la gobernanza. Esto puede incluir el cambio de propiedad. Se genera así un vínculo de doble vía entre la inestabilidad de las reglas de juego y la explotación de los recursos naturales. Por una parte, la inestabilidad de las reglas de juego aumenta el riesgo empresarial —el problema de captura (hold up) ligado a los recursos naturales - pero, por otra, la inestabilidad de los precios puede dar lugar a la inestabilidad de las reglas por razones distributivas y de apropiación de rentas. Perry y Olivera (2012) ejemplifican de manera clara este punto para el caso colombiano.

Detrás de los intentos de aumentar la apropiación en el período de bonanza suele estar, también, la intención de hacer más inclusivo el crecimiento tratando de mejorar la distribución del ingreso y reducir la pobreza (Collier y otros, 2009; Van der Ploeg, 2011). En los tres países analizados se implementaron políticas de inclusión más ambiciosas en el período de bonanza (CEPAL, 2014). Un rasgo positivo es que esas políticas no impidieron que el ahorro aumentara en el Perú y Colombia y se mantuviera constante en Chile. Sin embargo, las tasas de ahorro fueron bajas para un período de bonanza y para sostener el crecimiento a tasas altas. Ello podría deberse a que se favoreció a los sectores con menor propensión al ahorro. Asimismo, la escasa asignación de recursos a la inversión pública afectó el crecimiento y la inclusión por falta de inversión en infraestructura (Perrotti y Sánchez, 2011; Serven y Calderón, 2004). 


\section{B. Implicaciones de políticas e institucionales para la gestión de los períodos de bonanza}

De la literatura surge que los dos objetivos centrales durante un período de bonanza deberían ser canalizar la renta hacia la inversión en capital reproducible (físico y humano) e incentivar un cambio estructural que reduzca la dualidad, impulse la productividad total de los factores y aumente la diversificación productiva y de las exportaciones ¿Qué lecciones surgen de la comparación entre Chile, Colombia y el Perú? Si bien las tres economías presentaban dotaciones diferentes de recursos naturales desde el punto de vista de la cantidad y la composición y niveles de riqueza disímiles, el período de bonanza tuvo efectos similares: aceleró el crecimiento. Sin embargo, también se detectaron diferencias. La economía peruana fue la que mejor aprovechó el período de bonanza, pues se logró estabilizar la economía y consolidar un nuevo régimen macroeconómico, dejando atrás una historia de inestabilidad. Chile ya era una economía estable desde el punto de vista macroeconómico en 2003, pero no logró retomar las altas tasas de crecimiento que había alcanzado en años anteriores a 1998. Colombia era también una economía estable y mejoró su tasa de crecimiento promedio en forma similar a Chile. Pero más allá de esto, hay dos rasgos negativos: el crecimiento se fue debilitando con la reversión de la crisis y el cambio estructural no fue significativo. De hecho, hubo una cierta primarización de las exportaciones que aumentó la exposición al riesgo de variaciones en los términos de intercambio. A modo de conclusión, a continuación se plantean los hechos estilizados establecidos y se extraen conclusiones de política sobre las medidas que podrían tomarse para aprovechar mejor las oportunidades.

- Ahorro. Hacia 2003, Chile tenía las tasas más elevadas de ahorro e inversión. Sin embargo, esas tasas no variaron mucho en el período de bonanza, algo que sí ocurrió en Colombia. Los movimientos del superávit primario se correlacionaron negativamente con el superávit público y el mayor ahorro público no se vio reflejado en el ahorro total.

El aumento del ahorro cuando los precios son altos debe tener prioridad. Hay que evitar que las políticas de asignación del gasto público y las políticas tributarias estén abiertas a presiones de intereses diversos durante el período de bonanza. A menudo, las políticas de subsidio financiadas con rentas destinadas a favorecer a los sectores menos pudientes reparten recursos a toda la población sin distinciones. En países como la Argentina o el Brasil se aumentó el gasto en el sistema de seguridad social por la expansión de la cobertura durante el período de bonanza, una medida que desincentiva el ahorro individual y debilita las finanzas públicas para la etapa de envejecimiento. Para mejorar la 
situación se puede invertir parte de la renta en fondos soberanos para abordar el problema del envejecimiento de la población, como en el caso chileno. Esto también concuerda con el criterio de preservar la riqueza natural para las generaciones venideras. El desarrollo financiero favorece el ahorro de los sectores privados que perciben rentas de los recursos naturales y ayuda a agregarlo para financiar proyectos de mayor escala.

La noción de ahorro genuino o ajustado no desempeñó un papel en el diseño de políticas ni se implementaron reformas fiscales ambientales, que desalentarían el consumo de recursos naturales favoreciendo el ahorro genuino. Si bien en la actualidad se está avanzando mediante impuestos al carbono, reducir los subsidios al uso de energía constituye un paso obvio. Los Gobiernos de la región también deberían desarrollar capacidades para contar con cuentas nacionales "verdes", que tengan en cuenta las externalidades y el agotamiento en el uso y la producción de recursos naturales.

- Inversión. La tasa de inversión no subió en consonancia con el aumento de los recursos. Fue insuficiente en actividades para diversificar las exportaciones y la inversión pública estuvo por debajo de lo necesario para cerrar la brecha de infraestructura existente.

Debido a las fallas de mercado no se puede confiar totalmente en sus señales. Como se mencionó, Collier y otros (2009) subrayan que el rendimiento de los proyectos nacionales podría superar la tasa internacional de un fondo soberano. Es necesario desarrollar instituciones dentro del Estado para evaluar en forma centralizada la manera en que se asignan los fondos aportados por el período de bonanza, con miras a optimizar el rendimiento social. Asimismo, para facilitar el cambio estructural se deben coordinar las estrategias de inversión pública con las políticas de desarrollo productivo y considerar que la inversión en infraestructura y la privada se complementan y que más inversión significa menos presión sobre el banco central durante el período de bonanza si el sector inversionista importa los bienes de capital.

En los países de organización federal, la apropiación de rentas y los gastos financiados con ellas dependen muchas veces de reglas constitucionales. El gasto descentralizado y simultáneo de los estados favorecidos por el período de bonanza podría generar externalidades pecuniarias que lleven a la enfermedad holandesa. Además, el gasto en la propia región no necesariamente será el que genere la mayor rentabilidad social. Deberían diseñarse reglas que impidan a los estados subnacionales decidir el nivel 
de gasto durante un período de bonanza sin evaluar los efectos en la macroeconomía. La alternativa ofrecida al gobierno local sería participar en un fondo de inversiones en el exterior o invertir en regiones diferentes del país.

- Gestión macroeconómica. Conforme los estándares latinoamericanos, los tres países analizados estuvieron relativamente bien administrados. Contaron con flexibilidad cambiaria y con la intervención en el mercado de cambios para amortiguar las variaciones en la liquidez externa y también desarrollaron fondos soberanos. Sin embargo, las tres economías dependen significativamente de los ingresos derivados de los recursos naturales para financiar el gasto público, las importaciones y los pagos a factores del exterior. Los movimientos de capital tendieron a ser procíclicos, acentuando las fluctuaciones y distorsiones de los precios relativos.

La enfermedad holandesa impide la diversificación del sector transable. A corto plazo, el incremento de la inversión puede superar la capacidad de absorción y promover esa enfermedad. Como se dijo, una opción es colocar parte de las mayores rentas apropiadas por el Estado en fondos de inversión en el exterior. Estos fondos se invertirían en proyectos de alta rentabilidad, cuyo inicio se regularía para evitar la apreciación del tipo de cambio.

Es necesario coordinar los regímenes fiscal y monetario. La gestión de las reservas del banco central en el período de bonanza no debería hacerse de manera independiente de la política fiscal, las reglas macroprudenciales y el resultado del sector externo. Si el mayor superávit que genera el sector público en el período de bonanza se compensa con un mayor gasto privado, no se evita la prociclicidad. Las regulaciones macroprudenciales sirven para asegurar que no se producirá un aumento excesivo del crédito. Ante el incremento de los precios internacionales, varios países de la región recurrieron a la acumulación de reservas, en principio con el objetivo de evitar la apreciación del tipo de cambio, pero también para autoasegurarse ante una reversión en los flujos de capital.

Sin embargo, la acumulación de reservas reduce la percepción de riesgos y tiene efectos expansivos en el crédito. El banco central podría esterilizar el efecto monetario, pero puede resultar caro si genera un déficit cuasifiscal. Una razón importante para desincentivar la expansión del crédito al consumo en el período de bonanza es que ello va en contra de las necesidades del bono demográfico actual, una etapa en la cual el ahorro debería ser alto. En este sentido, un superávit fiscal más alto en el período de bonanza no solo tendría efectos estabilizadores en el ciclo sino que sería funcional para prepararse para la etapa de envejecimiento de la población. Se 
deberían implementar reglas fiscales preventivas como en el caso de Chile y el Perú. Es útil fijar la política fiscal en función de un balance fiscal estructural.

Las fallas de la arquitectura financiera internacional - un bien público global-genera costos porque obliga a los países a acumular activos seguros para cubrirse ante reversiones en los flujos de capital. Los países de la región deberían presionar en favor de mecanismos de préstamos anticíclicos a un costo razonable. El Grupo de los 20 (G20) es un ámbito para avanzar y tres países de la región pertenecen a él. También podría avanzarse en esquemas regionales de asistencia como el Fondo Latinoamericano de Reservas (FLAR) o esquemas de permutas financieras entre bancos centrales.

- Inversión extranjera. Los países avanzados invirtieron en activos de riesgo y los tres países analizados en activos seguros. El que más se aleja de este patrón es Chile. Un canal fundamental fue la inversión extranjera.

Los flujos de inversión extranjera aumentaron en el período de bonanza, aportando ahorro y tecnología de punta para extraer y procesar los recursos naturales. Sin embargo, el ahorro externo puede sustituir al nacional, restando incentivos para que este último aumente. Al realizar la evaluación de proyectos se debería tener en cuenta que la información asimétrica puede favorecer que las empresas multinacionales terminen apropiándose de una porción mayor de la renta. Si los dividendos futuros incluyen renta, se está comprometiendo el capital natural de las generaciones futuras y reduciendo su ingreso nacional. Deberían desarrollarse capacidades estatales para reducir la asimetría de información, así como explorar mecanismos eficientes que permitan adaptar la apropiación de rentas en función de los precios internacionales. Una alternativa que se utiliza sobre todo en el sector de los hidrocarburos es contar con empresas estatales que actúen como "testigos" para determinar el valor de la renta, pero esto frecuentemente da lugar a pujas de apropiación con esas empresas.

Para concluir, cabe subrayar que las recomendaciones anteriores requieren reformas del marco institucional y de las organizaciones y constituyen verdaderos desafíos a la capacidad de gobernanza. Por ello hay que tener en cuenta las restricciones de economía política (Aoki, 2001; Fanelli, 2007). Deben considerarse los aportes del enfoque de la maldición de los recursos naturales, pues las reformas pueden debilitar transitoriamente la gobernanza y facilitar la búsqueda de rentas o incrementar las fluctuaciones macroeconómicas con efectos distributivos adversos. 


\section{Bibliografía}

Acquatella, J., O. Bello y F. Berríos (2016), “Evidencia estadística de súper ciclos en las series de precios de los metales y el petróleo 1900-2015", Santiago, Comisión Económica para América Latina y el Caribe (CEPAL), inédito.

Aoki, M. (2001), Toward a Comparative Institutional Analysis, Cambridge, Massachusetts, MIT Press.

Arrow, K. y otros (2004), "Are we consuming too much?", Journal of Economic Perspectives, vol. 18, $\mathrm{N}^{\mathrm{o}} 3$.

Banco Mundial (2011), The Changing Wealth of Nations: Measuring Sustainable Development in the New Millennium, Washington, D.C.

Baunsgaard, T. B. y otros (2012), "Fiscal frameworks for resource rich developing countries", IMF Staff Discussion Note, N N SDN/12/04.

Bilge, E. y J. A. Ocampo (2012), "Super-cycles of commodity prices since the midnineteenth century", DESA Working Paper, febrero.

Brosio, G. y J. P. Jimenez (2015), “Equalization grants and asymmetric sharing of natural resources: options for Latin America", Urban Public Economics Review, vol. 21.

Catão, L., A. Fostel y S. Kapur (2007), "Persistent gaps, volatility types and default traps", IMF Working Paper, N ${ }^{\circ}$ 07/148, Washington, D.C., Fondo Monetario Internacional (FMI).

Cavalcanti, T., K. Mohaddes y M. Raissi (2011),"Commodity price volatility and the sources of growth", IMF Working Paper, No WP/12/12.

Cavallo, E. y T. Serebrisky (ed.) (2016), Ahorrar para desarrollarse. Cómo América Latina y el Caribe puede ahorrar más y mejor, Washington, D.C., Banco Interamericano de Desarrollo (BID).

CEPAL (Comisión Económica para América Latina y el Caribe) (2014), Pactos para la igualdad: hacia un futuro sostenible (LC/G.2586(SES.35/3)), Santiago.

Céspedes, L. F., R. Chang y Velasco (2014), "Is inflation targeting still on target? The recent experience of Latin America", International Finance, vol. 17, N 2.

Chang, R. (2007), "Inflation targeting, reserves accumulation, and exchange rate management in Latin America", Borradores de Economía, N ${ }^{o} 487$, Banco de la Republica de Colombia.

Collier, P. y B. Goderis (2007), Commodity Prices, Growth, and the Natural Resource Curse: Reconciling a Conundrum, University of Oxford.

Collier, P. y otros (2009), "Managing resources revenues in developing economies", OxCarre Research Paper, vol. 15, Oxford Centre for the Analysis of Resource Rich Economies.

Dasgupta, P. (2009), "The place of nature in economic development", Handbook of Development Economics, vol. 5, D. Rodrik y M. Rosenzweig (eds.), Amsterdam, North Holland.

di Bella, G. y otros (2015), "Energy subsidies in Latin America and the Caribbean: stocktaking and policy challenges", IMF Working Paper,15/30, Washington, D.C., Fondo Monetario Internacional (FMI).

Eichengreen, B. (2011), "Escaping the middle income trap", Berkeley, University of California.

Fanelli, J. M. (2015), “La bonanza de términos del intercambio y la integración financiera de América del Sur", Integración financiera y cooperación regional en América del Sur después de la bonanza de los recursos naturales: balance y perspectivas, A. Ramiro (coord.), Montevideo, Red Sur. 
(ed.) (2008), Macroeconomic Volatility, Institutions, and Financial Architectures. The Developing World Experience, Nueva York, Palgrave, Macmillan. (ed.) (2007), Understanding Market Reform in Latin America. Similar Reforms, Diverse Constituencies, Varied Results, Nueva York, Palgrave Macmillan.

Fanelli, J.M., J.P. Jiménez e I. López Azcúnaga (2015), “La reforma fiscal ambiental en América Latina", Documentos de Proyectos (LC/W.658), Santiago, Comisión Económica para América Latina y el Caribe (CEPAL).

FMI (Fondo Monetario Internacional) (2012a), "Fiscal regimes for extractive industries: design and implementation", Washington, D.C. [en línea] https:/ / www.imf.org/external/np/pp/eng/2012/081512.pdf.

(2012b), Macroeconomic Policy Frameworks for Resource-Rich Developing Countries - Analytic Frameworks and Applications - Supplement 2, Washington, D.C. (2009), "Fiscal rules: anchoring expectations for sustainable public finances" [en línea] https:/ / www.imf.org/external/np/pp/eng/2009/121609.pdf.

Frankel, J. (2010), "The natural resource curse: a survey", Universidad de Harvard, agosto, inédito.

Gourinchas, P. O. y H. Rey (2013), "External adjustment, global imbalances, valuation effects", Handbook of International Economics, vol. IV, G. Gopinath, E. Helpman y K. Rogoff (eds.).

Hamann, F., M. Hofstetter y M. Urrutia (2014), “ Inflation targeting in Colombia, 2002-2012", Borradores de Economía, No 818, Banco Central de Colombia.

Hamilton, K. (2008), “Wealth, Saving and Sustainability”, Environmental Department, Washington, D.C., Banco Mundial.

Hamilton, K. y R. Hassan (2006), "Measuring development prospects by greening the National Accounts", Initiative for Policy Dialogue Working Paper Series [en línea] http:/ / academiccommons.columbia.edu/item/ac:126628.

Hansen, N. J. y O. Sulla (2013), "Credit growth in Latina America: financial development or credit boom?", IMF Working Paper, No 13/106.

Hartwick, J.M. (1977), "Intergenerational equity and the investing of rents from exhaustible resources", American Economic Review, vol. 67, № 5.

Hotelling, H. (1931), "The economics of exhaustible resources", The Journal of Political Economy, vol. 39, $\mathrm{N}^{\mathrm{o}} 2$.

Jiménez, J.P. y V. Tromben (2006), "Política fiscal en países especializados en productos no renovables en América Latina", serie Macroeconomía del Desarrollo, No 46 (LC/L.2521-P), Santiago, Comisión Económica para América Latina y el Caribe (CEPAL).

Krautkraemer, J. A. (1998), "Nonrenewable resource scarcity", Journal of Economic Literature, vol. 36, $\mathrm{N}^{\mathrm{o}} 4$.

Lin, J.Y. (2012), New Structural Economics. A Framework for Rethinking Development and Policy, Washington, D.C., Banco Mundial.

McMillan, M. S. y D. Rodrik (2011), “Globalization, structural change and productivity growth", NBER Working Paper, No 17143.

OCDE/CEPAL/CIAT/BID (Organización de Cooperación y Desarrollo Económicos/Comisión Económica para América Latina y el Caribe/Centro Interamericano de Administraciones Tributarias/Banco Interamericano de Desarrollo) (2016), Estadísticas tributarias en América Latina y el Caribe 1990-2014, París, OECD Publishing.

Perotti, D. y R. Sánchez (2011), “La brecha de infraestructura en América Latina y el Caribe", serie Recursos Naturales e Infraestructura, No 153 (LC/L.3342), Santiago, Comisión Económica para América Latina y el Caribe (CEPAL). 
Perry, G. y M. Olivera (2012), Petróleo y minería: ¿bendición o maldición?, Fondo de Cultura Económica.

Prebisch, R. (1986), El desarrollo económico de la América Latina y algunos de sus principales problemas (E/CN.12/89), Santiago, Comisión Económica para América Latina y el Caribe (CEPAL).

Rodrik, D. (2006), "Industrial development: stylized facts and policies directions", Industrial Development for the 21st Century: Sustainable Development Perspectives, Nueva York, Naciones Unidas.

Rossignolo, D. (2015), “Efectos económicos y macrofiscales de los recursos naturales en América Latina", serie Macroeconomía del Desarrollo, $\mathrm{N}^{\circ} 170$ (LC/L.4112), Santiago, Comisión Económica para América Latina y el Caribe (CEPAL).

Sachs, J.D. y A.M. Warner (1995), "Natural resource abundance and economic growth", National Bureau of Ecoomic Research Working Paper, N 5398, Cambridge.

Serven, L. y C. Calderon (2004), "The effects of infrastructure development on growth and income distribution", Policy Research Working Paper, N ${ }^{\circ} 3400$, Banco Mundial.

Sinnot, E., J. Nash y A. de la Torre (2010), Natural Resources in Latin America and the Caribbean Beyond Booms and Busts?, Washington, D.C.

Smulders, S., M. Toman y C. Withagen (2014), "Growth Theory and 'Green Growth"', OxCarre Research Paper, $\mathrm{N}^{\mathrm{o}}$ 135, Oxford Centre for the Analysis of Resource Rich Economies [en línea] http://www.oxcarre.ox.ac.uk/files/ OxCarreRP2014135\%282\%29.pdf.

Van der Ploeg, F. (2011), "Natural resources: curse or blessing?", Journal of Economic Literature, vol. $49, \mathrm{~N}^{\mathrm{o}} 2$.

Venables, A. (2016), “Using natural resources for development: why has it proven so difficult?", Journal of Economic Perspectives, vol. 30, N 1. 
Capítulo VIII

\title{
La bendición o la maldición de los recursos naturales: un breve análisis empírico ${ }^{1}$
}

\author{
Ricardo J. Sánchez \\ Silvana Sánchez di Doménico \\ Beatriz Tovar de la Fe
}

Es un hecho contrastable que no todos los países que poseen recursos naturales abundantes alcanzan las cotas de desarrollo superiores y sostenibles en el tiempo que logran otros países que, en términos relativos, están menos dotados de esos mismos recursos. La coexistencia de países que tienen una dotación relativamente menor de recursos, pero que han logrado niveles de desarrollo elevados (como el Japón), con otros que, teniendo abundantes recursos naturales, no han logrado alcanzar un crecimiento económico sostenible (como Nigeria, México o la República Bolivariana de Venezuela) está entre los temas del debate acerca del papel que los recursos naturales desempeñan en el desarrollo y el bienestar de los habitantes.

En este debate es habitual encontrar dos grupos de autores claramente diferenciados. Un primer grupo aduce que los recursos naturales son un factor favorable que facilita el desarrollo de las economías que los poseen. A tal punto sostienen esta idea que califican estos recursos como una "bendición". Según ellos, la existencia de una relación positiva entre esa abundancia y un mayor nivel de desarrollo económico es posible porque los recursos permiten financiar las fases del desarrollo económico. Este podría ser el caso, por ejemplo, de Noruega. En contraste, un segundo grupo postula precisamente la relación contraria entre el crecimiento y la abundancia de recursos naturales, y llega a considerar esta abundancia como una "maldición", debido no solo a que su existencia genera desequilibrios importantes en la distribución del

\footnotetext{
Los autores agradecen la colaboración desinteresada de Martín S. Salvá en este estudio.
} 
ingreso, sino también a que parece ir unida a una mayor probabilidad de que surjan conflictos armados, luchas étnicas, corrupción y otros. Este podría ser el caso, por ejemplo, de algunos países africanos.

¿Es la riqueza en materia de recursos naturales una bendición o una maldición para los países que la poseen? Encontrar una respuesta única y acertada a esta pregunta resulta una tarea compleja. La revisión de la literatura en la que se presenta evidencia empírica al respecto sugiere que cualquier resultado es posible. Los datos se obtienen indagando sobre los diferentes canales que pueden relacionar la dotación de los recursos naturales con la distribución del ingreso, la pobreza o el crecimiento económico.

En este capítulo se procura abordar la relación entre los recursos naturales y la distribución del ingreso en América Latina y el Caribe. Para investigar el efecto de los recursos naturales en la distribución del ingreso, se construyó un panel de datos correspondientes a 20 países de América Latina y el Caribe, en el período de 1990 a 2011. La muestra de países estaba integrada por la Argentina, Belice, Bolivia (Estado Plurinacional de), el Brasil, Chile, Colombia, Costa Rica, el Ecuador, El Salvador, Guatemala, Honduras, Jamaica, México, Nicaragua, Panamá, el Paraguay, el Perú, Suriname, el Uruguay y Venezuela (República Bolivariana de).

La información que sustentaba la aplicación empírica se obtuvo de la Base de Datos Estadísticos de Comercio Exterior (BADECEL). Como medida de desigualdad se utilizó el índice de Gini, porque ofrecía más información relativa a distintos años y países. Dicho índice se obtuvo de CEPALSTAT, la base de datos y publicaciones estadísticas de la CEPAL. Además, y con el propósito de introducir la calidad institucional en el análisis, se utilizaron como variables representativas (proxy) de ella dos grupos de índices que en la literatura se utilizan ampliamente con ese fin: los indicadores de gobernabilidad, estimados por el Banco Mundial, y el índice de percepción de la corrupción, calculado por Transparencia Internacional.

Además de analizar la relación entre los recursos naturales y la distribución del ingreso, en la primera parte se hace una breve revisión crítica de la literatura empírica sobre los recursos naturales y la desigualdad, que sirve para identificar las variables relevantes y los modelos experimentales más adecuados para llevar a cabo el análisis. A continuación, en la siguiente sección, se expone el marco conceptual y se presentan los datos, el modelo y las estimaciones realizadas, para luego comentar los resultados obtenidos y cerrar el capítulo con una sección que contiene comentarios y reflexiones finales.

\section{A. Breve revisión de la literatura empírica}

En esta sección se realiza una revisión de la literatura empírica sobre la relación entre los recursos naturales y la desigualdad del ingreso en los países en desarrollo. El propósito es arrojar algo de luz sobre la cuestión de la desigualdad 
y también utilizar dicha revisión como base de la aplicación empírica que se llevará a cabo en la siguiente sección dedicada al marco analítico.

En el cuadro VIII.1 se presenta, de modo sintético, la literatura examinada. Por lo que se refiere al tipo de datos utilizados, en este cuadro se pone de manifiesto que en la mayor parte de los trabajos (17 de un total de 21) se utilizaron datos macroeconómicos. De los siete trabajos en los que se utilizaron datos microeconómicos, en tres se los utilizó en combinación con datos macro y, en otros dos, se usaron datos obtenidos a través de cuestionarios diseñados ad hoc (Narain, Guptab, y van 't Veld, 2008; Echeme y Ubani, 2010).

Además, y en relación con el número de países incluidos en el estudio, nuevamente la mayoría de los trabajos (13 de 21) se refiere a un conjunto más o menos amplio de países que suele incluir economías tanto desarrolladas como en vías de desarrollo. En lo que respecta al resto de los trabajos, algunos se centran en países en vías de desarrollo (India, Nigeria o Chile) y otros en países desarrollados (Estados Unidos o Australia), si bien en la mayor parte de ellos hay un interés por la relación entre la pobreza, el crecimiento o la calidad de vida, y la abundancia de los recursos mineros.

Por otra parte, y en lo que se refiere a la metodología empleada en el estudio, el cuadro VIII.1 permite dividir en dos grupos los trabajos revisados. En el primero de ellos se incluyen tres trabajos: uno meramente descriptivo en que se utilizan únicamente indicadores y herramientas estadísticas básicas, como el análisis de correlación (Lagos y Blanco, 2010), y otros dos en que, además de lo anterior, se utilizan herramientas estadísticas algo más sofisticadas (Echeme y Ubani, 2010; y Hajkowicz, Heyenga y Moffat, 2011).

En el segundo grupo, que engloba todos los trabajos en que se utiliza el análisis de regresión, el citado cuadro VIII.1 de nuevo permite hacer una distinción entre los trabajos en que se usan datos de sección cruzada (12) y aquellos en que se emplean datos de panel (siete) ${ }^{2}$. Esta distinción es importante porque utilizar datos de panel conlleva ventajas, entre las que se encuentra el hecho de que se toma en cuenta y se controla la heterogeneidad individual. Cuando se utilizan datos de series de tiempo o de sección cruzada, y se trabaja con muestras de empresas, estados o, como en este caso, países que son heterogéneos entre sí, la heterogeneidad no se puede controlar y ello puede dar lugar a resultados sesgados. Al trabajar con datos de panel, se controlan las variables de estado (observables o no observables) y las que no varían en el tiempo. De lo anterior se deduce que es preferible utilizar un modelo de datos de panel para capturar la heterogeneidad entre los países o las unidades que conforman la muestra.

En los datos de sección cruzada, se observa cada unidad de análisis en un único período de tiempo. Cuando la observación corresponde a dos o más períodos, se trata de datos de panel. Aunque se cuente con datos de panel, puede ocurrir que en la estimación del modelo se ignore la estructura temporal de los datos. En ese caso, todas las observaciones se consideran contemporáneas (pool de datos). 


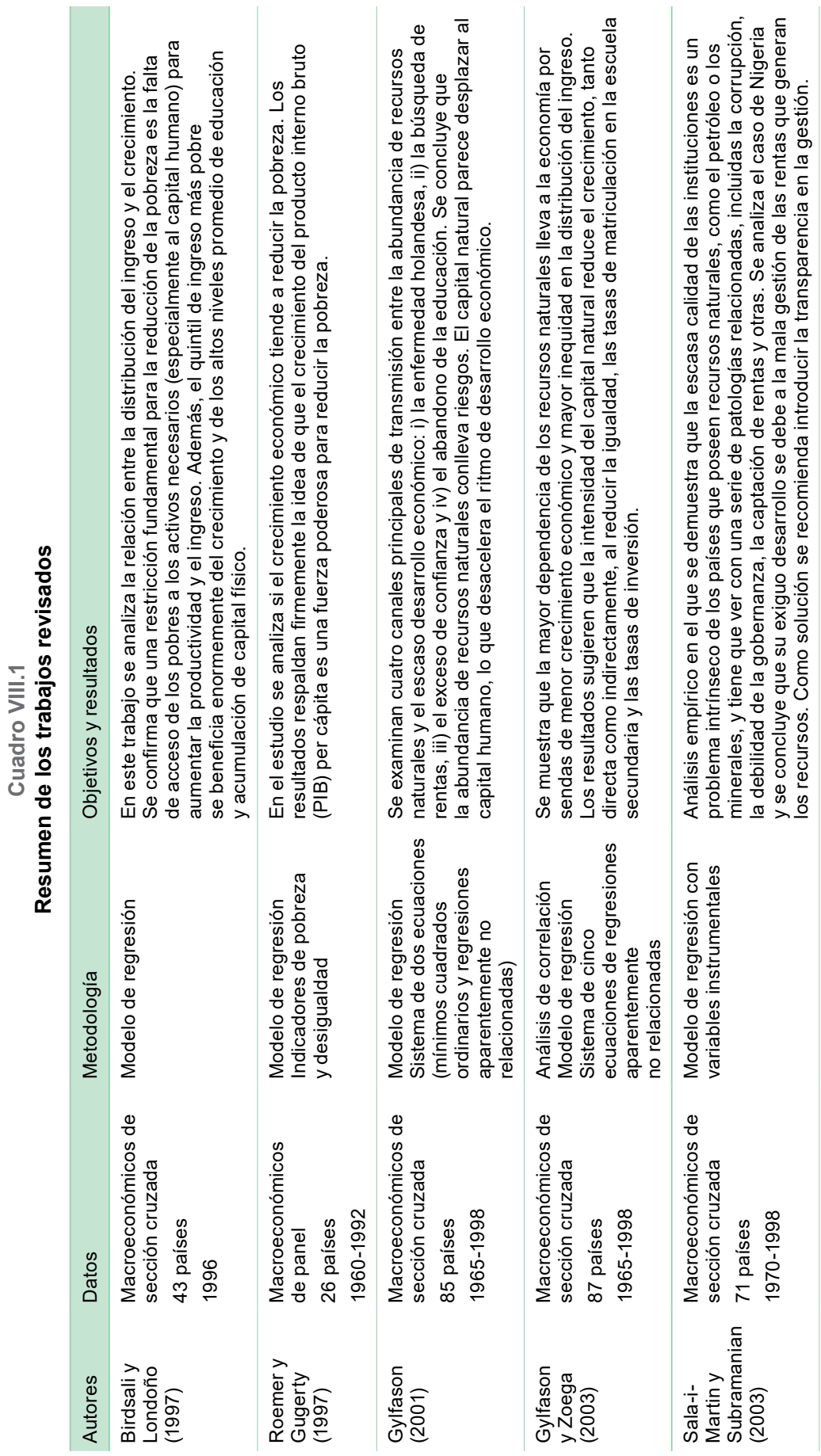




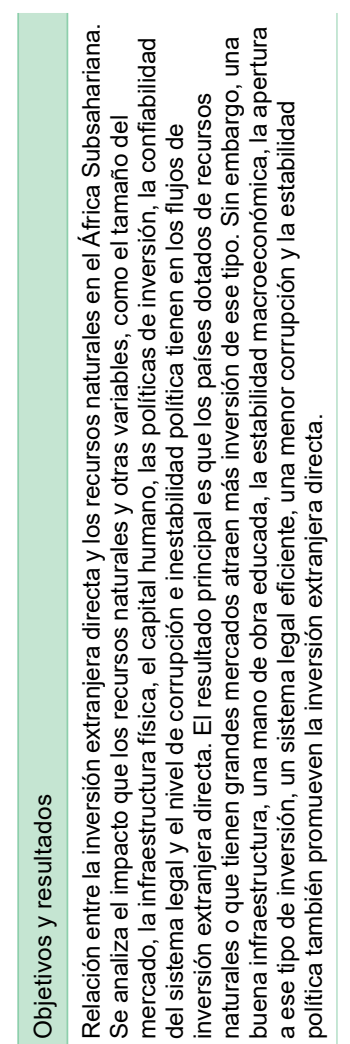

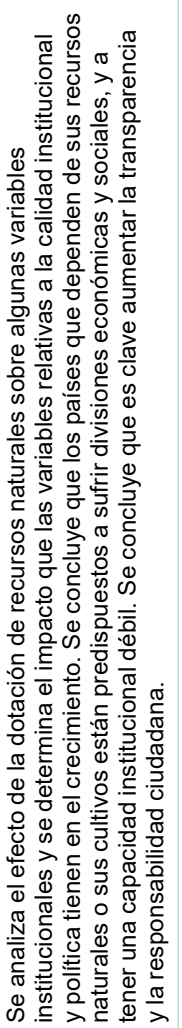

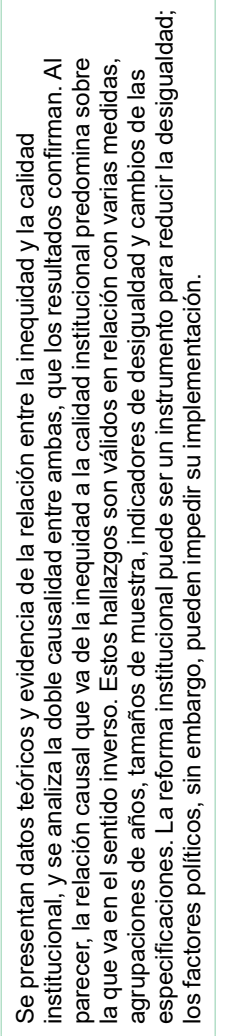

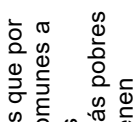

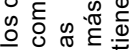

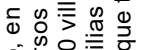
을

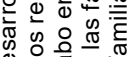

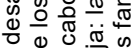
$\therefore \frac{\pi}{0} \frac{\pi}{0}$ Ф。율 ه

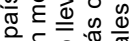

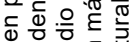
क्ष

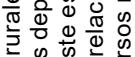

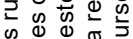

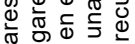

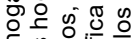

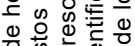
(1) 年

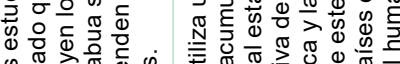

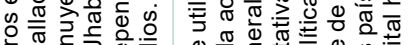
는

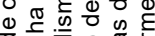

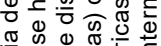

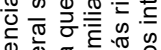

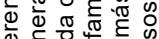

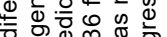

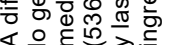

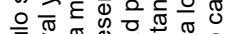

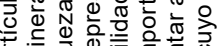
它 $0 \%$ क्.

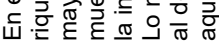
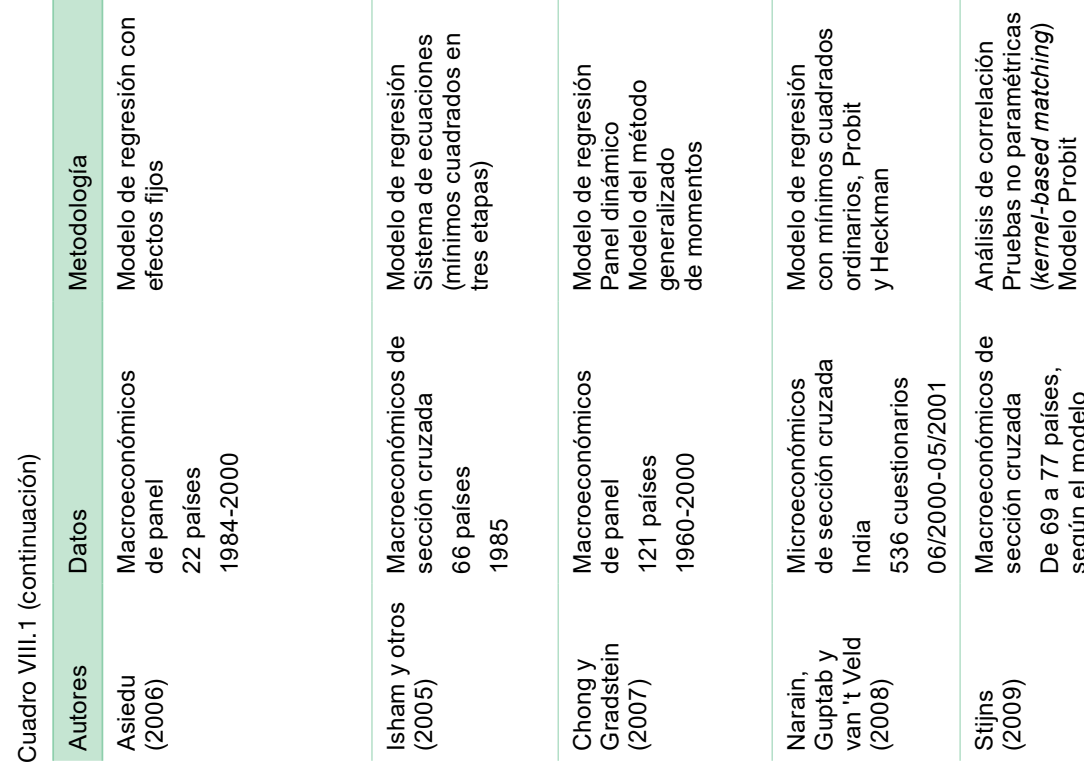

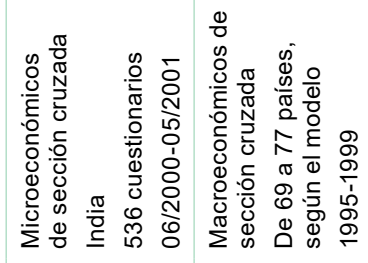

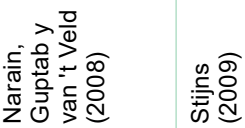




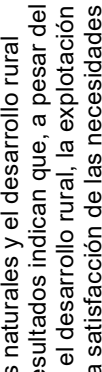

i) $\underset{0}{\infty}>\underline{\pi}$

की 类 in

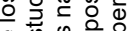

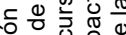
फ ฮั 뜽 웡응 은 두워워

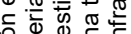
O.

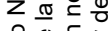

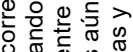
O. 匹

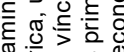
œ 응 क् : ช.

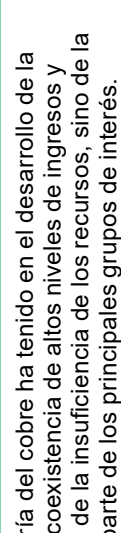
들 을

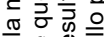
๑ 그의 원 잉웡 응두

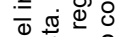
쥬 फ ब ब중 중 웡 ส

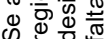

준 000 है心 :음

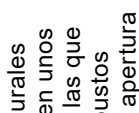
들 둥응 is

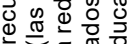
is on 뜰 훙 응쥬웜

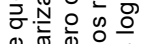
응 증 으응 की . 을 뜨. (ब)

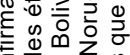

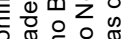
0 o हो है 궁잉 0 का की

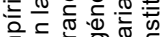
ㅎㅎㅇㅠ.

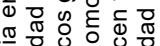
은 은

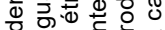
응

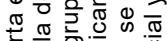

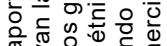
ஸे 온

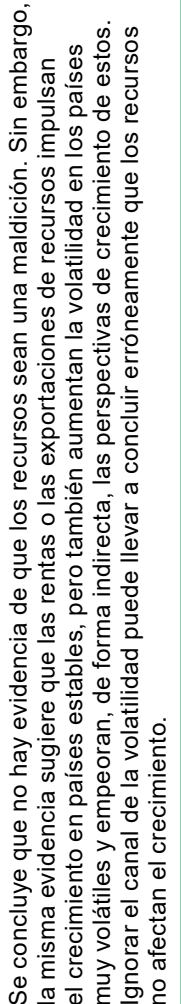

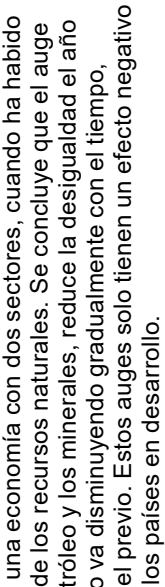

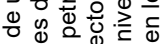

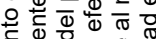
屯. ठ웡

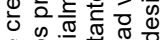
응 O 진 드은 흥 की 즈은 윤

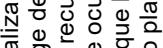
ส

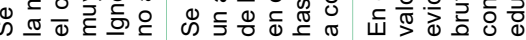

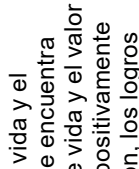

要

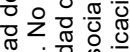

증

तु

ब

这包

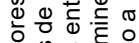

응 \& 80

O

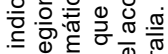
क

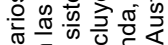
>

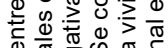
ब 들 Ф ن 잉 응 응 $\frac{\pi}{\pi}$ 중

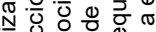

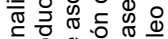

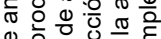

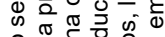

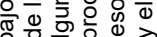
준

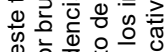
\& 흐음 욱읃 음

\begin{tabular}{|c|c|}
\hline 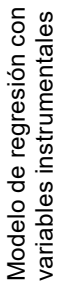 & 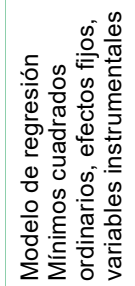 \\
\hline
\end{tabular}

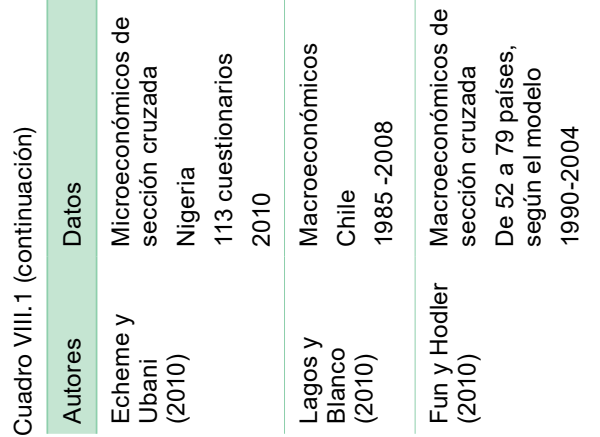

잉

:

热

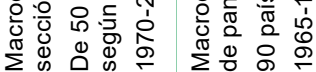

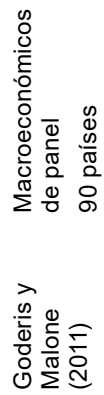

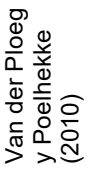

응

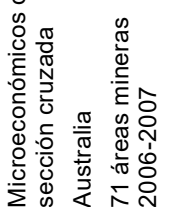

N

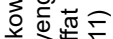
주웡ㅇㅇ 


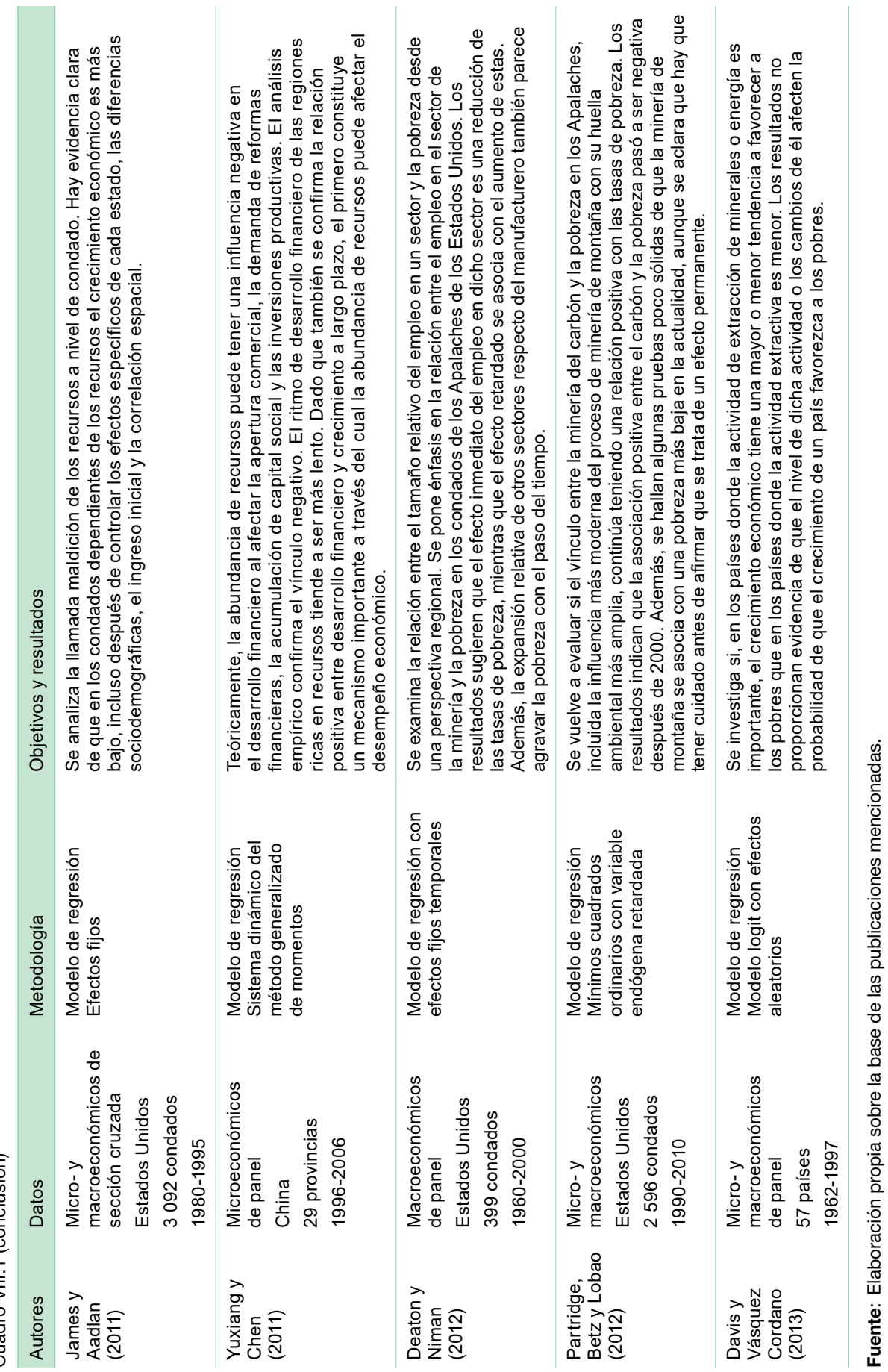


Por último, hay que destacar que en algunos trabajos (Sala-i-Martin y Subramanian, 2003; Van der Ploeg y Poelhekke, 2010; y Goderis y Malone, 2011) se señala adecuadamente la necesidad de utilizar variables instrumentales debido a la endogeneidad o la simultaneidad de algunas variables. En este sentido se puede mencionar, por ejemplo, la discusión sobre la simultaneidad entre la educación y la desigualdad.

De cualquier manera, los resultados más destacados de cada trabajo se sintetizan en el citado cuadro VIII.1, del que puede concluirse, en cuanto a la estimación econométrica de estos modelos, que es relevante contar con datos de panel en los que se incluyan variables relativas a la educación y la calidad de las instituciones, lo que conlleva la necesidad de utilizar variables instrumentales en la estimación (al respecto, véase también la sección B.3).

\section{B. Marco de análisis}

\section{Datos}

Como se mencionó antes, en este estudio se investiga el efecto de los recursos naturales en la distribución del ingreso, en un panel desbalanceado de países de América Latina y el Caribe entre 1990 y 2011. Como también se dijo, la muestra incluye 20 países de la región: Argentina, Belice, Bolivia (Estado Plurinacional de), Brasil, Chile, Colombia, Costa Rica, Ecuador, El Salvador, Guatemala, Honduras, Jamaica, México, Nicaragua, Panamá, Paraguay, Perú, Suriname, Uruguay y Venezuela (República Bolivariana de).

La revisión de la literatura puso de manifiesto que hay diferentes enfoques para estudiar este fenómeno. En la aplicación empírica que se presenta a continuación, se sigue la línea de los trabajos en los que se trata de analizar la relación entre la desigualdad y los recursos naturales utilizando el índice de Gini como medida de la primera. A este respecto, destaca la falta de consenso acerca del modelo apropiado para explicar la desigualdad del ingreso y se encuentran diversas propuestas en función del interés principal del trabajo, a saber: la relación entre la desigualdad, la dotación de factores y la apertura comercial (Spilimbergo, Londoño y Szekely, 1999); la relación entre la desigualdad y la corrupción ( $\mathrm{Li}, \mathrm{Xu}$ y Zou, 2000; Gupta Davoodi y Alonso-Terme, 2002; Gyimah-Brempong, 2002; y Gyimah-Brempong y Muñoz de Camacho, 2006); la relación entre la desigualdad y la calidad institucional (Chong y Gradstein, 2007); la relación entre la desigualdad y la educación (De Gregorio y Lee, 2002), y, por último, la relación entre la desigualdad y los recursos naturales (Buccellato y Alessandrini, 2009; y Fun y Holler, 2010), como es el caso del presente artículo.

En este trabajo se parte del modelo que Buccellato y Alessandrini (2009) utilizaron para analizar y obtener evidencia empírica sobre si la maldición de los recursos naturales existe o no, modelo al que se le incorporan algunas extensiones que se irán detallando a continuación. En concreto, se busca evaluar cómo la existencia de recursos naturales afecta la distribución del 
ingreso. En el modelo, cuya variable dependiente será el indicador de la medida de la desigualdad, se contemplan dos conjuntos de variables: uno directamente relacionado con la dotación de los recursos naturales, y otro que incluye los factores que, según se ha identificado en la literatura, afectan la distribución del ingreso (escolaridad, calidad institucional y otros), así como las variables de control que permiten capturar características propias de cada país de la muestra (tamaño, demografía y otras).

\section{El modelo}

Buccellato y Alessandrini (2009) proponen un modelo cuya variable dependiente es la medida de la desigualdad. El modelo puede representarse de la siguiente manera:

$$
D_{i, t}=\alpha_{0}+\alpha_{1} \text { Recursos naturales }_{i, t}+\gamma X_{i, t}+\varepsilon_{i, t}
$$

donde $D_{i, t}$ es el índice de Gini y $X_{i, t}$ es una matriz que contiene las variables de control que dan cuenta de las distintas características específicas de cada país que pueden afectar la distribución del ingreso. Por su parte, $\gamma$ es el vector de coeficientes asociados con las variables de control. El número de países considerados va de 18 a 22 según qué variables se incluyan. $\alpha_{0}+\alpha_{1}$ son los parámetros estimados, $i$ refiere a cada país de la regresión, $t$ a cada momento del tiempo y $\varepsilon_{i, t}$ es el error estadístico.

Como variable para medir en qué grado se depende de los recursos naturales se considera la participación del valor de las exportaciones de los productos básicos en el valor total de las exportaciones (Partcom). Con el propósito de analizar si la especialización en algún tipo de recurso natural tiene influencia en la desigualdad, en algunos de los modelos también se incluyen variables ficticias (dummy) que representan la importancia relativa del tipo de producto básico en las exportaciones $(D 1=1$, si el mayor porcentaje lo representan las exportaciones agrícolas, D2 $=1$, si lo representan las de materiales, y D3 $=1$, si lo representan las de minerales).

Por otra parte, con el propósito de controlar el efecto de la apertura al exterior, se utiliza la variable que representa el valor de las exportaciones totales en el PIB (Exptot GDP_bill). Esta variable permite "limpiar" los coeficientes correspondientes a la medida de los recursos naturales de los posibles efectos de la apertura y las variaciones del tipo de cambio. Además, para capturar los efectos del capital humano en los países, se usa el promedio de años de escolaridad (Promaesc) en la población económicamente activa $(\mathrm{PEA})^{3}$. Por último, para controlar el efecto del tamaño de los países, se agrega la variable relativa a la población en logaritmos (Logpob).

En una etapa posterior, con el propósito de introducir la calidad institucional en el análisis, se usan como variables representativas de ella dos índices ampliamente utilizados con ese fin en la literatura sobre el tema.

Es la única medida de los años de educación que se encuentra disponible en relación con los países de la muestra en el período analizado. 
El primer índice, que se denomina "control de corrupción" (cc per_rnk), es una medición del Banco Mundial que permite captar la percepción del grado en que se ejerce el poder público para obtener ganancias de uso privado $^{4}$. Dicho índice asume valores de 0 a 100, donde los mayores valores corresponden a los mejores resultados. El segundo, el "índice de percepción de la corrupción" (cpi-Score), es de Transparencia Internacional ${ }^{5}$ y permite medir el grado en que se percibe corrupción en el sector público y en un país determinado. Dicho índice se calcula en una escala de cero a diez, donde cero significa muy corrupto y diez significa ausencia de corrupción.

\section{Estimaciones}

La utilización del método de los mínimos cuadrados ordinarios para elaborar un modelo de la desigualdad del ingreso entre los países presenta problemas debidos a la heterogeneidad no observable (efecto país) ${ }^{6}$. Esto plantea la necesidad de utilizar modelos de panel en los que se tenga en cuenta dicha heterogeneidad. Por otra parte, como se apunta en la literatura reciente y es el caso en el presente trabajo, el uso de la educación y la calidad de las instituciones como variables explicativas de la desigualdad requiere estimar por variables instrumentales si se verifica la existencia de un problema de endogeneidad relacionado con las primeras. En una primera etapa, se estiman tres versiones de cada modelo que se denominan OLS, FIXED y RANDOM, según que la estimación corresponda a los mínimos cuadrados ordinarios, a un panel con efectos fijos o a un panel con efectos aleatorios, respectivamente ${ }^{7}$. Después, en algunos casos se vuelve a estimar instrumentando algunas de las variables para evitar problemas de endogeneidad.

\section{Resultados}

En las primeras estimaciones se siguió el modelo de Buccellato y Alessandrini (2009), por lo que no se incluyó la calidad de las instituciones. Las variables exógenas analizadas fueron Partcom, Exptot_GDP_bill, Logpob, Promaesc, D2 y D38. Después se estimaron varios modelos alternativos en los que se incluyeron todas las variables y posteriormente se excluyeron aquellas cuyos estimadores no resultaban significativos. Los resultados de las estimaciones, que se presentan en el cuadro VIII.2, se comentan a continuación.

\footnotetext{
Incluye formas de corrupción en pequeña y gran escala, así como la "captura" del Estado por las élites y los intereses privados.

Véase [en línea] http://www.transparency.org/.

6 Recuérdese que la estimación de los mínimos cuadrados ordinarios se realiza con datos de corte transversal.

7 A pesar de que las estimaciones con mínimos cuadrados ordinarios y datos de panel pueden ser inadecuadas, estos modelos también se incluyen en el presente trabajo debido a que se los utiliza en parte de la literatura empírica revisada y a que se tiene el propósito de analizar si la evidencia empírica obtenida con ellos se sostiene cuando se aplican modelos econométricos más adecuados.

8 Para evitar la multicolinealidad entre las variables ficticias, la variable D1, que representaba los países donde las exportaciones agrícolas eran el mayor porcentaje, quedó fuera (por ser la más relevante). Por consiguiente, los resultados están en función de ella.
} 


\section{Cuadro VIII.2}

\section{Resultados de las estimaciones realizadas con los mejores modelos}

\begin{tabular}{|c|c|c|c|c|c|}
\hline & OLS 1 & FIXED 1 & RANDOM 1 & IVFIXED 1 & IVRANDOM 1 \\
\hline & $\mathrm{b} / \mathrm{t} / \mathrm{se}$ & $\mathrm{b} / \mathrm{t} / \mathrm{se}$ & $\mathrm{b} / \mathrm{t} / \mathrm{se}$ & $\mathrm{b} / \mathrm{t} / \mathrm{se}$ & $\mathrm{b} / \mathrm{t} / \mathrm{se}$ \\
\hline \multirow[t]{3}{*}{ PARTCOM } & $-0,0300^{*}$ & $-0,0096$ & $-0,0138$ & $-0,0040$ & $-0,0089$ \\
\hline & $(-2,016)$ & $(-0,366)$ & $(-0,580)$ & $(-0,154)$ & $(-0,359)$ \\
\hline & $(0,015)$ & $(0,026)$ & $(0,024)$ & $(0,026)$ & $(0,025)$ \\
\hline \multirow[t]{3}{*}{ EXPTOT_GDP_BILL } & $-0,4479^{* * *}$ & $-0,0776$ & $-0,1289^{*}$ & $-0,0329$ & $-0,0974$ \\
\hline & $(-5,218)$ & $(-1,209)$ & $(-2,053)$ & $(-0,346)$ & $(-1,045)$ \\
\hline & $(0,086)$ & $(0,064)$ & $(0,063)$ & $(0,095)$ & $(0,093)$ \\
\hline \multirow[t]{3}{*}{ PROMAESC } & $-0,0072^{*}$ & $-0,0334^{* * *}$ & $-0,0252^{* * *}$ & $-0,0413^{* * *}$ & $-0,0299^{* * *}$ \\
\hline & $(-2,582)$ & $(-6,664)$ & $(-5,820)$ & $(-4,596)$ & $(-4,351)$ \\
\hline & $(0,003)$ & $(0,005)$ & $(0,004)$ & $(0,009)$ & $(0,007)$ \\
\hline \multirow[t]{3}{*}{ CC_PER_RNK } & 0,0003 & 0,0006 & 0,0005 & $0,0022^{* *}$ & 0,0009 \\
\hline & $(1,221)$ & $(1,497)$ & $(1,474)$ & $(2,905)$ & $(1,815)$ \\
\hline & $(0,000)$ & $(0,000)$ & $(0,000)$ & $(0,001)$ & $(0,000)$ \\
\hline \multirow[t]{3}{*}{ CONSTANT } & $0,6445^{\star * *}$ & $0,8055^{\star * *}$ & $0,7396^{* * *}$ & $0,8015^{\star * *}$ & $0,7545^{\star * *}$ \\
\hline & $(26,620)$ & $(19,424)$ & $(20,528)$ & $(9,000)$ & $(11,721)$ \\
\hline & $(0,024)$ & $(0,041)$ & $(0,036)$ & $(0,089)$ & $(0,064)$ \\
\hline $\mathrm{R}^{2}$ & 0,3719 & 0,4323 & & & \\
\hline $\mathrm{R}^{2} \mathrm{AJUSTADO}$ & 0,3499 & 0,3094 & & & \\
\hline
\end{tabular}

\begin{tabular}{lccccc}
\hline & OLS 2 & FIXED 2 & RANDOM 2 & IVFIXED 2 & IVRANDOM 2 \\
\cline { 2 - 6 } & $\mathrm{b} / \mathrm{t} / \mathrm{se}$ & $\mathrm{b} / \mathrm{t} / \mathrm{se}$ & $\mathrm{b} / \mathrm{t} / \mathrm{se}$ & $\mathrm{b} / \mathrm{t} / \mathrm{se}$ & $\mathrm{b} / \mathrm{t} / \mathrm{se}$ \\
\hline PARTCOM & $-0,0319^{*}$ & $-0,0072$ & $-0,0107$ & $-0,0044$ & $-0,0043$ \\
& $(-2,015)$ & $(-0,273)$ & $(-0,448)$ & $(-0,169)$ & $(-0,186)$ \\
\cline { 2 - 6 } & $(0,016)$ & $(0,026)$ & $(0,024)$ & $(0,026)$ & $(0,023)$ \\
\hline EXPTOT_GDP_BILL & $-0,4551^{* * *}$ & $-0,0792$ & $-0,1278^{*}$ & $-0,0475$ & $-0,1216$ \\
\cline { 2 - 6 } & $(-4,923)$ & $(-1,236)$ & $(-2,040)$ & $(-0,461)$ & $(-1,394)$ \\
\hline PROMAESC & $(0,092)$ & $(0,064)$ & $(0,063)$ & $(0,103)$ & $(0,087)$ \\
\hline CC_PER_RNK & $-0,0071^{*}$ & $-0,00331^{* * *}$ & $-0,0251^{* * *}$ & $-0,0407^{* * *}$ & $-0,0283^{* * *}$ \\
& $(-2,508)$ & $(-6,606)$ & $(-5,756)$ & $(-4,560)$ & $(-4,312)$ \\
\hline SCCCRANK & $(0,003)$ & $(0,005)$ & $(0,004)$ & $(0,009)$ & $(0,007)$ \\
\hline & 0,0001 & 0,0015 & 0,0012 & 0,0027 & $0,0037^{* * *}$ \\
& $(0,170)$ & $(1,705)$ & $(1,530)$ & $(1,786)$ & $(3,429)$ \\
\hline CONSTANT & $(0,001)$ & $(0,001)$ & $(0,001)$ & $(0,002)$ & $(0,001)$ \\
\hline & 0,0000 & $-0,0000$ & $-0,0000$ & $-0,0000$ & $-0,0000^{* *}$ \\
\hline$R^{2}$ & $(0,172)$ & $(-1,166)$ & $(-1,015)$ & $(-0,323)$ & $(-2,761)$ \\
\hline$R^{2}$ AJUSTADO & $(0,000)$ & $(0,000)$ & $(0,000)$ & $(0,000)$ & $(0,000)$ \\
\hline & $0,6487^{* * *}$ & $0,7952^{* * *}$ & $0,7271^{* * *}$ & $0,7981^{* * *}$ & $0,7062^{* * *}$ \\
\hline & $(23,045)$ & $(18,780)$ & $(18,649)$ & $(9,180)$ & $(11,095)$ \\
\hline & $(0,028)$ & $(0,042)$ & $(0,039)$ & $(0,087)$ & $(0,064)$ \\
\hline & 0,3721 & 0,4402 & & & \\
\hline
\end{tabular}

Fuente: Elaboración propia.

Nota: Los modelos OLS, FIXED y RANDOM indican que la estimación se efectuó por mínimos cuadrados ordinarios, panel de efectos fijos y panel de efectos aleatorios, respectivamente. La anteposición de IV significa que además se estimó por variables instrumentales. ${ }^{*} p<0,05^{\star *} p<0,01{ }^{* \star *} p<0,001$. 
En todos los modelos de mínimos cuadrados ordinarios que se estimaron, la variable Partcom (relacionada con los recursos naturales) señala que, si todo lo demás se mantiene igual, la desigualdad disminuye cuanto mayor es la participación de las exportaciones de recursos naturales en el total de las exportaciones. Por tanto, la evidencia empírica que se obtiene con estos primeros modelos es contraria a la hipótesis de la maldición de los recursos naturales y más bien señala lo contrario. Cuando los modelos de mínimos cuadrados ordinarios anteriores se vuelven a estimar utilizando técnicas de panel, el mejor modelo (según la prueba de Haussman) también indica que los recursos naturales no son una maldición sino una bendición.

No obstante, como ya se ha adelantado, en una parte importante de la literatura reciente (Collier, 2010; Engerman y Sokoloff, 2012) se señala la calidad de las instituciones como una variable que es clave para explicar la desigualdad y cuya ausencia podría sesgar los resultados de los modelos anteriores ${ }^{9}$. Además, otra preocupación sería la posible endogeneidad de las variables relativas a la educación y la calidad institucional, que haría preciso estimarlas por variables instrumentales. De todos modos, y con el propósito de comparar nuestros resultados con la evidencia empírica previa, procederemos de forma secuencial. Primero, analizaremos cómo cambiarían los resultados si incluyéramos la variable relacionada con la calidad de las instituciones e ignoráramos el posible problema de la endogeneidad. Finalmente, nos haremos cargo de este último estimando por variables instrumentales. El objetivo de esta estrategia es comprobar si los resultados obtenidos hasta ahora, según los cuales los recursos naturales serían una bendición, se mantienen cuando los modelos se ajustan para evitar los errores metodológicos que sesgan los resultados.

Introducir la calidad de las instituciones (en adelante, instituciones), tanto de forma lineal como al cuadrado, en los modelos de los mínimos cuadrados ordinarios, no cambia prácticamente nada respecto al modelo base (en el que no se incluye dicha variable) y no produce efectos significativos en ningún caso. Sin embargo, en los modelos de panel, aunque esta variable sigue sin ser significativa, su significatividad mejora cuando se incluye el término al cuadrado que, además, presenta el signo esperado ${ }^{10}$.

Comprobada la existencia de endogeneidad en las variables relativas a la educación y las instituciones, se vuelven a estimar los modelos

\footnotetext{
$9 \quad$ En el trabajo empírico, la calidad de las instituciones suele aproximarse a través de la corrupción (véase, por ejemplo, Chong y Gradstein, 2007). De hecho, probablemente sean dos caras de la misma moneda, por lo que a los fines de este estudio se utilizan como sinónimos.

$10 \mathrm{Li}, \mathrm{Xu}$ y Zou (2000), al analizar la influencia de esta variable en el índice de Gini, encontraron que el efecto no era lineal, sino que tenía forma de U invertida. Con el propósito de obtener evidencia en este sentido, en los modelos estimados se incluye la variable de forma lineal y al cuadrado.
} 
usando como instrumento las propias variables rezagadas ${ }^{11}$. Al centrar la atención en los modelos en que la calidad de las instituciones se aproxima de acuerdo con el índice del Banco Mundial, se observa que la variable instituciones es significativa o está muy cerca de serlo, según se trate del modelo de efectos fijos o de efectos aleatorios. La prueba de Haussman entre ambos modelos da como resultado un valor de 34,07. Esto permite rechazar la hipótesis nula y, por consiguiente, el modelo elegido es el de efectos fijos. Por otra parte, cuando se incluye la variable al cuadrado, los signos de las variables relevantes se mantienen acordes con la literatura, pero, en términos de la significatividad de los parámetros estimados, la balanza parece inclinarse a favor del modelo de efectos aleatorios, al igual que la prueba de Haussman. Por último, cuando para incorporar la calidad de las instituciones se utiliza el índice de Transparencia Internacional, dicha variable no es significativa en ningún modelo.

Los mejores modelos estimados ${ }^{12}$ (IVFIXED1 e IVRANDOM2 en el cuadro VIII.2) señalan, en línea con la literatura reciente, que la calidad de las instituciones es un factor relevante para explicar la desigualdad. El signo positivo del término de primer orden (cc_per_rnk) indica que una mayor calidad de las instituciones incrementa la desigualdad. Este resultado, que en principio puede parecer contradictorio, indica que la relación entre desigualdad y calidad de las instituciones no es lineal, como lo señala el signo negativo del término de segundo orden (scccrank) y como lo indica la evidencia empírica ofrecida por Li, Xu y Zou (2000). Además, estos modelos señalan la educación como un factor que disminuye la desigualdad, lo que también coincide con lo que se establece en la literatura. Por último, y en lo que se refiere a los recursos naturales (Partcom), ambos modelos parecen señalar que los recursos naturales suponen una bendición, aunque esta relación positiva no es significativa.

\section{Comentarios y reflexiones finales}

A pesar de las limitaciones que ya se han mencionado y que también presentaremos en esta sección, en este estudio nos inclinamos por afirmar que la idea de la maldición de los recursos naturales es, al menos, algo cuestionable. A la luz de los datos analizados, la variable que mide el grado en que se depende de los recursos naturales pierde significatividad cuando se pasa de la estimación de los mínimos cuadrados ordinarios a la de las variables instrumentales y a la inclusión de la variable relativa a la calidad de

11 Se llevó a cabo una prueba de endogeneidad de la variable educación y de la variable calidad de las instituciones. Las pruebas realizadas señalaron que es preciso instrumentar en ambos casos.

12 Aquellos que se estiman por variables instrumentales e incluyen las variables educación y calidad institucional. 
las instituciones ${ }^{13}$. La pregunta que surge en este punto es si ese hecho señala que la evidencia obtenida con estos modelos no es válida y se debe a que la modelización es discutible, al menos desde el punto de vista metodológico, $\mathrm{o}$, por el contrario, si esa falta de significatividad se debe solo al tamaño limitado de la base de datos actual.

La idea de que los recursos naturales pueden desempeñar un papel en el desarrollo de las naciones y la desigualdad de la renta no es nueva. Aunque en la literatura no existe un consenso absoluto sobre la naturaleza de la relación entre los recursos naturales y la desigualdad, al mismo tiempo no parece haber dudas acerca de las dificultades que su análisis plantea.

Por una parte, hay carencias graves de información. Es difícil formar paneles balanceados en los que se incluyan todos los países de interés durante períodos lo suficientemente largos. Los investigadores se enfrentan al dilema que supone hallar un punto de equilibrio entre contar con paneles de mayor tamaño utilizando datos de diversas fuentes, o contar con muestras menores, pero más comparables. Por otra parte, la heterogeneidad inobservable entre los países de interés y la causalidad (algunas veces en ambas direcciones) entre algunas de las variables del modelo también suponen problemas metodológicos que no son menores cuando se las ignora. Tenerlas en cuenta, por otra parte, agrava el problema de los datos.

Las dificultades anteriores probablemente están detrás de muchos modelos empíricos que son tan discutibles como los resultados que de ellos se desprenden. En esta línea, una primera conclusión que los modelos estimados en este trabajo parecen señalar de manera inequívoca es que la forma de medir importa tanto en lo que se refiere a la dimensión o la calidad de la base de datos, como a la definición del modelo.

Es preciso destacar que este trabajo es el primer producto de un proyecto de investigación a largo plazo cuya base de datos se irá ampliando y mejorando, lo que a su vez también permitirá mejorar los modelos y las estimaciones. Aunque se ha revisado la literatura empírica en la que se trata de cuantificar este fenómeno para identificar las variables relevantes y el modelo más adecuado, persisten importantes limitaciones de información que se agravan al instrumentar. Por consiguiente, los resultados obtenidos -que señalan que los recursos naturales no constituyen una maldición para los países de América Latina y el Caribe, y que estos últimos se comportan de manera similar al resto de los países- deben tomarse como preliminares y con esas limitaciones en mente. En cualquier caso, estos

13 Recuérdese que, en nuestro modelo, la dependencia de los recursos naturales se mide a través de la variable Partcom, que representa la participación del valor de las exportaciones de los productos básicos en el valor total de las exportaciones. 
resultados coinciden con los que se exponen en la literatura y los que se presentan en el estudio de Sinnott, Nash y de la Torre (2010):

Uno de los hallazgos clave de este informe, es que la fuerza de la evidencia econométrica y de los casos de estudio del registro histórico, indica que la "maldición de los bienes primarios" (que la abundancia de recursos naturales menoscaba el crecimiento económico a largo plazo), en caso de existir, no es ni fuerte ni inevitable. La evidencia predominante indica que la riqueza de recursos naturales, en promedio, ni socava ni promueve desproporcionalmente el crecimiento económico. Tampoco existe, al parecer, ninguna "maldición política" (que la abundancia de recursos naturales debilita las instituciones democráticas y estimula conflictos de gran escala), al menos en América Latina y el Caribe.

A la luz de la revisión de la literatura y el análisis empírico realizado, los autores creen que la maldición no radica en poseer una dotación más o menos abundante de recursos naturales, sino en la naturaleza de su explotación y aprovechamiento, que ocurre al amparo de una institucionalidad o una cierta forma de gobernanza que es, en definitiva, el interés de fondo de este libro. Por otra parte, y desde un punto de vista metodológico, estos resultados señalan que el modelo base adecuado para analizar este fenómeno es un modelo de panel donde se instrumentalicen las variables que presentan problemas de heterogeneidad. En los análisis econométricos que se realicen en el futuro se debería considerar lo siguiente:

- En la estimación se deben usar variables instrumentales y se deben incluir las variables relativas a la educación y la calidad de las instituciones. Además, es importante buscar instrumentos alternativos para no perder tanta información ${ }^{14}$.

- Dado que los resultados con respecto a la calidad de las instituciones parecen ser sensibles a la variable utilizada, sería conveniente probar con otras variables que pudieran representar la calidad institucional, e incluso se deberían utilizar varios instrumentos y decidir cuál es la mejor opción utilizando una prueba de Sargan.

- Se deben incorporar al modelo las variables iniciales (ficticias de especialización, D1 y D2), tanto de forma individual como cruzada con respecto a la corrupción.

- Se deben incluir en los modelos otras variables identificadas en la literatura que puedan contribuir a explicar los índices de Gini: renta per cápita, renta per cápita al cuadrado (efecto Kuznet), desigualdad en la educación, distribución inicial de bienes, gasto social, capital por trabajador y otras.

14 En algunos casos solo queda una observación por país, lo que no es recomendable para estimar efectos fijos. 


\section{Bibliografía}

Asiedu, E. (2006), Foreign Direct Investment in Africa: The Role of Natural Resources, Market Size, Government Policy, Institutions and Political Instability, United Nations University.

Birdsall, N. y J.L. Londoño (1997), "Asset inequality matters: an assessment of the World Bank's approach to poverty reduction", The American Economic Review, vol. 87, $\mathrm{N}^{\mathrm{o}} 2$.

Buccellato T. y M. Alessandrini (2009), "Natural resources: a blessing or a curse? The role of inequality", Centre for Financial and Management Studies, Discussion Paper, $\mathrm{N}^{\mathrm{o}} 98$.

Chong, A. y M. Gradstein (2007), "Inequality and Institutions", Review of Economics and Statistics, vol. 89, $\mathrm{N}^{\mathrm{o}} 3$.

Collier, P. (2010), "The political economy of natural resources", Social Research, vol. $77, \mathrm{~N}^{\circ} 4$.

Davis, G.A. (2009), "Extractive economies, growth and the poor", Mining, Society, and a Sustainable World, J. Richards (ed.), Berlín, Springer-Verlag.

Davis, G.A. y A.L.V. Vasquez Cordano (2013), "The fate of the poor in growing mineral and energy economies", Resources Policy, vol. 38.

De Gregorio, J. y J-W. Lee (2002), “Education and income inequality: new evidence from cross-country data", Review of Income and Wealth Series, vol. 48, Nº 3 .

Deaton, B.J. y E. Niman (2012), "An empirical examination of the relationship between mining employment and poverty in the appalachian region", Applied Economics, vol. 44.

Echeme, I.I. y E.C. Ubani (2010), "A correlation of natural resource management and level of development in developing countries: a case of Nigeria", Report and Opinion, vol. 2, $\mathrm{N}^{\mathrm{o}} 7$.

Engerman, S. y K. Sokoloff (2012), "The role of institutions in shaping factor endowments", Economic Development in the Americas since 1500: Endowments and Institutions, Cambridge University Press.

(2002), "Factor endowments, inequality, and paths of development among new world economies", NBER Working Paper, $\mathrm{N}^{\mathrm{0}} 9259$.

(1997), "Factor endowments, institutions, and differential paths of growth among new world economies: a view from economic historians of the United States", Economic Growth and Latin American Economic Historiography, S. Haber (ed.), Cambridge, MIT Press.

Fum, R.M. y R. Hodler (2010), “Natural resources and income inequality: The role of ethnic divisions", Economics Letters, vol.10,

Goderis, B. y S.W. Malone (2011), "Natural resource booms and inequality: Theory and evidence", Scandinavian Journal of Economics, vol.113.

Gupta, S., H. Davoodi y R. Alonso-Terme (2002), “Does corruption affect income inequality and poverty?", Economics of Governance, vol. 3.

Gyimah-Brempong, K. (2002), "Corruption, economic growth, and income inequality in Africa", Economics of Governance, vol. 3.

Gyimah-Brempong, K. y S. Muñoz de Camacho (2006), "Corruption, growth, and income distribution: are there regional differences?", Economics of Governance, vol. 7.

Gylfason, T. (2001), "Natural resources, education, and economic development", European Economic Review, vol. 45. 
Gylfason, T. y G. Zoega (2003), "Inequality and economic growth: do natural resources matter?", Inequality and Growth: Theory and Policy Implications, T. S. Eicher y S. J. Turnovsky (eds.), Cambridge, MIT Press.

Hajkowicz, S.A., S. Heyenga y K. Moffat (2011), "The relationship between mining and socio-economic well being in Australia's regions", Resources Policy, vol. 36.

Isham, J. y otros (2005), "The varieties of resource experience. Natural resource export structures and the political economy of growth", The World Bank Economic Review, vol. 19, $\mathrm{N}^{\mathrm{o}} 2$.

James, A. y D. Aadland (2011), "The curse of natural resources: An empirical investigation of U.S. counties", Resource and Energy Economics, vol. 33.

Lagos, G. y E. Blanco (2010), "Mining and development in the region of Antofagasta", Resources Policy, vol. 35.

Li, H., L. Xu y H. Zou (2000), "Corruption, income distribution, and growth", Economics and Politics, vol.12, $\mathrm{N}^{\mathrm{o}} 2$.

Narain, U., S. Guptab y K.van'tVeld (2008), “Poverty and resource dependence in rural India", Ecological Economics, vol. 66.

Partridge, M.D., M.R. Betz y L. Lobao (2012), “Natural curse and poverty in Appalachian America: Natural resources and the dynamics of income and wealth inequality in rural America", American Journal of Agricultural Economics, vol. $95, \mathrm{~N}^{\mathrm{o}} 2$.

Roemer, M. y M.K. Gugerty (1997), Does Economic Growth Reduce Poverty?, Harvard Institute for International Development.

Sala-i-Martin, X. y A. Subramanian (2003), “Addressing the natural resource curse: an illustration from Nigeria", NBER Working Paper Series, N 9804.

Sinnott, E., J. Nash y A. de la Torre (2010), Natural Resources in Latin America and the Caribbean: Beyond Booms and Busts?, Washington, D.C., Banco Mundial.

Spilimbergo, A., J.L. Londoño y M. Szekely (1999), "Income distribution, factor endowments, and trade openness", Journal of Development Economics, vol. 59.

Stijns, J.P. (2009), "Mineral wealth and human capital accumulation: a nonparametric approach", Applied Economics, vol. 41, No 23.

van der Ploeg, F. y S. Poelhekke (2010), “The pungent smell of 'red herrings': Subsoil assets, rents, volatility and the resource curse", Journal of Environmental Economics and Management, 60.

Yuxiang, K. y Z. Chen (2011), "Resource abundance and financial development: Evidence from China", Resources Policy, vol. 36. 

Capítulo IX

\section{Evidencia estadística de superciclos en las series de precios de los metales y el petróleo, 1900-2015}

Jean J. Acquatella

Omar D. Bello

Félix Berríos

En este capítulo se evalúa la evidencia estadística de componentes cíclicos de largo plazo en las series históricas del precio real de los metales y el petróleo crudo. Se encuentran pruebas de entre tres y cuatro superciclos en las series anuales de 1900-2015, con una duración media respectiva de 31,6 y 16 años en las fases de auge y caídas de los precios. El último superciclo se inició alrededor del año 2000, tuvo una duración media de 15 años y supera a los anteriores en la magnitud que alcanzó, con niveles de precio que no se veían desde la década de 1970. Sin embargo, este último período de auge ya concluyó.

Este resultado es robusto en relación con todos los bienes estudiados $\mathrm{y}$, en términos de los períodos analizados, actualmente se desarrolla la fase de caída de precios del superciclo en curso. Todas las series presentan reversiones sucesivas hacia sus niveles de tendencia de largo plazo, la que es ligeramente decreciente o plana respecto de los metales industriales y solo creciente en el caso del petróleo. Las series trimestrales de 1960-2015 evidencian comovimiento y persistencia, con una alta correlación entre los precios del petróleo crudo, el oro y la plata. Esta caracterización, junto a componentes cíclicos de duración media superior a tres décadas y a una década y media en sus auges y caídas, tiene implicaciones respecto de los 
horizontes de tiempo que debe considerar la política macroeconómica en los países exportadores de metales e hidrocarburos de la región.

La dinámica positiva que presentaron los precios reales de los productos básicos de exportación de América Latina durante la última década no tiene precedentes desde 1970. Impulsó una recuperación del crecimiento en la mayoría de los países de la región, con un aumento significativo del consumo y disminución de la pobreza, así como mejoras en los indicadores socioeconómicos de la población no vistas desde hacía más de tres décadas.

En términos de ingresos fiscales y del total de sus exportaciones, esa dinámica tuvo impactos importantes en los países de la región con alta dependencia de los sectores extractivos (minería metálica y petróleo). La gran rentabilidad que mostraron estos sectores durante el auge de precios indujo al arribo de nuevos proyectos de inversión que expandieron la capacidad exportadora de productos primarios, lo que reforzó aún más esa dependencia. En cinco países (Bolivia (Estado Plurinacional de), Ecuador, México, Trinidad y Tabago y Venezuela (República Bolivariana de)), los ingresos fiscales por la explotación y exploración de hidrocarburos alcanzaron entre el $30 \%$ y el $40 \%$ del ingreso fiscal total. Les siguieron Suriname y Colombia, con el $25 \%$ y el $12 \%$, respectivamente, durante el período 2010-2014, cuando se registraron los precios máximos del petróleo (véase el cuadro IX.1). Con respecto a los ingresos fiscales por explotación minera, en Chile y el Perú estos alcanzaron, respectivamente, el $28 \%$ y el $11 \%$ del ingreso fiscal total durante el período de auge de precios de los metales que se registró entre 2005 y 2008.

\section{Cuadro IX.1}

Ingresos fiscales por explotación de hidrocarburos y explotación minera (En porcentajes de los ingresos fiscales totales)

\begin{tabular}{|c|c|c|c|c|c|c|}
\hline & \multicolumn{3}{|c|}{ Explotación de hidrocarburos } & \multicolumn{3}{|c|}{ Explotación minera } \\
\hline & $2000-2003$ & $2005-2008$ & $2010-2014$ & $2000-2003$ & $2005-2008$ & 2010-2014 \\
\hline Argentina & 4,5 & 7,3 & 3,4 & $(:)$ & 0,4 & 0,4 \\
\hline $\begin{array}{l}\text { Bolivia (Estado } \\
\text { Plurinacional de) }\end{array}$ & 11,0 & 28,2 & 30,2 & 0,4 & 2,0 & 2,8 \\
\hline Brasil & 2,8 & 3,9 & 3,0 & 0,1 & 0,5 & 0,8 \\
\hline Colombia & 5,6 & 8,2 & 12,0 & 4,0 & 28,1 & 13,8 \\
\hline Ecuador & 29,3 & 35,3 & 38,2 & 3,2 & 17,5 & 6,5 \\
\hline México & 21,1 & 38,3 & 32,7 & 0,8 & 10,6 & 5,4 \\
\hline Perú & 3,2 & 5,9 & 6,9 & 0,5 & 1,5 & 1,3 \\
\hline Suriname & $\ldots$ & 20,7 & 24,8 & 2,1 & 2,1 & 0,4 \\
\hline Trinidad y Tabago & 31,3 & 51,8 & 40,2 & 0,3 & 0,8 & 1,0 \\
\hline $\begin{array}{l}\text { Venezuela (República } \\
\text { Bolivariana de) }\end{array}$ & 48,2 & 50,6 & 39,3 & 1,0 & 10,6 & 6,4 \\
\hline
\end{tabular}

Fuente: J.C. Gómez Sabaini, J.P. Jiménez y D. Morán, "El impacto fiscal de los recursos naturales no renovables en América Latina y el Caribe", Documentos de Proyectos (LC/W.658), Santiago, Comisión Económica para América Latina y el Caribe (CEPAL), 2015; CEPAL, Pactos para la igualdad: hacia un futuro sostenible (LC/G.2586 (SES.35/3)), Santiago, 2014 y Panorama Fiscal de América Latina y el Caribe, 2015 (LC/L.3961), Santiago, 2015. 
Las exportaciones de minería metálica llegaron a representar un $21,4 \%$ del total de las ventas externas de los países de América Latina y el Caribe, lo que casi ha duplicado su promedio del 11,7\% entre 2000 y 2003. El peso de la minería en las exportaciones totales triplicó su peso relativo en el PIB regional, lo que revela su importancia para el ingreso de divisas y el balance externo de la región. Con respecto a las exportaciones, en el período 2010-2012 la minería llegó a representar, en promedio, un 21,4\% del total de las ventas externas de los países de América Latina y el Caribe, lo que casi duplicó el promedio de la región entre 2000 y 2003. Los metales y el petróleo se caracterizan por presentar curvas de oferta altamente inelásticas a corto plazo, debido a los largos períodos de gestación de los procesos de exploración y desarrollo de nuevos yacimientos, y la expansión de los existentes. En esas condiciones, una aceleración sostenida de la demanda de metales industriales y de energía, como puede darse en ciertas fases de desarrollo industrial y de urbanización de economías grandes, ocasiona un aumento de los precios que solo se revierte cuando la oferta logra ajustarse gradualmente a lo largo del tiempo.

Entre 2000 y 2014, el consumo de metales en China creció a tasas superiores al $10 \%$ anual, pues ese país pasó de consumir aproximadamente del $10 \%$ a cerca del $50 \%$ de la producción mundial de metales. El consumo de metales también aumentó en otras economías emergentes como las de la Federación de Rusia, la India y la República de Corea, lo que estimuló los precios y motivó inversiones que incrementaron sustancialmente la capacidad del sector. A partir de 2011, el nivel de precio de los metales ha venido cayendo, de forma coincidente con la desaceleración del crecimiento en China. A nivel global, reflejó el fortalecimiento de la oferta de metales gracias a las inversiones anteriores y los ajustes recientes en su demanda. El precio del petróleo experimentó durante este período una dinámica de auge similar a la de otros bienes primarios, seguida también por una caída que se intensificó a partir de 2014 con la decisión de los países de la Organización de Países Exportadores de Petróleo (OPEP) de no ajustar su producción.

Una mayor comprensión de las dinámicas de largo plazo y de los determinantes que afectan el comportamiento de la serie de precios de los metales e hidrocarburos es crucial para los países de América Latina y el Caribe. En particular, una caracterización estadística de los componentes cíclicos de más largo plazo tiene implicaciones respecto del diseño de políticas macroeconómicas y reglas macrofiscales, entre otros mecanismos de estabilización. También incide en la operación idónea de los fondos soberanos de ahorro e inversión y en el nivel de prioridad que deberían tener las políticas de diversificación productiva. 
El presente trabajo contribuye al logro de ese objetivo mediante la caracterización econométrica de la serie de precios históricos del petróleo y los principales metales que exporta la región. A ese efecto, se estiman sus componentes cíclicos de distinta frecuencia o duración, las tendencias de largo plazo y el comovimiento y la persistencia (con énfasis en el análisis del último ciclo). Al respecto, se utilizaron series anuales de precios reales de siete productos básicos correspondientes al período 1900-2015: cuatro metales industriales (aluminio, cobre, estaño, hierro, zinc), dos metales utilizados como reserva de valor (oro y plata) y un hidrocarburo (petróleo). La periodicidad anual se seleccionó con el fin de captar los movimientos a largo plazo de esas cotizaciones. Entretanto, para captar dinámicas que ocurren en un lapso temporal menor se utilizaron series trimestrales de los precios de esos metales entre el primer trimestre de 1960 y el cuarto trimestre de 2015. También se tuvo en cuenta la evolución de los precios del petróleo y el gas natural durante ese último período.

Según la evidencia estadística en relación con todos los precios reales de los productos básicos considerados, hubo al menos cuatro superciclos. Su duración media fue de 31,6 años, y la máxima, de 43 años, mientras que la duración media de las fases de auge y caída de las cotizaciones reales fue de 16 años. Toda la evidencia apunta a que la fase de auge de precios reales del actual superciclo ya concluyó respecto de todos los productos básicos y actualmente transcurre la fase de reversión de precios. Desde 2011, el nivel de precio real de los metales ha caído en promedio un $45 \%$, mientras que en el caso del petróleo el descenso ha sido de un $60 \%$. De modo similar, se encontró evidencia de comovimientos entre los precios reales del cobre, el estaño y el zinc, así como entre el oro y la plata.

\section{A. Ciclos}

En esta sección se presentan los resultados de los componentes cíclicos estimados en las series de precios. Un ciclo se define como un período de tiempo que comprende una fase de auge (fase ascendente) y una de caída de precios (fase descendente). A su vez, el auge comienza en un mínimo local y termina con un máximo local, y viceversa, respecto de la caída de precios. En la presente sección se utiliza la definición de superciclo propuesta por Cuddington y Jerrett (2008). Se consideran superciclos los que abarcan períodos de entre 20 y 70 años, que se distinguen de ciclos más breves, es decir, de menos de 20 años. 


\section{Superciclos}

Las estimaciones de los superciclos se efectuaron con datos anuales de los precios del aluminio, cobre, estaño, zinc, oro, plata y petróleo correspondientes al período 1900-2015. Todas las series fueron deflactadas mediante la aplicación del índice de precios al productor de bienes básicos de los Estados Unidos. En los precios reales de los productos básicos incluidos en la muestra se encontró evidencia estadística de la presencia de al menos cuatro superciclos, según la definición utilizada en todas las series de precios reales estudiadas entre 1900 y 2015. Los precios reales del cobre, el estaño, el zinc, el oro y la plata experimentaron cuatro superciclos. Estos fueron cinco en el caso del aluminio y el petróleo crudo, incluido el superciclo actualmente en curso (véase el cuadro IX.2). Los superciclos estimados respecto de los precios reales de los metales tuvieron una duración media de 32,1 años. En el caso del petróleo, la duración media fue de 28,7 años. Es decir, ambos tuvieron duraciones cercanas a las tres décadas. La duración media de las fases de auge y caída de precios en estos superciclos fue de 16 años. Sin embargo, este promedio no revela la gran heterogeneidad detectada en la duración de los superciclos. Las caídas más dilatadas, de 29 años en el caso del cobre y 27 años en el del zinc, se encontraron en el superciclo previo al actual. Les siguen caídas de 24 años en el estaño y el petróleo en el superciclo anterior a este último. Por su parte, los auges más duraderos fueron de 27 años en el caso del oro y de 19 años en el de la plata y el estaño, todos encontrados en el superciclo previo al actual (véanse los cuadros IX.2 y IX.3).

\section{Cuadro IX.2}

\section{Superciclos: fechas de los máximos y mínimos}

\begin{tabular}{|c|c|c|c|c|c|c|c|c|c|c|c|c|c|c|c|}
\hline \multirow{2}{*}{ Metales } & \multicolumn{3}{|c|}{ Superciclo 1} & \multicolumn{3}{|c|}{ Superciclo 2} & \multicolumn{3}{|c|}{ Superciclo 3} & \multicolumn{3}{|c|}{ Superciclo 4} & \multicolumn{3}{|c|}{ Superciclo 5} \\
\hline & Mín. & Máx. & Mín. & Mín. & Máx. & Mín. & Mín. & Máx. & Mín. & Mín. & Máx. & Mín. & Mín. & Máx. & Mín. \\
\hline \multicolumn{16}{|c|}{ Industriales } \\
\hline Aluminio & $\ldots$ & 1905 & 1920 & 1920 & 1935 & 1949 & 1949 & 1961 & 1971 & 1971 & 1983 & 1996 & 1996 & 2009 & $\begin{array}{l}\text { En } \\
\text { curso }\end{array}$ \\
\hline Cobre & $\ldots$ & 1909 & 1936 & 1936 & 1952 & 1955 & 1955 & 1969 & 1998 & 1998 & 2013 & $\begin{array}{l}\text { En } \\
\text { curso }\end{array}$ & $\ldots$ & $\ldots$ & $\ldots$ \\
\hline Estaño & $\ldots$ & 1911 & 1925 & 1925 & 1936 & 1960 & 1960 & 1979 & 1997 & 1997 & 2014 & $\begin{array}{l}\text { En } \\
\text { curso }\end{array}$ & $\ldots$ & $\ldots$ & $\ldots$ \\
\hline Zinc & $\ldots$ & 1910 & 1931 & 1931 & 1947 & 1961 & 1961 & 1973 & 2000 & 2000 & 2014 & $\begin{array}{l}\text { En } \\
\text { curso }\end{array}$ & $\cdots$ & $\cdots$ & $\cdots$ \\
\hline \multicolumn{16}{|c|}{ Reservas de valor } \\
\hline Plata & $\ldots$ & 1918 & 1918 & 1941 & 1945 & 1960 & 1960 & 1979 & 1997 & 1997 & 2013 & $\begin{array}{l}\text { En } \\
\text { curso }\end{array}$ & $\ldots$ & $\ldots$ & $\ldots$ \\
\hline Oro & $\ldots$ & 1906 & 1906 & 1922 & 1938 & 1955 & 1955 & 1982 & 1998 & 1998 & 2014 & $\begin{array}{l}\text { En } \\
\text { curso }\end{array}$ & $\ldots$ & $\ldots$ & $\ldots$ \\
\hline Petróleo & 1909 & 1924 & 1924 & 1934 & 1942 & 1966 & 1966 & 1981 & 1995 & 1995 & 2009 & $\begin{array}{l}\text { En } \\
\text { curso }\end{array}$ & $\ldots$ & $\ldots$ & $\ldots$ \\
\hline
\end{tabular}

Fuente: Comisión Económica para América Latina y el Caribe (CEPAL). 
完商

产

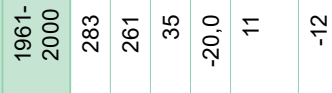

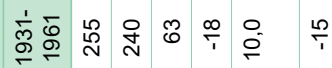

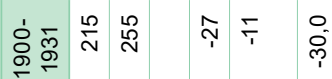

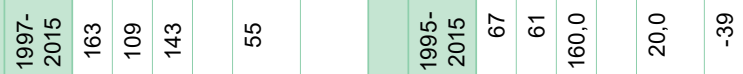

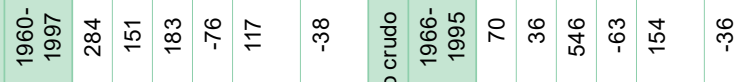

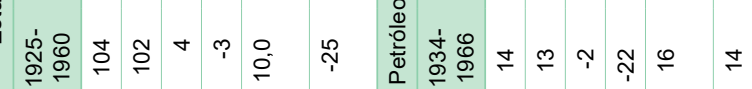

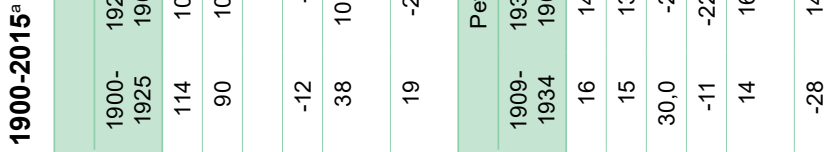

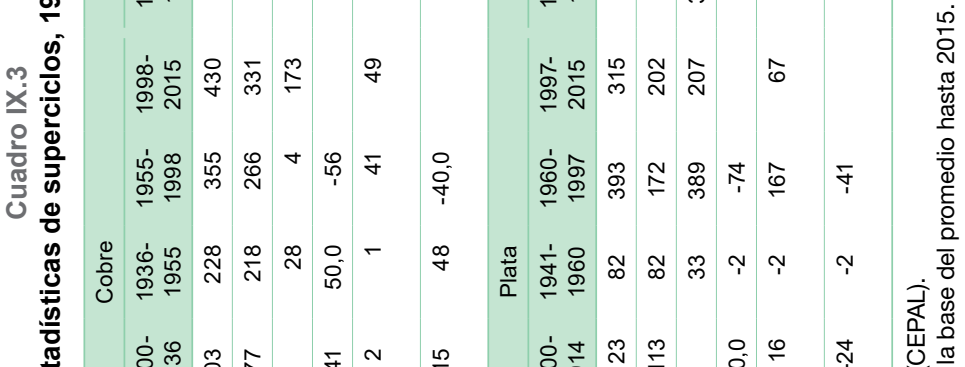

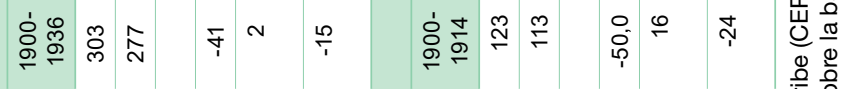

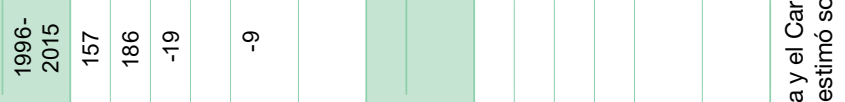

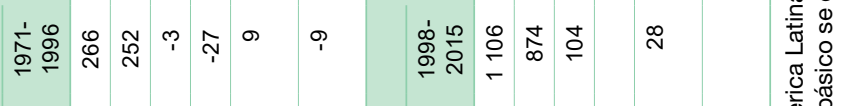

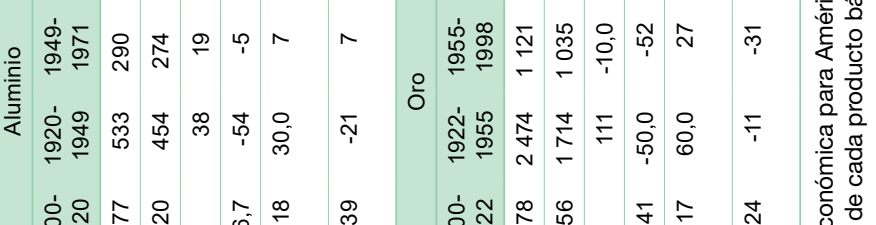

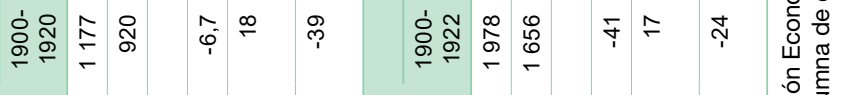

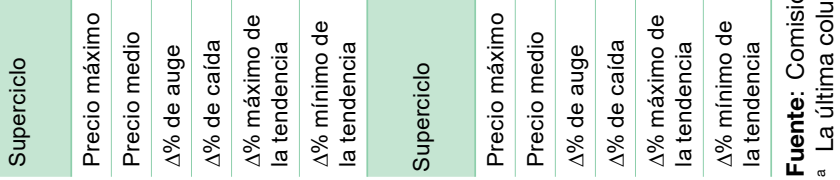


La magnitud de los cambios que registraron los precios en estos superciclos se puede medir como la diferencia entre el precio mínimo y el máximo alcanzados en la fase de auge o de caída (véase el cuadro IX.3). Respecto de todo el período 1900-2015 se encontró que la magnitud de esta diferencia fue superior al $100 \%$ en el $21 \%$ de los auges y caídas; superior al $40 \%$ en el $49 \%$ de los auges y caídas, y superior al $20 \%$ en el $67 \%$ de los auges y caídas en las series estudiadas.

La magnitud del ciclo también se puede medir como la máxima diferencia alcanzada entre el precio (sea mínimo o máximo) y el nivel correspondiente a su tendencia de largo plazo. Respecto de todo el período 1900-2015, la magnitud media de las desviaciones del nivel de precio por encima o por debajo de su nivel de tendencia a largo plazo fue del $24 \%$ y el $-14 \%$ en el caso de los metales industriales, del $47 \%$ y el $-26 \%$ en el del oro y la plata, y del $51 \%$ y el $-22 \%$ en el del petróleo. La magnitud de estas desviaciones aumentó en los dos últimos superciclos que han tenido lugar a partir de 1960. Las variaciones de precio de mayor magnitud se han dado en el petróleo, seguido del oro y la plata. Estos resultados son coherentes con el hecho de que los metales utilizados como reserva de valor (el oro y la plata) y el petróleo muestran comportamientos claramente diferenciados de los metales industriales. A continuación, se presentan los resultados encontrados respecto del superciclo más reciente.

\section{a) Duración, magnitud y fin del último auge de precios}

La fase de auge de precios del superciclo actual duró aproximadamente 15 años, muy cercana a la media de 14,6 años del conjunto de las fases de auge encontradas entre 1900 y 2015. Con respecto a la magnitud de este último auge, en todos los bienes estudiados, con excepción del aluminio, el máximo precio real alcanzado superó con creces el nivel de la tendencia a largo plazo. Por ejemplo, el precio real del cobre llegó hasta un $49 \%$ por encima de su nivel de tendencia; del estaño, hasta un 55\% por encima; del zinc, un $9 \%$; del oro, un $28 \%$; de la plata, un $67 \%$, y del petróleo, un $20 \%$. Sin embargo, al comparar las magnitudes de estas desviaciones por encima del nivel de tendencia con las alcanzadas en el superciclo anterior al actual (1960-1998, aproximadamente), se puede apreciar que no son excepcionales (véase el cuadro IX.3).

En todos los productos estudiados, esta metodología señala que la fase de auge de precios del superciclo en curso llegó a su fin, ya que en todos esos casos los precios reales ya alcanzaron sus últimos máximos y se encuentran actualmente dentro de fases de caída de precios, en dirección hacia sus niveles de tendencia de largo plazo. En cada una de estas series, el componente cíclico, que aquí se denomina superciclo, alcanzó su máximo nivel y comenzó a caer entre 2009 (aluminio) y 2014 (estaño). En el caso de los metales de reserva de valor, esto ocurrió entre 2013 (plata) y 2014 (oro), mientras que, en el del 
petróleo, ocurrió en 2009. Actualmente, todos estos bienes se encuentran dentro de una fase de caída de precios, pues han perdido hasta la fecha entre un $30 \%$ y un $60 \%$ del nivel que alcanzaron sus precios reales en el último máximo que puso fin a su fase de auge (véase el cuadro IX.3).

\section{b) Caracterización del superciclo previo al actual y heterogeneidad entre los ciclos}

El superciclo anterior al actual fue excepcional por su duración media de 37 años y porque el precio real del cobre y del oro experimentaron ciclos de 43 años. La fase de caída de precios del cobre y el zinc se prolongó durante 29 y 27 años, de modo que perdieron, respectivamente, el $56 \%$ y el $20 \%$ de su valor real en comparación con sus máximos previos, registrados en 1969 y 1973. Respecto de los otros metales, esta fase de caída se prolonga durante 20 años en promedio, desde el segundo shock petrolero de 1980 y hasta el inicio del superciclo actual, que comenzó alrededor de 2000. Durante esta caída, el aluminio, el estaño, el oro y la plata perdieron, respectivamente, el $27 \%$, el $76 \%$, el $52 \%$ y el $74 \%$ de su precio real en relación con su máximo anterior. A su vez, entre 1981 y 1995 el petróleo perdió el $63 \%$ de su precio real.

En este punto mínimo que marca el fin del superciclo previo y el inicio de la fase de auge del actual, los niveles de precio real se encontraban por debajo de su nivel de tendencia a largo plazo en un $-40 \%$ en el caso del cobre, un $-38 \%$ en el estaño, un $-12 \%$ en el zinc, un $-9 \%$ en el aluminio, un $-31 \%$ en el oro, un $-41 \%$ en la plata y un $-36 \%$ en el petróleo crudo. A partir de estos mínimos, durante los siguientes 15 años de auge del superciclo actual hasta alcanzar nuevos máximos, el precio real del cobre subió un $173 \%$; el del estaño, un $143 \%$; el del zinc, un $27 \%$; el del oro, un $104 \%$; el de la plata, un $207 \%$, y el del petróleo, un $160 \%$. Esto sugiere que parte del incremento que se registró durante el último auge de precios puede interpretarse como un rebote de los precios reales hacia sus niveles tendenciales a largo plazo (véase el cuadro IX.3).

Durante la fase de auge del superciclo anterior al actual, que tuvo lugar en la década de 1970 en torno a los shocks petroleros, las magnitudes de esta recuperación del precio real entre los niveles mínimo y máximo alcanzados fueron de un $4 \%$ en el caso del cobre, un $183 \%$ en el estaño, un $35 \%$ en el zinc, un $-10 \%$ en el oro, un $389 \%$ en la plata y un $546 \%$ en el petróleo. Estas estadísticas ilustran la gran heterogeneidad que existe en la duración y en las magnitudes de las desviaciones de precio observadas en las fases de auge y caída entre los distintos bienes estudiados. Esta heterogeneidad sirve para enfatizar que en ningún caso debe interpretarse que la estimación de superciclos en las series de precios de bienes primarios sea indicio de regularidades. La característica que sí es homogénea y se confirma en todas las series de precios estudiadas es que el comportamiento 
de los precios de estos bienes se caracteriza por reversiones sucesivas hacia sus niveles tendenciales a largo plazo. Este comportamiento es precisamente lo que imprime el carácter cíclico a las series, lo que niega la posibilidad de auges o caídas de los precios de forma permanente.

\section{c) Algunas implicaciones}

Los metales y el petróleo se caracterizan por presentar curvas de oferta altamente inelásticas a corto plazo. Ello es reflejo de los largos períodos de gestación inherentes a los procesos de exploración y desarrollo de nuevos yacimientos, que pueden superar las dos décadas, o de expansión de la capacidad actual en depósitos existentes, que suelen tomar alrededor de una década. Sin embargo, a largo plazo, estas curvas de oferta tienden a ser relativamente planas. Acomodan la demanda y reflejan nuevamente los costos marginales de producción de estos bienes. Estas características son coherentes con dinámicas cíclicas donde los períodos de aceleración de la demanda global pueden generar auges de precio prolongados. Estos solo se revierten a medida que la respuesta de inversión logra volver a expandir la capacidad de la oferta y devolver los precios a sus niveles tendenciales a largo plazo.

El alcance del presente estudio se limitó al trabajo estadístico y econométrico necesario para producir los resultados expuestos. Sin embargo, fue importante la constatación de: i) componentes cíclicos en las series de precios con duración media superior a tres décadas en el ciclo completo y a una década y media en sus fases de auge y caída; ii) magnitudes de variación de precios que superan el 40\% en el registro histórico 1900-2015, y iii) a su vez, sucesivas reversiones de los precios hacia el nivel del $100 \%$, respectivamente en la mitad y un quinto de todos los auges y caídas. Todo lo anterior sugiere los puntos generales que se exponen a continuación.

En primer lugar, se resalta la importancia para los países que se especializan en metales e hidrocarburos de evaluar su vulnerabilidad frente a variaciones cíclicas de los precios en horizontes temporales mucho más amplios que los que se utilizan normalmente para el diseño de los mecanismos de estabilización, como las reglas macrofiscales y los fondos soberanos de inversión. También se sugiere considerar las limitaciones que pueden tener los actuales mecanismos de estabilización como opciones viables para hacer frente a ciclos de largo plazo con rangos de duración y magnitud como los observados en las series de precios entre 1900 y 2015. En relación con este último punto, el reconocimiento de una variabilidad cíclica importante en los precios a largo plazo vuelve a poner de relieve el riesgo que conlleva la sobreespecialización en estos bienes. También demuestra la necesidad de revaluar la prioridad política que otorgan el Estado y el sector privado nacional al logro de una mayor diversificación del aparato productivo a mediano plazo (véase el gráfico IX.1). 
Gráfico IX.1

Superciclos: precio real de los metales industriales, 1900-2015 (En logaritmos)

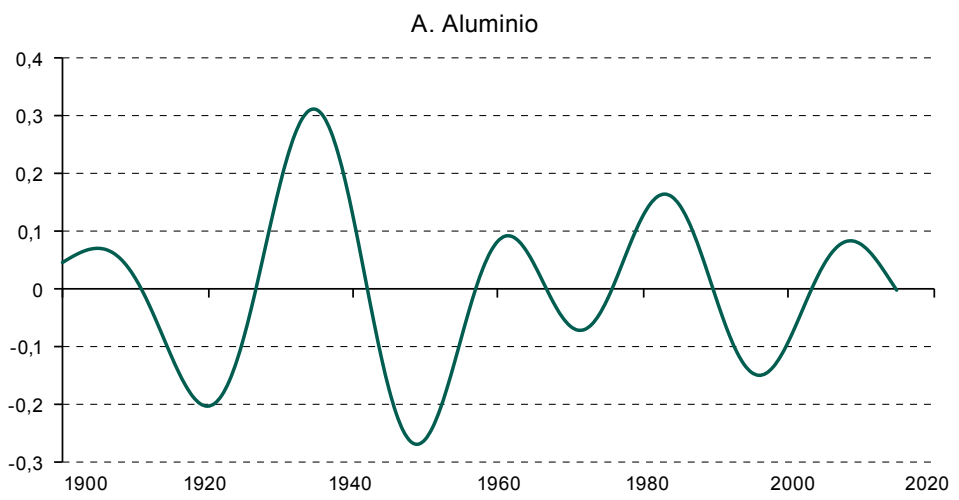

B. Cobre

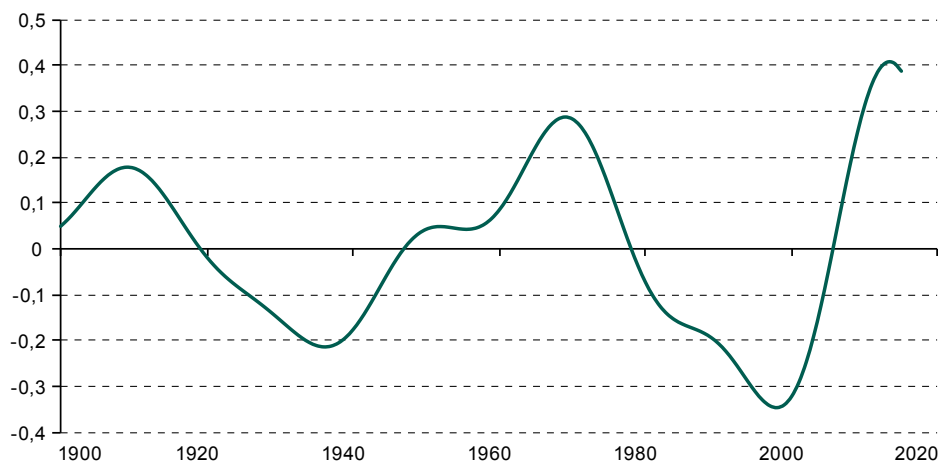

C. Estaño

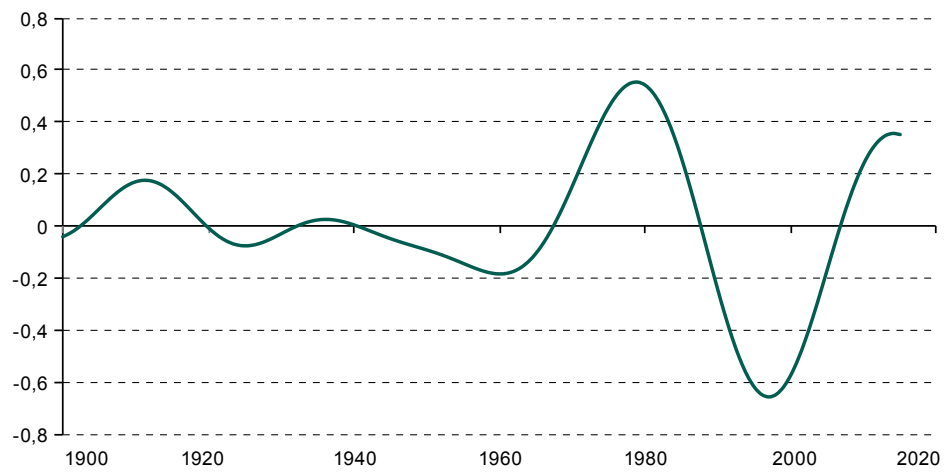


Gráfico IX.1 (continuación)

D. Zinc

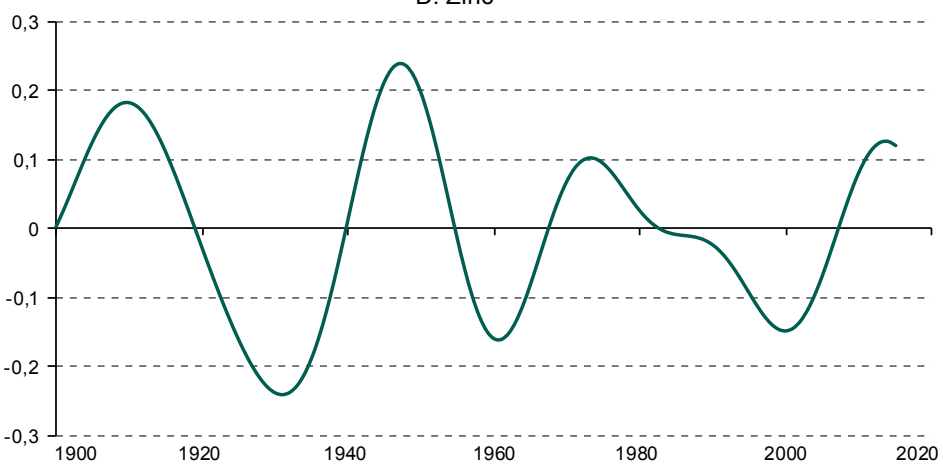

E. Oro

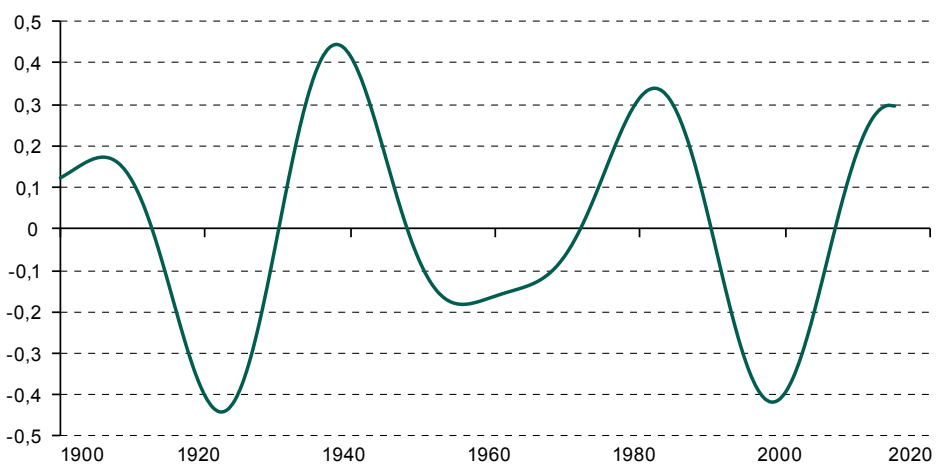

F. Plata

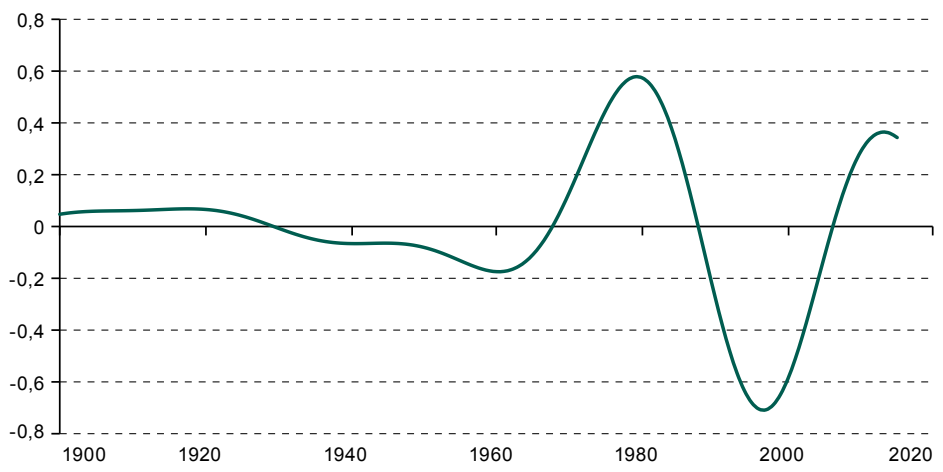


Gráfico IX.1 (conclusión)

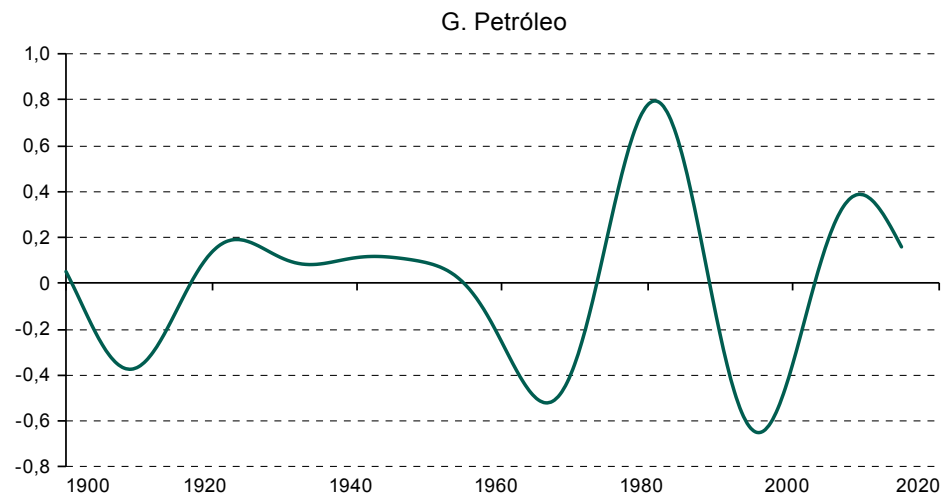

Fuente: Comisión Económica para América Latina y el Caribe (CEPAL).

\section{B. Tendencias}

En esta sección se describen las tendencias encontradas en las series de precios reales de los metales y el petróleo. Se estimaron dos tipos de tendencias. En las series anuales correspondientes al período 1900-2015, la metodología aplicada a la identificación de superciclos en la sección anterior permite obtener en la descomposición de las series de precios una tendencia a largo plazo, que en este caso se refiere a componentes cíclicos de una periodicidad superior a 70 años. A los efectos del presente trabajo, este fenómeno se denomina tendencia Cuddington y Jerret o tendencia CJ. Va variando muy gradualmente a lo largo del tiempo y reflejando la dinámica del precio real en horizontes superiores a siete décadas. En las series trimestrales 1960-2015, se estimaron las tendencias lineales por tramo a partir de la metodología de filtro L1 desarrollada por Yamada y Yoon (2015). Esta permite encontrar los puntos de quiebre en las series de precios reales, así como los cambios de signo que experimenta la tendencia lineal en los tramos resultantes entre esos puntos.

\section{Tendencia Cuddington y Jerret (CJ)}

La tendencia de largo plazo CJ muestra un comportamiento heterogéneo entre grupos de metales, así como entre estos y el petróleo. Los precios reales de los metales industriales, en particular los no ferrosos (cobre, estaño y zinc) exhiben una tendencia relativamente plana o ligeramente decreciente en relación con los niveles que alcanzaban a comienzos del siglo pasado. Por su parte, como se aprecia en el gráfico IX.2, el precio real del aluminio muestra una tendencia decreciente a lo largo de todo el período. Esta tendencia plana o ligeramente decreciente en el precio real de los 
metales industriales indica que el ritmo de exploración, descubrimientos, desarrollo tecnológico y productividad general de la minería se ha visto más que compensado hasta ahora por cualquier efecto de escasez relativa que se hubiera manifestado como una tendencia al alza del precio real de estos metales a largo plazo. Durante las primeras décadas del siglo pasado, el oro y la plata presentaron una tendencia decreciente, seguida por una creciente. Sin embargo, esta reversión de tendencias entre la plata y el oro ocurre con 50 años de diferencia. En el caso del precio de la plata, el cambio en el signo de la tendencia acontece en la década de 1940, mientras que, en el del oro, ocurre en la década de 1990 (véase el gráfico IX.3).

A diferencia de los metales, el petróleo registra una tendencia creciente a largo plazo en el período objeto de análisis. Durante la última mitad del siglo pasado, se intensificó la pendiente de esta tendencia del precio real del crudo. La tendencia creciente a largo plazo en el precio del petróleo durante los últimos 50 años puede asociarse a diversos factores. Entre ellos cabe mencionar el aumento del costo marginal de producción debido al agotamiento de los yacimientos tradicionales y el desarrollo de yacimientos en alta mar (por ejemplo, en el mar del Norte y el golfo de México), el mayor control de la oferta por parte de los Estados productores (con inclusión de cuotas de producción en el caso de la OPEP, así como el efecto de las coyunturas políticas en el Oriente Medio y las coyunturas financieras internacionales, entre otras). Este cúmulo de factores ha determinado un comportamiento a largo plazo del precio de este hidrocarburo que se diferencia claramente del de los metales (véase el gráfico IX.4). (En logaritmos)

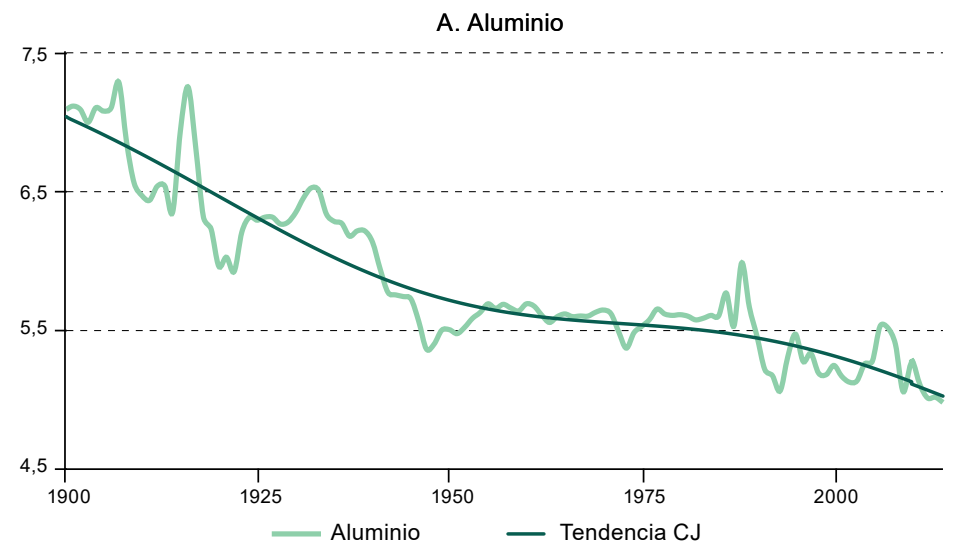


Gráfico IX.2 (conclusión)

B. Cobre

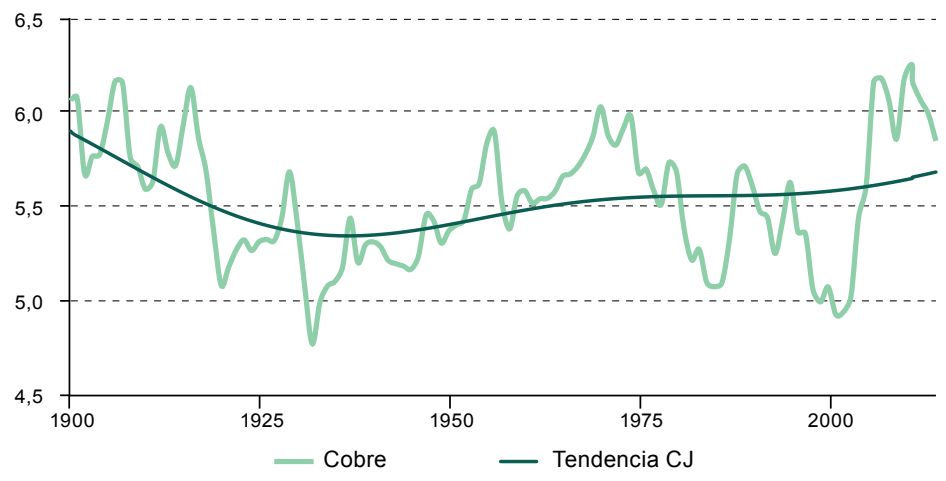

C. Estaño

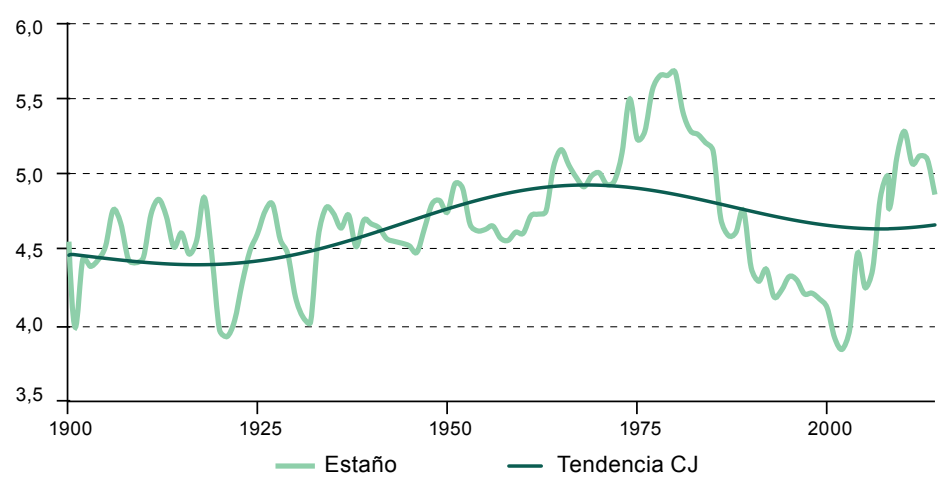

D. Zinc

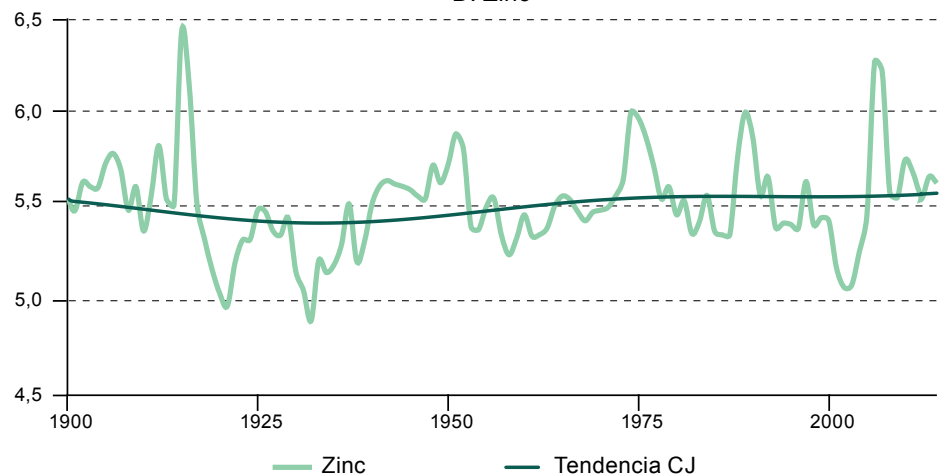

Fuente: Comisión Económica para América Latina y el Caribe (CEPAL). 


\section{Gráfico IX.3}

Metales utilizados como reserva de valor: precio real y tendencia Cuddington y Jerret (CJ), 1900-2015

A. Oro
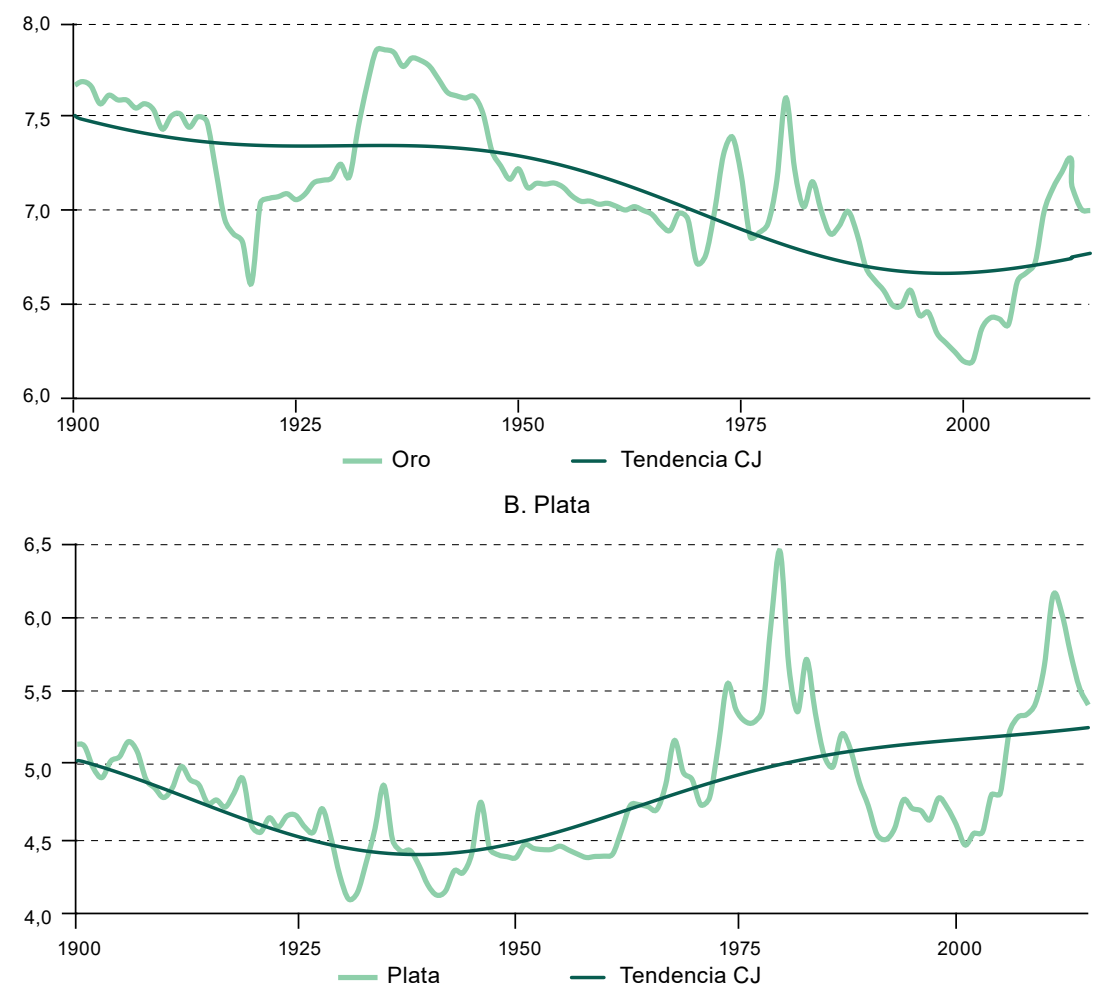

Fuente: Comisión Económica para América Latina y el Caribe (CEPAL).

Gráfico IX.4

Petróleo: precio real y tendencia Cuddington y Jerret (CJ), 1900-2015

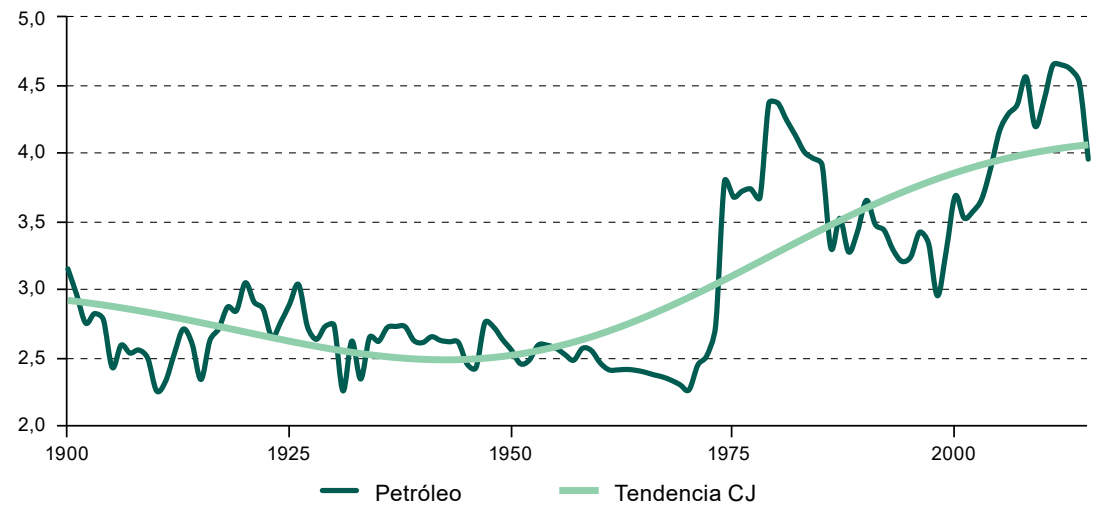

Fuente: Comisión Económica para América Latina y el Caribe (CEPAL). 


\section{a) Algunas implicaciones}

Del análisis de las tendencias a largo plazo de los precios se puede obtener información económica relevante para los países exportadores de estos bienes. La trayectoria de esta tendencia refleja el efecto resultante respecto de los precios reales de fenómenos económicos que actúan sobre la oferta de recursos no renovables a nivel mundial, en horizontes de muchas décadas. Por una parte, se aprecia la interacción entre las dinámicas de exploración, desarrollo de nuevos depósitos, cambio tecnológico y ganancias de productividad en los sectores extractivos. Por otra, se observa la dinámica de agotamiento de yacimientos, disminución de reservas y costos de operación en depósitos y campos marginales, entre otras restricciones de la oferta a largo plazo.

Un ejemplo reciente de cómo el cambio tecnológico puede modificar la estructura del mercado petrolero lo constituye el aumento constante que ha tenido la producción petrolera de los Estados Unidos. A partir de 2008, esta ha crecido casi un $90 \%$ y ha hecho que ese país vuelva a ser el principal productor mundial. El aumento responde al desarrollo de nuevas tecnologías de fracturación hidráulica, mediante las que es posible recuperar petróleo no convencional y gas de formaciones de esquistos, abundantes en los Estados Unidos, que antes eran inexplotables. Estas tecnologías permiten el rápido desarrollo de pozos con un bajo costo inicial, a menor escala y dentro de un ciclo de proyectos muy corto en relación con depósitos convencionales. De este modo se ha creado un mercado competitivo de pequeños productores, con costos de producción que oscilan en el rango de los 40 a los 60 dólares por barril.

\section{Tendencias lineales}

Con objeto de caracterizar de forma más detallada las tendencias observadas dentro del período más reciente entre 1960 y 2015, se aplicó el filtro L1 sobre la base de Yamada y Yoon (2014), utilizando datos trimestrales. Con esta metodología se identifican puntos de quiebre en la serie de precios, donde la tendencia cambia de signo. Entre estos puntos se obtiene una tendencia lineal por tramos (véase el cuadro IX.4).

Los resultados confirman el fin de la fase de auge del precio real respecto de todos los bienes estudiados. En efecto, la última tendencia creciente del precio real culmina en los dos primeros trimestres de 2007 (aluminio y zinc), en algún trimestre de 2011 (cobre, estaño, mineral de hierro, oro y plata) y en el primer trimestre de 2012 (petróleo), como se 
observa en el cuadro IX.4. En todas las series se detecta un punto de quiebre alrededor de 2001-2003 que marca el inicio de la última tendencia creciente (véase el cuadro IX.4). Este intervalo también es coherente con la ventana de tiempo que marca el inicio de la fase de auge del superciclo actual descrito en la sección II.1 respecto de los metales. Las tendencias lineales señaladas respecto de los precios reales del cobre, el estaño y el zinc son decrecientes desde mediados de los años setenta. La reversión del signo se produce a partir de 2001, lo que da inicio a la recuperación del precio real que tuvo lugar durante el auge del superciclo actual. Sin embargo, con este último auge no se logró que los precios reales de estos metales volvieran a los niveles registrados antes de 1980 (véase el gráfico IX.5).

En el caso del precio real del aluminio, las tendencias lineales estimadas muestran un decrecimiento desde 1960 y hasta la fecha. Esta situación también se observó en el resultado de la tendencia a largo plazo, obtenida de su descomposición en superciclos. Con respecto al mineral de hierro, las tendencias lineales estimadas son decrecientes entre 1977 y 2001. A partir de entonces se produce un cambio de signo que persiste hasta 2011. Durante este último auge, el precio real del hierro alcanzó máximos históricos que superaron los niveles de los últimos 50 años. Por su parte, las tendencias lineales por tramo de los precios reales del oro y la plata muestran un comportamiento menos heterogéneo que las de los metales industriales. Los máximos alcanzados durante el último auge llegaron a niveles similares a los registrados durante el último shock petrolero.

\section{Cuadro IX.4}

Tendencias lineales: fecha de cambio de signo

\begin{tabular}{|c|c|c|c|c|c|c|c|c|}
\hline \multicolumn{5}{|c|}{ Minerales industriales } & \multicolumn{2}{|c|}{$\begin{array}{l}\text { Minerales } \\
\text { utilizados como } \\
\text { reserva de valor }\end{array}$} & \multicolumn{2}{|c|}{ Hidrocarburos } \\
\hline Aluminio & Cobre & Estaño & $\begin{array}{l}\text { Minería } \\
\text { de hierro }\end{array}$ & Zinc & Oro & Plata & Gas & Petróleo \\
\hline $\begin{array}{l}\text { Trim 4, } \\
1984\end{array}$ & $\begin{array}{l}\text { Trim 2, } \\
1966\end{array}$ & $\begin{array}{l}\text { Trim 3, } \\
1979\end{array}$ & $\begin{array}{l}\text { Trim 4, } \\
1970\end{array}$ & $\begin{array}{l}\text { Trim 2, } \\
1974\end{array}$ & $\begin{array}{l}\text { Trim 3, } \\
1980\end{array}$ & $\begin{array}{l}\text { Trim 2, } \\
1920\end{array}$ & $\begin{array}{l}\text { Trim 3, } \\
1971\end{array}$ & $\begin{array}{l}\text { Trim 3, } \\
1970\end{array}$ \\
\hline $\begin{array}{l}\text { Trim 3, } \\
1988\end{array}$ & $\begin{array}{l}\text { Trim 4, } \\
1984\end{array}$ & $\begin{array}{l}\text { Trim 3, } \\
2002\end{array}$ & $\begin{array}{l}\text { Trim 3, } \\
1977\end{array}$ & $\begin{array}{l}\text { Trim 4, } \\
1982\end{array}$ & $\begin{array}{l}\text { Trim 3, } \\
2001\end{array}$ & $\begin{array}{l}\text { Trim 1, } \\
2003\end{array}$ & $\begin{array}{l}\text { Trim 1, } \\
1980\end{array}$ & $\begin{array}{l}\text { Trim 3, } \\
1980\end{array}$ \\
\hline $\begin{array}{l}\text { Trim 4, } \\
2001\end{array}$ & $\begin{array}{l}\text { Trim } 3 \text {, } \\
1989\end{array}$ & $\begin{array}{l}\text { Trim 1, } \\
2011\end{array}$ & $\begin{array}{l}\text { Trim 1, } \\
2001\end{array}$ & $\begin{array}{l}\text { Trim 4, } \\
1989\end{array}$ & $\begin{array}{l}\text { Trim 4, } \\
2011\end{array}$ & $\begin{array}{l}\text { Trim 4, } \\
2011\end{array}$ & $\begin{array}{l}\text { Trim 1, } \\
1995\end{array}$ & $\begin{array}{l}\text { Trim } 3 \text {, } \\
1998\end{array}$ \\
\hline \multirow[t]{2}{*}{$\begin{array}{l}\text { Trim 2, } \\
2007\end{array}$} & $\begin{array}{l}\text { Trim 1, } \\
2002\end{array}$ & & $\begin{array}{l}\text { Trim 3, } \\
2011\end{array}$ & $\begin{array}{l}\text { Trim 4, } \\
2002\end{array}$ & & & $\begin{array}{l}\text { Trim 4, } \\
2005\end{array}$ & $\begin{array}{l}\text { Trim 1, } \\
2012\end{array}$ \\
\hline & $\begin{array}{l}\text { Trim 2, } \\
2011\end{array}$ & & & $\begin{array}{l}\text { Trim 1, } \\
2007\end{array}$ & & & & \\
\hline
\end{tabular}

Fuente: Comisión Económica para América Latina y el Caribe (CEPAL). 
Gráfico IX.5

Metales industriales: precio real y tendencia lineal, del primer trimestre de 1960 al cuarto trimestre de 2015

(En logaritmos)

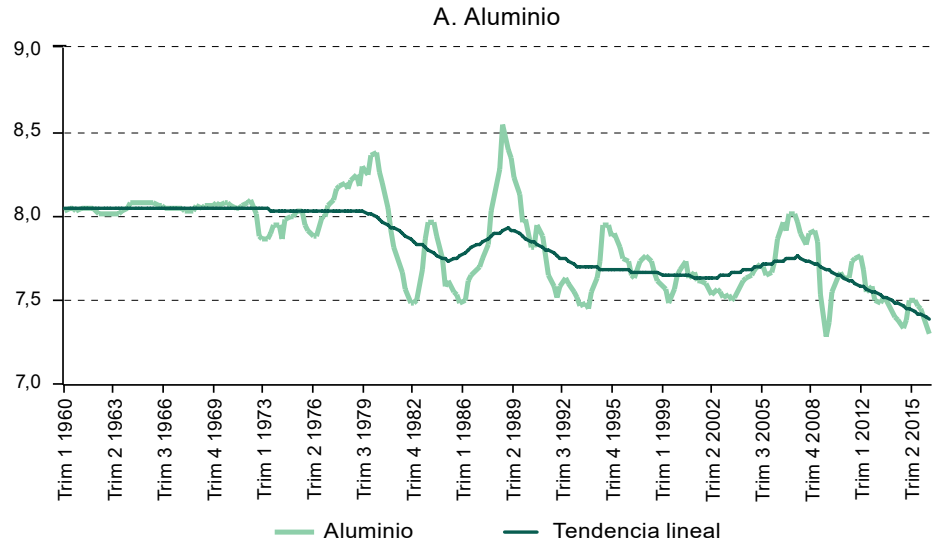

B. Cobre

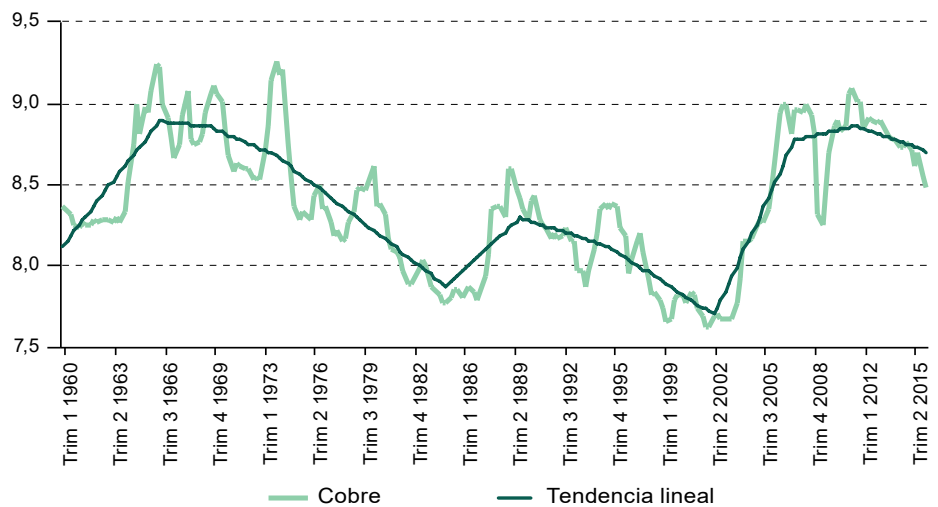

C. Estaño

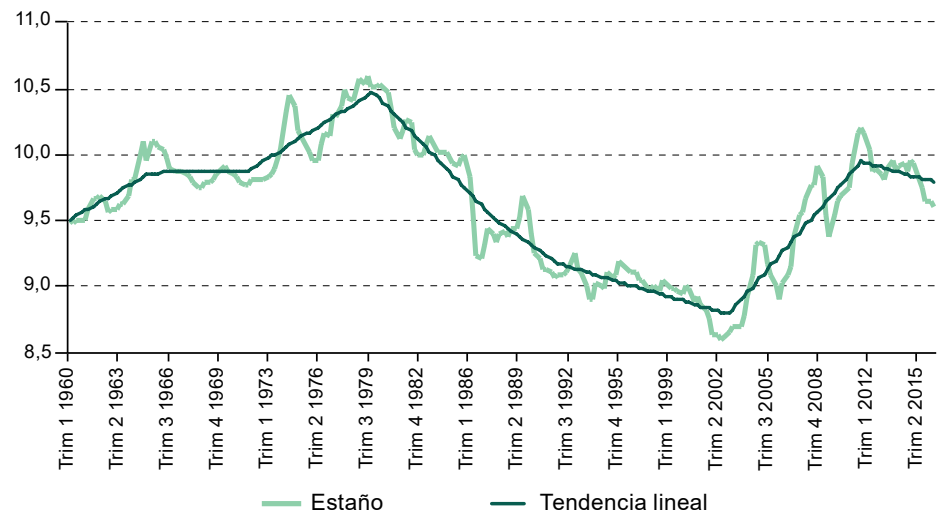


D. Zinc

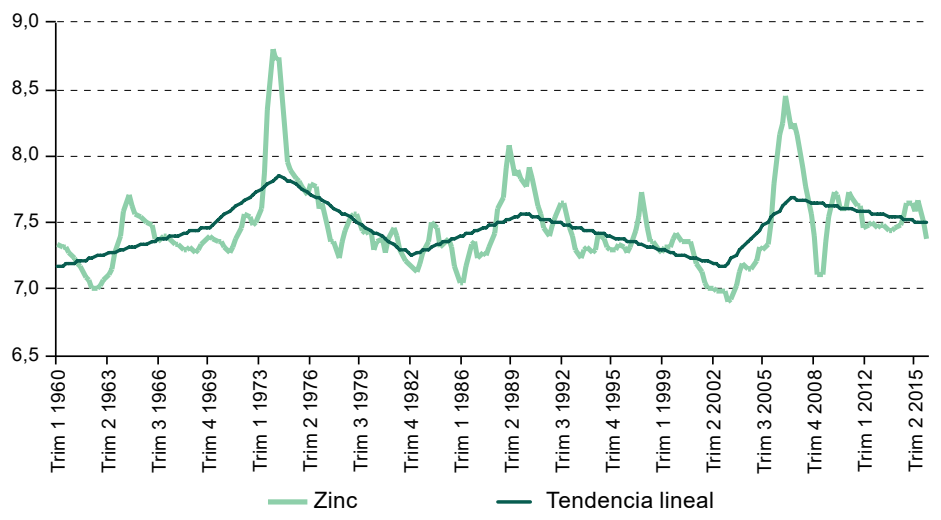

E. Mineral de hierro

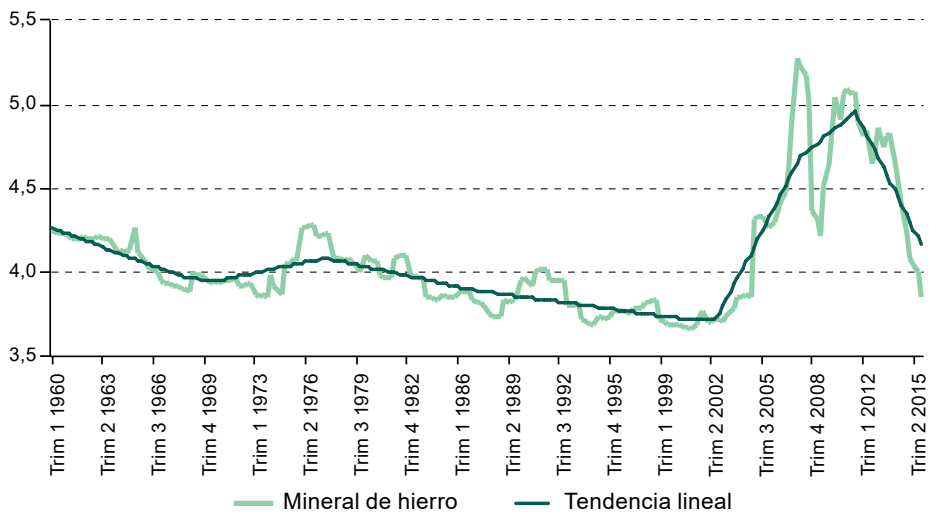

Fuente: Comisión Económica para América Latina y el Caribe (CEPAL).

Los cambios de signo en las tendencias lineales del precio real del petróleo coinciden con máximos asociados al superciclo previo (shocks petroleros de 1973 y 1980-1981) y los máximos alcanzados al final del auge del actual superciclo (primer trimestre de 2012). A partir de ese punto de reversión, el precio del petróleo experimentó un descenso gradual, similar al de otros bienes primarios, en respuesta a la desaceleración del crecimiento global. Sin embargo, a partir del último trimestre del 2014, la caída del precio del petróleo se tornó particularmente abrupta debido a la decisión de la Arabia Saudita, como actor clave de la OPEP, de no ajustar su producción en respuesta a la creciente sobreoferta en el mercado mundial. Dicha sobreoferta se ha atribuido principalmente al notable aumento que ha registrado la producción de petróleo de los Estados Unidos a partir de 2008. La decisión de la Arabia Saudita puede interpretarse como un shock de oferta, de naturaleza más bien geopolítica. 
Exacerbó la caída de precio que ya venía registrando el petróleo y ha hecho que su precio actual disminuya incluso por debajo de su nivel de tendencia a largo plazo, como se puede observar en el gráfico IX.4, y también por debajo del nivel del último tramo de su tendencia lineal, como se observa en el gráfico IX.6.

Gráfico IX.6

Petróleo: precio real y tendencia lineal, del primer trimestre de 1960 al cuarto trimestre de $\mathbf{2 0 1 5}$

(En logaritmos)

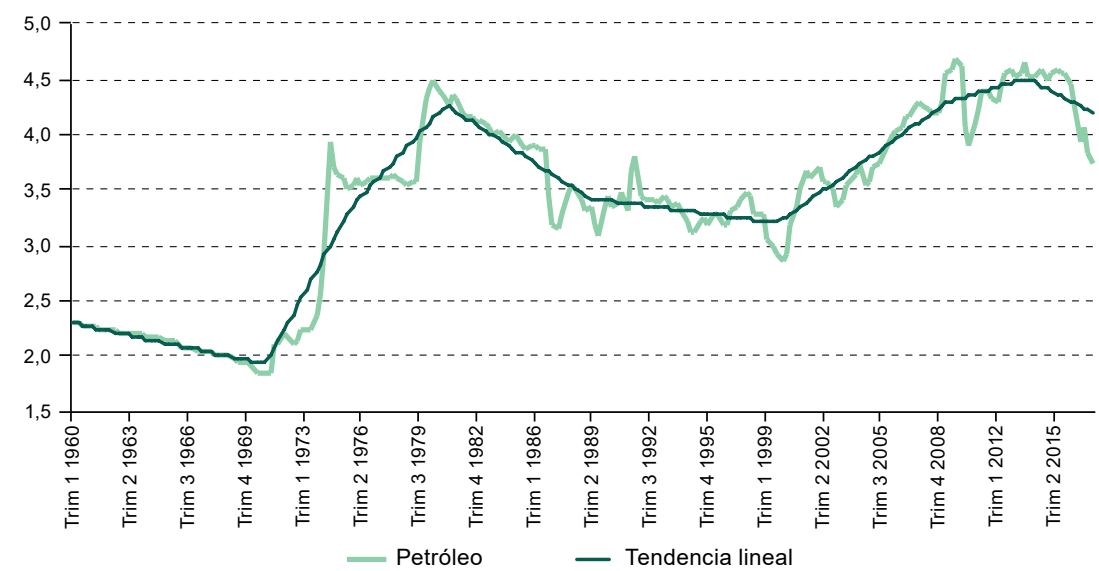

Fuente: Comisión Económica para América Latina y el Caribe (CEPAL).

\section{Comovimiento}

Para estudiar los posibles comovimientos de series, se toman como primer indicador las correlaciones cruzadas entre las series trimestrales de precios reales de los productos básicos entre 1960 y 2015 (véase el cuadro IX.5). La correlación más alta $(0,91)$ se nota entre el precio real del petróleo y el del oro. Entre los metales industriales se encuentra una correlación positiva, superior a 0,50, entre el precio real del cobre, por una parte, y el del estaño, el hierro y el zinc, por otra. A su vez, entre el precio real del oro y la plata se encuentra una correlación de 0,70.

Se realizó un análisis factorial para detectar posibles factores comunes en el grupo de metales industriales y el de metales utilizados como reserva de valor, que podrían explicar movimientos conjuntos de sus precios. Este análisis mostró que los metales industriales presentan entre sí un factor exógeno común que afecta a todos los metales de este grupo, por lo que sus precios tienden a moverse conjuntamente (véase el gráfico IX.7). El grupo de 
los metales de reserva de valor también presentó un factor común, distinto al encontrado respecto de los metales industriales. Ello era de esperarse, pues ambos subgrupos exhiben comportamientos diferentes.

\section{Cuadro IX.5}

Precios reales de los productos básicos: correlaciones cruzadas, del primer trimestre de 1960 al cuarto trimestre de 2015

\begin{tabular}{|c|c|c|c|c|c|c|c|c|c|}
\hline & Aluminio & Cobre & Estaño & Hierro & Zinc & Oro & Plata & Gas & Petróleo \\
\hline \multirow[t]{2}{*}{ Aluminio } & 1 & & & & & & & & \\
\hline & 0 & & & & & & & & \\
\hline \multirow[t]{2}{*}{ Cobre } & 0,36 & 1 & & & & & & & \\
\hline & 0 & & & & & & & & \\
\hline \multirow[t]{2}{*}{ Estaño } & 0,45 & 0,5 & 1 & & & & & & \\
\hline & 0 & 0 & & & & & & & \\
\hline \multirow[t]{2}{*}{ Hierro } & $-0,07$ & 0,56 & 0,39 & 1 & & & & & \\
\hline & 0,28 & 0 & 0 & & & & & & \\
\hline \multirow[t]{2}{*}{ Zinc } & 0,23 & 0,57 & 0,29 & 0,26 & 1 & & & & \\
\hline & 0 & 0 & 0 & 0 & & & & & \\
\hline \multirow[t]{2}{*}{ Oro } & $-0,43$ & $-0,01$ & 0,1 & 0,38 & 0,26 & 1 & & & \\
\hline & 0 & 0,92 & 0,13 & 0 & 0 & & & & \\
\hline \multirow[t]{2}{*}{ Plata } & 0,05 & 0,3 & 0,68 & 0,52 & 0,31 & 0,7 & 1 & & \\
\hline & 0,46 & 0 & 0 & 0 & 0 & 0 & & & \\
\hline \multirow[t]{2}{*}{ Gas } & 0,46 & 0 & 0,6 & 0,07 & $-0,02$ & $-0,16$ & 0,26 & 1 & \\
\hline & 0 & 1 & 0 & 0,32 & 0,79 & 0 & 0 & & \\
\hline \multirow[t]{2}{*}{ Petróleo } & $-0,44$ & $-0,11$ & 0,07 & 0,42 & 0,2 & 0,91 & 0,63 & 0 & 1 \\
\hline & 0 & 0,1 & 0,29 & 0 & 0 & 0 & 0 & 0,99 & \\
\hline
\end{tabular}

Fuente: Comisión Económica para América Latina y el Caribe (CEPAL).

a El número inferior indica el valor $p$.

\section{Gráfico IX.7}

Metales industriales y metales de reserva de valor: factores comunes, del primer trimestre de 1960 al cuarto trimestre de 2015 (En logaritmos)

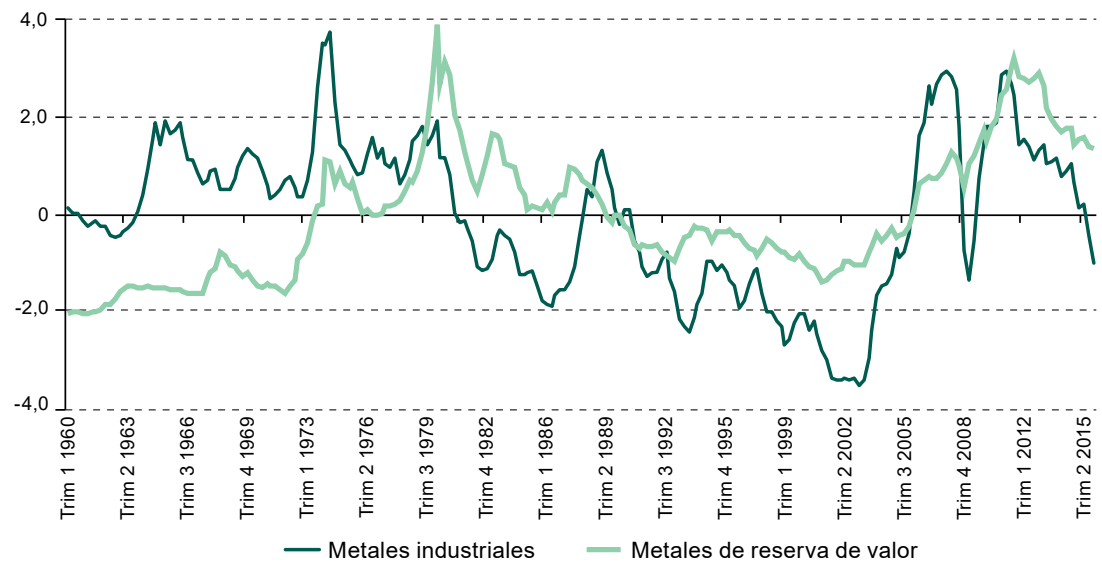

Fuente: Comisión Económica para América Latina y el Caribe (CEPAL). 
En general, los precios de los metales industriales responden a las dinámicas de la demanda y la oferta a corto y largo plazo. Entretanto, el oro y la plata se comportan más bien como activos financieros y se utilizan como reserva de valor en los períodos de mayor volatilidad global o riesgo en los mercados de capitales. En teoría, el factor común descrito en los metales industriales se debería poder asociar a algún índice global de producción industrial o construcción, que refleje los movimientos de la demanda mundial de estos metales como insumos básicos (respecto del período posterior a 1990, un candidato natural podría ser un índice de producción industrial y construcción de China). En el caso de los metales utilizados como reserva de valor, en teoría el factor común se debería poder asociar a algún índice de riesgo global, que refleje los movimientos de su demanda como activos de reserva de valor en períodos de volatilidad financiera.

En contraste, los precios reales del petróleo y del gas no presentaron ningún factor común. Este resultado se debe en parte a que, durante casi todo el período 1960-2015, el mercado de gas ha estado segmentado regionalmente con precios distintos en cada región. La globalización de ese mercado es todavía un fenómeno muy reciente, que se ha manifestado a través del creciente comercio de gas natural licuado por vía marítima y la expansión de las terminales de regasificación en todo el mundo. El uso creciente en los contratos de venta de gas de ajustes de los precios referenciados con las variaciones del precio internacional del petróleo crudo podría hacer que aumente la correlación observada entre sus precios en el futuro.

\section{Persistencia}

Con el objeto de proveer una medida de la persistencia de las series de precios reales de los productos básicos, se estimaron cuatro versiones de un modelo autorregresivo fraccionalmente integrado de media móvil (ARFIMA, por su sigla en inglés). Tras verificarse la escasa significancia de las estimaciones en las diferencias logarítmicas, se calculó el parámetro del orden de integración fraccional de la serie, $d$, que da cuenta de la persistencia de las series en niveles. Para ello, se utilizó el método de Robinson y el de mínimos cuadrados no lineales, con un modelo libre de componente autorregresivo y de media móvil. Los resultados se presentan en el cuadro IX.6. Como se observa, cuando se usó el método no paramétrico, con la excepción del precio real de la plata, todas las estimaciones se ubicaban en el intervalo $d \in(0,5,1)$, lo que refleja un comportamiento no estacionario en covarianza del nivel, pero con reversión a la media. 


\section{Cuadro IX.6}

Persistencia: estimación del parámetro de integración de facciones de las series ${ }^{a}$

\begin{tabular}{lrr}
\hline & MCO no lineales & Método de Robinson \\
\hline Cobre & 0,837 & 0,872 \\
\hline Aluminio & 0 & 0 \\
& 0,921 & 0,813 \\
\hline Estaño & 0 & 0 \\
& 0,84 & 0,954 \\
\hline Zinc & 0 & 0 \\
& 0,616 & 0,873 \\
\hline Oro & 0 & 0 \\
\hline Plata & 0,929 & 0,864 \\
& 0 & 0 \\
\hline Petróleo & 0,899 & 1,015 \\
& 0 & 0 \\
\hline
\end{tabular}

Fuente: Comisión Económica para América Latina y el Caribe (CEPAL).

a El número inferior indica el valor $p$.

En otras palabras, una vez producido un shock sobre la serie, este tiende a desvanecerse, pero de forma muy lenta. La lentitud está relacionada con el tamaño del parámetro $d$ estimado. Por ejemplo, al observar los estimadores paramétricos, el precio real del zinc experimentaría la reversión menos lenta $(d=0,616)$, mientras que las cotizaciones reales del aluminio, del oro y del petróleo presentarían la mayor persistencia del shock, por cuanto todos esos productos exhiben un $d$ del orden de 0,92. Como conclusión de esta sección, las estimaciones realizadas son indicativas de que los precios reales de los productos básicos incluidos en la muestra se caracterizan por un proceso de memoria larga ante los shocks.

\section{Algunas implicaciones}

En Heresi (2011) puede encontrarse una aplicación del uso de modelos ARFIMA al precio del cobre y su implicación de política. Mediante la estimación de ese modelo respecto de la serie de precios del cobre, el citado autor mostró que la economía chilena se vio sujeta por ese motivo a shocks de términos de intercambio transitorios, pero muy persistentes. Esto provocó presiones al alza del nivel de gasto público considerado como sostenible a largo plazo. La explicación de este resultado es que la serie de precios del cobre a largo plazo, por decisión del Comité de Expertos del Cobre, sigue un proceso MA (10), que equivale a un promedio de diez trimestres. Al utilizar esta información en el contexto de un modelo de equilibrio general para una economía pequeña y abierta, este autor encontró que el gasto fiscal ha seguido una trayectoria 
procíclica con respecto al precio de ese metal. Este resultado podría evitarse si se consideraran horizontes muchos más largos que diez trimestres en la estimación oficial del precio a largo plazo del cobre. El valor utilizado como referencia para el cálculo presupuestario debería ser la tendencia a largo plazo de la serie, a fin de evitar que las variaciones del precio de un producto básico se propagaran a la economía nacional.

\section{E. Conclusiones}

Se encontró evidencia estadística de la presencia de al menos cuatro componentes cíclicos de entre 20 y 70 años de periodicidad en todas las series de precios reales estudiadas en el período 1900-2015. La duración media de los superciclos estimados en el precio real de los metales y el petróleo fue de 31,6 años, y se registraron duraciones máximas de 43 años. La duración media de las fases de auge y caídas de los precios fue de 16 años, con duraciones máximas de 29 años.

Con respecto al último auge de precios de los productos básicos, su duración media de 15 años se acerca a la media de los auges anteriores, pero su magnitud superó la de los superciclos previos. Todos los productos estudiados, excepto el aluminio, alcanzaron niveles de precios reales que no se veían desde la década de 1970. Estos fueron incluso superiores en el caso del mineral de hierro, el oro y el petróleo crudo. Sin embargo, toda la evidencia apunta a que el período de auge concluyó. Actualmente nos encontramos en la fase de caída de los precios del superciclo en curso, con precios que vuelven a acercarse a sus niveles de tendencia de largo plazo.

Todas las series de precios estudiadas se caracterizan por reversiones sucesivas hacia sus niveles tendenciales de largo plazo, lo que niega la posibilidad de auges o caídas de precio permanentes. Los precios reales de los metales industriales experimentaron una pendiente decreciente o cercana a cero entre 1900 y 2015. El petróleo crudo es el único bien primario cuyo precio real muestra una tendencia creciente a largo plazo, sobre todo de 1950 en adelante.

Se encontró evidencia de comovimiento en los precios reales dentro del grupo de metales industriales y el grupo de metales utilizados como reserva de valor. Cada grupo presentó un factor común diferente. Se destaca la alta correlación existente entre los movimientos del precio real del petróleo y el oro entre 1960 y 2015, que no se manifiesta durante la primera mitad del siglo pasado. Las series de precios reales mostraron también una alta persistencia en todos los bienes estudiados. Esto significa que, tras una perturbación, los precios tardan mucho tiempo en volver a los niveles que presentaban antes de la ocurrencia de ese evento.

Toda esta evidencia en su conjunto, en particular la presencia de componentes cíclicos de duración media superior a tres décadas en el 
ciclo completo y a una década y media en sus fases de auge y caída de precios, apunta a horizontes temporales considerablemente mayores que los que suelen informar el diseño de los mecanismos de estabilización macroeconómica de uso más común, como las reglas macrofiscales y los fondos soberanos de inversión, entre otros. El reconocimiento de una variabilidad cíclica considerable en los precios a largo plazo de los metales y el petróleo plantea la pregunta de si es viable responder a estas dinámicas a través del fortalecimiento de los mecanismos de estabilización existentes. Una vez más, se hace hincapié en la vulnerabilidad que conlleva para los países mantener una sobreespecialización de sus exportaciones en estos bienes primarios. Como mensaje general, se sugiere reconsiderar la prioridad política y la urgencia que el Estado y el sector privado otorgan al logro de una mayor diversificación productiva a mediano plazo, por ser esta la mejor garantía de asegurar la estabilidad económica en el futuro.

\section{Bibliografía}

Acquatella, J. y otros (2013), "Rentas de recursos naturales no renovables en América Latina y el Caribe: evolución y participación estatal, 1990-2010", serie Seminarios y Conferencias, No 72 (LC/L.3645), Santiago, Comisión Económica para América Latina y el Caribe (CEPAL).

Altomonte, H. y otros (2013), Recursos naturales: situación y tendencias para una agenda de desarrollo regional en América Latina y el Caribe (LC/L.3748), Santiago, Comisión Económica para América Latina y el Caribe (CEPAL), diciembre.

Arezki, R. y O. Blanchard (2014), "Siete preguntas acerca de la caída reciente del precio del petróleo" [en línea] https://blog-dialogoafondo.imf.org/?p=4751.

Arezki, R. y otros (2013), "Testing the Prebisch-Singer Hypothesis since 1650: evidence from panel techniques that allow for multiple breaks", IMF Working Paper, $\mathrm{N}^{\circ} 13 / 180$, agosto.

Baxter, M. y R.G. King (1999), "Measuring business cycles: approximate band-pass filters for economic time series", The Review of Economics and Statistics, vol. 81, No4.

Bello, O. F, Cantú y R. Heresi (2011), “Variabilidad y persistencia de los precios de los productos básicos en América Latina", Revista CEPAL, No 103 (LC/G.2487-P), Santiago, Comisión Económica para América Latina y el Caribe (CEPAL), abril.

Benes, J. y otros (2012), "The future of oil: geology vs. technology", IMF Working Paper, $\mathrm{N}^{\mathrm{o}} 12 / 109$.

Blanchard, O. (1997), "The medium run", Brookings Papers on Economic Activity, $\mathrm{N}^{\circ} 2$.

Bry, G. y C. Boschan (1971), Cyclical Analysis of Time Series: Selected Procedures and Computer Programs, Nueva York, National Bureau of Economic Research (NBER).

Cashin, P., J. McDermott y A. Scott (1999b), "The myth of co-moving commodity prices", Discussion Paper Series, N ${ }^{\circ}$ G99/8, Banco Central de Nueva Zelanda.

Cashin, P. y J. McDermott (2002), "The long-run behavior of commodity prices: small trends and big variability", International Monetary Fund Staff Papers, vol. 49.

CEPAL (Comisión Económica para América Latina y el Caribe) (2014), Pactos para la igualdad: hacia un futuro sostenible (LC/G.2586 (SES.35/3)), Santiago.

Christiano, L. y T. Fitzgerald (2003), "The band pass filter", International Economic Review, vol. 44.

Carter, C., G. Rausser y A. Smith (2011), "Commodity booms and busts", Annual Review of Resource Economics, vol. 3, N 2. 
Cuddington, J., R. Ludema y S. Jayasuriya (2002), "Prebisch-Singer Redux", Documentos de Trabajo, $\mathrm{N}^{\circ}$ 140, Banco Central de Chile, febrero.

Cuddington, J. y D. Jerrett (2008), "Super cycles in real metals prices?", IMF Staff Papers vol. 55, $\mathrm{N}^{\mathrm{o}} 4$

Cuddington, J. y G. Nülle (2014), "Variable long-term trends in mineral prices: the ongoing tug-of-war between exploration, depletion, and technological change" Journal of International Money and Finance, vol. 42.

Deaton, A. (1999), "Commodity prices and growth in Africa", Journal of Economic Perspectives, vol. 13.

Erten, B. y J.A. Ocampo (2012), "Super cycles of commodity prices since the midnineteenth century", World Development, vol. 44.

Espinasa, R. (2016), "Brand new model, same old price", IDB Technical Note, N 937, Washington, D.C., Banco Interamericano de Desarrollo (BID).

Farooki, M. (2012), "China's metals demand and commodity prices: a case of disruptive development?", European Journal of Development Research, vol. 24.

FMI (Fondo Monetario Internacional) (2015), World Economic Outlook: Adjusting to Lower Commodity Prices, octubre.

Granger, C. y R. Joyeux (1980) "An introduction to long-memory time series models and fractional differencing", Journal of Time Series Analysis, vol. 1, No 1.

Grilli, E. y M. Yang (1988), "Primary commodity prices, manufactured goods prices, and the terms of trade of developing countries: what the long run shows", The World Bank Economic Review, vol. 2.

Heap, A. (2005), "China-The Engine of a Commodities Super Cycle", Nueva York, Citigroup Smith Barney.

Heresi, R. (2011), "Regla fiscal y ciclos de cobre: análisis para Chile", Universidad de Chile, inédito.

Hodrick, R. y E. Prescott (1997), "Postwar U.S. business cycles: an empirical investigation", Journal of Money, Credit, and Banking, vol. 29, $\mathrm{N}^{\mathrm{o}} 1$.

Hosking, J. (1981), “Fractional differencing”, Biometrika, vol. 68, No 1.

Hurvich, C. y B. Ray (1994), "Estimation of the memory parameter for nonstationary or noninvertible fractionally integrated processes", Journal of Time Series Analysis, vol. 16, No 1 .

Jacks, D., (2013), "From boom to bust: a typology of real commodity prices in the long run", NBER Working Paper N¹8874, Cambridge, Massachusetts, marzo.

Kim, S. y otros (2009), "\$ \$ell_1\$ trend filtering", SIAM Review, vol. 51.

Ocampo, J. A. y M. A. Parra (2010), "The terms of trade for commodities since the mid-19 ${ }^{\text {th }}$ Century", Journal of Iberian and Latin American Economic History, vol. 28, $\mathrm{N}^{\mathrm{o}} 1$, Madrid.

Pfaffenzeller, S., P. Newbold y A. Rayner (2007), "A short note on updating the Grilli and Yang commodity price index", The World Bank Economic Review, vol. 21, No 1.

Pindyck, R. y J. Rotemberg (1990), “The excess of co-movements of commodity prices", The Economic Journal, vol. 100, No 403.

Sillitoe, R.H. (1995), "Exploration and discovery of base- and precious-metal deposits in the Circum-Pacific Region during the Last 25 Years", Resource Geology Special Issue, vol. 19.

Yamada, H. y G. Yoon (2015), "Selecting the tuning parameter of the $\ell_{1}$ trend filter", Studies in Nonlinear Dynamics \& Econometrics, De Gruyter. (2014), "When Grilli and Yang meet Prebisch and Singer: piecewise linear trends in primary commodity prices", Journal of International Money and Finance, vol. 42. 


\section{Capítulo X \\ La gobernanza de los recursos naturales desde la mirada de los ciudadanos}

La discusión del concepto de gobernanza ha producido un rico debate sobre su alcance y papel transformador en los países de América Latina. Sin embargo, el término sigue confundiéndose con otros de similar raíz pero distintos significados, que en muchos casos están mediados por la mirada autorreferencial de académicos, políticos o agencias de cooperación internacional. En este artículo se propone una relectura de la gobernanza a partir del sustrato sobre el cual ejerce su influencia, en este caso los recursos naturales. Se propone reinterpretar el concepto a partir de la importancia de los recursos naturales en la opinión de los ciudadanos, para lo cual se citan y analizan algunos ejemplos de estudios de opinión pública que muestran las diferencias de criterio y - sin embargo- el interés potencial que existe en los atributos de la gobernanza. Esta última aparece expresada en la potente mirada de los ciudadanos sobre el cuidado, el desarrollo y el futuro de los recursos naturales, algo que debe tomarse en cuenta a la hora de proponer una visión sobre su gobernanza. Se incluye también una descripción de la gobernanza mundial y regional a la luz de la agenda económica, social y política de la región.

\section{A. Una gobernanza para la mayoría}

La palabra gobernanza está presente en la lengua castellana desde hace más de dos siglos. Su origen se remonta a la voz inglesa governance que, a su vez, tiene sus raíces en gouvernance, un vocablo francés que alude a la acción de 
gobierno o al arte de gobernar. Al parecer, originalmente hacía referencia al pilotaje de las embarcaciones, aunque también a las buenas costumbres, la conducta y el ideal de mando y control. Gobernanza también aparece como sinónimo de gobierno, dirección o administración.

La polivalencia de la palabra gobernanza es un dato comprobable. Tiene diferentes significados y sentidos, la mayoría atribuible a la amalgama de voces que representa. En ese sentido, "el laberinto que actualmente encierra el término governance es monumental, en el caso del idioma español se originó incluso de la propia traducción del inglés y del francés, desde los cuales se ha trasladado al español como gestión, administración, gobernación, gobernabilidad, gobernanza, gobierno, sistema de gobierno, régimen, administración de empresas, gestión de empresas, gestión de asuntos públicos, ejercicio de poder y política de buen gobierno, y gobernancia, principalmente" (Vicher, 2013, pág. 29).

En el diccionario de la Real Academia Española se define gobernanza como "acción y efecto de gobernar o gobernarse" y como "manera de gobernar que se propone como objetivo el logro de un desarrollo económico, social e institucional duradero, promoviendo un sano equilibrio entre el Estado, la sociedad civil y el mercado" (RAE, 2014). Si bien se trata de una definición inteligible y que no deja muchas dudas, la palabra gobernanza no es de uso muy común entre la población general.

Efectivamente, el concepto de gobernanza se emplea con frecuencia en los ámbitos académicos, en ciertas organizaciones de la sociedad civil y de manera ocasional en las esferas del gobierno o la administración pública. En cambio, como se señaló, no está presente en el lenguaje coloquial del ciudadano común. Así, aparece en los debates universitarios sobre el funcionamiento del sistema educativo en los países de América Latina (por ejemplo, cuando se habla de gobernanza escolar) pero no así en los programas curriculares de las escuelas primarias o secundarias de la región. Esto se comprueba al revisar los libros de texto de materias como ciencias sociales, educación cívica o formación ciudadana. En todos los casos el concepto de gobernanza está ausente y probablemente esa ausencia se refleja también en las aulas o salones de clase.

Incluso en los ámbitos académicos y de la política existe cierto desconcierto con respecto a la definición de gobernanza, confundida en reiteradas oportunidades con gobernabilidad, un término más frecuente en los medios de comunicación y en el lenguaje de los dirigentes políticos y los funcionarios de gobierno. Esto ocurre a pesar de que no existe en América Latina un uso específico de gobernabilidad ni una definición aceptada de gobernanza, de manera que algunos utilizan esta última "para diferentes objetos y con definiciones distintas... con varios sentidos en diferentes obras y a veces en un mismo texto" (Hufty, 2010, pág. 42). 
La desorientación en el uso de ambos conceptos (gobernanza y gobernabilidad) obliga a suponer que en realidad existen tantos conceptos de gobernanza como investigadores en este campo (Björk y Johansson, 2001). Un ejemplo de esto se observó en un taller sobre gobernanza y políticas de salud en el que se efectuaron entrevistas a investigadores, funcionarios y académicos de la Argentina, el Brasil, Colombia y México. El objetivo era saber un poco más sobre la comprensión y el conocimiento de las nociones de gobernanza y gobernabilidad entre los participantes del encuentro. Para sorpresa de sus organizadores, entre los académicos y funcionarios existía una "ausencia de coherencia conceptual", una "gran confusión, ambigüedad y variabilidad de significados" y un "uso indistinto de gobernanza y gobernabilidad como equivalentes o con significados variables" (Hufty, Báscolo y Bazzani, 2006, pág. 36).

Cabe recordar que en América Latina existen buenos ejemplos del análisis de la gobernanza en relación con la diversidad de temas de la agenda económica, política o social de la región, tanto por parte de los Gobiernos, como de las organizaciones sociales y las agencias de cooperación. La gobernanza aparece definida en función de distintas áreas de trabajo, a pesar de que no existe en la literatura "un texto que sintetice y sistematice el uso de este concepto" y "las definiciones varían relativamente en función de los estudios de caso, tan variados en su enfoque como en los temas abordados" (Mayorga y Córdova, 2007, pág. 7). Existen ensayos sobre la gobernanza del agua, la salud o las políticas anticorrupción (Zurbriggen, 2012), la gobernanza ambiental, la gobernanza de los recursos hídricos en la región andina, la gobernanza en comunidades campesinas con explotación minera (Decoster y otros, 2004) y la gobernanza y la tenencia de la tierra (FAO, 2012).

El interés por la gobernanza se incrementó en la última década y, de una u otra forma, facilitó su divulgación y comprensión en espacios no universitarios o no relacionados directamente con la política, la función pública o la cooperación. Sin embargo, a pesar de este mayor empleo del concepto en ámbitos no académicos, no ha sido posible demostrar fehacientemente que el uso y la comprensión de gobernanza llegaron realmente a un público más vasto y diverso. Por ahora solo se puede verificar la existencia de una apreciable cantidad de ensayos, investigaciones, congresos y seminarios, entre otros, en los que se la analiza, aunque con resultados tal vez muy dispares en cuanto a su comprensión, definición y empleo (Mayorga y Córdova, 2007).

Los aportes realizados por los investigadores son valiosos y revelan el creciente interés en el tema. Sin embargo, como se sugiere, se trata por ahora de una noción muy limitada a las esferas universitarias, del Estado o las organizaciones no gubernamentales, razón por la cual todavía 
prevalece en la conceptualización de su significado y su comprensión la mirada sumamente autorreferencial de esos grupos. Más aún, gobernanza sigue siendo un concepto en proceso de construcción y eso contribuye a que, con frecuencia, esa mirada autorreferencial desvirtúe y reduzca la posibilidad de llevarlo a una mayor diversidad de grupos de interés de la sociedad, para los que la gobernanza es sin duda una potente herramienta de transformación social, política e institucional.

El objetivo es lograr que cada vez más ciudadanos puedan apropiarse adecuadamente de la noción de gobernanza y extenderla a los distintos ámbitos de sus vidas y sus comunidades. Como se ha sugerido, el concepto de gobernanza no puede ser normativo o prescriptivo y cada sociedad debería desarrollar modelos de este concepto de acuerdo con sus diversas visiones y sin depender de un conocimiento unívoco (Hufty, 2010). Paradójicamente, uno de los obstáculos sigue siendo la intermediación entre la realidad económica, social y cultural de las comunidades y la idea o conceptualización que se pretende ofrecer sobre la gobernanza. Esto hace que a veces se formulen interpretaciones erróneas o quizás demasiado complejas, que pueden generar resquemores entre algunos grupos de interés.

Por ejemplo, en una serie de encuestas a los líderes de algunas organizaciones de pueblos indígenas, realizada a propósito de un programa sobre la gobernanza de los bosques gestionado por un organismo de cooperación internacional, se preguntó a los participantes sobre el tema, a partir de algunas premisas teóricas sobre el concepto. Como resultado surgieron posiciones controvertidas, acompañadas en algunos casos de expresiones de desánimo y desconfianza con respecto al papel y el valor de la gobernanza. Un líder indígena mexicano aseveró que "como yo lo veo, el mecanismo de gobernanza propuesto no asegura que se escuchará o se tomará en cuenta la voz de los pueblos afectados", mientras un líder de Costa Rica expresó tener "poca confianza en la estructura de gobernanza... tal como están dadas las propuestas... este modelo no funcionará" (FPP, 2008, pág. 14).

Las preguntas que surgen entonces se relacionan con saber de qué manera un concepto tan polivalente, polémico y en proceso de construcción puede atraer a los ciudadanos o las comunidades $\mathrm{y}$, al mismo tiempo, aportarles herramientas de participación, transparencia o monitoreo. Si bien los aportes realizados por investigadores y estudiosos en América Latina durante los últimos años han sido importantes, es necesario comenzar a difundir el concepto entre la mayor cantidad posible de grupos de interés, de manera de poder "aproximarlo y enriquecerlo desde nuestras propias necesidades y experiencias" (Whittingham, 2010).

Una de las formas de mostrar este alcance más amplio del concepto en la última década ha sido a través de la medición de determinados 
indicadores de gobernanza en distintos países. Aspectos como la estabilidad política, la libertad de expresión, la rendición de cuentas, la transparencia, la regulación, el Estado de derecho o el control de la corrupción se evalúan regularmente para llamar la atención de los Gobiernos sobre las falencias en sus acciones y, al mismo tiempo, alertar a los ciudadanos sobre sus deberes y derechos con respecto a sus gobernantes (Banco Mundial, 2017).

Sin embargo, los aportes de estas mediciones han sido tal vez un poco limitados para corroborar la extensión o la influencia del significado de gobernanza para el común de las personas. Más aún, algunos de estos programas insisten incluso en la confusión que prevalece en el uso y el significado del término. Se reconoce que es difícil captar la complejidad de la gobernanza en una sola definición, a pesar de que se acepta que la autoridad, la toma de decisiones y la rendición de cuentas son las tres dimensiones que mejor contribuyen a conceptualizarla. Así, la gobernanza determina quién tiene poder, quién toma decisiones, cómo otros jugadores hacen oír su voz y cómo se hace para rendir cuentas (IOG, 2017).

Si bien esta corta definición de gobernanza es útil a los efectos de entender un poco más la importancia del concepto - en tanto herramienta de interacción social o toma de decisiones-, una alternativa eficaz para llevarlo a la mayor cantidad posible de ciudadanos es recurrir al propio objeto sobre el cual esta ejerce su influencia. Es decir, como se vio en algunos trabajos hechos en la región con respecto al caso del agua, la tierra o la salud, una manera efectiva para llegar a la mayoría de los ciudadanos es apelar al sustrato al cual se aplica el concepto de gobernanza. Se parte de la idea de que el vocablo gobernanza, poco difundido y comúnmente afectado por la mirada autorreferencial o el desvío de conceptos similares, podrá comprenderse cabalmente si se lo asocia al objeto sobre el cual ejerce su influencia, que en este caso corresponde a los recursos naturales.

La idea es entonces recurrir a distintas formas de traducción del significado de gobernanza, en este caso a través de los cambios o modificaciones que el propio concepto genera en la sustancia en la que ejerce su influencia (los recursos naturales). Gobernanza es en sí mismo un término polisémico, controvertido y en general sujeto a múltiples interpretaciones, características que a veces lo convierten en una noción inocua a la hora de definir la compleja interacción entre el Estado y la sociedad o los niveles de toma de decisiones y de rendición de cuentas. En cambio, asociado a los recursos naturales, el concepto adquiere un peso específico y puede convertirse en una herramienta mucho más útil, analítica e inteligible para la mayoría.

Como se verá más adelante, los ciudadanos latinoamericanos pueden hoy reconocer con facilidad el valor y la importancia de los 
recursos naturales en su vida cotidiana, en sus economías o incluso en su ideal de país. Los recursos naturales están presentes en el imaginario de futuro, de desarrollo, de riqueza o identidad de los ciudadanos de los países de la región, razón por la cual es factible que puedan funcionar como buenos "intérpretes" de los atributos de su propia existencia futura o sostenibilidad. No ocurre lo mismo con la gobernanza, una noción que, por sí misma o fuera de contexto, tiene a veces muy poco para decir y ofrecer, especialmente cuando se confunden su significado y su sentido o cuando está teñida por la mirada autorreferencial de políticos, académicos, agencias o funcionarios.

La presencia y la relevancia de los recursos naturales para la población de los países de América Latina puede contribuir al entendimiento del concepto de gobernanza y, más importante aún, ayudar a interpretar las claves de su valor y jerarquía como una herramienta destinada a promover el desarrollo, la igualdad de oportunidades y la sostenibilidad. El peso específico de los recursos naturales puede contribuir a descifrar el alcance y la proyección de la gobernanza. Con un lenguaje accesible para la mayoría, y sin que esto signifique una pérdida de su valor o su sentido académico, no será necesario entonces internarse en el laberinto de los significados o las conceptualizaciones que hoy existen. La idea es logar que la gobernanza se manifieste a través de la accesibilidad, las cualidades y la importancia que tienen los recursos naturales para las personas. Entonces será posible que incluso los propios recursos naturales puedan ser definidos por los ciudadanos como patrimonios que se expresan de manera inseparable con respecto a su gobernanza.

\section{B. Gobernanza mundial y regional de los recursos naturales}

Los cambios demográficos recientes, incluidas las expresiones más urgentes de los movimientos migratorios y de refugiados, la situación del medio ambiente, especialmente el calentamiento global y la provisión de energía limpia, y la lucha contra la pobreza y la inseguridad son algunas de las manifestaciones visibles de la agenda de la gobernanza mundial. Se trata de una agenda construida a partir de acuerdos de cooperación para enfrentar los desafíos de la globalización, especialmente tras la experiencia de la crisis financiera de hace casi una década. Sin embargo, se trata también de una agenda de cooperación que ha oscilado entre el consenso mundial y la resistencia de los intereses de cada país, cuyas decisiones políticas internas con frecuencia obstaculizan algunos acuerdos mundiales alcanzados.

En la mayoría de los textos consultados se hace mención al concepto de gobernanza mundial como una alternativa coherente a los ideales de paz 
y cooperación internacional. Se pone el acento en la concertación mundial para generar equilibrios entre la política y los mecanismos de gestión de los intercambios comerciales. Así, el ideal de gobernanza mundial es un proceso de liderazgo cooperativo que reúne a los gobiernos nacionales, las agencias públicas multilaterales y la sociedad civil para alcanzar objetivos aceptados en común (Boughton y Bradford, 2007, pág. 11). Es también la capacidad del sistema internacional para proveer servicios de tipo gubernamental en ausencia de un gobierno mundial (PNUD, 2012, pág. 12).

En las últimas décadas, el reconocimiento de los serios efectos del cambio climático a mediano y largo plazo y de las repercusiones de la crisis financiera de 2008-2009 — que dieron lugar a momentos de tensión internacional - se tradujo en la celebración de acuerdos para una extendida gobernanza mundial. Sin embargo, como ocurrió en los años posteriores al fin de la Segunda Guerra Mundial, una vez pasada la tormenta y normalizadas las relaciones internacionales, estos intentos se debilitaron por efecto de la inercia generada por los cambios de orientación unilateral de algunos países o por la falta de coordinación horizontal entre los Estados.

El dilema sigue siendo cómo llamar la atención sobre la urgencia y la importancia de los problemas de la agenda de una gobernanza mundial cada vez más compleja, tanto entre los Gobiernos como entre los ciudadanos en general. Para muchos ciudadanos, la lejanía de las cuestiones mundiales frente a los problemas locales o nacionales constituye una barrera que tienen que superar. Un dato favorable es que en los últimos años aumentó al menos el interés en este tema, en buena cuenta influido por la agenda climática, migratoria y de seguridad. Mientras en 1997 una búsqueda en Internet encontraba solo 3.418 referencias a gobernanza mundial, siete años más tarde, a comienzos de 2004, esa búsqueda producía casi 90.000 resultados. Más aún, a mediados de ese mismo año se registraron más de 184.000 páginas en las que se mencionaba la gobernanza mundial (Biermann, 2004).

Si bien el mayor interés general revela preocupación, hay que insistir en que no será posible avanzar si no se pone el acento en las instituciones que funcionan como punto de referencia de la gobernanza, en particular en el caso de cuestiones como los recursos naturales o el medio ambiente. Esto requiere una coordinación más efectiva y expedita para enfrentar las disyuntivas de la globalización, en especial cuando la agenda de desafíos se acrecienta cada año que pasa. Esto es lo que ocurre justamente con los recursos naturales, en los que se ha hecho hincapié, aunque, con frecuencia, mediados por otros temas más abarcadores y urgentes que preocupan a los dirigentes o los propios ciudadanos, como la situación del ambiente, el calentamiento global o la lucha contra la pobreza. 
Efectivamente, la gobernanza de los recursos naturales a nivel nacional y regional dependerá de la coordinación y las decisiones mundiales en esos frentes, más perentorios y visibles y también más próximos a la idea de los denominados bienes públicos mundiales, donde se dirime una mayor o menor intervención del mercado y de los Gobiernos. Como ocurre con la provisión de los bienes públicos mundiales, el problema de la gestión de los recursos naturales está en el centro de atención. Sin embargo, a diferencia de los primeros, para los cuales no existen mecanismos supranacionales que actúen prima facie, para los recursos naturales puede decirse que ocurre lo contrario, pues la principal responsabilidad de su gestión o cuidado se atribuye a los Estados nacionales.

En ese sentido, la gobernanza de los recursos naturales a nivel regional y nacional depende de una dosis importante de corresponsabilidad mundial, para la cual hay que reforzar la coordinación y la complementariedad de las instituciones internacionales y regionales. La gobernanza mundial funciona como una estructura que restablece los dispositivos de cooperación, fortalecimiento institucional y regulación económica internacional y también como una herramienta de cambio que contribuye a traducir todos esos atributos en favor de los ciudadanos, que podrán guiarse hacia el análisis, la comprensión y la deliberación de las decisiones que se tomen en su representación.

El problema sigue siendo cómo transmitir la idea de una gobernanza mundial de los recursos naturales a los Estados nacionales o incluso al común de las personas. Parece claro que una parte de la solución consiste en la promoción de instancias regionales y nacionales, de manera que se reconozca a la gobernanza mundial como una plataforma común que amplía oportunidades y convierte a las personas en ciudadanos, es decir sujetos proactivos y con derechos y no reactivos y subordinados a las soluciones populistas y cada vez más dependientes de la expansión de la información y las comunicaciones, en especial la que se sostiene en las precipitadas redes sociales. Ciertamente, la gobernanza mundial debería proveer una estructura deliberativa y una parte de los contenidos que han de considerarse a nivel nacional y regional. Asimismo, debería proporcionar herramientas para un debate y una toma de decisiones que contribuyan a quebrar el discurso populista basado en premisas anacrónicas y nacionalistas (a veces más cercanas al siglo XIX), que ponderan la prerrogativa de los Estados nacionales para priorizar aspectos de soberanía frente al dilema de la globalización.

En ese sentido, un Gobierno consistente con la gobernanza mundial puede impedir que la levedad de las alarmas populistas dicte el ejercicio del poder, de manera que si los intereses comunes a largo plazo, como la conservación del medio ambiente o los derechos humanos para todos, no logran actuar como contrapeso frente a los intereses inmediatos del 
consumidor o la mentalidad estrecha y temerosa de los racistas, el dominio sin mediaciones de la opinión pública acabará por destruir la propia democracia (Berggruen y Gardels, 2013).

En América Latina, la gobernanza regional y, en general, la propia integración de los países dependen del peso y la efectividad de las políticas destinadas a reforzar la gobernanza mundial. En el caso de los recursos naturales esta influencia parece ser mucho más urgente, pues se trata de un aspecto constitutivo de la economía, la sociedad, la cultura y el futuro de la mayoría de los países de la región. En ese sentido, los propios ciudadanos de América Latina están hoy respondiendo más activamente a estos temas que sus líderes o sus Gobiernos unas décadas atrás.

Esto es lo que queda demostrado en un estudio de opinión pública en el que se interrogó a los ciudadanos del continente sobre su interés en la integración regional. Al parecer, el $89 \%$ de la población latinoamericana acepta la integración regional como política pública y el 77\% dice además que está de acuerdo con una integración económica. Más aún, a pesar de las diferencias políticas e ideológicas que han existido entre los Gobiernos de sus países en la última década, el estudio muestra que el $60 \%$ de los latinoamericanos aprueba la posibilidad de una integración política (Beliz y Chelala, 2016). El citado estudio es interesante para evaluar la mirada a favor de las perspectivas regionales de los ciudadanos de los países de América Latina y también para examinar de cerca las posiciones críticas con respecto a sus dirigentes, que siguen dudando de la legitimidad y efectividad de los organismos regionales de cooperación y gobernanza.

En esa misma línea, se ha insistido en que los Gobiernos deberían tratar de comprender mejor las ventajas de la cooperación, a partir justamente del fortalecimiento de sus instituciones y de una adhesión más firme y menos retórica de sus plataformas de gobernanza. En parte, la falta de confianza se debe a que muchos líderes políticos siguen basando los parámetros de la cooperación y la gobernanza regional en ideas de hace más de 20 años. Existe, en ese sentido, una visión anacrónica de la cooperación regional, que sigue poniendo el acento en el pasado y descuida una lectura más precisa de la agenda de la globalización en la región. Es como si para algunos líderes y dirigentes de América Latina, los enfrentamientos y dilemas de la Guerra Fría no hubiesen aún terminado.

La gobernanza de los recursos naturales a nivel regional es un terreno en el cual se puede comenzar a construir una parte importante de la agenda de integración. Sin embargo, debe saberse que esta gobernanza regional (y nacional) no es inmune a los cambios que se producen en la agenda internacional. Está sujeta a los cambios económicos, políticos y electorales que se producen en cada uno de los países, pero también (en oportunidades) a los cambios en la diplomacia y las relaciones con sus vecinos a nivel regional. 
En el caso particular de los recursos naturales, la agenda de la gobernanza regional incluye desafíos a nivel institucional, principalmente aquellos relacionados con el fortalecimiento de las normas fiscales y de regulación económica y de las políticas sociales y ambientales. Se trata de la construcción de instituciones dinámicas, acompañada de estrategias y políticas ordenadoras de la explotación, el aprovechamiento o la distribución de los recursos mediante acuerdos que faciliten el aumento de oportunidades para todos.

\section{Los recursos naturales en el imaginario de los ciudadanos}

Los recursos naturales han sido el motor de la economía y del avance intermitente de los países de América Latina. Esto se puede comprobar al revisar la historia económica de cada una de las naciones, desde la ocupación y colonización del territorio, hasta la etapa de organización nacional en el siglo XIX y la consolidación del modelo exportador 100 años después. De distinta manera, la identidad económica de la región giró en torno a sus recursos naturales y a las distintas expresiones de su exuberancia, explotación y paulatino deterioro.

Los recursos naturales están presentes en el ideal de riqueza y abundancia que moviliza a los ciudadanos y alimenta sus expectativas de desarrollo. Más aún, influyen y reafirman conceptos tan valiosos como los de abundancia, progreso, identidad o soberanía. Para muchos ciudadanos de a pie, la visión de los recursos naturales es la visión de su país.

Sin embargo, los recursos naturales también han sido señalados como la causa principal de las protestas y luchas sostenidas por comunidades, pueblos indígenas y grupos defensores del ambiente. En muchos países, los recursos naturales están asociados con escenarios de explotación y su abundancia constituye una de las causas de desigualdad y segregación, pues las propias élites nacionales lograron cambiar las reglas de juego a su conveniencia. En el caso boliviano, en la experiencia popular permanecen los períodos de explotación de la plata, el caucho y el estaño como antecedentes negativos de la extracción de recursos naturales, que dejó poco o nada para las regiones y el país en su conjunto. Estos traumas son importantes y no pueden minimizarse, pues se sustentan en las vivencias de varias generaciones, que han visto la explotación de recursos importantes sin que ello dejara beneficios sustanciales para la población (Ferrufino, 2007).

Por otra parte, los recursos naturales inspiraron los nombres de algunos países de la región, forjaron la simbología nacional y modelaron 
una parte importante de la afirmación soberana de las naciones. Su carácter prodigioso y la idea o imaginación de que se trata de patrimonios perennes o casi infinitos se convirtieron en atributos que tanto los ciudadanos como los Gobiernos celebraron y representaron en asombrosos datos y estadísticas.

La Argentina es un ejemplo claro de la presencia de los recursos naturales en los nombres de los países. Se trata de un territorio con una matriz agrícola-ganadera que, paradójicamente, se convirtió en el único ejemplo en el mundo de un país con nombre propio de origen minero. El Brasil también debe su nombre a un recurso natural, un árbol que los indígenas llamaron ibirapitanga (árbol colorado) y que los portugueses llamaron palo-brasa o "brasil" por su similitud con las brasas. Otro ejemplo interesante es Guatemala, un nombre originado en la lengua local que significa "lugar con mucha madera" o "lleno de árboles". Panamá, por su parte, significa en lengua local "lugar con abundancia de peces".

Los recursos naturales también alimentaron buena parte de la iconografía patriótica de los países de la región. Los símbolos patrios se refieren a la variedad y exuberancia de los recursos y a los productos derivados que los identifican. En el escudo del Brasil están presentes las plantas de café y tabaco y en el del Estado Plurinacional de Bolivia están el trigo y el Cerro Rico de Potosí (minas de plata). Asimismo, en los escudos de Colombia y la República Bolivariana de Venezuela se muestran cornucopias con frutas y minerales, algo que también aparece en el escudo peruano. Por su parte, en el emblema de Guayana asoman la caña de azúcar y el arroz y en el del Uruguay un buey que representa la abundancia. Por último, un escudo muy alegórico es el de Honduras, que además de frutos, flores y árboles, tiene representados recursos mineros como el oro y la plata.

En América Latina, los recursos naturales llevan consigo una fuerte carga ideológica respecto del potencial que representan. En torno a ellos se han creado imágenes utópicas y estereotipadas de su valor y riqueza. En muchos casos, esta mirada se acrecienta cuando aparece asociada a la mitología sobre un pasado de esplendor y exuberancia. Esto es así porque en solo seis países de la región habita en la actualidad poco más del $40 \%$ de las especies animales del planeta, algunas de las cuales están en serio peligro de extinción. Además, la región alberga el $20 \%$ de la superficie boscosa mundial, un porcentaje similar de reservas petroleras y casi un tercio del agua dulce del planeta (CEPAL, 2013).

Si bien el grueso de la población puede quizás reconocer los recursos naturales en sus respectivos países, en general la mayoría no tiene mucha noción de su envergadura. Un objetivo de estudio interesante puede ser concretar un mapa sobre el nivel de conocimiento, información, percepción 
o interés de los distintos grupos y segmentos de la población de América Latina respecto de los recursos naturales. ¿Qué se imaginan y esperan los ciudadanos o, en general, las comunidades en relación con estos recursos naturales? ¿Qué esperan de sus Gobiernos? ¿Cuánto conocen y cuánta información de calidad tienen sobre los recursos de sus países? Asimismo, ¿cuánto los asocian con el cuidado del ambiente, la sostenibilidad y su propio futuro y bienestar?

$\mathrm{Al}$ respecto, en una encuesta realizada en Colombia para conocer la opinión de la población sobre la Amazonia, se preguntó sobre la pertenencia o la propiedad de ese vasto territorio. En el estudio se incluyeron encuestas a comunidades de pueblos indígenas de aquel país. Según los resultados, un $45 \%$ de la población considera que la Amazonia colombiana es patrimonio "de todos los colombianos", mientras que un 34\% afirmó que es "de todo el mundo" y solo un $11 \%$ que es "de los pueblos indígenas". Por su parte, los pueblos indígenas fueron en sentido contrario: un 38\% afirmó que la selva amazónica les pertenece, un $34 \%$ que es patrimonio "de todo el mundo" y un $24 \%$ que es de los colombianos (Ipsos, 2010).

Estas respuestas hacen referencia a la disparidad de criterios que existe en la población respecto de una misma dotación natural, un contraste en que los valores culturales, las orientaciones políticas, los intereses económicos y la percepción de la situación actual del ambiente influyen en la opinión de las personas, que exigen ser tomadas en cuenta a la hora de construir una visión sobre su gobernanza. Así, por ejemplo, cuando en esa misma encuesta se preguntó a los colombianos sobre las principales causas del daño a la Amazonia, las opiniones fueron otra vez muy divergentes. Para la población general, las causas principales eran "el terrorismo y el narcotráfico", mientras que para los pueblos indígenas colombianos los causantes del daño eran "las topadoras de las empresas forestales" (Ipsos, 2010).

En un estudio de opinión pública realizado en la Argentina en 2016, se analizó la asociación que la población general hace entre su idea de recursos naturales y los conceptos de soberanía, riqueza, desarrollo y futuro del país. El estudio puede ser representativo de la situación en otros países de la región con un contexto similar. El objetivo fue exponer a la población a una serie de preguntas sobre el cuidado de los recursos naturales de acuerdo con determinados escenarios asociados a su explotación.

Se pidió a los encuestados que relacionaran los recursos naturales con los mencionados atributos y lo primero que surgió fue que, a pesar de la carga emocional de algunos conceptos y las expectativas de bienestar y progreso de otros, todos están presentes más o menos en partes iguales en la cabeza de los ciudadanos. Un $20 \%$ de los argentinos vincula los recursos 
naturales con la soberanía de su país, otro $20 \%$ con la riqueza, un $23 \%$ con el desarrollo y un $26 \%$ con el futuro (véase el gráfico X.1) (Poliarquía Consultores, 2016). La sensibilidad nacional que en principio conlleva la idea de soberanía de los recursos naturales tiene quizás la misma importancia que las ideas de riqueza, desarrollo o futuro. De la misma manera, la asociación del futuro o la riqueza del país con los recursos naturales, como expresiones de deseo o esperanza, no parecen tener una importancia mayor que la que se asigna al desarrollo o la soberanía.

\section{Gráfico X.1 \\ Argentina: respuesta a la pregunta " ¿cuál de las siguientes palabras cree que se asocia con los recursos naturales en el país?"}

(En porcentajes)

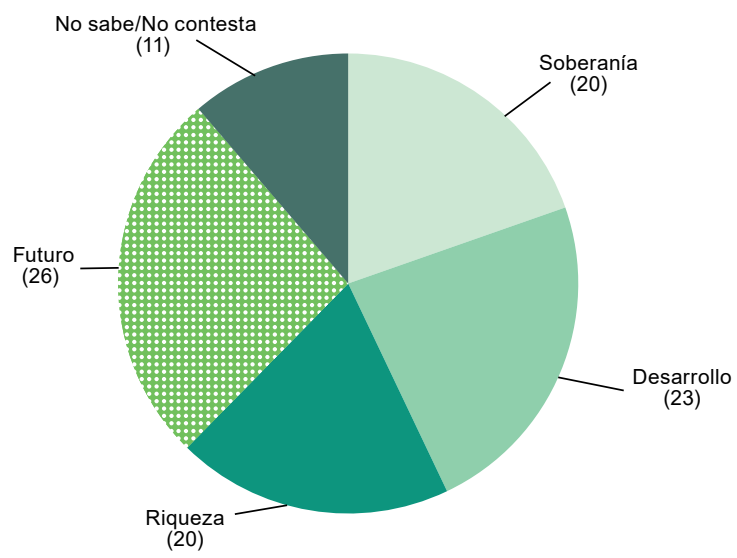

Fuente: Poliarquía Consultores, "Estudio de opinión pública nacional sobre recursos naturales, 2016", Buenos Aires, 2016, inédito.

Sin embargo, un análisis pormenorizado del citado estudio de opinión ofrece diversas aristas y, como en el caso colombiano respecto de la opinión sobre la propiedad y el usufructo de la Amazonia, muestra la diversidad de opiniones y percepciones de los recursos naturales. De esta manera, al hacer algunas correlaciones para el caso argentino surgió, por ejemplo, que la asociación entre recursos naturales y soberanía del país parece ser un tema de interés masculino (el $25 \%$ de los hombres se inclinó por esta relación en comparación con un $15 \%$ de las mujeres), mientras que la relación con la riqueza parece ser más importante para las mujeres que para los hombres.

La educación es también una variable interesante que influye en la relación de los recursos naturales con los atributos indicados. Las personas más calificadas, con educación superior, mostraron la menor cuota de dudas y solo un $4 \%$ no logró hacer correlación alguna, en comparación con 
un $10 \%$ y un $19 \%$ de la población con educación secundaria y primaria, respectivamente, que dudaron o simplemente no respondieron a algunas de las correlaciones. Por otra parte, quienes habían completado la educación secundaria y terciaria se inclinaban más por el futuro y menos por el desarrollo y la soberanía del país, mientras quienes habían completado el nivel primario identificaron en mayor medida los recursos naturales con la idea de desarrollo, una relación que paradójicamente atrajo menos a los grupos más calificados o con educación superior de la población.

\section{Corrección política y presencia del Estado en la visión de los recursos naturales}

En la última década, la preocupación por el cuidado y el futuro del ambiente y los recursos naturales aparece cada vez más en los estudios e investigaciones de opinión pública de muchos países de la región. Se ha comprobado que aumentó el interés de la población y los Gobiernos en estos temas, particularmente con respecto a la explotación minera y petrolera, aunque también y cada vez más en relación con el futuro de los bosques y la pesca. Sin embargo, hay que reconocer que en muchos casos prevalece en las opiniones y percepciones de la gente una preocupación que se apoya en un nivel muy bajo de información y conocimiento y revela una actitud que podría definirse como "políticamente correcta" con respecto al cuidado o el futuro de los recursos naturales. Esto también ocurre con los temas ambientales.

La cuestión de la corrección política no es un aspecto menor y en otros estudios se ha mencionado la importancia de su análisis a la hora de evaluar el verdadero interés de las personas y las comunidades en el futuro del ambiente (Cussianovich, 2015). La pregunta central es: ¿en qué medida el interés y la preocupación de las personas responden a los estímulos de la información que reciben (por ejemplo, a través de las redes sociales) o son fruto de un mayor conocimiento y deliberación sobre el porvenir o la sostenibilidad de los recursos en cada país? Asimismo, ¿en qué medida esa preocupación sobre los recursos naturales o el medio ambiente se disuelve cuando está mediada por la obtención de un beneficio económico a corto plazo o puede competir con la preocupación por otros temas cotidianos como el desempleo, el narcotráfico, la seguridad ciudadana y el acceso a la justicia, entre otros?

Esta situación también se debe a que hoy en día pocos ciudadanos están dispuestos a reconocer que no saben, saben poco o sencillamente no están interesados en los recursos naturales, pero muestran su preocupación, teñida —en muchos casos - de una fuerte mirada autorreferencial sobre su preservación. En un contexto de poca información, bajo nivel 
de conocimiento y una inquietud motivada por actitudes de corrección política, la pregunta que surge es cómo hacer para traducir el valor de los recursos naturales como una potencial fuente de beneficios, ingresos $o$ rentas capaces de resolver los problemas materiales a largo plazo.

Al preguntar a los ciudadanos “¿cuán interesados están usted, el Gobierno, la gente y las empresas en el cuidado de los recursos naturales en el país?" en el estudio de opinión pública realizado en la Argentina, la mayoría de las personas se declaró mucho más preocupada que el resto de todos los mencionados. Como se observa en el gráfico X.2, el 85\% de los argentinos cree que las empresas no están interesadas en el cuidado de los recursos naturales, el 75\% considera que "la gente" tampoco parece estar preocupada, mientras que un $61 \%$ opina que el Gobierno también muestra una actitud de desdén frente al cuidado de los recursos naturales. Sin embargo, lo más interesante de estas respuestas es que cuando se preguntó a los encuestados si estaban personalmente interesados o no en el cuidado de los recursos naturales, casi el $90 \%$ afirmó que sí lo estaba y solo un $10 \%$ (quizás más sincero y menos políticamente correcto) reconoció que el tema no le interesaba o le interesaba poco o nada (Poliarquía Consultores, 2016).

\section{Gráfico X.2}

Argentina: respuesta a la pregunta "¿cuán interesados están usted, el Gobierno, la gente y las empresas en el cuidado de los recursos naturales en el país?"

(En porcentajes)

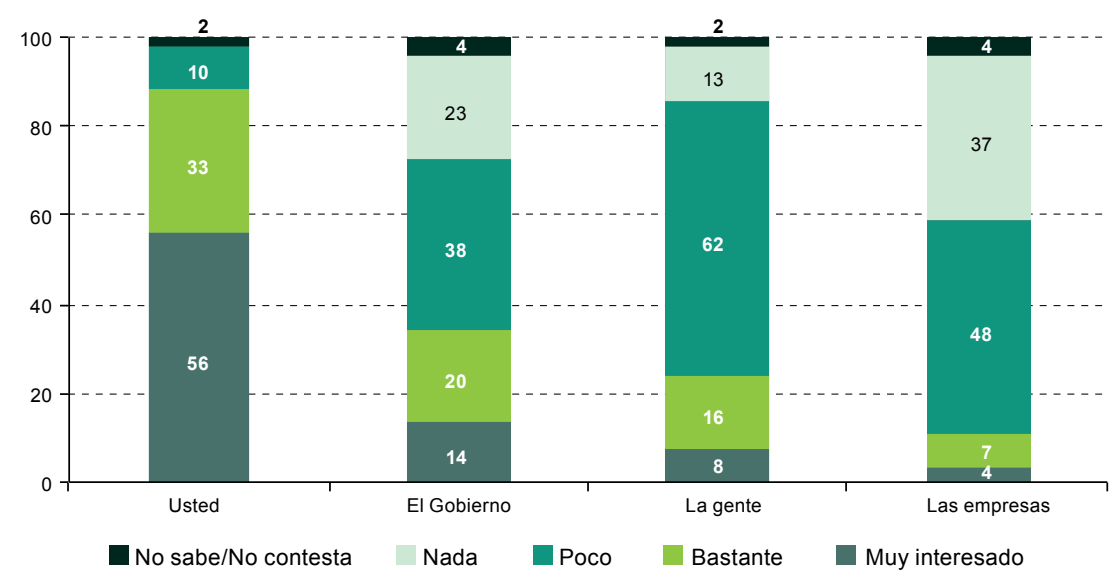

Fuente: Poliarquía Consultores, "Estudio de opinión pública nacional sobre recursos naturales, 2016", Buenos Aires, 2016, inédito.

Como se ha sugerido, uno de los aspectos que influyen en esta mirada autorreferencial y políticamente correcta respecto de los recursos naturales es la falta de información, a la que se suma la influencia del 
nivel de conocimiento y las representaciones e imágenes que a veces prevalecen sobre dichos recursos (por ejemplo, cuando se los asocia con el futuro, el desarrollo, la riqueza o la soberanía). La provisión de información de calidad es crucial para la evaluación de la actitud de las personas con respecto a sus recursos. En este punto, se considera que en América Latina la presencia del Estado es un factor decisivo en la opinión y percepción de los ciudadanos con respecto a los recursos naturales, especialmente en relación con los mecanismos de control o seguimiento y de preservación o cuidado.

En ese sentido, en una encuesta también realizada en la Argentina, aunque completada un año antes de la citada de 2016, se preguntó a la población qué debería hacerse en caso de que la extracción y explotación de un recurso natural generara algún tipo de impacto negativo. El objetivo era evaluar el comportamiento de los ciudadanos frente a hipótesis de riesgos para el ambiente durante el proceso de explotación de los recursos naturales. Las respuestas revelaron que el $68 \%$ consideró que debía detenerse la extracción de recursos naturales, seguido de un $24 \%$ que no tuvo ninguna respuesta y un $8 \%$ que afirmó que debería continuarse con la explotación de cualquier manera (Poliarquía Consultores, 2015).

Un año después se volvió a formular esa pregunta, aunque en esa oportunidad se agregó una referencia al control del Gobierno como una de las opciones de respuesta. El resultado fue que el porcentaje de personas que consideraban que debería frenarse la explotación cada vez que se produjera un impacto ambiental negativo se redujo del 68\% en 2015 al 53\% en 2016. Además, el 8\% que en 2015 consideraba que debía continuarse de cualquier manera con la explotación disminuyó al 3\% en 2016. Por último, el $24 \%$ de personas que tenía dudas o no sabía qué contestar en 2015, apenas alcanzó al 5\% de la población en 2016. La gran mayoría obviamente migró hacia la opinión de que debía continuarse con la explotación, pero con el "control del Gobierno", una opción que contó con el 39\% de las adhesiones (Poliarquía Consultores, 2016).

Sin duda, el factor "control del Gobierno" en la explotación de los recursos contribuyó a reducir el margen de personas sin opinión o con dudas y temores sobre el impacto, los riesgos y daños producidos por la explotación de los recursos naturales y el número de personas que, quizás aun con una actitud políticamente correcta, creían necesario frenar por completo las actividades extractivas. En otras palabras, la información sobre la existencia de un mecanismo de control público generó un cambio de actitud que disolvió gran parte de la corrección política observada en la opinión de los argentinos apenas un año antes. La presencia del Estado en el control de la explotación de los recursos naturales indudablemente forzó un cambio de actitud. 


\section{Gráfico X.3}

Argentina: respuesta a la pregunta "en caso de que la extracción y explotación de un recurso natural importante en el país genere un impacto negativo sobre el medio ambiente, ¿qué cree que se debería hacer?”

(En porcentajes)

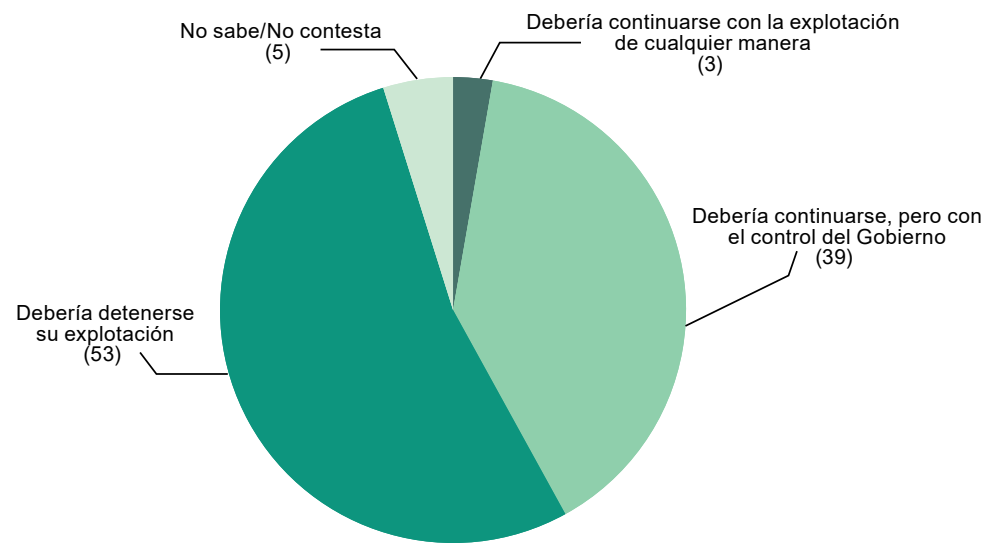

Fuente: Poliarquía Consultores, "Estudio de opinión pública nacional sobre recursos naturales, 2016", Buenos Aires, 2016, inédito.

\section{E. Conclusión: la conceptualización de la gobernanza de los recursos naturales}

Mejorar la comprensión de la gobernanza de los recursos naturales para la mayoría de los ciudadanos no es un objetivo menor. Supone traducir la mirada a corto plazo que se tiene de los recursos naturales en una perspectiva de beneficio duradero. La gobernanza debe concebirse como un instrumento que guía la explotación, el manejo y el usufructo sostenible de los recursos naturales, de manera que funcione incluso como mecanismo de reversión de las históricas políticas que redundaron en la pérdida de oportunidades para el crecimiento y el desarrollo de los países.

Se mencionó que la gobernanza como concepto académico pierde relevancia si no está referida específicamente a la sustancia o al sustrato sobre el cual ejerce su influencia, en este caso a los recursos naturales. El anclaje de la idea de gobernanza en dichos recursos es justamente lo que permitirá ampliar su significado más allá de la frontera de las teorías o las definiciones. Se trata de la transformación de la gobernanza "de las palabras" en la gobernanza "de los hechos". Poner el foco en los recursos naturales contribuye a eliminar la mirada autorreferencial del concepto de gobernanza, de la misma manera que la propia gobernanza de los recursos naturales puede contribuir a combatir los estereotipos sobre su abundancia 
o sus beneficios. De hecho, el concepto de gobernanza puede incluso ayudar a quebrar la propia idea de la "maldición de los recursos naturales".

Sin embargo, la gobernanza no debe concebirse como una herramienta para describir el progresivo declive o la "maldición" de los recursos naturales, sino más bien como un dispositivo que contribuye a reducir el impacto o el drama que supone aceptar su finitud. Con una mirada estratégica y a largo plazo, la gobernanza de los recursos naturales debe instalarse como el eje de las políticas públicas a favor de un equilibrio entre las expectativas del presente y la falta de una mirada de futuro, muy característica de la población de los países de América Latina. Para la mayor parte de la población, la gobernanza como concepto podría referirse simple y llanamente a la finitud de los recursos naturales.

Es, por lo tanto, un concepto que funciona como intérprete de las aspiraciones y hace posible que esta percepción de futuro de los recursos pase de un estado de deseos a otro de realidades. En un contexto regional cargado de representaciones que colocan a los recursos naturales en un marco de esplendor y casi perennidad, una nueva visión sobre su gobernanza deberá ser capaz de traducir el imaginario de abundancia e infinitud en acciones concretas. Con un lenguaje inteligible para los ciudadanos, la gobernanza deberá transformar la visión infinita de los recursos naturales en hechos tangibles, específicos y directamente relacionados con las necesidades de empleo, salud, educación, vivienda o justicia de la población.

Por otra parte, la preocupación políticamente correcta y autorreferencial por la situación de los recursos naturales, sostenida en la falta de conocimiento o información, será reemplazada por una preocupación más genuina y realista a partir de la intermediación de la gobernanza, que incluso debe facilitar la implementación de reglas y conductas claras con respecto a las responsabilidades que competen al Estado y a la sociedad en la gestión de los recursos. Convocar a la mayor cantidad posible de grupos de interés para la protección y el desarrollo de los recursos naturales es un objetivo del bien común y, en ese sentido, la gobernanza puede ayudar a cambiar esa mirada autorreferencial por una visión más colectiva y solidaria sobre la obtención de rentas, su gestión, distribución y aprovechamiento.

Gobernanza es también sinónimo de confianza pública, reglas de juego claras y salvaguardia del patrimonio. Más aún, como concepto analítico, se refiere a la contribución de distintos actores en el diseño de políticas públicas y al justo valor que tiene la participación de cada uno de ellos en ese proceso. Es por ello que, además de funcionar como un instrumento de gestión, funciona como una línea de base que produce equilibrio entre los distintos actores involucrados en el manejo 
y la gestión de los recursos. A su vez, este equilibro supone poner a disposición del otro intereses, conductas y expectativas sobre los resultados que se espera obtener de los recursos.

Por otra parte, la gobernanza de los recursos naturales ofrece al Estado un papel más proactivo como mediador y decisor, especialmente a la hora de enfrentar los desafíos en la resolución de conflictos, el auxilio material de los sectores más vulnerables o la protección de derechos. La gobernanza define o hace más visibles esos desafíos y propone alternativas para superarlos, asignando al Estado un papel más central y preponderante. En ese sentido, se han observado cambios en la opinión y percepción de los ciudadanos respecto de los recursos naturales cada vez que aparece la variable del control público o la presencia del Estado.

Entre otros objetivos, la gobernanza de los recursos naturales deberá mejorar los aspectos de la información y la comunicación con el fin de revelar las oportunidades que existen para traducir los recursos en progreso y bienestar y ampliar el diálogo y la deliberación a la mayor cantidad posible de grupos de interés de la región, con miras a aumentar la participación y reducir los niveles de conflictividad experimentados durante buena parte de su historia contemporánea.

\section{Bibliografía}

Altomonte, H. y R. Sánchez (2016), Hacia una nueva gobernanza de los recursos naturales en América Latina y el Caribe, Libros de la CEPAL, No 139 (LC/G.2679-P), Santiago, Comisión Económica para América Latina y el Caribe (CEPAL), mayo.

Banco Mundial (2017), Worldwide Governance Indicators (WGI), Washington, D.C. [base de datos en línea] http://info.worldbank.org/governance/wgi/\#home.

Beliz, G. y S. Chelala (2016), “El ADN de la integración regional. La voz de los latinoamericanos por una convergencia de calidad: innovación, equidad y cuidado ambiental", Nota Técnica, $\mathrm{N}^{\circ}$ 1120, Washington, D.C., Banco Interamericano de Desarrollo (BID), octubre.

Berggruen, N. y N. Gardels (2013), “La globalización 2.0 y los retos de la buena gobernanza", Gobernanza inteligente para el siglo XXI: una vía intermedia entre occidente y oriente, Buenos Aires, Taurus.

Biermann, F. (2004), “Global environmental governance: conceptualization and examples", Global Governance Working Paper, N ${ }^{\circ}$ 12, Amsterdam, Global Governance Project, noviembre.

Björk, P. y H. Johansson (2001), "Towards governance theory: in search for a common ground", Sundsvall, Mid Sweden University [en línea] https://pdfs. semanticscholar.org/4329/f2483aa88d18f3216fe55e66ada5e915b92b.pdf.

Boughton, J. y C. Bradford (2007), "Global governance: new players, new rules. Why the 20th-century model needs a makeover", Finance and Development, Washington, D.C., Fondo Monetario Internacional (FMI), diciembre.

CEPAL (Comisión Económica para América Latina y el Caribe) (2014), Pactos para la igualdad: hacia un futuro sostenible (LC/G.2586(SES.35/3)), Santiago, abril. 
(2013), Recursos Naturales: situación y tendencias para una agenda de desarrollo regional en América Latina y el Caribe (LC/L.3748), Santiago, diciembre.

Cussianovich, E. (2015), “Las actitudes políticamente correctas en favor del ambiente", Informe Ambiental Anual 2015, A. Pangracio, A. Nápoli y F. Sangalli (eds.), Buenos Aires, Fundación Ambiente y Recursos Naturales (FARN).

Decoster, J. y otros (2004), Gobernanza ambiental y territorial en comunidades afectadas por la explotación minera: la experiencia de las comunidades campesinas de la provincia de Espinar, Perú, Cusco, Asociación Kuraka.

FAO (Organización de las Naciones Unidas para la Alimentación y la Agricultura) (2012), Directrices voluntarias sobre la gobernanza responsable de la tenencia de la tierra, la pesca y los bosques en el contexto de la seguridad alimentaria nacional, Roma.

Ferrufino, R. (2007), "La maldición de los recursos naturales: enfoques, teorías y opciones", Coloquio Económico, N ${ }^{\mathrm{o}} 7$, La Paz, Fundación Milenio, noviembre.

FPP (Forest Peoples Programme) (2008), "Algunas opiniones de organizaciones de pueblos indígenas y organizaciones vinculadas a los bosques acerca del 'Fondo cooperativo para el carbono de los bosques' y propuestas para una 'Alianza Forestal Mundial'", Moreton-in-Marsh, febrero [en línea] http://www.forestpeoples.org/ sites/fpp/files/publication/2010/08/fcpfipsurveyfeb08sp.pdf.

Hufty, M. (2010), “Gobernanza en salud pública: hacia un marco analítico", Revista de Salud Pública, vol. 12, N 1, Bogotá, Universidad Nacional de Colombia.

Hufty, M., E. Báscolo y R. Bazzani (2006), "Gobernanza en salud: un aporte conceptual y analítico para la investigación", Cadernos de Saúde Pública, vol. 22, Río de Janeiro, Fundación Oswaldo Cruz.

IOG (Institute on Governance) (2017), "Defining governance", Ontario [en línea] http://iog.ca/defining-governance/.

Ipsos (2010), “Encuesta de Percepción Amazonas 2030”, Bogotá, inédito.

Mayorga, F. y E. Córdova (2007), “Gobernabilidad y Gobernanza en América Latina”, Working Paper, Ginebra, National Centre of Competence in Research (NCCR), inédito [en línea] http://www.institut-gouvernance.org/docs/fichagobernabilida.pdf.

PNUD (Programa de las Naciones Unidas para el Desarrollo) (2012), Reconfiguring Global Governance: Effectiveness, Inclusiveness, and China's Global Role, Beijing.

Poliarquía Consultores (2016), “Estudio de opinión pública nacional sobre recursos naturales, 2016", Buenos Aires, inédito. (2015), "Estudio de opinión pública nacional sobre recursos naturales, 2015", Buenos Aires, inédito.

RAE (Real Academia Española) (2014), Diccionario de la lengua española, Madrid, octubre.

Vicher, D. (2013), El laberinto de "governance": la gobernancia de los antiguos y la de los modernos, Toluca, Instituto de Administración Pública del Estado de México (IAPEM).

Whittingham, M. (2010), “Qué es la gobernanza y para qué sirve?”, Revista Análisis Internacional (RAI), N², Bogotá, Editorial Universidad Jorge Tadeo Lozano.

Zurbriggen, C. (2012), "Repensando la gobernanza en América Latina”, documento presentado en el Cuarto Congreso Uruguayo de Ciencia Política, Montevideo, Asociación Uruguaya de Ciencia Política, 14 a 16 de noviembre [en línea] http: / / www.aucip.org.uy/docs/cuarto_congreso/13121620\%20-\%20Zurbriggen,\%20 Cristina.pdf. 
Capítulo XI

\title{
Avances y retos en iniciativas y políticas de transparencia y rendición de cuentas en las industrias extractivas
}

\author{
Víctor Andrés Garzón \\ Michael Röesch
}

\begin{abstract}
A lo largo de su historia, la industria extractiva ha afrontado graves crisis. Debido al desarrollo cíclico de los precios, estas crisis han sido por lo general económicas. Sin embargo, hoy en día son también muy frecuentes y amenazantes las denominadas crisis reputacionales, que en su mayoría se originan en la mala gestión de los conflictos sociales y laborales o en los perjuicios al medio ambiente. En ese contexto, y con el paso del tiempo, han ido evolucionando los enfoques de relacionamiento y participación de los distintos actores y grupos de interés. En la actualidad, además de las cuestiones técnicas y financieras, es cada vez menos posible desarrollar un proyecto extractivo sin tener en cuenta los aspectos referidos a la gobernanza y a la participación de la sociedad civil, ya sea a nivel nacional o local'.
\end{abstract}

Los autores, Michael Rösch y Víctor Andrés Garzón, trabajan en el programa "Cooperación regional para la gestión sustentable de los recursos mineros en los países andinos", implementado por la cooperación alemana, a través de la Agencia Alemana de Cooperación Internacional (GIZ) y el Instituto Federal de Geociencias y Recursos Naturales (BGR). Las opiniones expresadas en este artículo pertenecen a los autores y de ninguna manera son posiciones institucionales de la GIZ ni de la cooperación alemana. 
De esta manera, en los debates sobre la gobernanza y la participación de las comunidades aparecen cada vez con más fuerza los temas referidos a la captura y redistribución de las rentas generadas por los proyectos extractivos. También se plantea el uso de recursos como el agua y el suelo, o problemas relacionados con la contaminación. Por otra parte, existe un reconocimiento de que se trata de la explotación de los recursos naturales de un país y, por lo tanto, de la obtención de un beneficio que, en principio, deberá redundar en la mejora de las condiciones de vida de sus ciudadanos. A su vez, en países con un sector extractivo bien consolidado se mantiene un nivel alto de conflictividad alrededor de las operaciones mineras, a pesar de los avances en términos de transparencia.

Un rasgo común de las diversas iniciativas y análisis sobre el sector extractivo es la necesidad de seguir mejorando los mecanismos de participación. Se trata de procesos donde los actores desean expresar sus preocupaciones e intereses y donde la transparencia aparece como uno de los atributos clave. Sin embargo, conviene señalar que la transparencia es un concepto muy amplio y abierto a distintas interpretaciones, algunas de las cuales no necesariamente están relacionadas con la gobernanza ni con el acceso a la información.

Así, por ejemplo, al buscar el término 'transparencia' en el Diccionario de la Real Academia Española, se encuentran definiciones más bien técnicas, relacionadas en muchos casos con las propiedades que tienen ciertos materiales para permitir el paso de la $\mathrm{luz}^{2}$. Por otra parte, al efectuar una simple búsqueda de la palabra 'transparencia' en Google, puede apreciarse que el motor de búsqueda ofrece aproximadamente 84.900 .000 resultados. En su gran mayoría están muy poco relacionados con las propiedades ópticas de los materiales y sí, en cambio, con cuestiones asociadas a los asuntos de gobierno, las instituciones o la visibilidad o integridad de los actos públicos. De esta forma, queda claro que el concepto de transparencia posee múltiples definiciones e interpretaciones, algunas de las cuales a veces dan lugar a malentendidos y falsas expectativas con respecto a su importancia en el diseño o la implementación de políticas públicas.

En la Agenda 2030 para el Desarrollo Sostenible que las Naciones Unidas pusieron en marcha en 2015, con sus 17 Objetivos de Desarrollo Sostenible (ODS), figura el objetivo 16, sobre paz, justicia e instituciones sólidas. En este objetivo se mencionan explícitamente la gobernanza y la necesidad de "reducir considerablemente la corrupción y el soborno en todas sus formas" (meta 16.5), aspirando además a "crear a todos los niveles instituciones eficaces y transparentes que rindan cuentas" (meta 16.6)" 
A efectos de este capítulo se entiende la transparencia, en un sentido básico, como la disponibilidad de información y la facilidad para acceder a ella. La hipótesis subyacente es que, mientras más información circule, mejores serán la calidad del debate público y la relación y confianza entre los actores. Al mismo tiempo, la mayor disponibilidad de información reduciría la ocurrencia de malas prácticas. Sin embargo, es cierto que hoy en día una de las grandes frustraciones asociadas a este concepto es que por lo general se espera un efecto inmediato de la mayor transparencia (o sea, más información), el aumento de la rendición de cuentas y la disminución de la corrupción, mientras que en la realidad esto no ocurre automáticamente.

Por otro lado, de lo acontecido en los últimos años vale la pena destacar el notable aumento de la información de que dispone el público en relación con el sector extractivo. Esto ha sucedido a pesar de los temores y preocupaciones en cuanto a que esa información podría hacer peligrar la competitividad de las empresas mineras o detener el desarrollo de nuevos proyectos, lo que finalmente no ha sucedido. Al margen de lo anterior, lo que sí puede ocurrir es que la disponibilidad de grandes cantidades de información resulte de cierto modo excesiva para los usuarios y entrañe cierta sobrecarga administrativa para los gobiernos y las empresas, lo que a su vez crea tres escenarios de riesgo:

i) que la transparencia se vuelva un ejercicio técnico de presentación de informes, con altos costos y bajo impacto;

ii) que se produzca un agotamiento de los actores involucrados en los procesos, $\mathrm{y}$

iii) que detrás del aparente exceso de información se oculte una falta de información relevante, sobre todo si esta no es útil o no ha sido analizada y validada por los actores.

Es probable que la transparencia, si no está enmarcada en un esquema de gobernanza más amplio, no tenga el impacto que se espera. La publicación de información no es suficiente si sus usuarios no la consideran creíble, útil, conducente a la rendición de cuentas y, por ende, propiciadora de cambios en la lógica de trabajo del sector. Por esa razón, es imprescindible partir desde los intereses y demandas de los usuarios, así como de procesos institucionalizados y participativos de validación de la información y su contextualización. En ese sentido, en el presente artículo se discutirá en qué condiciones y de qué manera las iniciativas de transparencia pueden tener impactos tanto a nivel internacional como nacional y subnacional. También se analizará cómo esos posibles impactos de los actores involucrados, y sobre ellos, contribuyen a un aumento cuantitativo y cualitativo de la transparencia, lo que puede redundar en una mayor rendición de cuentas. 


\section{A. La discusión sobre la transparencia en las industrias extractivas}

A partir de una posición crítica y generalizada, las estrategias de comunicación del sector extractivo (por lo menos hasta finales de los años noventa) podrían resumirse de la siguiente manera: proporcionar la menor cantidad posible de información y, en todo caso, hacerlo a último momento. La referencia al sector extractivo se hace en este caso de manera consciente, ya que tanto los gobiernos como el sector privado parecen haberse suscrito a esta estrategia, basándose en una cultura de la opacidad. Esta se sustenta en el temor de que la provisión de información puede afectar la competitividad del sector privado al revelar involuntariamente secretos operativos o de gestión, además de servir como base para que se cuestionen las prácticas, el comportamiento y las operaciones de las empresas. Sin embargo, estas premisas tienen hoy cimientos muy débiles. Por el contrario, surten el efecto de afianzar la idea de que existe efectivamente esa cultura de la opacidad. Sin dudas, ello hace que aumente aún más la desconfianza pública en las empresas y en las propias instituciones del Estado.

Desde hace por lo menos diez años, las exigencias de transparencia comenzaron a aumentar cada vez más, tanto para el sector extractivo como para otros sectores de la economía. Por ejemplo, la industria pesquera lanzó la Iniciativa de Transparencia de Pesca (FiTI) ${ }^{4}$. Se trata de un estándar de transparencia similar al más conocido de la Iniciativa para la Transparencia de las Industrias Extractivas (EITI) (véase el recuadro XI.1). Esto fue posible debido al aumento de la presión por parte de la sociedad civil y la ampliación del número de iniciativas de transparencia a nivel global. También contribuyó a la adopción de estas iniciativas la creación de mayor conciencia sobre la necesidad de cambios entre los grupos de interés involucrados. En diverso grado, entre estos se incluyen referentes de la ya mencionada sociedad civil, el gobierno y las empresas, así como de los propios accionistas y financistas internacionales.

Al respecto, otro factor que propició un aumento de la exigencia de una mayor transparencia y un mayor número de iniciativas fue el hecho de que la población utilizaba cada vez más los teléfonos celulares para distribuir material sobre malas prácticas industriales. Se trata de un crecimiento que se enmarca en el aumento general de los dispositivos y redes de comunicación que permiten exponer de manera inmediata los casos polémicos y conflictivos relacionados, por ejemplo, con las industrias extractivas. Aunque pueda haber dudas sobre la veracidad de los casos, son asuntos públicos que de cualquier manera requieren una respuesta por parte de las empresas y los gobiernos.

$4 \quad$ Véase [en línea] http://fisheriestransparency.org/. 


\title{
Recuadro XI.1
}

Iniciativa para la Transparencia de las Industrias Extractivas

\begin{abstract}
La Iniciativa EITI es una de las propuestas más exitosas del mundo en materia de transparencia. En su corto tiempo de existencia, se ha logrado su implementación en más de 50 países. Surgió a partir de la presión ejercida por una asociación de organizaciones de la sociedad civil (Publish what you pay) para que la empresa British Petroleum (BP) revelara los montos pagados al Gobierno de Angola por la explotación de petróleo, en vista de que dichos aportes no se veían expresados en un mayor desarrollo del país. Si bien la empresa reveló esos datos, se trató de un acto perjudicial para los intereses del Gobierno de Angola, puesto que exponía y comprometía información oficial sensible. Posteriormente, la reacción del Gobierno sugirió que en adelante el enfoque más apropiado para el abordaje de estos temas sería mediante una coalición de múltiples actores. En el marco de esa coalición, los gobiernos, la sociedad civil y las empresas comparten información y la validan conjuntamente, en temas como la concesión de las explotaciones de recursos, los ingresos tributarios y no tributarios y los montos pagados por las empresas a los gobiernos. Esta iniciativa ha tenido a lo largo de su historia un gran respaldo político y, desde su puesta en marcha en 2002, ha evolucionado como un estándar que integra más temas de discusión, con lo que se ha elevado el nivel de detalle y transparencia de la información. Hoy en día, a nivel mundial, en los más de 50 países donde se implementa, la EITI ha reportado más de 330 ejemplos de años fiscales en formatos de datos abiertos. Además, ha permitido transparentar la procedencia y destino de más de 2,4 billones de dólares por concepto de ingresos públicos en países ricos en recursos naturales.
\end{abstract}

Fuente:Elaboración propia, sobre la base de Iniciativa para la Transparencia de las Industrias Extractivas (EITI), "History of the EITI" [en línea] https://eiti.org/history.

Las exigencias de mayor transparencia se han traducido también en normativas, sobre todo dentro del ámbito fiscal (Unión Europea (UE), Estados Unidos, Bolsa de valores de Hong Kong, entre otros), ambiental y social (Declaración de Río sobre el Medio Ambiente y el Desarrollo y su Principio 10 sobre el acceso a la información, o Convenio sobre Pueblos Indígenas y Tribales, 1989 (núm. 169) de la Organización Internacional del Trabajo (OIT)). De este modo se establecieron estándares adicionales de transparencia y consulta, y de comunicación a nivel internacional. Además, el aumento de la disponibilidad de información se alimenta en parte de las iniciativas de gobierno abierto, la implementación de normas internacionales o la información transmitida voluntariamente por las propias empresas en respuesta a las presiones externas o como resultado de sus propios estándares 5 .

Sin embargo, el salto de la transparencia a la rendición de cuentas no es tan inmediato ni trivial. Incluso puede darse la paradoja de quedar en una zona de disponibilidad de información que no impacta, no genera debate o no promueve la rendición de cuentas, ni a nivel empresarial ni gubernamental. Se pueden documentar casos de países donde, si bien

Véase [en línea] https://www.opengovpartnership.org/. 
se implementan estándares como el de la EITI, han ocurrido grandes escándalos de corrupción relacionados con el sector extractivo o con la gestión de las rentas producidas por ese sector. No es de sorprender, por lo tanto, que muchos países ricos en recursos extractivos tengan hoy un desempeño muy desfavorable en el índice de percepción de la corrupción de Transparencia Internacional ${ }^{6}$.

El análisis del resultado de cruzar el citado índice de percepción de la corrupción con los países implementadores de la EITI (y teniendo en cuenta que el índice no está relacionado exclusivamente con la industria extractiva) permite concluir que hoy resulta insuficiente la mera implementación de estándares y la sola publicación de información sin mecanismos para que los ciudadanos discutan sus métodos, alcances y resultados. Por lo tanto, con el fin de asegurarse de que los estándares impacten en la población, será necesario realizar más ejercicios de pedagogía sobre el estándar implementado, sus objetivos, metodologías y alcances. Al mismo tiempo, habría que explicar la información ofrecida dentro de un contexto y un modo que sean entendibles y asimilables por la mayor parte de la población.

Más aún, en lo posible debería extenderse el ejercicio pedagógico hasta los aspectos relacionados con la rendición pública de cuentas por parte de las autoridades. Se debería explicar el impacto que produce la información que el gobierno proporciona a los diferentes grupos de interesados sobre el uso de los recursos y, lo que es más importante, sobre los beneficios que tendrán en cuanto a la calidad de vida de los ciudadanos en sus territorios. Sin estas premisas, es dudoso que la información encuentre eco en la población local, ya que sus efectos no se expresan en la realidad cotidiana de los ciudadanos, ni dice demasiado sobre las ventajas finales de obtener datos, promover la transparencia y acrecentar el acceso a la información.

Sin embargo, es importante destacar también que a pesar de los obstáculos que puedan aparecer en los procesos, ningún esfuerzo por aumentar la transparencia será en vano. De esta forma, sin la implementación de estándares o sin la adopción de principios de gobierno abierto, podría llegar a ser mucho peor el desempeño de los países ricos en recursos respecto de asuntos tales como la percepción de la corrupción o la existencia de una cultura de la opacidad. Más aún, todos los esfuerzos que se realizan favorecen a la postre, o incluso posibilitan, el debate sobre estos temas.

En los últimos años se han producido algunos cambios sustantivos en las estrategias de comunicación del sector extractivo. No obstante, hay que reconocer que, a pesar de ello, la falta de confianza en el sector se

6 Véase [en línea] https://www.transparency.org/news/feature/corruption_perceptions_index_2016. 
ha instalado con fuerza y ha creado una profunda cultura de sospecha. En la encuesta Latinobarómetro de 2015 se constatan los bajos niveles de confianza de la población de los países andinos en relación con las empresas privadas (a un 58,5\% les inspiran poca o ninguna confianza) o el Estado (a un $62,1 \%$, poca o ninguna confianza) 7 . Aunque las cifras no se refieren directamente al sector extractivo, se pueden tomar como indicadoras de una tendencia.

En el caso particular de la industria minera, la falta de confianza se ha convertido en un riesgo fundamental, ya que influye considerablemente en la posibilidad de realizar inversiones y desarrollar más operaciones. En los países que efectúan y fomentan la explotación de sus recursos naturales, los conflictos sociales y las protestas en contra de la actividad extractiva se han vuelto un fenómeno casi cotidiano. Al mismo tiempo, ha aumentado la demanda de información sobre las cadenas de suministro para las industrias internacionales. Esta demanda ha motivado nuevas iniciativas globales con miras a lograr un mayor nivel de transparencia y trazabilidad.

Los primeros esfuerzos siguieron un enfoque dirigido a la transparencia fiscal y a promover otras iniciativas relacionadas con los conflictos sociales y las violaciones de los derechos humanos. Ese ha sido el caso del proceso de Kimberley y el estándar para oro libre de conflicto, las guías de la Organización de Cooperación y Desarrollo Económicos (OCDE) sobre la diligencia debida en las cadenas de suministro en zonas de conflicto o el estándar para la producción de oro a nivel artesanal en condiciones de comercio justo o extracción justa (Fairtrade \& Fairmined $(\mathrm{FT \& FM}))^{8,9}, 10,11$. Como paso adicional, se están desarrollando estándares e iniciativas sobre temas ambientales, lo que ocurre, por ejemplo, con el Convenio de Minamata o el antes citado Principio 10 de la Declaración de Río sobre el acceso a la información ${ }^{1213}$.

Más allá de las exigencias de la sociedad civil, la transparencia y la rendición de cuentas se han convertido en factores críticos para las industrias extractivas, ya que el sector financiero busca reducir los riesgos de ver afectada su reputación en el financiamiento de proyectos mineros. A su vez, el sector privado, y sobre todo el financiero, han introducido sus propias iniciativas, requisitos y compromisos voluntarios. Los ejemplos son

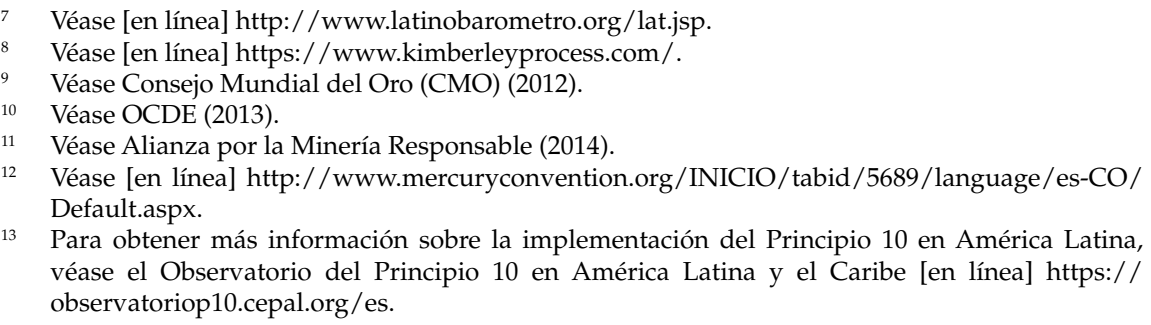

13 Para obtener más información sobre la implementación del Principio 10 en América Latina, véase el Observatorio del Principio 10 en América Latina y el Caribe [en línea] https:// observatoriop10.cepal.org/es. 
múltiples, e incluyen desde asumir la afiliación a la EITI como criterio para la evaluación de riesgos en diferentes financiadores internacionales, hasta la aplicación de normas de sostenibilidad en las decisiones, como es el caso del Banco Interamericano de Desarrollo, los criterios de la Corporación Financiera Internacional (IFC) o los del fondo soberano de Noruega. En el recuadro XI.2 se enumeran algunas de estas iniciativas y normas, tanto las de carácter jurídicamente vinculante como las de aplicación voluntaria ${ }^{14}$.

\section{Recuadro XI.2 \\ Enumeración de estándares internacionales seleccionados para la minería}

Aluminium Stewardship Initiative (ASI); Directrices de Berlín; Berlin Guidelines for Mining and Sustainable Development, 2002; Better Sourcing Standard; Conflict-Free Sourcing Initiative (CFSI)/Conflict-Free Smelter Program (CFSP); iniciativa CONNEX; Ley Dodd-Frank de reforma de Wall Street y protección al consumidor; evaluación del impacto ambiental en el marco de la Directiva 2006/21/CE sobre residuos de la minería; evaluación estratégica ambiental (EEA); Directiva sobre contabilidad de la Unión Europea; Directiva sobre transparencia de la UE; legislación de la UE sobre minerales de conflicto; Iniciativa para la Transparencia de las Industrias Extractivas (EITI); Fairtrade and Fairmined (FT/FM); código de sostenibilidad alemán (DNK); Global Acid Rock Drainage (GARD) Guide; Global Reporting Initiative (GRI); Hong Kong Stock Exchange Listing Requirements; Iniciativa para garantizar la minería responsable; Foro Intergubernamental sobre Minería, Minerales, Metales y Desarrollo Sostenible; Consejo Internacional de Minería y Metales: Good Practice Guidance for Mining and Biodiversity; Código Internacional para el Manejo del Cianuro; Código ISEAL de Buenas Prácticas para Establecer Estándares Sociales y Ambientales; Iniciativa sobre la Cadena de Suministro de Estaño; Proceso de Kimberley; London Bullion Market Association (LBMA); LBMA Responsible Gold Guidance (RGG); Convenio de Minamata sobre el Mercurio; Carta de los Recursos Naturales; Líneas Directrices de la OCDE para Empresas Multinacionales/Guía de debida diligencia de la OCDE para cadenas de suministro responsables de minerales en las áreas de conflicto o de alto riesgo; Alianza para el Gobierno Abierto; Alianza para las Contrataciones Abiertas; mecanismo regional de certificación de la Convención de Ramsar; Consejo de Joyería Responsable; Solutions for Hope $(\mathrm{SfH})$; programa "Hacia una minería sustentable"; Convenio sobre Seguridad y Salud en las Minas, 1995 (núm. 176); Declaración de las Naciones Unidas sobre los Derechos de los Pueblos Indígenas; Convenio sobre Pueblos Indígenas y Tribales, 1989 (núm. 169); Programa de las Naciones Unidas para el Desarrollo (PNUD): industrias extractivas; Pacto Mundial de las Naciones Unidas; Principios Rectores sobre las Empresas y los Derechos Humanos; Principios Voluntarios de Seguridad y Derechos Humanos; Guías sobre medio ambiente, salud y seguridad del Banco Mundial; Políticas de Salvaguardia del Banco Mundial/ Normas de Desempeño de la Corporación Financiera Internacional (IFC); Consejo Mundial del Oro (CMO): Conflict-Free Gold Standard (CFGS).

Fuente: Elaboración propia, sobre la base de Ch. Scholl y L. Rüttinger, "Approaches to reducing negative environmental and social impacts in the production of metal raw materials", 2017 [en línea] https://www.umweltbundesamt.de/sites/default/ files/medien/1410/publikationen/2017-08-18_texte_66-2017_umsoress_ summary.pdf.

14 Véase un análisis de los estándares internacionales y su eficiencia en Scholl y Rüttinger (2017). 


\section{B. Enfoques e instrumentos de transparencia respecto de la gobernanza de los recursos naturales}

El aparente aumento de la transparencia en las industrias extractivas impulsado por las iniciativas internacionales ha sido un importante generador de otros procesos innovadores. La transparencia creó nuevas oportunidades y opciones para los diferentes actores que buscan relacionarse entre sí, a la vez que incidir en el sector extractivo en general. Sin embargo, como ya se dijo, persisten los conflictos en torno a las operaciones mineras y petroleras en todo el mundo. Esto se debe en parte a que muchos de los avances en términos de transparencia han encontrado más eco en las ciudades que en las zonas rurales o en las comunidades afectadas por los proyectos.

Por otro lado, muchas veces el aumento de la transparencia no se ha traducido en mayor rendición de cuentas, ni tampoco en la eliminación de los propios conflictos. A su vez, ante la gran cantidad de estándares surgidos, también es posible que la multiplicidad de iniciativas haya terminado por producir en las empresas un desgaste en la idea y la práctica de la presentación de informes. Esto se debe a que su elaboración entraña costos que no necesariamente tienen réditos a nivel reputacional ni de su valorización bursátil.

Sin embargo, a pesar de todo lo anterior, hay que señalar que varios de los estándares e iniciativas internacionales de transparencia han conseguido al fin transformar el sector minero y muchos otros sectores económicos. Por el momento, los casos indicados son un primer paso importante e indispensable para avanzar hacia una buena gobernanza de los recursos naturales, especialmente en lo que respecta al caso de la minería. No obstante, como se ha mencionado, si esa información disponible y validada no se contextualiza y se adapta a la demanda y el interés concreto de los ciudadanos y, en particular, de los territorios influidos por el proceso productivo, todos los esfuerzos que se realicen serán insuficientes.

Una de las lecciones de la EITI se refiere a la necesidad de proveer información de calidad acerca de la industria minera o hidrocarburífera, sobre todo en relación con la necesidad de fomentar estándares de transparencia y apertura de dicha información. Sin embargo, a nivel territorial o local, donde se expresan la mayoría de los conflictos y las preocupaciones alrededor de las operaciones mineras, esta información agregada tiene en la práctica una relevancia muy limitada. Ante esta situación, en el Perú se están realizando ejercicios muy interesantes encaminados a establecer comisiones de la EITI en varias regiones del país, con el fin de implementar metodologías similares a nivel subnacional. Tales ejercicios no se han dado fácilmente y su consolidación aún requiere 
un gran esfuerzo conceptual y político. En ese sentido, uno de los aspectos clave para dar sostenibilidad a la iniciativa ha sido el anclaje institucional y la articulación entre los niveles central y regional de gobierno. En el Perú, se consolidaron los procesos de EITI a nivel subnacional en las regiones de Piura y Moquegua ${ }^{15}$. Actualmente se trabaja en el mismo sentido en otras dos regiones, las de Apurímac y Arequipa.

Una de las grandes fortalezas de muchos procesos ha sido la participación de múltiples actores. Tal como se plantea en el objetivo 17, las alianzas entre múltiples actores de los gobiernos, el sector privado y la sociedad civil aumentan el alcance de la cooperación y reducen las desigualdades entre los participantes. Es loable que en las iniciativas como la EITI, desde su propia estructura de gobernanza, se aplique un enfoque de múltiples actores. No obstante, esa modalidad requiere tiempo y grandes esfuerzos por parte de todos los involucrados en la negociación constante, incluido el ajuste de sus posiciones y expectativas. En términos de la inmediatez de los efectos y de los impactos, la EITI implica una gran incógnita que cada una de las partes debe resolver. Por lo que se refiere a las relaciones estables que promueve entre los actores (una de las bases de la gobernanza) significa un avance muy importante que influye positivamente en el diseño de políticas relacionadas con el sector, así como en su implementación y monitoreo.

Por otro lado, también las nuevas tecnologías, muchas veces englobadas en el concepto de la digitalización, coadyuvan a la formulación de nuevos enfoques que permiten abordar de manera diferenciada todo lo concerniente a la transparencia. Se mencionaron las posibilidades que hoy ofrecen los teléfonos celulares con relación al acceso, la documentación y la circulación de información sobre determinados casos, de manera inmediata y desde casi cualquier lugar del planeta. En esa misma línea, un ejemplo muy extendido es el análisis de las grandes cantidades de datos electrónicos, que hoy se conocen como macrodatos o big data. Se basa en técnicas avanzadas para obtener datos, sacar conclusiones, estimar tendencias e identificar buenas y malas prácticas. Por último, un tercer ejemplo es la tecnología de cadenas de bloques (blockchain), similar a la utilizada con la moneda digital bitcóin. Mediante operaciones matemáticas, esta tecnología contribuye a reducir las posibilidades de manipulación de los datos.

Todos estos nuevos enfoques permiten relacionar datos transparentados y asegurarlos a lo largo del tiempo. Aunque en la mayoría de casos no están exentos de riesgos, se trata de tecnologías que presentan un gran potencial para reducir varios de los problemas clave antes mencionados,

15 Para obtener más detalles sobre la implementación de la EITI a nivel subnacional en el Perú, véase Ministerio de Energía y Minas (2016). 
entre los que cabe destacar: i) el aumento de la relevancia de la información disponible a través de cruces con otras bases de datos e informaciones; ii) la reducción de la desconfianza en la información disponible, ya que esta se certifica electrónicamente; iii) la disminución de los costos burocráticos relacionados con la compilación y publicación de información relevante, y iv) la ampliación de la accesibilidad a la información.

Lo que aún no se resuelve con estas nuevas posibilidades tecnológicas es el peligro de que la transparencia a veces solo sea útil para un pequeño círculo de expertos y no para la mayoría de la población, incluidos los ciudadanos que viven en áreas remotas directamente afectadas por las operaciones extractivas.

\section{Impactos de la transparencia: ¿cuál es el papel de los diferentes actores?}

Pese a los esfuerzos de las empresas y los gobiernos por aumentar la transparencia y la accesibilidad de la información, los índices de confianza no mejoran. Esta situación da lugar a la hipótesis de que la gran cantidad de enfoques especializados sobre la transparencia ha redundado en la creación de grupos de especialistas y círculos de expertos que no siempre proveen información relevante para la sociedad en su conjunto. Esto, a su vez, plantea el problema de que parece necesario profundizar aún más los instrumentos y mecanismos para ganar la confianza pública. Se trata de una batalla constante que tanto el sector privado como el gobierno deberán atender.

En ese contexto, hay que insistir en que las reacciones producidas por la falta de confianza y el creciente nivel de conflictividad se han convertido, paradójicamente, en elementos de estímulo para la divulgación de información sobre los proyectos extractivos. Entre otros temas, esos informes se refieren a las iniciativas con la participación de múltiples actores, así como a las que se basan en la elaboración de informes corporativos $\mathrm{y}$ de sostenibilidad que ofrecen las empresas, de manera voluntaria y cada vez más elaborada, sobre los diversos aspectos relacionados con sus actividades ${ }^{16}$. Un ejemplo destacado de informe que muchas empresas han adoptado es el basado en los principios de la iniciativa mundial de presentación de informes (Global Reporting Initiative (GRI)) ${ }^{17}$.

Aunque sea de esperar que junto al aumento de la transparencia también ocurra un aumento de la confianza, hay que reconocer que en

16 Véase [en línea] https://resourcegovernance.org/sites/default/files/RWI_Enforcing_Rules_ App3.pdf.

17 Véase[enlínea]https://www.globalreporting.org/resourcelibrary/GRI-G4-Mining-and-MetalsSector-Disclosures.pdf. 
la actualidad esto no es necesariamente así. Como ya se ha mencionado, a pesar de los esfuerzos realizados por hacer que la información sea pública y accesible, es lamentable que esta todavía no llegue a todos los ciudadanos interesados. Ello se debe a que la información oficial, la información provista por requerimiento legal, la unilateral o incluso la provista por los informes corporativos, exigen mayores mecanismos de difusión y socialización de los resultados. También se debe proceder a su seguimiento mediante amplios debates que conduzcan a la formulación de mejores prácticas.

Hoy en día, junto con el número de estándares, ha aumentado la demanda de transparencia. Han aparecido nuevas cuestiones en la discusión internacional, como los beneficiarios reales, la transparencia de los contratos y las licencias y pagos por servicios ambientales ${ }^{18}$. Sin embargo, muchas veces se trata de temas altamente especializados, por lo que su aprovechamiento requiere conocimientos y capacidades específicas. Esto limita su llegada a un público más amplio, al tratarse de información que no siempre tiene aplicación directa a nivel local o regional.

Ahora bien, el hecho de que la información no sea de uso amplio no es un argumento en contra de la implementación de este tipo de iniciativas. Más bien esta situación plantea el desafío de buscar respuesta a una serie de preguntas sobre cómo lograr un mayor impacto a partir de tales iniciativas de transparencia. Esas preguntas son:

- ¿Quién puede usar qué tipo de información?

- ¿Qué información es relevante?

- ¿Qué capacidades son necesarias?

- ¿Cuál es el impacto de la información?

A continuación, se utilizará el ejemplo de la transparencia de los contratos para abordar las preguntas propuestas, procurando tener presente la lógica que define los intereses de cada uno de los actores y cada nivel de gobierno (nacional o subnacional). Para comenzar, el término transparencia de contratos en las industrias extractivas suele tener distintas connotaciones. Entre estas hay que destacar: i) el proceso de entrega de contratos o licencias y su posterior fiscalización, y ii) el contenido de los contratos y las licencias, así como acuerdos especiales.

El ejemplo de la transparencia de contratos es útil por su complejidad y tecnicidad, pero también porque ilustra lo que está detrás de cada grupo de actores, con inclusión de diferentes intereses y usos potenciales de la información. Se pretende poner de relieve los diversos intereses y capacidades de análisis según el tipo de actor relacionado con un mismo tema.

18 Véase Alfonso Sierra (2016). 


\section{Estado (nacional y subnacional)}

En términos de la coherencia de sus políticas, para los ministerios nacionales (de minería, hacienda y medio ambiente, entre otros) resulta importante conocer el contenido de los diferentes acuerdos y lo que estos implican respecto de su propia cartera. Para el ramo legislativo y los órganos de control, es pertinente observar los pasos del debido proceso y las posibles interferencias con otros intereses. La coherencia del contenido de los contratos con la legislación vigente es clave (por ejemplo, con respecto a la regulación antimonopolio o al medio ambiente). Esto tiene particular relevancia a la hora de detectar situaciones de riesgo de corrupción u otros tipos de incumplimiento.

En ese sentido, entre las capacidades que se necesitan para manejar situaciones relacionadas con este caso concreto cabe mencionar el conocimiento del contexto específico de la industria; el análisis y la sistematización de los acuerdos especiales; la evaluación y el monitoreo de evaluaciones del impacto ambiental, incluida su implementación; la integración de acuerdos especiales en las políticas públicas, en la auditoría de la producción y en la de insumos; la coordinación con el sector privado y los financiadores; las coordinaciones inter- e intrainstitucionales; la auditoría de eficiencia, y la estimación de costos, riesgos y ganancias debido a acuerdos especiales.

Por su parte, para las autoridades a nivel subnacional, es importante tener la capacidad de reaccionar ante los efectos de determinadas situaciones particulares que influyen en el diseño de las políticas públicas destinadas a mitigar riesgos a nivel local. La información disponible sirve para establecer negociaciones con las empresas y las comunidades, con respecto a la creación de alianzas público-privadas, así como a una responsabilidad social empresarial adecuada y coordinada. Dado que muchas veces los contratos también contienen disposiciones fiscales, es igualmente importante para las autoridades subnacionales saber si esos preceptos afectan a corto o mediano plazo las proyecciones de ingresos de las propias entidades subnacionales. Por último, en términos de desarrollo económico local, es pertinente saber hasta qué punto la prórroga de un contrato particular puede ampliar la demanda de empleo en las localidades vecinas.

En este caso, algunas de las capacidades necesarias para las autoridades subnacionales serían el análisis de contratos y de sus efectos sobre la jurisdicción local, el relacionamiento con diferentes actores y autoridades del orden nacional, y el diseño de políticas que aprovechen los acuerdos del contrato. Muchas veces, estas capacidades existen en un grado muy básico entre los funcionarios de los niveles subnacionales, o los propios funcionarios terminan aceptando ofertas laborales de los actores privados. 


\section{E. Sociedad civil (nacional e internacional)}

En muchos países, una de las demandas principales de la sociedad civil se refiere a la transparencia de los contratos y los acuerdos. El objetivo es poder observar de cerca las cláusulas específicas, las exenciones o las obligaciones especiales. Las organizaciones de la sociedad civil esperan poder realizar el seguimiento del cumplimiento de dichos acuerdos, así como litigar en contra de las cláusulas desfavorables. De esta manera, por un lado, se espera reducir los riesgos de corrupción y malversación de fondos y, por otro, evitar contratos y acuerdos desfavorables.

Con el fin de lograr estos objetivos o alcanzar un alto impacto en términos de sus resultados, los requisitos que deben cumplir los actores de la sociedad civil son por lo general muy altos. Por ejemplo, es indispensable poseer ciertos conocimientos y capacidades jurídicas para analizar la formulación de contratos complejos, entre otras cosas. Muchas veces los contratos son muy extensos. Por eso también se requiere de parte de los miembros de la sociedad civil cierta capacidad de encontrar y lidiar apropiadamente con los puntos más críticos de los documentos, así como llegar a conclusiones adecuadas a sus intereses.

Para las organizaciones de la sociedad civil a nivel nacional, y sobre todo internacional, es cada vez más posible adquirir capacidades o disponer de capacitación ${ }^{19}$. Mientras tanto, las comunidades locales o las organizaciones civiles de base no suelen disponer de la experiencia jurídica necesaria para realizar análisis o seguimientos. Por lo tanto, es probable que la transparencia de los contratos tenga más impacto y relevancia en organizaciones nacionales e internacionales que a nivel subnacional o local ${ }^{20}$.

\section{F. Sector privado}

En el caso del sector privado, hay que distinguir entre los diferentes tipos de actores, cada uno con intereses muy diversos y motivados por sus actividades. En primer lugar, están los productores, es decir, las empresas mineras. Son actores que suele mostrar un interés limitado en la transparencia de sus contratos, apoyados en su necesidad de preservar la confidencialidad e información para no poner en peligro su competitividad corporativa. Sin embargo, en el fondo se trata de una actitud destinada a proteger los acuerdos y contratos de una empresa en particular y no necesariamente de todo el conjunto. Esto es así porque la mayoría, si no la totalidad de los actores, busca

\footnotetext{
Véanse, por ejemplo, Open Oil (2013) y Columbia Center on Sustainable Investment (2013).

20 Véase, por ejemplo, el portal web [en línea] www.resourcecontracts.org, una iniciativa del Instituto para la Gobernanza de los Recursos Naturales, el Columbia Center on Sustainable Investment y el Banco Mundial, con apoyo de UK aid y Servicio Africano de Apoyo Jurídico (ALSF). En dicho portal están disponibles algunos contratos de operaciones extractivas.
} 
comparar sus contratos con los de sus pares o competidoras, o asegurar que sus condiciones no sean inferiores.

Así pues, el impacto esperado es asegurar un nivel equitativo de competencia, a la vez que evitar desventajas entre iguales y contendientes. En términos de capacidad, se requiere contar con sólidos recursos para el análisis jurídico y económico, pero tales facultades no suelen existir en empresas grandes y de nivel internacional, y menos en empresas locales y pequeñas. Por lo tanto, también dentro del sector privado existe una gran asimetría en materia de capacidad. En segundo lugar, los proveedores buscan con interés tener más y mejor información sobre el diseño y la envergadura de los proyectos, de manera que puedan establecer sus estrategias de oferta a las empresas operadoras.

Por otro lado, los compradores internacionales y quienes financian proyectos suelen ser los más favorecidos con la transparencia de los contratos en el sector privado. Muchas veces, esta les sirve para demostrar el cumplimiento de las reglas de diligencia debida o estimar y manejar riesgos, tanto reputacionales como financieros.

\section{G. Entidades internacionales, multilaterales y cooperación internacional}

Para los actores internacionales, la transparencia de los contratos implica reunir información y estadísticas que sirven a los organismos de la cooperación internacional cuando tienen que determinar necesidades y oportunidades de apoyo a los países. Son ejemplo de ello la citada Open Contracting Initiative y la denominada iniciativa para el Fortalecimiento de la Asistencia en Negociaciones de Contratos Complejos (CONNEX) ${ }^{21}$. Su objetivo, más allá de la transparencia, es apoyar a los gobiernos en las negociaciones de contratos con el sector extractivo. Hoy en día, CONNEX es una iniciativa que funciona en el marco del Grupo de los Siete (G7), el cual estableció tres pilares de trabajo: i) la integración y accesibilidad de la información mediante una plataforma virtual que facilita el acceso a la información de instrumentos relevantes y datos de contactos de expertos en negociación de contratos extractivos; ii) la asesoría independiente para negociaciones concretas, incluida la facilitación de apoyo a gobiernos en negociaciones concretas de contratos basados en códigos de conducta e intercambio de información, y iii) el fortalecimiento de la capacidad de los actores involucrados mediante la prestación de asistencia en metodologías para la formación de aptitudes en actores pertenecientes a países de renta baja que buscan mejorar su capacidad de negociación de contratos de manera coherente y con resultados favorables.

${ }_{21}$ Véanse [en línea] http://connex-unit.org/y yttps://www.bmz.de/g7/en/Entwicklungspolitische_ Schwerpunkte/Connex/index.html 
La iniciativa CONNEX pone de relieve que es fundamental centrarse en el uso de la información para poder complementar metodologías de transparencia e incidir en cambios medibles. Se reconoce que con ese fin se debe prestar especial atención al fortalecimiento de capacidades.

En relación con los otros temas planteados, pueden desarrollarse ejercicios similares sobre el análisis de intereses y capacidades de los actores.

\section{H. Conclusiones}

Existen avances importantes en cuanto a la transparencia del sector extractivo. En ese sentido, se han logrado aportes destacados a favor de la gobernanza de los recursos naturales. Gracias a la transparencia es que se han posibilitado debates que en otras circunstancias habrían sido imposibles de llevar adelante. Sin embargo, si el objetivo final es que la riqueza natural de los países se traduzca en una explotación responsable, con ganancias que beneficien a los ciudadanos de los países anfitriones de las operaciones, es indudable que aún debería haber más debates, más acuerdos y más evidencia sobre la rentabilidad de la explotación de los recursos naturales y la importancia de las inversiones en ese sector para los países. La transparencia en cuanto a los intereses y las cifras que dan sustento a la decisión de explotar los recursos del subsuelo es ahora un requisito indispensable. A ese respecto, se deben dar otros pasos que conduzcan hacia la rendición de cuentas, el debate informado y la construcción de acuerdos y programas de desarrollo.

Más allá de transparentar intereses y cifras, es importante también la transparencia en los procesos de decisión. En estos es fundamental la participación de la sociedad en la discusión de los temas. En ese sentido, las hipótesis planteadas en este artículo permiten llegar a una serie de conclusiones, a saber: i) que la transparencia y sus impactos dependen de los usuarios, es decir, de los actores, de sus intereses y competencias, y de la propia relevancia que tiene la información para cada uno de ellos, y ii) que aun cuando las expectativas de transparencia sean elevadas en lo que concierne a su implementación, se deben definir desde el inicio los impactos deseados y, a partir de esto, organizar dicha implementación de acuerdo a las expectativas que se tengan.

Como conclusión, cabe enumerar aquí algunos puntos sobre los que se debería tener especial cuidado a la hora de establecer los procesos de apertura hacia una cultura de la transparencia y un camino de nuevas políticas a favor de la gobernanza de los recursos naturales. Se trata de:

- Partir desde una perspectiva de la demanda y de los intereses de los diferentes actores o usuarios de la información publicada.

- Diferenciar el análisis de actores y evitar miradas monolíticas.

- Analizar y trabajar directamente sobre las diferencias que existen en las capacidades de los actores involucrados: esto 
incluye proveer recursos y contar con los tiempos necesarios para este análisis y capacitación.

- Manejar entre todos los actores involucrados las expectativas frente a los impactos de la transparencia y la inmediatez de sus efectos.

- No entender la publicación de la información como un acto puntual y de una sola vez, sino más bien como uno de los pasos que conducen al debate informado y a la rendición de cuentas.

- Validar la información por medio del enfoque de múltiples actores, que ha producido buenos resultados al considerar desde el inicio a los otros actores, lo que, además, ha aumentado la credibilidad.

- Percibir la transparencia como un proceso de gestión, tanto estatal como privado, y no como una demanda exclusiva de parte de la sociedad civil.

- Aprovechar los estándares internacionales, sin perder de vista las realidades y necesidades del país y de las localidades afectadas.

- Entender los alcances y las características de los estándares internacionales adoptados, a fin de evitar que surjan falsas expectativas, lo que, a su vez, puede conducir a la interrupción de procesos valiosos.

- Pasar de la transparencia a la rendición de cuentas y a los cambios reales en la lógica del trabajo y el relacionamiento del sector extractivo.

- Aprovechar las nuevas formas tecnológicas (por ejemplo, la tecnología de cadenas de bloques), que permiten validar y proteger información mediante sistemas no manipulables. De esta manera también pueden reducir los costos todos los actores involucrados.

- Incluir nuevos actores que por su mandato institucional puedan hacer aportes al debate: contralorías, defensorías del pueblo o instituciones nacionales y locales de derechos humanos, reguladores de mercado, entre otros. El hecho de que distintas instituciones estatales, empresas privadas (y públicas) y organizaciones de la sociedad civil validen conjuntamente la información es una manera de reducir los niveles de desconfianza, al menos en áreas específicas y respecto de problemas concretos.

\section{Bibliografía}

Alfonso Sierra, T. (2016), Hacia la transparencia socio ambiental. Análisis de los procesos EITI en América Latina y el Caribe: lecciones y propuestas, Lima, Red Latinoamericana sobre las Industrias Extractivas (RLIE).

Alianza por la Minería Responsable (2014), "Estándar fairmined para oro de minería artesanal y de pequeña escala, incluyendo metales preciosos asociados" [en línea] http:/ / www.responsiblemines.org/images/sampledata/ EstandarFairmined/Estndar\%20Fairmined\%202.0_2014_.pdf. 
Altomonte, H. y R. J. Sánchez (2016), Hacia una nueva gobernanza de los recursos naturales, Libros de la CEPAL, N 139 (LC/G.2679-P), Santiago, Comisión Económica para América Latina y el Caribe (CEPAL).

CMO (Consejo Mundial del Oro) (2012), "Conflict-free gold standard" [en línea] https://www.gold.org/sites/default/files/documents/Conflict_Free_Gold_ Standard_English.pdf.

Columbia Center on Sustainable Investment (2013), "Mining contracts. How to read and understand them" [en línea] https://s3.amazonaws.com/ s3.documentcloud.org/documents/1279596/mining-contracts-how-to-readand-understand-them.pdf.

EITI (Iniciativa para la Transparencia de las Industrias Extractivas) (2017), Informe de progreso, 2017. Acabar con el anonimato empresarial: la clave para la lucha contra la corrupción [en línea] https://eiti.org/sites/default/files/documents/eiti_ progress_report_2017_es.pdf.

(2016), El estándar del EITI 2016 [en línea] https://eiti.org/sites/default/ files/documents/a4_spanish_standard_web.pdf.

FiTI (Iniciativa de Transparencia de Pesca) (2017), "The FiTI standard" [en línea] http: / fisheriestransparency.org/wp-content/uploads/2017/05/FiTI_ Standard2017EN.pdf.

GRI (Global Reporting Initiative) (2013), "Mining and metals" [en línea] https:/ / www.globalreporting.org/resourcelibrary/GRI-G4-Mining-and-MetalsSector-Disclosures.pdf.

Leutner, J. y M. Rösch (2014), “Redes globales: la iniciativa de transparencia en las industrias extranjeras (EITI)", Fondos y redes globales: reduciendo la brecha entre políticas globales y la implementación nacional, L. Lázaro Rüther, C. Ayala Martínez y U. Müller, Ciudad de México, Instituto de Investigaciones Dr. José María Luis Mora.

Ministerio de Energía y Minas (2016), "Sistematización del proceso de la Iniciativa para la transparencia de las industrias extractivas en el Perú" [en línea] http:/ / www.cooperacionalemana.pe/Biblioteca/index/0/5.

NRGI (Instituto para la Gobernanza de los Recursos Naturales) (2014), Natural Resource Charter [en línea] https://resourcegovernance.org/sites/default/ files/documents/nrcj1193_natural_resource_charter_19.6.14.pdf.

OCDE (Organización de Cooperación y Desarrollo Económicos) (2013), “OECD due diligence guidance for responsible supply chains of minerals from conflictaffected and high-risk areas" [en línea] https://www.oecd.org/corporate/ mne/GuidanceEdition2.pdf.

Open Oil (2013), "Oil contracts. How to read and understand them" [en línea] http:/ / openoil.net/wp/wp-content/uploads/2013/11/oil-contracts-v1.2dec-13.pdf.

Revenue Watch Institute (s/f), "Where to get information on mining company operations" [en línea] https://resourcegovernance.org/sites/default/files/ RWI_Enforcing_Rules_App3.pdf.

Scholl, Ch. y L. Rüttinger (2017), “Approaches to reducing negative environmental and social impacts in the production of metal raw materials" [en línea] https:/ / www.umweltbundesamt.de/sites / default/files/medien/1410/ publikationen/2017-08-18_texte_66-2017_umsoress_summary.pdf.

Transparencia Internacional (2016), "Corruption perception index 2016" [en línea] https:/ / www.transparency.org/news / feature/corruption_perceptions_ index_2016. 
Capítulo XII

\title{
Regímenes fiscales vinculados a los recursos naturales no renovables en América Latina y el Caribe y su relación con el ciclo de precios: evolución reciente y desafíos pendientes
}

\author{
Michael Hanni \\ Juan Pablo Jiménez \\ Ignacio Ruelas
}

La evolución de los ingresos fiscales provenientes de la explotación de los recursos naturales ha mostrado grandes fluctuaciones en la última década. El desempeño de estos ingresos se relaciona tanto con las variaciones de los precios de los productos gravados como con los cambios de los distintos regímenes fiscales implementados.

Hacia finales de la década de 1990, pero sobre todo a partir de 2003, se registró un incremento significativo de los precios de los productos de exportación de América Latina y el Caribe. Sumada a diversas reformas tributarias, esta situación permitió destinar recursos a los sectores públicos de la región, con lo que se amplió el espacio fiscal de los países especializados en esos productos. Estas reformas centradas en el sector de los recursos naturales acentuaron la especialización de los sistemas tributarios, sobre todo en hidrocarburos y minerales. Durante ese período se avanzó en lo que se refiere a asegurar el control estatal de los recursos disponibles, se introdujeron nuevos tributos, se fortalecieron los esquemas de regalías y se crearon impuestos sobre los ingresos extraordinarios. 
La pronunciada caída de los precios de estos productos en los últimos años entrañó un declive en la relevancia fiscal de los ingresos obtenidos por ese concepto. A su vez, supuso un replanteo de los objetivos a seguir y de las herramientas a utilizar, de manera que se priorizara no solo el resultado fiscal, sino también la sostenibilidad de las inversiones y la producción del sector. De hecho, la interrupción de un ciclo prolongado de crecimiento de los ingresos fiscales provenientes de la explotación económica de los recursos naturales (2003-2012) representa un gran desafío para estos países. Esta situación se ha agravado con la caída registrada en los años más recientes y, sobre todo, con la incertidumbre que se plantea de cara a los próximos años en relación con los sectores extractivos a nivel global.

Este tema es de especial interés en América Latina por varias razones. Entre ellas cabe mencionar la alta especialización en recursos naturales que tienen varios países (sobre todo en América del Sur), las dificultades estructurales que registra la región para lograr una presión impositiva adecuada y la gran volatilidad de los ingresos tributarios. En este contexto, en el presente artículo se hace un repaso de las reformas de la tributación relacionada con los recursos naturales. Se establece una diferencia entre las implementadas en cada fase del ciclo, su evolución e impacto sobre las cuentas públicas y los desafíos que enfrentan los regímenes fiscales de los países especializados en la producción de recursos naturales.

\section{A. Instrumentos fiscales en las industrias extractivas}

\section{Características particulares del sector extractivo}

Las industrias extractivas de recursos naturales no renovables poseen ciertas características particulares que las diferencian claramente de las actividades productivas tradicionales. En primer lugar, las reservas con que cuenta cada país, y el flujo de ingresos fiscales que permitirían obtener, están sujetos a un proceso variable, pero a la vez inexorable, de agotamiento físico (Gómez Sabaini, Jiménez y Morán, 2015).

Además, se deberían destacar otros rasgos específicos de la explotación económica de hidrocarburos y minerales, a saber (Boadway y Keen, 2010; Gómez Sabaini, Jiménez y Morán, 2015):

- los grandes costos hundidos al inicio de los proyectos, que pueden entrañar problemas de inconsistencia temporal;

- las sustanciales rentas económicas que generan al ser su explotación altamente intensiva en capital, lo que promueve la concentración de rentas (Rossignolo, 2015);

- la elevada incertidumbre, representada por la volatilidad del precio internacional y el nivel de producción sujeto a hallazgos geológicos, el costo de los insumos y el riesgo político intrínseco; 
- las considerables asimetrías de información;

- la multiplicidad de negocios adicionales que pueden desarrollarse en torno a la explotación básica, y

- el considerable poder de mercado que llegan a tener determinados productores de estos recursos no renovables.

Todos estos aspectos adquieren una escala y relevancia macroeconómicas que distinguen singularmente a estos sectores. Además, realzan la importancia y la complejidad que tienen la tributación y el manejo fiscal de las rentas generadas por dichos sectores. Por otra parte, estas características generales cobran aristas particulares en un contexto regional caracterizado por la alta especialización en recursos naturales, las dificultades estructurales para recaudar impuestos, así como las grandes disparidades regionales y su relación con la concentración territorial de los yacimientos (Brosio y Jiménez, 2015).

\section{Propiedad de los recursos naturales y regímenes e instrumentos fiscales en las industrias extractivas}

Un primer aspecto a considerar se relaciona con la propiedad legal de los recursos. En este sentido, en los respectivos marcos jurídicos (en particular, las constituciones), se suele reconocer que los recursos naturales pertenecen a los Estados soberanos e integran el dominio público de sus ciudadanos (CEPAL, 2014). Sin embargo, existen múltiples caminos para traducir la propiedad del Estado sobre los recursos naturales no renovables en políticas concretas de explotación (Gómez Sabaini, Jiménez y Morán, 2015).

El diseño de un régimen fiscal aplicable a los recursos no renovables suele plantear una serie de desafíos en cuanto a los objetivos que se busca cumplir con su implementación. La dificultad principal consiste en lograr un balance entre la necesidad de los gobiernos de maximizar los ingresos fiscales derivados de estos sectores y los incentivos que se ofrecen a los agentes privados a fin de garantizar su participación en las actividades de exploración y producción.

En las industrias extractivas existen básicamente dos tipos de regímenes fiscales (Johnston, 1994): los sistemas de concesiones y los sistemas contractuales.

En los acuerdos de concesión, por lo general el Estado otorga a una empresa el derecho exclusivo a explorar, desarrollar, producir, transportar y comercializar los recursos naturales extraídos. En esos casos, el concesionario asume todos los riesgos y costos asociados a la explotación dentro de un área delimitada y por un período de tiempo determinado. En general, los operadores privados son los propietarios legales de la producción (no así de los recursos que permanecen en el terreno adjudicado) y tiene libertad para disponer de ella. A su vez, el Estado solo participa en la 
generación de rentas económicas mediante el cobro de regalías e impuestos. En las últimas décadas, los sistemas de concesiones han comenzado a ser vistos como incompatibles con la soberanía estatal. De hecho, los sistemas contractuales surgieron en ese entonces como resultado de los esfuerzos encaminados a modificar la naturaleza de las relaciones entre las grandes empresas privadas internacionales y los países que disponen de recursos no renovables (Gómez Sabaini, Jiménez y Morán, 2015).

Entre los sistemas contractuales suelen distinguirse dos tipos: i) contratos de producción compartida, en que el contratista privado recibe una parte de la producción final en compensación por los riesgos y servicios provistos, una vez cubiertos los costos financieros y operativos, y ii) contratos de servicios, ya sean "puros" (un porcentaje fijo de los ingresos netos después de cubrir los costos), "de riesgo" (donde el pago depende de la rentabilidad y las condiciones de mercado) o "híbridos" (como alternativa intermedia entre los anteriores). En la práctica internacional suelen encontrarse ejemplos de estos sistemas aplicados a la producción de petróleo y gas. No sucede así en el caso de la actividad minera, donde la explotación de los recursos suele realizarse mediante concesiones a empresas privadas.

Más allá de las ventajas y desventajas que los distintos tipos de sistemas fiscales puedan poseer para los países, no existe ninguna razón probada para preferir un sistema antes que el otro. Los términos fiscales de uno pueden reproducirse en el otro, de modo que es posible obtener los mismos resultados. Por lo tanto, una decisión mucho más importante en esta materia consiste en elegir y combinar los instrumentos recaudatorios que se aplican a las industrias extractivas en virtud de los distintos efectos económicos y fiscales asociados (Gómez Sabaini, Jiménez y Morán, 2015).

En los últimos años, ha habido una creciente diversificación de la cantidad y calidad de los instrumentos fiscales diseñados para su aplicación en las industrias extractivas, tanto de carácter tributario como no tributario ${ }^{1}$. La forma más directa de transformar los ingresos provenientes de la exportación de estos productos en recursos fiscales se ha basado en la participación de los gobiernos en su explotación, sea a través de una empresa pública o mediante la participación accionaria en el proyecto. Se suelen combinar los siguientes instrumentos tributarios que permiten recaudar fondos de esta actividad, ya sea pública o privada: i) regalías, habitualmente basadas en la producción, lo que permite asegurar, al menos, un pago mínimo por los recursos minerales; ii) el tradicional impuesto a la renta (muchas veces con alícuotas diferenciales), y iii) los impuestos sobre las utilidades, aplicables a las empresas dedicadas a la explotación de este tipo de recursos.

En los trabajos de Tordo (2007), Boadway y Keen (2010) y Gómez Sabaini, Jiménez y Morán (2017) puede encontrarse un análisis detallado del diseño específico de estos instrumentos. 
En una clasificación posible de estos instrumentos se distingue entre los que se basan en utilidades (o alguna definición de ingresos netos de costos vinculados) y los que se determinan en función de la producción, ya sea que recaigan sobre las reservas o sobre los insumos y servicios utilizados en la explotación. Además, existen diversos mecanismos que permiten al Estado participar, de manera activa o pasiva, en la producción o las ganancias de las empresas privadas ${ }^{2}$.

\section{Objetivos buscados y criterios de evaluación de los instrumentos fiscales}

El principal objetivo de los gobiernos, a propósito de los regímenes fiscales de las industrias extractivas, se orienta a la movilización de recursos (recaudación de ingresos fiscales) que contribuyan al financiamiento del Estado y permitan una distribución adecuada de las rentas generadas en el sector entre el gobierno y las empresas privadas (Gómez Sabaini, Jiménez y Morán, 2015). A ese respecto, se argumenta que los instrumentos basados en unidades o valores de producción (cargos fijos, derechos de uso, bonos y regalías fijas) tienden a mostrar, a priori, un mayor rendimiento fiscal en virtud de que por lo general se aplican a cantidades brutas sin considerar los costos de producción.

Por otro lado, los instrumentos basados en utilidades o renta (que no generan recaudación hasta que el proyecto alcance determinada tasa de retorno) producen un retraso en la obtención efectiva de los ingresos fiscales. Ello termina por mermar el potencial recaudatorio del gobierno, si bien su costo en términos de eficiencia o neutralidad suele ser menor.

Entre los objetivos de la tributación sobre recursos naturales se incluye la progresividad fiscal, entendida como la capacidad de lograr una participación estatal proporcionalmente mayor en las rentas de estos sectores en ciclos de auge de precios (o baja de costos). Mientras que los instrumentos que impactan desde las etapas iniciales del proyecto y se basan en variables fijas (regalías, bonos de signatura) suelen tener un efecto regresivo, aquellos basados en rentas y utilidades son más progresivos.

Una característica deseable para estos regímenes (y relacionada con el criterio anterior) es su grado de flexibilidad para adaptarse eficazmente a los cambios de las condiciones de mercado. Una mayor flexibilidad permite ajustar la participación relativa del sector público sobre las rentas del sector extractivo en función de los cambios en la rentabilidad del proyecto. Ello puede responder, por ejemplo, a las oscilaciones que se registran en variables como el precio internacional de los productos o los costos de extracción, de forma que se disminuye el impacto en términos de producción e inversión.

En Boadway y Keen (2010) puede encontrarse una exposición analítica de las distintas variantes existentes. 
Mientras que las regalías o los instrumentos basados en la producción tienen menos flexibilidad ante a los cambios del contexto, los instrumentos basados en renta o utilidades suelen ser más flexibles.

Cabe destacar además el concepto de estabilidad de los instrumentos y del régimen fiscal como una manera de tratar los cambios a lo largo del tiempo, o bien hacerlos predecibles. Los regímenes e impuestos poseen una inestabilidad intrínseca porque los gobiernos pueden ejercer el derecho de establecer y modificar la legislación tributaria a lo largo del período del proyecto.

En cuanto a la equidad o justicia distributiva, conciernen principalmente los criterios siguientes: i) la equidad horizontal reflejada en el trato impositivo hacia todas las empresas que generan un mismo nivel de renta económica; ii) la equidad vertical que permite evaluar el tratamiento tributario según la rentabilidad de los proyectos y la correspondiente capacidad de pago; iii) la equidad jurisdiccional relacionada con la distribución de los ingresos fiscales y los impactos que tienen que enfrentar las zonas donde se desarrolla la producción, y iv) la equidad intergeneracional, referida al agotamiento de los recursos y su aprovechamiento entre las generaciones actuales y las futuras. De entrada, las regalías y otros instrumentos fijos incorporan rigideces que limitan estos aspectos, por lo que tienden a ser menos equitativos.

Por último, estos instrumentos ameritan una evaluación desde el punto de vista de la dificultad, la administración y el cumplimiento. Dada la incertidumbre en cuanto a la rentabilidad futura de un proyecto, será mucho más complejo diseñar impuestos basados en esa variable que una regalía o un cargo por utilización del suelo, o un bono exigido ante nuevos descubrimientos.

En definitiva, la amplia gama de instrumentos fiscales disponibles incluye impuestos, regalías y cargos de variada base y estructura, cuyo diseño y adaptación dependen de las características, las necesidades y la capacidad de cada país. Como se insiste a lo largo de este capítulo, también depende del momento del ciclo de precios. No obstante, cada instrumento posee una serie de efectos económicos intrínsecos, no siempre compatibles, que deben ponderarse adecuadamente a fin de establecer cierto balance, sobre todo en lo que se refiere a la eficiencia económica, la equidad, la generación de ingresos y la eficiencia administrativa.

\section{B. Instrumentos utilizados, evolución y reformas recientes en la región}

En esta tercera parte se realiza una aproximación a la evolución de las diversas formas en que los Gobiernos de la región de América Latina y el Caribe han captado ingresos por la explotación de productos no renovables. 
Se describen, además, los principales cambios introducidos por los países en esta materia y se intenta relacionar los instrumentos utilizados con los objetivos perseguidos.

Para ello, se dividirá el análisis en tres períodos, relacionados directamente con el ciclo de precios. El primero es un ciclo previo a la bonanza (antes de 2003), que se caracterizó por precios relativamente estables y menores a los del superciclo que empieza en 2003, en que los países contaban con sus regímenes fiscales vigentes, compuestos principalmente por impuestos y derechos.

El segundo período se caracteriza por la importante alza de precios (2003-2012). En ese lapso los países intensificaron los cambios a los regímenes fiscales vigentes, mediante nacionalizaciones y nuevos impuestos y regalías, con la finalidad de aumentar la participación del Estado en las rentas de la actividad extractiva. En el tercer período (2013-2016), el sector se vio impactado por la crisis y la volatilidad de los precios, lo que ha derivado en que algunos países prioricen medidas que promuevan la inversión en estos rubros.

En términos generales, se observa que los sistemas fiscales que se aplican a las industrias extractivas de la región varían según el sector productivo. En el caso de la minería, los países cuentan con sistemas de impuestos y regalías. En el caso de Chile y Bolivia (Estado Plurinacional de), existen empresas estatales en ese sector. Por su parte, en los hidrocarburos, los países han tendido a emplear sistemas mixtos que combinan contratos de producción compartida e impuestos y regalías, así como la presencia de un productor estatal.

\section{Período previo a 2003}

El período previo al alza de los precios se caracterizó por cambios relacionados con el aprovechamiento y la distribución de los ingresos provenientes de las actividades extractivas. Los precios internacionales de ambos sectores (minería e hidrocarburos) eran relativamente bajos, por lo que se mantuvo una baja participación de la actividad extractiva en los ingresos fiscales de los países. Los instrumentos tenían por objeto, principalmente, estabilizar los ingresos ante la caída de los precios. También se observan cambios modestos, orientados a aumentar las rentas del Estado provenientes de estas actividades.

Respecto al sector minero, de acuerdo con Acquatella y otros (2013), el período 1990-2002 se caracterizó por una acumulación de inventarios que hacía que los precios se mantuvieran a niveles muy bajos. Ello fue resultado de la sobreoferta generada por la entrada en funcionamiento de varios megaproyectos mineros, además de la disminución de la demanda debido a la crisis financiera de 1997. Se suma a esta situación la 
desaceleración de la economía mundial en 2001, que afectó a los principales consumidores de metales, tales como los Estados Unidos, la Unión Europea y los países asiáticos, con la excepción de China y la República de Corea, que mantuvieron altos niveles de crecimiento económico.

En este contexto, los instrumentos fiscales utilizados por los países de la región para captar las rentas del sector fueron la imposición sobre la renta y las regalías. Como se verá más adelante, los ingresos públicos provenientes del sector fueron relativamente menores, aunque destacan los niveles registrados en Chile (con un promedio de un 1,5\% del PIB entre 1990-2002) y Jamaica (un 1,3\% del PIB).

En el sector de hidrocarburos, en los años noventa fue muy activa la participación privada, fruto de las reformas estructurales del sector relacionadas con la apertura a la inversión privada en exploración y producción, las reformas del régimen de transporte y refinación, así como la desregulación de las actividades de distribución y privatización de las empresas estatales, entre otras cosas (Acquatella y otros, 2013; Vera, 2017). A finales de esta década e inicios de la de 2000 se observa, en contraste, una participación gradual en los procesos de nacionalización, renegociación contractual, control de precios y mayor control estatal. A diferencia del sector minero, y en términos relativos, los ingresos fiscales del sector de los hidrocarburos fueron considerables durante este período en algunos países, entre los que cabe destacar Venezuela (República Bolivariana de) (con un promedio del 11,2\% del PIB entre 1990 y 2002), Trinidad y Tabago (6,9\% del PIB), el Ecuador (5,0\% del PIB), México (5,0\% del PIB) y el Estado Plurinacional de Bolivia (4,1\% del PIB).

\section{Período 2003-2012}

Ante la magnitud y la persistencia del ciclo alcista de precios que se inició en 2003, los países productores de la región encontraron argumentos suficientes para introducir reformas significativas en los regímenes fiscales aplicados a la producción de hidrocarburos y minerales, con el principal objetivo de incrementar y garantizar una adecuada captación de ingresos por parte del Estado.

Entre 2003 y 2012, las reformas legales más importantes dirigidas a asegurar la propiedad y el control público de los recursos naturales no renovables se enfocaron en el sector de los hidrocarburos (CEPAL, 2013). Estas medidas incluyeron la nacionalización de dicho sector mediante empresas mixtas en la República Bolivariana de Venezuela (entre 2005 y 2007), la nacionalización de hidrocarburos en el Estado Plurinacional de Bolivia (2006), la renegociación de contratos petroleros en el Ecuador (2010) y la expropiación del 51\% de las acciones de la empresa YPF en la Argentina (2012). 
En la mayoría de los casos también se ha aplicado el tradicional impuesto a la renta con tasas diferenciales, junto con otros gravámenes especiales, a menudo con tasas progresivas, a las empresas públicas o privadas dedicadas a la explotación de recursos no renovables. Durante el período 2005-2012, esto se ha reforzado mediante la introducción de nuevos instrumentos de recaudación.

A propósito, se destaca el caso del Estado Plurinacional de Bolivia, donde desde 2005 se introdujo el impuesto directo a los hidrocarburos (IDH). Este tributo, sumado a las regalías y participaciones al Tesoro General del Estado (TGE), hizo que la participación directa del Estado sobre el valor comercial de la producción alcanzara un $50 \%$. En el Ecuador, la reforma de la Ley de Hidrocarburos estableció el margen de soberanía, destinado a garantizar un ingreso mínimo al Estado ante posibles disminuciones de precios por un monto del $25 \%$ del valor bruto de producción. En la República Bolivariana de Venezuela, se aumentaron las tasas del impuesto sobre la renta del petróleo (50\%) a partir de 2006 y se crearon tres nuevos impuestos: i) el impuesto a la extracción de crudo; ii) el impuesto al registro de exportación, y iii) la contribución especial sobre precios extraordinarios y exorbitantes del mercado internacional.

Por otra parte, en vista de los niveles históricos que alcanzaron los precios internacionales de los recursos naturales no renovables, varios países también consideraron la aplicación de impuestos, derechos, participaciones o contribuciones vinculadas a precios o utilidades extraordinarias, como ha sucedido en Bolivia (Estado Plurinacional de) ${ }^{3}$, el Brasil, Colombia, el Ecuador, Trinidad y Tabago y Venezuela (República Bolivariana de). En la Argentina, en 2002 se procedió a redefinir los derechos de exportación. Junto con los siguientes incrementos de tasas, ello permitió una mayor participación del Estado en el valor comercial de las exportaciones de bienes, incluidos los hidrocarburos y los productos mineros.

El sector minero también observó un marcado activismo fiscal, mediante el establecimiento de las regalías, los impuestos específicos y los cambios en las tasas de derechos y aprovechamientos. También hubo nacionalizaciones, como la de la mina de Colquirí, en Oruro (Estado Plurinacional de Bolivia) (2012), país donde también se reestatizó la mina de estaño de Huanuni.

El hecho de que los gobiernos hayan reforzado otros mecanismos estatales de captación de rentas, como las regalías, que suelen basarse en la producción e impuestos específicos, ha sido especialmente importante en el sector de la minería, donde la captación de recursos por la vía de la

El impuesto adicional del 25\% sobre las utilidades extraordinarias fue derogado con la Ley de Hidrocarburos núm. 3058 (2005) y sustituido por la participación de Yacimientos Petrolíferos Fiscales Bolivianos (YPFB) en los nuevos contratos de operación. 
participación estatal en empresas ha sido de menor importancia relativa. Estas regalías e impuestos han permitido asegurar una participación mínima de los gobiernos, tanto nacionales como subnacionales, en la renta económica del sector extractivo. Durante este período, un número creciente de países introdujeron reformas en sus sistemas de regalías, derechos y aprovechamientos, incluidos el Perú (2004 y 2011), el Ecuador (2009), el Brasil (2011) y Colombia (2011) .

En el mismo sentido, en 2007 el Estado Plurinacional de Bolivia introdujo una regalía (en remplazo del anterior impuesto complementario de la minería) y una alícuota adicional del $12,5 \%$ a la tasa general del impuesto sobre la renta corporativa $(25 \%)$ con el fin de "gravar las utilidades adicionales originadas por las condiciones favorables de precios de los minerales y metales" ${ }^{\prime \prime}$.

En Chile (2005) y el Perú (2011) se introdujeron impuestos específicos para el sector minero, con tasas progresivas aplicadas sobre bases imponibles compuestas por las rentas operativas. Sin embargo, la aplicación de estos instrumentos se ha visto obstaculizada por la existencia de cláusulas de estabilidad tributaria en ambos países. Vale destacar que estos nuevos instrumentos también buscaban desalentar lo menos posible la inversión, ya fuese mediante deducciones o mediante la inclusión de la depreciación financiera del equipo de capital y los intereses.

Sin embargo, como señalan Acquatella y otros (2013), los avances en materia de progresividad del régimen fiscal han sido más claros y concretos en el sector petrolero que en el sector minero de los países de América Latina y el Caribe. La incorporación de este tipo de concepto en el tratamiento fiscal del sector minero es todavía muy incipiente en los países de la región ${ }^{6}$.

\section{Reformas de 2013 al presente}

En relación con lo anterior, las medidas más recientes ponen de relieve la necesidad de mantener o aumentar la contribución fiscal de los recursos naturales no renovables. También delatan una preocupación creciente por impulsar la inversión y la producción, así como la participación

\footnotetext{
En 2012, en el Brasil quedó instituida la tasa de control, monitoreo y fiscalización para el aprovechamiento de las actividades extractivas mineras en el estado de Minas Gerais, con la finalidad de financiar las actividades de los organismos públicos que actúan junto al sector minero. Ley núm. 3787 de 24 de noviembre de 2007.

6 Quizás la única excepción sea la del contrato del proyecto Pueblo Viejo, firmado entre el Gobierno de la República Dominicana y la firma Barrick Gold Corporation. En este contrato se estipula que, una vez que el proyecto haya alcanzado la tasa interna de retorno del $10 \%$, el Estado comenzará a participar con un $28,75 \%$ en la utilidad neta. En combinación con la regalía del 3,2\% y el impuesto sobre la renta del $25 \%$, este instrumento aproximaría la participación de la República Dominicana a un $50 \%$ de los flujos netos del proyecto en los años de operación.
} 
del sector privado. Durante los últimos años, varios países de la región promulgaron medidas de políticas dirigidas a incentivar la actividad en el sector extractivo y, al mismo tiempo, crear fondos sectoriales de inversión y ahorro a largo plazo.

Con los últimos cambios en el sector de los hidrocarburos se han priorizado objetivos como el fomento de la producción y la inversión y el grado de flexibilidad mediante la introducción de reformas estructurales del sector. Por ejemplo, se ha procurado aumentar la participación del sector privado (México) o promover la creación de programas y regímenes de incentivos a la producción (Argentina y Bolivia (Estado Plurinacional de)).

El cambio más emblemático de este período fue sin duda la reforma energética de México en 2013, que abrió el sector de los hidrocarburos a la participación de empresas privadas por primera vez desde la nacionalización de 1938. El motivo de la reforma se sustenta en la preocupación por la caída continua de la producción petrolera, así como en la falta de recursos que permitan financiar las inversiones necesarias para abordar esta tendencia. Mediante el marco regulatorio y fiscal establecido en las leyes secundarias promulgadas en 2014 se estableció el mecanismo para el otorgamiento de asignaciones correspondientes a la exploración y la explotación de hidrocarburos, así como los contratos que regirán la participación de empresas privadas en el sector.

En la Argentina, una preocupación similar con la caída de la producción de hidrocarburos incidió en la promulgación de varios cambios durante este período. En 2013 se creó el Régimen de Promoción de Inversión para la Explotación de Hidrocarburos, que permitía la exportación sin restricción y libre del pago de derechos de exportación de hasta un $20 \%$ de los hidrocarburos producidos en proyectos con un valor de inversión de 1.000 millones de dólares o más. En 2014, se modificó este régimen con el fin de extender sus beneficios a proyectos con inversiones por un valor de 250 millones de dólares o más.

También en la Argentina, en 2014 se modificó la Ley de Hidrocarburos con la intención de fomentar la inversión en el sector, sobre todo en los recursos no convencionales, mediante un nuevo tipo de concesión al que se aplicaban plazos más largos y menores tasas de regalías. Resulta importante señalar que con esta reforma también se restringió el uso de otros instrumentos fiscales de los gobiernos subnacionales, de modo que las regalías quedaron como la única forma de participar en la explotación de hidrocarburos en territorio argentino. A fines de 2014, se modificaron las tasas de los derechos de exportación aplicables a determinados productos de hidrocarburos. Se adoptó una escala móvil en línea con el 
precio del petróleo crudo Brent, con miras a fomentar la competitividad de los productores nacionales ${ }^{7}$.

En el Estado Plurinacional de Bolivia, en 2015 se aprobó la Ley de Promoción para la Inversión en Exploración y Explotación Hidrocarburífera con el fin de promover las inversiones en el sector. Los incentivos a la producción así previstos se financiarán principalmente mediante un nuevo fondo creado por la misma ley, el Fondo de Promoción a la Inversión en Exploración y Explotación Hidrocarburífera (FPIEEH), alimentado con el 12\% de la recaudación del IDH.

En el Brasil, en 2017 se crearon nuevos incentivos para fomentar los sectores nacionales del petróleo y el gas. En particular, se establecieron nuevas reglas relativas a las deducciones de los gastos de exploración y producción del impuesto sobre la renta corporativa y se previeron cambios de las retenciones que se aplican a los acuerdos de flete de los buques. Además, se extendió hasta 2040 el programa Repetro, un régimen aduanero especial para el sector.

En el sector minero, los objetivos enunciados en los cambios introducidos en este período reflejan una preocupación por impulsar la actividad minera, en especial con el fin de procurar un flujo continuo de inversión hacia el sector. Por ejemplo, en el Ecuador en 2013 se promulgó un paquete de medidas encaminadas a fomentar el desarrollo del sector minero, con lo que se reformuló la aplicación del impuesto a los ingresos extraordinarios (se aplicará después de que el concesionario recupere la totalidad de la inversión) y se establecieron topes en relación con las tasas de regalías.

De modo similar, Jamaica suprimió el pago del gravamen sobre la bauxita en 2014 como medida de apoyo al sector extractivo. En el mismo año, en el Perú se aprobó una modificación de la Ley General de Minería con el fin de ampliar los convenios de estabilidad tributaria hasta 15 años en el caso de nuevas inversiones de 500 millones de dólares o más.

De manera paralela, los países han implementado también medidas orientadas a aumentar la presión fiscal sobre el sector extractivo ante la necesidad de recursos con el objetivo de cerrar las brechas fiscales existentes y mejorar la captación de rentas. En México, con la reforma hacendaria de 2013 se introdujo, entre otras medidas, un derecho especial con una tasa del 7,5\% sobre las utilidades antes de impuestos, además de una tasa adicional del $0,5 \%$ sobre los ingresos brutos derivados de la enajenación de oro, plata y platino.

Este apoyo al sector continuó en 2015, cuando el Gobierno instituyó el Programa de Estímulo a la Producción de Petróleo Crudo. Mediante este programa se pagaron subsidios a la producción y a la exportación, de hasta 6 dólares por barril, hasta el fin del mismo año. 
Después de varios años de debate, en 2017 el Gobierno del Brasil introdujo varios cambios en la Compensación Financiera por la Explotación de Recursos Minerales (CFEM), una regalía minera. Se modificó la base gravable de la regalía, en la que se consideran los ingresos brutos en vez de los netos. También se procuró aumentar la tasa de la regalía en relación con determinados productos: mineral de hierro (del 3,5\%, reducida al $2 \%$ en el caso de los yacimientos marginales), niobio $(3 \%)$, diamantes $(2 \%)$ y oro $(1,5 \%)$.

\section{Indicadores y evolución de los ingresos fiscales provenientes de los recursos naturales no renovables en América Latina y el Caribe}

En esta sección se analizará la interacción del ciclo de precios y los regímenes fiscales aplicados al sector extractivo y cómo dicha interacción se manifiesta en la evolución de los ingresos fiscales provenientes de la explotación de recursos naturales no renovables en la región ${ }^{8}$. En primer lugar, se examinará la relación del ciclo de precios en sus diferentes fases y la recaudación de estos ingresos al nivel regional. Luego, se considerarán los resultados observados a nivel de los países, con especial hincapié en otros factores que inciden en la evolución de estos ingresos, como los cambios que se van dando en la producción y en los marcos fiscales.

En primer lugar, resulta innegable la importancia del ciclo de precios internacionales como factor clave detrás de la evolución de los ingresos fiscales provenientes de los recursos naturales no renovables en la región (véase el gráfico XII.1). El auge de estos precios, especialmente en términos nominales, debido al impacto sobre los mercados internacionales del rápido crecimiento de los países en desarrollo, sobre todo los de Asia, resultó en un aumento histórico de esos ingresos. De modo similar, la caída vertiginosa de los precios, como reflejo de una ralentización del crecimiento y la inversión en China y de los cambios estructurales en la oferta de estos productos (el alza en la producción de hidrocarburos en los Estados Unidos), dio lugar a una rápida disminución de los mismos ingresos.

Resulta importante dimensionar el incremento de los ingresos fiscales provenientes de los recursos en las últimas décadas. Entre 1990 y 2002, los principales países productores de América Latina y

A diferencia del análisis de los ingresos fiscales provenientes de recursos naturales no renovables que los autores han presentado en varias ediciones de la publicación sobre los ingresos tributarios en América Latina y el Caribe, en este capítulo se consideran solamente los ingresos relacionados con actividades de explotación. Ello significa que, en el caso de los hidrocarburos, se trata de ingresos provenientes de actividades de extracción de materias primas. 
el Caribe recaudaron alrededor de 471.000 millones de dólares en ingresos provenientes de la extracción de hidrocarburos y alrededor de 15.000 millones de dólares relacionados con la minería. Durante el período comprendido entre 2003 y 2016, estos ingresos sumaron un total de 1.981 millones y 199.000 millones de dólares, respectivamente.

\section{Gráfico XII.1 \\ América Latina y el Caribe: ingresos fiscales provenientes de recursos naturales no renovables, por producto, $e$ indicadores de precios internacionales relacionados, 1990-2016 (Índice 100=2010)}

A. Extracción de hidrocarburos (materia prima)

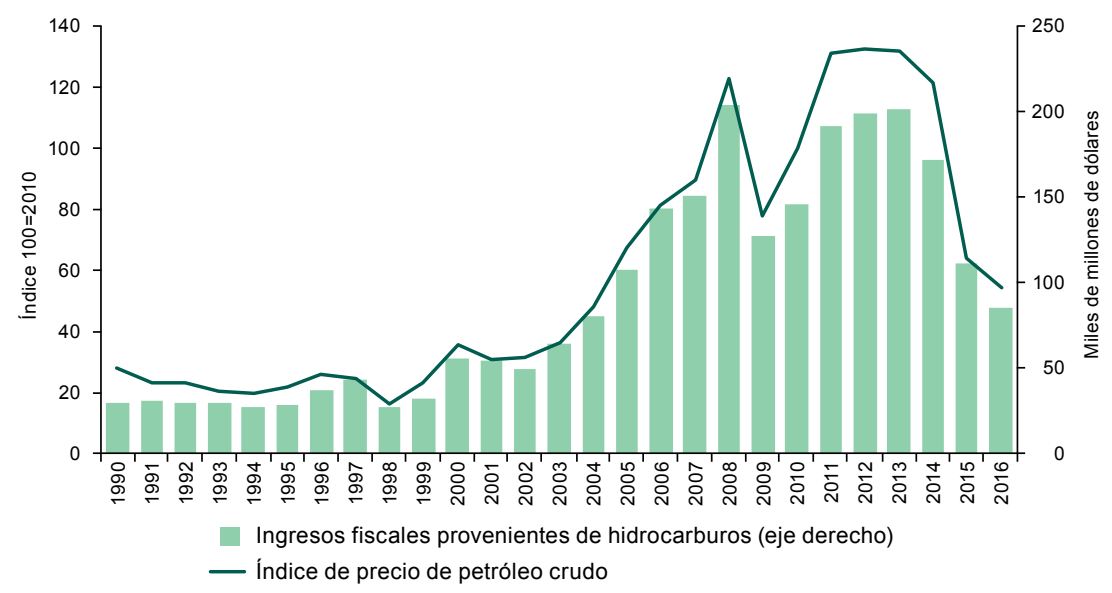

B. Productos mineros ${ }^{\mathrm{a}}$

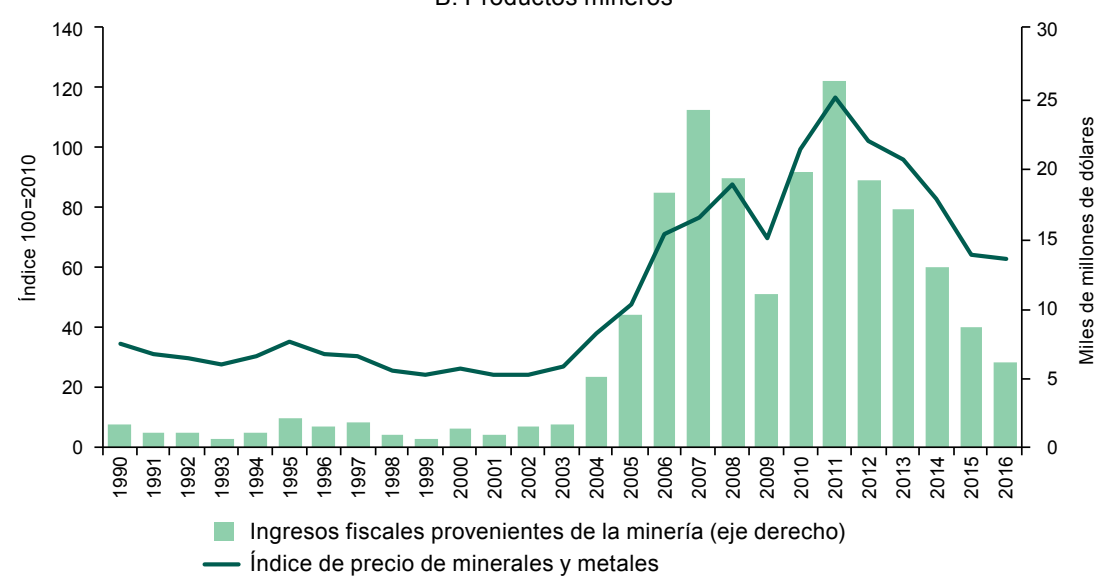

Fuente: Elaboración propia sobre la base de cifras de la Comisión Económica para América Latina y el Caribe (CEPAL).

a En la minería se incluyen la Argentina, Bolivia (Estado Plurinacional de), el Brasil, Chile, Colombia, Jamaica, México, el Perú, la República Dominicana y Suriname. En los hidrocarburos se incluyen la Argentina, Bolivia (Estado Plurinacional de), el Brasil, Colombia, el Ecuador, México, el Perú, Suriname, Trinidad y Tabago y Venezuela (República Bolivariana de). 
La volatilidad inherente de esa fuente de ingresos complica el manejo de la política fiscal en los países productores de recursos naturales no renovables. Esto es cierto sobre todo en los países en que esos ingresos han tenido una participación alta en los ingresos totales durante el período de auge del ciclo de precios. Como se ilustra en el gráfico XII.2, los ingresos provenientes de hidrocarburos y minería representaron el $30 \%$ o más de los ingresos totales en promedio durante 2010-2011 en Bolivia (Estado Plurinacional de), el Ecuador, México y Suriname, y más del $40 \%$ en Trinidad y Tabago y Venezuela (República Bolivariana de).

\section{Gráfico XII.2}

\section{América Latina y el Caribe (países seleccionados): participación de los ingresos fiscales provenientes de los recursos naturales no renovables en los ingresos públicos totales, $2000-2016^{a}$}

(En porcentajes)

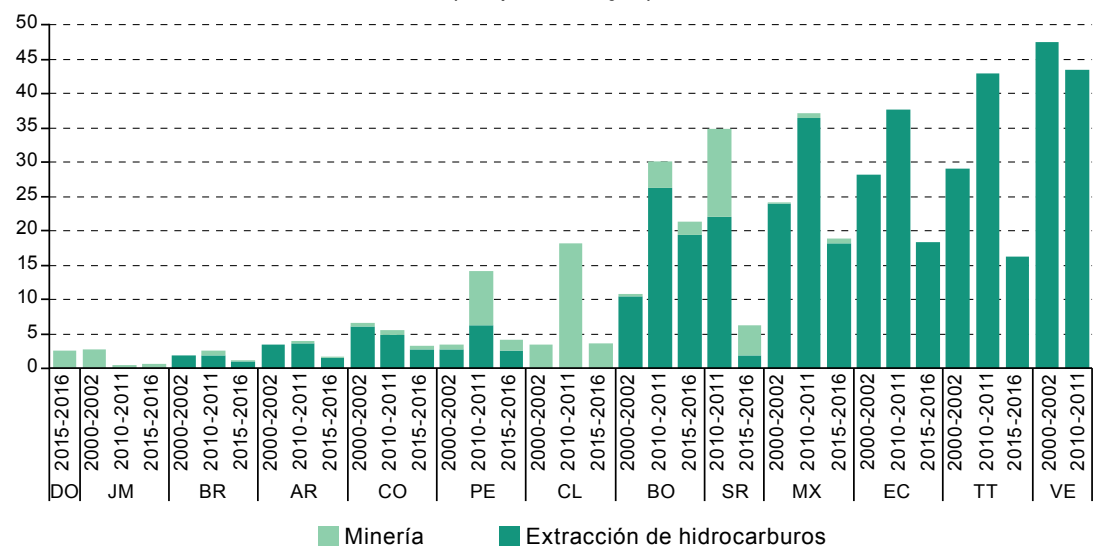

Fuente: Elaboración propia sobre la base de cifras de la Comisión Económica para América Latina y el Caribe (CEPAL).

a Las cifras corresponden a las siguientes coberturas de gobierno: Gobierno central (Jamaica, República Dominicana, Suriname, Trinidad y Tabago y Venezuela (República Bolivariana de)); gobierno general (Bolivia (Estado Plurinacional de), Brasil, Chile y Perú); sector público no financiero (Argentina, Colombia, Ecuador y México).

Como se describió anteriormente, los regímenes fiscales aplicados a la explotación de hidrocarburos y a la minería en la región son sustancialmente diferentes. Estas diferencias resultan en estructuras de ingresos muy distintas de un sector a otro (véase el gráfico XII.3A). En el caso de los hidrocarburos, a nivel agregado, la gran mayoría de los ingresos se derivan de instrumentos no tributarios. Estos por lo general consisten en rentas de la propiedad derivadas de regalías (que suelen tener alícuotas sustanciales) o de ingresos generados por productores estatales (por ejemplo, ingresos propios en el caso de PEMEX en México, ingresos de exportación en el caso del Ecuador) o por contratos de producción con empresas privadas. En cambio, los instrumentos tributarios típicos, 
como el impuesto sobre la renta corporativa, juegan un papel menor, ya que la mayor parte de la renta económica ya se ha gravado con otros instrumentos. Cabe destacar que estos hallazgos siguen siendo válidos en las distintas fases del ciclo de precios.

\section{Gráfico XII.3}

América Latina y el Caribe: ingresos fiscales provenientes de recursos naturales no renovables, por producto e instrumento, 2000-2016

(En millones de dólares)

A. Extracción de hidrocarburos (materia prima)

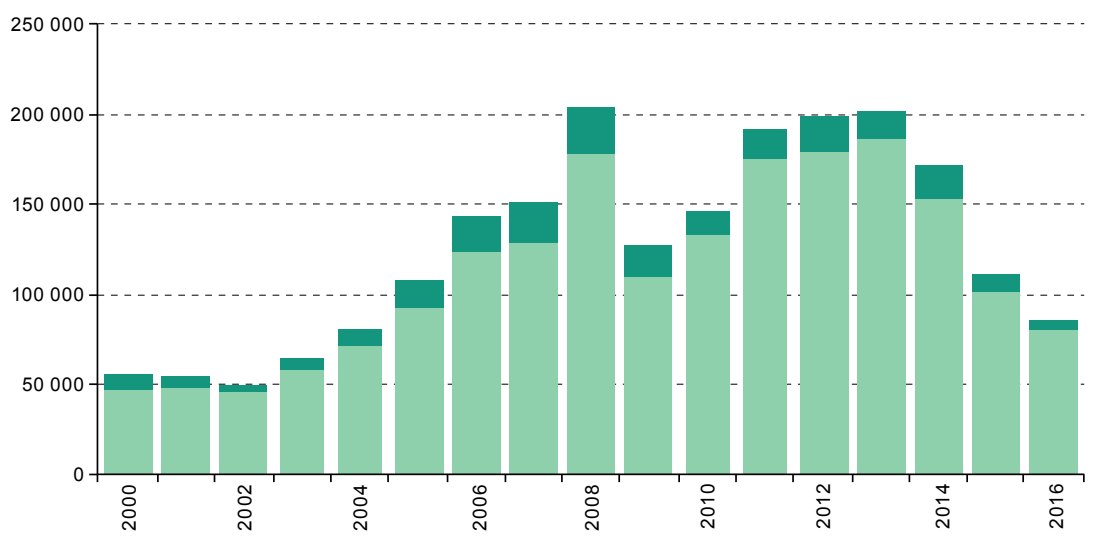

B. Minería

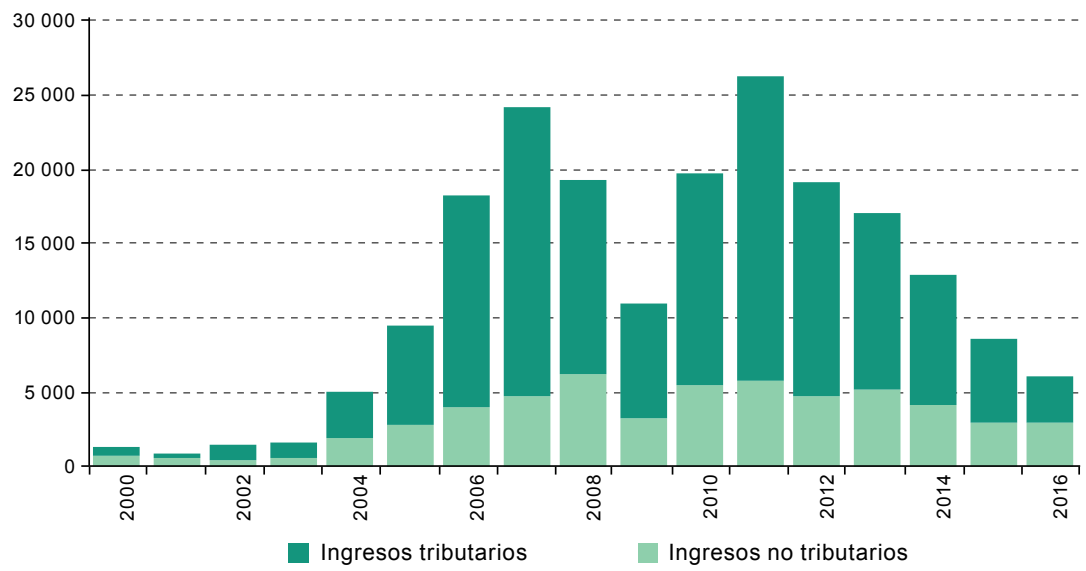

Fuente: Elaboración propia sobre la base de cifras de la Comisión Económica para América Latina y el Caribe (CEPAL).

Por el contrario, en el sector minero, el régimen fiscal predominante produce una estructura de ingresos muy diferente. Como ya se indicó, el régimen fiscal aplicado en la región al sector minero, compuesto en su 
mayoría por empresas privadas, se basa en dos instrumentos principales: el impuesto a la renta corporativo y las regalías, por lo general con alícuotas modestas. No obstante, como se observa en el gráfico XII.3B, durante el período de auge los ingresos tributarios representaron la gran mayoría de los ingresos totales del sector. Entre estos cabe mencionar el impuesto a la renta corporativa y otros impuestos específicos que gravan las ganancias, como el impuesto especial a la minería de Chile. A estos efectos, resulta importante destacar que en muchos países el pago de regalías, que también registró un aumento substancial, se puede deducir del cálculo del impuesto a la renta corporativa.

El diseño de los regímenes fiscales también tiene un gran impacto en la captura de rentas económicas derivadas de la explotación de recursos naturales no renovables. Durante el período de auge, los gobiernos se preocuparon cada vez más por este tema y, como se mencionó, tomaron medidas para mejorar su participación. Si bien el cálculo de la participación efectiva del Estado en estas rentas es conceptualmente directo, la falta de datos comparables obstaculiza su realización con estadísticas macroeconómicas. Sin embargo, sobre la base de una revisión de informes financieros de los principales productores de la región, resulta claro que existen diferencias significativas en la captura de rentas entre los sectores considerados, así como entre empresas privadas y estatales.

Como se observa en el gráfico XII.4, durante el período de auge (entre 2003-2011), se alcanzó un 77\% de participación efectiva del Estado en las ganancias (rentas) de los productores de hidrocarburos (en este caso, la mayoría es de propiedad estatal). En contraste, dentro el grupo de empresas mineras revisadas (sobre todo privadas) la participación efectiva del Estado fue de solo un $28,4 \%$. Este valor cae al $21,7 \%$ si se elimina de la muestra Codelco, el productor estatal de Chile. En el caso de esta última empresa, la participación del Estado en la renta económica generada está más en línea con la de las empresas que operan en el sector de hidrocarburos (de un $58 \%$ frente a un $77 \%$ ).

Las tendencias de los ingresos fiscales de los recursos naturales no renovables a nivel de los países reflejan y contrastan con las tendencias agregadas observadas a nivel regional. Entre los productores de hidrocarburos se pueden identificar por lo menos dos grupos que muestran diferencias importantes en la evolución de sus ingresos fiscales dentro del sector. En el primer grupo, compuesto por la Argentina, el Brasil, México, Trinidad y Tabago y Venezuela (República Bolivariana de), la recaudación registra tasas de variación muy en línea con las del precio al contado del petróleo crudo (véase el gráfico XII.5). 


\section{Gráfico XII.4}

América Latina y el Caribe: participación efectiva del Estado en las ganancias (rentas) generadas por la explotación de recursos naturales no renovables, 2003-2011 ${ }^{\text {a }}$

(En porcentajes)

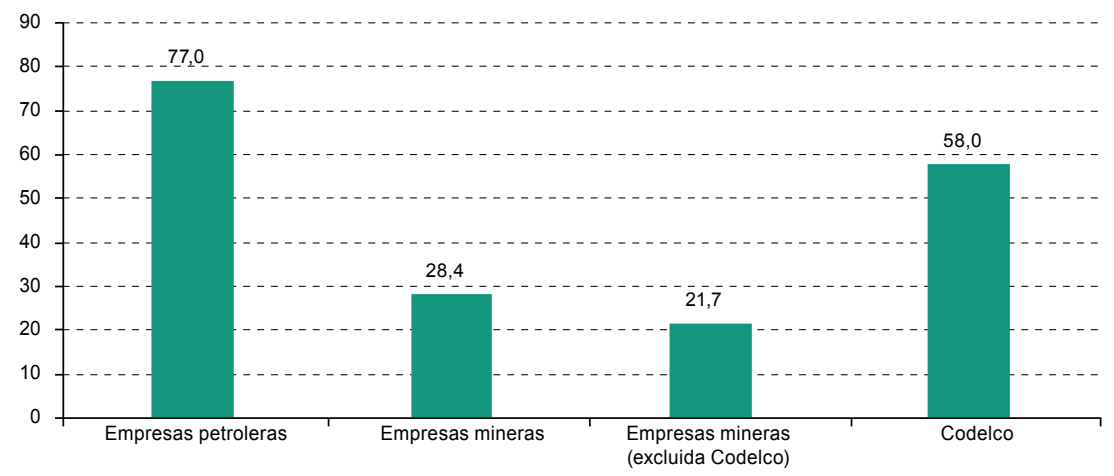

Fuente: Elaboración propia, sobre la base de cifras de Bloomberg.

a Las empresas mineras incluidas corresponden a Antofagasta PLC, Compañía de Minas Buenaventura SAA, Codelco, Fresnillo PLC, Grupo México SAB de CV, Hochschild Mining PLC, Industrias Penoles SAB de CV, Minera Frisco SAB de CV, Minsur SA, Sociedad Minera Cerro Verde SAA, Vale SA y Volcán Compañía Minera SAA. Los productores de hidrocarburos incluidos son Petrobras, Ecopetrol, YPF, Petróleos Mexicanos (PEMEX), Petróleos de Venezuela (PDVSA) y Petrotrin.

\section{Gráfico XII.5}

América Latina y el Caribe (países seleccionados): ingresos fiscales provenientes de la extracción de hidrocarburos, 2000-2016 (Índice: 100=2003, sobre la base de dólares corrientes)

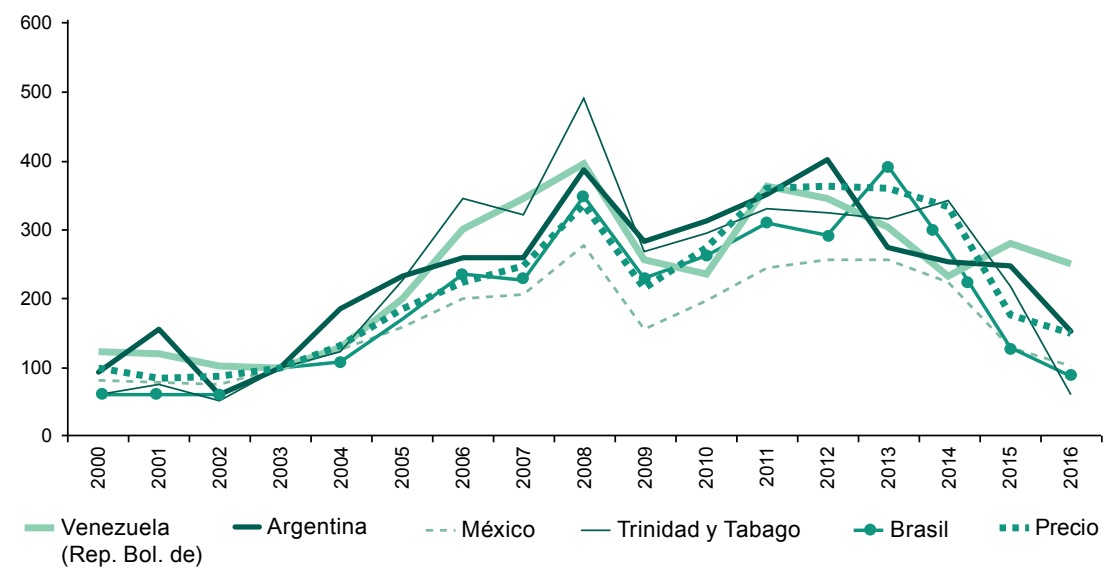

Fuente: Elaboración propia sobre la base de cifras de la Comisión Económica para América Latina y el Caribe (CEPAL).

En este primer grupo destaca el caso de México, cuyos ingresos muestran menos dinamismo al situarse por debajo de la curva del precio, lo que refleja en parte la reducción gradual de la producción petrolera en ese país durante el período. En cambio, en el Brasil los ingresos fiscales 
no registran un crecimiento acorde con el alza de la producción, lo que responde en parte a los pagos de impuestos menores sobre la renta debido al alto nivel de inversión observado.

Por su parte, el otro grupo de países (compuesto por Bolivia (Estado Plurinacional de), Colombia, el Ecuador y el Perú) registra tasas de crecimiento muy elevadas en sus ingresos fiscales provenientes de hidrocarburos durante el período de auge del ciclo de precios (véase el gráfico XII.6). Por un lado, esto refleja aumentos substanciales del nivel de producción de hidrocarburos en esos países durante este período. En Colombia y el Ecuador la producción petrolera aumentó de forma significativa en un $69 \%$ y un $24 \%$ entre 2003 y 2011, respectivamente. En cambio, se destaca la producción de gas natural en Bolivia (Estado Plurinacional de) y en el Perú. En este último caso cabe destacar la puesta en marcha del proyecto Camisea. En ambos países, y durante el mismo período analizado, la producción creció un $118 \%$ y un $2.092 \%$, respectivamente (OPEP, 2017).

\section{Gráfico XII.6}

\section{América Latina y el Caribe (países seleccionados): ingresos fiscales provenientes de la extracción de hidrocarburos, 2000-2016 (Índice: $100=2003$, sobre la base de dólares corrientes)}

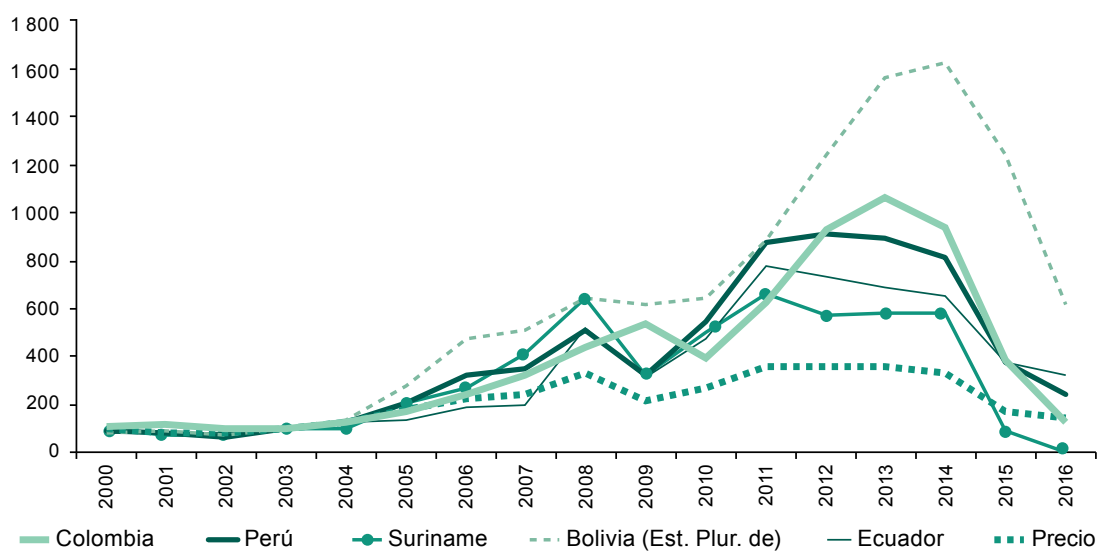

Fuente: Elaboración propia sobre la base de cifras de la Comisión Económica para América Latina y el Caribe (CEPAL).

El rápido aumento de estos ingresos en este grupo de países también se debió a los cambios introducidos en los regímenes fiscales, como se destacó anteriormente. Un caso ilustrativo es el del Estado Plurinacional de Bolivia (véase el gráfico XII.7), donde la recaudación proveniente del sector creció de manera significativa, debido a la introducción del impuesto directo a los hidrocarburos (IDH). En el Ecuador, los ingresos aumentaron de forma significativa en 2011 gracias a la renegociación de los contratos de producción existentes y la incorporación de nuevos instrumentos en 2010 (margen de soberanía). 


\section{Gráfico XII.7}

\section{Estado Plurinacional de Bolivia: ingresos fiscales provenientes} de la extracción de hidrocarburos, 1990-2016

(En porcentajes del PIB)

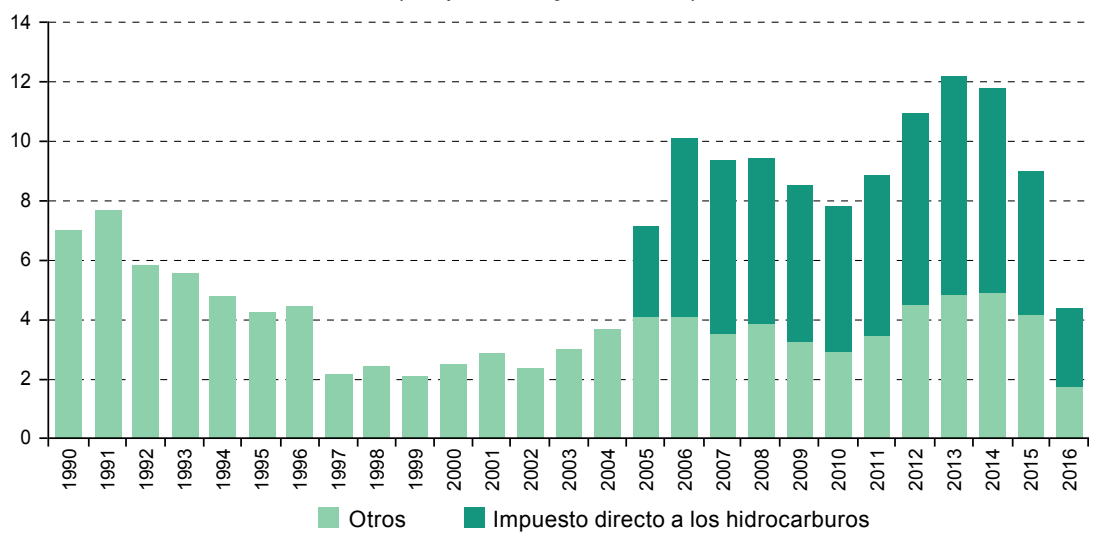

Fuente: Elaboración propia sobre la base de cifras de la Comisión Económica para América Latina y el Caribe (CEPAL).

Con respecto a los ingresos de la minería, casi todos los países de la región experimentaron grandes aumentos durante el período de auge. Quizás la única excepción sea Jamaica, donde estos ingresos han tendido a la baja durante ese período. Los datos presentados en el gráfico XII.8 ponen de relieve el crecimiento explosivo de los ingresos durante el período analizado, a menudo con tasas muchas veces superiores a las del nivel de precios. Esto refleja en parte el importante papel del impuesto a la renta corporativa en los ingresos mineros (con su alta elasticidad ante los cambios en los precios), un aumento de la producción en varios países y la adopción de nuevos instrumentos fiscales. Destacan los casos de Chile y el Perú, donde la evolución de la producción y la adopción de impuestos específicos (y de regalías en el segundo país) incidieron en las tendencias de los ingresos derivados de la actividad minera.

En algunos países, la adopción de nuevas medidas de política ha jugado un papel importante para impulsar la evolución de los ingresos fiscales. En la Argentina, la redefinición de los derechos de exportación en 2002 y los ulteriores incrementos de las tasas supusieron un aumento significativo de la participación del Estado en el valor comercial de la producción exportada durante el período de auge (véase el gráfico XII.9). De modo similar, en el Estado Plurinacional de Bolivia la adopción en 2007 de una regalía minera y la creación de una alícuota adicional para las empresas mineras aceleró el aumento de la recaudación, sobre todo en el período posterior a la crisis. 


\section{Gráfico XII.8}

América Latina y el Caribe (5 países): ingresos fiscales

provenientes de la minería, 2000-2016

(Índice: $100=2003$, sobre la base de dólares corrientes)

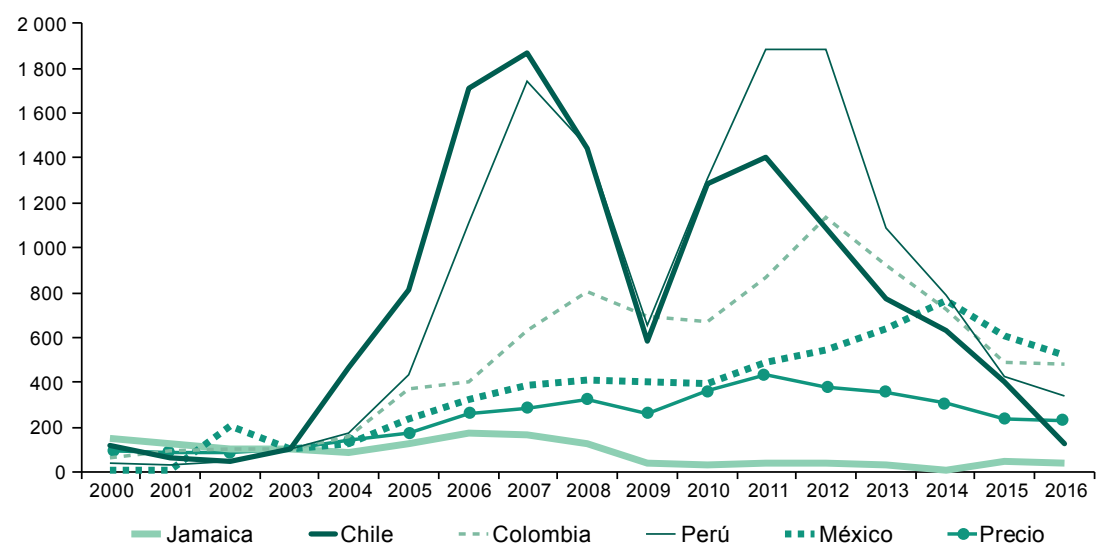

Fuente: Elaboración propia sobre la base de cifras de la Comisión Económica para América Latina y el Caribe (CEPAL).

\section{Gráfico XII.9}

América Latina y el Caribe ( 3 países): ingresos fiscales provenientes de la minería, 2000-2016

(Índice: 100=2003, sobre la base de dólares corrientes)

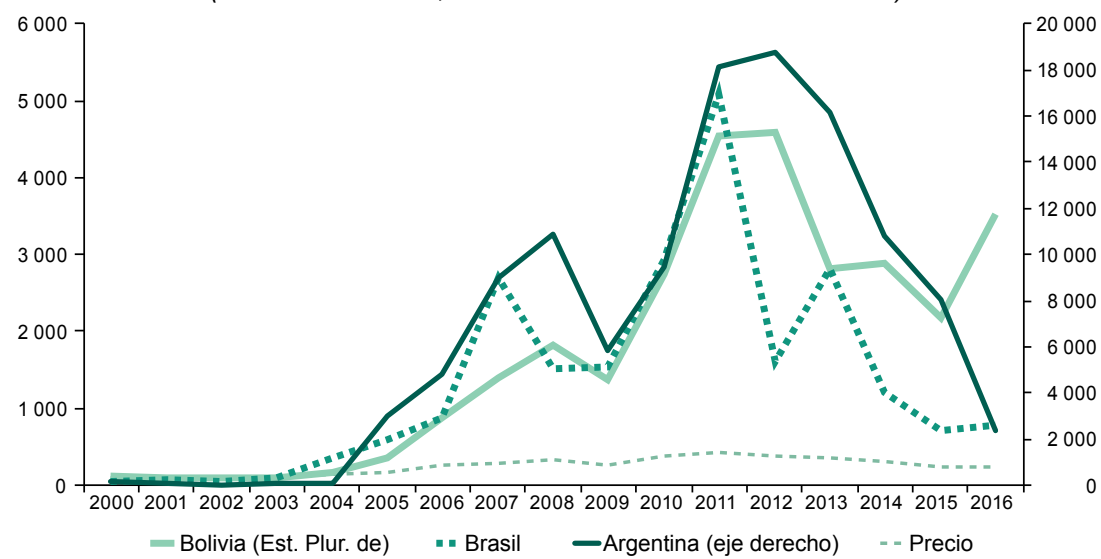

Fuente: Elaboración propia sobre la base de cifras de la Comisión Económica para América Latina y el Caribe (CEPAL). 


\section{Conclusiones}

Para los países de América Latina y el Caribe que están altamente especializados en la explotación de recursos naturales no renovables, el período analizado (2003-2016) se puede resumir en una famosa frase del escritor británico Charles Dickens: "Era el mejor de los tiempos, era el peor de los tiempos...". El alza en los precios internacionales de estos productos conllevó un incremento inédito de los ingresos fiscales provenientes del sector, lo que permitió una expansión del gasto público, en particular de la inversión pública y el gasto social. A la inversa, el desplome de los mismos precios a partir de 2012 en el caso de los minerales y metales, y de 2014-2015 en el de los hidrocarburos, socavó las cuentas públicas en varios países, lo que entrañó un aumento sustancial de los déficits fiscales.

En línea con las tendencias trazadas por los precios internacionales se puede describir también una evolución de los regímenes fiscales aplicados al sector extractivo en la región, así como cambios en los objetivos que se buscaban con las medidas adoptadas. En el período de auge, los gobiernos procuraron aumentar la presión fiscal sobre el sector y su participación en las rentas económicas generadas. Estos esfuerzos se moderaron, o incluso retrocedieron, a medida que los precios se desplomaban y los gobiernos intentaban proteger la producción y la inversión. Sin embargo, las particularidades del sector extractivo hacen que esta tarea, tanto en el período de auge como en el de caída, no haya sido fácil en la región y haya tenido resultados variados.

La combinación de la evolución de los precios internacionales y los cambios en los regímenes fiscales, así como en los niveles de producción, incidió de forma importante en la recaudación del sector extractivo durante el período objeto de análisis. En este capítulo se han constatado diferencias notables entre los sectores de hidrocarburos y de minería, tanto respecto del nivel y estructura de los ingresos percibidos como de su importancia en los ingresos totales de cada país. Conviene subrayar que los regímenes fiscales aplicados a cada sector producen muy distintas estructuras de instrumentos e ingresos fiscales, lo que implica también diferencias en términos de la volatilidad de la recaudación y la captación de rentas económicas.

Uno de los principales desafíos para los países productores de recursos naturales no renovables en la región reside en hallar una forma de balancear la necesidad de cerrar brechas fiscales y de asegurar una participación justa en las rentas económicas generadas por la actividad extractiva. Cada uno de los instrumentos fiscales analizados posee ventajas y desventajas a la luz de los objetivos perseguidos por los gobiernos. Es fundamental encontrar un balance entre la necesidad de obtener ingresos fiscales y el resto de los criterios (eficiencia, progresividad, equidad, estabilidad, flexibilidad), de manera que se asegure, por una parte, un flujo de ingresos públicos y, por otra, la sostenibilidad de la inversión y la producción en el sector. 


\section{Bibliografía}

Acquatella, J. y otros (2013), “Rentas de recursos naturales no renovables en América Latina y el Caribe: evolución y participación estatal, 1990-2010", serie Seminarios y Conferencias, $N^{\circ} 72$ (LC/L.3645), Santiago, Comisión Económica para América Latina y el Caribe (CEPAL).

Boadway, R. y M. Keen (2010), "Theoretical perspectives on resource tax design", The Taxation of Petroleum and Minerals: Principles, Problems and Practice, P. Daniel, M. Keen y C. McPherson (eds.), Nueva York, Routledge.

Brosio, G. y J.P. Jiménez, (2015); "Equalization grants and asymmetric sharing of natural resources: options for Latin America", Urban Public Economics Review, $N^{o} 21$, Santiago de Compostela.

CEPAL (Comisión Económica para América Latina y el Caribe) (2014), Pactos para la igualdad: hacia un futuro sostenible (LC/G.2586(SES.35/3)), Santiago.

(2013), Panorama Fiscal de América Latina y el Caribe, 2013 (LC/L.3580), Santiago.

Dickens, Ch. (2012), Historia de dos ciudades, Alianza Editorial.

FMI (Fondo Monetario Internacional) (2012), “Fical Regimes for Extractive Industries: Design and Implementation" [en línea] https://www.imf.org/ external/np/pp/eng/2012/081512.pdf.

Garnaut, C.R. y C. Ross (1983), Taxation of Mineral Rents, Clarendon Press, Oxford.

Gómez Sabaini, J.C., J.P. Jiménez y D. Morán (2017), “El impacto fiscal de los recursos naturales no renovables", Consensos y conflictos en la política tributaria de América Latina, Libros de la CEPAL, No 142 (LC/PUB.2017/5-P), J.C. Gómez Sabaini, J.P. Jiménez y R. Martner (eds.), Santiago, Comisión Económica para América Latina y el Caribe (CEPAL).

(2015), "El impacto fiscal de los recursos naturales no renovables en América Latina y el Caribe", Documentos de Proyectos (LC/W.658), Santiago, Comisión Económica para América Latina y el Caribe (CEPAL).

Jiménez, J.P. y V. Tromben (2006), “Política fiscal en países especializados en productos no renovables en América Latina", serie Macroeconomía del Desarrollo, N 46 (LC/L.2521-P/E), Santiago, Comisión Económica para América Latina y el Caribe (CEPAL).

Medinaceli, M. (2010), Contratos de exploración y explotación de hidrocarburos: América Latina 2010, Organización Latinoamericana de Energía (OLADE).

OCDE (Organización de Cooperación y Desarrollo Económicos) (2016), Estadísticas tributarias en América Latina y el Caribe 1990-2014, París, OECD Publishing.

Rossignolo, Darío (2015), “Efectos económicos y macrofiscales de los recursos naturales en América Latina", serie Macroeconomía del Desarrollo, No 170 (LC/L.4112), Santiago, Comisión Económica para América Latina y el Caribe (CEPAL).

Tissot, R. (2010), "Challenges of designing an optimal petroleum fiscal model in Latin America", Energy Working Paper, Washington, D.C., Inter-American Dialogue.

Tordo, S. (2007), "Fiscal systems for hydrocarbons: design issues", World Bank Working Paper, N 123.

Vera L. (2017), "La tributación en Venezuela: desafíos con sentido de equidad", Análisis, N² 2/2017, FES Tributación. 

Capítulo XIII

\section{Asignación del espacio fiscal y recursos naturales: un marco conceptual con perspectiva latinoamericana}

El objetivo del presente capítulo es examinar los vínculos entre la asignación del espacio fiscal y los recursos naturales desde una perspectiva conceptual. El análisis se centra en los recursos naturales no renovables en el caso de economías que, por un lado, son ricas en dichos recursos y, por otro, presentan ciertas características estructurales que son típicas de América Latina. Es decir, economías que, al no estar todavía plenamente desarrolladas, presentan rasgos como los que se describen a continuación: heterogeneidad estructural con reducida diversificación, importante incidencia de la pobreza, distribución del ingreso y debilidades institucionales y de gobernanza que se reflejan en la eficiencia del sector público, de las firmas y de los mercados.

A esto se debe agregar el hecho de que, en la dimensión demográfica, si bien la región se encuentra aún dentro de la llamada "ventana de oportunidad", debe ya comenzar a prepararse para la etapa siguiente de envejecimiento creciente. Ello incrementa la importancia de reflexionar sobre cómo deberían asignarse los recursos naturales de forma que se tenga en cuenta a todas las generaciones. Estos factores estructurales y su interacción influyen significativamente sobre el tamaño y la asignación del espacio fiscal y, por ende, sobre las políticas públicas para el desarrollo. 
¿Por qué tiene sentido estudiar específicamente el vínculo entre asignación del espacio fiscal y recursos naturales? De forma sintética y con el fin de motivar el análisis, podría decirse que: i) esos recursos aportan una parte muy relevante de los fondos fiscales en los países donde abundan; ii) las rentas provenientes de los recursos naturales presentan propiedades particulares como la volatilidad, el hecho de que se agotan, que sus precios suelen estar distorsionados y que afectan el medio ambiente; iii) la captación de rentas da lugar a conflictos distributivos, y iv) a consecuencia de todo lo anterior, el manejo del espacio fiscal exige un marco institucional, de políticas y de gobernanza específicamente adaptado.

El aporte básico que se desea realizar en el plano conceptual abarca tres dimensiones. La primera consiste en brindar una visión ordenada y sistematizada de los temas que son relevantes cuando se estudia la asignación del espacio fiscal en economías ricas en recursos naturales. Esos temas aparecen tratados en un cúmulo de bibliografía amplio y disperso. La segunda consiste en definir y discutir los temas de mayor relevancia para la región, dadas las especificidades estructurales antes mencionadas. La tercera se refiere a enfocar el análisis a partir de las prioridades que surgen del concepto de desarrollo sostenible. El criterio básico para evaluar la asignación del espacio fiscal será que el problema central que debe resolver una economía rica en recursos naturales es cómo transformar esos recursos en activos reproducibles y hacerlo de manera inclusiva y sostenible.

El trabajo se divide en tres secciones. En la primera se define el espacio o margen de maniobra fiscal y se lo vincula con los problemas de asignación de dicho espacio que son específicos de los recursos naturales, según se infiere de la literatura. El objetivo es ampliar el enfoque habitual sobre el tema, de forma que se pueda contar con una herramienta metodológica para organizar el estudio de las conexiones entre recursos naturales y políticas fiscales de asignación con una perspectiva de desarrollo sostenible. Se subraya el papel de las características de la región, la gobernanza, la coordinación de políticas y la incertidumbre.

En la segunda sección se analiza un conjunto de factores presentes en una economía rica en recursos naturales que inciden en tres propiedades, que a su vez determinan de manera directa los grados de libertad para asignar el espacio fiscal: la sostenibilidad, la estabilidad y la flexibilidad. Se estudian las particularidades que deben considerarse en un país rico en recursos naturales. En especial, los vínculos entre la riqueza pública y el concepto de ahorro genuino que propone el Banco Mundial (Banco Mundial, 2011; Lange, Wodon y Carey, 2018) y la relación entre precios y volatilidad macroeconómica, tanto por la vía de las reservas como de los flujos. En la última sección se recogen las conclusiones. 


\section{A. Recursos naturales, desarrollo sostenible y espacio fiscal}

El objetivo principal de este apartado consiste en identificar los factores que en diversas corrientes de la literatura se definen como relevantes para explicar el vínculo entre los recursos naturales y las políticas fiscales en la dimensión de la asignación. La intención no es realizar un estudio, sino mostrar la utilidad del concepto de espacio fiscal para comprender cómo esos factores se relacionan entre sí y por qué la gobernanza desempeña un papel de primer orden a la hora de entender la asignación de las rentas captadas por el sector público. En este sentido, se utiliza el concepto de espacio fiscal como herramienta metodológica para organizar el análisis e investigar vínculos.

En un principio, el espacio o margen de maniobra fiscal se definió de una forma restringida, que enfatizaba dos aspectos: la sostenibilidad fiscal y la movilización de recursos para el desarrollo. Por ejemplo, según el Comité para el Desarrollo (FMI/Banco Mundial, 2006), existe espacio fiscal cuando es posible llevar adelante los planes de gasto público sin comprometer la capacidad presente o futura de servir la deuda. En cuanto a la movilización de recursos para crear ese margen de maniobra, el objetivo es encontrar nuevas fuentes de recursos tributarios domésticos, formas de incrementar la eficiencia del gasto o posibilidades de ayuda externa. Heller (2005) presenta un enfoque similar y enfatiza que, al evaluar el espacio, hay que tener en cuenta la evolución intertemporal de los ingresos y los gastos.

En trabajos posteriores se amplió la visión del espacio fiscal. Así, según Rathin, Heuty y Lethouzé (2007) y Rathin y Heuty (2009), se trata de un instrumento que se utiliza para estudiar el proceso de determinación endógena de las políticas fiscales en el marco de una estrategia de desarrollo. Destacan además que se puede generar espacio con reformas que mejoren el marco institucional. Fanelli (2009) lo define como el "lugar" del diseño, la coordinación y la implementación de las políticas fiscales que se articulan a partir de las prioridades del desarrollo. Al estudiar la asignación, es ineludible tomar en cuenta el contexto, pues resulta evidente que, en los países de la región ricos en recursos naturales, las prioridades de asignación serán diferentes a las de países desarrollados con esas mismas ventajas, como el Canadá o Noruega, que están mucho más avanzados en la transición demográfica.

En esta visión más amplia del espacio fiscal, la coordinación y la gobernanza son centrales. Las políticas se conciben articuladas dentro de un espacio normativo y no de forma aislada, de manera que al llevar adelante una política será necesario considerar el costo de oportunidad de 
asignar los fondos a esa y no a otra. En un contexto de gobernanza pública de calidad, este ejercicio podría en gran medida ser rutinariamente realizado por la burocracia pública. Por ejemplo, podría haber un organismo que evaluara la rentabilidad relativa de todos los proyectos de inversión pública de manera conjunta. Sin embargo, fijar los objetivos no es tarea de la burocracia, sino de la política. Para evaluar alternativas de asignación del espacio fiscal es necesario hacer referencia a un enfoque del desarrollo y a las restricciones que imponen los conflictos distributivos entre grupos de interés que, en el caso de los recursos naturales, pueden convertirlos en una maldición (Van der Ploeg, 2011).

ElconceptodedesarrollosostenibleimpulsadoporlasNacionesUnidas y que llevó a la Asamblea General a definir los 17 Objetivos de Desarrollo Sostenible que se incluirían en la Agenda 2030 (Naciones Unidas, 2015) tiene dos virtudes útiles para estudiar la asignación fiscal. La primera es que se integra bien con la dimensión intertemporal inherente al concepto de sostenibilidad de la deuda que entra en la definición del espacio fiscal. En el informe Nuestro futuro común (Naciones Unidas, 1987) se definió el desarrollo sostenible como el que satisface "las necesidades del presente sin comprometer la capacidad de las futuras generaciones para satisfacer las propias". La segunda virtud es que asigna un papel relevante a los recursos naturales: se exige que el crecimiento económico respete la restricción asociada con el hecho de que la utilización de capital natural no es gratuita. Los recursos naturales se agotan.

En el diagrama XIII.1 se presentan los factores relevantes para el vínculo entre el espacio fiscal y los recursos naturales que se han descrito en la bibliografía. Se incluyen los elementos del contexto que inciden en la asignación del espacio fiscal, sea como fuente de restricciones o de oportunidades. Estos elementos son también útiles para ubicar el problema en el marco más general de la política fiscal y el desarrollo.

En la base del diagrama XIII.1 aparecen los recursos naturales y, en el tope, la meta de colocar a la economía en la senda del desarrollo sostenido. Con esto se simboliza que el aporte fundamental de los recursos naturales no renovables al desarrollo pasa por su transformación en capital reproducible. A ese fin es necesario asignar de manera óptima la renta a medida que se extrae. Los problemas de la asignación del espacio fiscal en lo relativo a los recursos naturales se pueden ordenar a partir de este principio. El recuadro de "características estructurales" se ha colocado a la izquierda para recalcar que los factores que aparecen dentro son fuente de restricciones importantes para el proceso de asignación del espacio fiscal, tanto porque limitan los instrumentos disponibles como porque inciden sobre las prioridades. 


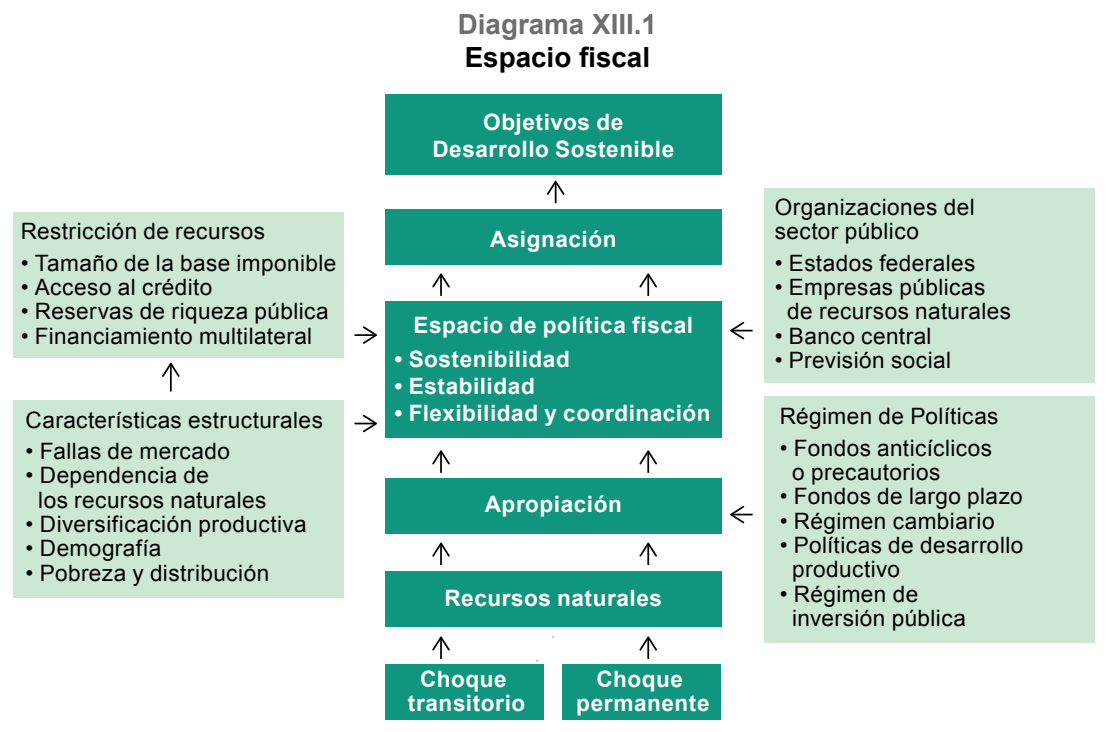

Fuente: Elaboración propia.

Las características estructurales de la región exigen que la transformación de recursos naturales en capital reproducible se haga de forma de promover la transformación estructural de economías que presentan heterogeneidad y problemas de inclusión. No se ahondará aquí sobre estos aspectos porque la relación entre las características estructurales de la región y los recursos naturales no renovables se trata en otro capítulo de este libro. No obstante, conviene señalar que la estructura económica define en gran medida la restricción de recursos que limita el espacio fiscal. Los factores más importantes, como el tamaño de la base imponible y el acceso al crédito, aparecen en el rectángulo de restricción de recursos.

Una parte importante de los problemas de asignación que son específicos de los recursos naturales se relaciona con dos aspectos: la captación y el tipo de choques que los afectan. Aparecen representados en la parte inferior y son la manifestación de características propias de la actividad: riesgos sustanciales por lo incierto de los descubrimientos, necesidad de hundir capital al principio del proyecto, variaciones en los precios y los costos de extracción, y riesgo de cambio tecnológico (Smith, 2012). Para el análisis de la asignación del espacio fiscal y el diseño de instrumentos de política es fundamental distinguir entre choques transitorios o permanentes debido a que las decisiones de asignación y las herramientas fiscales para adaptarse a ellos deben ser diseñadas en consonancia.

De manera más general, el conocimiento de los procesos estocásticos que generan los choques tiene gran valor a la hora de adoptar decisiones 
de asignación del espacio fiscal. Dado que ese conocimiento es muy parcial, ello es una fuente esencial de incertidumbre y, por ende, de errores de asignación. De ahí la necesidad de diseñar un régimen para el manejo de la asignación del espacio que se adapte específicamente a situaciones de incertidumbre y que considere choques de ciclo y de tendencia (Baunsgaard y otros, 2012; FMI, 2012 y 2015; Ossowski y Halland, 2016).

Los problemas relacionados con la captación de las rentas (definidas como precio menos costos, con inclusión del beneficio normal de la empresa que extrae) no son menos complejos. En principio, dado que la renta remunera un factor que no requiere acumulación previa, parece una alternativa óptima para alimentar el espacio fiscal. Sin embargo, debido a los conflictos por la captación, los recursos naturales pueden ser una fuente de dificultades, como lo puso de manifiesto la literatura sobre la "maldición de los recursos", sobre todo en Van der Ploeg (2011) y en el capítulo VII de este libro. La "maldición" incide sobre la calidad de la gobernanza y la estabilidad macroeconómica y, por esas vías, afecta tanto la disponibilidad de recursos fiscales como la calidad de su asignación.

Los canales a través de los que opera la captación de rentas son variados. Los esquemas fiscales básicos son los contratos para compartir la producción y los contratos de servicios, las subastas, los impuestos y regalías sobre los ingresos brutos con licencia de áreas, los beneficios de las empresas públicas extractivas y los subsidios al consumo de energía. A través de ellos el consumidor y las empresas captan rentas (Di Bella y otros, 2015; Fanelli, Jiménez y López Azcúnaga, 2015). Por otra parte, cada modalidad de captación tiene asociada una configuración de intereses, de forma que la economía política también es un factor que define la cantidad de rentas que pueden movilizarse para el desarrollo. Además, cada modalidad tiene una estructura de gobernanza que le es propia y que incide tanto sobre la captación como sobre el ritmo de extracción. Por otra parte, como el recurso se agota y está sujeto a obsolescencia, la decisión de cuánto extraer es central.

No obstante, sería difícil definir el ritmo óptimo de extracción basándose solo en consideraciones de eficiencia, que de cualquier forma no están bien establecidas en la teoría (Smith, 2012). Así, en la práctica, es sumamente difícil establecer cuáles son las mejores reglas de captación entre los actores involucrados para movilizar las rentas hacia el desarrollo, sin conocer ex ante a qué tipo de gobernanza y de equilibrio de economía política conduciría cada conjunto de reglas. Esto se debe a la incidencia de características tales como lo elevado de las rentas, la incertidumbre, la presencia de marcadas asimetrías de información entre las firmas (a menudo multinacionales) que facilitan la evasión y la elusión tributarias, así como la competencia impositiva entre Estados para atraer inversiones. Todo esto puede contribuir a que se deba renunciar a parte de la renta y desincentivar a los inversores debido a los altos costos hundidos con períodos largos 
de producción (FMI, 2012). Según un estudio del FMI (2012), un objetivo razonable consiste en tratar de obtener recursos desde el primer día y que los ingresos percibidos aumenten a medida que lo hacen las rentas. Con ese fin se combinan las regalías con los impuestos a las ganancias y subastas.

Los objetivos (con su ponderación relativa) que guían el uso del espacio fiscal y el marco institucional y organizacional, en principio son fijados en la esfera de la política. Sin embargo, son mediados y probablemente modificados en parte mediante el ejercicio de la autoridad en las organizaciones en que se delega la misión de gestionar recursos e implementar políticas. Por ello no sería correcto analizar la asignación del espacio fiscal sin considerar la dimensión de la gobernanza.

En relación con esto último, Altomonte y Sánchez (2016) brindan una definición de gobernanza que es afín al enfoque del espacio fiscal que aquí se propone. Consideran que "la gobernanza de los recursos naturales es el gobierno del sistema de relaciones y conductas que articulan el funcionamiento de la industria en su entorno social, político, económico y natural. Se trata del conjunto de mecanismos, procesos y reglas a través del cual se ejerce la autoridad sobre dicha actividad, de las conductas entre las partes, y la protección de la naturaleza y de los derechos básicos, y se refiere al funcionamiento de las instituciones en la amplia diversidad de agentes y reglas que influyen sobre ella, con miras al presente y al futuro". Los dos elementos centrales de la gobernanza, desde la óptica de la distribución del espacio fiscal son los regímenes de política y las organizaciones, que aparecen en los dos rectángulos de la derecha en el diagrama XIII.1.

Los elementos que aparecen en el rectángulo correspondiente a "regímenes de política" se analizan en la sección siguiente. Aquí solo interesa considerar que un régimen de políticas es un conjunto de reglas cuyo objetivo es crear incentivos específicos para un área determinada de la economía y cuya eficacia depende de la calidad del diseño y de la gobernanza del régimen. Por ejemplo, un fondo soberano puede ser adecuado para la asignación intertemporal, pero la calidad de la asignación dependerá de factores de economía política y de gerenciamiento (Reisen, 2008).

En el recuadro de "organizaciones" aparecen las de orden público, que desempeñan un papel relevante en la asignación de rentas. Es común que los Estados federales sean los dueños de la riqueza del subsuelo y, por lo tanto, sus decisiones de asignación explican en parte cómo se asigna el espacio. Dada la importancia de transformar la renta en capital producido, entran en el cuadro los organismos que se encargan de la inversión pública, sobre todo en infraestructura. Si se adopta la visión del Banco Mundial del ahorro genuino como medida de la transformación de renta en capital producido, también habría que incluir los organismos a cargo de la inversión en capital humano y del cuidado y gestión del medio ambiente. Obviamente, también corresponden a esa categoría las 
empresas estatales que explotan recursos naturales. La previsión social figura porque, en países como Chile, se asignan fondos para necesidades futuras de pagos de pensiones. Por último, se ha insertado el banco central ya que, sobre todo en las bonanzas, aumenta la presión para coordinar el uso del espacio fiscal con la política monetaria (por ejemplo, mediante la asignación de recursos a fondos anticíclicos) a fin de evitar presiones inflacionarias y apreciaciones de la moneda que generen lo que se conoce como 'enfermedad holandesa' (véase el capítulo VII de este libro).

¿Cómo coordinar las decisiones de organizaciones y regímenes de política diversos, de forma que el resultado final de la asignación esté en consonancia con la meta de transformar recursos naturales en capital reproducible? ¿Están diseñadas las reglas para que las decisiones descentralizadas contribuyan a lograr el equilibrio deseado? Estas preguntas son útiles para señalar por qué tiene sentido pensar en términos de espacio fiscal: ayudan a poner en primer plano que no se trata solo de que cada política $\mathrm{u}$ organismo sean eficientes en forma aislada. También es fundamental que las decisiones se coordinen en función de objetivos agregados.

En este sentido, es fundamental la gobernanza del espacio fiscal. Si la acción de gobierno se llevara a cabo en términos de trabajo en equipo, con una jerarquía única, el espacio fiscal sería en gran medida redundante. No obstante, si las decisiones tienen un grado de descentralización importante, es más fructífero concebir la asignación de rentas en términos de un equilibrio entre agentes que no necesariamente cooperan entre sí. Lo que importa desde el punto de vista de la gobernanza es cómo se implementan las políticas y cómo funcionan las organizaciones de facto y no de jure. Desde una perspectiva de facto, los intereses individuales de los políticos, los burócratas y los grupos de interés son determinantes para la captación de rentas de recursos naturales.

Según la discusión anterior, la eficacia en el cumplimiento de los objetivos de asignación de las rentas estará determinada ante todo por tres factores: la incertidumbre asociada con los choques que inciden sobre el flujo de rentas, los mecanismos de captación de rentas y el grado de coordinación de decisiones que no necesariamente están centralizadas. La falla en el manejo de estos tres factores afecta a tres propiedades que determinan la asignación del espacio fiscal: la sostenibilidad, la estabilidad y la flexibilidad.

\section{B. Sostenibilidad, estabilidad y flexibilidad}

Una vez que los recursos hayan sido extraídos y la renta captada por el sector privado o el público, una decisión de asignación básica para la autoridad fiscal es si ahorrar o consumir su parte de la renta. En los modelos teóricos de economía abierta (como sucede en el caso de las latinoamericanas), la tasa 
de interés es exógena y también lo son los precios. Por esa razón es posible, en principio, escindir las decisiones de producción de las de consumo y la trayectoria óptima de este último es decidida por un planificador benevolente con la ayuda de la ecuación de Euler (Dasgupta, Eastwood y Heal, 1978; Karp, 2017). Sin embargo, debido a las dificultades para determinar con precisión los procesos estocásticos que generan los choques de recursos naturales no renovables, las dificultades de gobernanza con raíz en conflictos distributivos y las fallas de coordinación antes mencionadas; en la práctica se hace necesario utilizar criterios más pragmáticos para asignar el espacio disponible. Así, los tres propósitos fundamentales que alimentan el pragmatismo son la necesidad de preservar la estabilidad macroeconómica, evitar la maldición de los recursos e impulsar el crecimiento. Aquí se estudiarán estas cuestiones. Por razones de espacio, este capítulo se limita a los aspectos conceptuales, pero en otro capítulo se analizan evidencias relacionadas con las políticas aplicadas en la región. El análisis se organiza en referencia a tres propiedades del espacio fiscal que los autores consideran factores determinantes para asignarlo: la sostenibilidad, la estabilidad y la flexibilidad.

La literatura con origen en la regla de Hartwick (1977) y desarrollada posteriormente por otros autores y el Banco Mundial (Hamilton, y Hassan, 2003; Hamilton, 2008; Banco Mundial, 2011; Lange, Wodon y Carey, 2018), para contribuir a que la economía transforme de manera eficiente el capital natural en capital reproducible (incluido el capital humano), sugiere que la autoridad debería monitorear el ahorro genuino, que en este caso se define como el ahorro tradicional neto del consumo de recursos naturales. El Banco Mundial resta un ítem de emisiones de dióxido de carbono y suma el incremento del capital humano. Sin embargo, en aras simplificar y centrar la atención en los argumentos relativos a los recursos humanos, se hará caso omiso de esas variables y también de la depreciación del capital productivo.

De esta manera, en función de la regla de Hartwick, si el ahorro genuino (también llamado ahorro ajustado) es superior o igual a cero, la riqueza se mantiene y lo mismo ocurrirá con la utilidad de las generaciones futuras. Si la población crece, esta regla debe corregirse, como se muestra más adelante. Se trata de una regla que no debería aplicarse de forma mecánica. En primer lugar, se deduce en términos teóricos, lo que permite hacer algo que no es posible en la práctica: medir el ingreso nacional neto en función de los precios sombra y luego corregir las externalidades con impuestos pigouvianos (Neumayer, 2010). Así, no desempeñan ningún papel las fallas de mercado que son un rasgo estructural de la región.

En segundo lugar, aunque existen versiones aplicables a la economía abierta, no se suelen considerar en la práctica. Esto minimiza los efectos de las pérdidas y ganancias de capital inducidas por cambios en los precios de los recursos naturales. En tercer lugar, no se discrimina entre ahorro 
público y ahorro privado, por lo que el espacio fiscal no tiene ningún papel que desempeñar. Por último, las fallas de coordinación y la maldición de los recursos están ausentes porque no hay problemas distributivos y de gobernanza ni desequilibrios macroeconómicos entre el ahorro y la inversión. Más adelante se presenta un esquema conceptual para estudiar las consecuencias que cabe esperar cuando un gobierno trata de ahorrar en línea con Hartwick y para hacer una aproximación a la forma en que se verían afectadas la sostenibilidad, la estabilidad y la flexibilidad.

La sostenibilidad es un requisito que proporciona al Estado cierto grado de libertad para decidir la asignación. Si está amenazada, las decisiones se verán subordinadas a la necesidad de estabilizar la deuda pública. Por ello no sorprende que todas las definiciones de espacio fiscal incorporen este requisito. Según la definición habitual de sostenibilidad fiscal, la suma del valor presente de los superávits del futuro en relación con el producto interno bruto (PIB) debe ser igual al monto actual de la deuda pública neta en relación con el PIB. La tasa de descuento utilizada se basa en la tasa efectiva: la tasa de interés sin contar la tasa de crecimiento. Por supuesto, no es fácil elegir una tasa efectiva en un contexto de incertidumbre. No obstante, este problema ya se ha discutido suficientemente (Escolano, 2010). Aquí se centrará la atención en el vínculo existente entre la sostenibilidad y los recursos naturales. Ello permitirá dar mayor relevancia a la hoja de balance del sector público y a la relación entre las reservas, los flujos y los precios de recursos naturales.

Se describe el ahorro del gobierno $\left(S_{t}^{G}\right)$ como:

$$
=S_{t}^{G}=T_{t}^{G}+E_{t}^{G}-C_{t}^{G}=\Delta K_{t}^{G}+\Delta A_{t}^{G}-\Delta B_{t}^{G}
$$

donde los impuestos $\left(T_{t}^{G}\right)$ son los no relacionados con rentas de recursos naturales; $E_{t}^{G}$ es la captación de rentas por cualquier vía (impuestos, dividendos de empresas del Estado, entre otras cosas) y $C_{t}^{G}$ es el consumo público. El ahorro se utiliza para acumular activos financieros $\left(\Delta A_{t}^{G}\right)$ (por ejemplo, mediante un fondo soberano), amortizar la deuda $\left(-\Delta B_{t}^{G}\right)$ o incrementar la reserva de capital público $\left(\Delta K_{t}^{G}\right)$. La inversión pública se registra sistemáticamente entre los gastos, pero no se lleva registro periódico de la reserva de capital productivo en la hoja de balance debido a la escasez de mediciones confiables. Esto hace que la riqueza observada del gobierno se vea influida por la relevancia de la riqueza que sí se registra $\left(\Delta A_{t}^{G}-\Delta B_{t}^{G}\right)$ en relación con la no registrada.

El ahorro genuino del gobierno $\left(S_{t}^{\prime}{ }^{G}\right)$ se diferencia del ahorro en que el primero deduce el consumo de recursos naturales $\left(\Delta Q_{t}^{G}\right)$ valuado a un valor unitario de renta $p_{t}$ (precio menos costos de extracción). El valor del consumo de recursos naturales cambiado de signo es igual a la renta monetaria recibida: $E_{t}^{G}=-p_{t} \Delta Q_{t}^{G}$. Por supuesto, es de esperar que 
$\Delta Q_{t}^{q G}<0$ si se están agotando los recursos sin que los descubrimientos compensen el consumo. Entonces:

$$
S_{t}^{\prime G}=T_{t}^{G}+E_{t}^{G}-C_{t}^{G}-E_{t}^{G}=T_{t}^{G}-C_{t}^{G}=\Delta K_{t}^{G}+\Delta A_{t}^{G}-\Delta B_{t}^{G}+p_{t} \Delta R_{t}^{q G}
$$

El incremento de la riqueza genuina del gobierno $\left(W_{t}^{\prime G}\right)$, se calcula a partir del ahorro genuino y toma en cuenta las reservas de recursos naturales existentes. Por esa razón, al incluir los recursos naturales en la hoja de balance, la variación de la riqueza no coincide con el monto de ahorro: hay que considerar las pérdidas y ganancias de capital que se producen de un período a otro por la variación del precio de las reservas de recursos naturales. Con el fin de centrar el análisis, aquí solo se consideran las variaciones de estos últimos precios. La ganancia de capital está dada por: $\Delta p_{t} Q_{t-1}^{G}=\hat{p}_{t} p_{t-1} Q_{t-1}^{G}$, donde $\hat{p}_{t}=\frac{\Delta p_{t}}{p_{t-1}}$. Este efecto no se considera en la contabilidad pública al no registrarse los activos de recursos naturales. Su significación puede ser grande. Chile, un país muy rico en recursos naturales según la última medición del Banco Mundial, tiene 44.279 dólares per cápita en concepto de capital contenido en el subsuelo. En este caso, un incremento del 1\% del valor es significativo en términos del PIB per cápita. El incremento de riqueza genuino se puede expresar entonces como:

$$
\Delta W_{t}^{\prime G}=S_{t}^{\prime G}+\hat{p}_{t} p_{t-1} Q_{t-1}^{G}=\Delta K_{t}^{G}+\Delta A_{t+1}^{G}-\Delta B_{t}^{G}+p_{t} \Delta Q_{t}^{G}+\Delta p_{t} Q_{t-1}^{G}
$$

Hay varias cuestiones de asignación del espacio fiscal asociadas con la ecuación (3).

En primer lugar, ¿qué ocurre si, para estar en línea con la regla de Hartwick, el sector público fija: $S_{t}^{\prime G}=0$ ? La riqueza no queda constante. Crece o decrece en función de las ganancias o pérdidas de capital: $\Delta W_{t}^{\prime G}=\hat{p}_{t} p_{t-1} Q_{t-1}^{G}$. Este efecto se desdibuja al evaluar la sostenibilidad de la forma habitual, porque los recursos naturales no están registrados en la hoja de balance del gobierno.

En segundo lugar, si para ilustrar con mayor claridad se supone que se cumple la regla de Hotelling (1931), se plantea que:

$$
\hat{p}_{t}=r
$$

El valor de los recursos naturales que están bajo tierra crecería a la tasa $r$ sin necesidad de ahorrar, puesto que los recursos se venderían a un precio más alto en el futuro. Si los recursos se venden en el extranjero, como sucede en gran medida en la región, la ganancia de capital refleja el hecho de que en el futuro, a medida que se vendan los recursos a un mayor precio habrá, para el país y su Gobierno, una transferencia positiva que producirá un incremento del espacio fiscal y el ingreso nacional. Sin embargo, ¿qué ocurre si el Estado extrae la renta a nivel interno (por ejemplo, si las empresas públicas venden petróleo)? Habría una 
transferencia sistemática de ingresos de consumidores y firmas hacia el sector público a medida que fuera aumentando el precio. De esta forma, no habría ganancia neta para el país.

Además, la suma adicional que el Estado invertiría al aumentar el valor de $E_{t}^{G}$ la tendría que dejar de gastar el sector privado. El resultado lógico es que el sector privado se empobrecería, dado que los recursos naturales que consume aumentarían de valor a la tasa $r$. ¿Se asignaría así el espacio fiscal creciente? Esto sería difícil si se incorpora la puja distributiva al análisis. Habría una gran presión política para que el gobierno transfiriera parte de sus ganancias de capital al consumidor o a las firmas mediante subsidios a la energía. Sería muy probable que la inversión pública descendiera por debajo de la regla de Hartwick. Los subsidios destinados a compensar el efecto distributivo negativo de aumentos del petróleo son habituales en la región cuando un choque favorece el precio de la energía (Di Bella y otros, 2015). De esta forma, la flexibilidad para asignar recursos se ve limitada por el conflicto distributivo. Se trata de un fenómeno bien estudiado en la literatura de la maldición de los recursos (Van der Ploeg, 2011).

En tercer lugar, ¿en qué invertir el producto de $E_{t}^{G}$ ? Si la renta se invirtiera en un fondo soberano, la tasa de crecimiento de la riqueza sería la misma que antes, la tasa $r$. Sin embargo, ¿qué ocurriría si se amortizara la deuda? Si la tasa de interés activa fuera mayor que la tasa del fondo soberano (como cabe esperar, sobre todo, si hay fallas en los mercados financieros), sería conveniente amortizar la deuda. ¿Qué hacer en un país de infraestructura inadecuada? Está claro que el aumento de la inversión pública haría crecer la riqueza del gobierno por dos razones. No solo porque la tasa de rentabilidad sería superior a $r$, sino porque el gobierno recaudaría más impuestos si la economía creciera más rápido (por ejemplo, es normal que la infraestructura genere externalidades para el sector privado) (Collier y otros, 2009).

Nótese, sin embargo, que esto no se refleja en la hoja de balance como un reforzamiento del patrimonio neto, porque no se registra. Además, es posible que el gobierno no cobre totalmente por el uso de la infraestructura y, por lo tanto, será el sector privado el que se apropie de los beneficios. De cualquier forma, esto plantea un problema distributivo, no de eficiencia. $\mathrm{Si}$ el gobierno invierte en activos financieros o en amortizar la deuda, su posición financiera parecerá más sostenible. Aun así, sería mejor invertir en infraestructura. Esto sugiere que el criterio de sostenibilidad utilizado habitualmente debería revisarse en el caso de países ricos en recursos naturales. Por supuesto, se han dejado a un lado los problemas de gobernanza. Por las razones antes subrayadas, es posible que el gobierno no tenga la capacidad de asignar el espacio fiscal a la inversión de manera eficiente. 
En la misma línea, si los recursos no se extraen, no hay nada que decidir y la riqueza de recursos naturales crece a la tasa $r$. No obstante, si se extraen y la gobernanza es deficiente, podría ocurrir que los recursos no se inviertan y se dilapiden, por ejemplo, en subsidios a la energía. Por falta de flexibilidad para asignar el espacio fiscal, el gobierno podría terminar por dejar los recursos naturales bajo tierra, lo que reforzaría la sostenibilidad fiscal, pero erosionaría el crecimiento potencial.

En cuarto lugar, ¿qué ocurre ante un choque imprevisto de los precios? Esta pregunta es clave para la estabilidad. Es más fácil ilustrar este punto tomando como base a Hotelling. En vista de que la paridad de Hotelling, se debe mantener por el principio de arbitraje, si se produce un choque que cambie el precio esperado de los recursos naturales o las tasas de interés, el precio presente del recurso debería ajustarse para que la paridad se restablezca.

El precio debe experimentar un salto no esperado. Es muy importante subrayar que esto no solo afecta los flujos de ingresos, sino también el precio de las reservas. Por ejemplo, si la tasa de interés disminuye o el $\hat{p}_{t}$ esperado aumenta, el precio de los recursos naturales debe aumentar. Esto robustece la hoja de balance del sector público porque incrementa su patrimonio neto. Si bien esta situación no se registra en la hoja de balance pública, el mercado la percibirá y se incrementará la sostenibilidad fiscal. Con ello, mejorarán las condiciones de acceso al crédito. Ambos efectos expanden el espacio fiscal.

Sin embargo, la experiencia de la región muestra que la asignación del mayor espacio encontrará restricciones importantes. Para empezar, si se aumentara la inversión pública y la capacidad de absorción fuera limitada, ello entrañaría una mayor presión sobre los precios no transables, lo que restaría competitividad e impediría la diversificación de la estructura (véase el capítulo VII de este libro). En esos casos, la recomendación es operar con fondos de estacionamiento para atesorar los fondos de forma transitoria y dosificar la inversión (Collier y otros, 2009). Otra restricción de estabilidad viene dada por el hecho de que la revalorización de las reservas, al aumentar el valor del colateral y la disponibilidad de divisas, incentiva la entrada de capitales. Ante esa situación, es crucial que la autoridad determine si el choque es transitorio o permanente. En el primer caso, la entrada de capitales sería procíclica y se debería neutralizar. En este punto, la política fiscal se debe coordinar con el funcionamiento del régimen monetario (véase el capítulo VII de este libro). Muchos países han optado por estrategias de autoseguro, mediante la acumulación y desacumulación de reservas. Por otra parte, si el choque es permanente, lo más importante es evitar la enfermedad holandesa. A ese efecto es clave la coordinación pero, en este caso, con la política de desarrollo productivo. 
En quinto lugar, dado que ni las reservas de recursos naturales en poder del sector público ni la reserva de capital se consideran en las evaluaciones de sostenibilidad, aunque sí se computan los fondos de estabilización y los soberanos, esto puede sesgar la asignación del espacio fiscal hacia la inversión financiera. Ello sucede en la medida en que se perciba que un fondo soberano, por ejemplo, rinde beneficios monetarios al sector público mientras que la inversión en infraestructura puede no hacerlo. Collier y otros (2009) han llamado la atención sobre este sesgo. Cuando el capital es escaso, como sucede en la región, y el sistema financiero no es avanzado, la tasa de rentabilidad de la inversión productiva puede ser más alta que el rendimiento de un fondo. Por ese motivo es conveniente asignar una parte mayor del espacio fiscal a la inversión.

En sexto lugar, el gobierno podría asignar el espacio fiscal de forma de mantener su riqueza constante: $\Delta W_{t}^{\prime G}=0$. A partir de la ecuación (3) se deduce que el gobierno podría cumplir ese objetivo y, aun así, desahorrar por un monto igual a la ganancia de capital que se estuviera obteniendo mediante la valorización de la riqueza existente bajo el suelo: $S_{t}^{\prime G}=-\Delta p_{t} Q_{t-1}^{G}$. Los recursos naturales consumidos. no se repondrían totalmente como exige el criterio de Hartwick, pues: $\Delta K_{t}^{G}+\Delta A_{t+1}^{G}-\Delta B_{t}^{G}=E_{t}^{G}-\Delta p_{t} Q_{t-1}^{G}$. Por supuesto, esta es una forma parcial de ver la cuestión. Para evaluar el criterio hay que tener en cuenta toda la economía, pero aquí se desea subrayar las implicancias para el espacio fiscal. Lo importante es que el mercado podría empezar a dudar de la sostenibilidad debido al desahorro, cuando en realidad la riqueza no varía.

En séptimo lugar, cuando el gobierno deja los recursos naturales bajo tierra, se comporta como un capitalista que ahorra el $100 \%$ de sus ingresos. Si la renta extraída se invierte en capital reproducible o un fondo, la riqueza sigue creciendo a la tasa $r$. No obstante, dado que el sector público no tiene por qué comportarse de ese modo, la pregunta es cómo se deberían asignar los fondos. En los modelos teóricos este problema no es relevante, porque siempre se invierte o se consume de forma óptima. Sin embargo, cuando no hay flexibilidad para decidir debido a presiones de economía política, puede ocurrir que la forma en que se asignan los fondos dependa de si el recurso se extrae o no.

Como se explicó, un gobierno podría tratar de no extraer los recursos naturales a fin de evitar que en una bonanza estos se dilapiden en consumo. Hay que recordar, no obstante, que en la variable $E_{t}^{G}$ se han agregado todas las formas de captación de rentas. Cada forma (empresas públicas, impuestos, regalías o contratos) brinda incentivos de extracción diferentes, por lo que las posibilidades de asignar fondos pueden depender en gran medida de la flexibilidad que brinde el marco institucional y de gobernanza para moldear los incentivos de extracción. Vista desde esta perspectiva, la regla de Hartwick es menos neutral de lo que parece. El 
nivel de consumo de recursos puede quedar en función de a qué ritmo, no necesariamente óptimo, se extraen los recursos de la tierra.

Por último, cabe tener en cuenta que lo que importa en el desarrollo sostenible es la riqueza per cápita, por lo que es necesario corregir la ecuación (3). Si las variables per cápita se denotan con letras minúsculas y con $n$ la tasa de crecimiento de la población, la ecuación de variación de riqueza se transforma en:

$$
\begin{aligned}
& \Delta w_{t}^{\prime G}=s_{t}^{G}+\Delta p_{t} \frac{q_{t-1}^{G}}{1+n}=\Delta k_{t}^{G}+\Delta a_{t}^{G}-\Delta b_{t}^{G}+p_{t} \Delta q_{t}^{G}+\frac{n}{1+n} \\
& \left(k_{t-1}^{G}+a_{t-1}^{G}-b_{t}^{G}+p_{t} r_{t-1}^{q G}\right)+\Delta p_{t} \frac{r_{t-1}^{q G}}{1+n}
\end{aligned}
$$

La diferencia central es que, para mantener constante la riqueza per cápita, hay que agregar el monto $\frac{n}{1+n}\left(k_{t-1}^{G}+a_{t-1}^{G}+p_{t} r_{t-1}^{q G}\right)$ de ahorro a fin de proveer de riqueza a los habitantes que se van agregando a la población año a año. Aquí surge un factor importante desde el punto de vista de la asignación del espacio fiscal en el contexto de la transición demográfica: en el caso de sociedades jóvenes o que están cursando el bono, el ritmo al que hay que agregar riqueza es mayor debido a que la tasa de crecimiento poblacional también lo es (Fanelli, 2015). En estas condiciones, ¿qué monto $h^{G}$ podría consumir por año el sector público y, aun así, mantener la riqueza per cápita constante en el nivel $w^{*}$ ? Ese monto sería:

$$
h^{G}=\frac{r-n}{1+n} w^{*}
$$

O sea, que se podría consumir a partir de la diferencia entre la tasa de interés y la tasa de crecimiento de la población, multiplicada por el nivel de riqueza deseado. Es más, si no se hiciera esto y se ahorraran todos los beneficios de la riqueza en un contexto en que el ingreso per cápita estuviese constante, la riqueza pública crecería por encima de la tasa de crecimiento $(g)$ al ritmo $(r-g)$. Como resultado, en lugar de ser los capitalistas cada vez más ricos, lo sería el Estado. Sería una forma poco atractiva de asignar el espacio fiscal.

\section{Conclusiones}

Se ha presentado un marco conceptual con el fin de organizar el análisis de los factores que inciden sobre la asignación del espacio fiscal. Se argumenta que el desafío consiste en transformar la renta en capital productivo y se evalúan indicadores tradicionales que apuntan a esta meta, como el ahorro genuino y la regla de Hartwick. El enfoque de espacio fiscal utilizado incluye la consideración del contexto estructural e institucional, porque al evaluar la asignación es necesario tener presentes tres aspectos: i) que la región necesita impulsar un cambio estructural que mejore la inclusión y la dinámica 
de crecimiento; ii) que la volatilidad con origen en los recursos naturales se transmite a la macroeconomía, porque las cuentas fiscales y externas dependen de los ingresos de recursos naturales, y iii) que hay debilidades institucionales y de gobernanza que pueden hacer que la abundancia de rentas devenga en una maldición. Como parte del marco conceptual, se definen tres propiedades del espacio fiscal (la sostenibilidad, la estabilidad y la flexibilidad) que inciden directamente sobre los grados de libertad para tomar decisiones de asignación y se utilizan como referencia analítica. Sobre esa base se puede llegar a las siguientes conclusiones principales.

Una ventaja relevante que posee el enfoque del espacio fiscal es que, al obligar a realizar un análisis conjunto de los recursos asignados a diferentes objetivos, resulta útil para determinar las fallas de coordinación entre políticas y pone de relieve la necesidad de estudiar los problemas de gobernanza que provocan la descoordinación. Dado que la gobernanza se entiende como el ejercicio de la autoridad en las interacciones entre las organizaciones, las políticas y los agentes económicos (todos con intereses particulares que tal vez no estén alineados con el objetivo fundamental de transformar rentas en capital), la economía política y las instituciones entran naturalmente en el análisis como determinantes de los grados de libertad y de la calidad de las decisiones de asignación. A este respecto, sobre la base de la amplísima bibliografía relativa a la maldición de los recursos, cabe considerar que el concepto de espacio fiscal puede servir para sistematizarla.

Las fallas de coordinación entre políticas pueden erosionar la sostenibilidad, incluso en el marco de una bonanza, cuando la asignación del espacio fiscal se gestiona de manera descentralizada. Por lo tanto, es necesario asegurar la coordinación entre la política fiscal y la monetaria. En un contexto volátil y de gobernanza complicada como el de las economías dependientes de los recursos naturales, es difícil tener la flexibilidad suficiente para adaptarse a cambios bruscos de precios. Por ello el régimen monetario, la formación de fondos anticíclicos y el diseño del régimen macroeconómico en general no pueden divorciarse del análisis de la asignación del espacio fiscal.

También se concluye que contar con información rutinaria sobre la riqueza en la hoja de balance del gobierno es importante para el diseño de políticas de promoción de la estabilidad en un país rico en recursos naturales no renovables. La razón es que las variaciones de los precios de los recursos apalancan sus efectos por la vía tanto de los flujos como de las reservas, lo que alimenta la volatilidad macroeconómica. La variación en el valor de las reservas puede aumentar la prociclicidad de los movimientos de capital al cambiar el valor del colateral. De este modo se aumenta la inestabilidad financiera y la probabilidad de cometer errores al asignar el espacio fiscal. Los esfuerzos para registrar correctamente las reservas en la hoja de balance deben incluir también el capital productivo que posee el 
Estado. Una buena medición de las reservas permitiría que las ganancias de capital entraran en el cuadro a la hora de tomar decisiones sobre asignación de ingresos por renta, sea al consumo o a la inversión. Además, haría más visible el efecto positivo de la inversión pública sobre la riqueza.

Cuando se considera por separado la hoja de balance pública, se concluye que tratar de adaptarse sin más a la regla de Hartwick o al criterio del ahorro genuino puede tener consecuencias colaterales en el plano de la distribución de la riqueza entre el Estado y los particulares. Estudiar los problemas distributivos que genera la variación del precio de los recursos naturales podría ser útil para diseñar políticas de redistribución que no operen mediante subsidios ineficientes, por ejemplo, al consumo de energía. Reducir la intensidad de los conflictos relacionados con la captación de rentas por medio de arreglos institucionales creíbles es crítico para mejorar la gobernanza.

Si la economía es excesivamente dependiente de un solo recurso y experimenta un choque negativo, es probable que buena parte del ajuste recaiga sobre la inversión pública, sobre todo en infraestructura. En un contexto así, asegurar la sostenibilidad a largo plazo y la estabilidad macroeconómica a corto plazo tiene la ventaja de que, cuando no existe probabilidad de una crisis macroeconómica o de problemas financieros con la deuda pública, las autoridades tendrán mayor flexibilidad para responder a los choques y reasignar a la inversión pública el espacio fiscal creado por los recursos naturales. Esta decisión puede ser muy rentable desde el punto de vista social si la tasa de rentabilidad de la inversión es muy superior a la tasa de un fondo soberano o a la pagada por la deuda. Sin embargo, si la capacidad de absorción de la economía es baja, es posible que la economía experimente lo que se conoce como enfermedad holandesa. Por ese motivo podrían ser de utilidad los fondos de estacionamiento de rentas transitorios (Van der Ploeg, 2011).

No obstante, los proyectos de inversión de alta rentabilidad podrían estar en el ámbito privado y no en el público en una economía en que el sector público fuese el que capta la renta en gran medida. Como se trata de una situación que no es improbable, habría que analizar mecanismos de gobernanza confiables que permitieran asignar de forma eficiente las rentas fiscales al sector privado. El fondo soberano típico realiza préstamos en el exterior. Con todo, podría ocurrir que la tasa de interés libre de riesgo fuese muy inferior al rendimiento de los proyectos del sector privado local. ¿Cómo serían los instrumentos y la gobernanza de asignaciones de este tipo? Es una pregunta que merece más investigación. Un mayor desarrollo financiero seguramente ayudaría en este sentido.

Algo similar puede argumentarse en lo que respecta a los Estados federales. Cuando estos captan las rentas por ser dueños de los recursos, por razones de economía política tienden a invertir en su propio territorio. 
Esto es particularmente válido con relación a la infraestructura. Cuando esto ocurre, tal vez sea mejor posponer la inversión. Sin embargo, habría que desarrollar mecanismos de gobernanza para que un Estado federal le pueda prestar a otro, de forma de no estar obligado necesariamente a invertir en su propio territorio. Lo mismo puede ocurrir con las empresas públicas que tienen un interés creado en reinvertir utilidades en el negocio, pero muchas veces no deben someterse a la disciplina del mercado.

Por supuesto, algunos mecanismos van en contra de esta tendencia. Los Estados federales invierten a través del sistema financiero y en la región hay empresas de propiedad mixta, lo que resta importancia a este problema. No obstante, es preciso recalcar que todas estas cuestiones deberían concebirse como parte del mismo problema: cómo desarrollar instrumentos para asignar eficientemente el espacio fiscal tomado como un todo, cuando hay pluralidad de nodos de decisión.

\section{Bibliografía}

Altomonte, H. y R. J. Sánchez (2016), Hacia una nueva gobernanza de los recursos naturales, Libros de la CEPAL, No 139 (LC/G.2679-P), Santiago, Comisión Económica para América Latina y el Caribe (CEPAL).

Banco Mundial (2011), The Changing Wealth of Nations: Measuring Sustainable Development in the New Millennium, Washington, D.C.

Baunsgaard, T. y otros (2012), "Fiscal frameworks for resource rich developing countries", IMF Staff Discussion Note, $\mathrm{N}^{\circ}$ SDN/12/04, Washington, D.C., Fondo Monetario Internacional (FMI).

Collier, P. y otros (2009), "Managing resources revenues in developing economies", OxCarre Research Paper, $\mathrm{N}^{\circ}$ 15, Oxford, Oxford Centre for the Analysis of Resource Rich Economies.

Dasgupta, P., R. Eastwood y G. Heal (1978), "Resource management in a trading economy", The Quarterly Journal of Economics, vol. 92, N², Oxford, Oxford University Press, mayo.

Di Bella, G. y otros (2015), "Energy subsidies in Latin America and the Caribbean: stocktaking and policy challenges", IMF Working Paper, $\mathrm{N}^{\circ} \mathrm{WP} / 15 / 30$, Washington, D.C., Fondo Monetario Internacional (FMI).

Escolano, J. (2010), "A practical guide to public debt dynamics, fiscal sustainability, and cyclical adjustment of budgetary aggregates", Technical Notes and Manuals, $\mathrm{N}^{\circ} \mathrm{TNM} / 10 / 02$, Washington, D.C., Fondo Monetario Internacional (FMI).

Fanelli, J. M. (2015), Asymmetric Demography and the Global Economy: On Growth Opportunities and Macroeconomic Challenges in an Aging World, Nueva York, Palgrave Macmillan.

(2009), "Volatilidad, ciclo y política fiscal en América Latina", Estudios Temáticos, Madrid, EUROsociAL Fiscalidad.

Fanelli, J.M., J.P. Jiménez e I. López Azcúnaga (2015), “La reforma fiscal ambiental en América Latina", Documento de Proyecto (LC/W.683), Santiago, Comisión Económica para América Latina y el Caribe (CEPAL). 
FMI (Fondo Monetario Internacional) (2015), “The commodities roller coaster: a fiscal framework for uncertain times", Fiscal Monitor, Washington, D.C., octubre. (2012), "Regímenes fiscales de las industrias extractivas: diseño y aplicación" [en línea] https:/ / www.imf.org/external/spanish/np/pp/2012/081512s.pdf.

FMI (Fondo Monetario Internacional)/Banco Mundial (2006), Fiscal Policy for Growth and Development: An Interim Report (DC2006-0003), Washington, D.C., abril.

Hamilton, K. (2008), "Wealth, saving and sustainability", Washington, D.C., Departamento del Medio Ambiente del Banco Mundial.

Hamilton, K. y R. Hassan (2003), "Measuring development prospects by greening the national accounts", Working Paper Series, N 45, Nueva York, Iniciativa para el Diálogo de Políticas Públicas [en línea] http:/ / academiccommons.columbia. edu/item/ac:126628.

Hartwick, J.M. (1977), "Intergenerational equity and the investing of rents from exhaustible resources", The American Economic Review, vol. 67, N 5, Nashville, Tennessee, American Economic Association.

Heller, P.S. (2005), "Understanding fiscal space", IMF Policy Discussion Paper, $\mathrm{N}^{\circ} \mathrm{PDP} / 05 / 4$, Washington, D.C., Fondo Monetario Internacional (FMI).

Hotelling, H. (1931), "The economics of exhaustible resources", The Journal of Political Economy, vol. 39, N², Chicago, The University of Chicago Press.

Karp, L. (2017), Natural Resources as Capital, Cambridge, Massachusetts, The MIT Press.

Lange, G.M., Q. Wodon y K. Carey (eds.) (2018), The Changing Wealth of Nations 2018: Building a Sustainable Future, Washington, D.C., Banco Mundial.

Naciones Unidas (2015), “Transformar nuestro mundo: la Agenda 2030 para el desarrollo sostenible" (A/RES/70/1) [en línea] https://undocs.org/es/A/RES/70/1. (1987), Informe de la Comisión Mundial sobre el Medio Ambiente y el Desarrollo: Nuestro Futuro Común (A/42/427), Nueva York.

Neumayer, E. (2010), Weak versus Strong Sustainability: Exploring the Limits of Two Opposing Paradigms, Northampton, Massachusetts, Edward Elgar Publishing.

Ossowski, R. y H. Halland (2016), Fiscal Management in Resource-Rich Countries: Essentials for Economists, Public Finance Professionals, and Policy Makers, Washington, D.C., Banco Mundial.

Rathin, R. y A. Heuty (2009), Fiscal Space: Policy Options for Financing Human Development, Londres, Earthscan.

Rathin, R., A. Heuty y E. Lethouzé (2007), "Fiscal space for what?: analytical issues from a human development perspective" [en línea] http://www.undp.org/ content/dam/aplaws/publication/en/publications/poverty-reduction/ poverty-website/fiscal-space-for-what/FiscalSpaceforWhat.pdf.

Reisen, H. (2008), "How to spend it: commodity and non-commodity sovereign wealth funds", Policy Brief, $\mathrm{N}^{\circ}$ 38, París, Organización de Cooperación y Desarrollo Económicos (OCDE).

Smith, J.L. (2012), "Issues in extractive resource taxation: a review of research methods and models", IMF Working Paper, N ${ }^{\circ}$ WP/12/287, Washington, D.C., Fondo Monetario Internacional (FMI).

Van der Ploeg, F. (2011), "Natural resources: curse or blessing?", Journal of Economic Literature, vol. 49, $\mathrm{N}^{\circ}$ 2, Nashville, Tennessee, American Economic Association. 

Capítulo XIV

\section{Implementación, adaptación y funcionamiento de los fondos soberanos de inversión}

Miryam Saade Hazin

Daniel Sotelsek Salem

Durante siglos, la relación entre recursos naturales y bienestar ha sido objeto de grandes debates entre economistas y fisiócratas. A partir de la era clásica, se manifestó un problema que hoy sigue presente y se refiere a la disputa por la captación de rentas (rent seeking) de los recursos naturales, como en el caso de los hidrocarburos y los minerales. La Revolución Industrial también supuso una mayor explotación de recursos naturales (por ejemplo, el carbón y la madera) como fuentes de energía. A su vez, las contiendas mundiales del siglo XX y los años posteriores provocaron un incremento del comercio de materias primas, de los transportes y de la construcción de infraestructuras. Todo ello ha tenido una clara conexión con un aumento sostenido de la demanda de recursos naturales y de la energía necesaria para economías en constante crecimiento.

A partir de los años cincuenta del siglo pasado, un grupo de economistas vinculados a la economía del desarrollo pusieron en el centro de la agenda la importancia de los recursos naturales. Este fue el caso de la hipótesis de Prebisch y Singer sobre el deterioro de los términos de intercambio 1 . Otro tanto sucedió con la propuesta de Rosenstein-Rodan sobre el gran impulso (Big Push). Estas y otras teorías ponían de relieve

Esto ha dado lugar al estudio detallado de los superciclos de los precios de los productos básicos. Las evidencias son variadas y, sin duda, los retardos en la reacción de la oferta ante incrementos de la demanda indican que la muestra y los períodos elegidos determinan si se cumple la hipótesis de Prebisch y Singer. 
la clara relación existente entre el desarrollo económico y los recursos naturales ${ }^{2}$. Hasta ese momento, no se habían tomado en consideración los problemas que vinculaban la gestión de los recursos naturales no renovables con la sostenibilidad (equidad entre generaciones) y la existencia del fenómeno conocido como la "enfermedad holandesa". En lugar de ello, las propuestas tenían en cuenta la restricción de divisas como un escollo fundamental para el desarrollo de las economías. Lo que se intentaba mediante la aplicación de modelos como el de las dos brechas de McKinnon era compatibilizar el ahorro interno con el externo, cuyo flujo (sobre todo en los países de menor desarrollo) provenía, fundamentalmente, de la explotación de recursos naturales tanto renovables como no renovables.

El objetivo de este capítulo es evaluar uno de los instrumentos que en los últimos años se ha impuesto con fuerza para canalizar ese ahorro por parte del Estado: los fondos soberanos de inversión (FSI) que, en 2017, según estimaciones del Sovereign Wealth Fund Institute (SWFI), alcanzaron 8,3 billones de dólares (cifra que asciende a 12,5 billones de dólares si se tienen en cuenta los fondos de pensiones). Ello indica la importancia de estudiar y analizar en profundidad un instrumento derivado, entre otras fuentes, de los beneficios de la naturaleza. Además de constituir un FSI que cumpla con determinados objetivos y permita administrar y utilizar las rentas, provenientes de los recursos naturales no renovables en este caso particular, se debe ir más allá y tratar de adoptar una estructura de reglas fiscales y presupuestarias que contribuyan a la gobernanza adecuada y eficiente de los recursos naturales no renovables. Esa ha sido la propuesta de la Comisión Económica para América Latina y el Caribe (CEPAL), basada en un verdadero desarrollo sostenible (CEPAL, 2014; Altomonte y Sánchez, 2016).

\section{A. Antecedentes y definición de los fondos soberanos de inversión}

El caso de Nauru, una isla del Pacífico meridional, es quizás uno de los ejemplos más utilizados para exponer la llamada maldición de los recursos naturales ${ }^{3}$. Durante la década de 1970, después de haber sido una de las economías más pobres a nivel mundial, Nauru se convirtió en una de las más ricas, gracias a la explotación de los fosfatos. No obstante, la sobreexplotación y el consecuente agotamiento de dicho recurso, aunados a

A dichos autores habría que agregar muchos más economistas del desarrollo que propusieron teorías y medidas de política que relacionaban la posibilidad de que las economías subdesarrolladas, mediante una buena gestión de sus recursos naturales, ayudaran a dinamizar el proceso de desarrollo.

3 Richard Auty introdujo en 1993 el concepto de la maldición de los recursos naturales. Este término se utiliza para indicar que los países que cuentan con dichos recursos en abundancia exhiben menores tasas de crecimiento económico que los que carecen de ellos. 
una mala gestión de las excepcionales ganancias percibidas durante varios años, desencadenaron la reversión del país a su situación de pobreza inicial ${ }^{4}$. Autores como Bauer (2014) han señalado que la experiencia de Nauru motivó a otros países a crear diversos fondos soberanos de inversión que buscan una adecuada gestión de los recursos naturales no renovables. Si Nauru hubiera implementado un fondo soberano en su momento, es muy probable que hoy la historia fuera diferente.

Antes de hacer una evaluación de los fondos soberanos de inversión (FSI), es necesario comenzar por definirlos y caracterizarlos. Si bien no hay un acuerdo unánime sobre la definición, al parecer se acepta que los FSI son un grupo muy heterogéneo, cuya clasificación siempre presenta excepciones. Al respecto se puede establecer una primera diferencia entre los FSI si se analizan variables como la organización (separada y no separada del gobierno), los objetivos de inversión (preservar la riqueza o diversificarla y hacerla crecer), el grado de transparencia (alto grado u opacidad en los datos) y la compensación a los gestores (incentivos o salarios fijos). Frente a dichas diferencias, no es nada sencillo encontrar una definición sobre los FSI, ya que no se sabe demasiado de este grupo de inversores institucionales. Si bien los FSI han hecho un esfuerzo importante con miras a aumentar la transparencia de sus inversiones, todavía deja mucho que desear la información disponible sobre el flujo de ingresos, así como sobre la rentabilidad y estrategia de las carteras.

Uno de los primeros en definir el término de fondo soberano de inversión fue Rozanov (2005). Más adelante, el FMI (2008) y el Tesoro de los Estados Unidos se preocuparon por la forma de centrar la definición y caracterizar los FSI. Durante la reunión del Grupo Internacional de Trabajo sobre Fondos Soberanos de Inversión, que tuvo lugar en Santiago de Chile en septiembre de 2008, emanaron los Principios de Santiago ${ }^{5}$. En ellos se definieron los fondos soberanos de inversión como estructuras de inversión para un propósito específico, cuya propiedad corresponde al gobierno general (Gobierno central y subnacional). Se puede decir que este tipo de fondos fue creado por el gobierno general con fines macroeconómicos: mantener, gestionar y administrar los activos con miras a alcanzar objetivos financieros y emplear una serie de estrategias que incluyeran la inversión en activos financieros extranjeros (FMI, 2008). En sentido general, los FSI se nutren de las rentas de explotación, así como de otras fuentes complementarias, entre las que se encuentran los superávits

4 De acuerdo con Bauer (2014), entre 1973 y 2007 el PIB de Nauru se redujo de 178 millones de dólares (25.500 dólares per cápita en dólares de 2005) a 19 millones de dólares (1.900 dólares per cápita), respectivamente.

5 Los Principios de Santiago son 24, algunos de los cuales incluyen subprincipios. Los 24 principios voluntarios están clasificados en tres tipos de estándares: i) marco legal, objetivos y coordinación con las políticas macroeconómicas; ii) marco institucional y estructura de gobierno, y iii) marco de gestión del riesgo y de la inversión. 
de la balanza de pagos, de bienes agrícolas, o de cualquier fuente de ahorro del presupuesto público. Ese puede ser el caso de los fondos de pensiones (definidos en una primera instancia como FSI con pasivos contingentes), las privatizaciones, entre otros.

Con el ánimo de colaborar y aportar claridad al mundo de los FSI, el Fondo Monetario Internacional (FMI) (2008) hizo un esfuerzo por ajustar las categorías de los fondos según su objetivo. Así, los clasifica en:

- Fondos de estabilización, cuyo principal objetivo es aislar el presupuesto y la economía de los efectos de la volatilidad, sobre todo cuando se habla de las variaciones del precio de las materias primas. Este tipo de fondos está compuesto por inversiones de corto plazo, es decir, activos líquidos y de bajo nivel de riesgo (por ejemplo, el Fondo Mexicano del Petróleo para la Estabilización y el Desarrollo (FMP) y el Fondo de Estabilización Económica y Social (FEES) de Chile).

- Fondos de ahorro, cuyo objetivo es distribuir la riqueza del país de modo que también se beneficien las futuras generaciones, mediante la transformación de recursos naturales no renovables en activos financieros. La inversión en estos fondos es a largo plazo y la composición de sus activos puede llegar a ser muy diversa y de alto riesgo, ya que en general se asigna más del 70\% de los activos a acciones y otras inversiones (por ejemplo, el Fondo de la Abu Dhabi Investment Authority de los Emiratos Árabes Unidos y el Fondo de ahorro patrimonial de la región de Alberta en el Canadá). El Fondo de estabilización patrimonial de Trinidad y Tabago, por su parte, tiene un doble objetivo: servir como estabilizador macroeconómico y como fondo de ahorro para futuras generaciones.

- Fondos de reservas para inversiones, cuyo objetivo es utilizar los excesos de las reservas internacionales de los bancos centrales en activos de mayor riesgo y obtener alguna rentabilidad adicional (por ejemplo, la Corporación de Inversiones de China (CIC) o la Corporación de Inversiones del Gobierno de Singapur (GIC)).

- Fondos de desarrollo, cuyo principal objetivo es invertir los recursos en proyectos de desarrollo social y de promoción industrial para mejorar el crecimiento del país (por ejemplo, Mubadala (Emiratos Árabes Unidos) y Khazanah (Malasia)).

- Fondos de pensiones, que son fondos de pasivos contingentes sobre determinados individuos en un momento del tiempo. Estos se diferencian de los FSI en que tienen un flujo de pasivos. En realidad los FSI también podrían considerarse de la misma forma, solo que en este caso el pasivo está determinado por los activos ambientales que se deberían sustituir; (por ejemplo, The New Zealand Superannuation Fund y el Fondo de futuros de Australia). 
Puede decirse que hubo dos situaciones que influyeron en esta oleada de FSI: la primera se refiere a la importante acumulación de reservas internacionales por parte de los países después de la crisis asiática de 1997. De acuerdo con el Banco Mundial, en 2012 esas reservas llegaron a los 12,5 billones de dólares. La segunda se refiere al auge de los precios de las materias primas.

Hay 102 fondos (74 FSI y 28 fondos de pensiones) que forman parte de la comunidad de inversores que suelen reunirse para analizar distintos asuntos (véase el cuadro XVI.1). En un inicio los FSI estaban vinculados a los productos básicos. Hoy en día esa proporción, de acuerdo con el SWFI (2017), es de un 56,6\% de fondos financiados por petróleo y gas. El 43,4\% restante corresponde a minería y otros tipos de actividades no relacionadas con los recursos naturales (SWFI, 2017). Entre 2010 y 2016, los activos de los FSI aumentaron de 4,4 billones a 7,5 billones de dólares $y$, si se suman los fondos de pensiones, el total alcanza los 12 billones de dólares (véase el cuadro XIV.1).

Cuadro XIV.1

Fondos soberanos de inversión (FSI) y fondos de pensiones

\begin{tabular}{|c|c|c|c|c|c|}
\hline & $\begin{array}{l}\text { Número de } \\
\text { fondos }\end{array}$ & $\begin{array}{c}\text { Porcentaje } \\
\text { del total }\end{array}$ & $\begin{array}{l}\text { Activos } \\
\text { (en millones } \\
\text { de dólares) }\end{array}$ & $\begin{array}{l}\text { Porcentaje } \\
\text { del total }\end{array}$ & $\begin{array}{c}\text { Promedio de activos } \\
\text { (en miles de millones } \\
\text { de dólares) }\end{array}$ \\
\hline FSI totales ${ }^{a}$ & 74 & 100 & 7704 & 100 & 104 \\
\hline $\begin{array}{l}\text { Fundados antes } \\
\text { de } 2000\end{array}$ & 21 & 28 & 5462 & 71 & 260 \\
\hline Fundados desde 2000 & 53 & 72 & 2242 & 29 & 42 \\
\hline Fundados desde 2005 & 40 & 54 & 1545 & 20 & 39 \\
\hline $\begin{array}{l}\text { FSI y fondos de } \\
\text { pensiones totales }\end{array}$ & 102 & 100 & 12033 & 100 & 118 \\
\hline $\begin{array}{l}\text { Fundados antes } \\
\text { de } 2000\end{array}$ & 42 & 41 & 8236 & 68 & 196 \\
\hline Fundados desde 2000 & 60 & 59 & 3797 & 32 & 63 \\
\hline Fundados desde 2005 & 43 & 42 & 2924 & 24 & 68 \\
\hline
\end{tabular}

Fuente: S. E. Kalb, "Sovereign wealth fund in the global capital markets: reintermediation and new collaborative models", CFA Institute Conference Proceedings Quarterly, vol. 32, № 4, CFA Institute, 2015.

a Excluye datos de los $22 \mathrm{FSI}$ de los Estados Unidos.

b Se basa en 28 fondos de pensiones y 74 FSI, y excluye los FSI de los Estados Unidos.

En realidad, a excepción del FSI de Noruega (que es un caso paradigmático por su organización e institucionalidad pero, sobre todo, por su magnitud), estos vehículos han tenido su origen en países emergentes durante la segunda mitad del siglo XX. En muchos casos se han establecido con fondos provenientes de la extracción de los recursos naturales. Uno de los más antiguos es el de Kuwait. A estos se suman, como buenos ejemplos, los fondos de la Arabia Saudita, China, los Emiratos Árabes Unidos y 
Singapur, en los que los recursos naturales constituyen cerca del $80 \%$ de los activos (Capapé, 2017) ${ }^{6}$.

En cuanto a su aceptación, cabe mencionar que antes de la crisis financiera de 2008-2009, los FSI alimentaban un apetito que resultaba excesivo para muchos Gobiernos europeos. Esto se debía al afán por invertir en países de la Organización de Cooperación y Desarrollo Económicos (OCDE), que se fue ampliando a países emergentes. Hasta ese momento la opinión no era muy positiva y se veían esas inversiones como una intromisión proveniente del extranjero. La situación dio un giro importante durante la crisis financiera mundial de 2008 y 2009, con el papel protagónico que jugó este tipo de fondos en el alivio financiero de algunos bancos europeos y en particular, estadounidenses, que presentaban serios problemas de liquidez. Tal fue el caso de entidades como Citigroup, Morgan Stanley, Merril Lynch, entre otras (Beck y Fidora, 2008; Gomes, 2008).

Si bien los FSI tienen una vocación de largo plazo y de coadyuvar al desarrollo sostenible, lo cierto es que las distintas dimensiones de la sostenibilidad (social, ambiental y económica) han marcado diferencias importantes en cuanto a los objetivos de esos fondos. Por una parte, están los que apuestan por el uso de los ahorros para mantener estables las economías. Por otra, los que tienen una clara vocación de largo plazo, sea mediante inversiones financieras (fondos de ahorros) o inversiones directas (fondos de desarrollo).

Una forma de determinar si los fondos son o no de estabilización a efectos de los balances fiscales tiene que ver con la liquidez de sus inversiones (deuda o depósitos) y el riesgo asumido más allá de lo que pueden indicar sus objetivos. No obstante, se plantean algunas interrogantes: ¿cómo debe ser el riesgo de los activos que asume? ¿Acaso los activos deben estar libres de riesgo? Aún más, ¿existen estos activos? Por ejemplo, el Fondo de Reserva de la Federación de Rusia, el Fondo de Regulación de Argelia o el Fondo de Estabilización Económico y Social (FEES) de Chile, entre otros, son meramente fondos de estabilización. Sin embargo, en sus carteras no hay activos libres de riesgos. Tampoco poseen liquidez absoluta y su comportamiento respecto a las categorías de bonos soberanos ha ido cambiando en los últimos años, a partir de las modificaciones de la regulación internacional y las normas de Basilea III.

Respecto a los pasivos provenientes de pensiones o jubilaciones, se puede decir que existe consenso, sobre todo en lo que se refiere a diferenciar los FSI de los fondos de pensiones públicos (FPP). No obstante, hay algunos

\footnotetext{
En esta lista, los tres FSI dependientes de recursos naturales más importantes y que en 2017 suman aproximadamente el 30\% son el Government Pension Fund Global (Noruega), con un total de activos de 954.000 millones de dólares; en segundo lugar, el FSI de Abu Dhabi, con 828.000 millones de dólares y, en tercer lugar, el FSI de Kuwait, con 524.000 millones de dólares.
} 
matices que se deben tener en cuenta ya que, en algunos casos, dentro del activo de los FSI se encuentran inversiones en los FPP. Estos se denominan fondos de reservas contingentes de pensiones, que sí podrían incluirse en la definición de FSI7.

También hay que tener en cuenta que algunos FSI de desarrollo y de equidad entre generaciones tienen implícitamente una deuda pendiente con las generaciones futuras, en el marco de un contrato social. Este aspecto genera mucha controversia en el margen, por lo que la consideración de FSI que tengan algún tipo de pasivo debería abordarse caso por caso (Monk, 2008). Es evidente la gran heterogeneidad de objetivos que han mostrado los distintos FSI a nivel mundial. En la sección siguiente se analizan los FSI, desde el punto de vista estrictamente financiero, con el fin de evaluar su rentabilidad y sus riesgos.

\section{B. Apertura de los fondos soberanos de inversión a nuevas carteras}

Cuando se habla del bienestar de la sociedad, tanto presente como futuro, es necesario considerar una dicotomía que se presenta a la hora de definir cómo esta invierte. Por una parte están los FSI en sentido amplio, que han crecido de forma considerable $y$, por otra, las necesidades en materia de inversión en infraestructura en los países menos desarrollados, las cuales han crecido mucho más debido a que no se ha reducido la brecha. Según las estimaciones más optimistas, para mantener la tasa de crecimiento del producto interno bruto (PIB) mundial hasta 2030 se necesitaría una inversión en infraestructura cercana a los 57 billones de dólares, lo que representa un incremento del $60 \%$ respecto a las décadas anteriores (Dobbs y otros, 2013). En el caso de América Latina, de acuerdo a un estudio realizado por Sánchez y otros (2017), la inversión total en infraestructura, medida como porcentaje del PIB, alcanzó una media anual de un 2,2\% entre 2000 y 2015. Esta cifra está muy por debajo de las necesidades de inversión estimadas (entre un 3,7\% y un 7,4\%, de acuerdo a los escenarios proyectados sobre la evolución del PIB regional) para alcanzar la cobertura universal de los servicios básicos de infraestructura y responder al crecimiento económico y poblacional.

En un inicio, los FSI no fueron diseñados para apoyar las infraestructuras de los países. No obstante, con el paso del tiempo y sobre todo debido al carácter urgente de la creación y modernización de las infraestructuras en muchos países de menor desarrollo, se han utilizado

Se puede decir que el Australian Future Fund o el New Zealand Superannuation Fund son fondos contingentes asimilables a los FSI, mientras que otros, como el Fondo de Inversión de Pensiones del Gobierno de Japón, que en 2017 mantuvo activos por 1,3 billones de dólares, no se incluyen en esta definición. 
con ese fin los recursos de algunos FSI. Su justificación principal consiste en crear las condiciones para lograr una mejora en el desarrollo económico y social. En este sentido, se puede tomar en cuenta la experiencia de países de desarrollo medio, como es el caso de Kazajstán y Liberia.

Hasta hace poco, la hipótesis del ingreso permanente guiaba la gestión de los FSI como el de Noruega: la idea consiste en limitar el gasto de los beneficios de los recursos a la cantidad equivalente del interés devengado y el valor presente neto de la riqueza, mientras que el resto se ahorraba para las generaciones futuras en activos externos. Actualmente existen varios trabajos que consideran que la HRP no tiene sentido en los países de menor desarrollo, debido a la escasez de capital y falta de acceso a los mercados. En estas circunstancias, la inversión en infraestructura social, por ejemplo, en la educación y la salud, parece tener prioridad debido a la alta rentabilidad que ofrece.

Entre las elecciones posibles se encuentra la alternativa de que los FSI diversifiquen sus activos mediante la inversión en las necesidades de infraestructura de los países. Hay que tener en cuenta que esta decisión, además de afectar los temas tradicionales relacionados con los movimientos de los tipos de cambio y la estabilidad fiscal, modifica las decisiones de gasto público en un sentido amplio. Las infraestructuras presentan un doble dividendo: por un parte constituyen una inversión (consumo futuro) que beneficia no solo a las generaciones presentes sino a las futuras. Por otra, la elección de proyectos específicos permite tener en la determinación del gasto una flexibilidad que no es posible (sobre todo teniendo en cuenta el ciclo político) cuando los recursos se destinan al gasto corriente. Junto a ello, hay que mencionar que la volatilidad tanto de los ingresos como de los gastos influye negativamente en las expectativas y la previsibilidad de las inversiones.

Para dedicar parte de los fondos a infraestructuras se debe tener en cuenta la capacidad interna en materia de recursos con miras a gestionar e implementar proyectos de gran envergadura. También se debe procurar una gestión de los riesgos específica y distinta a la que se aplica a los proyectos de inversión llevados a cabo por el sector privado. Un aspecto relevante a considerar es la relación entre el sector público y el privado, además del ciclo. Durante períodos de auge, en lugar de utilizar la cartera de proyectos evaluados, los fondos van a parar a instancias de poder que tienen en cuenta las expectativas de una población que va en aumento. Esto hace que se confiera prioridad a la creación de más infraestructura, en contraste con el mantenimiento o rehabilitación.

Aun cuando la inversión de los FSI sea en infraestructura, los ingresos son volátiles. Por lo tanto, conviene proceder con cautela y tener 
en cuenta una aproximación fiscal sostenible, mediante una estrategia de inversión sostenible ${ }^{8}$.

Los FSI como mecanismos de ahorro podrían cumplir este rol de inversores en infraestructuras dado que muchos de ellos (sobre todo los originados en los recursos naturales no renovables) tienen objetivos a largo plazo. No obstante, también es cierto que algunos fondos, como sucede en el caso de Chile, son más bien de estabilización frente a la volatilidad de los precios de los productos básicos. Cabe señalar que la tasa de rentabilidad de una inversión en infraestructura es mayor que la de los fondos centrados en las inversiones en activos líquidos, que obtienen menor rentabilidad a cambio de reducir su exposición al riesgo.

Por este motivo, es importante considerar cuál es el propósito del FSI, ya que esto resuelve la aparente dicotomía entre rentabilidad y riesgo. De todas formas, es necesario aclarar que, en el caso de activos líquidos, el cálculo de rentabilidad se puede observar de forma muy transparente. Entretanto, la rentabilidad en el caso de las inversiones en infraestructuras resulta algo más opaca, requiere un seguimiento estricto y no es lineal, sino que tiene que ver con la maduración del proyecto y las variables relacionadas con la incertidumbre.

No obstante, los FSI deben ser transparentes e informar cada año sobre sus resultados, lo que puede motivar ciertas decepciones cuando estos son menos importantes en las primeras fases del proyecto. Invertir en bonos del tesoro ayuda a solventar el riesgo de liquidez, pero esto no es eficaz a largo plazo. Los FSI podrían estabilizar la riqueza si las inversiones son de carácter anticíclico. En ese sentido, las inversiones en infraestructuras representan una buena elección de activos, sobre todo en programas de estímulos que traten de suavizar el ciclo en su fase descendente. Por otra parte, este tipo de inversiones pueden resultar una señal positiva respecto a las expectativas que tiene el sector privado en cuanto a seguridad y mejora en las barreras existentes respecto a la soberanía nacional9.

Arezki, Gylfason y Sy (2012) realizan una propuesta respecto a la formación de una plataforma global de inversiones en infraestructura para que los FSI puedan aplicar sus recursos en activos de largo plazo. Si

Una herramienta de mucha utilidad para evaluar los FSI en este contexto son los modelos de equilibrio general dinámico, como el modelo de deuda, inversión, crecimiento y recursos naturales (DIGNAR) que se ha aplicado en el caso de Liberia. Este es un país de escasos recursos financieros, pero que posee riquezas en hierro, oro, diamantes y potencialmente petróleo, a pesar de tener una baja recaudación por los recursos naturales (entre el $2 \%$ y el $4 \%$ del PIB).

9 Un buen ejemplo se encuentra en las inversiones realizadas por China, a través del Banco de Desarrollo de China, en África durante la pasada década y cómo esto ha estimulado la inversión de la Unión Europea, los Estados Unidos y Sudáfrica. 
bien la propuesta es global, describe de manera aplicada las ventajas de la plataforma, específicamente en el caso de África. Se tiene en cuenta que las necesidades se asientan en tres aspectos fundamentales: el demográfico (crecimiento de la población), la transición urbana (procesos de urbanización creciente) y la brecha de infraestructura existente hoy en día (Gutman, Chattopadhyay y Sy, 2015) ${ }^{10}$.

En esa propuesta se considera que la plataforma debería operar como una institución independiente para dar a las partes (FSI, agencias de calificación crediticia, compañías de seguro, instituciones financieras internacionales y bancos de desarrollo) información sobre los proyectos relevantes en infraestructura de una manera transparente (Rietveld y Toledano, 2017).

En cuanto a la organización de la plataforma, la idea es que sea un directorio independiente de la comunidad de inversión (incluido los FSI). Se preservarían los aspectos relacionados con los conflictos de intereses, así como las salvaguardias ambientales y sociales.

Como resultado de las implicaciones de política y el hecho que gran parte del crecimiento económico está condicionado por las actividades vinculadas a procesos de innovación tecnológica y su desarrollo en los últimos tiempos, surgen los fondos soberanos de riesgo (sovereign venture funds), que apuestan a las nuevas tecnologías y la innovación, las empresas emergentes y el capital de riesgo. Como se expone en ESADE Business School (2015), la entrada de los fondos soberanos en el capital de las empresas emergentes en fases muy tempranas de financiamiento pone de relieve la sofisticación de estos instrumentos y representa una apuesta estratégica por la economía digital (por ejemplo, Temasek y GIC). Así, los fondos soberanos han derivado parte de sus inversiones hacia dichos sectores que, en los últimos 50 años, han tenido un desarrollo sin precedente y han estimulado el comercio y las finanzas a nivel internacional. Por ejemplo, la República de Corea a principios de la década de 1960 tenía exportaciones por valor de 600 millones de dólares. En 2015, sus exportaciones superaban los 600.000 millones de dólares, debido en gran parte a la innovación y el desarrollo. Hoy en día esta situación no se limita a la República de Corea. Países como China, los Estados Unidos, la Federación de Rusia, Israel y Sudáfrica han apostado de manera decidida a la creación de empresas de base tecnológica (Santiso, 2015).

En respuesta a ello, los FSI han adaptado sus estrategias, estructuras y organización con miras a diversificar sus carteras e invertir en este sector de capital de riesgo. El modelo surgido se ha denominado "de participación

10 Las mismas condiciones iniciales, así como la constatación de necesidades urgentes en inversiones en infraestructuras confirman que la situación es equivalente en el caso de América Latina. 
en la propiedad", lo que coincide con los objetivos del fondo en materia de rentabilidad y riesgo a largo plazo y contribuye al desarrollo de los países donde se aplica.

En este sentido, muchos países han constituido FSI dedicados a la inversión en capital de riesgo, sobre todo en el sector de las telecomunicaciones y las nuevas tecnologías. Si bien hay casos de sobra conocidos, como el de Palo Alto o el de las empresas instaladas en el centro de Tel Aviv (Israel), también Singapur es un claro ejemplo de apuesta en este sentido, pues entre 2013 y 2015 se han realizado allí inversiones por valor de 3.500 millones de dólares. En Singapur, la empresa Temasek ha invertido en sectores financieros tecnológicos, tanto por la rentabilidad financiera de la inversión como con la posibilidad de que el país llegue a convertirse en el centro financiero más importante del mundo, lo que implica un doble dividendo según el objetivo del fondo. Otro ejemplo importante es el de China, que en 2015 creó un fondo de capital de riesgo por valor de 6.500 millones de dólares. Otros países, como los Emiratos Árabes Unidos o Qatar, participan activamente en esta línea.

En muchos casos se han producido alianzas con participación de los fondos. Por ejemplo, los FSI de Abu Dhabi, Nueva Zelandia y Alberta han creado una alianza de innovación para invertir en empresas emergentes junto a otros inversores. También cabe destacar la tendencia de algunos FSI a moverse geográficamente con el objetivo de desarrollar inversiones en capital de riesgo. Tal es el ejemplo del fondo Samruk Innovation, subsidiario del fondo de Kazajstán, que a partir de 2013 estableció una oficina en San Francisco (Santiso, 2015).

\section{El índice de gobernanza y su vínculo con los fondos soberanos de inversión}

Los índices de gobernanza de los recursos naturales han evolucionado con respecto a las variables que toman en consideración. En 2017, el Instituto de Gobernanza de los Recursos Naturales (2017) incluyó dentro del componente de gestión de ingresos un indicador relacionado con la gestión de fondos soberanos ${ }^{11}$.

En cuanto a la transparencia, también se ha producido un avance a partir del índice de Transparencia de Linaburg-Maduell, utilizado por el

\footnotetext{
11 Mediante este índice se evalúa la calidad de la gobernanza de 33 fondos soberanos (valorados en 3.300 billones de dólares). A diferencia de otros indicadores, los FSI de Colombia y Chile tienen mejor desempeño que los de Noruega y el Canadá. Entre los 11 de peor desempeño se encuentran 2 fondos soberanos de gran importancia en el mundo: la Autoridad Monetaria de la Arabia Saudita y la Autoridad de Inversiones de Qatar, que son opacos en cuanto a su administración y el destino de sus inversiones.
} 
SWFI, y del índice popularizado como el Índice de los Fondos Soberanos de Truman (Truman Scores) ${ }^{12}$. Como complemento de estos indicadores se han incorporado el Índice de Percepción de la Corrupción (de Transparency International) y el Índice de Libertad Económica (de la Heritage Foundation). Los resultados muestran una elevada correlación entre la posición que ocupan los FSI en estos dos índices y los creados a la medida para estos fondos. Noruega, Nueva Zelandia o Australia tienen bajos niveles de corrupción, un alto grado de democracia y un elevado nivel de libertad económica. Coincidentemente, obtienen las mejores puntuaciones en los índices de Linaburg-Maduell y el Truman Score. Por su parte, países menos democráticos, como China, los Emiratos Árabes Unidos, la Federación de Rusia y Kuwait, ocupan posiciones muy bajas en ambos grupos de índices. La excepción es Singapur (donde funcionan Temasek y el GIC), pues se trata de un país que, si bien presenta bajos índices de corrupción y un alto grado de libertad económica, obtiene bajas puntuaciones en los índices de Truman y Linaburg-Maduell.

El Revenue Watch Institute y el Vale Columbia Center on Sustainable International Investment realizaron una encuesta con 22 fondos soberanos a nivel mundial. De acuerdo con Bauer (2014), uno de los resultados de la encuesta indica que muchos de los fondos no tienen bien definidos sus objetivos, o simplemente no los cumplen.

Existen dos tipos principales de FDS. El primero abarca los fondos de desarrollo gestionados como fondos de activos y capital de riesgo. El segundo comprende los que invierten internacionalmente para mitigar la enfermedad holandesa y prevén que la rentabilidad sea para todos los individuos. Son del tipo I los fondos Kazanah (Malasia), Temasek (Singapur) y Mumtalakat (Bahrein). En estos casos, es muy importante tener en cuenta en el portafolio la relación entre concentración de autoridad política y diversificación, así como las tres variables significativas a la hora de establecer un fondo: la estructura de la autoridad política, la disponibilidad de capacidad financiera y la capacidad de generar crecimiento.

Como se mencionó en la definición, los FSI tienen ante todo el mandato de invertir fuera del país. Sin embargo, un 16\% del total de las inversiones son internas (Truman, 2008). Un 56\% de los FSI mantenían inversiones en infraestructura. Un $36 \%$ se centraba en la infraestructura social (por ejemplo, salud y educación), ya que la tasa de rentabilidad social es superior a la tasa de rendimiento de mercado. En todo caso, hay que ser muy precavido y bien organizado para tratar de mitigar el riesgo que

12 El índice incluye la estructura del fondo (objetivos, relación con la política fiscal e independencia de reservas internacionales), la transparencia y la rendición de cuentas (estrategias de inversión, auditorías e informes) y el gobierno y la conducta de los fondos (papel del gobierno, organización del directorio, política de riesgos, uso de derivados). 
implican estas inversiones. Por ello es necesario encontrar buenos socios, como pueden ser los bancos de desarrollo, incluido el Banco de Desarrollo de América Latina (CAF).

Por otra parte, los FSI deberían mantener una gestión separada de los bancos centrales o las autoridades monetarias. Es necesario que, además de considerarse como autoridades o gestores independientes, también se evalúen sus estrategias de inversión. Si bien algunos fondos no están totalmente separados a la hora de analizar dichas estrategias, estas no coinciden con las estrategias de las autoridades monetarias ${ }^{13}$.

Por último, frente al desafío de disminuir los riesgos, hay que tener en cuenta una buena gobernanza. Con ese fin se debe diferenciar entre inversor y propietario. Dentro del propio fondo, se debería prestar atención a la estructura, la autoridad, el funcionamiento y la composición. Ha de definirse con claridad quién toma las decisiones del fondo, quién gestiona y hace crecer el capital, así como la autonomía de la inversión, la gestión del riesgo, las clases de activos y las auditorías tanto internas como externas ${ }^{14}$.

\section{Reflexiones finales}

A partir del nuevo milenio, el auge de los precios de las materias primas trajo una nueva oleada de nuevos fondos soberanos de inversión. En general, y salvo algunas excepciones, la mayor parte de los FSI en un principio se crearon para administrar las rentas provenientes de los recursos naturales. Muchos de ellos se establecieron en países subdesarrollados que mostraban necesidades urgentes de gasto e inversión.

En la fase de auge de precios de los productos básicos, es razonable pensar que, si bien los FSI pueden servir varios objetivos de corto y largo plazo, de ahorro y de inversiones en infraestructura, entre otros, la situación resulta distinta en la fase de bajos precios. De ahí que sea necesario pensar en ahorrar el beneficio obtenido de la explotación de los recursos y aplicar el gasto con mesura. No obstante, invertir en liquidez sobre bonos del tesoro significa pasar el ahorro de los sectores menos favorecidos hacia los más favorecidos. Por ello, se podría pensar en invertir en fondos locales y fondos de inversión. Estos últimos podrían denominarse fondos de desarrollo soberanos. Sin embargo, existen problemas importantes

${ }_{13}$ Por ejemplo, la Autoridad Monetaria de la Arabia Saudita y el Fondo de Intercambio de la Autoridad Monetaria de Hong Kong no revelan independencia en su gestión, pero invierten casi el $60 \%$ de su portafolio en activos de riesgo, por lo que estos fondos podrían incluirse en la categoría de FSI.

14 La gestión de riesgo implica la gestión de la incertidumbre que, en el caso de los activos, es más fácil que la del riesgo de inversiones directas. En todo caso, se comprueba que los FSI, cada vez más, gestionan inversiones internas. 
en algunas regiones y sectores (Dixon y Monk, 2014) y, como menciona Bauer (2014), los FDS no pueden ser de todos y para todos.

En lo que se refiere a la forma en que ha ido variando el posicionamiento de los fondos con respecto a su cartera, cabe reflexionar nuevamente, no ya sobre la propia definición de un FSI, sino sobre cómo los ahorros de los Estados pueden contribuir al desarrollo sostenible en sus tres dimensiones. Una vez extraída la renta y asignada a los FSI, estos deben tomar una primera decisión respecto a los plazos. Si la visión es de corto plazo y se centra en la estabilización, es posible que el rendimiento de las inversiones y el riesgo sean menores, pero a cambio se asegura la sostenibilidad económica y social que provee la estabilidad. Si la visión es de largo plazo, la situación es bastante más compleja. Tanto los fondos de ahorro, como los de desarrollo o de pensiones, tienen esa visión. No obstante, la situación de la ecuación rentabilidad-riesgo es distinta a la hora de elegir el tipo de inversiones. Como se analizó durante el capítulo, estas pueden ser en capital físico (infraestructuras), capital humano (educación) o capital tecnológico (empresas de base tecnológica). Pensar en las generaciones futuras (o sea, ahorrar) no necesariamente va de la mano con el desarrollo.

Los fondos deben tener un manejo coordinado con la política macroeconómica, una estrategia de inversión óptima, transparencia en su gestión y responsabilidad en relación con las inversiones financieras en el exterior. Por último, es importante aclarar que, desde el punto de vista fiscal, las rentas de explotación tienen mucho que ver con la parte del ciclo de las materias primas. Durante el período de auge no hay mucha discusión en cuanto a la forma de gestión, ya que existen suficientes variaciones fiscales a favor del propietario del recurso. Sin embargo, durante el declive, la situación es más compleja y el comportamiento fiscal puede generar desinversiones y falta de incentivos a la producción.

Otro de los aspectos se refiere a la posibilidad de utilizar los FSI para proyectos nacionales. Si bien la respuesta es afirmativa, se deben tener en cuenta la inversión pública y el contexto para que esos proyectos contribuyan realmente al desarrollo. En segundo lugar, es importante separar la posición del gobierno como promotor de la inversión y propietario del FSI. Dado que muchas veces se producen interferencias, una de las mejores herramientas para minimizarlas es la diversificación, tanto de la cartera de activos como de la cartera de proyectos.

Aunque el objetivo de los FSI sea de estabilización y ahorro, si no hay integración con el contexto fiscal del país, estos fondos tendrán posibilidades limitadas de contribuir a su desarrollo. Por esta razón, deben tener una clara integración con la estructura y el presupuesto fiscal del gobierno, con la política monetaria del país e incluso con la política de financiación de las inversiones públicas, además de una gobernanza adecuada que priorice la rendición de cuentas y la transparencia en la gestión. 
Por otra parte, es preciso distinguir entre la integración con la política fiscal o con la política presupuestaria. Los FSI deben tener la capacidad de diseñar la transferencia de los recursos cuando el presupuesto lo requiera. Esto no significa tener capacidad de gasto, pues dicho gasto solo debe realizarse en el marco presupuestario.

En definitiva, las buenas prácticas en el manejo de los fondos soberanos son inminentes y van más allá de cuestiones estrictamente financieras. Incluyen políticas de inversión de los recursos, reglas fiscales y una gestión eficiente de los recursos, entre muchas otras especificaciones. Así, por ejemplo, contar con reglas fiscales bien establecidas (depósitos y retiros de los fondos) coadyuva a la aplicación de medidas anticíclicas que permitan mantener la estabilidad macroeconómica a largo plazo. En este sentido, la implementación de una gobernanza adecuada que logre un equilibrio general entre todos los sectores de la economía (de recursos naturales, financiero, real, fiscal, monetario, entre otros), representa un gran desafío para los gobiernos, la industria y la sociedad civil de los países que gozan de una gran riqueza natural. Sin embargo, el desafío va más allá y no es solo para los gobiernos. La gobernanza así concebida aún no tiene estructura conceptual ni está respaldada por un trabajo analítico desarrollado. Ello también supone, en el futuro, un desafío para los cooperantes y los organismos internacionales.

En el caso de América Latina y el Caribe, los beneficios económicos durante el último auge de precios de las materias primas no se utilizaron de manera eficiente. Se dejó pasar la oportunidad de transitar hacia mejores capacidades tecnológicas y de innovación, mayores niveles de educación y capacitación, así como hacia la diversificación productiva y la actualización de infraestructura que exige un desarrollo verdaderamente sostenible. En particular, el acrecentamiento de conflictos sociales y ambientales como resultado de las actividades mineras, y su consecuente impacto sobre el desarrollo de la minería en la región, ha exigido una completa transparencia en el manejo y la gestión de los ingresos provenientes de dichas actividades. La transparencia juega un papel clave en la socialización de las políticas, no solamente en el sector extractivo, sino en todo el ámbito de lo público. Ello implica una gobernanza de los recursos naturales más compleja, que va más allá de un solo sector. La transparencia genera certidumbre en el uso de los recursos y el alcance de las metas. También libera de presión política y social a los encargados de adoptar decisiones y de su implementación, en el contexto de una sociedad cada vez más participativa y conectada gracias al uso creciente de las redes sociales y los medios de comunicación electrónica.

Todavía no es tarde para corregir. Muchos países aún cuentan con una gran riqueza extractiva que se debería aprovechar adecuadamente, en beneficio de las generaciones actuales y futuras. Los encargados de la 
formulación de políticas tienen la tarea pendiente de planificar y gestionar los recursos de una forma estratégica y eficiente. Si bien es cierto que el auge de los precios contribuyó a la caída de los niveles de pobreza en muchos países ricos en recursos extractivos, las disparidades en la distribución del ingreso no disminuyeron en la misma magnitud. Esta situación, junto con los impactos sociales y ambientales que ha generado la industria extractiva, ha dado origen a mayores exigencias de la sociedad con miras a lograr una gestión mejor y más equilibrada de los ingresos provenientes de la explotación de los recursos naturales.

Se trata de actuar hoy con visión de largo plazo. Es cierto que los países tienen aún necesidades básicas apremiantes que deben atender. No obstante, parecería prudente y cada vez más necesario ir introduciendo o adaptando mecanismos de inversión (fondos soberanos) que permitan transformar el capital natural no renovable en otras formas de capital perdurable para lograr un verdadero desarrollo sostenible. Entre estas cabría incluir las relacionadas con educación, capacitación, infraestructura física y social, innovación y desarrollo tecnológico.

Determinados instrumentos, como la aplicación de un mayor financiamiento externo y las asociaciones público-privadas, quizás están teniendo cada vez más protagonismo ante la caída de los ingresos fiscales de la minería y la menor inversión extranjera observada en los sectores extractivos. Esta opción resulta más atractiva en economías en que el endeudamiento y el servicio de la deuda sean todavía bajos y manejables. A lo anterior cabe agregar la importancia que podría adquirir la recepción de inversiones por parte de los FSI. Durante los últimos años se ha ampliado la cartera de los FSI. Además de observarse inversiones financieras de corto, mediano y largo plazo (renta fija, acciones, bonos soberanos, entre otras), hoy están jugando un nuevo papel en las estrategias de desarrollo de muchos países las inversiones en diferentes sectores, como el de infraestructura, el residencial o el de recursos naturales. Más recientemente, se han ampliado a sectores tecnológicos, de empresas de reciente creación (capital de riesgo) y de mercados no cotizados. Al respecto, en los últimos años muchos gobiernos que tienen FSI de gran magnitud han fortalecido la inversión de recursos en dichos sectores, lo que abre nuevas posibilidades de inversión productiva en la región mediante proyectos de desarrollo que requieren importantes montos de capital. Esto podría dar lugar a una especie de alianzas público-privado-soberanas. Es evidente que los países de la región ricos en recursos extractivos deberían avanzar en las políticas de inversión y no reducir los gastos de inversión, en momentos en que se necesitan políticas anticíclicas para crecer de manera inclusiva.

No obstante, cuando se analizan los flujos de inversiones provenientes de los países que ahorran hacia los que ofrecen buenas oportunidades, surgen distintos obstáculos. Entre ellos cabe señalar la debilidad de las 
instituciones y de la gobernanza, la corrupción y la información limitada. Estos factores generan grandes asimetrías que a la postre limitan las oportunidades de inversión. Lo anterior reafirma la importancia de contar con una gobernanza adecuada de los recursos naturales en la región.

Entre los desafíos se encuentra el hecho de que los FSI tienen ante sí un panorama donde el precio de las materias primas no será el mismo del pasado. De ahí que sea fundamental asegurar inversiones rentables que permitan cubrir los objetivos de estabilidad, ahorro generacional y desarrollo. Los FSI siguen aplicando un enfoque tradicional en cuanto a la forma de posicionarse respecto a la conformación de la cartera, aunque han surgido nuevos desafíos que irán transformando su forma de actuar.

En todo caso, la mayoría de los FSI se gestionan de una manera adecuada. Su objetivo es proveer estabilidad económica y fiscal, transformar parte de las rentas extraídas de los recursos no renovables en activos con un rendimiento adecuado a largo plazo y, por último, canalizar una cantidad importante del ahorro hacia el desarrollo y el bienestar de las futuras generaciones.

\section{Bibliografía}

Alsweilem, K. y M. Rietveld (2017), Sovereign Wealth Funds in Resource Economies: Institutional and Fiscal Foundations, Nueva York, Columbia University Press.

Altomonte, H. y R. J. Sánchez (2016), Hacia una nueva gobernanza de los recursos naturales, Libros de la CEPAL, No 139 (LC/G.2679-P), Santiago, Comisión Económica para América Latina y el Caribe (CEPAL).

Arezki, R., T. Gylfason y A. Sy (eds.) (2012), Beyond the Curse: Policies to Harness the Power of Natural Resources, Washington, D.C., Fondo Monetario Internacional (FMI).

Auty, R.M. (1993), Sustaining Development in Mineral Economies: The Resource Curse Thesis, Londres, Routledge.

Bauer, A. (ed.) (2014), Managing the Public Trust: How to Make Natural Resource Funds Work for Citizens, Nueva York, Columbia Center on Sustainable Investment/ Revenue Watch Institute [en línea] https://resourcegovernance.org/sites/ default/files/NRF_RWI_Complete_Report_EN.pdf.

Beck, R. y M. Fidora (2008), "The impact of sovereign wealth funds on global financial markets", ECB Occasional Paper, $\mathrm{N}^{\circ} 91$ [en línea] https://ssrn.com/ abstract $=1144482$.

Bortolotti, B., V. Fotak y W. Megginson (2015), "The sovereign wealth fund discount: evidence from public equity investment", The Review of Financial Studies, vol. 28, $\mathrm{N}^{\circ} 11$, Oxford, Oxford University Press.

(2014), "The rise of sovereign wealth funds: definitions, organizations, and governance", BAFFI Center Research Paper Series, No 2014-163, Milán, Università Commerciale Luigi Bocconi. (2009), "Sovereign wealth fund investment patterns and performance", Nota di Lavoro, $\mathrm{N}^{\circ} 22$, Milán, Fondazione Eni Enrico Mattei.

Caner, M. y T. Grennes (2010), "Sovereign wealth funds: the Norwegian experience", The World Economy, vol. 33, $\mathrm{N}^{\circ} 4$, abril. 
Capapé, J. (2017), “Fondos soberanos: de la banca tradicional a la inteligencia artificial", Revista de Análisis Financiero, Instituto Español de Analistas Financieros (IEAF), octubre.

(2011), "Fondos soberanos y África", Las economías emergentes y el reequilibrio global: retos y oportunidades para España, J. Santiso (ed.), Madrid, Fundación de Estudios Financieros.

Capapé, J. y T. Guerrero (2013), "More layers than an onion: looking for a definition of sovereign wealth funds", ESADE Business School Research Paper, N ${ }^{\circ}$ 21, Barcelona, ESADE Business School.

Castelli, M. y F. Scacciavillani (2012), The New Economics of a Sovereign Wealth Fund, Sussex, Wiley.

CEPAL (Comisión Económica para América Latina y el Caribe) (2014), Pactos para la igualdad: hacia un futuro sostenible (LC/G.2586(SES.35/3)), Santiago, abril.

Chen, A., C. Mereu y R. Stelzer (2014), “Optimal Investment with Time-varying Stochastic Endowments" [en línea] https://papers.ssrn.com/sol3/papers. cfm?abstract_id=2458484.

Chen, X., J. Harford y K. Li (2007), “Monitoring: which institutions matter?", Journal of Financial Economics, vol. 86, N², Amsterdam, Elsevier.

Chhaochharia, V. y L. Laeven (2008), "Sovereign wealth funds: their investment strategies and performance", CEPR Discussion Papers, $N^{\circ} 6959$, Londres, Centro de investigación sobre políticas económicas.

Dixon, A.D. y A.H.B. Monk (2014), "Financializing development: toward a sympathetic critique of sovereign development funds", Journal of Sustainable Finance $\mathcal{E}$ Investment, $\mathrm{N}^{\circ} 4$, Taylor \& Francis.

Dobbs, R. y otros (2013), Resource Revolution: Tracking Global Commodity Markets, McKinsey Global Institute.

ESADE Business School (2015), Fondos soberanos 2015 [en línea] http://www. spainfinancialcentre.com/sites/default/files/fondos_soberanos_2015.pdf.

Estrin, S. y otros (2009), "The effects of privatization and ownership in transition economies", Journal of Economic Literature, vol. 47, $\mathrm{N}^{\circ} 3$, Nashville, Tennessee, American Economic Association.

Fernandes, N. (2009), "Sovereign wealth funds: investment choices and implications around the world", Documento de Trabajo, Lausana, IMD International.

FMI (Fondo Monetario Internacional) (2008), Sovereign Wealth Funds-A Work Agenda, Washington, D.C.

Gelb, A., S. Tordo y H. Halland (2017), "Sovereign wealth fund investments in the home economy", The New Frontiers of Sovereign Investment, M. Rietveld y P. Toledano (eds.), Nueva York, Columbia University Press.

Gomes, T. (2008), "The impact of sovereign wealth funds on international financial stability", Discussion Papers, N 08-14, Ontario, Banco de Canadá.

Gutman, J., S. Chattopadhyay y A. Sy (2015), Financing African Infrastructure: Can the World Deliver?, Washington, D.C., The Brookings Institution.

Hildebrand, P. (2007), "The challenge of sovereign wealth funds", Ginebra, 18 de diciembre [en línea] https:/ / www.bis.org/review/r071219d.pdf.

IFSWF (International Forum of Sovereign Wealth Funds) (2008), "Santiago Principles" [en línea] http:/ /www.iwg-swf.org/pubs/eng/santiagoprinciples.pdf.

Instituto de Gobernanza de los Recursos Naturales (2017), "Indice de la gobernanza de los recursos naturales 2017" [en línea] https:/ / resourcegovernance.org/.

Kalb, S.E. (2015), "Sovereign wealth fund in the global capital markets: reintermediation and new collaborative models", CFA Institute Conference Proceedings Quarterly, vol. 32, N 4, CFA Institute. 
Knill, A., B. Lee y N. Mauck (2009), "'Sleeping with the enemy' or 'an ounce of prevention': sovereign wealth fund investments and market instability" [en línea] https: / /admin.darden.virginia.edu/emUpload/uploaded2009/Mauck_ Paper_FinalVersion.pdf.

Martellini, L. y V. Milhau (2010), Asset-Liability Management Decisions for Sovereign Wealth Funds, EDHEC Business School.

Megginson, W. (2013), "Privatization trends and major deals of 2012 and 1H2013", The PB Report 2012 Report [en línea] https:/ /assets.kpmg.com/content/dam/ kpmg/pdf/2013/10/PBKPMGENI.pdf.

Megginson, W.L. y V. Fotak (2014), "Rise of the fiduciary state: a survey of sovereign wealth fund research", Documento de Trabajo, Universidad de Oklahoma/ Universidad de Buffalo.

Megginson, W.L. y J.M. Netter (2001), “From state to market: a survey of empirical studies on privatization", Journal of Economic Literature, vol. 39, $\mathrm{N}^{\circ} 2$, Nashville, Tennessee, American Economic Association.

Melina, G., S.S. Yang y L.F. Zanna (2016), "Debt sustainability, public investment, and natural resources in developing countries: the DIGNAR", Economic Modelling, vol. 52, Amsterdam, Elsevier.

Monk, A. (2008), "Is CalPERS a sovereign wealth fund?", Briefs, No 8-21, Chestnut Hill, Massachusetts, Center for Retirement Research, Boston College [en línea] http://crr.bc.edu/wp-content/uploads/2008/12/IB_8-21-508.pdf.

Rietveld, M. y P. Toledano (eds.) (2017), The New Frontiers of Sovereign Investment, Nueva York, Columbia University Press.

Rozanov, A. (2005), "Who holds the wealth of nations?", Central Banking Journal, vol. $15, \mathrm{~N}^{\circ} 4$.

Sánchez, R. y otros (2017), "Inversiones en infraestructura en América Latina: tendencias, brechas y oportunidades", serie Recursos Naturales e Infraestructura, N 187 (LC/TS.2017/132), Santiago, Comisión Económica para América Latina y el Caribe (CEPAL).

Santiso, J. (2015), España 3.0: necesitamos resetear el país, Barcelona, Planeta.

Schena, P.J. y R.S. Chaturvedi (2011), "Sovereign Wealth Funds, Debt Issuances, and the Development of Capital Markets", Medford, The Fletcher School [en línea] https://sites.tufts.edu/sovereignet/files/2011/11/Archives-SovereignWealth-Funds-Debt-Issuances-and-the-Development-of-Capital-Markets.pdf.

Scherer, B. (2009), "A note on portfolio choice for sovereign wealth funds", Financial Markets and Portfolio Management, vol. 23, $\mathrm{N}^{\circ} 3$, Springer.

Shleifer, A. y R. Vishny (1986), "Large shareholders and corporate control", Journal of Political Economy, vol. 94, N³, Chicago, The University of Chicago Press.

Sierra- Juárez, G. y D. Méndez García (2017), “Un modelo de inversión óptima para fondos soberanos: caso fondo mexicano del petróleo para la estabilización y el desarrollo", El Trimestre Económico, vol. 84, N³35, Ciudad de México, Fondo de Cultura Económica.

SWFI (Sovereign Wealth Fund Institute) (2017), “Funds Rankings” [en línea] http:/ / www.swfinstitute.org/fund-rankings/.

Truman, E.M. (2008), "A blueprint for sovereign wealth fund best practices", Policy Brief, N ${ }^{\circ}$ PB08-3, Washington, D.C., Peterson Institute for International Economics. 

Capítulo XV

\section{La conflictividad vinculada a los recursos naturales en América Latina: tendencias y mecanismos institucionales de respuesta}

La gobernanza de los recursos naturales se ha convertido en uno de los retos más importantes en la agenda para el desarrollo de América Latina y el Caribe. Los conflictos relacionados con el acceso, la propiedad y la gestión sostenible de los recursos naturales se incrementaron de forma notable en la última década y se han convertido en una preocupación central para gobiernos, empresas y ciudadanos. El significativo aumento de los precios internacionales de las materias primas permitió a muchos países de América Latina y el Caribe beneficiarse de importantes flujos de inversión extranjera directa (IED) durante la década pasada. Esta inversión tuvo un impacto positivo en el crecimiento económico y permitió aumentar las rentas disponibles para los Estados latinoamericanos exportadores de minerales e hidrocarburos.

Sin embargo, los beneficios económicos de la inversión dirigida a la explotación de recursos naturales se vieron empañados a menudo por impactos sociales y ambientales negativos. El incremento de la demanda de materias primas creó mayores presiones sobre los recursos naturales, de modo que propició el surgimiento de nuevas dinámicas de conflicto social.

El objetivo de este capítulo es describir las características más importantes de la conflictividad social asociada a los recursos naturales 
en América Latina. También se intenta explorar algunas de las respuestas más innovadoras que han puesto a prueba los países de la región para detectar dichos conflictos de manera tempana y, consecuentemente, prevenirlos y transformarlos. Estos mecanismos institucionales pueden ofrecer lecciones valiosas con miras a la implementación de los Objetivos de Desarrollo Sostenible (ODS) y apoyar los esfuerzos dirigidos a mantener la paz en la región.

\section{A. Estudio de la conflictividad}

Los conflictos sociales vinculados al acceso, el uso o la propiedad de los recursos naturales, así como a los impactos de las actividades económicas, están lejos de ser un fenómeno nuevo en América Latina. Sin embargo, existe una percepción generalizada de que el aumento de la presión sobre los recursos naturales en la última década ha contribuido a incrementar los conflictos sociales en número e intensidad. Aunque haya consenso sobre la tendencia general, no existen datos de calidad suficiente para determinar la magnitud del fenómeno. La región carece de una plataforma integrada de registro y análisis de datos sobre conflictos sociales que permita establecer patrones regionales y tendencias por país.

Por otro lado, el reciente aumento de los conflictos relacionados con los recursos naturales se inserta en un ciclo de gran movilización social que se hizo evidente desde comienzos de siglo en la mayoría de los países de la región ${ }^{1}$. Esto hace difícil establecer de manera taxativa el impacto del aumento de la demanda de recursos naturales sobre la conflictividad social en general. Al mismo tiempo, impide distinguir este fenómeno de otras expresiones de la política contenciosa.

Al respecto, en los últimos años se han establecido importantes redes de análisis, observatorios de conflictos sociales y un gran número de iniciativas de investigación académica para registrar casos de conflictos, estandarizar indicadores y comparar tendencias entre distintos países de América Latina ${ }^{234}$. Como consecuencia de esta riqueza de aproximaciones con fines de análisis se ha ido conformando una colección dispar de bases de datos que arrojan resultados diversos y, en ocasiones, contradictorios.

Véase PNUD/Fundación Unir Bolivia (2011).

Véanse, por ejemplo, el Atlas de Justicia Ambiental (EJ Atlas), y el Observatorio Social de América Latina (OSAL), establecido por el Consejo Latinoamericano de Ciencias Sociales (CLACSO).

3 Véase Observatorio Latinoamericano de Conflictos Ambientales (OLCA), Observatorio de Conflictos Mineros de América Latina (OCMAL), el mapa de conflictos socioambientales del Instituto Nacional de Derechos Humanos (INDH) de Chile y los informes Willaqniki de la Oficina Nacional de Diálogo y Sostenibilidad de la Presidencia del Consejo de Ministros de la República del Perú.

4 Véase Ramírez (2011) y PNUD (2016a). 
Las dificultades que han encontrado los investigadores para establecer bases de datos coherentes son de naturaleza conceptual y práctica. Por un lado, no existe consenso en torno a conceptos clave relacionados con la conflictividad social. Tampoco lo hay sobre la mejor manera de codificarlos. Por ejemplo, no existe una definición aceptada o consensuada de términos como conflicto, conflicto social o conflicto socioambiental ${ }^{5}$. Por otro lado, es posible establecer diferencias importantes en cuanto a la manera en que los investigadores se aproximan empíricamente a la conflictividad social. Las aproximaciones cuantitativas a ese fenómeno se concentran en la contabilización de eventos de protesta, el registro de episodios conflictivos o el análisis de percepciones. Las iniciativas que utilizan metodologías cualitativas pueden abarcar conflictos en distintas fases de desarrollo, con inclusión de situaciones de latencia que se expresan mediante distintos repertorios de acción colectiva.

Las fuentes de información que utilizan los investigadores también tienen un impacto en el resultado final. Mientras que algunos análisis se basan en la codificación manual de noticias aparecidas en medios de comunicación tradicionales, en otros se han incorporado mecanismos para el registro de información de fuentes abiertas de Internet con distintos niveles de cobertura ${ }^{6}$. Además, mientras algunos se valen exclusivamente de fuentes secundarias de información, otros recurren a instancias de observación o reporte directo desde el lugar de los hechos, de modo que incorporan situaciones que suelen pasar inadvertidas en la cobertura de los medios de comunicación tradicionales.

Las iniciativas de investigación existentes muestran una gran diversidad conceptual y una variedad de fuentes de información y de dimensiones de análisis. Algunas de las variables codificadas suelen incluir la localización geográfica de los conflictos, los actores, las demandas, los eventos conflictivos, los repertorios de acción colectiva y la respuesta estatal, así como determinados indicadores relacionados con la intensidad o el escalamiento de los conflictos (véase el cuadro XV.1). Si bien la región carece de un registro sistemático sobre la conflictividad social, los esfuerzos de investigación existentes permiten establecer tendencias generales y una base común que resulta útil para comprender distintos patrones de respuesta.

5 En distintas definiciones se enfatizan diferentes dimensiones del fenómeno. Por ejemplo, el INDH de Chile define los conflictos socioambientales como "aquellas disputas entre diversos actores (personas naturales, organizaciones, empresas privadas y/o el Estado) manifestadas públicamente y que expresan divergencias de opinión, posiciones, intereses y planteamientos de demandas por la afectación (o potencial afectación) de derechos humanos, derivada del acceso y uso de recursos naturales, así como por los impactos ambientales de las actividades económicas". Véase [en línea] http://www.indh.cl/mapadeconflictos.

6 Hasta la fecha no se han identificado en la región ejemplos relevantes del uso de herramientas para la contabilización automatizada de eventos en fuentes abiertas (análisis de macrodatos). 


\section{Cuadro XV.1}

\section{Componentes del análisis de la conflictividad}

\section{Conceptos}

- Conflicto social

- Protesta social

- Movilización social

- Acción colectiva

- Acción contestataria

- Participación política

no convencional

- Política contenciosa

- Luchas de resistencia

Variables

- Ubicación geográfica

- Unidad de análisis (eventos, episodios, ciclo del conflicto)

- Actores (demandantes y demandados, primarios y secundarios)

- Demandas (principales, secundarias)

- Repertorios de acción colectiva

- Respuesta estatal

- Evolución, escalamiento o intensidad del conflicto

- Resultados

\section{Fuentes}

- Prensa impresa de cobertura nacional y subnacional

- Cables de agencias internacionales de noticias

- Versiones electrónicas de periódicos en Internet

- Radio y televisión abiertas

- Medios alternativos en Internet, blogs y redes sociales

- Informes de asociaciones y organizaciones no gubernamentales (ONG) locales

Fuente: Elaboración propia.

\section{B. Hacia una caracterización de los conflictos vinculados a los recursos naturales}

La conflictividad vinculada a actividades económicas que requieren la explotación de recursos naturales presenta una gran diversidad en América Latina. Los datos incluidos en la plataforma en línea del Atlas de Justicia Ambiental (EJ Atlas), que quizás sea la base de datos más exhaustiva que existe sobre la región, permiten definir algunas tendencias relevantes ${ }^{7}$. Como se muestra en el cuadro XV.2, la codificación y el análisis de los 526 casos de conflictos registrados por el EJ Atlas respecto de 17 países de América Latina muestra que, hasta mayo del 2016, los conflictos asociados a industrias extractivas representaban más del $50 \%$ de los casos. Entre estos, los conflictos relacionados con la extracción de minerales superaban a los relacionados con hidrocarburos, en una proporción de cuatro a uno.

En esta muestra, a los conflictos asociados a industrias extractivas les siguen en orden de importancia los asociados al uso de biomasa en territorios específicos y a la gestión de los recursos hídricos. Sin embargo, es importante destacar que los conflictos vinculados a recursos naturales rara vez responden a causas únicas y a menudo incorporan disputas

\footnotetext{
Véase [en línea] https://ejatlas.org/. El análisis que aquí se presenta se basa en la codificación de la información pública disponible en la plataforma en línea del Atlas de Justicia Ambiental hasta mayo de 2016. El EJ Atlas se distingue de otras iniciativas de codificación de conflictos en que la información de gran parte de los casos registrados proviene de entidades con presencia en el territorio.
} 
relacionadas con distintos tipos de impactos económicos, sociales y ambientales. Así, un $42 \%$ de los conflictos en materia de minería codificados a partir del registro del EJ Atlas están vinculados a reclamos sobre el acceso y los derechos al agua. Del mismo modo, la mayoría de los conflictos asociados a la construcción de infraestructuras hidroeléctricas para la generación de energía están relacionados con los reclamos de comunidades sobre el acceso y los derechos al agua o a la tierra, así como la provisión de servicios públicos.

\section{Cuadro XV.2}

\section{Conflictos por tipo de actividad a mayo de 2016}

\begin{tabular}{lcc} 
& Número & Porcentajes \\
\hline Minería & 213 & 40,5 \\
\hline Biomasa & 80 & 15,2 \\
\hline Gestión de los recursos hídricos & 71 & 13,5 \\
\hline Hidrocarburos & 56 & 10,7 \\
\hline Gestión de residuos & 20 & 3,8 \\
\hline Conflictos industriales y de utilidades & 20 & 3,8 \\
\hline Construcción de infraestructura & 17 & 3,2 \\
\hline Justicia climática & 14 & 2,7 \\
\hline Conflictos sobre conservación y biodiversidad & 11 & 2,1 \\
\hline Conflictos sobre la tierra & 10 & 1,9 \\
\hline Recursos turísticos & 10 & 1,9 \\
\hline Nuclear & 4 & 0,8 \\
\hline Total & 526 & 100,0 \\
\hline
\end{tabular}

Fuente: Elaboración propia, sobre la base de datos del Atlas de Justicia Ambiental (EJ Atlas).

En la muestra de conflictos registrados por el EJ Atlas, hasta el $80 \%$ de los reclamos se dirigían a empresas privadas de distinta naturaleza. Un 60\% de estos casos tenían que ver con compañías transnacionales, aunque muchas empresas registradas como nacionales incluyen capital extranjero.

Además de las empresas, el $70 \%$ de los conflictos registrados incluyen también reclamos a instituciones de gobierno de distinto nivel. Los reclamos dirigidos primariamente a organismos públicos representan menos del $7 \%$ del total, lo que distingue los conflictos vinculados a recursos naturales de otros tipos de movilización social donde la mayoría de las demandas se dirigen al Estado ${ }^{8}$. En cuanto a los actores involucrados en las protestas, en su gran mayoría se trata de actores locales situados en los territorios donde se producen las afectaciones directas de los proyectos privados (campesinos, pescadores, comunidades de vecinos, organizaciones indígenas y de afrodescendientes, entre otros).

Véase PNUD/Fundación Unir Bolivia (2011) y Programa Estado de la Nación en Desarrollo Humano Sostenible (2011). 
Otros actores provenientes de fuera del territorio, tales como ONG, plataformas de la sociedad civil, académicos, partidos políticos o sindicatos, tienen una menor presencia. Sin embargo, son frecuentes los casos en que los residentes de los territorios actúan coordinadamente con alguno o varios de estos actores externos.

Por otro lado, con respecto a los repertorios de acción colectiva usados por los actores para expresar su descontento, el análisis de los datos del EJ Atlas permite constatar que prevalecen las acciones pacíficas sobre las más disruptivas. Las declaraciones públicas, las asambleas, las campañas, el activismo judicial y la producción de información alternativa constituyen cerca del $70 \%$ del total de las acciones registradas en contextos de conflictividad vinculada a los recursos naturales. El 30\% de los casos restantes corresponde a bloqueos (la vía más común), ocupaciones, marchas, huelgas y sabotajes. Contrariamente a la percepción que comparten algunos analistas, el recurso a la violencia es poco frecuente en la mayoría de las fases de los conflictos que involucran recursos naturales. $\mathrm{Si}$ bien las situaciones de escalamiento son las que atraen una mayor atención mediática, no son las más frecuentes en la región.

Por último, la base de datos del EJ Atlas permite inferir que, en contextos de conflictividad social vinculada a recursos naturales en América Latina, las demandas asociadas a los impactos ambientales de la actividad económica tienen prominencia sobre aquellas dirigidas a la distribución de los beneficios derivados de la explotación de recursos naturales y la participación en la toma de decisiones ${ }^{9}$.

\section{Sobre la conflictividad asociada a las industrias extractivas}

La prominencia de los conflictos asociados a industrias extractivas en América Latina está relacionada con el auge de los precios internacionales de los metales e hidrocarburos, que prevaleció principalmente en el decenio 2002-2012 ${ }^{10}$. Los conflictos sociales afectaron por igual a países con una larga tradición extractivista y a productores incipientes. A pesar de la gran diversidad en cuanto al tamaño y la ubicación de los emprendimientos extractivos de gran escala y las distintas trayectorias de los países productores, existe una base común a la mayoría de los conflictos que han afectado las operaciones de empresas de hidrocarburos y minería en la región.

Los conflictos asociados a las industrias extractivas tienen causas complejas, multidimensionales e interrelacionadas. Suelen derivarse de limitaciones, demostradas o potenciales, relacionadas con el ejercicio de

\footnotetext{
9 El análisis global del Consejo Internacional de Minería y Metales (ICCM) refleja resultados similares. Véase ICMM (2015).

10 Véase ICMM (2015), PNUD (2016b) y PNUD (2017).
} 
derechos por parte de quienes se oponen, incluidos los derechos humanos fundamentales. Los reclamos pueden responder a impactos reales $o$ percibidos y surgen en distintos momentos del ciclo de las industrias extractivas, que pueden ir desde la exploración y el otorgamiento de licencias de operación hasta el cierre de los proyectos.

Algunos de los factores comunes que están presentes en la mayoría de estos conflictos se enumeran a continuación:

- Factores asociados al impacto en el territorio, así como a la propiedad, el acceso y el uso de recursos naturales escasos. En muchos contextos la industria compite con las poblaciones locales por el acceso a la tierra y el agua, lo que contribuye a profundizar desigualdades de larga data que impactan en el desarrollo local. Además de las consecuencias locales para el medio ambiente, la extracción de recursos renovables y no renovables puede ocasionar desplazamiento de poblaciones, distorsiones en los mercados locales de bienes y servicios, disrupciones de distinto tipo en los patrones culturales, entre otras cosas. El incumplimiento de las obligaciones de empresas y el Estado con respecto a los mecanismos de participación y consulta alrededor del uso de los recursos naturales también es una fuente frecuente de tensiones.

- Factores asociados a expectativas incumplidas con respecto a los beneficios e impactos de la industria. En algunos sectores, las demandas de índole laboral superan con creces las relativas a los impactos sociales y ambientales de la industria ${ }^{11}$. La existencia de mecanismos compensatorios débiles y proyectos de responsabilidad social o ambiental insuficientes por parte de las empresas también puede intensificar el rechazo a la actividad industrial. A su vez, los cambios en las modalidades de la renta originada en las industrias extractivas han generado controversia entre gobiernos de distinto nivel y las comunidades.

- Diferencias en cosmovisiones y preferencias con respecto al modelo de desarrollo y la toma de decisiones sobre el uso de los recursos naturales. En América Latina, la expansión de la industria a menudo ha enfrentado reclamos relacionados con el incumplimiento de las garantías asociadas a los derechos de los pueblos indígenas. El rechazo a la imposición de un modelo de desarrollo basado en la explotación de recursos naturales también ha formado parte de las plataformas de oposición de comunidades y organizaciones locales. En algunos países, la falta de atención a las diferencias en cosmovisiones ha generado una creciente tendencia a la judicialización de los conflictos sociales vinculados a los recursos naturales.

11 Véase ANH y otros (2016) y PNUD (2017). 
- Factores asociados a la capacidad del Estado para regular la industria, evaluar los impactos de manera independiente y ofrecer medidas efectivas de mitigación. La falta de una legislación adecuada que se aplique a todo el ciclo de las industrias extractivas y la debilidad del Estado respecto de la implementación del marco que regula dichas industrias están detrás de muchas controversias en la región. Los reclamos asociados a los impactos ambientales de las industrias extractivas son prominentes en la mayoría de los conflictos entre empresas, gobiernos y comunidades. Otro tanto sucede con los reclamos al Estado por la ausencia de políticas de planificación territorial. También son usuales las críticas a la independencia y capacidad de las entidades públicas encargadas de regular los impactos ambientales de la industria, o los reclamos emanados de la implementación de mandatos institucionales que persiguen propósitos que pueden contradecirse entre sí en los territorios.

- Factores asociados a problemas de información. Es común que las empresas y comunidades se acusen mutuamente de usar información parcializada para promover sus propios intereses en contextos de conflictividad. Las partes suelen presentar narrativas radicalmente diferentes sobre los impactos de la industria en el territorio, los derechos y obligaciones de cada actor y las posibles vías de solución de los conflictos. Es habitual que los actores presenten sus intereses como incompatibles y conciban los conflictos como juegos de suma cero. En reiteradas ocasiones, la expresión de descontento ha desencadenado dinámicas de conflicto intercomunitario entre quienes se oponen a la industria y quienes se benefician de esta.

\section{La respuesta desde el Estado}

El aumento del número e intensidad de los conflictos relacionados con los recursos naturales ha contribuido al surgimiento de una gran diversidad de mecanismos de respuesta por parte del Estado, las empresas y la sociedad en los distintos países de la región. Los Estados latinoamericanos llevan más de una década ensayando diferentes tipos de respuestas institucionales ante la creciente conflictividad social. Aunque la mayoría de estas iniciativas se han implementado desde el órgano ejecutivo, es posible encontrar ejemplos relevantes en los gobiernos subnacionales o en entidades autónomas, como las instituciones nacionales de derechos humanos.

La respuesta institucional a este tipo de conflictividad ha evolucionado, desde iniciativas reactivas y poco coordinadas hasta 
mecanismos de respuesta altamente organizados que cuentan con protocolos, equipos dedicados y rutas de implementación específicas respecto de distintos tipos de conflictos. El Programa de las Naciones Unidas para el Desarrollo (PNUD) ha acumulado experiencia relevante en apoyo a las iniciativas nacionales dirigidas al fortalecimiento de las capacidades nacionales relacionadas con la prevención y gestión de los conflictos sociales en América Latina.

Aunque no existe un modelo único de intervención, es posible identificar patrones comunes en los mecanismos institucionales de respuesta desde el Estado $^{12}$. En términos generales, los mecanismos de respuesta para la atención de conflictos relacionados con recursos naturales pueden incluir variaciones en torno a cuatro componentes principales: i) sistemas de alerta y respuesta temprana; ii) mecanismos de intervención para la transformación de los conflictos; iii) mecanismos para la coordinación de la respuesta institucional, y iv) mecanismos dirigidos al fortalecimiento de capacidades de los actores involucrados.

\section{Sistemas de alerta y respuesta temprana (prevención operativa) ${ }^{13}$}

La región ha acumulado una importante experiencia en el diseño de sistemas de alerta y respuesta temprana ante los conflictos sociales. La producción de alertas tempranas se basa en mecanismos diseñados para la recolección y el análisis centralizado de información sobre las causas de un conflicto, su evolución y sus posibles impactos. Por su parte, los sistemas de respuesta temprana buscan prevenir el escalamiento de las tensiones mediante el diseño de protocolos de intervención inmediata dirigidos por equipos y entidades públicas con responsabilidades previamente acordadas. Los sistemas de respuesta temprana también pueden incluir el monitoreo de acuerdos o compromisos suscritos entre las partes a fin de evaluar su cumplimiento y evitar el resurgimiento de tensiones.

Distintas instituciones públicas de la región han establecido equipos interinstitucionales de coordinación que despliegan enlaces territoriales, metodólogos, facilitadores y expertos temáticos para proveer respuestas ante conflictos concretos y evitar escaladas. En los casos más avanzados, estos sistemas cuentan con plataformas informáticas de agregación, análisis, seguimiento, georreferenciación y visualización de información al servicio del sistema ${ }^{14}$.

Véase PNUD (2014, 2016a y 2017).

Véase PNUD/OEA (2015).

${ }_{14}$ Entre otros ejemplos relevantes cabe mencionar el Sistema de Información Geográfica para la Estrategia Territorial de Hidrocarburos (SIGETH). Véase también PAPEP/GTZ (2008). 


\section{Implementación de mecanismos de intervención para la gestión de conflictos sociales (prevención estructural)}

Este componente se refiere a la implementación de rutas para la resolución y transformación de conflictos que buscan dar respuesta a algunas de las causas profundas de las disputas entre las partes. Estas rutas de intervención generalmente se establecen una vez superados los episodios de violencia y se presentan como mecanismos que buscan reducir las tensiones de manera sostenida para prevenir escalamientos. Las rutas de intervención dirigidas a la gestión y transformación de conflictos pueden incorporar metodologías de diálogo entre múltiples actores, así como otras herramientas que coadyuven a la resolución pacífica de conflictos, tales como la facilitación, la mediación, la conciliación y el arbitraje ${ }^{15}$.

La premisa de partida con respecto a la implementación de metodologías de diálogo democrático es que es posible encontrar alternativas mutuamente beneficiosas para las comunidades, las empresas y la institucionalidad pública mediante la generación de espacios seguros, neutrales y transparentes que contribuyan a la resolución sostenible de los $\operatorname{conflictos}^{16}$. Desde hace más de una década, el PNUD ha incorporado el enfoque del diálogo democrático como un componente central en sus iniciativas dirigidas a fortalecer la gobernabilidad democrática en América Latina y el Caribe ${ }^{17}$. Este enfoque permite promover entendimientos sostenibles entre actores polarizados en un marco que respeta y fortalece la institucionalidad pública, lo que a la larga contribuye a la búsqueda de soluciones sostenibles.

En este contexto, el diálogo no es visto como una acción aislada con miras a prevenir escaladas de violencia, sino como un proceso de cooperación que busca transformar relaciones conflictivas y fortalecer la gobernabilidad democrática. En muchas ocasiones la implementación de estas metodologías requiere de la presencia de una tercera parte neutral y equipos técnicos especializados.

\section{Mecanismos de gestión y coordinación institucional}

El resultado de los procesos de diálogo suele derivar en compromisos de las partes con miras a la implementación de acciones a corto, mediano y largo plazo. La atención de las causas profundas de los conflictos requiere esfuerzos sostenidos a lo largo del tiempo que involucran a distintos actores institucionales. Por ello, un elemento crucial de las estrategias ensayadas por los Estados latinoamericanos para la atención de la conflictividad social es la organización de la respuesta institucional.

\footnotetext{
Véase Pruitt y Thomas (2008).

Véase PNUD (2016a y 2017).

Véase Pruitt y Thomas (2008).
} 
En la mayoría de los casos, la respuesta del Estado ante los conflictos vinculados a recursos naturales requiere intervenciones de más de una entidad pública. La búsqueda de soluciones sostenibles a los conflictos sociales demanda mecanismos de coordinación de la respuesta que asignen responsabilidades claras a actores institucionales de distinto nivel. Una respuesta efectiva y sostenible hace necesario establecer $a$ priori el conjunto de mecanismos administrativos que deben activarse de manera coordinada para la búsqueda de soluciones a los conflictos. Las decisiones sobre la intervención de los organismos públicos dependen de sus competencias legales y de las capacidades institucionales, operativas y financieras de que disponen.

De esta forma, las respuestas institucionales dirigidas a la construcción de acuerdos para la resolución de conflictos suelen incluir mecanismos de monitoreo del grado de cumplimiento de los compromisos asumidos por parte del Estado, así como de otras partes involucradas en el conflicto. Su incumplimiento puede fácilmente producir escalamientos y reducir el espacio político para la resolución alternativa de conflictos.

\section{Desarrollo de capacidades para la solución pacífica de conflictos}

El alto grado de polarización ha motivado a distintas entidades públicas a diseñar mecanismos dirigidos a fortalecer la capacidad de las partes en conflicto en relación con la búsqueda de soluciones sostenibles. En el marco de estas intervenciones se han realizado esfuerzos de capacitación de representantes de las comunidades, funcionarios de enlace de las empresas y representantes de organismos públicos de distinto nivel en materia de herramientas de diálogo y negociación.

También se ha expresado en instancias para la provisión de información sobre el marco legal que regula la industria, la rendición de cuentas respecto a la ejecución de los recursos públicos asociados a regalías, la información de carácter oficial relativa a proyectos específicos y otros temas relevantes para la resolución de los conflictos. La experiencia demuestra que el acceso a información de calidad, veraz y completa contribuye a la definición de cauces para dirimir las diferencias.

Cuando estos mecanismos se implementan a nivel comunitario, también pueden contribuir a reducir las asimetrías de información que son determinantes en la búsqueda de soluciones sostenibles al conflicto mediante mecanismos alternativos. En las experiencias más exitosas, estos procesos desembocan en estrategias participativas relacionadas con el monitoreo y el seguimiento de los impactos de la industria en los territorios. 


\section{E. Institucionalización de los mecanismos de respuesta}

Con la gran variedad de respuestas institucionales ensayadas en América Latina ante la conflictividad social se han buscado soluciones a dilemas comunes, por lo que representan valiosas lecciones para los encargados de la adopción de decisiones. En primer lugar, los mecanismos de respuesta muestran diferencias importantes en cuanto a su grado de complejidad. Las propuestas más sofisticadas para atender la conflictividad cuentan con protocolos de actuación, rutas de implementación, estándares formales para la elaboración de productos de los sistemas establecidos, recursos humanos altamente capacitados, presupuestos estables y mecanismos de evaluación.

En segundo lugar, existen variaciones importantes con respecto al encaje institucional de los sistemas diseñados por los Estados con miras a la prevención y gestión de los conflictos sociales. La tendencia general en la región ha sido concentrar los mecanismos de respuesta del Estado en instancias de alta jerarquía con el fin de facilitar la toma de decisiones y la coordinación interinstitucional, tanto de manera horizontal como vertical, con actores que tienen presencia en el territorio. En distintos países de la región pueden encontrarse comisiones presidenciales, grupos interministeriales, juntas intersectoriales, sistemas nacionales y un largo catálogo de fórmulas institucionales.

Por último, la búsqueda de modelos de intervención sostenibles ha derivado en su formalización mediante leyes, decretos, resoluciones administrativas, acuerdos gubernativos, reglamentos y directivas de política pública ${ }^{18}$. Aunque estos instrumentos contribuyen a la institucionalización formal de los sistemas diseñados para dar respuesta a la conflictividad, la trayectoria de la región parece indicar que no son suficientes. Los sistemas establecidos desde el Poder Ejecutivo suelen tener horizontes temporales que rara vez trascienden la gestión de una administración de gobierno.

\section{F. Algunas conclusiones}

La conflictividad vinculada a los recursos naturales no es nueva en América Latina. Sin embargo, los datos disponibles permiten inferir que el número y la intensidad de estos conflictos se incrementaron de forma significativa

Véase Ain (2016). Entre otros ejemplos relevantes cabe mencionar el Decreto Supremo N ${ }^{\circ}$ 056-2009 de la Presidencia del Consejo de Ministros del Perú, por el que se creó una Comisión Multisectorial de Prevención de Conflictos Sociales integrada por representantes de 17 ministerios y entidades. En Colombia, mediante el Decreto № 2890 de diciembre del 2013 se estableció una Comisión Intersectorial de Alertas Tempranas (CIAT) compuesta por dos ministros, las fuerzas de seguridad y otros entes especializados. En Guatemala, por acuerdo gubernativo 125 del 2014 se estableció la Comisión Presidencial de Diálogo, compuesta por cuatro ministerios y dos secretarías de la presidencia. 
durante la última década, como resultado del aumento de la demanda de materias primas y los importantes flujos de inversión extranjera que atrajo la región. Los especialistas esperan que este tipo de conflictividad siga en aumento. Además de choques de origen externo, es previsible que factores como el aumento de la población, la expansión de las fronteras agrícolas y los efectos acumulativos del cambio climático, sigan aumentando la presión sobre recursos escasos. Estas tendencias requieren la búsqueda de mecanismos de respuesta por parte de los gobiernos para ofrecer soluciones sostenibles a las causas profundas de la conflictividad social.

Esa situación impone la necesidad de invertir en mecanismos para la prevención y gestión temprana de crisis y episodios de violencia, junto con la implementación de rutas de intervención que permitan a las partes atender las causas profundas de los conflictos, sobre todo aquellas relacionadas con distintas manifestaciones de exclusión. Como se ha descrito en este capítulo, América Latina cuenta con una valiosa experiencia acumulada que puede iluminar rutas para la atención de la conflictividad social vinculada a los recursos naturales. Los Gobiernos de la región han establecido mecanismos institucionales que incluyen sistemas de alerta y respuesta temprana, instancias de diálogo entre múltiples actores con miras a encontrar soluciones sostenibles, mecanismos de coordinación que ordenen la respuesta institucional y fórmulas para el fortalecimiento de la capacidad de prevención y gestión de conflictos sociales.

Desde hace más de una década, el Programa de las Naciones Unidas para el Desarrollo ha apoyado los esfuerzos nacionales orientados a la prevención y la gestión de conflictos sociales en América Latina. Esta experiencia acumulada arroja lecciones que resultan relevantes para mejorar la gobernanza de los recursos naturales en la región, un reto fundamental para la implementación de la nueva agenda de desarrollo contenida en los Objetivos de Desarrollo Sostenible (ODS). La sistematización de esta riqueza de aproximaciones es una tarea pendiente que puede representar una contribución crucial para el diseño de intervenciones dirigidas a sostener la paz en la región. 


\section{Bibliografía}

Ain, G. (2016), "Algunas respuestas del Estado frente a la conflictividad", inédito.

ANH (Agencia Nacional de Hidrocarburos) y otros (2016), Diagnóstico de la conflictividad social: estrategia territorial para la gestión equitativa y sostenible del sector hidrocarburos, Bogotá.

EJ Atlas (Atlas de Justicia Ambiental) [en línea] https:/ / ejatlas.org/.

ICMM (Consejo Internacional de Minería y Metales) (2015), Research on CompanyCommunity Conflict, Londres [en línea] https://www.icmm.com/website/ publications/pdfs/social-and-economic-development/8515.pdf.

INDH (Instituto Nacional de Derechos Humanos) (2018), "Mapa de conflictos socioambientales" [en línea] http://mapaconflictos.indh.cl/\#/.

OCMAL (Observatorio de Conflictos Mineros en América Latina) [en línea] https://www.ocmal.org/.

OLCA (Observatorio Latinoamericano de Conflictos Ambientales) [en línea] http://www.olca.cl/.

PADEP/GTZ (Programa de Apoyo a la Gestión Pública Descentralizada y Lucha contra la Pobreza/Organismo Alemán de Cooperación Técnica) (2008), Manual gerencial del sistema de gestión de conflictos sociales, La Paz.

PNUD (Programa de las Naciones Unidas para el Desarrollo) (2017), Estrategia territorial de hidrocarburos: balance y lecciones aprendidas, Bogotá.

(2016a), Más allá del conflicto, luchas por el bienestar. Informe nacional de desarrollo humano, 2015/2016, Ciudad de Guatemala.

(2016b), Diálogo y gobernanza de los recursos naturales en el Perú: 24 avances representativos, Lima.

(2014), Institucionalidad para el diálogo y la prevención de conflictos: el caso peruano, Lima.

PNUD (Programa de las Naciones Unidas para el Desarrollo)/Fundación Unir Bolivia (2011), Los conflictos sociales en América Latina, La Paz.

PNUD/OEA (Programa de las Naciones Unidas para el Desarrollo/Organización de los Estados Americanos) (2015), Guía práctica para el diseño de sistemas de alerta y respuesta temprana de conflictos sociales, Panamá.

Presidencia del Consejo de Ministros del Perú (2015), Informes de la Oficina Nacional de Diálogo y Sostenibilidad [en línea] http://www.pcm.gob.pe/ etiqueta/willaqniki/.

Programa Estado de la Nación en Desarrollo Humano Sostenible (2011), Cuarto Informe Estado de la Región Centroamericana en Desarrollo Humano Sostenible, San José.

Pruitt, B. y P. Thomas (2008), Diálogo democrático: un manual para practicantes, Washington, D.C., Programa de las Naciones Unidas para el Desarrollo (PNUD)/Instituto Internacional para la Democracia y la Asistencia Electoral (IDEA)/Organización de los Estados Americanos (OAS).

Ramírez, P. (2011), "Acciones colectivas en Centroamérica”, documento preparado para el Cuarto Informe Estado de la Región Centroamericana en Desarrollo Humano Sostenible, San José.

SIGETH (Sistema de Información Geográfica para la Estrategia Territorial de Hidrocarburos) [en línea] http:/ / sigeth.saecl.co/. 


\section{Capítulo XVI \\ Pasivos ambientales mineros: retos para la sostenibilidad}

Carlos de Miguel Mauricio Pereira

En este capítulo se examina la situación de los pasivos en América Latina y el Caribe y sus presiones ambientales. Se describen además algunos elementos vinculados con su gestión, monitoreo y remediación, así como con los aspectos preventivos asociados al cierre de faenas mineras. Se resalta la importancia de contar con marcos de ordenación, tanto legales como institucionales, que faciliten la aplicación efectiva del principio de quien contamina paga, y de disponer de fuentes y estructuras de financiamiento para llevar a cabo actividades de remediación. Por último, se muestran diversas experiencias internacionales en el tratamiento y rentabilización de los pasivos ambientales mineros, así como el potencial del análisis de los riesgos para incluir la resiliencia de las comunidades afectadas.

Es indudable el peso específico que tiene la minería dentro de la economía de numerosos países de América Latina y el Caribe. Sin embargo, su naturaleza extractiva, las externalidades negativas sobre el medio ambiente asociadas al proceso productivo y los riesgos potenciales que presentan para la salud de las personas la emisión y la acumulación de diversos contaminantes, ocasionan costos que podrían contrarrestar parte de los beneficios económicos. Además, los beneficios y costos se distribuyen en forma desigual, lo que da pie a crecientes conflictos socioambientales.

Evitar o mitigar los impactos socioambientales negativos requiere de una gestión ambiental adecuada a lo largo de todo el ciclo extractivo. 
El cierre de minas, las faenas mineras abandonadas y la remediación de sitios contaminados cuando termina el proceso de extracción son elementos centrales para una gestión sostenible de la minería, dadas sus implicaciones potenciales sobre el entorno. Los puntos en común de las definiciones de "pasivo ambiental minero" se relacionan con los conceptos de faenas mineras abandonadas o paralizadas, costos socioambientales y riesgo. En muchos casos, una faena abandonada o paralizada se considera un pasivo ambiental minero solamente si existe un riesgo significativo para la vida, la salud de las personas o el medio ambiente, por lo que el análisis del riesgo es también esencial.

Además, es importante considerar que los pasivos ambientales mineros muchas veces han tenido su origen en décadas o incluso siglos, por lo que su identificación, catastro y análisis de riesgos no es simple. Cuando no es posible asignar la propiedad y las responsabilidades, la gestión y remediación de sus impactos socioambientales muchas veces termina recayendo en el Estado. Pese a los costos sociales que ello supone, muy pocos países de la región presentan una legislación sobre pasivos ambientales mineros y solo se encuentran leyes relativas al cierre de faenas que, si bien buscan prevenir los pasivos del futuro, no logran hacerse cargo de los pasivos ambientales mineros que se crearon en el pasado.

En la próxima sección se analiza el estado de los pasivos ambientales mineros en América Latina y el Caribe, con inclusión de las legislaciones nacionales, las definiciones existentes y el número de pasivos catastrados en algunos países. A continuación, se analizan distintas alternativas de gestión, entre las que se encuentran las preventivas y correctivas. En la siguiente sección se describe el concepto de riesgo, aspecto fundamental para definir un pasivo ambiental minero, que puede complementarse con un enfoque de resiliencia para hacer partícipes a las comunidades de las decisiones y los planes de desarrollo. Luego se analiza el concepto de reactivación de pasivos mediante la minería secundaria y, en la última sección, se presentan las conclusiones y recomendaciones.

\section{A. Estado de los pasivos ambientales mineros en América Latina y el Caribe}

El surgimiento de pasivos ambientales mineros se explica por múltiples factores, entre los que cabe destacar la ausencia de regulación, la fiscalización limitada y la falta de recursos financieros. Si bien existe legislación aplicable al cierre de faenas mineras en varios países de la región, solo en algunos, como el Perú, se ha promulgado una ley específica sobre pasivos ambientales mineros. El bajo nivel de fiscalización sobre el terreno, junto con prácticas inadecuadas de extracción y manejo de los residuos, constituyen también limitantes para la correcta gestión de los pasivos ambientales mineros. Además, la falta o la insuficiencia de inventarios de estos que contengan 
la ubicación de las faenas mineras (muchas de ellas abandonadas), así como la información de su riesgo, no permiten la aplicación adecuada de políticas públicas y entorpecen la aplicación eficiente de los escasos recursos disponibles. En efecto, la limitación de los recursos financieros públicos y las bajas provisiones de las empresas privadas para remediar y rehabilitar los sitios contaminados imponen un desafío adicional.

El grado de formalidad y el tamaño de las empresas extractivas también influyen en el abandono de las faenas mineras. De acuerdo con Altomonte y Sánchez (2016), la minería grande y mediana son las que destinan mayores recursos a enfrentar esta problemática, aunque no están exentas de producir pasivos y, por consiguiente, causar costos socioambientales. A su vez, la minería de menor escala y la informal destinan menos recursos a la remediación y presentan un menor cumplimiento de las normas ambientales. En Yupari (2003) se resalta la importancia de la pequeña minería y la minería artesanal en la creación de pasivos ambientales mineros, sobre todo en Bolivia (Estado Plurinacional de), Colombia, el Ecuador y el Perú.

Si bien existe una idea común de lo que es un pasivo ambiental minero, cada país posee definiciones diferentes y con distinto grado de formalización, ya sea en la legislación nacional, decretos ministeriales o estudios específicos. La falta de una definición estandarizada hace que, dependiendo del país, se asocien conceptos diferentes a un mismo problema. Con ello, las obligaciones y enfoques de restauración también difieren, lo que dificulta la colaboración y el intercambio de experiencias entre países.

En el cuadro XVI.1 se describen las principales definiciones de pasivos ambientales mineros en Bolivia (Estado Plurinacional de), Chile, Colombia, México y el Perú. De estos países, solo en el Perú la definición de "pasivo ambiental minero" se encuentra dentro del marco de una ley, mientras que en Chile y Colombia forma parte de anteproyectos de ley. A su vez, en Bolivia (Estado Plurinacional de) y México solo existen simples definiciones de pasivos ambientales. A modo ilustrativo, en SERNAGEOMIN/BGR (2008) se señala que los componentes de una faena minera abandonada o paralizada consisten en el conjunto de instalaciones y lugares de trabajo de la industria extractiva minera, tales como minas, plantas de tratamiento, fundiciones, refinerías, maestranzas, talleres, casas de fuerza, campamentos, bodegas, depósitos de residuos y, en general, la totalidad de las labores, instalaciones y servicios de apoyo e infraestructura necesaria para el funcionamiento de la operación.

Para que una faena minera abandonada o paralizada se considere un pasivo ambiental minero, también es necesario que presente un riesgo para la comunidad. Por ello, en las definiciones del cuadro XVI.1 se incluyen diversos conceptos relacionados con el riesgo, como "riesgo significativo", "riesgo inminente" y "riesgo permanente y potencial". 


\section{Cuadro XVI.1}

\section{América Latina (5 países): definiciones de pasivos ambientales mineros ${ }^{\mathrm{a}}$}

\begin{tabular}{|c|c|c|}
\hline País & Definiciones & Publicación \\
\hline $\begin{array}{l}\text { Bolivia (Estado } \\
\text { Plurinacional de) }\end{array}$ & $\begin{array}{l}\text { No existe una definición oficial de "pasivo ambiental } \\
\text { minero", pero sí se delimita pasivo ambiental como: } \\
\text { - "el conjunto de impactos negativos perjudiciales } \\
\text { para la salud y/o el medio ambiente, ocasionados } \\
\text { por determinadas obras y actividades existentes } \\
\text { en un determinado período de tiempo", y } \\
\text { - "los problemas ambientales en general } \\
\text { no solucionados por determinadas obras } \\
\text { o actividades". }\end{array}$ & $\begin{array}{l}\text { Decreto Supremo } \\
\text { núm. } 24.176 \text {, de } 8 \text { de } \\
\text { diciembre de } 1995\end{array}$ \\
\hline Chile & $\begin{array}{l}\text { "Faena minera abandonada o paralizada, } \\
\text { incluyendo sus residuos, que constituye un riesgo } \\
\text { significativo para la vida o salud de las personas } \\
\text { o para el medio ambiente". }\end{array}$ & $\begin{array}{l}\text { Anteproyecto de Ley sobre } \\
\text { Remediación de Pasivos } \\
\text { Ambientales Mineros } \\
\text { de } 2005\end{array}$ \\
\hline Colombia & $\begin{array}{l}\text { "Deterioro o daño ocasionado a los recursos } \\
\text { naturales como consecuencia de actividades que } \\
\text { generan contaminación o detrimento del medio } \\
\text { ambiente (Oblasser, 2016). Es una obligación que } \\
\text { se origina en pérdidas significativas de bienestar } \\
\text { o riesgos inminentes para las personas, que se } \\
\text { presentan como consecuencia del detrimento de } \\
\text { los recursos naturales renovables, cuando este } \\
\text { detrimento supera los niveles social, técnica o } \\
\text { legalmente aceptables y ha sido causado por una } \\
\text { actividad minera". } \\
\text { "Son considerados pasivos ambientales } \\
\text { la obligación de asumir el costo de un } \\
\text { deterioro ambiental del suelo, el aire, el agua } \\
\text { o la biodiversidad, que no fue oportuna y/o } \\
\text { adecuadamente mitigado, compensado, manejado, } \\
\text { corregido o reparado, la cual deberá ser asumida } \\
\text { por el propietario, poseedor o tenedor del sitio } \\
\text { donde se encuentre, independiente de cualquier } \\
\text { acción civil, sancionatoria o administrativa que el } \\
\text { Estado pueda iniciar". }\end{array}$ & $\begin{array}{l}\text { Informes de entes privados } \\
\text { y universidades al } \\
\text { Ministerio de Minas } \\
\text { y Energía, entre otros }\end{array}$ \\
\hline México & $\begin{array}{l}\text { "Aquellos sitios contaminados por la liberación de } \\
\text { materiales o residuos peligrosos, que no fueron } \\
\text { remediados oportunamente para impedir la } \\
\text { dispersión de contaminantes, pero que implican } \\
\text { una obligación de remediación". }\end{array}$ & $\begin{array}{l}\text { Reglamento de la Ley } \\
\text { General para la Prevención } \\
\text { y Gestión Integral de los } \\
\text { Residuos }\end{array}$ \\
\hline Perú & $\begin{array}{l}\text { "Aquellas instalaciones, efluentes, emisiones, } \\
\text { restos o depósitos de residuos producidos } \\
\text { por operaciones mineras, en la actualidad } \\
\text { abandonadas o inactivas y que constituyen } \\
\text { un riesgo permanente y potencial para la salud } \\
\text { de la población, el ecosistema circundante } \\
\text { y la propiedad". }\end{array}$ & $\begin{array}{l}\text { Ley núm. } 28.271 \text { que } \\
\text { regula los Pasivos } \\
\text { Ambientales de la } \\
\text { Actividad Minera }\end{array}$ \\
\hline
\end{tabular}

Fuente: Elaboración propia, sobre la base de A. Oblasser, "Estudio sobre lineamientos, incentivos y regulación para el manejo de los pasivos ambientales mineros (PAM), incluyendo cierre de faenas mineras. Bolivia (Estado Plurinacional de), Chile, Colombia y el Perú", serie Medio Ambiente y Desarrollo, № 163 (LC/L.4208), Santiago, Comisión Económica para América Latina y el Caribe (CEPAL), 2016; M. Saade, "Buenas prácticas que favorezcan una minería sustentable: la problemática en torno a los pasivos ambientales mineros en Australia, el Canadá, Chile, Colombia, los Estados Unidos, México y el Perú", serie Macroeconomía del Desarrollo, № 157 (LC/L.3885), Santiago, Comisión Económica para América Latina y el Caribe (CEPAL), 2014.

a Si no se encuentran definiciones de pasivos ambientales mineros, se incluye la de pasivos ambientales en general. 


\section{Número de pasivos y su estado en la región ${ }^{1}$}

Si bien desde épocas precoloniales se han generado pasivos ambientales mineros, solamente desde mediados de la década de 2000 se comenzaron a crear inventarios y catastros de pasivos ambientales mineros. En la mayoría de los países de la región, los esfuerzos iniciales por realizar este levantamiento se deben a iniciativas internacionales que con el tiempo se han institucionalizado. Para desarrollar un poco más esta temática, se hace necesario aumentar la disponibilidad y frecuencia de la información sobre los pasivos ambientales mineros, además de promover la homogenización de criterios para la medición de riesgos.

En el Estado Plurinacional de Bolivia se levantó información durante los años 2005 a 2008 y 2011, lo que ha permitido catastrar un total de 973 pasivos ambientales mineros. Un $7 \%$ de estos se clasificaron como de alta prioridad de remediación, sobre la base del riesgo asociado a su potencial generación de drenaje ácido. En 2014, el Servicio Geológico Minero estimó que el inventario de pasivos ambientales mineros incluye el 40\% del total existente en el Estado Plurinacional de Bolivia.

En Chile, el Servicio Nacional de Geología y Minería (SERNAGEOMIN) es el encargado de realizar los inventarios de faenas mineras abandonadas o paralizadas (FMA/P) del país. En el período 2003-2014 se han catastrado 492 faenas en esta condición. La medición del riesgo de las FMA/P se ordena a partir de categorías relacionadas con contaminación, flujos hacia el exterior o colapso masivo, problemas de seguridad y usos de terreno, entre otros. También se ha desarrollado el Atlas de Depósitos de Relaves, que incluye depósitos de relaves activos, no activos, abandonados y aquellos de los que no se tiene información. Sin embargo, en el país aún no se presenta un inventario o un atlas específico de pasivos ambientales mineros.

En Colombia, el Ministerio de Minas y Energía desarrolla el inventario de áreas con actividad minera en estado de abandono. Hasta 2015, se ha inventariado un total de 449 áreas mineras en estado de abandono. Por otro lado, el Ministerio de Ambiente y Desarrollo Sostenible ha identificado unos 522 pasivos ambientales mineros mediante la solicitud de información a varios actores en el sector.

Uno de los países más avanzados en la región en cuanto a la legislación sobre pasivos ambientales mineros y la creación de inventarios es el Perú, donde se realizan inventarios anuales desde 2006. Las últimas cifras publicadas por el Ministerio de Energía y Minas dan cuenta de 8.854 pasivos ambientales mineros inventariados hasta 2016. Los riesgos evaluados para su priorización corresponden a temas de seguridad, salud humana y ambiente físico, así como riesgos para la fauna silvestre y la conservación.

Esta sección se basa en Oblasser (2016). 


\section{B. Causas y principales problemas socioambientales vinculados con los pasivos ambientales mineros}

La importancia de la rehabilitación y remediación de un pasivo ambiental minero radica en la necesidad de controlar sus impactos negativos sobre la sociedad y el medio ambiente. De no gestionarse correctamente el pasivo, se podrían generar altos costos que, en muchos casos, superarían los de las labores preventivas.

Según cuál sea el tipo de pasivo analizado, se manifiestan diversos impactos que se transmiten al medio ambiente, como el escurrimiento superficial, la infiltración y el drenaje ácido, que afectan directamente las aguas superficiales, subterráneas y diversos ecosistemas. También se destacan los efectos de arrastre de material particulado que puede contener compuestos tóxicos para la salud humana y el medio ambiente. Según la Defensoría del Pueblo (2015) del Perú, los principales impactos ambientales de las actividades mineras se relacionan con el destino y localización de los relaves, el escape de drenaje ácido (rico en minerales) y las bocaminas sin llenar.

En Martínez (2003) se describen riesgos relacionados con las fases productivas de la minería. Con respecto a la fase de cierre y remediación se señala que, si se abandonaran las instalaciones mineras, con el paso del tiempo aumentaría la inestabilidad y el deterioro de las membranas que protegen los relaves y los depósitos estériles, con lo que serían mayores las posibilidades de contaminación.

A su vez, los factores que condicionan la vulnerabilidad social y ambiental ante estos pasivos dependen muchas veces de su extensión y localización, así como de su cercanía a vías de contaminación y transporte de los elementos contaminados como el agua, el aire y el suelo (Figueroa, 2011). En este sentido, es relevante la distancia entre los pasivos ambientales mineros y los posibles receptores de la contaminación como: centros poblados, caminos, recursos hídricos, zonas agropecuarias y áreas silvestres. A modo de ejemplo, los impactos sobre los recursos hídricos podrían deberse a la cercanía de relaves abandonados que presenten drenaje ácido o a derrumbes de excavaciones subterráneas que podrían cambiar la circulación hídrica.

Según Figueroa (2011), también existen condiciones climáticas como el nivel, intensidad y frecuencia de las precipitaciones que pueden aumentar la filtración e infiltración de las aguas de relaves, el arrastre de material o los derrumbes. Estos efectos podrían verse incrementados en el futuro a causa del cambio climático. Por su parte, los vientos producen impactos directos al transportar materiales y partículas livianas con altos niveles de concentración de metales. La sismicidad de la zona donde 
se ubican los pasivos ambientales mineros también puede ocasionar inestabilidad de los taludes, en mayor medida que las instalaciones mineras abandonadas y sin mantenimiento. Otro factor de riesgo guarda relación con los tipos de suelo donde se emplazan estos pasivos y su grado de permeabilidad.

En suma, los pasivos ambientales mineros constituyen un riesgo para la sociedad y el medio ambiente, muchas veces asociado con la seguridad física y la contaminación. Estos riesgos pueden afectar a las personas, al medio ambiente y a las actividades económicas productivas, lo que muchas veces desencadena altos grados de conflictividad con las comunidades cercanas.

\section{La importancia de la gestión de los pasivos ambientales mineros}

Para gestionar correctamente los pasivos ambientales mineros es necesario definir las diferencias entre la gestión de un pasivo y el cierre minero. Los pasivos ambientales mineros se circunscriben a un período histórico donde las faenas están inactivas o abandonadas, mientras que el plan de cierre se asocia con aquellas faenas que aún se encuentran activas o que lo estarán en un futuro. Por lo anterior, la gestión de pasivos ambientales mineros busca mitigar, remediar y prevenir daños mediante la aplicación de un plan de remediación, mientras que la gestión del cierre de faenas busca prevenir daños futuros y evitar la creación de nuevos pasivos.

En otras palabras, la gestión de pasivos se puede separar entre la correctiva de los pasivos ambientales mineros existentes y la preventiva de los pasivos ambientales mineros futuros (cierre de faenas). Por último, no siempre se identifica al responsable de la creación de los pasivos. Por ese motivo, el financiamiento de su gestión suele realizarse con fondos públicos. Entretanto, en el cierre de minas sí se identifica al responsable, al que en general se le exigen garantías (Oblasser y Chaparro, 2008).

La gestión de los actuales pasivos y la prevención de los futuros deben involucrar la aplicación de diversos principios ambientales ${ }^{2}$. La mayor parte de estos se encuentran consagrados en los 27 principios de la Declaración de Río sobre el Medio Ambiente y el Desarrollo de 1992. Por ejemplo: i) el principio de la introducción de la variable ambiental en la toma de decisiones (Principio 4); ii) el principio de prevención; iii) el principio precautorio (Principio 15); iv) el principio del que contamina, paga (Principio 16); v) el principio de responsabilidad común pero diferenciada (Principio 7); vi) el principio de participación (Principio 10), y vii) el principio de los

2 Véanse mayores detalles sobre los principios ambientales en Moreno y Chaparro (2008). 
derechos intergeneracionales (Principio 3). En este sentido, las legislaciones y normativas nacionales deben incluir y hacer cumplir estos conceptos, decididamente ligados a la búsqueda del desarrollo sostenible.

Hay que señalar que existen condiciones para que la gestión ambiental sea eficaz y eficiente en un país, como la existencia de un marco legal y regulatorio, instrumentos económicos y normas específicas. La correcta aplicación de estos instrumentos también depende de que la institucionalidad que la lleve a cabo esté dotada de recursos y de facultades adecuadas dentro de un marco procedimental. Por último, es necesario crear instancias de participación ciudadana y esquemas de colaboración público-privada que promuevan visiones integradoras.

\section{Gestión correctiva}

El primer paso de la gestión correctiva es contar con inventarios que permitan identificar y evaluar el riesgo potencial de los pasivos ambientales mineros $y$, a partir de ello, priorizarlos para su remediación. Es fundamental la existencia de una legislación específica sobre esta materia, de modo que las instituciones encargadas puedan tener atribuciones fiscalizadoras y sancionatorias. Muy pocos países de la región poseen una ley de pasivos ambientales mineros, por lo que es necesario que se profundice en esta materia.

Las medidas correctivas de estos pasivos están en línea con el principio de que quien contamina paga y deben incluir estándares de regeneración y de remediación basados en criterios objetivos. Para que este principio se haga efectivo, es necesario que se asignen las responsabilidades respectivas a fin de determinar quién debe financiar y ejecutar la remediación. Sin embargo, al no poder identificar o localizar a quien generó el pasivo, el Estado muchas veces es quien se encarga de la remediación para evitar otros daños potenciales. De esta manera, el pasivo ambiental se convierte en un pasivo contingente en el marco de la política cuasifiscal.

En cuanto al financiamiento de estas medidas, en Oblasser (2016) se identifican diversas fuentes para que el Estado pueda cubrir los costos de no identificar a los responsables directos del pasivo. Entre estas cabe mencionar: i) fondos presupuestarios; ii) multas, cargos o impuestos específicos a actividades contaminantes; iii) fondo de protección ambiental $\mathrm{u}$ otros fondos concursales para ejecutar proyectos de remediación; iv) alianzas público-privadas, y iv) asistencia internacional, entre otras. En la región se destacan diversas gestiones correctivas que han buscado remediar los pasivos ambientales mineros. En Oblasser (2016) se exponen diversos ejemplos de remediación, que a continuación se resumen.

En el Estado Plurinacional de Bolivia se destaca la Corporación Minera de Bolivia (COMIBOL), que se encarga de regenerar diques de 
colas y centros mineros. Esta iniciativa de remediación se ha caracterizado por el desarrollo de obras civiles destinadas al control de la contaminación y la cobertura de los pasivos.

En Chile resaltan algunos proyectos de remediación de relaves, en general por medio de alianzas público-privadas. Muchas de estas actividades se enmarcan en planes de descontaminación o del Sistema de Evaluación de Impacto Ambiental. En su mayoría, corresponden al retiro y reubicación de residuos mineros, aunque también se han puesto a prueba tecnologías como la fitoestabilización, la biorremediación y la extracción y tratamiento de agua subterránea, entre otras.

En el Perú se han realizado numerosos esfuerzos de remediación. En este sentido, se destaca el trabajo conjunto entre el Estado, el sector privado y la comunidad. En 2008, se descontaminaron aguas ácidas en la subcuenca del río Tingo, en el departamento de Cajamarca. A partir de 2012 entró en funcionamiento la empresa estatal Activos Mineros S.A.C., dedicada a la remediación de pasivos ambientales mineros y el tratamiento de relaves en diversas zonas del país.

\section{Gestión preventiva}

La gestión para prevenir los futuros pasivos ambientales mineros se encuentra mucho más institucionalizada en la región que la propia gestión correctiva. En la mayoría de los países, es posible encontrar leyes específicas sobre el cierre de faenas mineras, así como leyes ambientales más generales que incluyen el cierre de un proyecto y la aplicación de evaluaciones de impacto ambiental, en las que se tiene en cuenta el ciclo completo del proyecto minero. También se consideran garantías financieras y se estipulan los costos previstos de la remediación. De esta forma se evita la creación de futuros pasivos ambientales mineros y de nuevos costos para el Estado.

En la mayoría de los países donde se desarrolla la minería, se elaboran leyes y códigos que reglamentan la actividad minera y el cierre de faenas. Los planes de cierre establecen las condiciones de estabilidad física y química de la faena y deben ser seguidos por la empresa extractiva con el fin de mitigar sus impactos negativos sobre el medio ambiente. En la región se destaca la Ley que Regula el Cierre de Faenas e Instalaciones Mineras en Chile (Ley núm. 20.551), el Reglamento Ambiental para Actividades Mineras (Decreto Supremo núm. 24.782) en Bolivia (Estado Plurinacional de), las obligaciones al término de una actividad minera (Ley núm. 685, art. 209) en Colombia y la regulación del cierre de minas (Ley núm. 28.090) en el Perú. En la mayoría de las normativas también se incluyen garantías y provisiones contables exigibles a las empresas para asegurar el cumplimiento de estas actividades. 
Uno de los instrumentos de gestión ambiental más difundidos en la región son las evaluaciones de impacto ambiental, que permiten considerar los aspectos ambientales en la elaboración, gestión y cierre de un proyecto. En la evaluación del impacto ambiental de un proyecto minero se tienen en cuenta todas sus fases, con inclusión del cierre de operaciones y, si es necesario, de programas de restauración con miras a prevenir impactos negativos sobre el medio ambiente. La CEPAL (2018) menciona que la mayoría de los 33 países de la región cuentan con este instrumento, que además incluye la participación ciudadana. Junto con lo anterior es necesario que se desarrolle el seguimiento y monitoreo de los compromisos ligados a la evaluación, con el fin de que se materialice una gestión integral del proyecto.

\section{Monitoreo de los pasivos ambientales mineros y actividades posteriores al cierre}

Debido a que los pasivos ambientales mineros son numerosos y su remediación no se efectúa de manera inmediata, es necesario que se mantengan el monitoreo y el control a fin de evitar riesgos potenciales y posibles impactos negativos sobre la comunidad. A su vez, después de remediar un pasivo ambiental minero y cuando se desarrollan las actividades posteriores al cierre de una faena, deben incluirse tareas vinculadas con su mantenimiento y monitoreo físico, geoquímico, hidrológico y biológico (MINEM, 2010). También resulta relevante mantener un vínculo estricto con las comunidades cercanas al sitio para hacer un seguimiento de las funciones y responsabilidades acordadas con estas y establecer una participación adecuada en la toma de decisiones en torno al monitoreo.

El Gobierno de Chile está realizando un primer esfuerzo para lograr un monitoreo continuo de los relaves mineros. Esta iniciativa se enmarca en el Programa Nacional de Minería Alta Ley y con ella se busca desarrollar sistemas de monitoreo de la estabilidad física y química de depósitos de relaves con el fin de proporcionar información en tiempo real a las compañías mineras, las comunidades y el Gobierno. Este proyecto tiene como objetivo reforzar la gestión operacional, reducir la percepción de riesgo, promover la comunicación entre las partes y mejorar la respuesta ante situaciones de emergencia ${ }^{3}$. Este ejercicio podría reproducirse o incluirse en los planes de monitoreo de actividades de naturaleza extractiva de otros países.

\section{Recomendaciones internacionales}

A nivel internacional se han desarrollado diversos estudios sobre los pasivos ambientales mineros, su impacto y gestión. Un tema recurrente se asocia con la necesidad de contar con una institucionalidad adecuada que permita abordar específicamente esta temática. Dicha institucionalidad

\footnotetext{
Véase [en línea] http://programaaltaley.cl/archivo-iniciativas/relaves/.
} 
también debe tener las atribuciones y los recursos necesarios para realizar el monitoreo y control de los pasivos ambientales mineros.

La CEPAL y la Organización de Cooperación y Desarrollo Económicos (OCDE) han desarrollado diversas evaluaciones de desempeño ambiental adaptadas a las características de los países de América Latina. Estas evaluaciones resaltan la importancia de una correcta gestión minera, en especial de la pequeña minería y la minería artesanal, así como de la formalización de la minería informal, con el fin de hacer que disminuyan las presiones y riesgos para la salud de las personas y el medio ambiente. En las evaluaciones se recomienda mantener una relación transparente e informada entre las comunidades cercanas a los lugares de explotación y las actividades extractivas, con miras a evitar y reducir los conflictos socioambientales.

En la primera evaluación de desempeño ambiental de Chile (OCDE/ CEPAL, 2005) se recomendó que el sector minero redujera su impacto ambiental en término de emisiones al aire y el agua y con respecto a sitios y tranques de relaves abandonados, entre otros. En la segunda evaluación de desempeño ambiental del citado país (CEPAL/OCDE, 2016b) se resaltó la necesidad de aumentar la información sobre las operaciones mineras de pequeña escala y sus efectos sobre el medio ambiente. También se recomendó mantener y actualizar de manera sistemática los registros de los riesgos, la ubicación y el estado de los pasivos ambientales mineros; establecer mecanismos financieros relacionados con la imposición de cargos para descontaminar e instituir un fondo con ese objetivo. Se resalta que no existe reglamentación específica sobre la remediación de zonas contaminadas y que tampoco existe ningún organismo específico responsable de investigar y descontaminar esas tierras.

En años recientes se han destacado otros avances, como la política nacional de Chile respecto de la gestión de sitios con presencia de contaminantes (año 2009), la entrada en vigor de la ley que regula el cierre de faenas e instalaciones mineras de 2012 y la realización de los primeros estudios sobre la ubicación y el estado de los pasivos ambientales mineros. Si bien la ley relativa al cierre de faenas e instalaciones mineras exige que todas las nuevas actividades mineras obtengan la aprobación de sus planes de cierre, esto no se aplica a las faenas ya abandonadas.

Por su parte, en la evaluación de desempeño ambiental de Colombia (OCDE/CEPAL, 2014) se hace hincapié en la minería del oro, principalmente la artesanal e ilegal. Se señala que más del $50 \%$ de las pequeñas empresas mineras no cumplen su obligación de informar sobre los residuos peligrosos que producen. Además, se observa que la minería ilegal es responsable de la emisión de una gran cantidad de sustancias químicas peligrosas para el medio ambiente. Por ello, se recomienda profundizar el control de residuos y seguir una estrategia correctiva integral de los 
terrenos contaminados a fin de evitar los riesgos sobre la salud y el medio ambiente. Con respecto a los pasivos ambientales mineros se recomienda un uso más intensivo y amplio de los seguros ambientales obligatorios en los proyectos de mayor tamaño y riesgo. El seguro minero-ambiental (garantía de cumplimiento de las obligaciones ambientales) incluye el desmantelamiento de sitios y la rehabilitación ambiental posterior al cierre. En la evaluación también se ponen de relieve las presiones ejercidas sobre la diversidad biológica a causa de la presencia de la minería en zonas de importancia ecológica.

En la evaluación de desempeño ambiental del Perú (CEPAL/ OCDE, 2016a) se recomienda mantener y profundizar la remediación de los pasivos ambientales mineros y priorizar sus riesgos. Además, se promueve el apoyo a la pequeña minería y la minería artesanal con asistencia tecnológica y esquemas de promoción de la comercialización, con miras a lograr economías de escala, estructuras formales y la adopción de tecnologías y prácticas ambientalmente sostenibles. También se recomienda continuar e intensificar los esfuerzos encaminados a eliminar la minería ilegal y formalizar la informal. Otra recomendación es que la minería artesanal utilice técnicas y estándares internacionales para prevenir el deterioro ambiental y sus consecuencias sobre la salud y la calidad de vida de las personas.

Respecto de los pasivos ambientales mineros en el Perú, en la evaluación se recomienda ampliar la información sobre riesgos, aprovechar su potencial económico, determinar la propiedad y las responsabilidades y diseñar e implementar mecanismos de monitoreo. También se sugiere incrementar los esfuerzos de remediación, con especial énfasis en los sitios abandonados y de mayor riesgo, establecer la responsabilidad y las necesidades de financiamiento para la remediación de los pasivos ambientales mineros abandonados y aprovechar la cooperación internacional en materia técnica, así como asegurarse de que los planes de remediación sean aprobados $\mathrm{y}$ fiscalizados por las entidades competentes.

La Organización Latinoamericana y del Caribe de Entidades Fiscalizadoras Superiores (OLACEFS) realizó en 2016 una auditoría sobre pasivos ambientales (OLACEFS, 2016) que abarcó ocho países de la región (Colombia, Chile, Ecuador, México, Paraguay, Perú y República Dominicana) y dos provincias de la Argentina (Buenos Aires y Santa Fe). Entre los mayores retos detectados en esta evaluación se destacan los inventarios incompletos de pasivos ambientales, la escasa capacidad operativa para sancionar, la existencia de minería ilegal, la escasez de mecanismos de supervisión y monitoreo y la falta de un marco normativo para sancionar a los infractores de la normativa ambiental.

$\mathrm{Al}$ respecto, las principales recomendaciones señaladas en ese documento son: i) que se fortalezca el marco normativo sobre pasivos 
ambientales; ii) que se establezca un concepto de pasivo ambiental; iii) que exista una institucionalidad adecuada para llevar a cabo la prevención, el control y la restauración de pasivos ambientales, así como la mitigación de sus efectos negativos; iv) que las instituciones estén dotadas de recursos humanos y materiales; v) que exista un proceso de planificación para la correcta gestión integral de los pasivos, y que se aseguren la rendición de cuentas y la participación ciudadana; vi) que existan sistemas de información que permitan inventariar y tomar acciones sobre los pasivos, que se fortalezca la evaluación de impacto ambiental para el manejo adecuado de los residuos; vii) que se identifiquen los generadores de pasivos con el fin de hacer cumplir el principio de quien contamina paga; viii) que se cuente con un marco normativo adecuado; ix) que existan mecanismos para la remediación y la mitigación de los efectos negativos de los pasivos, y x) que se desarrollen análisis de eficacia en función de los costos de las medidas destinadas a la gestión de pasivos, entre otros.

\section{Mecanismos de financiamiento}

La rehabilitación y remediación de los pasivos ambientales mineros son fundamentales para eliminar los impactos socioambientales que estos pueden ocasionar. Sin embargo, debido a la dificultad para identificar a los responsables de los pasivos ambientales mineros abandonados, muchas veces estas tareas recaen en el Estado. Por ello, es importante diseñar mecanismos adecuados de financiamiento que incentiven la implementación efectiva del principio de quien contamina paga.

Respecto de la gestión preventiva de los pasivos, existen diversas garantías financieras para prevenir el riesgo de insolvencia de las empresas extractivas y evitar que la carga financiera se traspase posteriormente al Estado. Las garantías financieras pueden aplicarse mediante diversos instrumentos, como los que enumera la Agencia de Protección Ambiental de los Estados Unidos (EPA) en la Ley de conservación y recuperación de recursos (Ley RCRA) y que permiten asegurar el tratamiento, almacenamiento y eliminación definitiva de los residuos peligrosos. Entre estos instrumentos se señalan:

- Fondos fiduciarios: donde la empresa deposita el dinero que ha de emplearse durante y con posterioridad al cierre de faenas.

- Garantías: la empresa puede obtener una garantía para el cumplimiento de todos los requisitos de cierre y posteriores al cierre. Si la empresa no cumple los requisitos especificados, la compañía que emitió la garantía es responsable de los costos. También se exige a la empresa que establezca un fondo de reserva para que el emisor de la garantía pueda pagar la remediación. 
- Carta de crédito: una empresa minera puede obtener una carta de crédito de una institución facultada a tal efecto. La carta de crédito debe ser por un monto igual al de la estimación del costo de cierre y se debe aumentar si el costo estimado se incrementa. La empresa también debe establecer un fondo de reserva para que la institución que emite la carta de crédito pueda pagar si la empresa no cumple con sus obligaciones de cierre y posteriores al cierre.

- Seguro: la empresa minera puede obtener un seguro por un valor al menos igual al costo estimado para los gastos de cierre y posteriores al cierre. Este monto es el que la aseguradora está obligada a pagar conforme a la póliza y debe aumentar en línea con el aumento de la estimación del costo.

- Prueba financiera: se busca obtener pruebas que demuestren y documenten que la empresa minera tiene activos suficientes ubicados dentro del país para cubrir los costos de las actividades posteriores al cierre.

- Garantías corporativas: una empresa minera puede obtener una garantía de otra compañía que garantice la cobertura de los costos de cierre y posteriores al cierre.

En los Estados Unidos existe un amplio sistema de garantías que se relaciona con fondos en fideicomiso, fondos de empresas, instrumentos del Estado, boletas de garantía, bono de compañías de seguro, garantías corporativas, retención de utilidades, pruebas financieras, prendas y seguros, entre otros. En el Canadá, por su parte, cada provincia regula la actividad minera, pero en general se exige un plan de rehabilitación y una garantía expresada en depósitos en efectivo, bonos del gobierno, boletas de garantías bancarias y garantías corporativas, entre otras. Al aumentar la actividad minera se aprecia una progresividad en las garantías que se ajustan en forma anual. En Australia, a los proyectos mineros de mayor impacto ambiental se les exige una garantía bancaria mediante un bono de cumplimiento incondicional o un monto en efectivo. Este monto también es progresivo, en función del avance de las actividades mineras.

En tanto, en la Unión Europea, la Directiva sobre responsabilidad medioambiental en relación con la prevención y reparación de daños medioambientales (Directiva núm. 2004/35/CE) ha hecho que los operadores tomen seguros o garantías financieras para prevenir y reparar el daño medioambiental. En España, en el marco de la Ley de Responsabilidad Medioambiental (Ley núm. 26/2007, que responde a la Directiva núm. 2004/35/CE), se busca prevenir, evitar y reparar los daños medioambientales. Con este fin, la Ley dispone el establecimiento de diversos mecanismos como las garantías financieras (seguros de 
responsabilidad medioambiental) y dos instrumentos financieros. Uno de ellos es el Fondo de Compensación de Daños Medioambientales, que se constituye a partir de un recargo sobre las primas de las garantías financieras y sirve de complemento a los seguros privados. Este fondo, gestionado por una entidad pública adscrita al Ministerio de Economía y Función Pública, incluye la gestión de los residuos de las industrias extractivas. El otro es el Fondo estatal de reparación de daños medioambientales (cuya gestión al momento de su creación corresponde el Ministerio de Medio Ambiente), que administra recursos del presupuesto general del Estado con el fin de cubrir los costos para prevenir, evitar y reparar los bienes de dominio público de propiedad estatal.

En Chile, por ejemplo, la Ley que regula el cierre de faenas e instalaciones mineras exige la presentación de un plan de cierre aprobado por el SERNAGEOMIN y una garantía financiera antes que comiencen los trabajos de exploración. Entre las garantías se pueden encontrar: i) certificados de depósito a la vista; ii) boletas bancarias de garantía a la vista; iii) certificados de depósitos de menos de 360 días, y iv) cartas de crédito contingentes emitidas por un banco cuya clasificación de riesgo sea del tipo A o superior. Los requisitos para aprobar los planes de cierre de las faenas mineras dependen de que la capacidad mensual de extracción de mineral sea inferior o superior a $10.000 \mathrm{t}$ de mineral bruto. En este esquema, las empresas de menor capacidad de extracción se someten a un régimen simplificado, mientras que las que tienen mayor capacidad se rigen por un procedimiento de aplicación general. En el último caso es donde se aplica uno de los requisitos sobre el establecimiento de las garantías financieras. En 2016, el SERNAGEOMIN resolvió sobre 47 proyectos asociados al procedimiento de aplicación general, de los cuales se aprobaron 17.

Mientras tanto, en la Argentina se establece la obligatoriedad de una garantía financiera por parte de los operadores mineros y se hace obligatoria la contratación de un seguro ambiental para garantizar el financiamiento de la recomposición del daño que pudiera producir y sugiere a los operadores que integren un fondo de restauración ambiental.

En el Perú, por medio de la Ley núm. 28.090 de 2003, donde se normó el cierre de minas, también se incluye la obligatoriedad de constituir garantías financieras que aseguren el plan de cierre. De hecho, el titular de actividad minera no podrá desarrollar las operaciones de exploración, ni de explotación y procesamiento minero, si no ha constituido previamente las garantías. Otro instrumento que se ha utilizado en relación con el cierre de una faena es el de los pools de garantías. Mediante este sistema se busca asegurar a un colectivo con el fin de diversificar riesgos al incluir empresas de distinto tamaño y diferentes tipos de minerales. Este pool muchas veces es entregado por el Estado, sobre todo a las empresas 
dedicadas a la mediana y pequeña minería, para que cubran sus riesgos, ya que muchas veces no pueden acceder a los mercados tradicionales. El sistema de pools también lo han aplicado compañías privadas. Por ejemplo, en España es de destacar el Pool Español de Riesgos Medioambientales (PERM), fundado por siete empresas. Se encuentran instrumentos similares con fines de remediación ambiental en Dinamarca, Francia, Italia y los Países Bajos, que cubren la contaminación gradual proveniente de instalaciones industriales fijas y garantizan los gastos realizados por el asegurado en situaciones de urgencia, con miras a prevenir o limitar los daños a terceros. También se han aplicado pools de garantías para el financiamiento de la remediación de pasivos nucleares, como sucede con el pool suizo relacionado con daños ambientales.

Con el fin de llevar a cabo la gestión correctiva principalmente de los pasivos ambientales mineros, se han creado fondos fiduciarios cuyo financiamiento puede provenir de ingresos fiscales generales o de cargos a industrias específicas. Los fondos pueden utilizarse para financiar la remediación de los sitios afectados por un sector extractivo o por múltiples sectores. Los recursos se utilizan cuando las partes responsables no son identificadas, no se encuentran o no pueden pagar. Algunos fondos permiten solicitar el reembolso a las entidades privadas por las operaciones de remediación ya financiadas.

Entre los primeros fondos públicos a nivel internacional se destacan el Abandoned Mine Reclamation Fund (AMRF), establecido en 1977, y el Superfund de 1980, ambos de los Estados Unidos. El AMRF es administrado por el Departamento del Interior y centra su atención en la minería del carbón. En este caso, se financia principalmente con pagos de las empresas, en función de las toneladas de carbón producidas y de si su extracción ha sido superficial o subterránea. El Superfund es administrado por la Agencia de Protección Ambiental y remedia sitios contaminados, con independencia del sector económico en el que se origine la contaminación. Sus ingresos provienen del fondo general del Estado, aunque en sus inicios se financiaba principalmente mediante impuestos a industrias específicas (véase el cuadro XVI.1).

A nivel internacional, también se han empleado asociaciones público-privadas como mecanismos de financiamiento para la gestión y el tratamiento de pasivos ambientales mineros específicos. De este modo se alivia la carga financiera del Estado, aunque se requiere un marco legal e institucional que permita el involucramiento de privados. Destacan algunas iniciativas como la del proyecto Restor-Action Nunavik del Canadá y los convenios para el retiro de relaves en la localidad de Andacollo, suscritos entre la Subsecretaría del Medio Ambiente de Chile y las compañías mineras Dayton y Teck. 
La cooperación internacional y los préstamos internacionales también financian estudios sobre pasivos ambientales mineros y su remediación. En cuanto a la cooperación internacional bilateral, se puede mencionar la del Instituto Federal de Geociencia y Recursos Naturales (BGR) de Alemania, que tiene diversos proyectos en Bolivia (Estado Plurinacional de), Colombia, Chile, el Ecuador y el Perú, y la de la Agencia de Cooperación Internacional del Japón (JICA), con proyectos de remediación en Chile, como el Fortalecimiento de la capacidad institucional en la gestión ambiental minera y, en el Perú, como el Proyecto de Remediación de Pasivos Ambientales Mineros de Ex Unidades Mineras, entre otros. También existe financiamiento de instituciones multilaterales, como el Banco Mundial y el Banco Interamericano de Desarrollo (BID), que canalizan sus recursos de forma directa o a través de otros organismos, como el Programa de las Naciones Unidas para el Desarrollo (PNUD). El Banco Mundial tiene numerosos proyectos vinculados con la gestión sostenible de la minería. Entre otros, cabe citar el proyecto de Gestión ambiental minera para una producción sustentable, financiado por el BID, implementado por el PNUD y ejecutado por la Secretaría de Minería de la Argentina.

\section{E. Análisis de riesgos y resiliencia en torno a los pasivos ambientales mineros}

El manejo de riesgos es una herramienta crucial para poder analizar y dimensionar el posible impacto de un pasivo ambiental minero sobre las comunidades aledañas. En esta línea, es fundamental un plan de manejo de riesgos para gestionar las condiciones técnicas, económicas y sociales que permitan aumentar el grado de adaptación ante posibles impactos. Junto con lo anterior, es importante realizar un análisis de resiliencia comunitario para complementar el enfoque basado en los riesgos. Esto contribuye a generar las condiciones y el conocimiento necesarios para implementar medidas que involucren la participación de la comunidad, a fin de fortalecer sus capacidades y gestionar estrategias sostenibles de manejo de riesgos.

De acuerdo con la CEPAL (2010), es prioritario que las autoridades de los gobiernos, además de identificar y catastrar los sitios mineros abandonados puedan evaluar sus riesgos y vincularlos con la existencia de pasivos ambientales mineros. También es recomendable jerarquizar los distintos niveles de riesgo con la finalidad de priorizar el tratamiento de los pasivos más riesgosos para la sociedad.

En Martínez (2003) se presenta la terminología básica sobre riesgo, definido como una pérdida potencial asociada a la amenaza sobre un sistema y su grado de vulnerabilidad. A su vez, según la CEPAL (2012), el riesgo se evalúa sobre la base de tres componentes: i) el agente o amenaza; ii) la exposición, y 
iii) la vulnerabilidad. En estas definiciones se incluye el grado de incertidumbre vinculado a la probabilidad de ocurrencia del evento y a su tamaño. Por ello, en línea con el principio precautorio, es necesario que junto con el análisis de riesgo se elaboren planes encaminados a aumentar la seguridad y disminuir la vulnerabilidad de las comunidades y el medio ambiente.

En el manual de evaluación de riesgos de SERNAGEOMIN/BGR (2008) se enuncian dos enfoques metodológicos, uno para medir el riesgo de contaminación y el otro para medir los riesgos en materia de seguridad. En cuanto al riesgo por contaminación, deben confluir tres factores en forma simultánea: el contaminante, el receptor y la vía de exposición. Mientras tanto, para el riesgo en materia de seguridad se necesitan dos factores simultáneos: un escenario de peligro y la presencia de un receptor de dicho escenario. Tras identificar la presencia de los factores de riesgo se recomienda estimar la probabilidad de ocurrencia y la severidad de las consecuencias, y realizar una evaluación que permita priorizar las faenas mineras abandonadas o paralizadas, siguiendo los pasos descritos en el cuadro XVI.2.

\section{Cuadro XVI.2 \\ Pasos para evaluar riesgos y priorización de faenas mineras abandonadas o paralizadas}

\begin{tabular}{ll}
\hline Pasos & Descripción \\
\hline Escenarios de peligro & Identificar las situaciones que implican un riesgo. \\
\hline Receptores potenciales & Identificar los posibles afectados. \\
\hline Probabilidad de ocurrencia & Estimar la probabilidad de que ocurra cada escenario de peligro. \\
\hline Severidad de las consecuencias & Estimar la severidad de las consecuencias sobre los receptores. \\
\hline Matriz de riesgos & $\begin{array}{l}\text { Aplicar una matriz de riesgos para distinguir entre los riesgos } \\
\text { significativos y los no significativos y, a partir de ello, catalogar } \\
\text { las faenas como pasivos ambientales mineros o no. }\end{array}$ \\
\hline $\begin{array}{l}\text { Evaluación de Riesgos Detallada } \\
\text { (ERD) }\end{array}$ & $\begin{array}{l}\text { Aplicar una metodología de Evaluación de Riesgos Detallada } \\
\text { (ERD) en aquellos casos en que exista cierto grado de } \\
\text { incertidumbre sobre la evaluación simple realizada. }\end{array}$ \\
\hline Evaluación de Riesgos Acumulada & $\begin{array}{l}\text { Realizar una Evaluación de Riesgos Acumulada (ERA), } \\
\text { que consiste en la revisión de la evaluación desarrollada } \\
\text { (ERA) }\end{array}$ \\
\hline Priorización & $\begin{array}{l}\text { Clasificar las FMA/P resultantes en función de un orden } \\
\text { de prioridad, de acuerdo con la magnitud de los riesgos } \\
\text { que presentan. }\end{array}$ \\
\hline
\end{tabular}

Fuente: Elaboración propia, sobre la base de Servicio Nacional de Geología y Minería (SERNAGEOMIN)/ Instituto Federal de Geociencias y Recursos Naturales (BGR), Manual de evaluación de riesgos de faenas mineras abandonadas o paralizadas (FMA/P), Santiago, 2008.

Un paso complementario al análisis tradicional de riesgos se relaciona con la gestión de la resiliencia de las comunidades cercanas a las situaciones de peligro. En general, la resiliencia se define como una condición inherente y adquirida que se logra mediante la gestión de los riesgos a lo largo del tiempo a nivel individual, doméstico, comunitario y social, de manera que se minimicen los costos, se fortalezca la capacidad de gestionar y mantener 
el impulso del desarrollo y se maximice el potencial transformador (PNUD, 2013). En otras palabras, mediante este enfoque se busca que los actores tengan una visión común de los riesgos que enfrentan, que conozcan sus mecanismos de adaptación y que los potencien con el fin de elaborar estrategias y políticas de desarrollo pertinentes.

En diversas metodologías internacionales se propone incluir en la gestión de riesgos el enfoque de resiliencia de las comunidades. Mediante estas metodologías se pueden construir hojas de ruta a partir de información de los riesgos existentes y las características del entorno evaluado, con miras a aumentar la capacidad de adaptación de las comunidades y elaborar programas de desarrollo comunitario. En la aplicación de este enfoque se pone especial énfasis en las percepciones y características de los grupos relacionados y afectados por el riesgo, a fin de buscar brechas y dificultades con respecto a la capacidad de resiliencia y elaborar planes para robustecerla (OCDE, 2014; PNUD, 2014).

Algunos de los países que buscan involucrar a las comunidades en la gestión de la minería son el Canadá y los Estados Unidos. En el Canadá, resalta la Iniciativa para las minas abandonadas. A partir de diversos talleres realizados con las partes interesadas, se elaboraron diversos principios que permitirían una mayor transparencia en términos de decisiones y acceso a la información y que reciben apoyo del Ministerio de Minas. Estos principios son:

- La remediación de las minas abandonadas o huérfanas debe basarse en la preocupación por la salud, la seguridad, el respeto a la integridad ecológica y el desarrollo sostenible.

- El trabajo de construcción de inventarios y remediación debe seguir teniendo sólidos fundamentos científicos y basarse en una buena comunicación entre todas las partes.

- Deben continuarse los trabajos relacionados con la eliminación de los futuros abandonos, incluido el endurecimiento de los enfoques regulatorios.

- Debe aplicarse el principio de "quien contamina paga".

- Las normas de destino final y de regeneración deben ser aceptables para las comunidades locales.

- Debe haber transparencia y divulgación en todos los procesos de toma de decisiones.

- Todos los esfuerzos deben abarcar el concepto de equidad.

- Aunque el objetivo debe ser la recuperación integral de todos los sitios, el enfoque debe ser rentable y basarse en un método aceptable de priorización de sitios (en cada jurisdicción). 
En los Estados Unidos, la EPA presenta un esquema participativo con las comunidades en las labores de gestión correctiva. Este esquema está ampliamente documentado en el Superfund Community Involvement Handbook (Agencia de Protección Ambiental, 2016), donde se detallan los siguientes objetivos:

- Asegurar una participación temprana, frecuente y significativa en la comunidad.

- Mantener al público bien informado de las actividades en curso y previstas.

- Alentar y permitir el involucramiento.

- Escuchar atentamente lo que dice el público.

- Considerar la posibilidad de cambiar las acciones planificadas, a partir de comentarios o inquietudes del público.

- Explicar a los miembros de la comunidad cómo la EPA examinó sus comentarios, lo que tiene previsto hacer y por qué se tomó esa decisión.

Estos elementos son un buen ejemplo de la aplicación efectiva del Principio 10 de la Declaración de Río en el contexto del sector minero.

\section{F. Reflexiones finales y recomendaciones}

En el presente artículo se ha resaltado la importancia de la correcta gestión de los pasivos ambientales mineros. Si bien la actividad minera produce diversos beneficios económicos, es necesario que se mantenga y refuerce el control de sus externalidades negativas, así como de sus impactos nocivos. Para obtener más información al respecto, se debe profundizar en la elaboración de catastros e inventarios de pasivos ambientales mineros que den cuenta de su localización y sus potenciales impactos, tanto sociales como ambientales.

Además, es necesario impulsar un enfoque preventivo, lo que requiere una institucionalidad adecuada que cuente con los recursos apropiados para llevar a cabo las actividades de regulación y fiscalización, así como el desarrollo y aplicación de garantías financieras que eviten que la carga financiera se traspase luego al Estado. En este sentido, destacan los planes de cierre de minas, que en los últimos años se han ido constituyendo en varios países de la región, y cuya correcta aplicación permite establecer las condiciones para evitar que se originen nuevos pasivos ambientales mineros en el futuro. Pese a los diversos esfuerzos de las empresas privadas, muchos de los pasivos se pueden relacionar con la pequeña minería, la minería informal y la ilegal, o con el hecho que se trate de pasivos históricos. La legislación existente muestra que hay pocos instrumentos legales que hagan especial énfasis en pasivos ambientales mineros, por lo que se recomienda su elaboración. 
Por último, dado que cualquier riesgo potencial (o percibido) puede desencadenar conflictos socioambientales, es necesario que la gestión preventiva y correctiva incluya la participación de la ciudadanía en las diversas etapas del proyecto minero, incluido el seguimiento posterior al cierre. Por ello, se torna clave el monitoreo permanente de los pasivos que permita proporcionar información creíble y oportuna a la comunidad y a los encargados de adoptar decisiones. Ese componente de riesgo de los pasivos impone la necesidad de una gestión integral y de que se involucren todos los actores, así como de conocer las capacidades de adaptación y de resiliencia ante escenarios en los que pueda producirse un daño ambiental concreto. La minería secundaria para reactivar un pasivo y contribuir a la gestión de sus riesgos es una opción que se puede tener en cuenta, aunque también deben darse las condiciones institucionales, legales, técnicas y económicas para que sea viable.

\section{Bibliografía}

Agencia de Protección Ambiental (2016), Superfund Community Involvement Handbook, Washington, D.C. [en línea] https://semspub.epa.gov/work/ HQ/100000070.pdf.

Altomonte, H. y R.J. Sánchez (2016), Hacia una nueva gobernanza de los recursos naturales, Libros de la CEPAL, N 139 (LC/G.2679-P), Santiago, Comisión Económica para América Latina y el Caribe (CEPAL).

CEPAL (Comisión Económica para América Latina y el Caribe) (2018), Acceso a la información, la participación y la justicia en asuntos ambientales en América Latina y el Caribe: hacia el logro de la agenda 2030 para el desarrollo sostenible (LC/TS.2017/83), Santiago.

(2012), "Efectos del cambio climático en la costa de América Latina y el Caribe: riesgos", Documentos de Proyectos (LC/W.483), Santiago.

(2010), El desarrollo sostenible en América Latina y el Caribe: tendencias, avances y desafíos en materia de consumo y producción sostenibles, minería, transporte productos químicos y gestión de residuos. Informe para la decimoctava sesión de la Comisión sobre el Desarrollo Sostenible de las Naciones Unidas (LC/R.2161), Santiago.

CEPAL/OCDE (Comisión Económica para América Latina y elCaribe/Organización de Cooperación y Desarrollo Económicos) (2016a), Evaluaciones del desempeño ambiental: Perú 2016. Aspectos destacados y recomendaciones (LC/L.4174), Santiago. (2016b), Evaluaciones del desempeño ambiental: Chile 2016 (LC/L.4195), Santiago.

Defensoría del Pueblo (2015), “¡Un llamado a la remediación!: Avances y pendientes en la gestión estatal frente a los pasivos ambientales mineros ehidrocarburíferos", Informes Defensoriales, $\mathrm{N}^{\circ} 171$, Lima.

Figueroa, M. (2011), “Evaluación preliminar de riesgos medioambientales de faenas mineras abandonadas/paralizadas mediante SIG en la II región de Antofagasta, Chile", memoria para optar al título de geógrafa, Santiago, Universidad de Chile.

Martínez, Z. (2003), "Guías prácticas para situaciones específicas: manejo de riesgos y preparación para respuestas a emergencias mineras", serie Recursos Naturales e Infraestructura, $\mathrm{N}^{\circ} 57$ (LC/L.1936-P), Santiago, Comisión Económica para América Latina y el Caribe (CEPAL). 
MINEM (Ministerio de Energía y Minas) (2010), Guía para la elaboración de planes de cierre de pasivos ambientales mineros, Lima, Dirección General de Asuntos Ambientales Mineros.

Moreno, C. y E. Chaparro (2008), “Conceptos básicos para entender la legislación ambiental aplicable a la industria minera en los países andinos", serie Recursos Naturales e Infraestructura, Nº 134 (LC/L.2893-P), Santiago, Comisión Económica para América Latina y el Caribe (CEPAL).

Oblasser, A. (2016), “Estudio sobre lineamientos, incentivos y regulación para el manejo de los pasivos ambientales mineros (PAM), incluyendo cierre de faenas mineras. Bolivia (Estado Plurinacional de), Chile, Colombia y el Perú", serie Medio Ambiente y Desarrollo, № 163 (LC/L.4208), Santiago, Comisión Económica para América Latina y el Caribe (CEPAL).

Oblasser, A. y E. Chaparro (2008), "Estudio comparativo de la gestión de los pasivos ambientales mineros en Bolivia, Chile, Perú y Estados Unidos", serie Recursos Naturales e Infraestructura, N 131 (LC/L.2869-P), Santiago, Comisión Económica para América Latina y el Caribe (CEPAL).

OCDE (Organización de Cooperación y Desarrollo Económicos) (2014), Guidelines for Resilience Systems Analysis, París, OECD Publishing [en línea] http:/ / www. oecd.org/dac/Resilience\%20Systems\%20Analysis\%20FINAL.pdf.

OCDE/CEPAL (Comisión Económica para América Latina y el Caribe/ Organización de Cooperación y Desarrollo Económicos) (2014), Evaluaciones del desempeño ambiental: Colombia 2014 (LC/L.3768), Santiago, Comisión Económica para América Latina y el Caribe (CEPAL).

(2005), OECD Environmental Performance Reviews: Chile 2005, París, OECD Publishing.

OLACEFS (Organización Latinoamericana y del Caribe de Entidades Fiscalizadoras Superiores) (2016), Auditoría coordinada de pasivos ambientales: informe regional [en línea] http://www.olacefs.com/wp-content/uploads/2016/10/02-InformeRegional-ACPA-11oct16.pdf.

PNUD (Programa de las Naciones Unidas para el Desarrollo) (2014), CommunityBased Resilience Analysis (CoBRA). Implementation Guidelines, Nairobi.

(2013), Cambiando con el mundo: plan estratégico del PNUD 2014-2017, Nueva York.

Saade, M. (2014), "Buenas prácticas que favorezcan una minería sustentable: la problemática en torno a los pasivos ambientales mineros en Australia, el Canadá, Chile, Colombia, los Estados Unidos, México y el Perú", serie Macroeconomía del Desarrollo, N 157 (LC/L.3885), Santiago, Comisión Económica para América Latina y el Caribe (CEPAL).

SERNAGEOMIN/BGR (Servicio Nacional de Geología y Minería/Instituto Federal de Geociencias y Recursos Naturales) (2008), Manual de evaluación de riesgos de faenas mineras abandonadas o paralizadas (FMA/P), Santiago.

Yupari, A. (2003), Informe "Pasivos ambientales mineros en Sudamérica", Santiago, Comisión Económica para América Latina y el Caribe (CEPAL)/Instituto Federal de Geociencias y Recursos Naturales (BGR)/Servicio Nacional de Geología y Minería (SERNAGEOMIN). 


\section{Capítulo XVII \\ Conclusiones: asuntos críticos de la gobernanza y los desafíos regionales}

Uno de los rasgos más distintivos en relación a la última bonanza de los recursos naturales y los desafíos de su gobernanza en los países de América Latina y del Caribe es la inclusión de una amplia variedad de materias, conceptos y nuevas temáticas. Todo lector interesado en este tema hallará en este libro algunas claves para comprender los problemas de la gobernanza de los recursos naturales durante los períodos de bonanza, pero también algunas explicaciones, sugestivas y con cierto grado de detalle, sobre los procesos, las decisiones y los factores que impidieron que una gobernanza adecuada se convirtiera finalmente en una realidad durante la bonanza del decenio comprendido entre 2002 y 2012. El objetivo de esta publicación es profundizar en el análisis de temas que son inherentes a la gobernanza de los recursos naturales y que deberían ser de utilidad a la hora de reflexionar sobre lo que es preciso cambiar para transitar hacia un nuevo paradigma de desarrollo. Esta publicación, al mismo tiempo que contribuye a entender por qué no fue posible aprovechar ese período de bonanza, ofrece algunas señales de cómo es posible alcanzar ese objetivo en el futuro.

En ese sentido, las hipótesis y lecciones que figuran en los capítulos de este libro brindan una primera conclusión: el fin de la bonanza económica, alimentada por la explotación intensiva de los recursos naturales, solo significó el final de un momento de intenso aprovechamiento de tales recursos, pero que no necesariamente se tradujo 
en un cambio estructural conectado a un desarrollo más sostenible en la región. Una adecuada gobernanza permitiría aprovechar mejor esos recursos naturales, potenciando sus atributos en los momentos de mayor prosperidad, como los ciclos de alza de precios y de mayor demanda de materias primas.

En este libro se encontrarán capítulos con contenidos más teóricos y conceptuales y otros que priorizan la descripción de casos o los ejemplos para explicar ideas o nociones que merecen una lectura y una explicación más complejas. Por otro lado, si bien los análisis aquí contenidos no definen la gobernanza de los recursos naturales de manera explícita, la mayoría - sino la totalidad - lo hacen implícitamente. De alguna forma, puede decirse que la gobernanza de los recursos naturales en este libro se expresa o se explica a través de los temas examinados en cada uno de sus capítulos. Es decir, la mayoría de los autores hablan y se refieren a la gobernanza sin hablar de gobernanza.

En este sentido, no hay dudas que la gobernanza de los recursos naturales en los países de América Latina y el Caribe no puede escindirse de los temas, los conceptos o los escenarios en los cuales logra expresarse (por ejemplo, el aumento de precios en la región durante el decenio mencionado y su cambio de comportamiento actual). Parece complicado hablar de este tema sin hacer referencia y sin analizar, por ejemplo, la abundancia, los ciclos de precios, el espacio fiscal, la transparencia, las decisiones políticas o, incluso, los reclamos sociales en torno a los recursos naturales. En esa línea, una segunda conclusión que se deriva de la lectura de los capítulos de este libro es que cada uno de los gobiernos de la región, luego de la experiencia del auge de precios de sus materias primas, deberá exigir y exigirse una más adecuada y efectiva gobernanza en su relación con los múltiples actores que participan del complejo proceso de explotación, aprovechamiento y distribución de la renta de los recursos naturales a fin de apoyar un desarrollo más sostenible e inclusivo.

En tal contexto, ¿cuál es la importancia de reflexionar sobre la gobernanza de los recursos naturales? Es la de examinar el aporte de la gestión de los recursos naturales al desarrollo pleno e inclusivo. El significado de la gobernanza no es sencillo, es una noción cambiante, abierta y polisémica, como puede verse en los diferentes capítulos de este libro. Como se señala en uno de ellos, el Instituto de Gobernanza del Canadá, que ha dedicado casi 30 años al análisis del tema, reconoce después de décadas de estudio que dada la complejidad de la gobernanza es difícil captarla en una simple definición. No obstante, agrega que es crucial tener presente al menos tres dimensiones constitutivas: la autoridad, la toma de decisiones y la rendición de cuentas. Así, la gobernanza determina quién 
tiene poder, quién toma decisiones y cómo los actores hacen oír su voz, y cómo se rinde cuentas de ello"1.

En el caso de la gobernanza de los recursos naturales estas tres dimensiones son sustanciales. Sin embargo, no fue posible abarcarlas completamente en este libro dada la complejidad del contexto económico, político y social de los países de América Latina y el Caribe. El examen de estas dimensiones debe concretarse en las problemáticas relativas a los recursos naturales de los países de la región. De esta manera se podrá comprender mejor la relación entre el poder, la toma de decisiones y el rol de los actores. La definición es importante, pero tendrá aún más relevancia si se relaciona con los temas y conceptos que contribuyen a definir la propia cuantía de los recursos naturales.

Esto último es lo que se puede apreciar en cada uno de los capítulos reunidos en este libro, que tratan de la sostenibilidad, la distribución o el ahorro, pero también de la institucionalidad, el marco legal o la resolución de conflictos en relación a los recursos naturales. En suma, se destaca la necesidad de explicar de qué se habla en la región cuando se hace referencia a la gobernanza de los recursos naturales. Como señalamos antes, algunos autores hablan de gobernanza sin hablar de gobernanza, lo que muestra cuánto más útil es focalizar la discusión en los temas que funcionan como sustrato de la definición.

En consecuencia, de los capítulos del libro surge la importancia de examinar los elementos que constituyen la definición de la gobernanza, más que de procurar establecer un axioma sobre la misma. En tal sentido, se propone que tales elementos refieren a la estructura de gobierno sobre los recursos naturales, al sistema de relaciones y conductas que articulan el funcionamiento de las industrias extractivas y transformativas y su vinculación con el conjunto de las políticas públicas, así como también a la necesidad de comprender el entorno social, político, económico, natural, normativo y administrativo en el que se desempeñan. Junto con ello, se comprenderá el conjunto de mecanismos, procesos y reglas a través de los cuales se ejerce la autoridad sobre esas actividades, las conductas entre las partes, la protección de la naturaleza y de los derechos básicos, entre otros factores relevantes. Este es el contexto en el cual se podrá relacionar a la gobernanza con la propiedad de los recursos, la fiscalidad de su explotación y el destino de las rentas en favor del desarrollo.

Es necesario explicar las ventajas y posibilidades que ofrecen los ciclos de auge. El desafío hoy es mostrar que la gobernanza de los recursos naturales para los países de la región trasciende los períodos o ciclos de

Instituto de Gobernanza del Canadá [en línea] https://iog.ca/what-is-governance/. 
bonanza. Se puede concebir a la gobernanza de los recursos naturales como una plataforma, una condición, una herramienta, por ejemplo, que posee la capacidad de contribuir a la reproducción de las rentas y a la transferencia de ingresos a lo largo de todo el espacio físico y a lo largo del tiempo.

Si se acepta que el espacio de acción de la gobernanza de los recursos naturales es primordialmente el ámbito público ampliado y que, dentro de este ámbito, el Estado es uno de los referentes cardinales que contribuyen a transferir la acción directa de dicha gobernanza, se podría esperar que las conclusiones de los capítulos de este libro giren en torno a esos sujetos de referencia. De hecho, las instituciones y la ampliación de la capacidad de los gobiernos para arbitrar políticas públicas en favor de una buena gobernanza de los recursos son dos aspectos irremplazables de este proceso.

Los sujetos de los mensajes sobre una adecuada gobernanza no son siempre evidentes. Este libro es útil para deliberar sobre la manera en que se pueden identificar mejor los destinatarios de las recomendaciones sobre la gobernanza, en el sentido de segmentar la información y ofrecer una gama más amplia de lecciones y ejemplos concretos a la luz de lo ocurrido en América Latina durante la pasada década y media.

En el libro queda bien establecida la necesidad de afianzamiento o fortalecimiento de la acción política del Estado, como mediador y decisor frente a los desafíos impuestos por la agenda de cambio y transformación de las economías de la región. Hay un reconocimiento del valor de la gobernanza para identificar o hacer más visibles esos desafíos y, además, para posicionar al Estado en un papel más central y preponderante, equilibrado por la presencia de los actores que son cruciales para la gobernanza.

El reconocimiento de las dificultades y del dinamismo de la gobernanza y la interacción de los actores, también conduce a una recomendación: es imprescindible que la reflexión sobre la gobernanza sea un ejercicio continuo.

\section{Los desafíos de la gobernanza de los recursos naturales}

La gobernanza de los recursos naturales está relacionada con la capacidad de los gobiernos para arbitrar políticas públicas destinadas a enfrentar los retos de la explotación de los recursos naturales, como los dilemas asociados a la distribución y sostenibilidad de las rentas obtenidas y la forma en que se articulan los actores participantes y la rendición de cuentas. Se trata de un proceso no exento de obstáculos. Las decisiones políticas relacionadas con la extracción de los recursos del subsuelo involucran no solamente los costos económicos asociados a los métodos exploratorios o al propio sistema 
extractivo, sino también los costos ambientales y sociales que refieren, en este caso, a determinados sujetos (y objetos) de constitución finita, frágil o sensible. Algunos capítulos de este libro muestran esa fragilidad en contextos o escenarios que hasta pocos años no generaban ningún tipo de preocupación pública o resistencia social. Cuestiones como la ocupación del territorio para las labores de extracción, el uso excesivo del agua o el impacto directo de las operaciones sobre la fauna o la flora son algunos ejemplos.

En todos los eventos de este tipo la prevalencia de la decisión política adecuada o correcta es categórica. A pesar de que existen maneras de medir los costos y los beneficios en una actividad como la minería, esta es una de las actividades extractivas que más polémica y conflictos ha generado durante los años del reciente auge de precios y de demanda de materias primas. En realidad, la cuestión de la decisión política está instalada en muchos sectores de la actividad extractiva, pero tal vez en ninguno ha tenido tanto impacto social, económico, político y ambiental como ocurrió en el caso de la minería.

Existen países donde los gobiernos (nacionales o locales en posición de tomar decisiones) resolvieron autorizar proyectos que no contaban con el debido consentimiento de las comunidades o se apoyaban en un consenso social muy débil. En la mayoría de casos la decisión de continuar con los proyectos se efectuó sin mediar ninguna otra intervención de actores o grupos sociales involucrados en los procesos, por lo que el resultado de las autorizaciones fue el aumento del rechazo a las operaciones mineras o, incluso, la extensión de ese rechazo a la actividad minera en general. Más aún, la decisión política de los gobiernos, al no estar legitimada socialmente, produjo un aumento de la conflictividad social, la que a su vez derivó en demandas asociadas a otros factores de descontento.

Este ejemplo incluye una serie de componentes y variables para los cuales una estrategia adecuada de gobernanza de los recursos naturales puede ofrecer alternativas. En principio, la gobernanza surge como la plataforma que contribuye a ponderar el peso de los beneficios esperados de la explotación de los recursos naturales en relación a los costos que el proceso genera. Los distintos actores involucrados en este proceso expresan sus necesidades e intereses económicos y también su posición política respecto del procedimiento que da curso a la explotación. En ese sentido, una adecuada gobernanza ayuda a la autoridad política a decidir sobre esos intereses en concordancia con las preocupaciones sociales del proyecto minero y con las que imponen las restricciones ambientales.

De esta forma, tal y como aparece en varios pasajes de este libro, una gobernanza efectiva eleva esa restricción ambiental a un nivel de mayor visibilidad, al mismo tiempo que ordena las prioridades sociales y económicas de los grupos involucrados y del propio Estado. Más aún, 
como plataforma o herramienta de equilibrio, contribuye a la resolución de conflictos asociados a la equidad intergeneracional, en el sentido de que bajo cualquiera de las reglas que se apliquen para maximizar los beneficios futuros de las rentas de los recursos naturales, contribuye a reforzar la autoridad del Estado para preservar ese capital para el futuro. La propia gobernanza refuerza esa potestad para decidir sobre las reglas que son aplicables al ritmo de extracción de los recursos naturales y también a la toma de decisiones sobre el ahorro o la inversión de las rentas derivadas.

Como se menciona en uno de los capítulos referidos a la inversión de los fondos soberanos, se trata, al final de cuentas, de cálculos sobre la inversión de rentas que se sostienen en decisiones políticas. De hecho, en el libro, la cuestión de los fondos soberanos de inversión es recurrente en la mayoría de los autores y uno de los capítulos aborda especialmente el tema. En algunos casos se lo ha analizado en relación con el espacio fiscal, la inversión de capital o la solidaridad intergeneracional y, tal como aparece definido en todos esos trabajos, se trata de estructuras de inversión que, por lo común, tienen un objetivo económico y financiero determinado, aunque detrás de su identidad prevalezca la decisión política de la autoridad pública en relación a su continuidad y su propiedad.

Como se menciona en diversos pasajes de este libro, los fondos soberanos neutralizan el menoscabo que se origina en la enfermedad holandesa, a la vez que permiten el establecimiento de políticas contracíclicas que reducen el peso de las fluctuaciones de los precios de las materias primas. Asimismo, estos fondos sirven para evitar la tentación del uso de las rentas obtenidas por la explotación de los recursos en el financiamiento del gasto corriente, un evento también muy dependiente de las decisiones políticas. En la última década de auge económico, sin embargo, no todos los gobiernos consideraron este instrumento. La decisión de ahorrar e invertir y, en menor medida, de sostener o financiar gastos corrientes, es tal vez uno de los espacios de acción de la gobernanza de los recursos naturales y el mejor escenario en el que esta puede mostrar de manera fehaciente su eficacia en el manejo de las expectativas públicas respecto de las rentas o ingresos logrados. Nuevamente, hay detrás una decisión de la dirigencia o la autoridad política que esté posiblemente más dispuesta a sucumbir a la tentación del gasto corriente, que al ahorro o la inversión. Para cualquiera de los encargados de tomar decisiones en los países de la región durante la década de auge de ingresos, la pregunta central era ¿por qué no gastar hoy, cuando es necesario y hasta vital hacerlo? En estas instancias, una pregunta pertinente hubiese sido ¿qué parte de este gasto está dirigido al ahorro y qué parte a la inversión en salud, educación, tecnología o infraestructura?

En el contexto de la última bonanza, el financiamiento de los gastos corrientes merecería por sí mismo un análisis exhaustivo. También en ese análisis el peso de la decisión política es relevante, como lo es el 
de la gobernanza, especialmente a la hora de actuar como antídoto para evitar la tentación del gasto en el corto plazo o aún en el mediano plazo. En todo caso, la gobernanza reduce la posibilidad de la ocurrencia de decisiones poco planificadas y, por lo tanto, más sujetas al pragmatismo de las prácticas opacas o poco transparentes de gobierno. Al respecto, hay que mencionar que en el libro hay solo algunas referencias sobre estos escenarios y muy poco o casi nada sobre las causas por las cuales los encargados de tomar decisiones se inclinan por políticas poco planificadas.

Sin embargo, en el caso del ahorro y la inversión, aunque de manera especial en el de la inversión en fondos soberanos, los casos y ejemplos proliferan y, como dijimos, es tal vez uno de los temas más recurrentes de este libro. Sobrevuela en los capítulos sobre los fondos de inversión un interés particular en examinar de cerca su derrotero, sus posibilidades de rendimiento financiero o su eficacia política.

Los fondos soberanos representan, tal vez, uno de los ejemplos de aplicación de una política de ahorro e inversión inspirada en buenas prácticas de política para los recursos naturales. Son estos los escenarios más adecuados y convenientes para que en el corto y mediano plazo se apliquen políticas de extensión de las rentas de los recursos naturales en el largo plazo. Esta es una de las razones por la cuales, en el libro, la mayoría de los autores hacen mención a estos fondos de una manera positiva. Así, la gobernanza de los recursos naturales surge asociada a los fondos soberanos a través de la equidad intergeneracional, el combate a la enfermedad holandesa, el mantenimiento del stock de capital, la citada batalla contra la tentación del financiamiento de gastos corrientes, el sostenimiento de eventuales sistema de pensiones y la eficacia, en algunos países, para sobrellevar los efectos más difíciles de las crisis financieras como ocurrió en 2008-2009.

La transparencia es, sin duda, uno de los terrenos más significativos sobre los que se han logrado avances importantes en relación con la gobernanza de los recursos naturales en los países de América Latina y el Caribe. La gobernanza es sinónimo de confianza pública, de reglas de juego claras y de salvaguarda patrimonial. Más aún, como concepto analítico, se refiere a la contribución de los distintos actores al diseño de políticas públicas y al justo valor que tiene la participación de cada uno de ellos en ese proceso. Por eso es que, además de funcionar como un instrumento de gestión, funciona también como una línea de base del equilibrio entre los distintos actores involucrados en su manejo y gestión. Este equilibro implica asimismo poner a disposición del otro intereses, conductas y expectativas sobre los resultados que se espera obtener de los recursos.

La cuestión de las reglas de juego es un aspecto crucial que aparece en varios pasajes de los capítulos de este libro. Se relaciona en parte con la intervención del Estado en temas sensibles para otros actores, 
especialmente en lo referido al manejo de las estrategias y las políticas de prevención y resolución de conflictos o, en el caso de los agentes privados, de los cambios en las condiciones asociadas a la fiscalidad o a las garantías ofrecidas a las inversiones en emprendimientos asociados a la explotación de recursos naturales. Sin duda, uno de los desafíos de la gobernanza de los recursos naturales en la región debe ser garantizar que las reglas de juego en el proceso extractivo no se modificarán, excepto que se obtenga el consenso o acuerdo de las partes. Lo contrario es generalmente muy contraproducente o termina por inducir a la toma de decisiones progresivamente más arbitraria, injusta o desmedida, lo que finalmente se constituye en un hecho que va en detrimento del interés público. Más aún, la propia capacidad de equilibrio que reviste la gobernanza, hace posible que en términos de reglas de juego puedan existir instancias que permitan modificaciones de esas mismas reglas.

Ligado a esto último, la cuestión de la transparencia es un tema decisivo en la agenda de la gobernanza de los recursos naturales, en particular entre los sectores con más visibilidad, como el minero y el de hidrocarburos. Los capítulos referidos a estas actividades hacen referencia a los desafíos sociales y ambientales en relación a los Objetivos de Desarrollo Sostenible (ODS) y al cumplimiento del Acuerdo de París, aunque es preciso recordar también las valiosas citas y referencias a pactos $\mathrm{y}$ acuerdos, $\mathrm{y}$ también instrumentos, marcos normativos, estándares e iniciativas que aparecen a lo largo de este libro y que han sido considerados como dispositivos para mejorar la gobernanza. En la mayoría, sino en todos, el marco de referencia es la transparencia y la rendición de cuentas, aunque detrás de todo ellos aparece el marco general asociado a la importancia de la provisión de información y la promoción del diálogo, dos aspectos de la gobernanza y la institucionalidad que lograron extenderse ampliamente por iniciativa de las organizaciones de la sociedad civil y, en segunda instancia, por gobiernos y empresas.

Hoy en día no es posible hablar de la gobernanza de los recursos naturales si no se apoya en firmes políticas de promoción de la transparencia, incluida la decisión política de los gobiernos de sostenerla. Como se ha mencionado en este libro, es probable que la transparencia, si no se enmarca en un sistema de gobernanza más amplio, no logre el impacto que se espera. Más aún, la mera publicación de información proveniente de las empresas o del propio Estado en relación a las industrias extractivas no es suficiente si los ciudadanos, como usuarios de esa información, no la consideran creíble, útil e influyente en los procesos de rendición de cuentas. Al respecto, uno de los capítulos de este libro aborda con precisión y con algunos buenos ejemplos la interrelación entre información, transparencia y rendición de cuentas.

De esta manera, el aumento de la transparencia en las industrias extractivas, impulsado por las iniciativas internacionales, entre ellas las 
de las Naciones Unidas, ha sido un importante generador de procesos innovadores en países donde hace unos pocos años era imposible pensar en la adhesión de la opinión pública. La transparencia impulsó nuevas oportunidades y opciones para los diferentes actores que buscan relacionarse entre sí, a la vez que incidió positivamente en el sector extractivo en general. Por eso, en los últimos años se incrementaron las iniciativas relacionadas con la promoción de la transparencia en distintas instancias de la actividad pública y privada, pero fundamentalmente la adhesión y difusión de los resultados que ha logrado en la reducción de la creciente conflictividad social asociada a las industrias extractivas.

Sin embargo, es necesario aún pasar a otros estadios de transparencia y confianza en las empresas y los gobiernos relacionados con las operaciones o la promoción del denominado extractivismo en los países de América Latina. La transparencia genera certidumbre en el uso de los recursos y el alcance de las metas de equidad, liberando de alguna forma la presión política y social que existe sobre los encargados de tomar decisiones en el contexto de una sociedad cada vez más conectada por el uso creciente de las redes sociales y los soportes de comunicación inteligentes.

Nuevamente, como se hace referencia en este libro, la influencia de la decisión política sostenida en la legitimidad del Estado para liderar los procesos de cambio es un elemento central. Más allá de dar a conocer las cifras relacionadas con la producción o la explotación de los recursos naturales, o de trasparentar los intereses de las empresas, de los gobiernos o de otros agentes de la sociedad que participan en estos procesos, es importante trasparentar los procesos de decisión.

Se trata de promover la participación de la sociedad dado que el impacto o el peso de la transparencia en el proceso de explotación de los recursos naturales depende de quienes son los usuarios o beneficiarios de la misma. Ciertamente, las partes interesadas son las únicas capaces de fortalecer estos procesos de cambio y, en esos procesos, la gobernanza de los recursos juega un rol principalísimo por cuanto transparenta la información sobre las operaciones, las rentas obtenidas, la distribución y las utilidades.

La cuestión de la legitimidad no es menor y está llamada a forjarse desde el Estado, en lo que se ha definido como una legitimidad primaria sostenida por los actores que participan en los procesos de explotación de los recursos. Es sobre estos últimos, que ofrecen una forma de legitimidad secundaria, donde la gobernanza opera con más prontitud, ya que se trata de una legitimidad susceptible al cambio por los vaivenes de los ciclos de la extracción, o los ciclos de los precios cuya naturaleza genera desconfianza y resistencia entre los sectores que no reciben beneficios de las rentas y, además, cargan con los costos sociales y ambientales del proceso de explotación de los recursos. 
Al respecto, es nuevamente la minería la actividad donde más se visibilizan estas diferencias y en tal sentido son notables las disconformidades y las profundas diferencias de criterio que subsisten entre quienes participan directamente de los procesos de generación de rentas de los recursos naturales y quienes están involucrados de manera indirecta. Se trata, a veces, de desavenencias entre miembros de comunidades no muy distantes unas de otras, aunque también de individuos que mantienen posiciones encontradas dentro de las propias comunidades. En este escenario, el Estado es el único capaz de ofrecer la legitimidad que procesos de este tipo requieren, especialmente porque se trata del actor con la aptitud necesaria para disponer de la gobernanza en contextos que den cuenta del interés común.

La gobernanza adecuada de los recursos naturales es, sin duda, la plataforma ideal para garantizar la estabilidad económica y social de las comunidades involucradas en el largo y engorroso proceso de explotación de los recursos, dado que se trata, por definición, de procesos con un fuerte impacto sobre el equilibrio social y cultural de las comunidades, que a veces están ligadas a entornos rurales y con economías de subsistencia. Como se ha señalado, los riesgos inherentes de la explotación de los recursos naturales incluyen alteraciones en el mercado laboral local, en el movimiento errático de los precios locales por influencia de una alteración ejercida por influencia externa, por los fenómenos irreversibles de migración masiva de personas, ya sea por el atractivo que revisten las operaciones y la infraestructura asociada a estos emprendimientos o por procesos de expulsión, entre otros factores.

En esa línea, un problema adicional es la determinación del grupo o colectivo que recibirá los beneficios, tanto en el presente como en los ciclos largos de producción en el sector extractivo. En esta delimitación sobre la distribución de los beneficios, además del gobierno, deberán tomarse en cuenta los agentes privados asociados a la explotación y a comunidades afectadas. Vinculado a este tema, surgen nuevamente los dilemas asociados a la propiedad de los recursos o al reparto de costos y beneficios a nivel nacional o local y los consiguientes conflictos en las localidades, las comunidades y las familias enfrentadas entre sí o contra el Estado o los agentes privados por el reparto de la renta o, primordialmente, por el costo emergente que recae sobre los entornos natural y social.

En todos estos procesos, con frecuencia, se dejan de lado las instituciones y las normas asociadas al ejercicio democrático del poder. Un aspecto que, según hemos mencionado, una adecuada gobernanza corrige justamente al contribuir con la generación de instituciones fuertes y la participación activa y coherente de los distintos actores que interactúan entre sí y se nutren de las decisiones políticas soberanas del Estado. 
Este último aspecto, el de la institucionalidad, al margen del tema de la transparencia, se aborda en un capítulo que hace referencia a la calidad de las instituciones y a la necesidad de arbitrar medidas para su ponderación como factor que influye en los escenarios de desigualdad.

América Latina es una región muy prolífica en instrumentos que pueden contribuir enormemente a la mejora de la gobernanza de los recursos naturales. Existen constituciones políticas actualizadas que han incorporado aspectos sociales y ambientales, leyes y regímenes tributarios que relacionan los recursos naturales con el espacio fiscal o sistemas legales específicos surgidos de la adhesión de los países a instrumentos internacionales y que están destinados a la protección del ambiente y los pueblos indígenas. En este terreno, hay que recordar además el peso de la interacción del Estado con los otros actores, en que existe una perspectiva de derechos y en el que la mediación y el liderazgo del Estado es crucial, sobre todo porque se trata de una agenda pendiente para algunos grupos de la sociedad y para la cual se requiere una actitud más proactiva que reactiva de la autoridad pública.

Así, una vez analizados de cerca los temas de este libro que asocian la agenda de la gobernanza de los recursos naturales con la agenda de cambios que los países están esperando, es posible ver las oportunidades que se abren durante los períodos de prosperidad alimentada por el auge de precios de las materias primas. Existe en la región, en ese sentido, una institucionalidad en ciernes sostenida por leyes desarrolladas, lo que en principio nos lleva a reflexionar sobre cuánto de las expectativas puestas en la gobernanza de los recursos naturales tiene que ver con las leyes propiamente dichas y cuánto con la aplicación o la aceptación de los marcos legales. Este es un tema que merecería también un análisis adicional.

Asimismo, otro de los temas que merece una revisión es la relación e interacción entre los niveles subnacionales dentro del espacio geográfico relacionado con la explotación de los recursos naturales. Efectivamente, la cuestión nacional o el carácter local de este proceso se debate en el libro, especialmente en lo que tiene que ver con la distribución de costos y beneficios. Para algunos autores la dimensión nacional es preponderante sobre la local debido a que se garantiza la gestión sostenible de los recursos de una manera más eficiente que en el ámbito local donde la presión económica obliga a tomar decisiones que reducen la capacidad de acción de la propia gestión sostenible. En esa línea, la cuestión local de los procesos productivos, incluidas las incidencias en los lugares físicos donde se realiza la explotación, plantea el tema de la apropiación de las rentas y lo eleva a un debate sobre si esta debe ser efectivamente local o nacional. Como se menciona en algunos capítulos, esto se traduce en pujas distributivas que, en gobiernos con estructuras federales, se hacen aún más complejas en términos de gobernanza. 
Sin duda, al igual que la transparencia, la preocupación por la conflictividad es la que mayor atención ha concitado en los países de la región y sobre la cual una adecuada gobernanza de los recursos naturales puede contribuir a dar respuestas. Nuevamente, las decisiones del gobierno o, en general, de la autoridad política (nacional o local) en relación a los conflictos son importantes. En este libro se analizan en particular los temas relacionados con los instrumentos para evitar la conflictividad, los acuerdos sectoriales, las políticas de transparencia y rendición de cuentas, las consultas previas, los diálogos entre múltiples actores y las ventajas y desventajas de las licencias para operar en el sector minero y, en menor grado, en el de los hidrocarburos.

Además de los tradicionales instrumentos de conciliación y arbitraje, una metodología más reciente que se cita con frecuencia es el diálogo o la generación de coaliciones o alianzas entre múltiples actores, alentadas en los últimos años por compromisos y metas internacionales como los Objetivos de Desarrollo Sostenible a los cuales se dedica un capítulo de este libro.

Los Estados, las organizaciones de la sociedad civil y las empresas o representantes del sector privado interactúan y comparten información y opiniones sobre su intervención y sus intereses en los procesos de explotación de los recursos naturales, especialmente en la distribución y el beneficio de las rentas. La gobernanza de los recursos naturales efectiva y participativa es la llamada a reducir el impacto y los riesgos sociales inherentes a todo cambio en el comportamiento social e institucional de las comunidades, pero también en el establecimiento de nuevos tipos de vínculos con la autoridad política o los referentes de los grupos sociales beneficiados con la explotación. Contribuye a mantener el equilibrio en los conflictos asociados a los recursos naturales, un aspecto que - como se ha mostrado en uno de los capítulos- no es un fenómeno nuevo en los países de América Latina y el Caribe. En el libro, los casos de algunos países se ponen como ejemplo de los conflictos en la minería durante la última década y media.

Más aún, analizando el cuadro de situación de la conflictividad en la región, parece inexorable que el peso de la gobernanza vaya en aumento, en paralelo a lo que se prevé será un incremento de casos y del ímpetu (y quizás virulencia) de los conflictos asociados a los recursos naturales en la región durante los próximos años. La presión sobre los recursos, pero también los cambios ocasionados por las migraciones, la demanda de mayor distribución de las rentas o la afectación del ambiente son algunas razones que explican la búsqueda de ese equilibrio a partir de una buena gobernanza. En este tipo de escenarios, los Objetivos de Desarrollo Sostenible son muy explícitos a la hora de fijar metas, de manera que la gobernanza de los recursos naturales debería contribuir a mejorar la capacidad de los gobiernos para alcanzar ese delicado equilibrio. 
Ahora bien, es interesante observar que la referencia a la importancia de una adecuada gobernanza de los recursos naturales a lo largo del libro adquiere peso. La mayoría, sino la totalidad de los autores de este libro es consciente de esto, especialmente en relación con el aprovechamiento de la bonanza de precios, demanda de materias primas y rentas obtenidas por los países de la región, y cuestionan la existencia de una gobernanza inadecuada para los fines del desarrollo sostenible. Una mala gobernanza es un problema complejo porque implica distorsiones y limitaciones en la toma de decisiones de política económica que muchos países a veces no consiguen tomar, por sus propias limitaciones o porque no se logra romper con los prejuicios o estereotipos asociados al papel de los recursos naturales en el proceso de consolidación de un desarrollo sostenible.

El cambio del tipo de gobernanza de los recursos naturales es, justamente, la herramienta más adecuada para quebrar esos estereotipos, incluidos los generados por las propuestas de estudio que analizan las condiciones y la potencialidad de las economías de los países de la región en relación a la abundancia y, a partir de allí, en términos de maldición o bendición de los recursos. Muchos trabajos introducen este debate y, si bien se inclinan por descartar las propuestas asociadas a la maldición, se inclinan también por centrar la atención en las consecuencias de la gobernanza vigente, por ejemplo, en el peso que tiene sobre la debilidad institucional, incluidos los problemas de falta de transparencia o de rendición de cuentas.

La gobernanza no define las políticas, pero sí constituye el marco de interrelaciones entre actores e instituciones interesadas para gobernar los recursos naturales. Una gobernanza efectiva, que cuente con las partes interesadas y que busque un desarrollo más inclusivo y sostenible, siempre será el camino más apropiado en un contexto de mayor bonanza económica en las economías de la región, pero también en uno donde la prosperidad no altere las reglas de juego o no incremente las externalidades sobre los entornos políticos, sociales o ambientales. La conflictividad socioambiental en la explotación de los recursos naturales y su débil gobernanza permite visualizar las desventajas que trae aparejada una profundización de los sectores extractivos y primarios por sobre la manufactura, el valor agregado o la industrialización. Muestra, en resumen, los riesgos de la reprimarización.

Una adecuada gobernanza contribuye también a superar los desafíos impuestos por los regímenes fiscales asociados a los recursos naturales, especialmente en el caso de la minería que, como se ha mostrado recurrentemente en los capítulos de este libro, ha sido el foco de críticas por su extremado carácter regresivo. La gobernanza pone la atención en el fortalecimiento de un sistema o régimen fiscal que, alimentado por la explotación de recursos naturales no renovables, pueda generar un balance adecuado entre las necesidades que tiene el Estado de maximizar 
sus beneficios en contraposición con los incentivos que el propio Estado debe ofrecer y garantizar a quienes deseen intervenir en los procesos de exploración, explotación y operación de dichos recursos.

Como instrumento destinado al manejo ecuánime de estructuras complejas, como las del espacio fiscal en los países de América Latina, la gobernanza funciona eficazmente neutralizando situaciones como la volatilidad o la fiebre de precios de los recursos, escenarios que se vieron en los años de bonanza durante la última década y media. Por otro lado, en la mayoría de los autores que analizan el espacio fiscal o los regímenes fiscales son relevantes los esfuerzos de transformación de los recursos en capital reproducible y sostenible en el tiempo. En todos estos casos asoma nuevamente la intermediación de la institucionalidad, la transparencia y la relación entre múltiples actores que la gobernanza ayuda a equilibrar y mediar.

Por otro lado, traducir la mirada de corto plazo que se tiene de los recursos naturales en una perspectiva de beneficio de larga duración es lo que se muestra también mediante el análisis de los precios de las materias primas de los países de la región, un tema recurrente a lo largo de los distintos capítulos de este libro. Lograr un mayor entendimiento de las dinámicas de largo plazo y de los determinantes que afectan el comportamiento de los precios es crucial para los países de la región. Hemos visto como tener a mano datos sobre los componentes cíclicos de más largo plazo tiene implicaciones para el diseño de políticas macroeconómicas y reglas fiscales que influyen en los mecanismos de estabilización o en la decisión de los fondos soberanos de ahorro e inversión o, también, en los procesos de priorización de las políticas de diversificación productiva.

Finalmente, uno de los desafíos más importantes de la gobernanza de los recursos naturales es dar relevancia a los temas ambientales. El primer objetivo de la gobernanza es ofrecer las herramientas para lograr un equilibrio entre los aspectos económico, social y ambiental de la explotación de los recursos, no solo como un enunciado teórico, sino ofreciendo herramientas específicas para lograr este fin. Entre otras cosas, esto implica un esfuerzo para alcanzar la compatibilidad y la interacción entre los cuatro aspectos de la sostenibilidad (económico, social, institucional y ambiental) que, a su vez, están destinados a conjugarse y traducirse en desarrollo sostenible.

La bonanza es un término recurrentemente asociado a la "bendición" o la "maldición" de los recursos naturales. Contradictoriamente se observa a la bonanza como "bendición" o "maldición", y tanto este libro como el que le precedió asumen una posición. Debemos aprovechar la "bendición" tanto de tener los recursos, como de la bonanza, y usarlos para un desarrollo pleno, con igualdad, y prepararse para los períodos cuando 
la bonanza no exista. Sin embargo, la historia de la región también nos muestra la incapacidad de traducir bonanza y bendición en desarrollo sostenible y justicia social, por lo que la agenda para cambiar el paradigma es un requisito fundamental para un futuro con progreso e igualdad. En este libro se han planteado una gran cantidad de temas y reflexiones dirigidas a ese fin.

Hoy en día entre el público en general y los gobiernos en particular es cada vez más visible la preocupación por la sostenibilidad ambiental, que quizás se considera el lado más frágil o más incierto de la gestión sostenible de los recursos. La mayoría de los capítulos de este libro así lo ponen de manifiesto explícita o implícitamente. Esto es así porque, en parte, sigue prevaleciendo la idea que se trata de un aspecto más reciente del cual se tiene menos certezas o el que ha generado más perplejidad y preocupación, y es, justamente, una de las razones por las cuales muchos de los autores de este libro enuncian a los factores ambientales como los que cada vez más deben restringir la toma de decisiones respecto de la manera en que se explotan los recursos naturales.

Esto significa que la sostenibilidad ambiental es ciertamente la más directamente constreñida por las externalidades de la explotación de los recursos. De hecho, en el análisis de los costos de explotación, por lo común se ha puesto el acento en los costos económicos, luego en los sociales y finalmente en los ambientales. En décadas más recientes, este orden se ha visto alterado y cada vez más es prioritaria la inclusión de costos ambientales.

$\mathrm{Al}$ respecto, hay que recordar que hasta hace algunas décadas, la idea de agotamiento de los recursos tenía una presencia secundaria en los estudios sobre la explotación de los recursos naturales en los países de América Latina. El foco de atención era casi con exclusividad el análisis de su impacto económico y las eventuales consecuencias sociales de la explotación sobre las poblaciones o comunidades asociadas de manera directa. En la historia económica y social de los países de la región, existen innumerables ejemplos sobre los conflictos generados, aunque como indica uno de los capítulos sobre los conflictos relacionados con los recursos naturales, el aumento de las protestas asociadas a estos, en años recientes, forman parte de un ciclo de elevada movilización social general y no solo en torno a los recursos naturales.

De cualquier forma, la conflictividad social y ambiental ha sido en los últimos años la cara más visible de la gobernanza vigente en los procesos de explotación, manejo y distribución de costos y beneficios asociados a los recursos naturales. Ese tipo de gobernanza se relaciona con los escenarios del manejo anacrónico de las distorsiones macroeconómicas generadas por la volatilidad de precios que experimentó la región en relación a sus 
bienes primarios, incluidos los flujos fiscales y de divisas asociadas a estos. Como se ha sugerido a lo largo de este libro, la adecuada gobernanza de los recursos está llamada a reducir el peso o la dependencia de dichos recursos en favor de una mayor diversificación productiva, evitando al mismo tiempo los riesgos de la reprimarización de la economía.

Una buena parte de los capítulos de este libro ha hecho referencia a estos temas, aun cuando existe una recurrencia a determinadas cuestiones específicas asociadas a la influencia del ciclo de precios, el espacio fiscal, la distribución de los costos y beneficios, la relación entre abundancia y desigualdad, la equidad intergeneracional, los fondos soberanos, la transparencia y la conflictividad, que han captado la mayor atención. Sobre estos es que versan la mayoría de los conceptos, experiencias, ejemplos y lecciones. Son temas objeto de la gobernanza de los recursos naturales, destinada a promover una explotación responsable de los recursos naturales con leyes, instituciones y políticas públicas que prioricen el respeto del ambiente y la sociedad, tanto para esta generación como para las futuras, de la misma forma que lo son los derechos de los pueblos originarios y los de todos aquellos que contribuyen al progreso de nuestras sociedades. 


\section{Publicaciones recientes de la CEPAL ECLAC recent publications}

\section{www.cepal.org/publicaciones}

Informes Anuales/Annual Reports

También disponibles para años anteriores/Issues for previous years also available

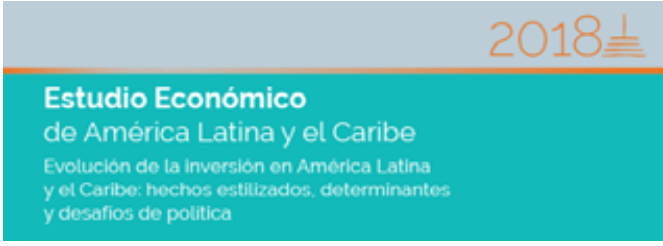

Estudio Económico de América Latina y el Caribe 2018 Economic Survey of Latin America and the Caribbean 2018

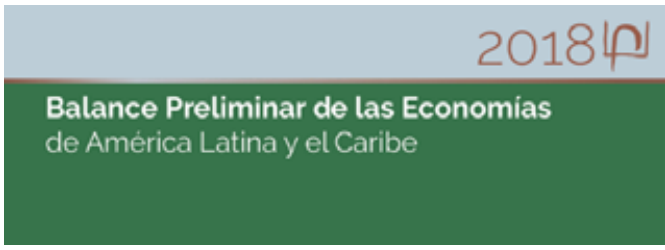

Balance Preliminar de las Economías de América Latina y el Caribe 2018

Preliminary Overview of the Economies of Latin America and the Caribbean 2018

\section{8橉}

Panorama Social

de América Latina

Panorama Social de América Latina 2018

Social Panorama of Latin America 2018

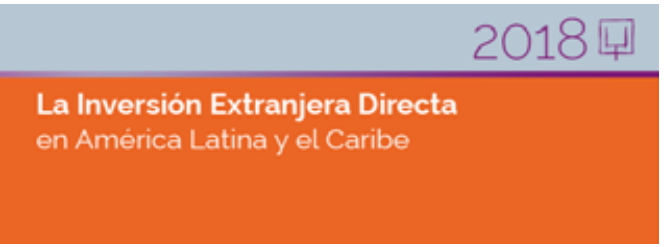

La Inversión Extranjera Directa en América Latina y el Caribe 2018

Foreign Direct Investment in Latin America and the Caribbean 2018

\section{8}

\section{Anuario Estadistico}

de América Latina y el Caribe

Statistical Yearboo $h$

for Latin America and the Caribbean

Anuario Estadístico de América Latina y el Caribe 2018 Statistical Yearbook for Latin America and the Caribbean 2018

\section{8 曲}

Perspectivas del Comercio Internacional de América Latina y el Caribe

Las tensiones comerciales exigen

una mayor intogración regional

Perspectivas del Comercio Internacional de América Latina y el Caribe 2018

International Trade Outlook for Latin America and the Caribbean 2018 


\section{El Pensamiento de la CEPAL/ECLAC Thinking}

Desarrollo e igualdad: el pensamiento de la CEPAL en su séptimo decenio. Textos seleccionados del período 2008-2018

La ineficiencia de la desigualdad

The Inefficiency of Inequality

Horizontes 2030: la igualdad en el centro del desarrollo sostenible Horizons 2030: Equality at the centre of sustainable development

Horizontes 2030: a igualdade no centro do desenvolvimento sustentável

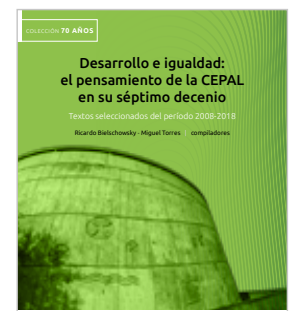

(6)

\section{Libros y Documentos Institucionales/Institutional Books and Documents}

Acuerdo Regional sobre el Acceso a la Información, la Participación Pública y el Acceso a la Justicia en Asuntos Ambientales en América Latina y el Caribe Regional Agreement on Access to Information, Public Participation and Justice in Environmental Matters in Latin America and the Caribbean

Hacia una agenda regional de desarrollo social inclusivo: bases y propuesta inicial ATowards a regional agenda for inclusive social development: bases and initial proposal

\section{Libros de la CEPAL/ECLAC Books}

Logros y desafíos de la integración centroamericana: aportes de la CEPAL

Envejecimiento, personas mayores y Agenda 2030 para el Desarrollo Sostenible: perspectiva regional y de derechos humanos

La inclusión financiera para la inserción productiva y el papel de la banca de desarrollo

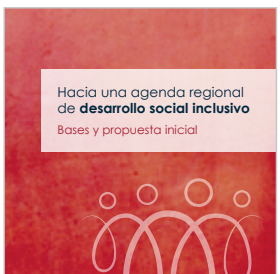

(6)
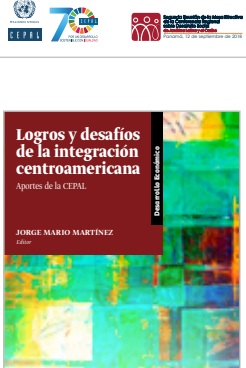

(2)
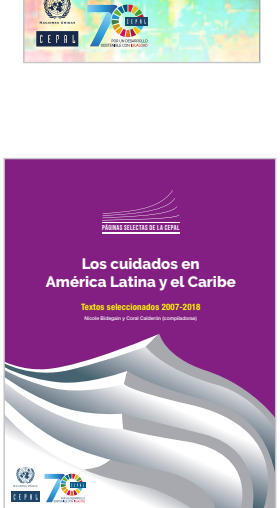

\section{Páginas Selectas de la CEPAL/ECLAC Select Pages}

Los cuidados en América Latina y el Caribe. Textos seleccionados 2007-2018

Empleo en América Latina y el Caribe. Textos seleccionados 2006-2017

Desarrollo inclusivo en América Latina. Textos seleccionados 2009-2016 
Revista CEPAL/CEPAL Review

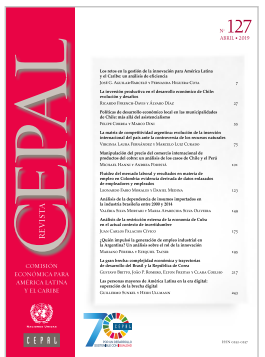

Notas de Población

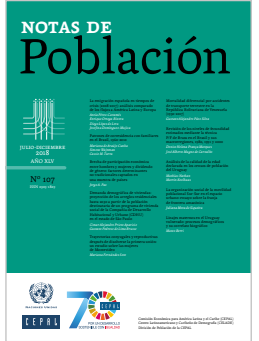

Documentos de Proyectos Project Documents

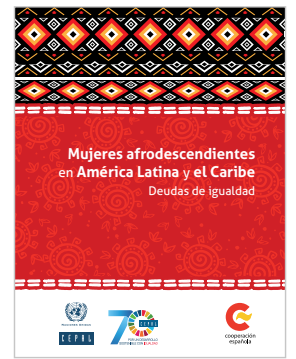

Coediciones/Co-editions

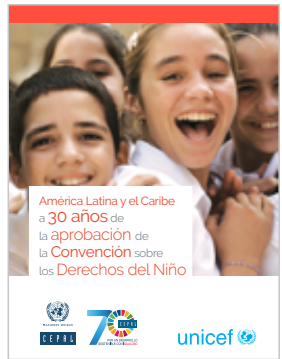

Series de la CEPAL/ECLAC Series

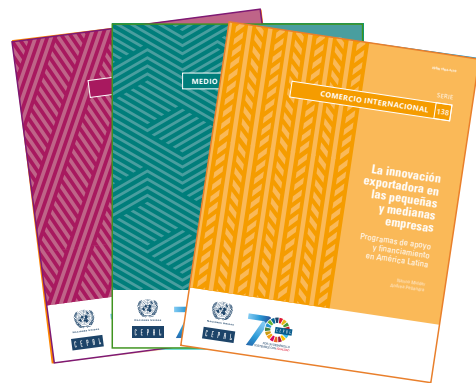

Observatorio Demográfico

Demographic Observatory

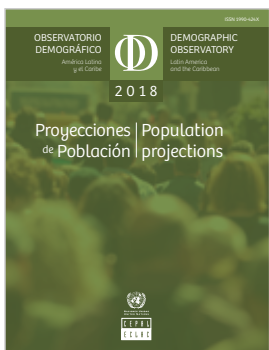

Metodologías de la CEPAL

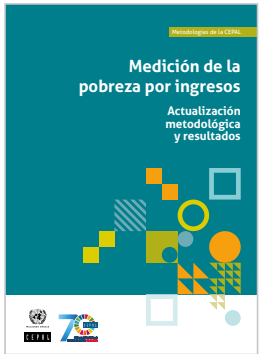

Copublicaciones/Co-publications

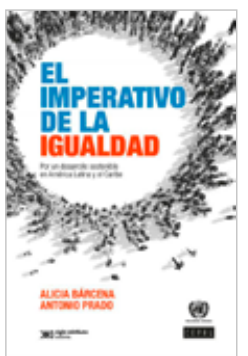





\section{La bonanza de los recursos naturales para el desarrollo}

Dilemas de gobernanza

\section{RICARDO J. SÁNCHEZ} Editor
El escenario principal de los análisis que se presentan en este libro es el contexto regional que tuvo lugar desde inicios de siglo, cuando

comenzó un ciclo de bonanza de precios y rentas provenientes de los recursos naturales, hasta su final, unos pocos años atrás. Se trató de una bonanza que, contrariamente a lo deseable, no se tradujo en un proceso virtuoso de transformación productiva y de cambio hacia la igualdad, lo que mostró la existencia de dilemas en materia de la gobernanza de los recursos naturales.

Este libro propone una reflexión sobre dichos dilemas, como continuidad de diversos documentos institucionales en el tema y, en particular, de la publicación Hacia una nueva gobernanza de los recursos naturales en América Latina y el Caribe, de 2016. La Comisión Económica para América Latina y el Caribe (CEPAL) ha reconocido la necesidad de ejercer una adecuada gobernanza de estos recursos en los países de la región, así como de favorecer instancias y mecanismos de coordinación regional en los aspectos fiscal, tecnológico, comercial y de infraestructura, entre otros, que apoyen un manejo más sostenible de los recursos en favor de un desarrollo más incluyente y menos vulnerable.

Para ello, se postula un cambio de paradigma en la relación del Estado con el sector privado y la sociedad civil, en que el Estado, si bien cumple un rol de liderazgo por su capacidad para actuar en favor del bien común, lo hace en interacción con otros actores, como las comunidades, las empresas y la sociedad civil.

\section{LIBROS

